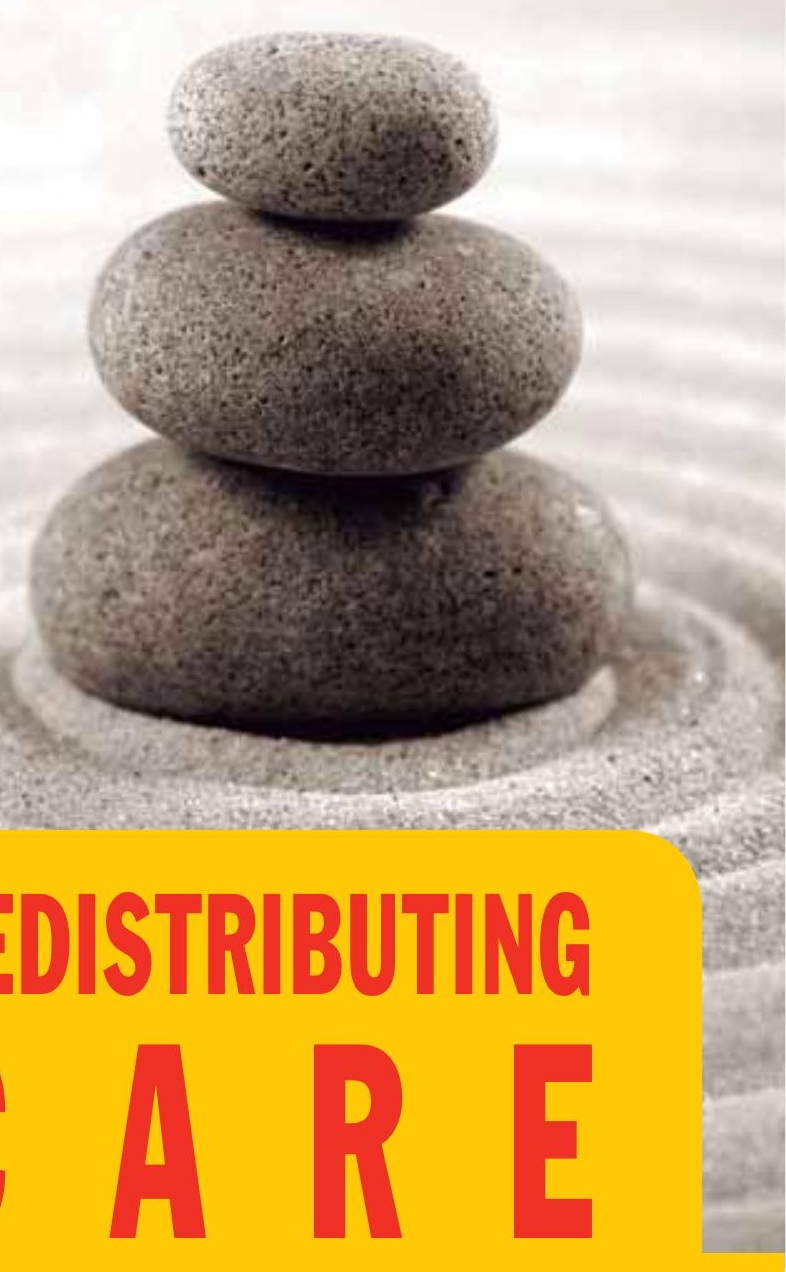

\title{
REDISTRIBUTING
}

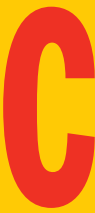

\section{THE POLICY}

\section{CHALLENGE}

\section{Coral Calderón Magaña}

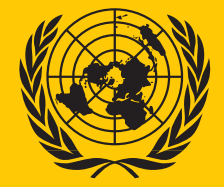

Coordinator

UNITED NATIONS

$$
\text { E C L A C }
$$




\section{REDISTRIBUTING}
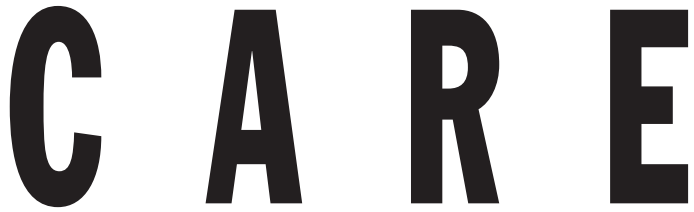

THE POLICY

CHALLENGE

Coral Calderón Magaña

Coordinator

UNITED NATIONS

E C L A C 


\section{Cuadernos de la CEPAL}

\section{1}

Alicia Bárcena

Executive Secretary

Antonio Prado

Deputy Executive Secretary

Sonia Montaño

Chief, Division for Gender Affairs

Ricardo Pérez

Chief, Documents and Publications Division

This book was prepared under the supervision of Sonia Montaño Virreira, Chief of the Division for Gender Affairs of the Economic Commission for Latin America and the Caribbean (ECLAC), and coordinated by Coral Calderón Magaña, research assistant with the same division. Nathalie Lamaute-Brisson, Patricia Provoste and Ana Ferigra Stefanovic provided substantive collaboration.

The authors would like to express particular thanks to Irma Arriagada, expert on public policies on gender equality, and Maureen Clarke Clarke, Executive President of the National Institute of Women of Costa Rica, for their valuable comments.

This document was published in the framework of the project "Improving the quantification of unpaid work performed by women for poverty eradication policies" of the United Nations Development Account.

United Nations Publication

ISSN: 0252-2195

ISBN: 978-92-1-221062-9

LC/G.2568-P

Sales No. E.13.II.G.9

Copyright ( $\odot$ United Nations, September 2013. All rights reserved Printed in United Nations, Santiago, Chile

Applications for the right to reproduce this work are welcome and should be sent to the Secretary of the Publications Board, United Nations Headquarters, New York, N.Y. 100017, United States. Member States and the governmental institutions may reproduce this work without prior authorization, but are requested to mention the source and inform the United Nations of such reproduction. 


\section{Summary}

Foreword

Prologue

Engendering economic progress.

Devaki Jain

A. Learning from the nine studies

1. Differences in the countries' demographics and financial capacities, and their impact on women's double work burden 23

2. The impact of inequality and poverty............................................ 24

3. Low education levels and the links with poverty and indigenous populations.......................................................... 27

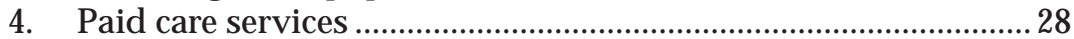

B. Other places, other issues .....................................................................29

1. The universality of unequal allocation of time ..............................2 29

2. Time-use studies from other places.................................................... 31

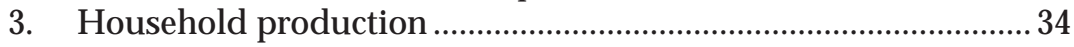

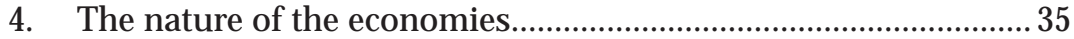

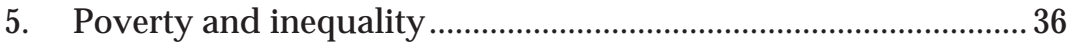

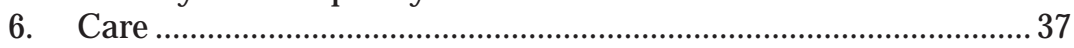

C. A platform for women of the South ………...........................................39

1. A gendered view from the South...................................................... 39 


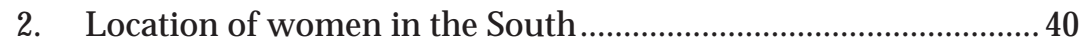

3. Towards a platform for the South.................................................. 41

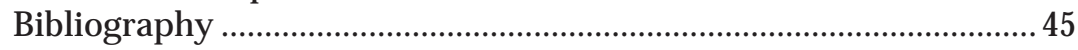

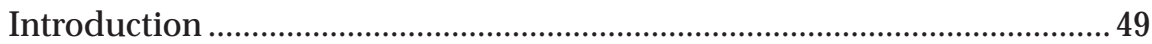

\section{Part one}

Impoverishing work and policy blindness

Chapter I

Redistributing care: towards a public policy nexus

Nathalie Lamaute-Brisson

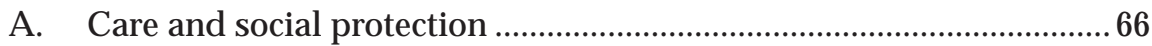

1. Defining care: the social reproduction perspective........................67

2. Care in social protection.................................................................... 70

3. From employment-based social protection to

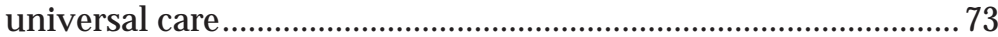

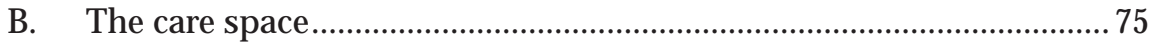

1. The actors in the institutional equation and

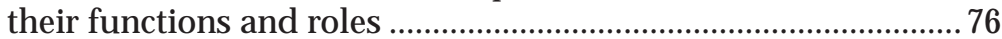

2. The care space and its economic setting .........................................79

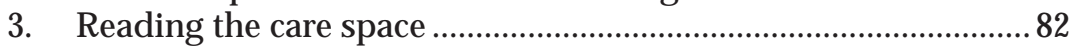

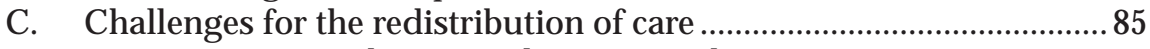

1. Moving past the reconciliation paradigm ……................................ 86

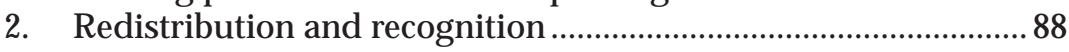

3. Establishing care services as a universal pillar

4. Making care services the locus of a public policy nexus..............92

D. Care, employment and territorial production development...............93

1. Critical policy loci in the employment system .............................94

2. Labour market access, employability and production

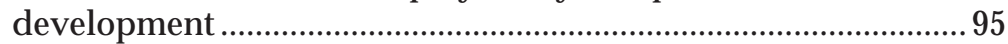

3. Production chains and employment and production

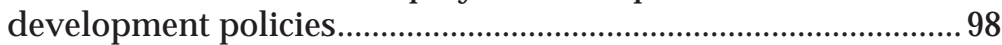

4. From care services to occupational desegmentation .....................99

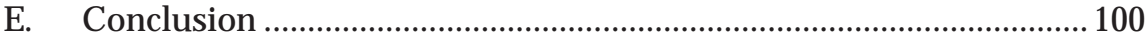

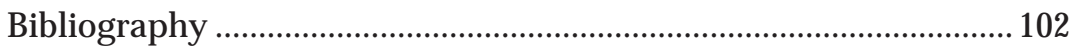

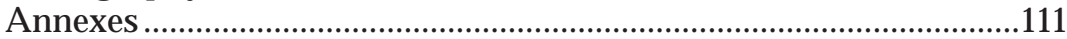

Chapter II

Social protection and the redistribution of care in Latin America and the Caribbean: the breadth of policy

Patricia Provoste Fernández

A. Why redistribute care? 


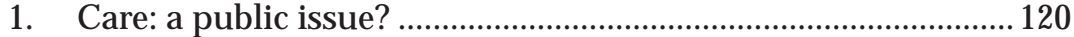

2. Maternalism and poverty .......................................................... 122

3. Women's liaison role at the heart of care …………....................... 123

4. The challenges for gender analysis................................................ 124

B. Care and maternalism in the region's social policies...........................125

1. Social protection and care ................................................................. 125

2. From wives to mothers: care in development paradigms..........129

3. After the crisis: continuity and change in social protection...... 132

C. The provision and redistribution of care …………............................... 134

1. Public-sector care services ……….................................................136

2. Time for caring and for earning: squaring the circle................... 146

3. Money for caring: conditional cash transfers............................... 152

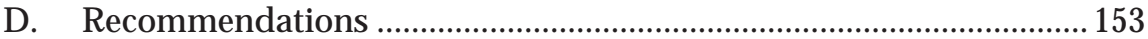

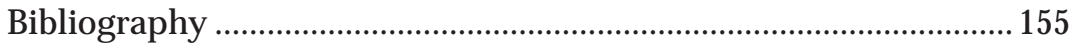

Chapter III

The utilization of time-use surveys in public policy....

Flavia Marco Navarro

A. The relevance of time-use surveys for equality policies .................... 160

1. What time-use surveys in Latin America tell us........................... 162

2. Possible applications for time-use surveys in sectoral policies

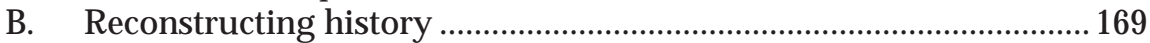

1. The route taken: building inter-institutional partnerships ........169

2. Institutionalizing time-use surveys at national institutes of statistics

3. Political and institutional factors affecting the utilization of time-use surveys in public policies.

4. Factor interaction: the politics of policymaking .......................... 181

C. Challenges ........................................................................................... 182

1. Methodological challenges for national institutes of statistics

2. Political and institutional challenges for mechanisms for the advancement of women ...................................................... 186

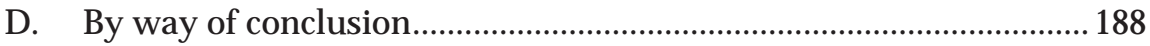

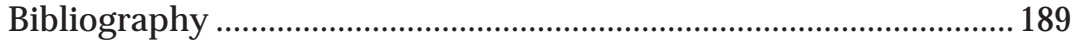

Chapter IV

Women's work: some considerations deriving from an integrated approach based on time-use surveys and employment statistics. Corina Rodríguez Enríquez

A. The conceptual and methodological framework for collecting information on work. 


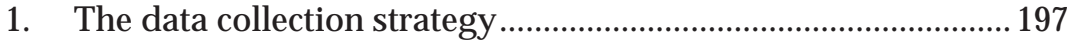

2. The grey area of goods production for the home.........................198

B. Women's production work in the system of national accounts: what time-use surveys add ..................................................2200

C. What do time-use surveys reveal about the work of

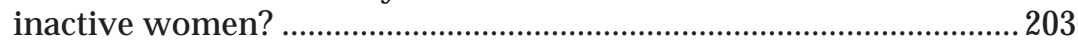

1. Inactivity in labour force surveys .................................................2204

2. Are inactive women different from active ones?..........................204

3. The work of inactive women.......................................................... 208

4. The relationship between inactive women's time use and their socioeconomic position ...................................................2 213

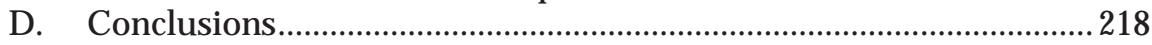

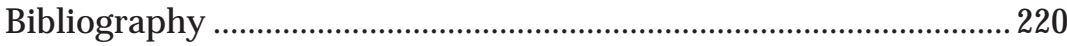

\section{Part two}

Experience concerning the sexual division of labour and public policy.

\section{Chapter I}

Is a new patriarchal family model taking shape in rural areas?

Liudmila Ortega Ponce

A. The specialization of women in unpaid work outside the production boundary.

B. Women and economic activity: between the market and the family sphere.

C. Working rural women: combining economic activities and care responsibilities

D. Women in production for own use: between tradition and invisibility

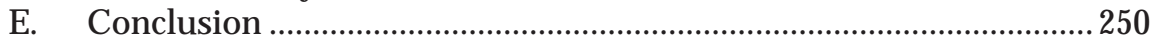

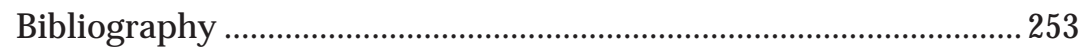

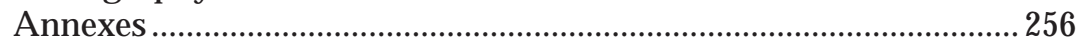

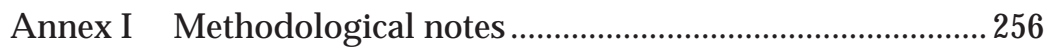

Annex II Tables ............................................................................... 260

Annex III Measurement of labour participation and time devoted to production for own use.

Chapter II

Models of the intrahousehold division of total labour:

Ecuador and Mexico

Soledad Salvador (with the collaboration of Estefanía Galván)

A. Theoretical framework for the analysis ..............................................269

1. Sexual division of labour and social organization of care ........270

2. Time-allocation models ................................................................... 271 


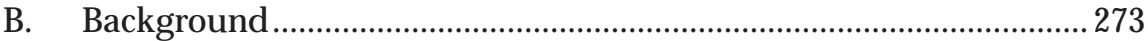

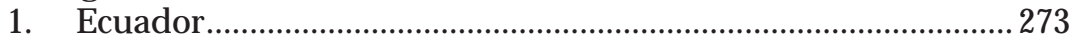

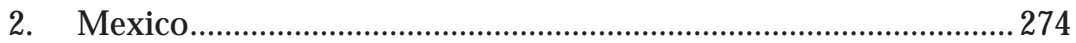

C. Descriptive analysis ..........................................................................224

1. Typology of two-parent households (with and without children) according to the sexual division of labour within the couple.

2. Typology of lone-parent households.............................................282

D. Bargaining models in two-parent households (with and

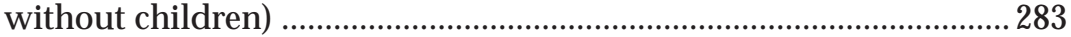

1. Summary of results from Ecuador and Mexico............................285

E. Determining factors of unpaid work in lone-parent

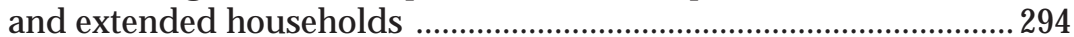

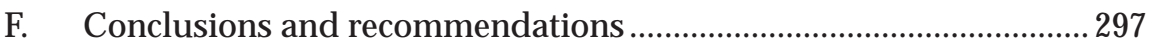

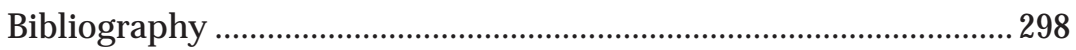

Chapter III

Social protection and unpaid work: redistribution of caregiving tasks and responsibilities, a case study of Costa Rica. 301

Pablo Sauma

A. Sociodemographic scenario and demographic estimates of care needs

1. Analysis from the perspective of households ..............................303

2. Demographic projections of care needs ..........................................303

3. An approximation of levels of dependency among older adults

B. Care provision to children and dependent older people ...................306

1. Arrangements in the domestic sphere ...........................................306

2. Provision of formal direct care services by third parties.............314

C. The care space: an unbalanced institutional equation.........................318

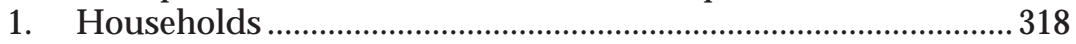

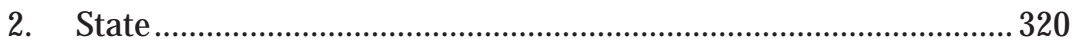

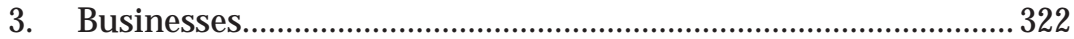

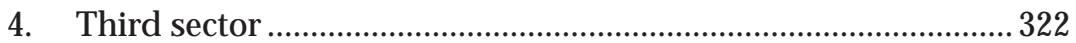

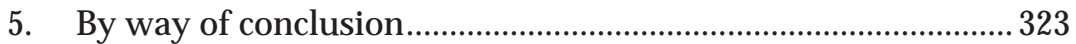

D. Relationships between the care space and the employment system

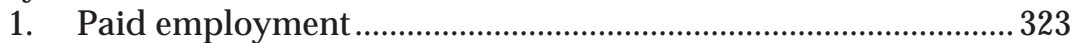

2. Linkages between households and the employment system

E. Public policy for the redistribution of caregiving tasks and responsibilities

1. Care as part of the social protection system 
2. Policies of employment and productive development for women 332

Bibliography

Chapter IV

Social protection and unpaid work: redistribution of caregiving tasks and responsibilities, a case study of Ecuador

Alison Vásconez Rodríguez

A. Macrodata on productive and reproductive work in Ecuador

B. Sociodemographic context and demographic estimates of care needs

1. Demographic trends

2. Structure of Ecuadorian households and projected demand for care.

C. Care of children and dependent older adults .......................................346

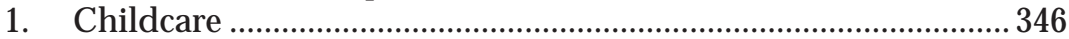

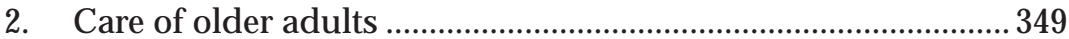

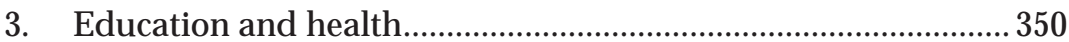

D. Arrangements in the domestic sphere .................................................352

E. Institutional equation in the care space: justice mechanisms and principles

F. Relationships between care work and the employment

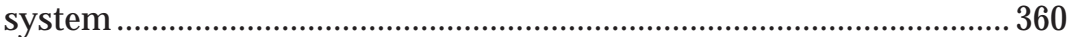

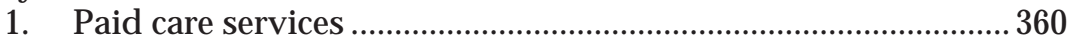

2. Domestic service employment .....................................................360

3. Characteristics of the population participating in the labour market: labour market segmentation

4. Relationship between work in the labour market and care work in the home

5. Identifying gaps in the current system of care 366

G. Scenario for a public policy nexus to redistribute caregiving tasks and responsibilities

1. Ecuador's legal framework for maternity protection and for supporting workers with family responsibilities ..........367

2. Gender perspective in Ecuador's social policy matrix ................372

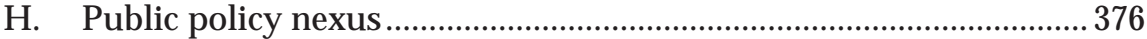

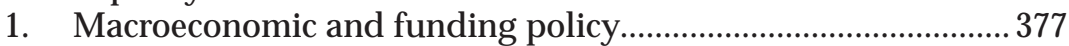

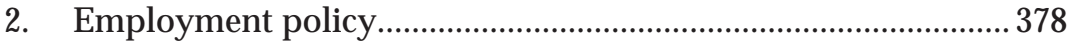

3. Social protection and care policies...............................................379

4. Production and productivity policies ..............................................382

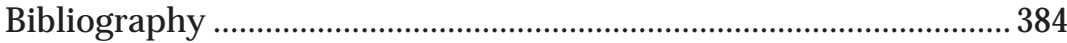




\section{Chapter V}

Home care and the recovery of subjectivity: the case of Mexico 385 Atenea Flores-Castillo

A. Population ageing and disability in Latin America and the Caribbean

B. Psychological care in the home care for the vulnerable population programme in Mexico City 390

1. Characteristics of the home care for the vulnerable population programme in Mexico City

2. Home-based psychological care in one Mexico City health district.

C. Dimensions of care.

1. Care from a psychoanalytical and philosophical perspective....

2. Care from the perspective of the recipient ................................401

3. Care from the perspective of the caregiver ................................405

4. Caregiving from the economic perspective................................409

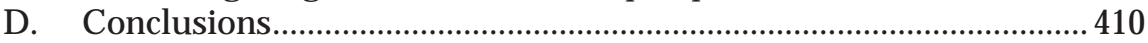

Bibliography .......................................................................... 412

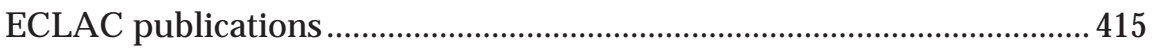

\section{Tables}

\section{Prologue}

1 Comparative economic and demographic characteristics of Costa Rica, Ecuador, Guatemala and Mexico ..................................23

2 Work participation rates in India, based on different censuses........32

\section{Part one}

IV.1 The general production boundary ………...........................................197

IV.2 Mexico and Ecuador: inactive women's rate of participation in unpaid work, by activity type

IV.3 Mexico and Ecuador: share of inactive women's total time spent on different activities, by days of the week

IV.4 Ecuador: inactive women's rate of participation in different activities, by income quintile, 2007 .....

IV.5 Ecuador: distribution of inactive women's time use from monday to friday, by activity and income quintile, 2007

\section{Part two}

I.1 Ecuador, Guatemala and Mexico: average time devoted to the production of goods and services within and outside the production boundary defined by the system of national accounts, total rural population aged 15 years and over 
I.2 Ecuador and Mexico: participation in and average amount of time spent on production activities within and outside the production boundary defined by the system of national accounts, rural men and women aged 15 years and over

I.3 Guatemala: participation in and average amount of time spent on production activities within and outside the production boundary defined by the system of national accounts, rural men and women aged 15 years and over.

I.4 Ecuador: participation in and average amount of time spent on production activities within and outside the production boundary defined by the system of national accounts, employed rural men and women aged 15 years and over

I.5 Guatemala: participation in and average amount of time spent on production activities within and outside the production boundary defined by the system of national accounts, employed rural men and women aged 15 years and over

I.6 Mexico: participation in and average amount of time spent on production activities within and outside the production boundary defined by the system of national accounts, employed rural men and women aged 15 years and over.

I.7 Ecuador, Guatemala and Mexico: participation in and average amount of time spent on production activities within and outside the production boundary defined by the system of national accounts, heads of household and their spouses, rural population aged 15 years and over.

I.A-1 Time-use variables from the time-use surveys conducted in Ecuador, Guatemala and Mexico.

II.A-1 Ecuador, Guatemala and Mexico: average time spent by the total urban population aged 15 years and over on the production of goods and services within and outside the production boundary defined by the system of national accounts

II.A-2 Ecuador and Guatemala: labour participation rate for economic activity within the production boundary defined by the system of national accounts based on time use by sex and age, total rural population aged 15 years and over.

II.A-3 Mexico: labour participation rate for economic activity within the production boundary defined by the system of national accounts based on time use by sex and age, total rural population aged 15 years and over 
II.A-4 Ecuador: participation in and amount of time spent on the production of goods and services within and outside the production boundary defined by the system of national accounts, by type of activity, rural population aged 15 years and over .262

II.A-5 Guatemala: participation in and average amount of time spent on the production of goods and services within and outside the production boundary defined by the system of national accounts, by type of activity, rural population aged 15 years and over

II.A-6 Mexico: participation in and average amount of time spent on the production of goods and services within and outside the production boundary defined by the system of national accounts, by type of activity, rural population aged 15 years and over

II.A-7 Ecuador, Guatemala and Mexico: distribution of rural households comprising a head of household and spouse by the couple's employment status

II.A-8 Ecuador and Guatemala: distribution of rural households by source of income

II.A-9 Ecuador: participation in and average amount of time spent on the production of goods and services within and outside the production boundary defined by the system of national accounts, by source of income of the household and sex, rural population aged 15 years and over

II.A-10 Guatemala: participation in and average amount of time spent on the production of goods and services within and outside the production boundary defined by the system of national accounts, by source of income of the household and sex, rural population aged 15 years and over

II.1 Ecuador and Mexico: average time spent by those aged over 12 on paid work, unpaid work and personal activities, by sex

II.2 Ecuador and Mexico: average time spent by those aged over 12 on paid and unpaid work in nuclear households, by type of household, relationship and employment status, by sex

II.3 Ecuador and Mexico: average time spent by those aged over 12 on paid and unpaid work in extended households, by type of household, relationship and employment status, by sex

II.4 Ecuador and Mexico: average time spent by people aged over 12 on paid and unpaid work according to age of youngest child, by sex 
II.5 Ecuador: typology of two-parent families by time spent on paid work (PW) and unpaid work (UW) by heads of household and partners

II.6 Mexico: typology of two-parent families by time spent on paid work (PW) and unpaid work (UW) by heads of household and partners

II.7 Ecuador: time spent on unpaid work (UW) by female heads and children in lone-parent households, by employment status of woman and age of youngest child

II.8 Mexico: time spent on unpaid work (UW) by female heads and children in lone-parent households, by employment status of woman and age of youngest child

II.9 Ecuador: elasticities of the tobit model for male heads or partners in couple households, conditional upon positive unpaid work (UW)

II.10 Ecuador: elasticities of the tobit model for female heads or partners in couple households, conditional upon positive unpaid work (UW) ....

II.11 Mexico: elasticities of the tobit model for male heads or partners in couple households, conditional upon positive unpaid work (UW)

II.12 Mexico: elasticities of the tobit model for female heads or partners in couple households, conditional upon positive unpaid work (UW) .

II.13 Ecuador and Mexico: determining factors of unpaid work (UW) of female heads of lone-parent households

II.14 Ecuador and Mexico: determining factors of unpaid work (UW) of female heads of extended lone-parent households

II.15 Ecuador and Mexico: determining factors of unpaid work (UW) of female heads of extended two-parent households .296

II.16 Ecuador and Mexico: determining factors of unpaid work (UW) of male heads of extended two-parent households

III.1 Costa Rica: prevalence of dependency in the population aged 65 years and over living in individual households, estimated on the basis of their difficulty in performing activities of daily living, 2005

III.2 Costa Rica: daily average social time, participation rates and daily average effective time spent on activities among the population aged 12 years and over, by sex, 2004

III.3 Costa Rica: distribution of household members performing direct care tasks, by sex and kinship with the male or female head of household, 2004

III.4 Costa Rica: daily average effective time spent on caregiving and support tasks and on paid work by employed people aged 12 years and over, by sex, 2004 
III.5 Costa Rica: daily average effective time spent on caregiving and support tasks and on paid work by employed women aged 12 years and over, by type of dependent at home, 2004 .......327

IV.1 Ecuador: forms of childcare, 2005-2008 ……...................................342

IV.2 Ecuador: aggregate indicators of weekly workload, 2007................353

IV.3 Ecuador: profile of women caregivers, 2007......................................353

IV.4 Ecuador: distribution of the time spent by women in urban and rural areas on unpaid domestic and care work, by activity, 2007

IV.5 Ecuador: women and men's burden of unpaid domestic work, by hours of work in the labour market, 2007 ..........................366

IV.6 Ecuador: main shortcomings in the care system ..............................367

V.1 Disability prevalence at a threshold score of 50 (those experiencing very significant difficulties in their

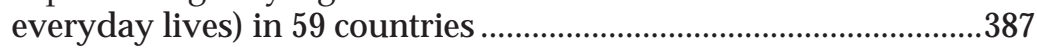

V.2 Estimated prevalence of severe disability..........................................388

V.3 Main causes of years lived with disability (YLD) by sex, 2004 .....388

\section{Figures}

\section{Prologue}

1 International comparison of average time spent on unpaid work

\section{Part one}

I.1 Elementary structure of a social protection system .71

IV.1 Mexico: share of total time spent on primary and secondary activities for self-consumption, by age range and sex, 2009

IV.2 Mexico: share of total time spent on primary and secondary activities for self-consumption, by education level and sex, 2009

IV.3 Mexico: share of total time spent on primary and secondary activities for self-consumption, by kinship and sex, 2009

IV.4 Mexico and Ecuador: distribution of active and inactive women by age range

IV.5 Mexico and Ecuador: distribution of active and inactive women by education level..

IV.6 Mexico and Ecuador: distribution of active and inactive women by number of children under 12

IV.7 Mexico and Ecuador: distribution of inactive women's working time between activity categories, by days of the week

IV.8 Ecuador: inactive women's rates of participation in selected activities, by income quintile, 2007 
IV.9 Ecuador: distribution of inactive women's time use from monday to friday, by activity group and income quintile, 2007

\section{Part two}

I.1 Ecuador: shares of men and women in the total time devoted to production activities within and outside the production boundary defined by the system of national accounts, by area of residence, population aged 15 years and over .228

I.2 Guatemala: shares of men and women in the total time devoted to production activities within and outside the production boundary defined by the system of national accounts, by area of residence, population aged 15 years and over

I.3 Mexico: shares of men and women in the total time devoted to production activities within and outside the production boundary defined by the system of national accounts, by area of residence, population aged 15 years and over.

I.4 Ecuador and Mexico: shares of men and women in the total time spent on production activities that fall outside the production boundary of the system of national accounts by type of activity, rural population aged 15 years and over.

I.5 Ecuador, Guatemala and Mexico: shares of men and women in the total time spent on market production and production for own use, rural population aged 15 years and over.

I.6 Mexico: labour participation rate according to the framework of the International Labour Organization (ILO) and the system of national accounts (SNA) and broader labour participation rate based on time use by sex and age group, rural population aged 15 years and over

III.A-1 Question on labour participation and time devoted to production for own use in the national time-use survey of Mexico, 2009

III.1 Costa Rica: daily average effective time spent on paid and unpaid work, by sex and age group, 2004

III.2 Costa Rica: daily average effective time spent on paid and unpaid work, by sex and per capita household income decile, 2004

IV.1 Ecuador: time spent per week on work in the labour market and on care work, by sex, 2003-2009

IV.2 Ecuador: age structure of demand for care (qualitative scale), 2009 and 2025.

IV.3 Ecuador: time spent on domestic work and work in the labour market by people under the age of 15 years, by enrolment in the education system, 2007 
IV.4 Ecuador: average time spent per week on domestic support work and unpaid care work, by area and ethnic self-identification, by sex, 2007

IV.5 Ecuador: average time per week spent on domestic support work and unpaid care work, by income quintile, by sex, 2007 .

IV.6 Ecuador: distribution of the working population in domestic service and the total working population, by level of education, 2010

\section{Boxes}

\section{Part one}

I.1 Direct care and support activities........................................................69

I.2 The roles of actors in the care space ...................................................77

I.3 Nancy Fraser's principles of justice for gender equality ……............90

I.4 Lessons learned from the creation or expansion of care services in Latin America: Argentina, Chile, Colombia and Mexico ..............97

III.1 The institutionalization of gender and time-use statistics: lessons learnt in the Philippines.

\section{Part two}

I.1 Production activities and the scope of the production boundary of the system of national accounts. 226

I.2 Time use of rural indigenous women............................................243

III.1 Profile of male caregivers ..................................................................314

V.1 Sociodemographic profile and physical dysfunctionality...............394

\section{Diagram}

\section{Part two}

IV.1 Ecuador: institutional equation in the care space 



\section{Foreword}

The data for Latin America are eloquent: in all 18 countries where time use has been studied, women's total work time (the sum of paid and unpaid work) is greater than men's, and women spend more time on unpaid work. Conversely, men devote more time to paid work than women do.

Caregiving forms part of unpaid work. Redistributing it is crucial to balancing the time that people spend on work. With this in mind, public policies should be designed to increase universal access to care systems and close the gaps that disadvantage women.

This document gives an account of the inequalities that arise from the prevailing work imbalance and the challenges involved in overcoming them. Here, ECLAC reviews the progress made in incorporating unpaid work into social protection policies in the region, looking in particular at the redistribution of caregiving in society and proposals to improve socially equitable economic development. Progress and setbacks regarding gender equality, as well as the new conflicts and needs which arise from these models, are analysed in a number of articles whose common theme is the redistribution of care work in society.

This publication represents the culmination of work that started in 2011 with a project conducted jointly by ECLAC and the Swedish International Development Cooperation Agency (SIDA) on social protection and unpaid work performed by women. This was followed by the United Nations Development Account project entitled "Improving quantification of women's unpaid work in support of poverty eradication policies".

The time-use surveys implemented in several countries in recent years have helped to turn a spotlight on women's excessive work 
burden and lack of economic autonomy. They have also helped to place policies on work-family reconciliation and on caregiving on the regional public agenda. Expert meetings on the implementation of surveys and questions on time use have also helped to position the issue, foster the learning process in national statistical offices and boost data quality and the international comparability of surveys.

Part of the research on care work presented in this publication was discussed at the workshop "Towards the construction of a care system in Ecuador", held in Quito in March 2012, in the workshop "Unpaid work and women's social protection", held in San José in February 2012, and at the seminar "Time policies, time for policies", held in Santiago during the forty-sixth meeting of the Presiding Officers of the Regional Conference on Women in Latin America and the Caribbean, which took place in Santiago in November 2011.

This publication has two parts. Part 1 adds to the discussion on how recognizing the sexual division of labour affects public policies. Part 2 uses data such as that collected in Costa Rica, Ecuador, Guatemala and Mexico to portray their experiences in this area. The renowned Indian economist, Devaki Jain, offers an overview of the care economy in the region, and in the world more broadly, based on the findings set forth in both parts of this book.

One of the most interesting proposals made in this publication is to replace the terms economically active and economically inactive with active in the labour market and inactive in the labour market, respectively. This would confer visibility on the proportion of the economically active population whose work is unpaid. The description active in the labour market would make it plain that the idea of activity is being established strictly in relation to the world of employment (or paid work). Another possibility is to create the category active in the home, which would capture the population which is economically active but is not paid for care work performed in the household. The proportion of women in this category would be considerably higher than that of men.

In this book, ECLAC continues to address the issue of care in the region, in particular the need for universal access to social services systems that are able to meet the care demands of societies. This would enable half of the region's population - women - to participate actively and fully in the economic and social development of their countries.

\section{Alicia Bárcena}

Executive Secretary

Economic Commission for

Latin America and the Caribbean 


\section{Prologue Engendering economic progress}

Devaki Jain ${ }^{1}$

Gendered analysis of economic, political and social spaces not only reveals discrimination and the lack of understanding of women and their contributions (the usual laments), but also leads to a better understanding of intersectionality and of political and economic theories and contributes to a more precise measurement of social, political and economic realities. The outcome of this improvement in measurement directly affects the achievement of goals, which are universally defined in terms of justice and progress, however elusive and controversial the term.

Feminist explorations of these domains and issues have grown exponentially in the last few decades. ${ }^{2}$ International institutions, including the United Nations and its agencies, the World Bank, universities and high-profile think tanks, are all exploring gender and collecting information on gendered experience in various disciplines and programmes (Jain, 2005). These explorations have revealed new realities, new values and new synergies that propel economic and political advancement. However, they have also revealed the value of

I acknowledge with gratitude the assistance in all aspects of the production of this paper of Deepshikha Batheja

2 Publications by Feminist Economics (http://www.feministeconomics.org/), Indian Association for Women's Studies (IAWS) (http:/ / www.iaws.org/), UN-Women (http: / / www.unwomen.org/), International Association for Feminist Economics (http://www. iaffe.org/). 
difference, not only in terms of gender, class and race, but also with regard to geographical and cultural characteristics, the strength of the economy and political ideologies, thereby challenging generalizations and definitions.

Scholars and activists who explore gendered analysis are proposing new meanings for the term value (Jain and Elson, 2012). This work vividly illustrates the intersectionality of the political, economic and social spheres, as well as the link between biology and opportunity.

Deconstructing the work of women - across location, economy, culture, environment and even political history-constitutes a revelatory journey from the philosophical (Flores-Castillo, chapter V, part 2) ${ }^{3}$ to the physical and enables the quest for a just economic and political order.

Time is a critical factor in women's lives, as is their role in human reproduction. These two attributes are inextricably linked, whatever the location and its many characteristics. While it could be suggested that the sexual division of labour is the outcome of biology, many would argue that it stems from the combination of biology and patriarchal cultures.

However, there are many examples where these inherited burdens of sexual and social reproduction have been shifted by political ideologies. Under the socialism practiced in Cuba, policies have aimed at fostering women's equality since 1959 (Nunez Sarmiento, 2012). Czechoslovakia used to be a model for free childcare services, before the fall of the Berlin wall. Today, the Scandinavian model of economic initiatives includes high rates of public expenditure for childcare, "switching roles", paternity leave and so on (Jain, 1995). Nevertheless, the burdens and inequalities have not disappeared, so the quest for an equilibrium continues.

This preface reviews nine brilliant research papers using data from four countries in Latin America, which offer insights into women's roles and how they play out in terms of stimulating macroeconomic policy responses by the State. It then links the papers to similar exercises and explorations in other continents of the South, showing the variations in emphasis that emerge due to the strong differences not only in the nature of the economies, but in the roles that women and men play in those economies. Next, I review time-use studies in other regions and discuss how such explorations can be useful for improving the lives of women and men, girls and boys. I also call attention to other domains of measurement failure or flawed valuation and other attempts to evaluate progress and respond to women's work, such as recognizing the expansion of informal workers and providing them with organizational

See chapter V. 
support. Finally, the preface closes by raising questions and offering proposals for reconstructing political economy design for the South.

The review of these nine papers provides a background for developing new ideas and perspectives on building a just and equitable political economy, a form of economic reasoning, derived from other measures of progress. This exercise enables the building of bridges and frameworks across and with other continents of the South.

The latest Human Development Report (UNDP, 2013), entitled "The Rise of the South: Human Progress in a Diverse World", calls attention to the ability of some of the countries in the South to weather the storms of global financial fractures, as well as their self-confidence and attempts to consolidate their power by linking across continents. Furthermore, the report of the thirty-third session of the Economic Commission for Latin America and the Caribbean (ECLAC, 2010a), remarks that the anticipated loss of momentum in the developed economies could possibly be offset by the crucial role played by the emerging economies, which are better placed to expand their aggregate domestic demand: "These economies have fiscal scope to increase public spending, financial systems unhampered by poor-quality assets and levels of international reserves that should allow them to maintain comfortable levels of liquidity" (ECLAC, 2010a, pp. 23 and 26). An example of such a partnership of the continents of the South is the association of Brazil, Russia, India, China and South Africa (BRICS) (Jain, 2013a). Such intercontinental alliances offer a window of opportunity for feminists to pull together their understanding of economic progress and to negotiate their ideas with these clubs and other institutions.

Here the key entry point is measures and measurement, with a focus on how valuation both enables and disables a country's attempts at building a just and equitable society and economy. Reviewing these studies across the continents leads to some suggestions on new measures of political economy, which provide space for the assertion of human rights.

\section{A. Learning from the nine studies}

The nine brilliant essays ${ }^{4}$ not only explore women's contributions to society and economy in Latin America, but record and assess the

\footnotetext{
"Redistributing Care: Towards a Public Policy Nexus", by Nathalie Lamaute-Brisson; "Social Protection and the Redistribution of Care in Latin America and the Caribbean: The Breadth of Policy", by Patricia Provoste Fernandez; "The Utilization of TimeUse Surveys in Public Policy", by Flavia Marco Navarro; "Women's Work: Some Considerations Deriving from an Integrated Approach Based on Time-Use Surveys and Employment Statistics", by Corina Rodríguez Enríquez; "Total Work and Gender
} 
responses of the State, the society and economic policy to this reality. Time-use studies provide the foundation for the explorations, as well as the argumentation.

These time-use studies not only offer a laboratory of high-quality research into reality, but also provide the basis for a practical programme that both accommodates women as equal citizens and promotes economic and political justice.

These essays consider and illustrate all the issues related to the conceptualization of women's work: paid versus unpaid labour; unpaid labour that produces goods and services that can be included in the System of National Accounts (SNA); unpaid labour that provides services that do not go into the SNA; the neglected area of producing goods for self-consumption, which again does not enter into formal accounting; and caring for children and adults, a role that is deeply embedded in the sexual division of labour. The essays address these issues from the perspective of finding solutions based on detailed descriptions and analyses of a set of four Latin American countries: Costa Rica, Ecuador, Guatemala and Mexico. The experiences vary, as indeed they should, as a result of the specific characteristics of the economy and demography of the different countries.

Flavia Marco (chapter III, part 1) highlights the importance of timeuse studies and describes how they are still at "the propositional and enabling-legislation stage rather than at the programmatic stage". She then shows possible applications for time-use surveys in employment policies, social security policies, poverty-alleviation policies, healthcare policies and education policies. She suggests that we need a new interpretive framework which allows decision makers to challenge existing policies using empirical evidence from time-use surveys.

Corina Rodríguez (chapter IV, part 1) also supports the application of time-use research, citing the extensive literature on the unpaid dimension of women's work. Although largely invisible, this unpaid labour is essential to the functioning of the system, since it minimizes the cost of reproducing the workforce and caring for dependants (children, older adults and the sick): "The importance of women's unpaid work, both for its systemic contribution and as a determinant of persistent

Relations in Rural Populations of Ecuador, Guatemala and Mexico", by Liudmila Ortega Ponce; "Models of the Intrahousehold Division of Total Labour: Ecuador and Mexico", by Soledad Salvador; "Social Protection and Unpaid Work: Redistribution of Caregiving Tasks and Responsibilities - Case Study of Costa Rica", by Pablo Sauma; "Redistribution of Care Work and Responsibilities: The Case of Ecuador", by Alison Vásconez Rodríguez; and "Home Care and the Recovery of Subjectivity: The Case of Mexico", by Atenea Flores-Castillo. 
gender inequities in the labour market, has made it a subject of inquiry that has a particular contribution to make to the formulation of equality policies... In these circumstances, time-use surveys have become an essential way of producing information that can be used to ascertain, quantify and value the unpaid work people do."

The analysis, ideas and suggestions of the authors can be grouped under the following four sections.

\section{Differences in the countries' demographics and financial capacities, and their impact on women's double work burden}

The essays reveal the link between the overall macroeconomic situation and the ground-level situation of women. The countries in the sample range from a population of 4.727 million in Costa Rica to 114.8 million in Mexico. They also vary substantially in per capita income and public spending. For instance, Ecuador does not have a prosperous economy, yet it spends around $10 \%$ of its GDP on public goods (as of 2012). Many of the differences in their experience and proposals stem from these variations in their economic and demographic profiles, as shown in table 1.

Table 1

COMPARATIVE ECONOMIC AND DEMOGRAPHIC CHARACTERISTICS OF COSTA RICA, ECUADOR, GUATEMALA AND MEXICO

\begin{tabular}{|c|c|c|c|c|c|}
\hline Country & $\begin{array}{l}\text { Population } \\
\text { (2013) }\end{array}$ & $\begin{array}{l}\text { Per capita } \\
\text { income } \\
(2012)\end{array}$ & $\begin{array}{l}\text { Poverty } \\
\text { headcount } \\
\text { ratio }^{\text {a }}\end{array}$ & Age composition & Gini coefficient \\
\hline Costa Rica & 4.9 million & $\$ 9402$ & 18.5 (2010) & $\begin{array}{l}0-14 \text { years: } 24.9 \% \\
15-64 \text { years: } 68.6 \% \\
65 \text { years and over: } 6.5 \%\end{array}$ & $0.492(2010)$ \\
\hline Ecuador & 15.8 million & $\$ 5457$ & 39.1 (2010) & $\begin{array}{l}0-14 \text { years: } 30.9 \% \\
15-64 \text { years: } 63 \% \\
65 \text { years and over: } 6.1 \%\end{array}$ & 0.495 (2010) \\
\hline Guatemala & 15.4 million & $\$ 3347$ & $54.8(2006)$ & $\begin{array}{l}0-14 \text { years: } 41.4 \% \\
15-64 \text { years: } 54.1 \% \\
65 \text { years and over: } 4.4 \%\end{array}$ & 0.585 (2006) \\
\hline Mexico & 119.3 million & $\$ 9946$ & $36.3(2010)$ & $\begin{array}{l}0-14 \text { years: } 30.2 \% \\
15-64 \text { years: } 63.7 \% \\
65 \text { years and over: } 6.1 \%\end{array}$ & $0.481(2010)$ \\
\hline
\end{tabular}

Source: Economic Commission for Latin America and the Caribbean (ECLAC) [online] http://www.cepal.org/ celade/default.asp?idioma=IN, http://estadisticas.cepal.org/cepalstat/WEB_CEPALSTAT/Portada.asp?idioma =i http://websie.eclac.cl/sisgen/Consultalntegrada.asp [date of reference: 20 June 2013].

a Measured by the respective national poverty line in each country.

In some countries, the demographic profile has changed so much that caring for the old has become more important than caring for the young. For example, in Costa Rica, the population aged 65 years and above represents $6.5 \%$ of the total population, versus $4.4 \%$ in Guatemala (see table 1). 
Atenea Flores-Castillo (chapter V, part 1) writes that several European and a few Latin American countries are already experiencing population ageing, which will become a general phenomenon in developing countries in the medium term. In Latin America and the Caribbean, older persons will double as a percentage of the total population between 2010 and 2050, from 10\% today to an estimated $21.7 \%$. Pablo Sauma (chapter III, part 2) also points to this in his study of Costa Rica: "According to a conservative estimate, assuming that the percentage of the older adult population cared for in nursing homes continues grow at the same rate as in the past 10 years, by 2025 there will be one older adult in one in four Costa Rican households (25\%) and more than one older adult in $7 \%$ of households, while just over $10 \%$ of all Costa Rican households will comprise only older adults (that is to say, around $45 \%$ of all households with older adults among their members)."

\section{The impact of inequality and poverty}

Latin America clearly needs to prioritize "care" and the importance of men sharing this domain of work. More people need care than there are people to provide it, so it really is a job opportunity.

Inequality and the proportion of poor households also affect how women are either used or allowed to play out their own roles. For example, the case study of Ecuador, Guatemala and Mexico finds that the link between poverty and women's double burden of paid and unpaid domestic work is particularly strong in Guatemala, which has a high poverty headcount ratio of $53.7 \%$ and a very high Gini coefficient.

Patricia Provoste also writes that "Although time-use figures show the overburdening of women with unpaid work to be a constant in all the countries and all sections of society, this burden appears to be particularly heavy in two very different situations requiring different types of activities: in the countries and sectors which are poorest and/ or where the State's social protection capacity is small, and in those countries where the State has developed a substantial range of services, programmes and transfers that add to the liaison time and labour of women who "qualify" to receive them on behalf of their families" (Provoste, chapter II, part 1).

In most parts of the world, more women are engaging in formal work than in the past, though with striking variation among countries. While this outbound work has many repercussions apart from its impact on household-related work, it generally implies a double burden for women, which needs to be offset by the availability of others to provide that support, whether through State services or the hiring of domestic 
help. "In 12 countries (including the three of interest in this study, Mexico, Ecuador and Guatemala) women's participation in rural employment climbed by $15.6 \%$ between 2000 and 2008 , thus outpacing the increase in men's participation, which rose by 5.7\%" (Ortega, chapter I, part 2). This trend toward increasing formal employment has largely been driven by the cultural changes associated with women's desire to have an identity in their own right, autonomy and economic independence.

The Regional Human Development Report for Latin America and the Caribbean notes that the "growing involvement of women in paid work has not been accompanied by an equivalent upswing in the participation of men in unpaid domestic tasks.... Moreover, the fact that no monetary valuation is attached to unpaid domestic work makes it difficult to calculate the economic contribution of those (mostly women) who carry out this kind of work." The report goes on to say that these irregularities in work distribution and calculation have "adverse effects on gender equality and the empowerment of women, and at the same time reduce the visibility and perceived importance of their interests in public policies... It will be very difficult to bring about any real improvement in social equality until a more profound cultural transformation at the family level has been achieved" (UNDP, 2010, pp. 33-34).

In 2010, at the eleventh session of the Regional Conference on Women in Latin America and the Caribbean, ministers and high-level representatives discussed the challenges related to gender equality, with respect to women's autonomy and economic empowerment. ${ }^{5}$ The conference proposed that "the key to ending the primary inequality between men and women is to change the social, political, cultural and, in this case, economic bases that underpin the sexual division of labour" (ECLAC, 2010b, p. 67). The recommendations focus on the State to take all the necessary steps, whether legislative, institutional, educational, health-related, fiscal or related to women's participation in decisionmaking, in order to do away with gender biases in the labour market and overcome the wage gap, segmentation and discrimination. Earlier recommendations, from the tenth session of the Regional Conference on Women in Latin America and the Caribbean held in Ecuador in 2007, focused on the advancement of women at the highest level. ${ }^{6}$ Other initiatives by ECLAC, such as the 2010 Millennium Development Goals Report, highlight the gender equality agenda (United Nations, 2010, chapter IV).

See Brasilia Consensus [online] http:/ / www.eclac.cl/mujer/noticias / paginas /6/40236/ ConsensoBrasilia_ING.pdf [date of reference: 24 June 2013].

6 Quito Consensus [online] http://www.eclac.cl/publicaciones/xml/5/29555/dsc1i.pdf [date of reference: 24 June 2013]. 
The patriarchal family model is grounded in socioeconomic and cultural constructs whereby males assume the role of head of household and breadwinner and have power and authority over the female members of the household, who occupy a subordinate position and whose primary role is the performance of domestic chores and caregiving. This model appears to be on the decline in Latin America, albeit to varying degrees in the different countries, as described by Liudmila Ortega:

"The economic and social foundation of the patriarchal model in rural areas of Ecuador, Guatemala, Mexico has undergone significant changes, leading to processes that have tended to reduce women's economic dependence on male providers. However, gender inequality in the area of unpaid work persists, as confirmed by the disparities between employed men and women - to the disadvantage of womenin their participation in and time contribution to care work. Then there is the invisibility of the economic contribution of rural women in the area of market production, pointing to the influential cultural attitudes and ideological positions inherent to the system" (Ortega, chapter I).

The issue of class and the role of the State come to the fore as more women engage in paid work and there is a pressure on the State to provide services, like care of children and the aged. If the women working outside the home belong to the middle or upper classes, then they can hire others to do their household work and thus do not need the State's services. For poorer women, the outbound paid work is added on to their household domestic work, creating a double burden. Furthermore, when the State provides childcare or aged-care services, the quality is often lower than private services, especially if it is targeted toward the less privileged, poor and marginalized communities, such as immigrants. Here again, stereotypes emerge, as it is mainly women who work as service providers in these institutions. Finally, wages tend to be low in occupations dominated by women, which perpetuates inequality in these services.

A variety of ongoing studies have fleshed out the issue of the "global care chains" (Pérez, 2010) that are behind the remittances sent by migrant women. These women move to a more developed country to carry out paid care work, leaving another female family member to care for their own children, thus forming transnational networks. But if these women have moved to earn a higher income from doing household chores or providing domestic services, the trap is that other women are playing their role back home. There is no escape from the historically embedded sexual division of labour!

This translates into dual-provider households, where the head and spouse have different workloads. In Guatemala, where employed male 
heads of household have little involvement in total care work $(30.7 \%)$, most employed female spouses combine paid employment and care work, without the assistance of any institutional mechanisms to help reconcile the two.

\section{Low education levels and the links with poverty and indigenous populations}

Liudmila Ortega highlights how lack of education becomes an impediment to women's development in Guatemala and other Latin American countries (chapter I, part 2). She notes that new employment opportunities have been created in more productive, higher-paying jobs in the countries of Latin America as closer links are forged between rural areas and more economically buoyant urban areas. "Low education levels are a barrier to obtaining such jobs in non-agricultural sectors, as they call for specialist knowledge that rural women do not possess." In all three countries included in her study, but especially in Guatemala, only a very small percentage of women have completed secondary school or a technical course of instruction (13 years or more of schooling). Hence, they do not fulfil the requirement for the more productive, higher-paying jobs. Even if women attain the requisite level of education and skill, they are often unable to find quality employment due to various forms of discriminatory practices, such as gender-based wage differentials. ECLAC data show that in Latin America, women with higher levels of education (10 years and more) earn only $70 \%$ of what men earn. ${ }^{7}$

In a case study on Ecuador and Mexico, Soledad Salvador provides evidence of the poverty-education link for indigenous populations (chapter II, part 2). Data for Ecuador show that an indigenous woman in a rural area, with a low level of education, experiences the worst conditions for being overworked. Data for Ecuador and Mexico further indicate that the indigenous population, living in rural areas in households with young children, have the heaviest unpaid work burden and the most striking gender differences.

The gender gaps are widest among the indigenous and rural populations, as men spend more time on paid work and women spend more time on unpaid work. In Ecuador, the overall work burden is greatest for indigenous men and women. Taking the employed population alone, total time indicators increase and gender gaps are doubled among the rural population and tripled among the indigenous population.

See ECLAC [online] http:/ / estadisticas.cepal.org/cepalstat/WEB_CEPALSTAT/Portada. asp [date of reference: July 2013]. 


\section{Paid care services}

For Ecuador, Alison Vásconez (chapter IV, part 2) shows that the vast majority of workers in care or care-related sectors (namely, personal services, health, education and training) are employed by the public sector in health and education and by the private sector in childcare and education. More than $65 \%$ of men working in these sectors are in education and health; in the case of women, $60 \%$ work in education and domestic service. Most men working in service sectors are professionals or technicians. In contrast, the majority of women are unskilled workers, so even though they are formally employed by the government or the private sector, they are not working in high-value-added jobs, and their potential pay is correspondingly low.

Pablo Sauma makes a similar point: "The redistribution of care tasks in the home and consolidation of care as part of the social protection system would release time for women to increase their labour force participation. However, as participation alone is not enough to ensure greater equality between men and women, two additional types of policy should be implemented: employment policies that promote women's employment and reverse the mechanisms producing or reproducing discrimination against women in employment systems; and productive development policies that improve the level and quality of jobs (especially those of women), including production chains" (Sauma, chapter III, part 2).

While this expansion of care services is expected to provide excellent opportunities, it might not be enough to create all the quality jobs required by women who are already in the labour force but are either unemployed or working in low-quality jobs and by women who wish to work and whose time will be gradually released as the care network is consolidated. To increase the impact of expanded services, production growth must also be supported through direct linkages with caregiving.

Nathalie Lamaute-Brisson (chapter I, part 1) contributes to the debate with a new concept of a "care space", which "comprises a set of production activities and flows of goods and services that serve to meet people's material and emotional needs (in accordance with social norms)." She offers several ideas on how to achieve the aim of universal provision of care services in order to facilitate women's participation in labour markets by freeing up their time, create direct and indirect jobs in production chains and optimize the absorption of the female workforce, while progressively constructing an employment model for these services based on labour relations. This composite suggestion sets the 
stage for connecting time-use studies, the concern for women's double burden, the lack of monetary recognition and so forth.

ECLAC (2010b) also recommends that not only should the roles of the State, market and society be expanded, but men should increase their participation in dependent care tasks, as prerequisites for achieving a society where men and women are both breadwinners and caregivers.

\section{B. Other places, other issues}

Measuring value as a function of time allocation provides both a method of uncovering inequality and an indication of where support is required. If value were measured in terms of the time spent by men and women on various activities over the course of a 24 hour day, then the hierarchies of value would be turned upside down. Women would always come out on top! Women divide their time between the household drudgery of the three Cs (child care, cooking and cleaning) and householdbased production, none of which are included in traditional accounting measures. In addition, many women work outside the home in informal jobs that are not reported and thus are not measured. Consequently, a time-based measure of value would completely fracture the mindset imposed by hierarchies.

The nine essays in this volume, while revealing the variations in the location of women in the economy, basically address the issue of the stereotyping of women's roles. Whatever their place in the social structure or their economic role, the burden of home-based work -including caring for children, the aged and the sick and providing food for their families - falls on their shoulders. The poorer the woman's family, the greater her work burden.

The chapters explore the many ways in which the State, society and data systems have dealt with these issues. They come out with strong proposals, such as assigning a monetary value to women's work and then building these areas into the SNA; ensuring that the State provides good-quality care services; and encouraging men to share this work.

\section{The universality of unequal allocation of time}

The embedded tradition of women being solely responsible for household-maintenance work - the three Cs- is universal (Jain and Chand, 1982). A study of time use in China by the National Bureau of Statistics (2008) looks at how Chinese men and women divide their time between paid and unpaid work and compares the findings with other 
countries, such as Australia, Japan and the United States (see figure 1). The study quantifies the difference in the time that men and women spend on paid and unpaid work. It finds that the gender difference in time use is dramatically greater for unpaid work than for paid employment, based on comparative data for the countries in the North.

Figure 1

INTERNATIONAL COMPARISON OF AVERAGE TIME SPENT ON UNPAID WORK (Minutes per day)

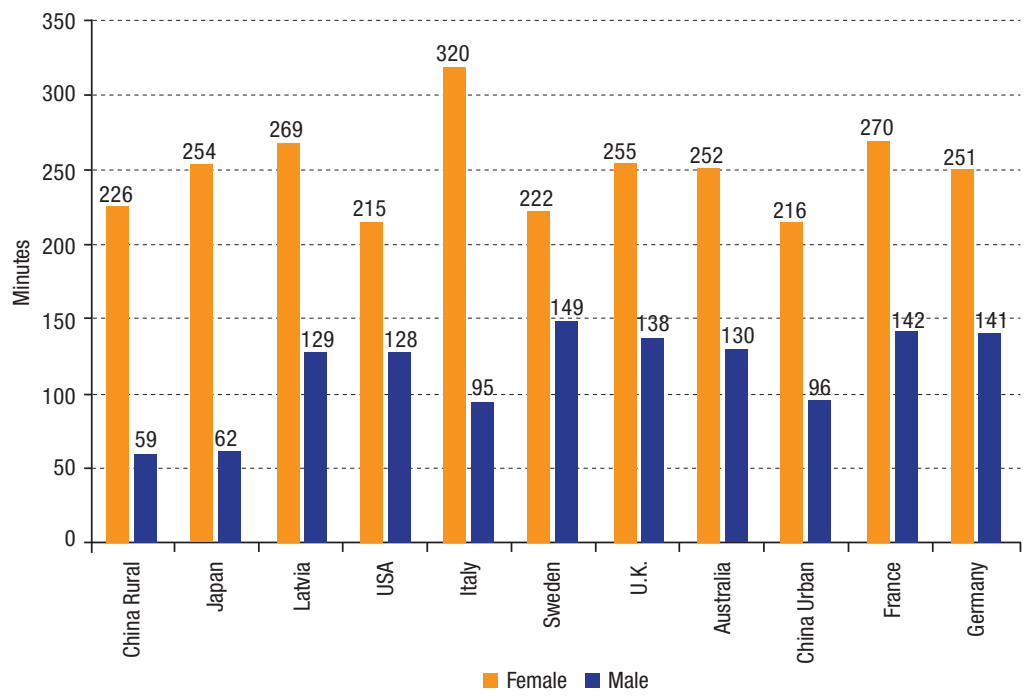

Source: Summary on 2008 Time Use Survey, National Bureau of Statistics, China.

This may explain why the dominant discourse on the issue of gender-based inequality in the North centres on care and on why men should share this work. Furthermore, the inequality in terms of time use is particularly striking in Italy and Japan, which are both deeply patriarchal societies. Curiously, Chinese men and women both spend relatively less time on unpaid work, with some of the lowest rates among all countries.

Many decades ago, the Bureau of Statistics in Japan published a survey on social life in Japan called Survey on Time Use and Leisure Activities, based on collecting time-use data on leisure, culture and health of a sample population in 1976. The same issue was uncovered, namely, that women had less leisure time than men. In addition, women were typically dismissed from their jobs during their reproductive years and re-employed after that period, as employers did not want to provide maternity leave. At that time, when asked about this deep inequality and 
discrimination, Japanese spokeswomen argued that they really loved having children and caring for the home, and they were not unhappy that the men went away to bars and geisha houses! This anecdote illustrates the deep variations across continents in terms of the issue of discrimination and the need for tailored responses by the State and society.

Some countries of the South (including cases in Latin America) are less deeply drowned in deprivation and have a lower incidence of abject poverty. For example, Argentina, Chile and Uruguay all have some form of social security. Latin America is not a homogenous region, however, and other countries, especially in Central America, have fewer or weaker social policies (Cecchini and Martínez, 2012). Studies of other continents, other economies and other failures in valuation show that apart from monetizing unpaid work, and apart from shifting the traditional sexual division of labour, there are other basic issues that time-use studies reveal, which need to be highlighted.

\section{Time-use studies from other places}

A time-use study conducted in India in 1978 (Jain, 1996) tested the hypothesis that the workforce participation rate of women in India was underestimated. The study compared the findings of different censuses and socioeconomic surveys conducted in the country from 1961 to 1978, for the states of Rajasthan and West Bengal. Table 2 presents the results.

The table presents a broad spectrum of data on participation rates from secondary and primary sources, at the state, village and sample household levels. The definitions and denominators are such that the calculations are comparable. The last column of the table, on time disposition, is computed by grouping the observed activities of all members of the 171 sample households (Budlender, 1999).

As indicated in rows 2 and 5, the percentage of the male population that is gainfully active is remarkably high. Across all the surveys and all the areas or levels of estimation, the figure for males in Rajasthan is around $89-90 \%$ and for West Bengal $81-93 \%$.

Figures for women and children vary depending on the methodology used: from 15 to $98 \%$ in the case of Rajasthan females and 8 to $62 \%$ for West Bengal; 6 to 56\% for Rajasthan children and 3 to $45 \%$ for West Bengal children. The width of the range suggests that the gainful activity of women and children is not captured by the existing research methodology with the same precision as the gainful activity of men. The numbers changed when a time-use methodology was applied. 


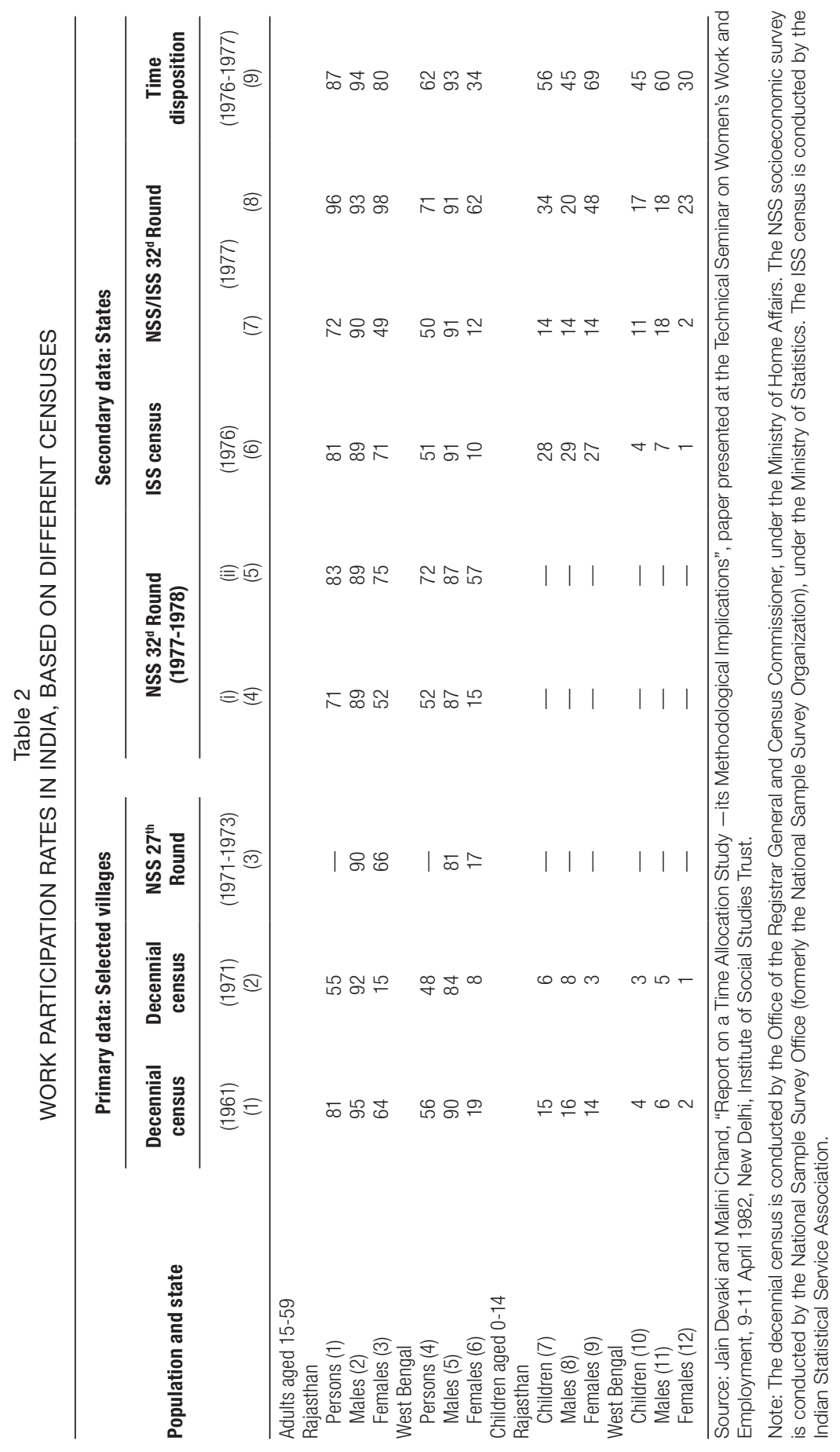


The surveys and tables highlight the fact that women were deeply engaged in gainful activities, although it was often missed by traditional accounting methods. The poorer they were (in this case stratified through land classes), the greater their labour force participation. In fact, their work participation rate (WPR) was higher than that of the men in their households. The publicizing of this fact was intended to shift the standard perception that men were the primary household breadwinners and that women's income was supplementary - a hierarchy that discriminated against women when it came to offers of credit or support to women. By showing that there were more women in the labour force than men, especially among the poor, the study called into question the stigma associated with women's work and challenged the lower ranking in the hierarchy of importance. The systematic undervaluing of women's contribution to the household and the economy has important implications for the design of policies targeting poor households, which had always assumed that men were the principal economic agents (Jain, 2013b).

This finding led to the shifting of many perceptions. For example, advocacy efforts began to focus on identifying women as workers and recognizing their economic status, so that they would be protected by labour laws. As the founder of the Self-Employed Women's Association (SEWA) stated, "We need to put poor women at the centre of economic reform and planning; we need to recognize their work as key to removing poverty. Focusing on employment will boost our economy at every level" (Bhatt, 2013).

This aspect of the quest to understand and value women's work via time-use studies is somewhat different from the goal of reconstructing the sexual division of labour or assigning a monetary value to unpaid work. It constitutes a re-identification of the worker as a member of the labour force. In many cases, this first step is the most enabling among the poorest women, even above monetizing or giving visibility to their role in household work and care.

A number of time-use studies examine how women participate in their families' income-generating activities without being recognized as wage earners. For example, in the family-based production of carpets from Kashmir, women prepare the warp and weft, while men use the loom. The women's preparatory tasks are not reported as "work" or an economic activity. Hence, any change in the technology used for preparing the loom would displace the women workers, yet the job loss would be invisible. Time-use and motion studies of this craft revealed this invisible economic work and protected the women's roles. 


\section{Household production}

Another area which is crucial for women is household production. For instance, India is the largest producer of milk in the world. The Amul development programme created a model for linking individual milk producers, many of whom are women, to a global network through village-level cooperatives. Here, women's identification as entrepreneurs or self-employed workers highlights the value of their work and gives them access to the kind of support that enables them to upscale their work. These women need organization and upscaling. With new modes of production, such as dispersed production with long value chains, these home-based workers need valuation not only of their household work, the three Cs, but also of their income-generating work.

So, while paid work does indeed have a positive impact on women's empowerment, as measured by a range of indicators, organized power is crucial for workers. An analysis of field studies in developing countries like Afghanistan, Bangladesh, Brazil, Egypt, Ghana, Pakistan, Palestine, Nigeria and Sierra Leone finds that an overwhelming majority of women with paid employment are concentrated in "informal economic activities characterized by irregular and unpredictable returns for their labour and difficult, often exploitative working conditions" (Kabeer, Sudarshan and Milward, 2013).

For women in the lowest rungs of the economy, earning a livelihood is perhaps more crucial than sharing domestic work or measuring and giving visibility to their contribution to the care economy. The primary concern is to acquire food for herself and her children. In very poor households, if the woman has a means of livelihood —even as a sex worker or a garbage picker or a domestic worker- the man plays the role of house mother.

Cornwall, Oliveira and Gonçalves (2013) write about women who are providing economic support yet still do not get recognition or rights: "Women's economic empowerment has gained an ever more prominent place on the international development agenda. Access to an independent income and the ability to determine how that income is spent is well recognized as playing a significant part in women's ability to enjoy greater control over their lives and their choices. And yet for millions of women around the world, poor working conditions, lack of recognition and rights, and lack of sources of security undermine some of the more positive, empowering aspects of entry into paid work. Many of those women work in the informal sector, doing jobs that they themselves may not even recognize as work... Some of the jobs that these workers undertake lie within the care economy, privatized and 
occluded from public view and often subject to stigma and other more symbolic forms of marginalization. Others exist on the very margins of the visible economy, dealing with its detritus and with the symbolic and actual dirt of human existence."

This is especially important for domestic workers because of the elision of paid work and what would otherwise be unpaid care work. It helps to assert the identity of worker for women who live in the homes of their employers and are exploited as part of the family.

\section{The nature of the economies}

The economies of the South are strikingly different in nature and in their primary concerns. For example, in Africa, analysis of time-use data reveals the significance of the household economy (Kes and Swaminathan, 2006). Women are primarily responsible for food processing, crop transportation and weeding and hoeing, while men do most of the land clearing.

"Women's significant, though understated, roles in economic production (agriculture and the informal sector, predominantly) and their pivotal position in household management and welfare (food preparation, health and hygiene, childcare and education) are central to sub-Saharan Africa's economic development and social survival. Time use data confirm the evidence available in the agricultural sector, showing that women are indeed the continent's principal food producers and have primary responsibility for assuring food availability in the family: they are therefore central to the attainment of sub-Saharan Africa's food security goals and to meeting family nutritional needs. There is of course the "usual" sexual division of labour. Women are the principal gatherers and users of wood for fuel and water for washing and cooking: how they do this critically affects the pace and extent of environmental degradation and the fertility of the soil. Women have primary responsibility for child rearing and family health: on this the future productivity of the country's human resource base depends" (Kes and Swaminathan, 2006).

Another dimension of these different places is the role of children, not only as surrogate mothers but as producers and workers in the formal sense. In sub-Saharan Africa, children and adolescents, particularly girls, also have important economic roles in their household. In Tanzania, girls have a heavier work burden than boys at all ages (Mason and Khandker, 1997). In Uganda, girls work 21.6 hours per week, while boys 18.8 hours a week (Uganda Demographic and Health Survey, in Ritchie, Lloyd, and Grant, 2004). A cross-country study of South Africa and Kenya also shows 
that girls spend more time on non-SNA work in the form of household chores than do boys (Ritchie, Lloyd and Grant, 2004). Liudmila Ortega Ponce's study of Guatemala (based on time-use data) also finds that the sexual division of labour is replicated from a young age (see chapter I, part 2).

In Mongolia, a time-use survey shows that most women and children are engaged in informal sector work, mainly as unpaid family labour (United Nations, 2003). Close to 37\% of children aged $12-15$ years and over are engaged in work classified under GDP activities, mainly in the informal and livestock sectors. Cattle grazing is an economic activity dominated by young boys. In societies that practice female seclusion, more boys and men are often engaged in both economic activities and activities that are usually associated with women, such as domestic workers, nurses and vendors.

\section{Poverty and inequality}

The nature and spread of poverty is grim in many areas of the South, in particular South Asia and Africa. There is no form of social insurance at all, which creates its own set of issues and problems (Dabir and Athale, 2011).

Extreme poverty changes the priorities for concern and action. For example, in Africa, poor households depend heavily on their members' time and labour for the provision of goods and services that are essential for their well-being and survival. "When faced with severe time constraints, and lacking the economic resources to access market substitutes, these households may have to resort to making trade-offs between activities which may directly affect their members' well-being. These may be short-term intersectoral trade-offs, as well as intergenerational tradeoffs with reaching consequences. The negative impact of these trade-offs can be observed in various dimensions of 'human poverty' such as food security, child nutrition, health and education. For instance, time that has to be allocated to care responsibilities may cause individuals to forego certain responsibilities in subsistence agricultural production which may adversely affect agricultural output and consequently threaten household food security and compromise child nutrition and health" (Kes and Swaminathan, 2006).

The HIV/AIDS epidemic in Africa had a strong impact on women's roles. Traditionally, elder women always provided the last-resort refuge for their families, so they were deluged with the sick and orphans, who required separate homes. If the care of sick children had been socialized by the State, then there may have been less devastation. The issue here 
was not about reallocating domestic work to men or monetizing unpaid family care, but of governments intervening to provide the care.

Bollinger, Stover and Seyoum (1999) investigate the labour losses associated with the AIDS epidemic in Ethiopia. They find that the time women spend on agriculture fell from 33.6 hours per week for non-AIDSaffected households to between 11.6 and 16.4 hours for AIDS-affected households. The most time-consuming activity for women in HIV/AIDSaffected households is nursing at home, which amounts to 50.2 hours per week on average. The study highlights the trade-off between women's childcare responsibilities and nursing duties. Women in non-AIDSaffected households spend 25.7 hours per week caring for children, while women in AIDS-affected households spend between 1.9 and 13.1 hours per week on childcare.

\section{Care}

The current literature includes a number of interesting explorations of women's work, including studies that link production and reproduction and expositions of the care economy. Care work is largely in the hands of women, and its lack of recognition at all levels is at the heart of women's labour issues. Recent studies are therefore addressing the measurement of care work, reward mechanisms and its link with the stereotyping of the sexual division of labour.

This field is being transformed with the proposal of new concepts such as giving formal value to care, so that it can be factored in structurally and included in social protection systems. In the chapter "Redistributing Care: The Challenge of Public Policies", Nathalie Lamaute-Brisson argues that "since with liberalization, globalization and more education, women are entering the formal labour market, they have less and less time for their traditional care work. It is thus essential to redistribute total work, both paid and unpaid, but especially the unpaid care work done within the home, basically by women. Accordingly, a more active role for the State, the market and society is recommended, together with male participation in personal care, as necessary conditions for progress towards a society in which men and women alike are both breadwinners and caregivers" (chapter I, part 1).

This approach is reminiscent of a movement started in Great Britain in the 1970s, called wages for housework, which called for the remuneration of household chores. At that time, many feminists from the South were critical of the movement. They considered it off-track to ask for the monetization of housework given that many women in the South, 
especially among the poor, received no recognition or remuneration for work that explicitly added to GDP, such as weeding or threshing.

Valeria Esquivel, of the National University of General Sarmiento in Buenos Aires, while appreciating the utility of time-use data in revealing unpaid care and its implications for public policymaking (in terms of providing public infrastructure), emphasizes the need for a more precise definition of the care economy. Care basically refers to the care provided to children, the old, the sick, the disabled and other members of society, and it encompasses the provision of health, nutrition and education and activities such as cooking, washing, cleaning, and the general upkeep of the household. Infrastructure facilities such as water and energy are not part of care. Esquivel suggests that the concept of care needs to be defined before undertaking the data analysis to distinguish between unpaid SNA work and care.

This is an important categorization for countries characterized by deep poverty, an agrarian economy and a sharp need for income-earning opportunities. It highlights the need for the State to provide these basic civic amenities, which are taken for granted in most countries of the North and in many parts of Latin America and East Asia. However, they are extremely inadequate and unavailable in large tracts of sub-Saharan Africa and South Asia. The separation of "services" and valuation enables policy, as it reveals the central importance of the State's role in providing these basic civic amenities.

Community-driven facilities like the corn-grinding mill in Burkina Faso, which allowed women to save time and was operated as a group service, or India's government-sponsored Integrated Child Development Services (ICDS) scheme, which is built around a community, offer examples of how to reduce the burdens of the really poor. The ICDS is India's response to the challenge of providing preschool education and increasing learning capacity, on the one hand, while reducing malnutrition and child morbidity and mortality, on the other. The programme provides free meals and preschool education, sponsored by the State. ${ }^{8}$

These are some of the ways in which countries with a very high incidence of poverty and extreme poverty need to handle the burden of household work.

\footnotetext{
8 See Department of Women and Child, Government of India [online] http:/ /wcddel.in/ icds.html [date of reference: May 2013].
} 


\section{A platform for women of the South}

\section{A gendered view from the South}

In the 1970s, economists began reworking development models by introducing new statistical indicators to measure progress or change. The so-called indicator movement began in the mid-1970s with the development of the Physical Quality of Life Index (PQLI) (Morris, 1996), which was soon followed by barefoot economics (Max-Neef, 1981), the first meeting of The Other Economic Summit (TOES) ${ }^{9}$ in 1984 and ethical economics (Henderson, 1991). Each of these ideas puts forward new indicators or measures of economic and social transformation to advance an alternative economics (Jain, 2005).

Studies of gendered experiences revealed the existence of other economies, other political spaces, other social relations and behaviours, other values and other measures of value (Henderson, 1996). Henderson notes that current economic thinking (and measures) ignores the unpaid contributions of the household and community. She writes that the market economy "cannibalizes" these contributions and that the entire economic edifice rests on them.

According to Eisler (2008), "current economic models fail to take into account life-supporting activities of nature". She discusses alternate economic analyses and how they provide important insights for constructing a "partnerist economic theory... They provide the building blocks for an economic model that includes all six of the sectors that actually compose economic systems: the household economy, the unpaid community economy, the market economy, the illegal economy, the government economy and the natural economy. Once we recognize all these economic sectors, we can envision a new theoretical framework for economics."

The most common measure of progress is currently gross domestic product (GDP). What is GDP, and what does it measure? According to a group of mischievous indicator specialists at Yale University, "the GDP and its various proxies — rates of growth, expansion, recoveryhave become the very language of the nation's economic reportage and debate. We literally cannot think about economics without them. Yet these terms have increasingly become a barricade of abstraction that separates us from economic reality. They tell us next to nothing about what is actually going on. The GDP is simply a gross measure of market activity, of money changing hands. It makes no distinction whatsoever

See the web site at http:/ /www.toes-usa.org. 
between the desirable and the undesirable, or costs and gain. On top of that, it looks only at the portion of reality that economists choose to acknowledge - the part involved in monetary transactions. The crucial economic functions performed in the household and volunteer sectors go entirely unreckoned. As a result, the GDP not only masks the breakdown of the social structure and the natural habitat upon which the economy - and life itself - ultimately depend; worse, it actually portrays such breakdown as economic gain."10

In 2008 French President Nicolas Sarkozy established the Commission on the Measurement of Economic Performance and Social Progress in response to concerns about the limits of GDP as a measure of economic performance and social progress. A number of leading economists were appointed to the commission, including Professor Joseph E. Stiglitz, Professor Amartya Sen and Professor Jean-Paul Fitoussi. The primary objective of the commission was to outline new metrics that take into account factors like education, gender equality and environmental sustainability.

As these examples show, valuation and how it is measured have been on the agenda for a long time. Women need to add their voice to this discussion, putting forward propositions not only for accounting for unpaid work or housework, but also for identifying and reporting other areas that are neglected by traditional measures of work and productivity.

\section{Location of women in the South}

While paid work has had a positive impact on women's empowerment, as measured by a range of indicators, it has been the strongest and most consistent for women in formal employment. A recent volume of essays (Kabeer, Sudarshan and Milward, 2013) on studies conducted in Afghanistan, Bangladesh, Brazil, Egypt, Ghana, Pakistan, Palestine, Nigeria and Sierra Leone shows that women engaged in formal paid work make up only a small minority of working women. "The overwhelming majority of women in these as in most developing countries are concentrated in informal economic activities characterized by irregular and unpredictable returns for their labour and difficult, often exploitative working conditions. Furthermore, impacts were largely restricted to changes at the level of individual women and their families. The new hyper-mobility of capital, able to pursue cost-cutting strategies on a global scale, has meant that multinational companies can

10 Clifford Cobb, Ted Halstead, and Jonathan Rowe, "If the GDP Is up, Why Is America Down?", The Atlantic Monthly, October 1995, pp. 59-77. 
relocate, or use the threat of relocation, to bring the disciplinary pressure of large pools of unemployed or underemployed workers to bear on the unionized workforce. Moreover, the fragmentation of production processes and the pursuit of flexible labour market strategies have replaced the concentrated and stable workforce of the earlier period with a disaggregated, dispersed, largely informal —and increasingly female- workforce. The structure of such work inhibits the emergence of collective identity interests. The difficulties that women workers face in becoming unionized by virtue of their location in precarious forms of work would therefore appear to have been further compounded by these changes in the environment for organization" (Kabeer, Milwad and Sudarshan, 2013).

Considering that these are the locations of women, what are the economic programmes supporting these millions of women? Efforts need to focus on organizing their collective strength, not only to consolidate their identity, but also to improve their bargaining position. To this end, time-use studies should be used for designing policy and increasing women's leverage, not just for monetizing care work or asking men to share the burden. It should be made a tool for enabling women (Jain, 2013b).

Many of the advantages gained from international production and global trade chains originate in cheap labour, feeding developedcountry retailers making vast profits. This labour often consists of workers so desperate for an income that they are forced to work in illegal, overcrowded and highly precarious - not to say downright inhumaneconditions that fall far short of any safety, health or environmental standards. In Bangladesh alone, it is estimated that at least 1,800 garment workers have been killed in factory fires and building collapses since 2005. Women are often overrepresented in the garment sector, which accounts for an estimated $85 \%$ of workers in the global clothing industry. It is suggested that employers prefer women because they are excluded from male-dominated union movements and so are less likely to strike, and also because they are paid less, even where they do the same work as men (The Guardian, 2013).

\section{Towards a platform for the South}

International institutions, including the United Nations and its agencies, the World Bank, universities and high profile think tanks, are now exploring gender and collecting information on gendered experience in various disciplines and programmes. In earlier decades, institutions like the World Bank proposed that investing in women would lead to significant outcomes, for example, that investing in women's education 
would lead to a fall in fertility rates. Such approaches were widely criticized by feminists as being instrumentalist and inadequate for achieving the intended goals.

More recently, Branisa, Klasen and Zielger (2013) examine the effect of gender inequality in social institutions and its relationship to development outcomes. By characterizing and applying the recently developed Social Institution and Gender Index (SIGI) ${ }^{11}$ and its subcomponents, they show that countries which display higher levels of discrimination against women also performing poorly on a range of development indicators. They argue that if policymakers and donors can improve their targeting of discriminatory social institutions, the resulting programmes will not only empower women and girls and secure their fundamental human rights, but also contribute to poverty reduction, economic growth and development. The study also finds that the level of corruption is higher in countries where social institutions inhibit the freedom of women to participate in social life. Here is yet another reason for valuing women! Finally, the paper shows that these gender inequalities are rooted in gender roles that evolve from (often informal) institutions which shape everyday life and form role models which people try to fulfil and satisfy. This points to the ways in which women are also trapped by perceptions of what is a role model.

The 2008 global financial crisis has woken up the emerging economies. Prior to the crisis, the Southern countries were more engaged with the North than with each other. However, after the economies of the North went into crisis and dragged the South into it too, developing nations have woken up to the idea of bonding across our continents, as evidenced by the BRICS group. As Prashad states, "The call for participation is not a call for a parochial localism. Abdalla proposed that the States of the South forge regional linkages to take advantage of what they could share with each other and to create solidarity blocs that would be able to withstand the pressure from the North. Small States, weakened States and States with elites who had no stomach to stand against the G7 would be strengthened by such solidarity" (Prashad, 2013, pp. 13132). Solidarity would also enable the countries of the South to resist the exploitative production chains associated with the manufacturing structure through which they generate a large share of their income.

Prashad also puts forth the idea of a Bank of the South, which would provide both a form of liberation and a mechanism for sharing wealth and opportunity within the South family. The South Commission came to a

11 The Social Institutions and Gender Index (SIGI), launched in 2009 by the OECD Development Centre, was the first attempt to capture, quantify and measure social institutions that discriminate against women and girls. 
similar conclusion: "Finance has proved to be the critical missing link in the entire range of south activities. Schemes of cooperation whether in trade, production and investment, education or science and technology, need adequate financial resources to be viable. We have selected several areas in which cooperation in financial matters or financing of cooperation in economic matters is greatly needed in the long run... notably a South Bank, which would initially finance trade and ultimately provide development finance" (South Commission, 1990, p. 165).

The BRICS platform, in its current form, is limited in many ways. One particular limitation is that the BRICS association has not endorsed an ideological alternative to neoliberalism. Although BRICS is the first formation in thirty years to "challenge the settled orthodoxy of the global North", the association does not promise any kind of revolutionary transformation in the world order. "It might emerge out of convulsions from below, where there is no appetite for tinkering with a system that most people see as fundamentally broken" (Prashad, 2013, pp.131-32).

As far back as 1987, the chairman of the South Commission, Dr Julius Nyerere, anticipated the dangers for the countries in the Southern continents if they did not form their own economic clubs and mobilize their own resources to design their own political economy destiny (Jain, 2013a).

It is critical to create a platform in the South for discussing where women are located and for negotiating a better position in the new arrangements in the international agreements. The MDG agenda is also being reconstructed for the post-2015 period. The United Nations is already recruiting intellectuals, committees and governments to research and design the new agenda. The process is more participatory this time: everything is available online, and everybody, even citizens of individual countries, is invited to give their views on what should be the post-2015 development agenda. This is an opportunity for the countries of the South to demand that sustainable development goals (SDGs) be designed taking into account the views of women from the South. An agenda for the South should move away from globalization to enable building both advice and resistance from South continents.

Outreach work needs to shift from addressing issues related to gendered identity to giving opinions on the larger spaces where political economy decisions take place. Many globally constructed ideas are now being discussed, such as the creation a South Bank mentioned above, the use of cash transfers to reduce the impact of poverty and the expansion of access to tax havens, an idea that was brought up at the Group of Eight (G8) summit held in June 2013. 
Nevertheless, it is important to engage with the regional agendas, especially in the continents of the South. The regional United Nations agencies need to set up their own MDG-style goals, to ensure that they are relevant and can be monitored at the regional level. Women in these regions need to participate in proposing this alternative, to ensure that the goals are intercontinental rather than global.

Therefore, the countries of the United Nations should create a design for women to implement and then set up country-level systems, with parallel systems in the regional United Nations offices to monitor the initiative. There are enough regional and interregional mechanisms to do this. South Asia has the South Asian Association for Regional Cooperation (SAARC), and though it has been weakened by the conflicts between South Asian countries, there are dozens of sub-SAARC links and associations that can design the agenda. Africa is in an even better position, with the African Union and many subcontinental agencies. Latin America is also building a continental identity, through subjectspecific networks. The new SDG agenda could thus be led by women's understanding of inequality and poverty. Such intervention would make it unnecessary to demand a gender focus, as women would lead the process with a gendered understanding of development.

This goal of gender equality and women's empowerment has evolved out of international mandates, especially those of the United Nations. The United Nations, being a world body, chooses issues and emphases that are as universal as possible. For example, care work and violence against women are universally experienced whether the women are in a rich country or a poor country. However, turning gender equality into a global agenda has limited the possibility of differentiating priorities based on conditions of difference. Furthermore, these goals are not attainable without major changes to the macroeconomy and external pressures.

There is space for the continents of the South and advocates for justice to work together and to engage with the new arrangements for sharing experience and building economic and political justice, as a goal of progress. Rebuilding measures of progress and doing advocacy intercontinentally could be important roles for the women of these regions and the regional United Nations agencies. The time for this is now, as the global economy is trembling with uncertainties. Women are the most affected by its crises, and they are also the most energetic and creative thinkers in the world. 


\section{Bibliography}

Arza, Camila and others (2012) "Gendered impacts of globalization employment and social protection", Gender and Development Paper, No. 16, United Nations Research Institute for Social Development (UNRISD).

Bhatt, Ela (2013), "Looking back on four decades of organizing: the experience of SEWA", Organizing Women Workers in the Informal Economy. Beyond the Weapons of the Weak, Naila Kabeer, Ratna Sudarshan and Kirsty Milward (eds.), Zed Books Radical Publishing House.

Bollinger, L., J. Stover and E. Seyoum (1999), The Economic Impact of AIDS in Ethiopia, The POLICY Project, Futures Group International/Research Triangle Institute (RTI)/Centre for Development and Population Activities (CEDPA).

Branisa, Boris, Stephan Klasen and Maria Zielger (2013), "Gender inequality in social institutions and gendered development outcomes", Washington, D.C., World Bank.

Budlender, Debbie (1999), The Policy Implications of Time Use Surveys: Lessons from South Africa, Department of Statistics, South Africa.

Cecchini, Simone and Rodrigo Martínez (2012), "Inclusive Social Protection in Latin America: A Comprehensive, Rights-based Approach", Libros de la CEPAL, No. 111 (LC/G.2488-P), Santiago, Economic Commission for Latin America and the Caribbean (ECLAC). United Nations publication, Sales No. E.11.II.G.23.

Corner, Lorraine (2002), "Time-Use Data for Policy Advocacy \& Analysis: A Gender Perspective and some International Examples", National Seminar on Applications of Time Use, UN-Women [online] http://www. unwomen-eseasia.org/projects/eeg/ecogov-apas/EEGProjectsActivities / TimeUseMeetIndia200210/paperLC.pdf [date of reference: May 2013].

Cornwall, Andrea, Creuze Oliveira and Terezinha Gonçalves (2013), "If you don't see a light in the darkness, you must light a fire': Brazilian domestic workers' struggle for rights", Organizing Women Workers in the Informal Economy. Beyond the Weapons of the Weak, Naila Kabeer, Ratna Sudarshan and Kirsty Milward (eds.), Zed Books Radical Publishing House.

Dabir, Neela and Naina Athale (2011), From Street to Hope: Faith-Based and Secular Programs in Los Angeles, Mumbai and Nairobi for Street-living Children, SAGE Publications.

ECLAC (Economic Commission for Latin America and the Caribbean) (2012a), Social Panorama of Latin America 2012 (LC/G.2557-P), Santiago.

(2012b), Structural change for equality: an integrated approach to development (LC/G.2524(SES.34/3)), Santiago.

(2010a), Time for equality: closing gaps, opening trails (LC/G.2432(SES.33/3)), Santiago.

(2010b), What kind of State? What kind of equality? (LC/G.2450/Rev.1), Santiago, December.

ECLAC/OECD (Economic Commission for Latin America and the Caribbean/ Organisation for Economic Cooperation and Development) (2012), Latin American Economic Outlook 2012: Transforming the State for Development, Paris [online] http:/ / www.oecd.org/dev/americas / 48965859.pdf [date of reference: May 2013].

Eisler, Riane (2008), The Real Wealth of Nations: Creating a Caring Economics, BerrettKoehler Publishers. 
Esplen, E. (2009), Gender and Care, Overview Report, London, Bridge Publications.

Hammill, Matthew (2005), "Income inequality in Central America, Dominican Republic and Mexico: Assessing the importance of individual and household characteristics", Estudios y Perspectivas series, No. 43 (LC/L.2480-P), Mexico City, ECLAC subregional headquarters in Mexico. United Nations publication, Sales No. E.06.II.G.7.

Henderson, Hazel (1996), Creating Alternative Futures: The End of Economics, Connecticut, Kumarian Press Books for a World that Works.

(1991), Paradigms in Progress: Life beyond Economics, Indianapolis, Knowledge Systems.

Hirway, Indira (2003), "Using time use data for estimating informal sector in developing countries: conceptual and methodological issues with reference to South Asia", paper presented at the International Association for Time Use Research (IATUR) conference, Brussels.

Hitoshi Mikami (2009), “Time Use Survey in Japan”, Statistics Bureau and Statistics Center, Management and Coordination Agency.

Jain, Devaki (2013a), "BRICS in a continent of hope", The Asian Age, 5 April. (2013b), "On measures of value and their purpose", paper presented at the National Workshop on Women's Work, Employment and the Indian Economy organized by the Centre for Women's Development Studies (CWDS), April.

(2011), "The contribution of women from the lowest income groups to the economy: how time-use studies can enable an accurate valuation", paper presented at the forty-sixth meeting of the Presiding Officers of the Regional Conference on Women in Latin America and the Caribbean, Santiago.

(2007), "The value of time use studies in gendering policy and programmes", paper presented at the International Seminar on Mainstreaming Time Use Survey in the National Statistical System in New Delhi.

(2005), Women Development and the UN: A Sixty Year Quest for Equality and Justice, Bloomington, Indiana University Press.

(1996), "Valuing work: time as a measure", Economic and Political Weekly, vol. XXXI, No. 43, October.

(1995), Minds, Not Bodies. Expanding the Notion of Gender in Development, Beijing. (1985), "The household trap: report on a field survey of female activity patterns", Tyranny of the Household: Investigative Essays on Women's Work, Devaki Jain and Nirmala Banerjee (eds.), New Delhi, Shakti Books.

Jain, Devaki and Dianne Elson (2012), Harvesting Feminist Knowledge for Public Policy, New Delhi, SAGE Publications India Pvt. Limited.

Jain, Devaki and Malini Chand (1982), "Report on a time allocation study: its methodological implications", paper presented at the technical seminar on women's work and employment, Institute of Social Studies Trust, 9-11 April.

Kabeer, Naila, Ratna Sudarshan and Kirsty Milward (eds.) (2013), Organizing Women Workers in the Informal Economy. Beyond the Weapons of the Weak, Zed Books Radical Publishing House.

Kapoor, S. (2012), "The economics of demography: Africa, India and China", Africa Quarterly. Indian Journal of African Affairs, vol. 52, No. 3.

Kes, Aslihan and Hema Swaminathan (2006), "Gender and time poverty in SubSaharan Africa", Gender, Time Use, and Poverty in Sub-Saharan Africa, C.M. Blackden and Quentin Wodon, Washington, D.C., World Bank. 
Mason, A. D. and S.R. Khandker (1997), "Household Schooling Decisions in Tanzania", Washington, D.C., World Bank.

Max-Neef, Manfred (1981), From the Outside Looking In: Experiences in Barefoot Economics, Sweden, Dag Hammarskjöld Foundation.

Morris, David (1996), Light in the Tunnel: The Changing Condition of the World's Poor, The Brown University Op-Ed Service, August.

National Bureau of Statistics of China (2008), "Summary on 2008 Time Use Survey" [online] http://australian-time-users-group.org/assets/docs/chinese-tus08. pdf [date of reference: May 2013].

Nunez Sarmiento, Marta (2012), "Cuban development alternatives to marketdriven economies: a gendered case study on women's employment", Harvesting Feminist Knowledge for Public Policy, Devaki Jain and D. Elson (eds.), Sage Publications.

Pérez, Amaia (2010), Cadenas globales de cuidado: ¿Qué derechos para un regimen global de cuidados justo?, Santo Domingo, International Research and Training Institute for the Advancement of Women (INSTRAW).

Prashad, V. (2013), The Poorer Nations: A Possible History of the Global South, Leftword Books.

Razavi, Shahra (eds.) (2012), Seen, Heard and Counted: Rethinking Care in a Development Context, London, Wiley-Blackwell Publications.

(2007), "The political and social economy of care in a development context: contextual issues, research questions, and policy options", Programme on Gender and Development Paper, No. 3, Geneva, United Nations Research Institute for Social Development (UNRISD).

Razavi, Shahra and Silke Staab (2012), Global Variations in the Political and Social Economy of Human Care: Worlds Apart, London, Routledge Publications.

Ritchie, A., C.B. Lloyd and M. Grant (2004), "Gender differences in time use among adolescents in developing countries: implications of rising school enrollment rates", Policy Research Division Working Paper, No. 193, New York, Population Council.

Sen, Nandini (2012), "The unsung warriors", Africa Quarterly, Indian Journal of African Affairs, vol. 52, No. 3, New Delhi, Indian Council for Cultural Relations.

South Commission (1990), The Challenge to the South: The Report of the South Commission, Oxford University Press.

The Guardian (2013) [online] http:/ /www.guardian.co.uk/world/2013/may/13/ fashion-chain-finance-safety-bangladesh-factories [date of reference: 23 May 2013].

UNDP (United Nations Development Programme) (2013), Human Development Report 2013. The Rise of the South: Human Progress in a Diverse World, New York, Oxford University Press.

(2010), Regional Human Development Report for Latin America and the Caribbean 2010. Acting on the Future: Breaking the Intergenerational Transmission of Inequality, New York.

United Nations (2010), Achieving the Millennium Development Goals with equality in Latin America and the Caribbean: Progress and challenges (LC/G.2460), Santiago, Economic Commission for Latin America and the Caribbean (ECLAC). (2003), "Country experiences: some practical cases. Part III: Time-use data unlock gender-friendly policies: the case of Mongolia", Integrating Unpaid Work into National Policies (ST/ESCAP /2236). 



\section{Introduction}

The purpose of this publication is to offer a substantial sample of the thinking over recent years about time use, its measurement and the policies associated with it in the region. Numerous studies and some policies have engaged with this field of knowledge. ${ }^{1}$ Much of the available literature has been written by academics in the United States and Europe, primarily feminist economists. In Latin America, in the main, the subject of care and its importance and meaning have come on to the gender agenda since the tenth session of the Regional Conference on Women in Latin America and the Caribbean, held in Quito in 2007.

A number of social phenomena underlie this debate. In the first place, the democratic context and the existence of gender equality policies for the last 25 years have been propitious to both the measurement of and debate about time use and its distribution between men and women. These two circumstances have given wider currency to ideas which originated in the earliest days of feminist thinking and were strengthened by their incorporation into the international agenda of the 1990s, particularly the Beijing Platform for Action. The sexual division of labour, one of the most powerful of all social, economic and cultural

1 See, for example, Sonia Montaño and Coral Calderón (coords.), "El cuidado en acción entre el derecho y el trabajo", Cuadernos de la CEPAL, No. 94 (LC/G.2454-P), Santiago, Chile, Economic Commission for Latin America and the Caribbean (ECLAC). United Nations publication, Sales No.: S.10.II.G.35., one in the series of ECLAC publications that can be consulted on the website of the ECLAC Division for Gender Affairs [online] www.cepal.org/mujer. See also the pioneering studies of María de los Ángeles Durán and the work of Cristina Carrasco.

2 See Economic Commission for Latin America and the Caribbean (ECLAC), Women's Contribution to Equality in Latin America and the Caribbean (LC/L.2738-P), Santiago, Chile, 2007 [online]: http://www.eclac.cl/cgi-bin/getProd.asp?xml=/publicaciones/ $\mathrm{xml} /$ 0/29400/P29400.xml\&xsl=/mujer/tpl-i/p9f.xsl\&base=/mujer/tpl/top-bottom. xslt, and What Kind of State? What Kind of Equality? (LC/G.2450(CRM.11/3)), Santiago, Chile, 2010 [online]: http:/ /www.eclac.cl/id.asp?id=40123. 
structures, has not disappeared, and it is cyclically renewed whenever the importance of women's work is addressed.

Secondly, concerns about personal care and public responsibilities have been given urgency by demographic changes and the resulting social care needs and demands. There are more and more dependent people requiring special care and social protection within a rights framework, and public- and private-sector services are still few and far between. Consequently, women continue to bear the main responsibility for elder care, even as older adults become increasingly numerous, and for the still sizeable child population, and this is without considering the changes in public health systems that have left households - and, once again, women - to cope with the processes of health and sickness.

However, it is the acknowledged need to bring more women into the workforce that has led societies and some governments to think about what Darcy de Oliveira (2005) has called a re-engineering of people's time. $^{3}$ The incorporation of women into the workforce does indeed call for a new pact that includes redistribution of time as a way of countering the labour market segmentation, unprotected working conditions and wage gaps affecting the female population. Numerous studies have shown that it is the lack of alternatives to family responsibilities that is preventing even educated women from securing higher-quality jobs with social protection.

The care concept is a multidisciplinary one that requires the sexual division of labour to be understood as part of a non-inclusive development model where service provision (by women, without payment) is in crisis. Society is faced with a crisis in the social organization of care, by which is meant the interrelationship between economic and social care policies. What is at issue is how provision of the care that underpins the workings of the economic and social system is to be distributed and managed. Analysing the social organization of care means considering the demand for care and the people providing services, and also the welfare regime responsible for meeting that demand. The social organization of care entails distribution of responsibility for the provision of welfare between the market, families, the community and the State (Arriagada and Todaro, 2012). ${ }^{4}$

3 Rosiska Darcy de Oliveira, "Reengenharia do tempo", paper presented at the thirtyeighth meeting of the Presiding Officers of the Regional Conference on Women in Latin America and the Caribbean, Mar del Plata, Economic Commission for Latin America and the Caribbean (ECLAC), 7 and 8 September 2005 [online] http://www.eclac.cl/ mujer/reuniones/mesa38/R_Darcy.pdf.

$4 \quad$ Irma Arriagada and Rosalba Todaro, Cadenas globales de cuidados: el papel de las migrantes peruanas en la provisión de cuidados en Chile, UN Women, 2012 [online] http:/ / www.cem. cl/pdf/cadenas_Chile.pdf. 
Care (both paid and unpaid) and human reproduction have been treated as an externality of the economic system (Carrasco, 2003; ${ }^{5}$ Picchio, 19996). A constant in the different schools of economics over the centuries has been their tendency to overlook the domestic sphere and its relationship with the rest of the economic system, or to carry out only a partial or faulty analysis.

Care, whether paid or unpaid, creates value, but it also reproduces or confronts cultural values and structures such as the family and the sexual division of labour. Care is bound up with women's agency, the autonomy of individuals (both givers and receivers of care), the role of institutions, public policies and the role of the market and the State. Given all this, a rights-based approach to the analysis of care should strike just the right balance between criticism of welfarism, integration of the concept of total work (the sum of paid and unpaid work) into policy analysis and the redistribution of time between the sexes and institutions (State, market and family).

Care as a subject for research and public policy is in transition, away from its association with subjectivity and affect (the logic of sacrifice) and towards full recognition as a right, and thus as a global public good. The studies presented here help to make the connection between phenomena of different types such as demographic change, the shifting epidemiological profile, female education and women's entry into the paid labour market, and State responses in the light of this concept.

Women pay an extra cost in society because it is they who devote themselves to reproductive tasks (greater social costs in the form of health care, lower rates of participation in paid work). The evidence also shows that women receive a lower wage than men for the same job and that they are overrepresented in care-related careers (health care and education, for example), which are the lowest paid, and have far less of a presence in cutting-edge careers such as engineering. Given this situation, the analysis of care from an economic, social and cultural perspective aims to lay bare the various difficulties women face. The analysis of care confronts traditional economics by setting a value on unpaid work, and with traditional sociological analysis by extending the study of unpaid work beyond the boundaries of the family.

The region's persistently high levels of social inequality make it a global outlier, and, partly as a result, social protection analyses have

Cristina Carrasco, "Los tiempos de trabajo: entre la casa y el mercado. Nuevas aproximaciones de análisis de resultados", paper presented at the Meeting of Experts on Time-use Surveys, Santiago, Chile, 11 and 12 December 2003.

6 Antonella Picchio, "Visibilidad analítica y política del trabajo de reproducción social", Mujeres y economía, Cristina Carrasco (ed.), Barcelona, Icaria-Antrazyt, 1999. 
focused not only on risks or changes arising in the life or work cycle but also on structural situations of poverty, unprotected employment and non-access to basic rights. It is for this reason that social protection policies have emphasized assistance for the vulnerable rather than the universalization of social welfare.

Freedom of time use is a dimension of welfare, and time, like money, is distributed unequally within households. Time poverty is thus a form of want, a deficit that affects freedom. However, a view of poverty that equates it with a lack of income or resources below a certain threshold reveals nothing about the allocation of time within households, even if domestic production is required to bring consumption up to the level of non-poverty; official measures do not properly gauge household needs.

Despite all this, time poverty is still not considered in poverty alleviation policies. Nonetheless, time-use surveys can be very helpful, even for initiatives centred on income poverty. There has been a shift of focus in income poverty alleviation policies in the last two decades, involving the application of wide-coverage programmes pursuing a variety of procedures and objectives that encompass service provision and income transfers, sometimes conditional on certain requirements being met. These initiatives are mainly oriented towards women, and empowerment and social recognition for women have been among their unintended effects, but often too they treat them as intermediaries between families and the State whose time elasticity can be taken for granted.

This book is divided into two parts. The first contributes to the discussion on the implications of acknowledging the sexual division of labour in public policy. The second presents the experience in these areas by analysing data from countries including Costa Rica, Ecuador, Guatemala and Mexico.

The concept of total work, models for the household division of labour, the redistribution of care work and care from the perspective of subjectivity are some of the topics reviewed from a variety of standpoints. The economist Devaki Jain introduces the book's nine chapters, giving an overview that also brings in experiences from other regions of the world. On the basis of this cross-reading, Jain argues that the unequal division of time between men and women is universal.

The first part of the document offers a number of perspectives on the care economy, especially time-use surveys, the measurement of unpaid work in the national accounts, and public social protection policies and their relationship to gender equality, in addition of course to a careful look at the redistribution of care in societies, an issue some countries in the region are starting to address. Nathalie Lamaute- 
Brisson, Patricia Provoste, Flavia Marco and Corina Rodríguez are the authors who address this challenge.

In her article "Redistributing care: towards a public policy nexus", Lamaute-Brisson proposes redistribution of care tasks and responsibilities as part of a nexus of interconnected policies to reverse the maternalist perspective characterizing the distribution of care, together with the employment policies to go with this proposal. Her suggestion is for universal provision of care services, freeing up women's time to facilitate their participation in paid employment, create direct jobs and generate scope for productive linkages while progressively constructing an employment model that does away with the structure of occupational segmentation. To meet this challenge, it will be necessary to begin changing employment regimes through policies that incorporate gender equality in respect of labour market participation, working conditions, pay and access to social protection.

The spaces of care are unbalanced. Provision is preponderantly carried out within households, to the detriment of women's economic autonomy. These spaces are also highly fragmented: on the one hand, markets for care services are segmented; on the other, poor households have no access at all to these markets and only limited access to the benefits of the few reconciliation policies that exist, such as parental leave. Accordingly, there is a need to consider total work by linking two central, interrelated goals:

(i) increase labour market access for all women (in terms of both participation and paid working time), irrespective of their family status (mother, daughter or spouse), activity status (inactive, unemployed, employed) or type of employment (as wage earners or in self-employment, for example). This means evening out the work-life balance for men and women, freeing up the latter's time and inducing men to take a significant degree of responsibility for the care of human beings;

(ii) doing away (gradually) with the occupational segmentation affecting women because of different mechanisms of discrimination against them in the home and employment system.

The universal caregiver model (with everyone acting as both breadwinner and caregiver) is undoubtedly the best option for achieving gender equality. It represents a turn away from androcentrism, reduces the likelihood of opposing roles (men as breadwinners, women as caregivers) opening up earnings gaps, and makes it possible to equalize leisure time, i.e., redistribute the burden of care between men and women. 
In "Social protection and the redistribution of care in Latin America and the Caribbean: the breadth of policy", Provoste analyses the implications of redistributing care in Latin America and its nexus with social protection. For her, the redistribution of personal care is crucial to social protection in the region in the twenty-first century. The need may be said to be urgent, arising as it does not only out of political and cultural trends towards gender equality in the public and private spheres but also out of profound transformations in society (ageing, rising levels of education and paid work among women and new morbidity profiles, among other things) that are rendering traditional care services, norms and social arrangements obsolete and ineffective. The author argues that there has been little progress with the conditions under which care is provided, and that this is still largely confined to the home. Of the three elements reviewed, services, time and money, the progress that augurs best for the redistribution of care has been in increasing the visibility of unpaid work in the home, which still has little impact on the design of services and cash transfer policies. She emphasizes the need for conceptual and methodological integration of the goal of egalitarian redistribution of care into different areas of policy and services for different target groups. In particular, she argues, progress is needed towards integrated, comprehensive dependency policies, with a focus on new linkages between the market, the State, the community and the family that do not depend on women.

Conceptual recognition of the family as a sphere of social protection, the author stresses, opens the way to recognition for domestic work and the role of women in the functioning of the economy and the welfare of society through the unpaid work done in the home. This was one of the key proposals of the tenth session of the Regional Conference on Women in Latin America and the Caribbean (Quito, August 2007), whose participants agreed, among other things:

(xiv) To adopt measures in all spheres of institutional democratic affairs and, in particular, in economic and social areas, including legislative measures and institutional reforms, to ensure recognition of unpaid work and its contribution to families' well-being and to countries' economic development, and to promote its inclusion in national accounts;

(xxiii) To develop instruments, especially time-use surveys, for periodically measuring unpaid work performed by women and men in order to make such work visible and recognize its value, to incorporate their results into the System of National Accounts and to design economic and social policies accordingly; 
(xxvii) To adopt the necessary measures, especially of an economic, social and cultural nature, to ensure that States assume social reproduction, caregiving and the well-being of the population as an objective for the economy and as a public responsibility that cannot be delegated.

The Quito Consensus reflects the progress made with government measures to bring about gender equality and with analyses and debates in academia, in the women's movement and in the international bodies and cooperation agencies operating in the region, by demonstrating the contribution made by women to the welfare of society and arguing for the need to recognize unpaid work and redistribute it in society at a time of transformations that have rendered traditional models of welfare organization unsustainable.

The social protection role of the family lies mainly in care tasks carried out within the family itself and in paid or unpaid work undertaken outside the home to secure other resources or services as required to provide people with protection.

However, recognition of women's unpaid work, particularly care work, and of its importance for welfare has not proved easy to mainstream in analysis and public policy, where, notwithstanding acknowledgement of gender discrimination in public spaces and the economy, women's role in care and housework is still taken as given.

It is this set of factors that creates the need for policies to secure an egalitarian redistribution of total work, both paid and unpaid, productive and reproductive. In this context, a two-pronged rights and gender equality approach is required, with policies treating care as a factor in development.

In her article "The utilization of time-use surveys in public policy", Marco stresses that although 18 time-use surveys have been carried out in the region, efforts to integrate their results are only just beginning. She analyses the politico-institutional factors that are furthering or hindering efforts to incorporate survey findings into public policy design and evaluation in ways that might improve the linkages between the two and exploit these surveys' potential as a technical input for evidence-based equality strategies. She deals with the cases of Costa Rica, Ecuador, Mexico and Uruguay, reviewing the surveys conducted and the steps taken to integrate them into public policies.

The author argues that there are still major challenges to be overcome before these surveys are fully institutionalized at national institutes of statistics, such as planning their implementation so that they can be repeated periodically as part of regular household survey rounds, while 
lack of resources is a permanent obstacle. For the study, the author applied a questionnaire to national institutes of statistics, national mechanisms for the advancement of women and independent experts. Efforts to integrate surveys into the region's public policies have centred on the redistribution and, particularly, the recognition of unpaid work. Marco analyses the way they have been incorporated into policies on employment, social security, poverty alleviation, health care and education.

Women in Europe and the United States became critical of the invisibility of domestic and care work and began to conduct studies to make it explicit as early as the middle of the last century, but this research became further-reaching in the 1980s, centring on the issue of reconciliation between employment and family responsibilities. Latin American women increasingly entered the labour market (albeit with large differences between countries) in that decade as well, with one of the driving forces being the effects of structural adjustment programmes on household incomes and welfare. The dramatic economic situation and inability of women to exercise their rights were compounded by the problems of entering paid employment while simultaneously retaining their responsibility for family care and housework, intensified in many cases by the withdrawal of the State from the provision of health and education services. The result of this situation was that, as the years passed, feminists in the region also sought to give visibility to unpaid work and to redistribute it within the family and society.

However, the robust theoretical and conceptual output of feminist economics and sociology in particular on the subject of unpaid work has suffered from a shortage of the data needed to demonstrate and value this. Time-use surveys have filled a major gap here as a technical instrument in the service of political demands for the exercise of rights. This was the view taken in the Beijing Platform for Action, which enshrined a number of commitments for progress in this area, in response to which the United Nations proposed the International Classification of Activities for Time-Use Statistics (ICATUS) in 1997. An adaptation of this classification to meet the needs of Latin America and the Caribbean has been drafted and is now at the testing stage. Subsequently, in the Quito Consensus, approved by the tenth session of the Regional Conference on Women in Latin America and the Caribbean, the States undertook to develop time-use surveys, incorporate their findings into the System of National Accounts and design economic and social policies accordingly.

There is a direct relationship between unpaid work and employment, since for women in the region the time spent on the former is inversely proportional to the time they can give to the latter. This is why the design of active employment and labour market policies ought 
to take the situation into account, not to promote part-time jobs for women, but to create linkages with other sectoral policies, encourage the redistribution of unpaid care work and promote working and organizational practices that allow time to be used more equitably, something that requires a rethink of the idea that time spent at work is the only occupation in the day.

Dialogue between public policies and gender indicators is not easy. Not only will the degree of interest and commitment be greater or lesser depending on the political or social actor concerned, but there is often a lack of awareness of the existence and usefulness of these indicators. It is usually hard enough as it is for gender indicators to be taken into account in sectoral policy design, and it will be harder still with timeuse indicators, since policymakers are more accustomed to dealing with gender indicators such as those relating to employment than with those relating to women's unpaid work.

From time-use survey findings, it is clear that there is a need to analyse the state of care redistribution and social protection policies.

In "Women's work: some considerations deriving from an integrated approach based on time-use surveys and employment statistics", Rodríguez focuses on women's work, basing her analysis on time-use surveys and employment statistics. Women's work is an essential element in the functioning of the economic and social system. Labour market participation is the most visible dimension of women's contribution to wealth creation and to households' material living standards and economic survival. Unpaid work, argues the author, is the other side of the coin.

Time-use surveys, which are increasingly common in the region's countries, have allowed some initial assumptions to be formulated: (i) time use differs between men and women; (ii) women work more and for longer on housework and care tasks; (iii) the time spent by men on housework and care does not increase when women work in the labour market; (iv) partly as a result, the intensity of time use is greatest for women who are active in the labour market (a situation usually known as women's double shift). Labour force surveys are used to measure and characterize women's paid work. The author proposes to consider the existence of a general production boundary, which would include production within the System of National Accounts and production outside it. Thus, activities carried out by people at any time of day or night would be included in one of these categories.

In consideration of the statistically invisible work thus done by women, a variety of efforts have been made to bring this to light, and 
with it the gender inequities present in society, a fundamental issue for the formulation of equality policies.

This is particularly the case with women classified as inactive in the employment statistics. There is a well-known debate around the term itself, since women who are inactive in the labour market are assumed to be so mainly because they are very active in the home, where they are responsible for unpaid care and housework.

In these circumstances, time-use surveys are essential for producing information that can be used to ascertain, quantify and value the unpaid work people do. ${ }^{7}$ This information has also been used to calculate the value of such unpaid work in societies for the satellite accounts. In the case of Mexico, it has been put at the equivalent to $23 \%$ of GDP.

Considering, for example, goods and services produced by households for their own use extends the range of production included in the System of National Accounts. As the national case studies show, activities of this type are underexplored by labour force surveys and, although modest in scale as a proportion of all work done, they can represent a substantial contribution by some population groups in particular, including certain groups of women.

The authors of the second part of the document focus on care work from various perspectives, analysing territorial differences, subjectivity in care and its distribution between men and women.

In her study entitled "Is a new patriarchal family model taking shape in rural areas?", Ortega analyses the changes observed in the patriarchal model in rural areas of Ecuador, Guatemala and Mexico, based on processes that tend to break women's economic dependence on the male breadwinner. To this end, she reviews the patterns of time use of rural Ecuadorian, Guatemalan and Mexican women, both individually and within the head of household/spouse relationship. She examines the different roles assumed by women -in relation to those of men- as producers of goods and services for economic activity, that is production for the market, production for own use and care work.

For a general review of time-use surveys, see Valeria Esquivel and others, "Explorations: time-use surveys in the South", Feminist Economics, vol. 14, No. 3, 2008. Time-use surveys in the region are reviewed in Vivian Milosavljevic and Odette Tacla, "Incorporando un módulo de uso del tiempo a las encuestas de hogares: restricciones y potencialidades", Mujer y desarrollo series, No. 83 (LC/L.2709-P), Santiago, Chile, Economic Commission for Latin America and the Caribbean (ECLAC), July 2007. United Nations publication, Sales No. S.07.II.G.57. 
The author maintains that, notwithstanding these changes, inequity between the genders persists in the sphere of unpaid work. This is confirmed by the disparity, to the disadvantage of women, in how care work is shared between men and women and in the amount of time contributed to these tasks. This situation is compounded by the invisibility of the economic contribution made by rural women to market production, which points to the cultural and ideological burden associated with that system.

In "Modelling the intra-household division of total work: the cases of Ecuador and Mexico", Salvador analyses the distribution of total work (paid and unpaid) between the members of the different types of households and the determinants of this. Two-parent, single-parent and extended households are distinguished, as the organization of work within these will have different logics depending on the sexual and intergenerational division of labour. The study is conducted for Ecuador and Mexico on the basis of time-use surveys and employment and income surveys in these two countries.

The evidence available shows that women, and especially employed women, have the greatest overall workload. Unpaid work takes up the greater portion of women's time, by contrast with the situation for men, and within this category it is housework that represents the greatest workload and is most unequally distributed between the sexes.

The information for Ecuador and Mexico also shows that indigenous people, those in rural areas and households with small children have the largest burden of unpaid work and present the starkest gender differences.

In "Social protection and unpaid work. Redistributing care responsibilities and tasks: a case study in Costa Rica", Sauma concentrates on the rigidity of the sexual distribution of work as one of the remaining barriers in the path towards gender equality. This rigidity is especially great when it comes to the responsibility assigned to women for caring for people in their households, which constrains the equality of the sexes vis-à-vis paid work and other public activities. The main challenge to removing this barrier is the redistribution of total work, both paid and unpaid, with care in the home most prominent among the latter.

In "Social protection and unpaid work. Redistributing care responsibilities and tasks: the case of Ecuador", Vásconez discusses recent changes in the orientation of the country's welfare regime, which have opened up a debate on the State's role as provider and regulator of basic social services, recognition of work as a central factor in welfare and growth, and the need to target social and economic policies for the 
reduction of inequality. At the same time, the recent international crisis has revealed not just the powerlessness of economic systems to ensure the sustainability of employment and development but the existence of a very diverse array of survival methods among families in their efforts to cope with crises and sustain the systems themselves. Survival has largely been achieved through domestic and care work, which has also been responsible for the provision of social services in the absence of the State. Women have traditionally been responsible for this provision, usually to the detriment of their own opportunities and welfare, and with negative consequences for the economy and society's welfare.

In "Home care and the recovery of subjectivity: the case of Mexico", Flores focuses on the effects of population ageing upon the requirements for and availability of labour for care work, and its consequences (in the form of unpaid or poorly paid work) for the independence and autonomy of women from the perspective of emotion and affect. Thus, the productivist economic argument for recommending care services needs to be complemented by a comprehensive approach to care recipients, irrespective of their place in the economic system, their age or any other individual characteristic. In other words, besides considering what happens to society as a whole and within the family, there is a need to find out what people experience while they are receiving and providing care. The aim must be to provide care services that include the psychological dimension, then, in order to construct a new care economy: new actors, new relationships between them and new activities outside the home.

In Latin America and the Caribbean, most attention has been paid to the excessive strain placed on women's working time when they enter the labour market while retaining their domestic obligations unaltered. In fact, women were overworked before this. "A woman's work is never done" is still a widely used saying. But society has changed. As noted earlier, increasing labour market participation by women, combined with growing levels of education and civic participation, has gradually given shape to the idea that time too is a right and to demands for a redistribution of the domestic burden through service provision and the acceptance of responsibility by men and society. The arguments range from an equal right to free time and the necessity of time for civic, economic or social participation to the responsibility of all institutions for personal care and to a rejection of women's exploitation in the home. Taken together, these ideas are revolutionary when set against those of earlier generations.

As a result of national and international political efforts, the influence of the women's movement and the social and cultural changes 
that took place in the second half of the twentieth century, it is possible to observe substantial progress towards gender equality in Latin America and the Caribbean. However, there are still some critical issues that are delaying progress towards equality, even as social and economic change itself creates new areas and manifestations of inequality. Among the main barriers that persist is the rigidity of the sexual distribution of labour, which continues to assign responsibility for personal care in the home to women and limits equality between the sexes in paid work and other public activities.

To deal with this barrier, it is essential to redistribute total work, both paid and unpaid, but especially the unpaid care work done within the home, basically by women. A more active role for the State, the market and society is recommended here, together with male participation in personal care, as necessary conditions for progress towards a society in which men and women alike are both breadwinners and caregivers.

According to Marco's article, work is usually thought of as a source of income, even wealth, or at least as a way of obtaining the economic sustenance necessary to live. But there is a type of work that impoverishes whoever does it: unpaid work. As is well known, this is done predominantly by women and includes care work, child rearing, housework and community or voluntary work. It meets society's care and welfare needs and makes a vital contribution that has nonetheless been denied visibility and even the status of work. While this is still largely the case in academia, official statistics and public policies, there have been substantial changes; at the conceptual level in particular, there have been huge contributions from feminist economics and sociology, which have transcended their disciplinary boundaries and begun to penetrate into other scientific and political spheres. 



\section{Part one}

Impoverishing work and policy blindness 



\section{Chapter I \\ Redistributing care: towards a public policy nexus}

Nathalie Lamaute-Brisson ${ }^{1}$

As a result of national and international political efforts, the influence of the women's movement and the social and cultural changes of the second half of the twentieth century, substantial progress has been made towards gender equality in Latin America and the Caribbean (ECLAC, 2010b). However, there are still some critical issues that are delaying progress towards equality, since social and economic change itself has been crystallizing new forms and manifestations of inequality. Among the main barriers that persist is the rigidity of the sexual distribution of labour whereby women are responsible for personal care in the home, while sexual equality in paid work and other public spheres remains limited.

It is thus essential to redistribute total work, both paid and unpaid, but especially the unpaid care work done within the home, mainly by women. Accordingly, a more active role for the State, the market and society is recommended, together with male participation in care of persons, as necessary conditions for progress towards a society in which men and women alike are both breadwinners and caregivers (ECLAC, 2010b).

The author is grateful to Corina Rodríguez Enríquez, Atenea Flores-Castillo and Virginia Guzmán for their thoughtful comments and to Inés Reca for her sagacious advice. 
Specifically, what policies are required for a new care economy? Different types of policies have already been proposed (and in some cases are known to have been implemented in Latin America), encompassing care services, time for care and money for care (Provoste, 2011). The contention is, however, that the complexity of the relationship between care and the rest of the economy, together with the need for conditions conducive to women's economic independence, make it necessary to consider a redistribution of care responsibilities and tasks as a strategic goal that needs to be tied in with other areas and types of public policy.

Setting out from this, a four-stage argument will be developed. First, a conceptual case will be made for treating care as a field of social protection, within the framework of social reproduction.

Second, given that the redistribution of care responsibilities entails a new institutional equation to reconfigure both the relationships between basic institutions such as the State, firms, families and nonprofit organizations and the relationships between men and women within and beyond the family, the aim will be to construct the idea of a "care space". The challenge then will be to characterize concrete care spaces where the (manifold) challenges of redistribution can be met.

Third, this paper will outline a proposed paradigm shift for established policies and discourses in the region (and elsewhere) that approach this redistribution from the standpoint of reconciliation between (paid) work and the family (women). The lessons learned in Europe and the region about the conceptual basis of reconciliation and the actual effects of different reconciliation policies in reducing gender inequalities call for a re-examination of the linkages or interactions structuring the traditional sexual division of paid and unpaid work.

From this arises, lastly, the need to treat the redistribution of care responsibilities as part of a nexus linking care policy - the universal provision of care services- with employment and territorial production development policies, taking into account the cultural dimension of sex/ gender systems.

\section{A. Care and social protection}

How does care tie in with social protection? Although care is among the policies of European welfare States, and feminists have scrutinized both the analyses (Esping-Andersen, 1990) and the specific shape of welfare States and regimes, where care is concerned (Lewis, 1992; Sainsbury, 1993 and 1994; Orloff, 1993 and 1996; Martínez, 2005 and 2010), the question is still unanswered because the debate about the definition of care itself 
remains open. There are also different ways of understanding social protection and its institutions. The aim of this section is to link together care and social protection in order to establish the background against which the social organization and economics of care will be approached, using a new institutional equation as the basis.

Having first defined care from the perspective of social reproduction, this paper will analyse the role of social protection in the latter, transcending the idea of (social) risk that is often the cornerstone of thinking about social protection by introducing a rights approach. This approach engages with the need to go beyond the boundaries of paid work as the main reference category for social protection if a universal right to give and receive care is to be realized.

\section{Defining care: the social reproduction perspective}

It is possible to distinguish two major tendencies in efforts to define the work of care provision: one that treats care as the act of raising and bringing up children and one that approaches it in terms of the work of producing the labour force. From the first perspective, it is "work that provides a face-to-face service that develops the capabilities of the recipient" (England, Budig and Folbre, 2002, p. 459). From the second, social reproduction encompasses various types of work - mental, manual and emotional- carried out to provide whatever care is historically, socially and biologically determined as necessary to maintain life and reproduce the next generation (Laslett and Brenner, 1989, p. 383).

The first tendency, based on the idea of child-rearing, focuses only on dependent persons, although the idea of dependency is debatable (Esquivel, 2011) given that care is for all, even those who are self-sufficient.

Again, this tendency concentrates only on interpersonal relationships by conjoining feelings, responsibility and recipients' responses. Fisher and Tronto (1990) emphasize that there are a number of overlapping types or phases of care work: "caring about", "taking care of", "caregiving" and "care-receiving".

With the second approach, conversely, while the existence of interpersonal relationships is recognized, a broader perspective is taken. For one thing, this approach can encompass care provision in which the emotional dimension of caring about another's welfare is absent or for which there is no reward or compensation (care-receiving). ${ }^{2}$ For another,

Murillo (2003) thus emphasizes the sacrifice involved when there is a high degree of dependency. 
it can look beyond interpersonal relationships to consider the division of work between basic housework (cleaning, washing, ironing) and the tasks involved in direct, i.e., interactive care, with the former being an input into direct care. Thus, Albelda, Duffy and Folbre (2009) consider the interactive activities of direct care and care-supporting activities. In the former, relationships develop between caregivers and those being cared for as a result of interpersonal contact and, where applicable, the beneficiary's cooperation. ${ }^{3}$ Thus, there are processes in which care is jointly produced.

If the focus is placed on the production of new generations of the workforce (for wage employment) and taxpayers (and of the current workforce), the reproduction tendency is characterized in economics (Folbre, 2006; Picchio, 2001) by a functionalist bias that needs to be overcome.

Firstly, the functions performed by new generations as producers of value in the national economy are, a priori, undetermined. Depending on the development models applied and the performance of economies, care provision will help to produce a workforce that will go into wage employment or small-scale production for the market (self-employed workers, workers assisting in a family business) and human resources who will not succeed in participating in economic activity because of the latter's own shortcomings. ${ }^{4}$

Secondly, according to the historical sociology developed by Laslett and Brenner (1989), care is for the whole life cycle, from childhood to old age. Conversely, from an economicist perspective that focuses on people's role in the production of goods and services, the "human capital metaphor" does not apply to older people, as Folbre (2011) acknowledges. It is true that, from this same perspective, these could well be classified as a superannuated workforce. Indeed, Edwin Witte (1937), one of the

\footnotetext{
Folbre and Yoon (2008) distinguish three types of care: supervision of people being cared for, direct care and indirect care. Supervision is a reference to Folbre's (2006) analogy with a fireman to determine the time spent providing care: the author distinguishes between active caring time, meaning activities carried out with children (like the time a fireman spends actually fighting fires), and time spent in a state of readiness (the time the fireman is on call) or availability to deal with any eventuality. This latter time is essentially supervision time. It may be argued that supervision is actually a component of direct care, since it forms part of the relationship between the care provider and the person cared for.

4 In a number of Latin American and Caribbean countries, emigration for work reasons to the countries of the North or other countries in the region (ECLAC, 2010b), higher open youth unemployment and the existence of inactive workers, whether discouraged or available, who remain outside employment systems are all revealing phenomena. The latest employment surveys in Mexico and Haiti, for example, incorporate the concept of available inactive workers, i.e., people who neither had nor sought a job in the reference period for these surveys (the week before the interview) but who stated that they were available should any job opportunity arise. See INEGI (2005) and IHSI (2010).
} 
Box 1.1

DIRECT CARE AND SUPPORT ACTIVITIES

Distinguishing direct care from the housekeeping that supports it is conceptually useful, whatever the differences in the composition of care work that might exist between countries and regions and between households by socioeconomic level.

1. Separating direct care from housekeeping makes it possible to relate care tasks and their content or meaning to historically contingent representations of people requiring care and the ways in which care is provided.

2. This internal division in care production has implications for the analysis of inequalities between women in care production. For example, Duffy (2005) shows for the United States that the profiles of jobs involving direct care and indirect care are different, as, accordingly, are the profiles of people doing these jobs. Jobs involving care of the "bringing up" type are professionalized and call for significantly higher levels of formal education than jobs involving basic tasks. When it comes to setting a monetary value on hours of unpaid work, the values assigned to the different types of tasks (direct care, indirect care) are based on the specific skills required or deployed. In the case of Mexico, for example, this has led to hours of direct care being given a greater weighting in the distribution of the total monetary value of unpaid work than they have in the total time spent on unpaid work (Blancas, 2011).

3. Lastly, as Esquivel (2011) points out, "the extent to which domestic work is traded in the market depends on households' technology and monetary incomes, and this reminds us that the distribution of domestic work and unpaid care cannot be considered without reference to income inequality and poverty levels". This means that two things need to be taken into account for public policy purposes. First, besides care policies as such, consideration needs to be given to public investment in infrastructure and social services to relieve the burden of housework for all women, especially in rural areas. Second, this internal division of care production provides a better basis for considering crisis response strategies, and especially compensation for the costs in terms of forfeited earnings of taking on a greater burden of housework or direct care. This is important for the design of policies to minimize the impact of shocks on the household economy, and women's economic opportunities in particular.

Source: Prepared by the author.

earliest architects of the United States social security system, considered that companies' pension contributions were virtually equivalent to the economic amortization of the capital goods used in the production of goods and services for the market. ${ }^{5}$

5 Other economic rationales have been put forward to justify pension spending on the future superannuated workforce: decreasing worker turnover and instilling loyalty, and alleviating the burden of care on workers with responsibility for looking after older people, with a view to increasing the productivity of the current workforce (Smith, 2004). 
However, this argument ignores a group of people who did not take part in these processes, or did so only sporadically: housewives, the core category in the reproduction approach itself. Today's female caregivers produce and maintain both the new workforce and the existing one, but they also produce new generations of caregivers and replace old caregivers. The argument similarly overlooks people debarred by disability from participating in these production processes. In fact, care work in the home concerns all household members, irrespective of any role they might play in the production of goods and services, for the market or otherwise.

Care provision is thus the set of activities, processes and faceto-face relationships whereby (all) human beings are directly or indirectly produced and maintained, materially, psychologically and cognitively, in everyday life or sporadically, on an intergenerational and intragenerational scale. It comprises the social structures, norms and representations current at the time and contributes, in one way or another, to their reproduction and, potentially, their modification.

\section{Care in social protection}

Social protection is often conceived as protection from socially recognized risks associated with a reduction or loss of resources resulting from unemployment, sickness, accidents or disabilities, maternity, old age and, in some countries, the loss of people's ability to care for themselves. However, the idea of care as the basis for the reproduction of the population requires a change of outlook.

Théret (1995 and 1997) provides a definition of social protection that answers this concern, setting out from a representation of society as organized into three orders: the political order, which is one of power accumulation; the economic order, of capital accumulation; and the domestic order, where the population is reproduced.

The domestic order is not sustained by an accumulation logic of its own, but is rather an instrument subordinated to the power and capital accumulation logics (Théret, 1992a). Small-scale production for the market (in the traditional sense of the production of real goods and services) produces a surplus which capital appropriates, while the political order subjects it to the obligation of taxation. Meanwhile, smallscale market production dedicated to the production of the workforce as a fictitious commodity is instrumentalized by the economic order, ${ }^{6}$

6 Workforce status is the product of a symbolic appreciation of the capabilities and skills of individuals in the economic order. In the wage relationship, the employer is sold the time-limited right to use the worker's capabilities and skills. The wage is the "objectified form" of the workforce. 
which absorbs the potential workforce in the production of goods and services for the market.

In this context, social protection is what "secures the economic conditions for reproduction of the primary 'natural' resource represented by the population and its life capital for both economic activity and political power. Consequently, it is bound up with the biological reproduction of the human species in its twofold representation as labour force and political force" (Théret, 1997, p. 204). The social protection system is understood as a set of four types of relationships between the three orders (see figure I.1).

Figure I.1

ELEMENTARY STRUCTURE OF A SOCIAL PROTECTION SYSTEM

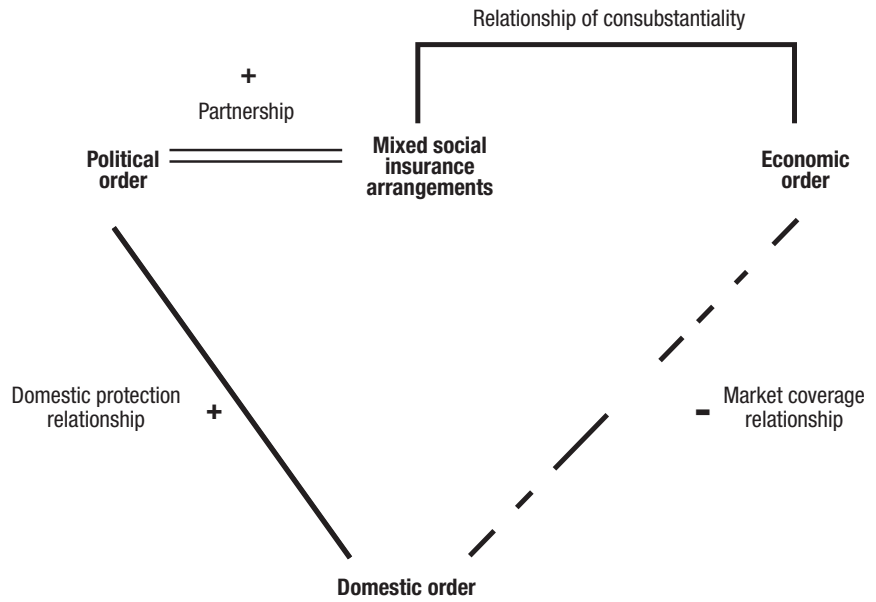

Source: Bruno Théret, "De la comparabilité des systèmes nationaux de protection sociale dans les sociétés salariales. Essai d'analyse structurale", Recherches \& Régulation Working Papers, series E, No. 1995-1, 1995.

A relationship of consubstantiality between social protection and the economic order is based on recognition that when the population is incorporated into wage employment, the labour market is unable to ensure on its own that wages match the reproduction needs of employees.

This obliges the political order to enter into a partnership with the economic order, since the protection, oversight and reproduction of the population's "life capital" is among the responsibilities that form the basis of the sovereignty and legitimacy of the State.

On the strength of its partnership with the economic order, the State enters into a direct relationship of domestic protection with the domestic order that links State legal mechanisms of political tutelage over the family to the monetary and economic mechanisms of lifelong 
reproduction of each generation. This relationship provides access, via social insurance agencies, to the collective means of consumption, i.e., to whatever goods and services are available for individual or family consumption, be it through social welfare or insurance cash transfers or through distribution in kind of social and public services (Théret, 1997, p. 206).

The relationship of direct protection for the domestic order ties in with a market coverage relationship for wage earners' reproduction. This reproduction depends, first, on wages and, second, on other incomes distributed in the market (private insurance transfers, personal saving income, company benefits, consumer subsidies).

The market coverage relationship is fundamental because it determines the ex ante structure of social protection (resulting from the gap between market incomes and needs) and closes it ex post. In fact, the monetary/financial circuit of social protection runs from the economic order to the domestic order. The contributions paid by wage workers and firms are turned into benefits by social welfare institutions. These benefits are then used to acquire the collective and individual means of consumption in the domestic order. These means of consumption, in turn, by enhancing the "life capital" of individuals, contribute to the formation of individual value that will receive recognition from the labour market or firms as a remuneration of which part will be deducted for the contributions paid to social welfare institutions (Théret, 1997, p. 207).

In this elementary structure of a social protection system, care is crucial. The output of the wage-earning workforce is rooted in the household economy. ${ }^{7}$ Invariably overlooked by economics, the household economy encompasses the care activities carried out by the unpaid labour of household members with their means of production, such as the home itself, equipment and installations and physical capital (Ironmonger, 1996), and with goods and services produced for self-consumption or purchased in the market, and is structured in accordance with the sexual division of labour. ${ }^{8}$

7 Théret (1992a, pp. 103-104) speaks of the household economy, encompassing the production of services for household members themselves, whose value was estimated for France by Chadeau and Fouquet (1981). Taking all domestic tasks together, in the late 1970 s this economy accounted for about $54 \%$ of total working hours and, depending on the monetary evaluation used, represented between 32\% and 77\% of France's market gross domestic product.

8 In the domestic order as a whole, gender determines the roles of men and women through households' means of reproduction (fertility), means of production (labour and assets) and means of consumption (Lamaute-Brisson, 2012). 
However, the connection between the household economy and production of the workforce for the economic order is debatable. In fact, the production of human resources, i.e., human energies, capabilities, knowledge and skills (Bertaux, 1977), serves for both small-scale production of goods and services for the market and for capitalist production (Bertaux, 1992), and indeed for any other economic system (Meillassoux, 2001). The household economy thus constitutes the common basis for allocating the workforce, in the broad sense of the term, to the independent work of producing goods and services (LamauteBrisson, 2012).

From this perspective, it is necessary to supplement the approach taken by Théret (1992a and 1997), who focused on the emergence of the institutions responsible for social protection as a consequence of the historical shift from self-employment (in agriculture or crafts) to wage labour. Social protection can cover self-employed work through an extension of the domestic protection relationship, as has happened in several countries of Latin America (Bertranou, 2009; Bertranou and Casalí, 2007), through the market coverage relationship, or through a combination of the two. ${ }^{9}$

\section{From employment-based social protection to universal care}

Incorporating self-employment work into the analysis is crucial, since the expansion of wage employment in the Latin American countries has differed greatly from the processes seen in the European countries (Lautier, 1987). For one thing, wage employment is reversible over the course of a working lifetime (Lautier, 1987 and 1999), either in the short or the long run, something that is manifested in labour mobility (Roubaud, 1994; Huyette, 1994 and 1997; Márquez, 1998; Chacaltana, 2006; Martínez, 2005; Schkolnik, 2006; Weller, 2007; FAO, 2010). For another, self-employment is still a major source of livelihoods, accounting for $28 \%$ of the employed population in Latin America between 1996 and 2005, according to estimates by the International Labour Organization (ILO) (Bertranou, 2009, p. 8).

Furthermore, the increase in informal working is both an obstacle to the extension of employment-based social protection and evidence of its restricted scope. Labour relations are becoming increasingly informal

Even where wage employment is extensive and almost universal, as it has been in a number of European countries, the historical development of social protection systems in Théret's sense has taken place in a variety of ways, spreading from certain core groups of protected wage earners to different strata or populations with a variety of links to employment systems (Lautier, 1999). 
in both rural and urban areas (Willson and Caro, 2010; Klein, 2009; FAO/ ECLAC/ILO, 2010). Informal (and usually unregistered) self-employment has also persisted or expanded, depending on economic circumstances, this being one of the forms of employment chosen by women who have to cope with the constraints imposed by care obligations.

All this shows the need to think of social protection as encompassing care, decoupling it when necessary from employment.

Separating care policies from employment can obviate the difficulties of extending social protection systems to workers who are currently excluded (informal wage workers, whether or not forming part of subcontracting chains, and informal and formal self-employed own-account workers and employers). Furthermore, since households may have combinations of different types of employment when there is more than one person in work, universalization is the best formula for covering all forms of employment within households, as well as women classified as inactive and women who are unemployed, so that they can be incorporated into employment.

Decoupling care policies from employment is also a way of preventing mobility within the employment system, or between this system and the outside (the inactive population), and stop employment from becoming an obstacle in the way of access to these policies, as it is now for access to employment-based social protection and pensions. These policies could perhaps play a role in mitigating the most extreme instances of female mobility between employment and inactivity in the short and medium run (Weller, 2007).

Making access to care as part of social protection independent of employment means adopting a universal rights perspective. Théret's approach is also useful here, as he considers that social protection institutions are responsible for distributing the collective means of consumption on the basis of a system of individual rights to the social and economic resources of the State. The deficit of monetary rights in the economic order, i.e., the gap between wages (and other earnings) and needs, is recognized by the State as a social credit. This entails the issuance of social rights and, ultimately, of credit rights in the political order itself, which thereby secures its legitimacy. ${ }^{10}$ With this approach, the right to receive and provide care (Pautassi, 2007) can be established as the point of entry to social protection for all human beings.

10 In this perspective, Theret notes that the "liberal" type of State found in the typologies of the welfare State does not correspond to the category of the welfare State. This type rejects the idea of the State having a social debt to wage earners and leaves it up to private organizations (in this case, private insurance firms) to make good the market deficit. 
To sum up, care is a constituent element in the reproduction of the population, ${ }^{11}$ where it operates as an instrument of capital and power accumulation and as a resource for the small-scale production of goods and services for the market. Accordingly, it is part of the field of social protection that secures the economic conditions for the reproduction of the population on the primordial basis of rights, including the right to receive care and the right to provide it.

Because of the universality principle, the rights perspective creates the challenge of thinking about social protection in a way that goes beyond the employment approach - focused on wage work, formality and stable wage employment- which characterized it in its origins.

To give substance to this vision, it is necessary to consider care from the perspective of its social organization, encompassing both the domestic sphere (family) and the non-domestic sphere (the State, firms, non-profit organizations and communities), in order to work out the lines along which the right to provide care might be redistributed. The next section, accordingly, will develop the idea of the care space.

\section{B. The care space}

The care space comprises a set of production activities and flows of goods and services that serve to meet people's material and emotional needs (in accordance with social norms). It encompasses two spheres: the domestic sphere, centred on the domestic order and families, ${ }^{12}$ and the nondomestic sphere, which is reserved for the State, firms in the economic

11 There are indications in Théret's thinking (1999) of a still incipient but promising conceptualization of people as complex beings whose identity is multiple because of their participation in the different orders and the roles they adopt in each, and in common spaces. Théret refers to Servet (1998), who argues that only with an approach that addresses the individual is it possible to construct a difference between the sexes: economics can describe some outcomes of this differentiation, but its categories do not engage with the construction of this essential difference. This is crucial, according to Théret (1999), for considering the domestic order. That order, where the difference between the sexes is promordial because of their role in the reproduction of the human species, would be destroyed if it were only a collection of individuals. This conceptualization has interesting implications for interpersonal care relationships that involve feelings, values and knowledge, so that the psychological dimension of care provision comes into play.

12 For measuring time spent on care provision within the home, there is an experimental International Classification of Activities for Time-Use Statistics (ICATUS) and a regional proposal called the Classification of Time-Use Activities for Latin America and the Caribbean (CAUTAL). The regional classification was developed recently to standardize and compare information collected in time-use surveys and provide a picture of the situation in Latin America. In the unpaid household work category, this tool includes housekeeping and care for household members, along with support for other households or the community. 
order and those carrying out small-scale production in the market with a specialization in care provision, non-profit organizations (with or without volunteer staff) and communities. ${ }^{13}$ The non-domestic sphere comprises all activities delimited by the production boundary of the System of National Accounts, while the domestic sphere is that of productive activities falling outside this production boundary.

\section{The actors in the institutional equation and their functions and roles}

The care space is shaped by a particular institutional equation, namely the combination of the roles and mechanisms that form the basic institutions, which are the family, the State and firms, plus nonprofit organizations and communities. ${ }^{14}$ This equation represents the relationships constituting the social protection system in Théret's (1997) sense. The mechanisms working outward from the State to firms are at the service of the partnership between the political and economic orders. Those working outward from the State to households belong to the domestic protection relationship, while market coverage rests on relationships running from firms to households, as opposed to relationships of coverage by non-profit organizations. These are delegated by the State or the economic order, which provides them with the financing to participate in household protection.

13 Care activities within the production boundary are measured using the classification of economic activities with its different categories (the International Standard Industrial Classification of All Economic Activities and national classifications). Four or five major activity groups can be highlighted: health care, education, care for children and the young (if separate from education) and the social services running insurance and social assistance for families (both public-sector and non-profit organizations). To these may be added the paid work of domestic staff. Albelda, Duffy and Folbre (2009) use the occupational classification to distinguish between interactive care activities and support activities carried out by paid workers. For example, doctors and nurses are included in the interactive care category while secretaries, managers, cooks and laundry workers belong to the support activities category.

14 In developing countries, non-govenmental organizations (NGOs) have established themselves directly or indirectly in the field of care, supplementing or even replacing the work of foundations or other associations and the State (Destremau and Lautier, 2006). Community organizations are also involved in the provision of care services, whether on their own initiative (Pautassi and Zibecchi, 2010) or within a public policy framework (Razavi and Staab, 2008). 
Box 1.2

THE ROLES OF ACTORS IN THE CARE SPACE ${ }^{a}$

\section{The family}

The family is generally seen only as a place where direct care and housework are carried out. Members of a household invest their time and income in it. However, it is possible to distinguish welfare production from welfare linkage (Martínez, 2005). Welfare production comprises "activities which, like those carried out by markets and States, translate into goods and services" (Martínez, 2005, p. 40). Welfare linkage refers to "activities that can be delegated (like shopping and chores, bill-paying or transporting members of the family) and activities that cannot (such as planning and organizing, controlling the finances and distributing household tasks)" (Martínez, 2005, p. 41). ${ }^{\text {b }}$ When welfare is considered as the reproduction of human beings, welfare linkage by households depends on care policies and the infrastructure and services to supplement them (transport, for instance). It also depends on the household's economic resources and the allocation of roles within it.

Welfare linkage is crucial to any change in gender relations. Women's access to paid work in European countries, thanks to the externalization of care, has not been matched on the same scale by male involvement in care activities. With this idea of linkage, the family becomes the central institution, i.e., the starting and ending point for the policies and strategies of firms or non-profit organizations. Consequently, measuring changes induced within the family and in its relationships with other institutions, in terms of both their nature and their implications for women's autonomy, will be the main focus of policy evaluations.

Households produce care services on the basis of a threefold division of care work that ties in with the complex of kinship or non-kinship relationships forming the household: (i) a division of labour by sex between adults and between children in which greater demands are placed upon women and girls, (ii) an intergenerational division of labour between parents and children, and between grandparents, children and grandchildren, and (iii) an intragenerational division between children belonging to the household and child domestic workers, or between boys and girls belonging to the household (brothers and sisters, for example).

Another input for households is care provided free of charge by other households by virtue of kinship or non-kinship relationships (fictive kinship, neighbours) and of a variety of principles underlying these relationships (reciprocity between households, exploitation of child labour).

Although paid domestic service is performed within the boundaries of the home, for analytical purposes it does not form part of the domestic sphere as such, but rather opens up this sphere to relationships between households as employers and the labour market.

\section{The State}

The State is at the top of the care space because it is potentially a rulemaking and redistributive entity. Three essential functions are considered here: (i) the regulation of roles and activities, relationships within institutions 
Box 1.2 (concluded)

and relationships between them (it is assumed that the State, in its role as an employer, complies with the rules it issues on labour relations), (ii) the production of infrastructure and services and (iii) financing, carried out both through the fiscal system and through social security agencies (social assistance and insurance).

\section{Firms}

Firms produce care services, including those that embody the nonaccumulation logic of small-scale production for the market, i.e., ownaccount caregivers. As employers, firms determine the effective access of their employees to time for care, to care services financed by the firms themselves and to financing for care services bought in from outside the firm.

\section{Non-profit organizations}

Non-profit organizations are quite heterogeneous (NGOs, foundations, associations and others). What unites them is precisely that they are not profit-seeking. Communities or groups operating under customary laws are different but can be grouped in with these organizations by the fact of their operating outside the logic of accumulation. Non-profit organizations and communities involve themselves in the provision of care services or in the provision of infrastructure for care production.

Source: Prepared by the author.

a A description of the relationships between actors in the care space can be found in annex I.1.

b This distinction cuts right across the division of care work. Some linkage activities belong to the category of interactive care (companionship or transport) while other are support activities (chores, organization of the home).

The four major types of institutions mentioned operate in the following areas:

(i) production and distribution of care services (interactive and support activities),

(ii) financing of services or of access to them,

(iii) regulation of the production of care services, and

(iv) regulation of the way the workforce is used in the production of care services.

Thus, these institutions form a relational area in respect of four types of relationships:

(i) the relationships whereby care responsibilities and activities are allocated to individuals, inside and outside households,

(ii) care relationships between people who need care or (if selfsufficient) request it, and care providers, 
(iii) inter-institutional relationships between the different actors or institutions organizing or regulating care or access to care and those providing it, and

(iv) the employment relationships between caregivers and the institutions they are attached to (including households employing caregivers) and the institutions regulating their work. ${ }^{15}$

\section{The care space and its economic setting}

The configuration and dynamic of the care space depend on the position it occupies in the economy as a whole and on the public policies that directly or indirectly influence inter-institutional relationships and production activities. The position of the care space in the economy is determined by its relationship with the employment system and with the economic structure.

\section{(a) The relationship with the employment system}

According to Picchio (2001), a labour force regulation function for economic activity is carried out within households, involving arbitrage between unpaid reproductive work and paid work in accordance with the demand for labour and conditions in the market for (paid) labour. In fact, the assignment of housekeeping and direct care to women means that arbitrage operates differently for men and women, depending on representations, employment opportunities and the relationship between pay and the costs of participation in both wage work and selfemployment. In effect, men choose between work that is paid, whether by a wage or otherwise, and leisure. ${ }^{16}$ Women choose between paid work and unpaid work, i.e., between different combinations of paid and unpaid work, depending on the (demographic) burden of care.

For them, care responsibilities are an obstacle to participation in paid work or a constraint on their performance in the system of employment, since they determine their time availability and influence their individual productivity at work (taking into account the critical role

15 See the graphic representation of the care space in annex 1 for a description of the mechanisms underlying the relationships between institutions.

16 With respect to what is commonly termed paid work, it would be more accurate, for both men and women, to speak of work in production activities that are within the production boundary of the System of National Accounts (SNA). Although these activities mainly take the form of paid work in today's world, the production of goods for people's own consumption and use that falls within the SNA production boundary generally relies on unpaid work. Furthermore, some unpaid labour is involved even in the production of goods and services for the market within the SNA production boundary (auxiliary family workers), especially on smallholdings and in informal microentreprises. 
played by the organization of production). In the case of self-employed women, this constraint may be regarded as a factor in market access and the choice of sectors of activity.

As well as flows of labour from households to the employment system, there are flows the other way, from the employment system to households, that is to say, to inactivity, owing to the expulsion of employed labour at times of crisis or because job-seekers become discouraged. Return flows are also part of the normal workings of the employment system because of the seasonal character of certain activities or labour management methods that involve a high level of employee turnover. Household members' history of occupational mobility between the different activity categories (employed, unemployed, inactive) is the manifestation of dynamic relationships between the care space and the employment system.

Employment policies or social protection policies (pensions, family allowances, unemployment benefits, conditional transfers), including those with fertility goals, determine the direction and strength of mobility flows between the different activity status categories. For example, setting out from the implicit or explicit assumption that women are an adjustment variable in the wage labour market, different policies implemented in various European countries (Belgium, France, Germany and the Netherlands) have encouraged them to enter that market or given them incentives to withdraw from it (Morel, 2006), particularly in the case of women with low skills or little vocational experience.

As a result of intra-household and individual arbitrage (Rizavi and Sofer, 2004) and the workings of the employment system, which vary with public policy and economic conditions, flows between activity status categories are determined by the arrangements that arise within the care space. Whether directly or via the economic resources that finance reproduction, these arrangements affect caregivers' time availability and the delegation of care responsibilities and tasks within or outside the household (something that may include employment of domestic workers, especially migrants).

New work-life balances are thus struck at the individual and household levels. At the individual level, those in employment arrive at different combinations of paid and unpaid work (Milosavljevic and Tacla, 2008), with one or other type of work often becoming predominant. At the household level, linkages with the employment system result from the distribution of paid and unpaid working time between household members (Salvador and Pradere, 2009; Salvador, 2009). 
Other connections arise between the care space and the employment system. Households recruit paid caregivers (whether professional or otherwise) or domestic workers to carry out support activities. Like publicsector care services, firms and non-profit organizations specializing in the provision of care services employ specialized or unspecialized labour to carry out interactive care and care support activities. Using care services, meanwhile, allows caregivers to hold or seek a job.

The volume of employment in care activities and the quality of jobs depend on the level of demand for care services, the evolution of earnings across economic sectors and the type of regulation applied to the provision of care services outside the home. For example, Penn (2007) shows how the type and level of regulation applied to the provision of care services by private-sector firms in Britain has driven up costs to such an extent that the private sector is asking for the current rules to be eased.

\section{(b) The relationship with the economic system}

The care space and the economic system are interconnected by the linkages between the production and distribution of care services and other economic activities.

Warner and Zhilin (2006) deal with the "childcare services sector" within the context of a regional economy driven by an increase in household final demand financed by the State. There are backward and forward economic linkages in care services. These employ workers, use goods or services produced by other establishments as inputs and thus produce induced effects: the spending of earnings by people working in the branches of activity that supply goods and services to care establishments. Depending on the effects of this new income on their living standards, households may change the level or quality of care.

These linkages are of a multiplier type. Output multipliers can be calculated when there is rising demand for care services because of public transfers, as can employment multipliers when there is an effect on new job creation. ${ }^{17}$ The value of the multipliers is obviously small because of leakage to the rest of the economy, i.e., purchases or savings by employed people outside a given regional economy.

17 In the case of the United States, Warner (2006) notes that economic analysis carried out on the 50 states indicated that multipliers for the childcare sector were comparable to those of other social infrastructure sectors such as higher education, training and primary and secondary education, and greater than those for retail and service firms, which are usually what local development policies target. 


\section{Reading the care space}

To reconstitute specific care spaces and monitor the construction of "national care systems" (Salvador, 2011), it is necessary to consider the different perspectives that can be applied to the above, depending on the level of analysis (macro, micro, meso) and the sphere of analysis (institutions and markets).

At the macro level, the institutional equation as a set of relationships between the State, families, firms, non-profit organizations and communities needs to be reconstituted using the different mechanisms already described. It is important to stress that there is not just one single care space but, when concrete cases are considered, a fractal space. This can be broken down by the populations receiving care and the spheres of care associated with them, with socioeconomic stratification being a more or less critical fragmentation factor depending on how arbitrage operates in public policies.

In fact, the size and nature of specific spaces will depend on the demography of the target populations in relation to the demographic transition, recognition of a universal right to care, and the economic resources mobilized. Care areas, i.e., sectors of activity such as the education sector or the health sector, are determined by the specificities of each in accordance with the population type. Childcare is related to education (including preschool education) and health care (reproductive health). Care for older people with chronic diseases or people with disabilities primarily means health care, including psychological treatment. Lastly, care deficits in poor households or those lacking time to provide care, inequalities in economic resources and the strengthening or displacement of inequalities by public policies all contribute to differences between socioeconomic strata in the extent and configuration of the care space (Razavi and Staab, 2008).

At the micro level, the focus of analysis is on the organization of care work within institutions (households, firms) and the use by them of care services from any kind of provider (public, private, collective, individual or other).

Household care arrangements result in differing demographic burdens for the people in charge of care. Besides a straightforward care dependency ratio, the intra-household distribution of care responsibilities and tasks needs to be considered. Delegating the care of young children (aged 0 to 5) to older children (aged from 8 or 10 to 15), especially daughters, is a strategy that has been documented in different countries such as Haiti (Lamaute-Brisson, 2010) and Chile in the case of women carrying out seasonal work in export agriculture (Willson and Caro, 
2009). Such delegation could be taken as evidence of a care deficit: young caregivers are not themselves being cared for while they provide care.

As is well known, the configurations of care work (activities, time, productivity) in households are the outcome of the conditions of care production: financial resources, the technology on which support activities are based and access to basic social services. Poor households usually have access to basic or outdated technologies, which means that support activities take up a lot of time, are relatively unproductive and cut into the time available for interactive care. ${ }^{18}$ In these households, the (relative) maintenance deficit (for which traditional indicators such as basic health indicators might serve as a proxy) is compounded by a personal development deficit (among children), since in less poor or richer households women tend to devote more time to personal development activities.

Another type of analysis can be applied to the structure and workings of markets or quasi-markets for care services, ${ }^{19}$ and likewise to employment in these services (Duffy, 2005; Albelda, Duffy and Folbre, 2009; Esquivel, 2010).

An important subject is the gap that can arise between the supply of and demand for care services (Escobedo and others, 2002). Excess supply -whose existence can be inferred from information on numbers of free or unused places and other indicators- is essential. Besides specific problems on the supply side, there is the problem of service usage. The crucial aspects (apart from availability, physical accessibility, pricing and affordability) are the quality, suitability and reliability of services. The existence of alternatives (inside or outside the home) to what is available in a particular market can be critical too. In the case of the expansion of market-based childcare services in Great Britain, mothers have preferred to use free infant education services, which in addition are perceived as providing an initial induction into school (Penn, 2007).

From the different studies carried out in recent years on the economy of childcare in Latin America and the Caribbean (Rodríguez, 2007; Marco, 2007; Staab and Gherhard, 2008; Lamaute-Brisson, 2010; Salvador, 2011) it can be gathered, first, that care spaces are currently unbalanced. They are characterized by a preponderance of care provision

18 The same thing happens when, for lack of economic resources or because incomes are unreliable, the day-to-day maintenance of household members involves spending time on food shopping day after day.

19 The term quasi-market is used for services provided by non-profit organizations and communities or by the State, as profit is not an aim of these bodies and this influences pricing. 
within households, to the detriment of women's economic autonomy. Second, these spaces are very fragmented. What emerges is that care service markets are segmented because poor households are unable to access them at all, while there is only limited access to the benefits of the few reconciliation policies that exist (Moreno, 2008), such as parental leave (Colinas, 2008; ECLAC, 2010b). This is compounded, in some cases, by the production or reproduction of inequalities by socioeconomic level, driven by public policies that adjust the quality of childcare services to the socioeconomic level of households or subsidize high-level care services for wealthier households, as happens in Argentina (Razavi and Staab, 2008) and Mexico (Staab and Gherhard, 2008). ${ }^{20}$

Nonetheless, a great deal remains to be done to reconstitute concrete care spaces, taking into account the differences between urban and rural areas, and between territories. Little light has been shed on the different types of relationships constituting this space and, more specifically, on the relationship between the State and firms, on firms specializing in service provision, the type of services they provide and their role in the production system, markets for care services and care provision by non-profit organizations.

There is also much to be done to ascertain care needs, expectations and demands vis-à-vis the supply of care services or mechanisms for obtaining them. Demographic estimates of care needs give an idea of the number of people who can be served and the demographic burden of care. By definition, however, only apparent care needs are expressed by the care dependency ratio (Batthyány, 2004; Budlender, 2008). ${ }^{21}$ There is a need to build up a more accurate picture of real needs, taking account of epidemiological profiles, care arrangements and their limitations, and the conditions of care production that tend to lead in one way or another to care deficits.

20 The studies mentioned do not usually deal with the care provision role of NGOs.

21 A care dependency ratio is calculated by analogy with the demographic dependency ratio, with weights assigned to the age groups requiring care depending on whether or not they need more intensive care than can be provided by potential caregivers. These calculations do not make explicit reference to the sex of caregivers: the denominator of the ratio is the total population aged 15 to 74 . From the standpoint of the redistribution of responsibilities between men and women, however, these estimates can be used to measure the challenges for both sexes. Other methods set out to measure the size of population groups in accordance with economic criteria such as parents' participation in the labour market. Setting out from the idea that this participation generates a potential demand for care for young children (aged 0 to 6), census information is used to calculate the number of children whose parents work. To this is added the number of children whose parents are studying (and do not have time to care for them) and the number of children whose parents are not in the labour market but do use paid care services (reflecting demand that has been expressed and met) to obtain the total number of children requiring care. 
It is clear that the central challenge is to construct a new care economy, i.e., an economy whose internal distribution is altered by the operation of new institutional equations so that the share of the nondomestic sphere becomes larger, enhancing the welfare of all. New institutional and economic mechanisms can be established to foster the emergence of new types of interdependence between actors, but also between the care space itself, on the one hand, and the employment system and economic structure, on the other.

This means revisiting the reference framework of public care policies in Latin America, i.e., the set of reference norms or images on the basis of which State intervention criteria are decided, together with the goals of public policy as thus modified (Muller, 1990).

For one thing, the set of (theoretical) relationships constituting the care space requires a challenge to the paradigm of reconciliation between unpaid reproductive work and paid (wage) work that underpins policies in the region.

For another, considerations concerning the role of the care space in the economy require the complexity of the linkages and dislocations between the care space and the employment system and that of production networks (within and outside the care economy) to be incorporated into public policy design.

\section{Challenges for the redistribution of care}

The idea of reconciliation refers to the arbitrage of time, space and financial resources needed to cope with care obligations and work obligations. As is well known, there are a variety of viewpoints on reconciliation ${ }^{22}$ and types of reconciliation..$^{23}$ Beyond this, however, current reconciliation policies are rooted in a maternalist paradigm that limits the options for changing the sexual division of total work in the

22 Ollier-Malaterre (2008, p. 49) notes the diversity of the approaches taken to the relationship between domestic obligations (care and others) and the occupational obligations of the labour market. In addition to reconciliation, there are a number of related ideas, such as the work-life balance and the integration or harmonization of work and family life.

23 In general, there may be said to be two major currents of reconciliation policies: those inspired by policies implemented in developed countries when creating welfare States in the region and those designed to combat poverty. Moreno (2008, pp. 111-112) says of the second type of policies that "most policies with reconciliation effects in the region were not designed with reconciliation as the primary goal, since their original intention was to meet other needs, particularly support for poor families. This ties in with the fact that universal programmes to meet the reconciliation needs experienced by the general population are usually lacking." 
home, as it tends to perpetuate the occupational segmentation of women in employment.

Consequently, public policies cannot be confined to facilitating women's participation in the labour market by freeing up their time through the redistribution of care responsibilities, but must also seek to make segmentation a thing of the past. Moving past the reconciliation paradigm thus means, first, altering the reference framework on the basis of Fraser's (1997) principles of justice, which set out from the complex of principles of socioeconomic and cultural (in)justice organizing the sexual division of labour, and thence occupational segmentation.

Similarly, the fact of universal care services being available does not automatically lead to greater participation in the labour market by women, both because of problems in matching the supply of services to care needs and because of the absorption capacity of the employment system. Nor does it open the way to desegmentation. It is therefore necessary to consider linking care policies with employment and economic development. The idea is to place care services at the centre of a territorially based nexus of care, employment and production development policies that addresses the critical intersections between the care space, employment systems and production chains.

\section{Moving past the reconciliation paradigm}

The idea of reconciliation assumes a relationship of harmonious coexistence between individuals and interests characteristic of conflicting worlds (Junter-Loiseau, 1999). It aims to shift the boundary between reproductive working time and paid working time so that women wage earners can adapt to the requirements of the employment available, which can lead them to relinquish any ambition to enter the paid employment market.

Reconciliation is based on a model constituted by the family and stable wage employment, leaving out those who have a family but no job and those who have a job but no family.

With regard to those who do have jobs, importing the idea of reconciliation wholesale and applying it to the region's countries (in both policy and analysis) tends to obscure the heterogeneity of employment systems. Evaluations of reconciliation policies acknowledge the coverage deficit resulting from the way they are targeted on formal employment, thus excluding women in the informal sector. However, little consideration has been given to the reconciliation needs and 
care arrangements of self-employed workers, most of whom are informal. ${ }^{24}$ This holds true for women participating in informal wage work, except in some instances such as that of women carrying out seasonal work in export agriculture in Chile (Willson and Caro, 2009).

As for those who do not have jobs, reconciliation is not something that is integrated into Latin American social assistance programmes targeted on the poor and, among these, on women classified as inactive (Lautier, 2004; Arcidiácono, Pautassi and Zibecchi, 2010) or lacking income. This is the case with the conditional transfer programmes that have been introduced in the region over the last 20 years, with the exception of some schemes such as the provision of care for preschool children by certain social and community organizations in Buenos Aires, for example (Pautassi and Zibecchi, 2010). These programmes change women's time use by increasing their burden of unpaid work. In effect, they force women into a linkage role in the reproduction of human beings (taking their children to doctor's appointments, attending meetings and carrying out voluntary work in communities), as González de la Rocha (2006) and Arriagada and Mathivet (2007) have shown. Women also take on the unpaid work formerly done by children benefiting from these programmes (Skoufias, 2001; Skoufias and Parker, 2001).

The instrumentalization of mothers by the State (Molyneux, 2007) is in fact the main plank of the reference framework for reconciliation. The principal goal is to reconcile female roles from a maternalist perspective (Orloff, 1996): the traditional role of caregiver and the more or less novel one of worker in the production of goods and services for the market. ${ }^{25}$ Reconciliation policies are therefore highly feminized (Junter-Loiseau, 1999). ${ }^{26}$

In addition, this maternalist character tends to perpetuate occupational segmentation, as the experience of a number of European countries has shown (Morel, 2006; Metso, 2006; Marc and Zajdela,

24 See, for example, Hernández and others (1996).

25 Pailhé and Solaz (2009) have shown that questions about reconciliation in French demographic surveys conducted after the Second World War were framed from a perspective that centred on women as mothers. Questions dealt with the legitimacy of mothers' work, the links between mothers' employment and birth rates, justifications for the interruption to mothers' careers and the factors making it hard to return to employment.

26 It must be acknowledged, however, that steps have been taken towards reconciliation of work and family life for men: a number of countries in the region have introduced parental leave for care (ECLAC, 2010b). Both in the region and in European countries, it is still rare for such leave to be taken up (Méda, 2008). Explanatory factors include the profitability of its use for men's careers and negative perceptions of those applying for leave. 
2005). In the case of the Swedish model, the high level of economic participation by women, especially mothers, is due to the large numbers working part-time in the public sector. A society-wide choice prevails: mothers have to organize their time so that they can care for their children in the domestic sphere. Parental leave helps them to do this, and the organization of childcare services forces them to, since these services are available only for children over 1 and operate parttime (Marc and Zajdela, 2005).

It follows from the above that two central, interrelated goals must be pursued jointly:

(i) increasing labour market access for all women (in terms of both participation and paid working time), irrespective of their family status (mother, daughter or spouse), activity status (inactive, unemployed, employed) or type of employment (as wage earners or in self-employment, for example). This means evening out the work-life balance for men and women by freeing up the latter's time and inducing men to take a significant degree of responsibility for the care of dependants, and

(ii) doing away (gradually) with the occupational segmentation affecting women because of different mechanisms of discrimination against them in the home and in the employment system.

\section{Redistribution and recognition}

Criticism of the maternalist character of reconciliation both in home care provision and in the structuring of paid employment markets has resulted in a new emphasis on the vital importance of the cultural, symbolic dimension of reference frameworks (Crompton, 2009).

Some authors have looked beyond maternalism in the strict sense to revisit the principle of separation/hierarchization between the sexes (Hirata and Kergoat 2004), which allocates the caregiving role to women even in the case of care for the elderly or disabled, an issue which reconciliation does little or nothing to address even though it is women who take charge of day-to-day care (Batthyány, 2009 and 2011) and instrumentalization of women is currently rife in policies designed to meet these populations' needs in the region (Provoste, 2011; FloresCastillo, 2011). 
The segmentation of production in paid labour markets - the result in Latin America of the marked productive heterogeneity of development models (ECLAC, 2010a) - is compounded by the way firms culturally discriminate between different population categories identified by selected characteristics, including personal characteristics (Reich, Gordon and Edwards, 1973; Rubery, Fagan and Maier, 1996) such as age, sex or "race". The stereotypes surrounding the capabilities and behaviour of women and men are well known (Anker, 2001), and these underpin subtle strategies or mechanisms for allowing or disallowing the participation of women (Quiñones, 2009; Rico and Marco, 2009) or assigning a low status to care work among tertiary activities (Budig and Misra, 2008).

Cultural discrimination also influences the occupational status and attainments of self-employed women and, prior to this, the construction of women's capabilities (education, skills tied to the home), time use and access to productive and financial assets.

This can be translated into the language of Fraser's (1997) paradigm: in very general terms, the division between paid productive work and unpaid reproductive work is the result of marginalization and exploitation mechanisms (resulting in income gaps and the inability to attain to adequate material living standards and leisure time), linked to mechanisms of cultural domination. ${ }^{27}$ These mechanisms are androcentrism or the withholding of visibility and respect.

The actual configurations of these material and cultural mechanisms are determined by different combinations of the principles of (in)justice governing them (see box I.3), as manifested in different models of gender relations. With the universal breadwinner model, men and women are able to participate in employment because there is a redistribution of care responsibilities from households and women to the State and the market. With the caregiver parity model, women's role as caregivers is publicly recognized as equivalent to men's role as breadwinners, entitling them to similar levels of dignity and welfare, and there is support for care provision within the home. With the universal caregiver model aspired to, men have to move closer to the working pattern of women by taking on a role as caregivers.

27 According to Fraser (1997), cultural domination is present when groups are subjected to patterns of interpretation and communication that are alien and/or hostile to their own. 
Box 1.3

NANCY FRASER'S PRINCIPLES OF JUSTICE FOR GENDER EQUALITY

Fraser (1997) proposes a set of seven interrelated principles to be used in evaluating the actual configurations of the sexual division of work. Some of these principles, which are described below, relate to the socioeconomic injustices inherent in the traditional gender order; they are the anti-poverty, anti-exploitation, income equality, anti-marginalization and leisure-time equality principles. Then there are the principles that relate to injustices based on cultural and value differentiation, namely the anti-androcentrism and equality of respect principles. ${ }^{a}$

(i) The anti-poverty principle refers to the provision of resources to free individuals, and especially women, from income poverty;

(ii) The anti-exploitation principle means leading a life free of any kind of economic dependency (at least where basic needs are concerned) that makes women vulnerable to the exploitative use of their bodies by any family member (partner or adult son), employers or supervisors and the State;

(iii) The income equality principle means the reduction of income gaps between men and women;

(iv) The principle of equality of leisure time between men and women is in opposition to women's time poverty as determined by the traditional sexual division of labour. The idea of time poverty is crucial to this principle, and can be measured by time-use surveys covering all activities. In most cases, the time-use surveys available in Latin America and the Caribbean concentrate only on working time. Even so, freeing up women's time creates opportunities for them to enjoy more leisure time;

(v) The principle of equal respect means the recognition of women as people, the aim being to displace a representation that depicts them chiefly as sex objects, and recognition of their work;

(vi) The anti-marginalization principle refers to women's confinement in the domestic sphere. This principle is a call for new opportunities for women to be able to participate in the employment system or political life. It consequently requires the dismantling of cultural traditions hostile to women both in paid work and in politics. This principle could be extended to confinement in spaces, activities or occupations typified as female;

(vii) Lastly, the anti-androcentrism principle is an invitation to change the socialization of individuals by approaching this on the basis of representations that do not reproduce male roles as the norm.

Source: Nancy Fraser, Justice Interruptus. Critical Reflections on the "Postsocialist" Condition, New York, Routledge, 1997.

a This classification is arbitrary in a way because the socioeconomic and cultural realms are so closely intertwined. It does serve, though, to highlight the importance of the perceived differences that constitute gender.

b Here, Fraser notes that women who have no other means of support for themselves and their children are especially vulnerable to abusive husbands or supervisors, or to procurers, and that welfare policies should help to prevent such exploitation by supporting women who are trying to leave destructive relationships of this kind via the provision of alternative sources of income (Fraser, 1997, p. 46). 
Although all three models enable women to attain living standards above the poverty threshold and give them options for leaving oppressive relationships, the universal caregiver model (with everyone acting as both breadwinner and caregiver) is the best option for attaining gender equality. It represents a turn away from androcentrism, reduces the likelihood of opposing roles (men as breadwinners, women as caregivers) opening up earnings gaps, and makes it possible to equalize leisure time. Consequently, the inter-institutional redistribution of care responsibilities should take place alongside interpersonal redistribution (within households).

\section{Establishing care services as a universal pillar of social protection}

What is proposed here is that inter-institutional redistribution be organized on the basis of universal provision of care services with a twofold objective: first, to increase the economic participation of women, insofar as services free up time for those who are inactive and lighten the burden of total work for those in employment; second, to compensate for inequalities in family care provision, which result in a variety of care deficits both for children and for dependent older people and people with disabilities. ${ }^{28}$

In the case of children, the redistributive impact of care services has been demonstrated, particularly as regards social mobility (OECD, 2006) and educational attainments (Sojo, 2011). Such services correct inequalities at the start of children's lives (Esping-Andersen, 2004, and Waldfogel, 2005, cited in Méda, 2008) by mitigating the deficiencies affecting households or unskilled caregivers, always provided external care provision is professional and properly regulated. These services also free up time for the older siblings mobilized in poor households to care for young children.

In addition, care services can become a tool for intra-household negotiations over the interpersonal redistribution of care responsibilities. Use of these services opens up options for the empowerment of women by making it easier for them to participate in labour markets and earn income of their own. It is also crucial for care services to be designed so that they promote redistribution of responsibilities within the home, building on the experience acquired in the promotion of new masculinities (Barker, 2008).

28 This option does not exclude other care policies such as parental leave or time off to care for other dependent family members, which should be extended in one way or another to self-employed workers. 


\section{Making care services the locus of a public policy nexus}

The reasons for choosing care services as a core area of strategy lie in existing interactions and those still to be constructed between different spheres of public policy: the care space, the employment system and the economic structure. The effects expected from the development of care services in terms of job creation and production chains will now be considered. For these effects to be attained, it is essential to adopt a territorial or regional development perspective.

\section{(a) Creating jobs and new employment rules in care services}

Creating care services, which by definition are labour-intensive, is bound to lead to new jobs. These should be used to:

(i) deconstruct stereotypes and promote the existence of institutions and individuals for a redistribution of care tasks within households, at least those that play a linking role in the reproduction of human beings,

(ii) promote new standards that progressively break down the norms and behaviours underlying occupational segregation and thus segmentation in employment systems, and

(iii) develop labour relations that value the role of caregivers, recognizing their contribution to society and the economy and respecting their rights as workers, without creating gender-based income gaps. ${ }^{29}$

\section{(b) Production chains and industrial policies}

The effects of implementing care services in terms of backward and forward production linkages have already been mentioned in the analysis of the care space. The production chain approach in the region's economy applies not only to childhood care services but also to the (physical and mental) health services needed to care for older people, in both the urban and rural economies (Cordes, 1996). These linkages in turn are determinants of job creation. Industrial policies should be oriented towards greater development of production chains and, at the same time, a greater role for women in their different links.

This proposal is partly inspired by the views of Filgueira and Rico (2010), who argue that the State should take on six roles: collectivizing care services, transferring money to families with disabled older people, caring for caregivers, providing incentives for a redistribution of work and time-use models, creating rules to prevent gender discrimination in the labour market and regulating to ensure virtuous linkages between paid work and care work. 


\section{(c) Care services, the local economy and territorial production development}

It is essential for policies to be grounded in local settings. In the first place, the specifications and scale of care services have to take account of the region's territorial disparities in respect of social deprivation, economic activity and employment, and the reproduction of poverty. Deprivation and poverty are reinforced in territories where low levels of schooling and high levels of overcrowding, unemployment and adolescent motherhood persist (ECLAC, 2010a). Mechanisms are needed to equalize conditions in different territories, as are policies to develop basic social services in order to free up poor women's time.

In the second place, local economies, which are constituted on the basis of different mechanisms associated with geographical spaces and their appropriation (available natural resources, transport costs, concentration of firms and their externalities, relationships with other local economies, etc.), determine the configuration of local employment systems and employment opportunities there. Likewise, the size of multiplier effects in demand for goods and services, and thence employment and incomes, depends on the propensity of the regional economy to consume local goods and services and its propensity to import goods and services from other regional economies.

\section{Care, employment and territorial production development}

The employment system is a fabric of heterogeneous structures linked together by regulation mechanisms that make it possible for them to reproduce dynamically (Lautier, 1990). Its origin lies in the very heterogeneity of production structures (forms of competition, organizational structures in branches or sectors of activity, productivity levels). It is constructed as a set of relative positions in the hierarchy of wage employment or in the universe of self-employment and at the same time as a set of mobilities between different activity categories and different jobs (Lautier, 1998). ${ }^{30}$

The employment system is governed by an employment regime comprising employment policies, the principles underlying them, and mechanisms and impacts affecting the number and quality of jobs. The configuration of this regime partly depends on the room for manoeuvre

30 In view of this, mobility has come up as a possible area for public policy (Gazier, 2003 and 2005), which it should be, since women's mobility usually differs from men's (Weller, 2007) because of the sexual division of care work. 
allowed by the production model and its growth potential, the handling of the macroeconomy and production development, and the linkages between employment and social protection. Any gender or other biases (associated with race, ethnic origin, age, etc.) in employment policy will also have an influence.

In Latin America, employment regimes have been characterized in recent years, broadly speaking, by weak labour institutions with a dearth of employment policies in two areas. The first is vocational training for personnel who already possess skills and groups with problems of employability, such as young people and women (Weller, 2009). The second is the generation of direct employment for targeted groups or in special situations (crises, times when seasonal demand for labour is low). With the exception of some temporary job creation or emergency programmes and microenterprise support programmes, policies of this type have been almost absent from rural areas in recent years (Klein, 2009). On the whole, both types of policy lack a comprehensive gender perspective. ${ }^{31}$

In this context, the challenge is to find a way of beginning to change employment regimes by means of policies that incorporate gender equality with respect to labour market access, working conditions, pay and access to social protection.

The loci of employment and production development policies will now be identified on the basis of a general representation of the employment system (see annex I.2). In each locus, the analysis starts with the effects expected from the implementation and expansion of care services and goes on to propose employment and territorial production development policies that are consistent with the principles of justice (see annex I.3).

\section{Critical policy loci in the employment system}

Men and women alike can decide whether to participate in economic activity, seek employment, work for themselves or perhaps even employ others. These decisions are taken in the light of individual constraints and preferences. However, they are also influenced by the stereotypes that govern people's outlook on the world in respect of gender roles and by perceived opportunities in terms of the availability

31 For example, Klein (2009) recognizes that while programmes of support for rural microenterprises have helped to "improve household incomes [and] improve women's participation rates", they have not addressed childcare because the microenterprises supported usually operate out of people's homes. 
of jobs and their characteristics (employment type, working time and pay), all with an eye to the costs of entering the labour market.

Individuals who seek employment and do not find it are unemployed or perhaps return to inactivity. Others take part in production processes as wage workers or as self-employed workers, either by choice or because they are excluded from wage employment. Production processes are underpinned by firms' mix of capital and labour and thus by labour productivity, which, together with the methods used to access different types of markets (weak or outstanding, volatile or stable), determines the quantity and quality of the jobs to be taken up.

An increased influx of inactive or unemployed women into the labour market is the first outcome to be expected from the creation of care services, both within these services themselves and in other branches of activity. Workforce skills, and thus the professionalization of caregivers, are the first thing for employment policy to address in respect of the jobs opened up in the new care services (see annex I.2).

The production chains that develop as care services are created will reflect the potential of existing firms or those created as new opportunities arise. They need to be strengthened, however, to ensure that they are virtuous, and in particular that they benefit self-employed women, and to increase the potential multiplier effects on employment. Production chains are thus the second area for employment policies to address in coordination with industrial polices (see annex I.2).

Lastly, although care services free up women's time, how does providing them lead to occupational desegmentation in the employment system? The term segmentation refers to the mechanisms for assigning labour to jobs, and these are the third field for employment policies to deal with in coordination with the medium- and long-term provision of care services (see annex I.2).

\section{Labour market access, employability and production development}

The absorption of part of the inactive and unemployed female population relies on two mechanisms. First, creating care services itself produces new jobs, in addition to any that might result from the construction of social infrastructure..$^{32}$ Second, the availability of these

32 Job creation in the construction of social infrastructure will take place if the decision is made to increase public investment instead of reallocating existing infrastructure to care services, as was done in Mexico's programme (Staab and Gerhard, 2010). The absorption of women in construction activities would require them to be given training in this area. 
services can be incorporated into women's decision-making. Naturally, the affordability of care services compared to alternative (paid or unpaid) caregivers inside or outside the home, their perceived quality, including hours, and transport costs are also a factor.

Effective entry into the labour market depends, first, on the match between the skills of the potential workforce and the labour requirements of firms. A second factor is the absorption capacity of firms involved in the production of care services or in other branches of activity, whether they have linkages with care services or not. ${ }^{33}$

The problem of the employability of the available workforce arises here. If the decision is taken to create care services with a low level of professionalization, the issue hardly arises. The supposition is that externalized care is merely an extension outside the home of the skills women have already acquired. Insofar as the externalization of care is meant to reduce inequalities in the opportunities and welfare of those requiring care, however, professionalization is unavoidable.

Given this requirement, a lack of skills is very likely to be an obstacle to employment for a fairly substantial proportion of inactive women. However, in the case of childcare, for example, there is the option of gradual professionalization combining the creation of care services with a policy of vocational training on the job and in training institutions. To start with, services would operate with an open distribution of day-care personnel, with some employees who were highly skilled in intermediate supervision and other less skilled or unskilled employees who would in turn be candidates for vocational training (see annex I.3). ${ }^{34}$

It is also essential to enhance the absorption capacity of firms. This requires territorially based production development policies. It needs to be a priority in rural areas, where measures to foment non-agricultural rural activities can open up opportunities for rural women, who have a lower participation rate (48.7\%) than urban women (53.1\%). ${ }^{35}$

33 Absorption capacity is usually a function of: (i) growth prospects in goods and services markets, including production chains, (ii) the characteristics of firms' mix of capital and labour and (iii) the availability of idle production capacity.

34 With this in view, there is a need to design and implement strategies for converting existing community care services and reorienting them towards the development of a professionalized profile, considering the costs and advantages of this conversion.

35 "In vast areas of the countryside, focusing exclusively or predominantly on agricultural development means entrenching a situation of poverty, marginalization and endemic stagnation." Giving encouragement instead to non-agricultural businesses or activities entails "an acceptance of the need to treat richer and poorer rural areas differently", adapting policy to these situations (reduction of transaction costs in the former, public investment in the latter) to "put in place conditions that make these areas more attractive to the private sector" (Reardon, Berdegué and Escobar, 2004, p. 29). 
Box 1.4

LESSONS LEARNED FROM THE CREATION OR EXPANSION

OF CARE SERVICES IN LATIN AMERICA: ARGENTINA, CHILE, COLOMBIAAND MEXICO

Different care policies centring on the provision of care services have been implemented and analysed in the region. In particular, these include the Programme of Day Nurseries and Child Day Centres for Single Working Mothers and Fathers in Mexico, Chile's programme of day-care centres and nurseries (Chile Crece Contigo) and the Community Homes programme of the Colombian Institute for Family Welfare. In Argentina, the State has subsidized the provision of community care services in the poorest areas (Razavi and Staab, 2010; Faur, 2008), in addition to subsidizing private-sector care services for better-off households.

Among the different goals shared by policies for creating or expanding children's care services in the countries referred to is that of increasing the supply of labour from "beneficiary" women living in households in the lower income quintiles or on the bottom rungs of the categorization of households by economic resources. In Colombia, mothers employed in community homes also live in poor households. In the cases of Mexico and Chile, there are other explicit stipulations relating to women's willingness to work ("seeking work") or to their occupation ("having a job"), especially an informal one in the case of Mexico.

The analyses available on these policies or programmes show what needs to be avoided in the light of the twofold objective proposed here on the basis of Fraser's (1997) principles of justice (increased labour market access for women combined with desegmentation of the employment system).

1. These policies are clearly framed from the perspective of reconciliation between work and family, as they consider women exclusively in their role as mothers.

2. While in some cases, such as that of Colombia, it has been shown that access to the new care services has had positive effects both on the incorporation of women into the labour market (via recruitment to jobs in these services and the freeing up of their time) and on their level of employment (with an increase in hours worked), in all four countries the working conditions of women in these care services themselves reflect the marginalization and lack of respect which are at the root of occupational segmentation and income divides. Nor has there been any fundamental shift in the prospects for a lasting exit from poverty.

(a) Colombia and Mexico opted to give self-employed status to women providing care services attracting a State subsidy. The earnings of caregivers are generally low.

(b) In Chile, the pay of salaried women teachers at preschool establishments is among the lowest in the education sector or is very low relative to the salaries paid in other professions requiring similar levels of education. The education level and professional experience of these teachers are not rewarded by substantial pay increases over the years. 
Box 1.4 (concluded)

3. It can be assumed that a strategy characterized by low costs (low pay or low subsidies for self-employed women workers), little or no effort to professionalize care service providers and low quality standards will result in low-quality services being provided to low-income households. In Mexico and Argentina, care services are not seen as a tool for levelling out inequalities between children or for providing poor children with more and better care than they can get at home or from poor- or low-quality care services. In the case of Mexico, the programme is all about care and has no educational element at all, so that it does not provide a pathway into the education system.

4. As Staab and Gerhard (2010) also point out, a peculiarity of the programmes in both Mexico and Chile is that the professional services they provide do nothing to challenge social stratification, since they do not supply a setting where children from different socioeconomic strata might meet.

Source: Prepared by the author on the basis of Shahra Razavi and Silke Staab, "Underpaid and overworked. A cross-national perspective on care workers", International Labor Review, vol. 149, No. 4, December 2010; Stefano Farné, "Políticas para la inserción laboral de mujeres y jóvenes en Colombia", Documentos de proyectos, No. 251 (LC/W.251), Santiago, Chile, Economic Commission for Latin America and the Caribbean (ECLAC), 2009 [online] http://www.eclac.org/publicaciones/ xml/7/37537/2009-226_W251_Colombia.pdf; and Silke Staab and Roberto Gerhard, "Childcare service expansion in Chile and Mexico: for women or children or both?", Series Paper, No. 10, Geneva, United Nations Research Institute for Social Development (UNRISD), 2010.

\section{Production chains and employment and production development policies}

Production chains usually include a gender dimension. Abramo (1996) insists that it is necessary to analyse what happens in firms that are not at the end of a particular production chain "with the objective of examining what type of work and worker are to be found there or, in other words, who is included in the virtues of the production modernization process, and who excluded". For this it is necessary to analyse the quality of jobs in terms of skills, working conditions, access to social protection, the possibility of unionization and collective bargaining, and pay.

As Weller (1998, p. 23) recalls, "conceptually, it is possible to differentiate between a more virtuous form of production linkage, following the [...] template of 'flexible specialization' based on the dissemination of 'best production practices' with beneficial effects for labour relations and employment quality, and a 'race to the bottom' type of flexibility oriented mainly towards cost-cutting, with all the consequences this has for job characteristics". 
Production chains of the second type have prevailed in Latin America, and it has been shown that women hold poorly paid, lowquality jobs in subcontracting chains (ECLAC, 2010b). To promote virtuous linkages favouring firms run by women or with a large female presence in their workforces, industrial policy should:

(i) enable microenterprises and small and medium-sized enterprises (SMEs) to overcome barriers to entry into the new market for care service inputs (access to information, support for investment, etc.),

(ii) enhance the capacity of microenterprises to meet the requirements of the new care services, and

(iii) establish relationships between care services and microenterprises to reduce uncertainty for the latter, for example by way of contracts that secure the conditions of sale or supply over reasonably long time horizons (see annex I.3).

\section{From care services to occupational desegmentation}

Doing away with occupational segmentation is clearly a (very) long-term goal. More modestly, the challenge is to set desegmentation in motion, which means:

(i) Gradually constructing a new employment model in care services and their production chains, based on: (i) a more or less balanced presence of women and men in the workforce; (ii) appreciation for care work in the form of fair pay, with the minimum wage as the baseline; (iii) equal pay for men and women doing the same job; ;6 (iv) management of mobility from part-time jobs to full-time jobs in a way that leaves intact the scope for choice and opportunities if at any time women (or men) prefer part-time jobs; (v) the option for both women and men to work flexible hours;

(ii) Educating and professionalizing women and men for care services. This would form part of a vocational training policy which would also open up the range of occupations available to women beyond the traditional ones. Incorporating men into care services would also drive a wedge into the segmentation confining women to activities perceived as typically female;

36 If the decision is taken to delegate the provision of care services to private-sector firms, rules for unbiased workforce management must form part of the delegation contracts alongside regulations governing the quality and equitable distribution of the services provided. 
(iii) Using production chain development policies to enhance the ability of women operating microenterprises to formulate and implement market strategies and increase women's access to material resources for the creation of new services; and

(iv) Deconstructing stereotypes over the medium and long term by promoting new roles and attitudes among the boys and girls receiving care services as a space of socialization for the new generations. This means integrating specific support services into care services, aimed at the parents (or guardians) of the children cared for and at those caring for the elderly (see annex I.3).

\section{E. Conclusion}

To sum up, the aims of universal provision of care services are to facilitate women's participation in labour markets by freeing up their time, create direct and indirect jobs in production chains and optimize the absorption of the female workforce, while progressively constructing an employment model for these services based on labour relations that represent a departure from the occupational segmentation template. Achieving the potential for job creation in care services and elsewhere requires industrial or production development policies to match the creation or expansion of these services. This brings into play the design and implementation of all the different policies, but most especially production development: it is vital to give national guidelines a local or regional application and work with the constraints and opportunities in local economies that determine the scale of the effects to be expected from the policy nexus.

This nexus is not without its dilemmas. ${ }^{37}$ With regard to the goals proposed, there is a conflict between that of raising the participation rate or, better still, the employment rate among women and that of progressively desegmenting employment, even if this takes place on an intergenerational scale. For what is achieved in the short or medium term is greater access to the labour market along segmented lines, which consolidates segmentation. This dilemma is particularly critical in the case of production chains, which is why positive action is proposed here to prioritize microenterprises run by women.

There is also the problem of reconciling the affordability of care services with decent pay for care work to reflect the status it merits. Care

\footnotetext{
${ }_{37}$ Instances of conflict between these two types of public policies can be found in Christopherson (1997).
} 
activities are very labour-intensive, and there is a structural conflict between service quality and the scope for productivity gains. ${ }^{38}$ One option is to freeze the progression of caregivers' pay, but the cost is poorer service quality. Another is to subsidize services to offset growth in wage costs and use mechanisms for smoothing financing across territories and socioeconomic levels to ensure they are affordable.

There is also a fine line between taking care services as a model for the desegmentation of jobs and creating new segmentation boundaries with "protected" care services.

It is worth stressing again that the scale of women's access to employment, and particularly high-quality employment, depends on the net job creation capacity of national and local economies. Employment policies are necessary to combat the selectivity of the job market and mitigate the marginalization and exclusion, often irreversible, that this selectivity gives rise to (Freyssinet, 2004, p. 59). But they have only a limited effect on the level of employment when set against the real impact of job-intensive economic growth.

Looking beyond the general outlines given here, sound design of the nexus between care policies, employment policies and territorial production development policies depends on the particular situations in the countries as determined by their development levels, financial capacity and institutions. In most cases social protection mechanisms are fragmented, as is shown in a number of cases by the lack of coordination between, for example, conditional transfer programmes and other insurance and social protection mechanisms.

Fragmentation also arises from the kinds of arbitrage that contribute to the reproduction of inequalities. Supporting or providing second-rate care services for poorer sections of the population, with relatively untrained caregivers employed on unsatisfactory terms (Razavi and Staab, 2008; Farné, 2009), is one of the options that tend to have this effect, even when these services expand the range of possibilities open to women. Similarly, subsidizing private-sector care services for populations in wealthy areas while keeping or developing second-rate services for the poor, as has happened in Argentina (Faur, 2008; Razavi

38 These conditions may give rise to the Baumol effect, which concerns the evolution of wages in service activities characterized by high labour intensity and low productivity gains. Because wages in these services tend to adjust to wage increases in other branches of activity with larger productivity gains, the relative unit cost of care tends to rise. This can lead to a reduction in demand for services and rising inequality between those who can afford the dearer services and those who cannot, as well as reducing the profitability of services (OECD, 2004). 
and Staab, 2008), confirms and perpetuates the fault lines between social groups, both for women and for children of both sexes.

These are situations with the potential for conflicts of objectives, both within and beyond social policy. Razavi and Staab (2008) point out that conditional cash transfers have apparently shifted public investment into basic social services in some countries, citing the cases of Brazil (Melo, 2007) and South Africa (Lund, 2008). This is intriguing, since investment in care services infrastructure might be the most effective way of increasing demand at an early stage. Otherwise, the public sector would be confining its effort to paying caregivers, without thereby giving a substantial enough boost to regional demand.

Another source of conflict might be the roles allocated to the State, on the one hand, and the private sector and non-profit organizations, on the other, in the provision and regulation of care services. Although the issue has been left open here, it is acknowledged that a catalytic and regulatory role at least for the State is a necessary condition for designing the new institutional equation and redrawing the boundaries of the care economy.

\section{Bibliography}

Albelda, Randy, Mignon Duffy and Nancy Folbre (2009), Counting on Care Work. Human Infrastructure in Massachusetts, University of Massachusetts.

Abramo, Laïs (1996), Mercados laborales, encadenamientos productivos y políticas de empleo en América Latina y el Caribe [online] white.oit.org.pe/spanish/260ameri/ oitreg/activid/proyectos/actrav/edob/material/cadenas/pdf/cp5.pdf.

Anker, Richard (2001), "Theories of occupational segregation by sex: an overview", Women, Gender and Work. What is Equality and How do We get There?, Martha Fetherolf Loutfi (ed.), Geneva, International Labour Organization (ILO).

Arcidiácono, Pilar, Laura Pautassi and Carla Zibecchi (2010), "La experiencia comparada en materia de clasificación de desempleados y destinatarios de programas de transferencias de ingresos condicionadas", Trabajo y Sociedad, No. 14, vol. XIII [online] http://www.scielo.org.ar/scielo.php?pid=S151468712010000100001\&script=sci_arttext.

Arriagada, Irma and Charlotte Mathivet (2007), "Los programas de alivio a la pobreza Puente y Oportunidades. Una mirada desde los actores", Políticas Sociales series, No. 134 (LC/L.2740P), Santiago, Chile, Economic Commission for Latin America and the Caribbean (ECLAC).

Barker, Gary (2008), "Engaging men and boys in caregiving: reflections from research, practice and policy advocacy in Latin America", paper presented at the Expert Group Meeting Equal sharing of responsibilities between women and men, including care-giving in the context of HIV/AIDS [online] http:// www.un.org/womenwatch/daw/egm/equalsharing/EGM-ESOR-2008EP1Gary\%20Barker.pdf. 
Batthyány, Karina (2011), "Hacia un sistema nacional de cuidado: preferencias de la población y propuestas para el cuidado", paper presented at the XII International Meeting on Gender Statistics, Aguascalientes, 5-7 October [online] http://www.inegi.org.mx/eventos/2011/encuentro_genero/doc/1606S3-04KarinaBatthyany-UDELAR_InmujeresUruguay.pdf.

(2009), "El cuidado de los adultos mayores en los hogares de Montevideo. Algunos elementos para el debate", Hacia un sistema nacional integrado de cuidados, Montevideo, Red Género y Familia.

Bertaux, Daniel (1992), "Le contrôle de la production anthroponomique comme enjeu de la modernité", International Review of Sociology, vol. 3, No. 1.

(1977), Destins personnels et structure de classe. Pour une critique de l'anthroponomie politique, Paris, Presses Universitaires de France (PUF).

Bertranou, Fabio (2009), Trabajadores independientes y protección social en América Latina Argentina, Brasil, Chile, Colombia, Costa Rica, Uruguay, Santiago, Chile, International Labour Organization (ILO).

Bertranou, Fabio and Pablo Casalí (2007), Los trabajadores independientes y la seguridad social, Buenos Aires, Ministry of Labour, Employment and Social Security / International Labour Organization (ILO).

Blancas, Arturo (2011), “Cuenta satélite del trabajo no remunerado de los hogares de México (2003-2009)", paper presented at the IX International Meeting on Public Policies, Time-Use and Care Economy: the importance of national statistics [online] http://cedoc.inmujeres.gob.mx/Seminarios/ utiempo/2011/29agosto/Sesion1/Arturo_Blancas.pdf.

Budig, Michelle and Misra Joya (2008), How Care Work Employment Shapes Earnings in a Cross-National Perspective, Geneva, United Nations Research Institute for Social Development (UNRISD).

Budlender, Debbie (2008), The Statistical Evidence on Care and Non-Care Work across Six Countries, Ginebra, United Nations Research Institute for Social Development (UNRISD) [online] http://www.unrisd.org/unrisd/website/document.nsf/ ab82a6805797760f80256b4f005da1ab / f9fec4ea774573e7c1257560003a96b2/ \$FILE/BudlenderREV.pdf.

Chacaltana, Juan (2006), "Trayectorias laborales de jóvenes peruanos", Los jóvenes y el empleo en América latina. Desafíos y perspectivas ante el nuevo escenario laboral, Jürgen Weller, Bogota, Economic Commission for Latin America and the Caribbean (ECLAC)/Mayol ediciones/German Agency for Technical Cooperation (GTZ).

Chadeau, Ann and Annie Fouquet (1981), "Peut-on mesurer le travail domestique?", Economie et statistique, No. 136, September.

Christopherson, Susan (1997), "Childcare and elderly care: what occupational opportunities for women?", OECD Labour Market and Social Policy Occasional Papers, No. 27.

Colinas Lourdes (2008), “Economía productiva y reproductiva en México: un llamado a la conciliación", Estudios y Perspectivas series, No. 94 (LC/MEX/L.838/ Rev.1), Mexico City, ECLAC subregional headquarters in Mexico.

Cordes, Sam M. (1996), Health Care Services and the Rural Economy, Federal Reserve Bank of Chicago [online] http://www.chicagofed.org/digital_assets/others/ events/1996/changing_rural_economy/1996_changing_rural_economy_of_ the_midwest_cordes.pdf. 
Crompton, Rosemary (2009), "The normative and institutional embeddedness of parental employment: its impact on gender egalitarianism in parenthood and employment", Gender Equality. Transforming Family Divisions of Labor, Janet C. Gornick and Marcia K. Meyers, The Real Utopias Project Series, London, Verso Publishers.

Destremau, Blandine and Bruno Lautier (2006), Analyse et comparaison des systèmes de protection sociale du monde en développement. Eléments de typologie de méthode, Paris, Réseau IMPACT.

Duffy, Mignon (2005), "Reproducing labor inequalities. Challenges for feminists conceptualizing care at the intersection of gender, race and class", Gender and Society, vol. 19, No. 1.

ECLAC (Economic Commission for Latin America and the Caribbean) (2010a), Time for equality: closing gaps, opening trails (LC/G.2432(SES.33/3)), Santiago, Chile. (2010b), What kind of State? What kind of equality? (LC/G.2450(CRM.11/13)), Santiago, Chile, June.

England, Paula, Michelle Budig and Nancy Folbre (2002), "Wages of virtue: the relative pay of care work", Social Problems, vol. 49, No. 4.

Escobedo, Anna, David Moreno and Ester Fernandez (2002), Surveying Demand, Supply and Use of Care. Consolidated Report, Barcelona, Fundación CIREM.

Esping-Andersen, Gosta (2004), "Untying the Gordian knot of social inheritance", Research in Social Stratification and Mobility, vol. 21.

(1990), The Three Worlds of Welfare Capitalism, Princeton, Princeton University Press.

Esquivel, Valeria (2011), "La economía del cuidado: un recorrido conceptual", Aportes al debate del desarrollo en América Latina. Una perspectiva feminista, Norma Sanchís, Red de Género y Comercio [online] www.generoycomercio.org. (2010), "Trabajadores del cuidado en la Argentina. En el cruce entre el orden laboral y los servicios de cuidado, Revista Internacional del Trabajo, vol. 129, No. 4.

FAO/ECLAC/ILO (Food and Agriculture Organization of the United Nations / Economic Commission for Latin America and the Caribbean/International Labour Organization) (2010), Politicas de mercado de trabajo y pobreza rural: Un análisis comparado en América Latina, Santiago, Chile.

Farné, Stefano (2009), “Políticas para la inserción laboral de mujeres y jóvenes en Colombia", Project Documents, No. 251 (LC/W.251), Santiago, Chile, Economic Commission for Latin America and the Caribbean (ECLAC) [online] http:/ / www.eclac.org/publicaciones/xml/7/37537/2009-226_W251_Colombia.pdf.

Faur, Eleonor (2008), The "Care Diamond": Social Policy Regime, Care Policies and Programmes in Argentina, United Nations Research Institute for Social Development (URISD) [online] http://www.unrisd.org/unrisd/website/ document.nsf / 8b18431d756b708580256b6400399775/695f3b781b8ea414c12575 3700562c23/\$FILE/ArgentinaRR3.pdf.

Filgueira, Fernando and Nieves Rico (2010), “La economía política del tiempo y del cuidado. Desafíos para la matriz de protección social", paper presented at the International Seminar on Care Policies, Gender and Wellbeing, United Nations Population Fund (UNFPA)/Economic and Social Development Institute (IDES)/United Nations Children's Fund (UNICEF), Buenos Aires, 14-15 October. 
Fisher, Berenice and Joan Tronto (1990), "Towards a feminist theory of caring", Circles of Care, F. Abel and M. Nelson (eds.), Albany, State University of New York.

Flores-Castillo, Atenea (2011), “Cuidado y subjetividad. Una mirada a la atención domiciliaria", Mujer y Desarrollo series, No. 112 (LC/L.3441), Santiago, Chile, Economic Commission for Latin America and the Caribbean (ECLAC).

Folbre, Nancy (2011), "Reflections. Nancy Folbre interviewed by Shahra Razavi", Development and Change, vol. 42, No. 1, International Institute of Social Studies. (2006), "Rethinking the child care sector", Journal of the Community Development Society, vol. 37, No. 2.

Folbre, Nancy and Jayoung Yoon (2008), "El cuidado de los niños: lo aprendido mediante encuestas sobre uso del tiempo en algunos países de habla inglesa", La economía invisible y las desigualdades de género. La importancia de medir y valorar el trabajo no remunerado, Washington, D.C., Pan American Health Organization (PAHO).

Fraser, Nancy (1997), Justice Interruptus. Critical Reflections on the "Postsocialist" Condition, New York, Routledge.

Freyssinet, Jacques (2004), “Quelques enseignements de l'expérience”, Projet, 278, January.

Gazier, Bernard (2005), "Marchés transitionnels du travail et restructurations: vers une gestion collective des transitions" [online] http:/ / halshs.archives-ouvertes. $\mathrm{fr} /$ docs /00/27/02/16/DOC/BGIRESrestruct05.doc.

(2003), Tous sublimes, vers un nouveau plein-emploi, Paris, Flammarion.

González de la Rocha, Mercedes Eugenia (2006), Procesos domésticos y vulnerabilidad; perspectivas antropológicas de los hogares con Oportunidades, Publicaciones de la Casa Chata, Centre for Research and Higher Learning in Social Anthropology (CIESAS).

Hernández, Patricia and others (1996), "Childcare needs of female street vendors in México City", Health Policy and Planning, vol.11, No. 2, Oxford University Press.

Hirata, Helena and Danièle Kergoat (2004), "Division sexuelle du travail professionnel et domestique. Evolution de la problématique et paradigmes de la "conciliation", Actes du Colloque International: Marché du travail et genre: comparaisons internationales Brésil-France, São Paulo, April.

Huyette, Pierre (1994), "Du secteur informel au système d'emploi en Colombie", Ph.D. thesis, Université de Picardie-Jules Verne.

IHSI (Institut Haïtien de Statistique et d'Informatique) (2010), Enquête sur l'Emploi et l'Economie Informelle (EEEI). Premiers résultats de l'Enquête Emploi (Phase 1), Portau-Prince [online] http:/ /ihsi.ht/pdf/eeei.pdf.

INEGI (National Institute of Statistics and Geography) (2005), Encuesta Nacional de Ocupación y Empleo. Una nueva encuesta para México, Mexico City.

Ironmonger, Duncan S. (1996), "Counting outputs, capital inputs and caring labor: estimating gross household product", Feminist Economics, vol. 2, No. 3.

Junter-Loiseau, Annie (1999), "La notion de conciliation de la vie professionnelle et de la vie familiale: révolution temporelle ou métaphore des discriminations?", Les Cahiers du Genre, vol. 24.

Klein, Emilio (2009), Condicionantes laborales de la pobreza rural en América Latina, Santiago, Chile, Food and Agriculture Organization of the United Nations (FAO). 
Lamaute-Brisson, Nathalie (2012), "Enquêtes auprès des ménages en Haïti et perspective de genre (1999-2005)", Mujer y Desarrollo series, No. 113 (LC/L.3442), Santiago, Chile, Economic Commission for Latin America and the Caribbean (ECLAC).

(2010), “Economía del cuidado de la niñez en Haití: proveedores, hogares y parentesco", Mujer y Desarrollo series, No. 95 (LC/3130-P), Santiago, Chile, Economic Commission for Latin America and the Caribbean (ECLAC).

Laslett, Barbara and Johanna Brenner (1989), "Gender and social reproduction: historical perspectives", Annual Review of Sociology, No. 15.

Lautier, Bruno (2004), "Une protection sociale mutualiste et universelle: la condition de l'efficacité de la lutte contre la pauvreté", Régime de croissance, vulnérabilité financière et protection sociale en Amérique latine. Les conditions "macro" de l'efficacité de la lutte contre la pauvreté, Financiamiento del Desarrollo series, No. 140 (LC/L.2001-P), Bruno Lautier, Jaime Marques-Pereira and Pierre Salama, Santiago, Chile, Economic Commission for Latin America and the Caribbean (ECLAC).

(1999), “Les politiques sociales en Amérique Latine. Propositions de méthode pour analyser un éclatement en cours", Cahiers des Amériques Latines, No. 30.

(1998), "Pour une sociologie de l’hétérogénéité du travail", Revue Tiers-Monde, No. 15.

(1990), "La girafe et la licorne. Secteur informel et système d'emploi en Amérique latine (Brésil, Colombie)", Informalité, formation et emploi : une comparaison entre la Colombie et le Nordeste brésilien, Bruno Lautier (coord.), Amiens, Rapport GreitdCreppra/Ministry of Education.

(1987), "Fixation restreinte dans le salariat, secteur informel et politique d'emploi en Amérique Latine", Tiers-Monde, No. 110, April-June.

Lewis, Jane (1992), "Gender and the development of welfare regimes", Journal of European Social Policy, vol. 1, No. 3.

Marc, Céline and Hélène Zajdela (2005), “Emploi des mères et politique familiale: doit-on s'inspirer du "modèle suédois"?", Document de travail, No. 45, Centre d'Etudes de 1’Emploi (CEE) [online] http:/ / www.cee-recherche.fr/fr/doctrav / politique_familiale_mod\%E8le_suedois_45.pdf.

Marco Navarro, Flavia (2007), “El cuidado de la niñez en Bolivia y Ecuador: derecho de algunos, obligación de todas", Mujer y Desarrollo series, No. 89 (LC/L.2843-P/E), Santiago, Chile, Economic Commission for Latin America and the Caribbean (ECLAC).

Márquez, Gustavo (1998), “El desempleo en América Latina y el Caribe a mediados de los '90", paper presented at the Seminar Labour Market: Between Solidarity and Loyalty, Inter-American Development Bank (IDB), Montevideo, 19-20 May.

Martínez Franzoni, Juliana (2010), “Welfare regimes in Latin America: capturing constellations of markets, families, and policies", Market, State and Society in Contemporary America, William Smith and Laura Gómez Mera (eds.), WileyBlackwell.

(2005), "La pieza que faltaba: uso del tiempo y regímenes de bienestar en América Latina", Nueva Sociedad, No. 199, September-October.

Méda, Dominique (2008), "Pourquoi et comment mettre en oeuvre un modèle à "deux apporteurs de revenu/deux pourvoyeurs de soins", Revue française de socio-economie, Second semester, No. 02. 
Meillassoux, Claude (2001), "Les tâches de l'ethnologie", Journal des anthropologues, No. 84 [online] http:/ /jda.revues.org/2542.

Melo, Marcus André (2007), “Unexpected successes, unanticipated failures: social policy from Cardoso to Lula", Democratic Brazil Revisited, Timothy Power and Peter Kingston (eds.), Pittsburgh, University of Pittsburgh Press.

Metso, Milka (2006), “Le rendez-vous manqué? L'Etat social finlandais, la régulation du travail et l'introuvable égalité entre les sexes", paper presented at the International Meeting "El Estado y la regulación social. ¿Cómo reflexionar sobre la coherencia de la intervención pública?", Centro Nacional de Investigación Cientifica, University of Paris I, Sorbonne Economic Centre, Paris, 11-13 September.

Milosavljevic, Vivian and Odette Tacla (2008), "Las encuestas del uso del tiempo: su diseño y aplicación", La economía invisible y las desigualdades de género. La importancia de medir y valorar el trabajo no remunerado, Washington, D.C., Economic Commission for Latin America and the Caribbean (ECLAC)/ Higher Council for Scientific Research (CSIC)/ Pan American Health Organization (PAHO).

Morel, Nathalie (2006), "From subsidiarity to "free choice". Child and elderly care policy reforms in France, Germany, Belgium and the Netherlands", Social Policy and Administration, vol. 41, No. 6 .

Moreno Ruiz, María José (2008), "Políticas conciliatorias entre los ámbitos productivo y reproductivo en América Latina: una cuestión estratégica para abordar la desigualdad", Políticas sociales y género. Los problemas sociales y metodológicos. Tomo II, serie Dilemas de las Políticas Públicas en Latinoamérica, Gisela Zaremberg (coord.), Mexico City, Latin American Faculty of Social Sciences (FLACSO).

Muller, Pierre (1990), Les politiques publiques, Paris, Presses Universitaires de France (PUF),

Murillo, Soledad (2003), "Cara y cruz del cuidado que donan las mujeres", paper presented at the International SARE 2003 Congress: “Cuidar cuesta: costes y beneficios del cuidado", Bilbao.

OECD (Organisation for Economic Cooperation and Development) (2006), Starting Strong II, Paris.

(2004), Bébés et employeurs. Comment réconcilier travail et vie de famille, vol. 3 [online] http://www.keepeek.com/Digital-Asset-Management/oecd/socialissues-migration-health/bebes-et-employeurs-comment-reconcilier-travail-etvie-de-famille-volume-3_9789264108370-fr.

Orloff, Ann Shola (1996), "Gender in the welfare State", Annual Review of Sociology, vol. 22.

(1993), "Gender and the social rights of citizenship: The comparative analysis of gender relations and welfare states", American Sociological Review, vol. 58, No. 3.

Pailhé, Ariane and Anne Solaz (2009), Entre famille et travail. Des arrangements de couple aux pratiques des employeurs, Paris, La Découverte.

Pautassi, Laura and Carla Zibecchi (2010), “La provisión de cuidado y la superación de la pobreza infantil. Programa de transferencias condicionadas en Argentina y el papel de las organizaciones sociales y comunitarias", Políticas Sociales series, No. 159 (LC/L.3198-P), Santiago, Chile, Economic Commission for Latin America and the Caribbean (ECLAC). 
Penn, Helen (2007), "Childcare market management: how the United Kingdom Government has reshaped its role in developing early childhood education and care", Contemporary Issues in Early Childhood, vol. 8, No. 3.

Picchio, Antonella (2001), Un enfoque macroeconómico "ampliado" de las condiciones de vida, Departamento de Economía Política, Universidad de Modena.

Provoste Fernández, Patricia (2010), "Protección social y redistribución del cuidado en América Latina y el Caribe: el ancho de las políticas", Santiago, Chile, Economic Commission for Latin America and the Caribbean (ECLAC), unpublished.

Quiñones, Mariela (2009), “Cambios organizacionales y nuevas formas de desigualdad", Privilegiadas y discriminadas. Las trabajadoras del sector financiero, María Nieves Rico and Flavia Marco, Cuadernos de la CEPAL, No. 93 (LC/G.2403-P), Santiago, Chile, Economic Commission for Latin America and the Caribbean (ECLAC), July.

Razavi, Shahra and Silke Staab (2010), “Underpaid and overworked. A crossnational perspective on care workers", International Labor Review, vol. 149, No. 4, December.

(2008), The Social and Political Economy of Care: Contesting Gender and Class Inequalities, New York, United Nations Department of Economic and Social Affairs.

Reardon Thomas, Julio Berdegué and Germán, Escobar (2004), “Empleo e ingresos rurales no agrícolas en América Latina: síntesis de implicaciones de políticas", Empleo e ingresos rurales no agrícolas en América Latina, Dirven Martine, Seminarios y Conferencias series, No. 35 (LC/L.2069-E), Santiago, Chile, Economic Commission for Latin America and the Caribbean (ECLAC).

Reich Michael, David Gordon and Richard Edwards (1973), "A theory of labor market segmentation", American Economic Review, vol. 63, No. 2, May.

Rico, María Nieves y Flavia Marco (2009), “Privilegiadas y discriminadas. Las trabajadoras del sector financiero", Cuadernos de la CEPAL, No. 93 (LC/G.2403-P), Santiago, Chile, Economic Commission for Latin America and the Caribbean (ECLAC).

RizaviSayyid,Salman and CatherineSofer(2004), "Travaildomestiqueetorganisation des temps de vie dans les ménages: une comparaison internationale", Actes du Colloque International: Marché du travail et genre: comparaisons internationales Brésil-France, São Paulo, April.

Rodríguez Enríquez, Corina (2007), “La organización del cuidado de niños y niñas en Argentina y Uruguay", Mujer y Desarrollo series, No. 90 (LC/L.2844-P), Santiago, Chile, Economic Commission for Latin America and the Caribbean (ECLAC).

Roubaud, François (1994), L'économie informelle au Mexique. De la sphère domestique à la dynamique macro-économique, Paris, Karthala.

Rubery, Jill, Colette Fagan and Friederike Maier (1996), “Occupational Segregation, Discrimination and Equal Opportunity", International Handbook of Labour Market Policy and Evaluation, Günther Schmid, Jacqueline O'Reilly and Klaus Schömann (eds.), Edward Elgar.

Sainsbury, Diane (ed.) (1994), Gendering Welfare States, London, Sage.

(1993) "Dual welfare and sex segregation of access to social benefits: income maintenance policies in the UK, the US, the Netherlands \& Sweden", Journal of Social Policy, vol. 22, No. 1. 
Salvador, Soledad (2011), "Hacia un sistema nacional de cuidado en el Uruguay", El desafío de un sistema nacional de cuidados para el Uruguay, María Nieves Rico (coord.), Seminarios y Conferencias series, No. 66 (LC/L.3359), Santiago, Chile, Economic Commission for Latin America and the Caribbean (ECLAC).

(2009), Configuración social del cuidado en hogares con niños/as y con adultos/as mayores y politicas de corresponsabilidad, paper prepared for the project "Apoyo a las políticas públicas para la reducción de las inequidades de género y generaciones" (G/INE/UNIFEM/UNFPA), Montevideo.

Salvador, Soledad and Gabriela Pradere (2009), "Análisis de las trayectorias familiares y laborales desde una perspectiva de género y generaciones", paper prepared for the project "Apoyo a las políticas públicas para la reducción de las inequidades de género y generaciones" (G/INE/UNIFEM/UNFPA), Montevideo.

Schkolnik, Mariana (2006), "Trayectorias laborales de los jóvenes chilenos peruanos", Juventud y mercado laboral. Brechas y barreras, Marcelo Charlín and Jürgen Weller, Santiago, Chile, Economic Commission for Latin America and the Caribbean (ECLAC)/Latin American Faculty of Social Sciences (FLACSO)/ German Agency for Technical Cooperation (GTZ).

Servet, Jean-Michel (1998), L'euro au quotidien, Desclée de Brouwer, Paris.

Skoufias, Emmanuel (2001), PROGRESA and Its Impacts on the Human Capital Welfare of Children and Adults in Rural Mexico: A Synthesis of the Results of an Evaluation by IFPRI, Washington, D.C., International Food Policy Research Institute (IFPRI).

Skoufias, Emmanuel and Susan Parker (2001), "Conditional cash transfers and their impact on child work and schooling: evidence from the PROGRESA Program in Mexico", Economía, vol. 2, No. 1.

Smith, Peggie R. (2004), "Elder care, gender and work: the work-family issue of the 21st century", Berkeley Journal of Employment and Labor Law, vol. 25, Berkeley [online] http:/ / papers.ssrn.com/sol3/papers.cfm?abstract_id=1087688.

Sojo, Ana (2011), "De la evanescencia a la mira: el cuidado como eje de políticas y de actores en América Latina", Seminarios y Conferencias series, No. 67 (LC/L.3393), Santiago, Chile, Economic Commission for Latin America and the Caribbean (ECLAC).

Staab, Silke and Roberto Gerhard (2010), "Childcare service expansion: in Chile and Mexico for women or children or both?", Series Paper, No. 10, Geneva, United Nations Research Institute for Social Development (UNRISD).

Théret, Bruno (1999), “Vers un socialisme civil? L'épreuve de la contrainte démocratique de différenciation de la société", Capitalisme et socialisme en perspective. Evolution et transformation des systèmes économiques, Bernard Chavance and others (eds.), Paris, La Découverte.

(1997), “Méthodologie des comparaisons internationales, approches de l'effet sociétal et de la régulation: fondements pour une lecture structuraliste des systèmes nationaux de protection sociale", L'Année de la régulation, vol. 1.

(1995), "De la comparabilité des systèmes nationaux de protection sociale dans les sociétés salariales. Essai d'analyse structurale", Recherches E Régulation Working Papers, series E, No. 1995-1.

(1992a), "Régimes économiques de l'ordre politique. Esquisse d'une Théorie régulationniste des limites de l'état", Économie en liberté, Paris, Presses Universitaires de France (PUF). 
(1992b), "Esquisse d'une conception topologique et régulationniste de l'interdépendance entre le rapport salarial et 1'Etat-providence", Cahiers du GRÉTSÉ, No. 11, Montréal, Groupe de recherche et d'étude sur les transformations sociales et économiques.

Waldfogel, Jane (2005), "Public policy and child outcomes: new evidence on parental leave and child health", paper presented at the Fourth Annual Conference of the Blue Cross Blue Shield of Massachusetts Journalism-Work/Family, 12-13 May.

Warner, Mildred (2006), "Putting child care in the regional economy: empirical and conceptual challenges and economic development prospects", Journal of the Community Development Society, vol. 37, No. 2.

Warner, Mildred and Liu Zhilin (2006), "The importance of child care in economic development: a comparative analysis of regional economic linkage", Economic Development Quarterly, vol. 20, No. 1, February.

Weller, Jürgen (2009), “El fomento de la inserción laboral de grupos vulnerables. Consideraciones a partir de cinco estudios de caso nacionales", Project Documents, No. 306 (LC/W.306), Santiago, Chile, Economic Commission for Latin America and the Caribbean (ECLAC).

(2007), "La flexibilidad del mercado de trabajo en América latina y el Caribe. Aspectos del debate, alguna evidencia y políticas", Macroeconomía del Desarrollo series, No. 61 (LC/L.2848-P), Santiago, Chile, Economic Commission for Latin America and the Caribbean (ECLAC).

(2001), "Procesos de exclusión e inclusión laboral: la expansión del empleo en el sector terciario", Macroeconomía del Desarrollo series, No. 6 (LC/L.1649-P), Santiago, Chile, Economic Commission for Latin America and the Caribbean (ECLAC).

(1998), "La evolución del empleo en América Latina en los años noventa", paper presented at the XXI International Congress of the Latin American Studies Association (LASA), Chicago, Illinois, 24-26 September [online] http:/ / cdi.mecon.gov.ar/biblio/docelec/dp1109.pdf.

Willson, Anjelica and Pamela Caro (2009), “Temporeras de la agroexportación en Chile: tensiones y desafíos asociados a la relación entre la vida laboral y familiar", Mujer y Desarrollo series, No. 94, (LC/L.3117-P/E), Santiago, Chile, Economic Commission for Latin America and the Caribbean (ECLAC).

Witte, Edwin E. (1937), "Old age security in the social security act 45", Journal of Political Economy, vol. 1, No. 27. 


\section{Annexes}

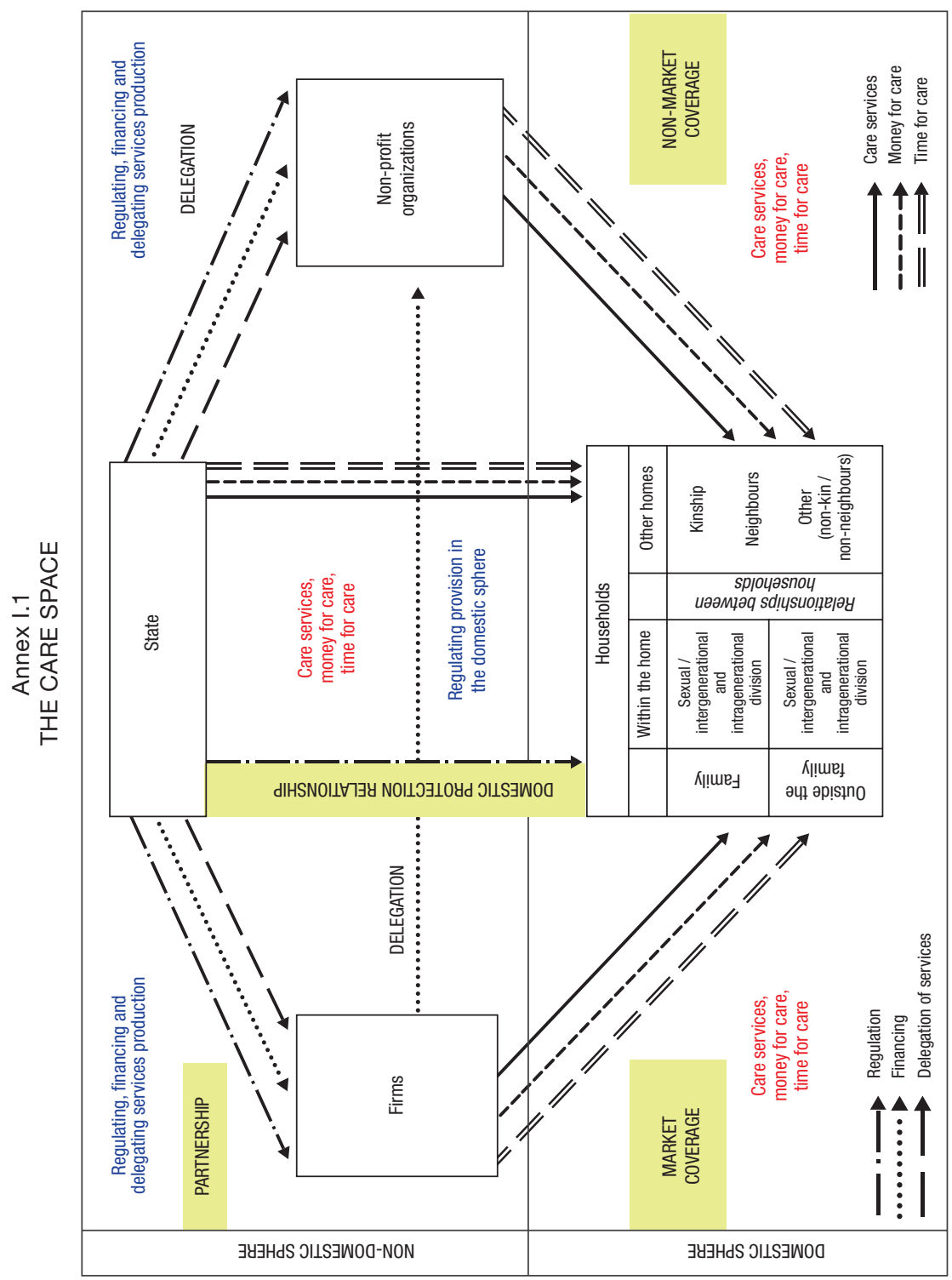


The relationships between actors are grounded in the different roles they take on:

\section{The State}

- $\quad$ Regulates the different care actors (roles, rights and obligations in respect of care responsibilities), service markets and labour relations between institutions and caregivers, and between the subjects of the right to care and caregivers. It also lays down the rights of individuals or households and the eligibility criteria for access to public services or benefits.

- $\quad$ Provides financing to both firms and non-profit organizations to encourage their involvement in care production and to socialize some of the costs associated with the production of services or the mechanisms facilitating access to care.

- $\quad$ Transfers resources to households so that they can buy in services or employ caregivers (personal care at home).

- Involves itself in the production of public care services for households or delegates this production to firms or non-profit organizations. Delegation entails contracts between the State and the firms or non-profit organizations.

\section{Firms}

- $\quad$ Provide households with care services.

- Develop methods for delegating services to households (healthcare models with transfer of activities and costs to households).

- $\quad$ Apply regulations on reconciliation between reproductive work and paid work in their capacity as employers. May develop relationships with non-profit organizations so that their employees have access to care services (for example by purchasing non-profit organizations' vouchers for their employees).

\section{Non-profit organizations}

- Provide households with care services, with or without State financing.

- Set up systems of vouchers for firms and then operate as intermediaries between firms and their employees.

\section{Households}

- Purchase and consume the care services produced by publicsector bodies, specialized private-sector firms or non-profit organizations. 
- Recruit labour for the internal production of care services, be these domestic workers or professional caregivers, and consume the services produced.

- $\quad$ Organize the reproduction of their members (Martínez, 2005) by following (or not) the template for the sexual division of total work and the sexual, intergenerational and intragenerational division (within and outside the family) of care work.

These mechanisms are theoretical. While they are among those that do already exist in different countries, their selection and implementation depend on the State recognizing care as a public policy matter. 


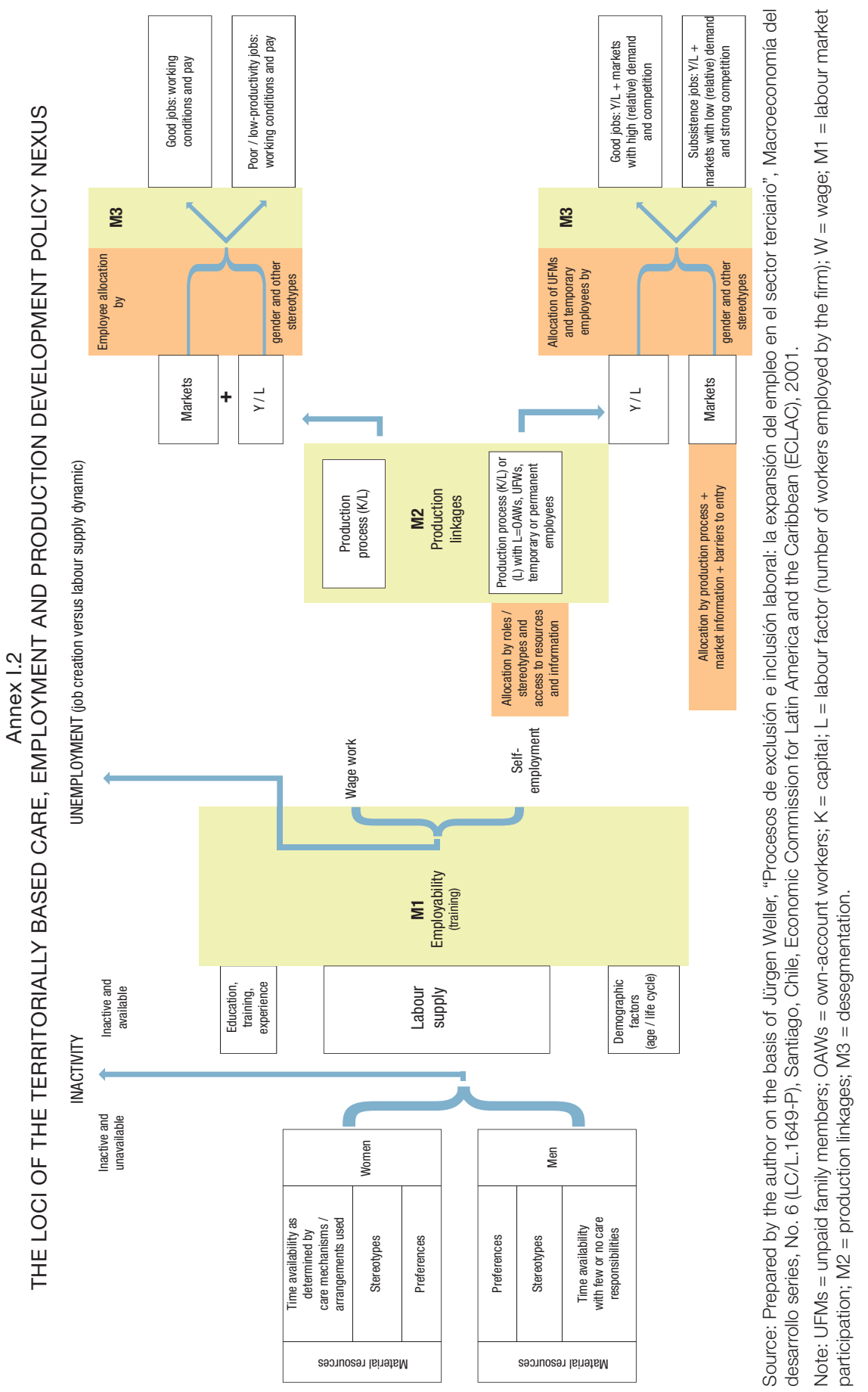




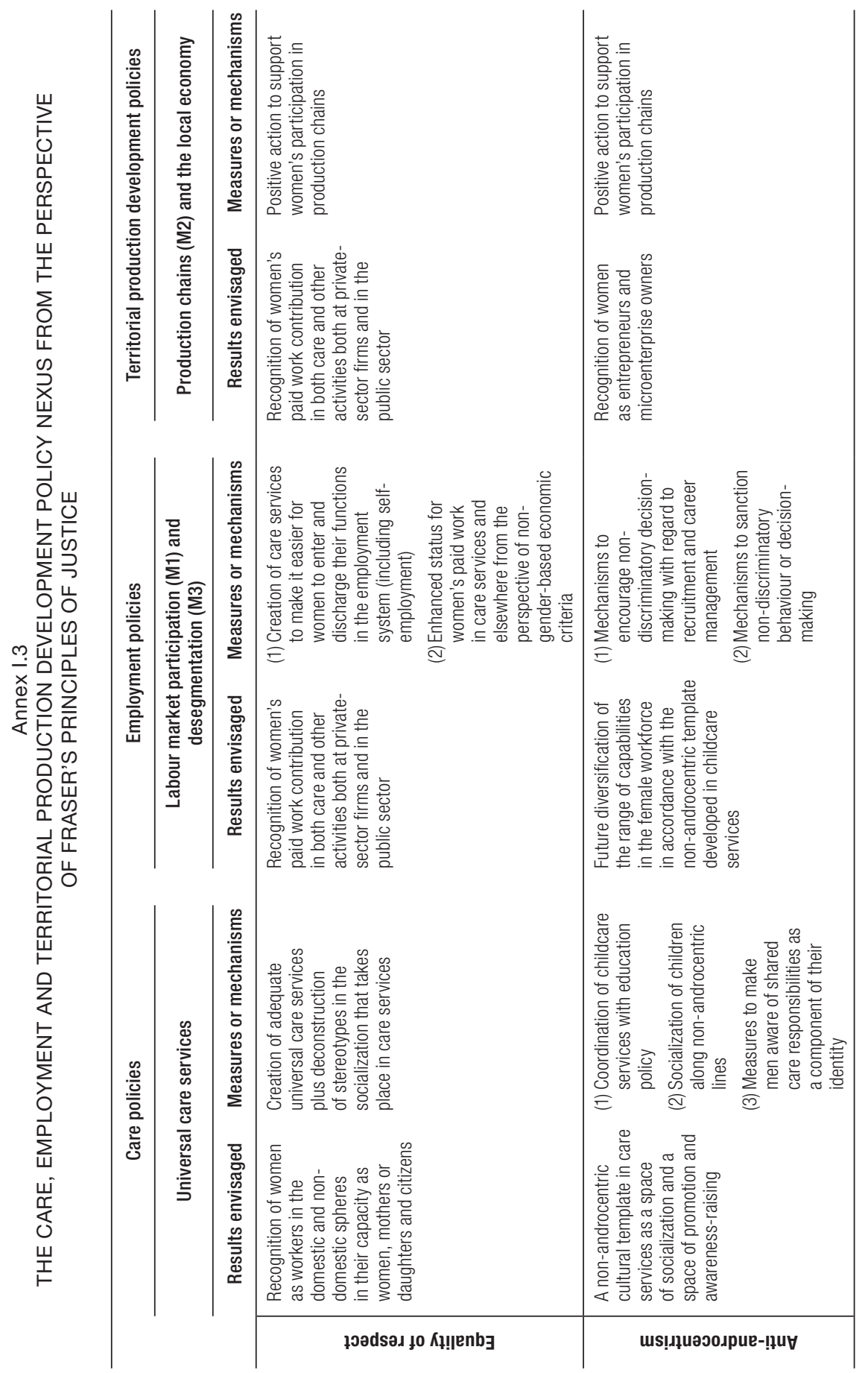




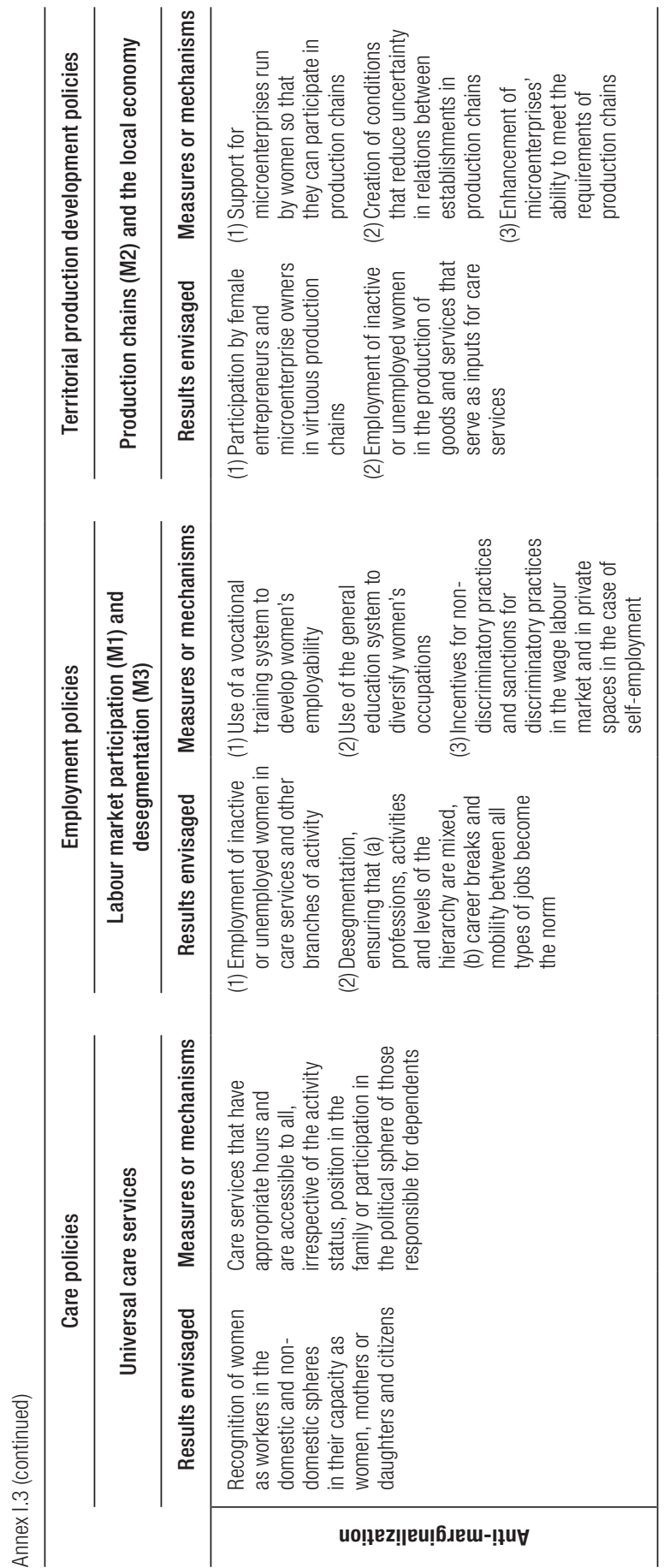




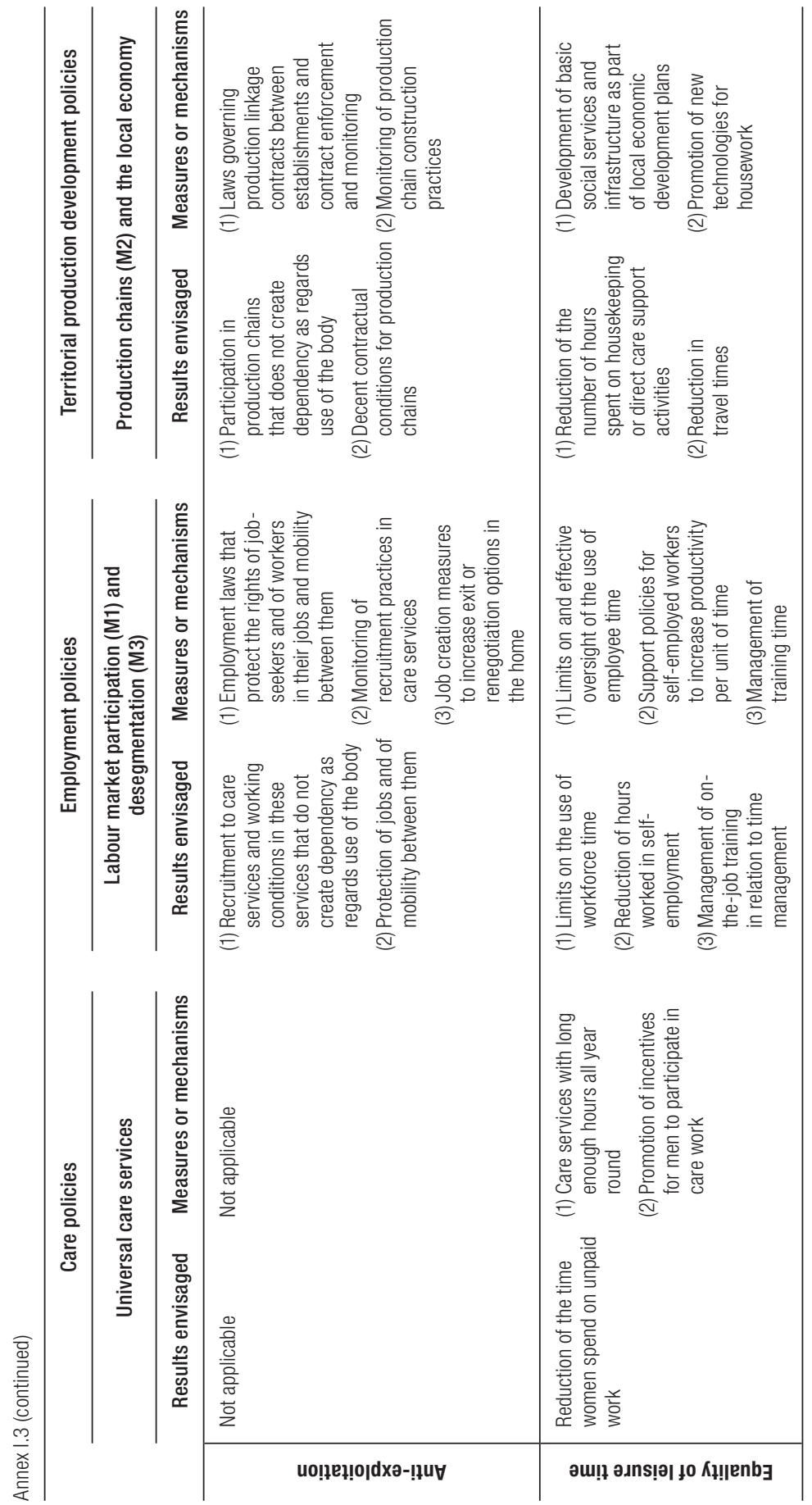




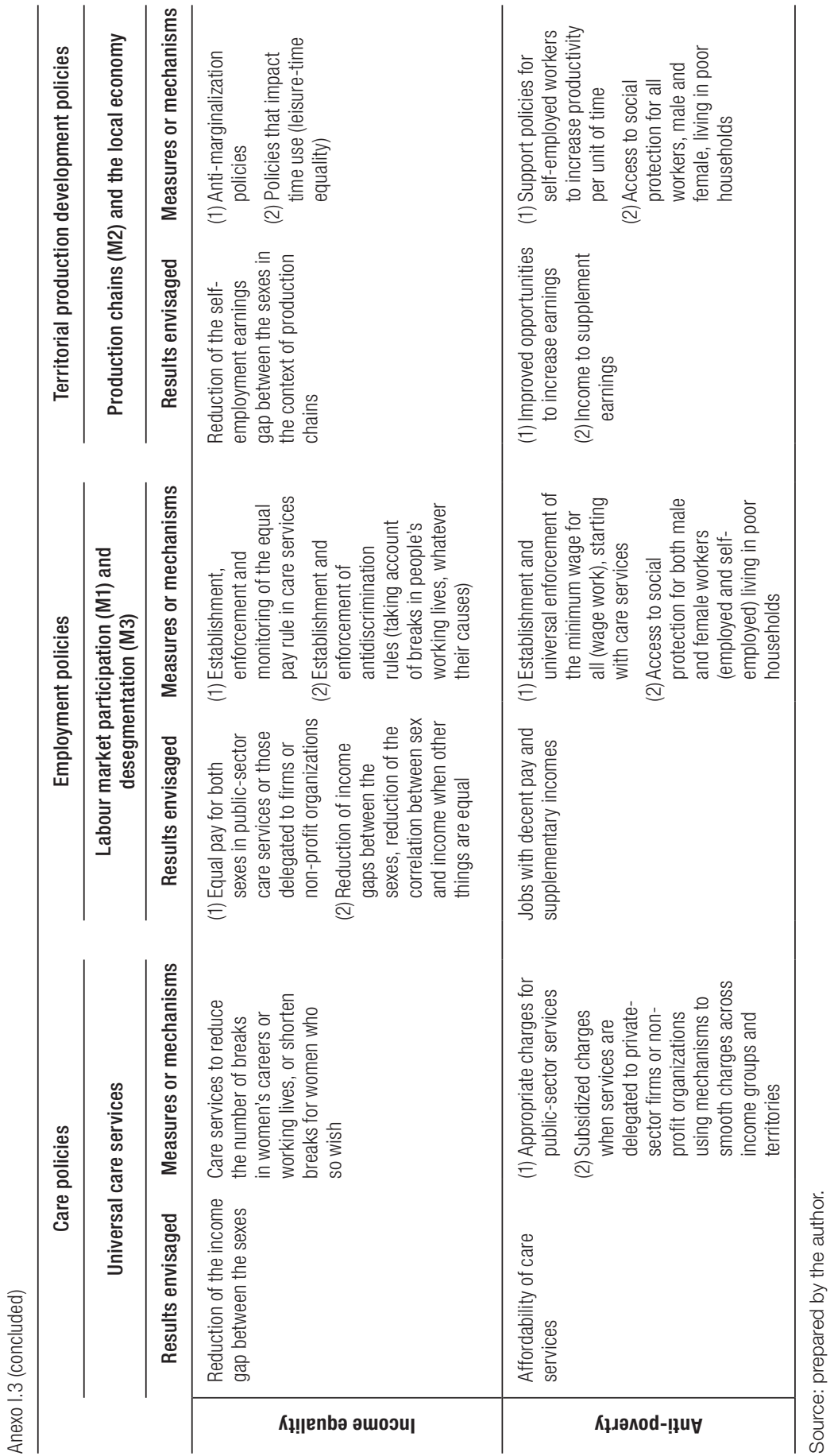


Chapter II

\title{
Social protection and the redistribution of care in Latin America and the Caribbean: the breadth of policy ${ }^{1}$
}

\author{
Patricia Provoste Fernández
}

The idea underlying the welfare State, it may be said, is of an interdependent society where the idea of responsibility is widely shared.

AMARTYA SEN

The gender dimension of social protection policies and their effects on women's autonomy and empowerment have been analysed from various angles, all converging on the sexual division of labour and the ability of policies to shift this in the direction of gender equality. The present analysis takes the same approach from the perspective of care redistribution, examining the potential offered by social welfare policies for a shift towards a concept of care as a universal right, and thus as a State duty and a responsibility shared not only between women and men, but between the different institutions in society as well.

The present article is a summary version of "Protección social y redistribución del cuidado en América Latina y el Caribe: el ancho de las políticas", Mujer y Desarrollo series, No. 120 (LC/L.3560). 
The basis for this review is the growing interest that States and public policy analysts in the region have been taking in social protection, an interest that has been deepened by successive crises and their aftermath, and by a growing awareness of the structural character of poverty. The role inevitably played by care in social protection creates an opportunity to mainstream this foundational aspect of gender relations in social policy and use its potential to take further steps towards equality. This potential does not loom large, however, for most analysts and policymakers. The care economy and unpaid care services do not usually feature as something to be acknowledged, regulated or safeguarded in social protection systems. As will be argued in this analysis, the concept of care as a domestic responsibility for women, as an instrument and even as an explicit or implicit policy goal has permeated what are now century-old social policies in the region, adapting to the paradigm shifts that have preceded them at different stages of development.

\section{A. Why redistribute care?}

The redistribution of the care of dependent persons is crucial to social protection in Latin America and the Caribbean in the twenty-first century. The need may be said to be urgent, arising as it does not only out of political and cultural trends towards gender equality in the public and private spheres but also out of profound transformations in society (ageing, rising levels of education and paid work among women and new morbidity profiles, among other things) that are rendering traditional care services, norms and social arrangements obsolete and ineffective. It is a need, however, that does not have any one single pattern or universal solution, since it depends on the different social, demographic and economic processes at work in the region's countries.

The efforts made to characterize the types of welfare regimes providing the framework for social protection policy in the region are a good starting point for considering the redistribution of care in different contexts. It seems essential for this approach to be taken, and some authors have begun to do so. In the process, it seems necessary to refrain from treating the crisis of care as a balance sheet of care required and caregivers available (ECLAC, 2009), when the problem lies in a social and gender order (Montaño, 2010) that has not succeeded in turning the changing profile of care into an opportunity for an egalitarian reordering of society.

\section{Care: a public issue?}

Despite the issue now having taken on a degree of urgency, policy progress towards the redistribution of care has been very slow, although 
there have certainly been advances in the region, driven by national mechanisms for the advancement of women, the women's movement and a cultural shift in gender relations which has manifested itself in diffuse but effective ways. The commitments which the governments of Latin America and the Caribbean adopted in Quito in $2007^{2}$ and ratified in Brasilia in $2010^{3}$ have given rise to numerous initiatives for recognizing and valuing unpaid care work, particularly in the shape of legal and constitutional reforms and the production of official information on time use. There have also been some pension reforms, an increase in the supply of childcare and other measures along these lines.

This is not enough to redistribute care, however. On the one hand, care policies for different social groups (children, the sick or disabled, the dependent elderly) have been uncoordinated at the State level. Each has its beneficiaries, its resources, and its laws and institutions. The synergies between them have yet to be identified. On the other hand, there has been little progress with the conditions of care provision in the domestic sphere and with the new equation that is needed between all the agents involved in the production of care and of the welfare of the population. Progress in giving greater visibility to unpaid care work in the home has yet to have much of an impact on the design of services and cash transfer policies.

The fact is that, as a number of authors have argued, policies still assume that care is a women's problem which the State may (or may not) support. There is still no recognition of a universal human right to receive and provide care under conditions of equality and dignity (Pautassi, 2007), or of the need to redefine the roles of the sexes and of institutions in this task. This is not just a policy limitation, but is also a result of the absence of broad public debate and citizen consensus about the kind of society, State and relationships between genders and generations that we want, about the roles and rights of those receiving care and those giving it, and about the standards, services and resources each society is willing to put in place to guarantee them. These omissions are having economic, social and political consequences: the reproduction of poverty in the countries and the continuing expropriation of women's time and autonomy, which limits the citizenship of those providing care and those being cared for.

Tenth session of the Regional Conference on Women in Latin America and the Caribbean, Quito, 6 to 9 August 2007.

3 Eleventh session of the Regional Conference on Women in Latin America and the Caribbean, Brasilia, 13 to 16 July 2010. 


\section{Maternalism and poverty}

The problem of how to approach care is part of a historical context of public policy contradictions: even as progress has been made with recognition of women's rights and measures against gender discrimination, the policy assumptions and templates that perpetuate women's domestic duty have been retained, and indeed have shown a chameleon-like ability to adapt as the different development models have succeeded one another. The core of social policy is still maternalist in a classically patriarchal sense, and this is plain to see in policies and services targeted at the most vulnerable population. Conditional cash transfer programmes are the clearest contemporary expression of this maternalist stance (Rodríguez, 2011), which is associated with another policy contradiction, that between the declared goal of eradicating poverty and the constraint that policies place upon women's autonomy by assigning them a "privileged" role as homemakers. This limits their ability to participate in the labour market or increases their total work time, thus undoubtedly contributing to poverty and to socioeconomic differentiation in the impact of the gender order. The instrumental conception of women as the link between social policy benefits and the family is found in governments and organizations of very different types, insofar as they all follow the paradigmatic prescription of targeting public spending by channelling it through the (mothers of the) poorest families rather than moving towards universalist systems involving rights and the promotion of decent jobs, along the lines proposed by the International Labour Organization (ILO).

Maternalist design is a feature not only of conditional cash transfer programmes but also of policies to reconcile family life and work, public services for the population requiring care (children, the disabled, the dependent elderly) and basic health and education services, encompassing a huge spectrum of the State's operations and -although this is not well studied- of those of the so-called third sector, ${ }^{4}$ which works with poverty and personal care.

A sector-by-sector review of policies and services aimed at the groups with the greatest care needs reveals a variety of situations and differences of pace as regards maternalism. Where children are concerned, the growing focus on initial education is creating opportunities (not always exploited) to decouple childcare from the employment (and exclusive responsibility) of women. Proposals for ageing populations have incorporated gender considerations, at least in international analyses, but the same does not hold to any appreciable

4 The third sector comprises social and community organizations in civil society. 
extent in the case of disabilities. The importance of the home is reiterated, without any real effort to resolve the problem of who is doing the caring.

The strength and pervasiveness of maternalism also reveal the difficulties facing national mechanisms for the advancement of women when it comes to integrating care redistribution goals into mainstream policies, either because they share the maternalist outlook or because they have little ability to make a difference.

\section{Women's liaison role at the heart of care}

Maternalism is reproduced because the State and the economic and social system need the liaison role played by women - or sometimes another household member- between families and the institutions on which welfare depends (the market, the State, the third sector). Following this line of analysis, it could be argued that, at least in today's world, care is primarily the work of linking or coordinating (more or fewer) resources, products and services, and this places the focus more squarely on the liaison role than on some kind of division of care tasks between families, the State and the market. Setting out from this, it is possible to formulate questions or proposals for a redistribution of care in which these linkages (and not just domestic life) are based on gender equality.

Theoretical advances placing unpaid domestic work at the heart of economic reproduction and the organization of our societies have strengthened this conclusion (Lamaute-Brisson, 2011; Martínez, 2005; Rodríguez, 2005, among others). Thus, the proposed redistribution of care, rather than (or as well as) being a process of reallocating responsibilities, would involve a transformation of the ties linking the market, the State, families and the third sector, where the family (in its liaison role) is not just one institution alongside others but the centre (or submerged base) of the system. Where social protection policies and analyses are concerned, the failure to consider these linkages is arguably one of their main conceptual and practical limitations.

Looked at in this light, some aspects of the liaison role played by women in the region are particularly important. Although timeuse figures show the overburdening of women with unpaid work to be a constant in all the countries and all sections of society, this burden appears to be particularly heavy in two very different situations requiring different types of activities: in the countries and sectors which are poorest and/or where the State's social protection capacity is small, and in those countries where the State has developed a substantial range of services, programmes and transfers that add to the liaison time and labour of women who "qualify" to receive them on behalf of 
their families. Considering care from the liaison perspective in different national, socioeconomic and family contexts is still an incipient task in the region.

\section{The challenges for gender analysis}

Whereas analyses of social protection simply ignore the liaison role and its basis in gender inequality, gender analyses present certain weaker or less developed aspects in this regard:

(i) They pay more attention to women's excessive burden of care in the home than to liaison activities. Nonetheless, LamauteBrisson's analytical proposal in this book is an advance in this direction. The Classification of Time-use Activities for Latin America and the Caribbean (CAUTAL) should be revised to ascertain whether it has developed to reflect this proposal adequately. ${ }^{5}$ Although it mainly focuses on what happens within households, this classification has improved the measurement of time spent on liaison functions.

(ii) They tend to be State-centred, in the sense of prioritizing the care redistribution role of the State at the national level (principally through regulations and services), with some attention to the role of the market but little appreciation of the role of other actors such as those of the third sector and local agencies and institutions (aspects which LamauteBrisson also picks up on in her article for this publication).

(iii) They mainly deal with dependent care, neglecting the time spent caring for self-sufficient individuals (chiefly household heads), a key aspect of gender inequality that is not well reflected in time-use analyses.

(iv) Lastly, they use an implicit model of young adult women whose children are minors, with analyses and proposals turning on the obstacles to these women's participation in public life, thus neglecting women's other care and social protection needs. Underdeveloped fields include intergenerational care arrangements (although some

The proposal was presented for the first time in August 2009 at a technical meeting to refine the time-use classifier for Latin America and the Caribbean held as part of the seventh Meeting of Experts on Time-use Surveys, where the main recommendations for improvement were also presented. This is a tool for planning, implementing, processing and presenting the findings of time-use surveys based on time-use questionnaires. 
interesting analyses have been carried out on international care chains), the care needs of elderly women and their contribution to care in different cultural, social and national contexts and, lastly, the care role played by childless young women. Care in rural and indigenous contexts is also underexamined, and these are all areas where informationgathering is required.

\section{B. Care and maternalism in the region's social policies}

\section{Social protection and care}

The Economic Commission for Latin America and the Caribbean (ECLAC) (2006) and other international and academic bodies have stressed how crucial social protection policies are for rights-oriented development and as a condition for productive development with social equality. This emphasis comes at a point in history when recurrent economic crises and persistent social inequality in the region have called into question social policies oriented by neoliberal macroeconomic thinking. What needs to be analysed here is how unpaid care work has been integrated into the paradigms of social protection policies and what potential the current phase of critical review of the model offers for redistributing such work.

The view of social protection as the outcome of linkages between different components in society is based on the welfare regime analysis model adopted by influential authors such as Esping-Andersen. ${ }^{6}$ His work is part of a school of thought that has sought to explain the role played by public policies in social welfare in developed countries, taking into account the different methods used to link them to the institutions of the family, the State and the market. Adopting this approach, albeit adjusted for a less economically, socially and institutionally developed context than in the developed world, and for the considerable heterogeneity between the region's countries, ECLAC (2009, p. 149) argues: “Through welfare regimes, the State, markets and families play a role in promoting social protection".

In the global context, the region is distinguished by persistently high levels of social inequality, and partly as a result social protection analyses have focused not only on the risks or changes that are part of the life and employment cycle, but also on structural situations of

Gøsta Esping-Andersen (1999) characterizes three models of welfare regimes that have arisen in the developed world: the liberal, social democratic and conservative models (cited in ECLAC, 2006). 
poverty, poor-quality employment and lack of access to basic rights. This has led to social protection policies emphasizing vulnerable sections of society rather than the universalization of social welfare.

Conceptual recognition of the family as a component of social protection opens the way to recognition of the domestic sphere and the role of women in the functioning of the economy and the welfare of society through the unpaid work they do in the home. This was one of the key positions taken at the tenth session of the Regional Conference on Women in Latin America and the Caribbean (Quito, August 2007), whose participants agreed, among other things:

(xiv) to adopt measures in all spheres of institutional democratic affairs and, in particular, in economic and social areas, including legislative measures and institutional reforms, to ensure recognition of unpaid work and its contribution to families' well-being and to countries' economic development, and to promote its inclusion in national accounts;

(xxiii) to develop instruments, especially time-use surveys, for periodically measuring unpaid work performed by women and men in order to make such work visible and recognize its value, to incorporate their results into the System of National Accounts and to design economic and social policies accordingly;

(xxvii) to adopt the necessary measures, especially of an economic, social and cultural nature, to ensure that States assume social reproduction, caregiving and the well-being of the population as an objective for the economy and as a public responsibility that cannot be delegated.

The Quito debates and agreements unquestionably provided a fillip to government actions and to the analyses and debates that followed in academia, the women's movement and international and cooperation organizations operating in the region by demonstrating the contribution made by women to the welfare of society and arguing for the need for recognition and social redistribution of unpaid work in a context of transformations that have rendered traditional models of welfare organization unsustainable.

Time-use statistics (Milosavljevic and Tacla, 2007) and figures demonstrating the greater burden of total work borne by women were key inputs at the Quito Conference (ECLAC, 2007). ${ }^{7}$ These statistics have

The Gender Equality Observatory for Latin America and the Caribbean, created under the auspices of the tenth Regional Conference on Women in Latin America and the Caribbean held in Quito in 2007, includes total working time, i.e., the hours spent by 
provided a sound empirical basis for a new generation of analyses of the sexual distribution of labour and characterization of the different aspects of unpaid work, prominent among them being care for household members, whether direct - as when people are helped to perform basic functions - or in the form of activities conducive to the physical and emotional well-being of the family group.

Progress in this field of analysis includes particularly the "development of the so-called 'care economy', an area that specifically includes all the activities, goods and services needed for the day-today social reproduction of women and men, especially as this connects to countries' economic development and social gender relationships" (Rodríguez, 2005, cited in Pautassi, 2007, p. 10).

If these analyses are accepted, the role of the family in social protection lies mainly in the care tasks carried out in the context of family relationships and in the paid or unpaid activities performed outside the home to secure other resources or services as needed for the protection of individuals.

However, recognition of women's unpaid work, particularly care work, and of its importance to welfare has not easily transferred to the mainstream of analysis and public policy, where, despite acknowledgement of gender discrimination in public spaces and the economy, women's role in care and housework is still taken for granted.

Sonia Montaño (2010, p. 26) argues that what is in crisis is the sexual division of labour and that this is connected with the emancipatory cultural shift led by women: "Given how ancient the sexual division of labour is, the question must be why it has now acquired the character of an urgent social problem. This is undoubtedly due to demographic factors such as the longevity and quality of life of men and women, the demographic transition that has resulted in women caring increasingly for the elderly rather than for children, transformations in the family, global care chains in which female migration has become important for remittances and family subsistence and, last but not least, the fact that more or less educated women want to be financially independent, have their own incomes and benefit from the educational capital they have accrued. The so-called crisis of care is in fact a symptom of women's emancipation."

This set of factors is what lies behind the need for policies to foment an egalitarian redistribution of total work, paid and unpaid, 
productive and reproductive. In this context, there is a need for policies that treat care as an element of development from both a rights-based and a gender equality approach.

Countries with smaller welfare gaps need to work on care policies for the elderly in the shorter term, given the increasing prevalence of dependency and chronic diseases with age. This calls not only for personal care, for which women can no longer be left responsible, but also for capacity in health-care systems and different services to meet the needs of older people (a majority of them women), whose rights are beginning to be recognized as a policy objective. In addition, there is a great deal of work to be done as regards the social welfare of children and the poorest in both urban and rural areas. This includes moving towards childcare policies that are decoupled from women's work, as the present situation is still a constraint on equality for the female workforce.

Countries with the largest welfare gaps are faced with needs that tend to be largely concentrated among the young and underemployed, as well as standing in greater need of childcare policies. A lack of good job opportunities results in high emigration, with thousands of women going to swell the care workforce in developed countries and even some countries within the region itself, thereby contributing to the welfare of their own families and to the national economy. The relative inability of the State and market to generate social welfare in these countries results in greater pressure on families, as can be observed in indicators such as a higher proportion of people declaring out-of-pocket spending on health care, greater dependence on remittances from abroad and a higher proportion of extended families and stepfamilies.

At the same time, this migration of women to countries where there is demand for care work raises other questions about the link between social protection, gender inequalities and the globalization of labour markets. A variety of ongoing studies have fleshed out the issue of the "global care chains" (Pérez, 2010) that are behind the remittances sent by migrant women. These women move to a more developed country to carry out paid care work, leaving another woman from the family to care for their own children and thus forming transnational care networks. This phenomenon has major implications for national economies, for families and for the social protection policies of sending and receiving countries, and it has turned care into a globalized system and a fundamental component of economic globalization.

In summary, analyses agree in treating social protection as an outcome of linkages between different institutions, including the family. However, the way these linkages work is not always spelt out, beyond some general references to the greater or lesser burden falling on the 
family. The relationship between this burden and the unpaid work done by women within a framework of patriarchal relationships has been documented mainly by analyses carried out from a gender perspective.

\section{From wives to mothers: care in development paradigms}

The relationship between social protection policies and the field of care of dependent persons can be best understood within the broader framework of the major development cycles in Latin America.

Regarding the sexual division of labour, a number of authors (Pautassi, 2002; Provoste, 2003; Molyneux, 2006; Martínez and Voorend, 2009) have argued that the wage model of access to rights is underpinned by a traditional conception of the family as headed by a wage-earning man and a dependent wife, who has access to health care, housing, a pension, holidays and other benefits because of her legal status as spouse, as do the children of the marriage, all this being underpinned by the contract of employment. This social policy mainstream clearly exerts pressure on women to be full-time wives and mothers. But it is not the only stream: wage-earning women now gain access to specific employment rights whose purpose is to provide them with guarantees in their role as caregivers for their children.

However, the protection given to female wage workers is governed by a similar conception, namely preservation of their child-rearing role. Neither discrimination in employment nor inequalities in the domestic sphere are thematized. Meanwhile, the developmentalist stage is also a time when the right to vote and other civil and political rights accrue to women. Accordingly, development models may attach themselves to a social policy mainstream, but these are not the only policies, since there is also room for the development of other rights or for the continuation of earlier methods of accessing rights, ${ }^{8}$ which are sometimes mutually contradictory.

Access to rights through employment became far more uncertain in the last quarter of the twentieth century with the globalization of markets and the repercussions this had on production methods and employment relationships.

The free market model led to a loss of employment stability and protection as flexibility and deregulation became the hallmarks of policy

For example, humanitarian methods of contributing to welfare are of remarkably long standing, having existed since the colonial period in the form of private, religious or indeed public charity, while public health and education policies foreshadowing today's social policies were developed in the nineteenth and early twentieth centuries. 
in this area (ECLAC, 2010a). One of the main outcomes expected from the free play of market forces was that people would be able to meet the costs of their own health care and retirement, freeing the State from part of this burden, on the assumption that the amount and quality of employment would improve. It is important to note that this paradigm was not implemented fully in any country: the free market did not lead to full employment or better employment, and neither the social apparatus of the State nor employment-based access to rights was completely dismantled.

This shift has translated into substantial changes in the role played by policy in gender relations. For one thing, the labour market deregulation of the neoliberal model and the rise of insecure and unprotected employment particularly affected women, whose employment was often of this type, so that they were left with only limited access to social rights via employment either as workers or as dependent wives, since the situation of male breadwinners also worsened.

For another thing, the new paradigm guided many of the sectoral reforms and modernization processes undertaken by the region's States in the closing decades of the twentieth century in areas such as health care, education and pension systems, with a two-pronged approach of privatization and targeting. In the area of health care, there has been growth in private financing systems which various evaluations have found to result in discrimination against women, who have to pay more for health-care plans, for example, because of the likelihood of their becoming mothers, an "additional cost" which is charged to all women. ${ }^{9}$ More recent reforms, in Chile for example, have sought to relieve the burden on the public sector by promoting home care for the chronically sick or patients discharged early from hospital (Provoste and Berlagoscky, 2002), with women bearing the burden of the new care arrangements needed for these policies to work.

The reforms made to pension systems in the heyday of neoliberalism have tended to weaken the solidarity and redistribution principles of wage-based models by introducing individual funding mechanisms (the preponderance of which varies by country), with the result that new types of gender inequality and discrimination have arisen. ECLAC conducted a set of studies from this perspective on the pension reforms carried out up to 2004 in a number of the region's countries. The studies "reveal clear inequalities in pension coverage and amounts, and these become especially significant if it is considered that [women] retire earlier and live longer" and that they participate in the labour market less continuously and earn less. This is compounded by

9 The situation in Chile is documented by Barría (2002). 
"explicitly discriminatory provisions" such as "the use of actuarial tables that make distinctions between male and female life expectancy for benefit calculation purposes. Thus, [...] a smaller pot divided by a larger number of years results in a lower pension" (Marco, 2004, p. 7).

In this period, the principle of targeting benefits on the poorest generally resulted in services and benefits being decoupled from employment and no longer depending on people's contractual status, but on their ability to demonstrate poverty or extreme need. This system reinforced or reinvented the role of women as a direct link between State and family. Their role as mothers came more to the fore than their role as wives. This being so, targeted social policy may be said to be more "maternalist" than wage-based policy, which is more "spousist", although both take women's place in the home for granted (Provoste, 2003).

As Jeanine Anderson (2007, pp. 215-216) argues, referring to "'maternalism' and its species" in her analysis of family-oriented policies and programmes in the Andean countries: "Social welfare policymakers usually treat women as disinterested implementers of programmes that will benefit their children and families and, by extension, other families nearby." The author adds that "this is an approach that women themselves are very willing to share or make their own. They themselves have trouble differentiating situations in which they are acting as a conveyor of benefits to others from situations in which they are receiving benefits that are legitimate and appropriate to their own situation."

Nonetheless, it is also possible to observe other processes in this period that boosted gender equality. Globalization has provided a substantial international agenda, inaugurated at the State level in 1975 with the first World Conference on Women and accompanied by substantial social and political pressure from an emerging feminist movement, the most vigorous since the early twentieth century. It is paradoxical that, as noted by ECLAC (2010b), it was this period of increasing State weakness that saw the creation of national mechanisms for the advancement of women, which assume a more interventionist State and have, at least in theory, the capacity to question the traditional gender roles encouraged by historical models of development, by disseminating the idea that women are subjects of rights on their own account.

It was thus that the subject of discrimination against women came on to the public agenda, even as international organizations became increasingly vocal, major legislative changes were made and a variety of government programmes began to encourage female participation in labour markets, whether as a right or as a necessary measure for combating poverty in the countries. Thus, as in the developmentalist stage, progress was made with rules and programmes favourable to 
women's autonomy and rights even as privatized services and targeted programmes reinforced gender inequalities.

Taking stock of this stage, it can be said that both in the developmentalist period and in the free market period there were social protection policies that entrenched women's role as caregivers in the home even as gender policies advanced into other areas of women's rights. Although policies have concerned themselves to some degree with the barriers to female participation in public life, they have paid less attention to the barriers that persist in private life. This is one of the greatest constraints (although not the only one) on the policy contribution to gender equality in both social policy models.

\section{After the crisis: continuity and change in social protection}

The globalized free market model was called into question in turn because of the persistence of social inequalities and the successive global economic crises that showed its promises to be unviable, and this, along with other dramatic disruptions of global impact, such as the fall of the Soviet system, brought the ideas of uncertainty, insecurity and vulnerability to centre stage (Bauman, 2002) as real and growing social and political issues.

From the perspective of inclusive development (ECLAC, 2010a), the challenge facing our societies now is to secure a minimum of basic social rights for all and thus reduce the region's huge inequalities. For this, it is indispensable to achieve growth strong enough to generate the necessary resources and combine this with redistributive fiscal policies, while at the same time creating decent job opportunities to increase people's autonomous capabilities, reducing the fiscal burden without increasing the vulnerability of families and individuals.

These concerns and difficulties have come up in varying degrees and forms in the different countries of Latin America and the Caribbean, whose histories have left them with different institutional and economic response capabilities and with dissimilar and even divergent political approaches. A special group are those countries that have implemented constitutional and political reforms which recognize economic, social, cultural and environmental rights as human rights, i.e., as justified not by want but by the basic dignity of human beings, and thus as universal rights binding upon States.

Although constitutional reforms do not ensure that States will be able to guarantee the effective enjoyment of such rights, they do give a direction of intent to government policies and plans. New measures 
aiming at inclusion and equality can be found even in countries that have not incorporated economic, social, cultural and environmental rights into their constitutions, giving a new legitimacy to the principles of universality and solidarity as the basis of social policy, or at least to the idea of a more socially responsible State.

Nonetheless, the battery of instruments and criteria available does not differ greatly from those applied in earlier times. There has been no wholesale abandonment of neoliberal ideas about the free market -a portion at least of the population is expected to "buy" at least some of its health care, education and pension provision, albeit with improved market regulation in these sectors - and about the targeting of social spending: conditional transfer programmes, one of the most widely used social tools in the region, according to Sojo (2007), offer a rejuvenated version of the targeting principle.

In the sphere of gender policies, substantial progress has been made in the early years of the twenty-first century. Where approaches to care are concerned, the constitutional reforms of countries such as the Bolivarian Republic of Venezuela, the Dominican Republic, Ecuador and the Plurinational State of Bolivia have included explicit acknowledgement of the importance to society of women's unpaid work and its contribution to national economies. Several countries have brought in new legal and constitutional reforms to combat discrimination and violence against women. A new generation of pension reforms in a number of countries such as Argentina, Chile and Uruguay have improved the situation of women by means of mechanisms such as compensation for lower pension incomes, the introduction of minimum pensions for those who have never paid retirement contributions (including the many women whose active lives have been spent on unpaid work in their homes) or cash compensation for years spent bringing up children. With this recognition, unprecedented in the region, care work has thus been incorporated into social protection systems.

In the employment sphere, there have been legal reforms designed to establish fathers' responsibility for childcare and - mainly but not exclusively at private-sector firms- work-family reconciliation initiatives that are usually treated as benefits for women, which limits the effort to extend the family responsibilities of fathers. Nonetheless, more flexible working hours and weeks and home working have increasingly undermined job protections and security in ways that not only affect women most but have entrenched their exclusive responsibility for family care.

As in earlier stages, however, there are contradictory trends. The priority given to the fight against poverty and the idea that this 
effort had to precede gender equality have limited the application of universalist criteria and expanded the targeting of social spending under new formulas, relying once again on a maternalist model of social programmes, where the key is the care work done by mothers from the poorest households. Consequently, the goal of redistributing care between women and men, and between the different actors in the social protection system, is still far from being established in the public policy mainstream.

To sum up, the role of women in family care has been present since the earliest days of social policy in the region. Furthermore, this role may be said to have made a crucial contribution to policy implementation, but to have done so on the basis of unavowed assumptions and conceptions that have taken this role for granted and have naturalized and instrumentalized it, insofar as policies have relied on women staying at home and being available to implement State prescriptions designed to meet the needs of families, for which they are assumed to be responsible.

In recent years, as a result of pressure from the women's movement and the cumulative experience of national mechanisms for the advancement of women, the role of care has been thematized as the basis of gender discrimination and as an object of policy, and this has begun to call the assumptions of social policy into question. Progress is still inadequate, however, and one of the main obstacles to it is the targeted conception of anti-poverty policies. This reveals the continuing weakness of the conception of social protection policies from a gender equality perspective and as an instrument for the universalization of social rights.

\section{The provision and redistribution of care}

The conception of care as a universal right whose exercise needs to be underpinned by gender equality requires a new equation between the market, the State, families and the community that defines the responsibilities of each actor and the new forms of linkage between them. From this perspective, the universal right to care is conceived as encompassing, first, the guarantees and mechanisms ensuring decent care provision for those requiring it and, second, the conditions for implementing care appropriately (Pautassi, 2007) and the distribution of responsibilities between different agents in respect of both facets of the right to care. This objective engages a wide range of legislative, economic, fiscal, employment, urban, social and cultural policies, some of which will be addressed in this review, with the focus on the main devices whereby the State acts most directly in the provision of care 
and incorporates this into welfare systems, summed up in the triad of services, time and money. ${ }^{10}$ The formulation refers to "services catering directly to those requiring care (such as infant schools or residences for older adults), time off for working people to care for family members at home, or cash transfers to assist families financially" (Tobío and others, 2010, p. 151).

The care needs that are important for policy purposes are those deriving from the temporary or permanent inability (because of age, sickness or some other circumstance) to conduct basic activities that most people can carry out for themselves. From this perspective, the main groups of people requiring care are minors, some older adults and the sick and disabled, i.e., all those of any age who are in a situation of dependency because they need support to carry out one or more basic functions.

However, policies need to take account not just of care needs but also of demand for care and effective care practices. Durán (2006, p. 65) notes as a source of demand for unpaid labour that deriving from "those who are overemployed in paid activities", on top of that deriving from the dependent population.

It cannot be forgotten that care is also provided to people who can look after themselves, as is the case with many adult men. As Tobío (2010, p. 26) puts it, "this is one of the characteristic features of inequality between women and men. Women prepare men's food, make their beds and wash and iron their clothes even though there is no reason why grown men cannot carry out these tasks for themselves. In this case, being cared for is a manifestation of power and reveals the depth of gender asymmetries."

The point made here leaves unresolved the need to distinguish care requirements and demands deriving from physical dependency from those resulting from social prescriptions or voluntary family arrangements, as in the case of women who agree variously to devote themselves to work in the market or work in the home. Policies have to be designed not only to provide services to those who need them and redistribute care work, but also to alter the cultural traditions that place women at the service of men.

10 There are variations in the way these three components of care are formulated. Pautassi uses the formulation of Ellingstaeter (1999, p. 41), who refers to the availability of "time for caring, money for caring and childcare services" (Pautassi, 2007, p. 10). Astelarra, following Lewis and Giullari (2005, cited in Astelarra, 2006, p. 36), expands the formula, noting that the requisite public policies encompass: time, including time for work and time for caring; money, to purchase care and for caregivers; and care services for children, the elderly and dependents. 
Comprehensive provision for situations of dependency is a growing field for legislation, policy and analysis in developed countries. ${ }^{11}$ In the region, on the other hand, little has been done as yet to link up policies and conceptions relating to dependency and its relationship with care.

Traditional sectoral developments have continued, as in the case of health care, giving rise to specific and usually unconnected standards, institutions and programmes. Nonetheless, there is now an outgrowth of policies that are beginning to come to grips with care as a wider issue requiring unified criteria, with an explicit link to the paid work of women, as is the case with the government plan of President Laura Chinchilla in Costa Rica.

\section{Public-sector care services}

One of the main challenges for the region is to develop services and institutions that can deal with different types of care needs experienced by people in a situation of dependency from the perspective of the right to care (including that of both care recipients and caregivers) and of nationwide responsibility and solidarity. The development of services for three major population groups requiring care will be reviewed: minors, older adults in need of support, and the sick or disabled.

\section{(a) Children of preschool age: from nursery to initial education}

A lack of public-sector childcare services for the youngest children has repeatedly been cited as one of the main obstacles to the integration of mothers into the labour market, insofar as it has kept alive the idea that one of women's main domestic responsibilities is the rearing of children. The first nurseries and kindergartens in the twentieth century were set up to assist mothers working for the public sector and firms to carry out their functions, as an employment right.

In the same period, the active concern of governments with early childhood care centred on nutritional and immunological health deficiencies, which were addressed by means of dietary and preventive care at the primary health-care level, albeit to differing degrees in the different countries. These initiatives were implemented with the involvement of mothers. The development of nurseries and kindergartens,

11 In 2006, for example, Spain passed the Promotion of Personal Autonomy and Care of Dependent Persons and Families Act. This law provides for a National System of Dependent Care guaranteeing various types of services and resources in support of all those with one of the three levels of dependency it defines on the basis of the level of assistance required to perform basic functions. Under specific conditions, payment to the family member providing care is among the types of support that may be considered. 
whether run by the State or by solidarity initiatives, took place in the context of poverty reduction and was not intended to cover all children.

More recently, there has been a growing belief, encouraged by international conferences and agreements, that preschool education is indispensable to all-round development in childhood, and early education has accordingly been coming to occupy a substantial, if still inadequate, place in education policies.

Meanwhile, the employment of home carers (nannies) is still a major feature of the region, with these forming part of the still large percentage of women carrying out paid domestic service work, enabling other women who have the income to do so to delegate care and other domestic tasks to them. As already mentioned, paid domestic care is also linked to migration between the region's countries, with a group of recipient countries and a group of source countries for female workers in this sector. This situation shows that childcare methods are highly segregated by the socioeconomic status of families.

Although there has been progress at the pre-primary level, especially for five-year-olds, this is still inadequate and there are major deficiencies at earlier ages, when many children remain in their families' care. These deficiencies tend to be greatest in the countries, areas and sections of society with the largest welfare gaps.

In the group of countries with the greatest social protection gaps, women's labour force participation rates are high but initial education coverage is lower, and the proportion of large or extended families and stepfamilies is greater. This suggests that strategies of task distribution between women are in operation, i.e., that in poorer sections of society some women go out to work (or emigrate) while others take charge of care and of visits to support services and programmes. This is the situation revealed both by the analyses of "global care chains" already mentioned and by others looking at seasonal workers. A much-cited obstacle to progress towards greater satisfaction of women's needs is the problem of hours, which are often unsuited to working mothers (or fathers), the reason being that factors other than women's autonomy are considered when services are designed.

This brief review bears out the analyses showing that, in the matter of childcare, a greater social protection burden still falls upon women in lower-income families.

Both gender analyses and those dealing with childhood signal an urgent need to increase the number of care centres decoupled from mothers' paid work and designed for the needs of children and not 
working mothers. This also means moving towards more universal service provision, rather than limiting it to the lower-income population.

A similar idea of universal entitlement and shared responsibility should likewise apply in all health-care services and programmes for the youngest children, which rely on children being accompanied by their mother and occasionally another family member, especially in the poorest sectors. Particularly at the earliest ages, health services continue to be a key component of childcare, with rapid and efficient liaison between the family and public (or private) health systems being essential. If there is one thing apart from environmental sanitation that has brought down mortality and raised levels of human development in Latin America and the Caribbean, it is the expansion of a primary health-care network working with mothers in the poorest sectors and these women's availability to take their children for regular health check-ups. Reforms to health systems have often taken it for granted that this key element in their success will remain and have not adapted to a changed social, employment and demographic environment by bringing in changes to care models (such as hospitalization with an accompanying adult or in the home, and early discharge) which, like community prevention programmes, intensify the demands on women's time (Provoste and Berlagoscky, 2002).

Here it is important for the necessary linkage of health and education systems with families to be understood as a shared responsibility for both parents and for it to be made to fit in with the working hours of both on the basis of an innovative distribution of responsibilities, involving for example a more prominent role for schools and childcare centres. To devise more realistic methods, it is necessary to have a detailed knowledge not only of the supply of and demand for day-care establishments, but also of all the work currently done to liaise with health and education services and other public services and of the time and tasks involved, with efforts likewise being made to ascertain what organizational characteristics are facilitating or impeding the shift towards shared responsibility.

\section{(b) Older people: providing and receiving care}

Although gender analyses of care have focused on child-rearing responsibilities, they are increasingly looking at the elderly, a growing segment of the region's population. The issue of care at this stage of life has a twofold gender dimension, firstly because women bear the main responsibility for providing the care the elderly require, and secondly because a majority of older people are women, who live longer and on less income than men. Thus, the care needs of these women increase with age (Huenchuan, 2009) even as they continue, in many cases, to 
contribute to the family and community. At the same time, the fertility decline and reductions in family sizes are reducing the scale of the family support networks potentially available to older people.

The provision of services for the elderly needs to be understood within the framework of the incipient development of policies for older people in the region. These have an important precedent in the Regional Strategy for the Implementation in Latin America and the Caribbean of the Madrid International Plan of Action on Ageing, approved in 2003, progress on which is being followed up in the region by the Latin American and Caribbean Demographic Centre (CELADE)-Population Division of ECLAC from a human rights perspective (Huenchuan, 2009). According to the guidelines in that instrument, older people are citizens with enforceable rights to an autonomous, decent and active old age, as part of what should be "a society for all ages". More recently, under the auspices of the second Regional Intergovernmental Conference on Ageing in Latin America and the Caribbean (Brasilia, 2007), efforts have been made to produce an inter-American convention on the rights of the elderly that gives more closely targeted protection to this section of the population (Huenchuan and Rodríguez-Piñero, 2010).

Analyses show progress with legislation, policies and programmes to improve the living conditions of older people, especially in countries with older populations and greater social policy capabilities. They also report, however, that in all countries "a significant proportion of the older adult population still lacks access to social security, health care or basic services", given "the generally precarious nature of the protection mechanisms provided by the State" (Huenchuan, 2009, p. 16). These failings are often due to "the deep-rooted notion that problems of ageing are a matter for the private sphere rather than an issue calling for collective solidarity" (Huenchuan, 2009, p. 16). Consequently, the duty of providing care to this section of the population also falls upon women.

One point ECLAC has been making is that ageing has occurred more quickly in the region than in the most developed countries, but without the same pace or degree of progress in policy and service implementation. At the first Regional Conference on Ageing, held in 2003, it was estimated that the population aged 60 and over in the region $(8 \%$ of the total in 2000, or over 41 million people) would reach $14.1 \%$ in 2020 , or more than 98 million people, and $23.4 \%$ in 2050 (ECLAC, 2003, p. 3).

Another aspect that comes out, despite the heterogeneity of the over-sixty group, and that differentiates the region from the countries of the Organisation for Economic Co-operation and Development (OECD), is the steady rise since 2005 in economic participation rates among older people, which can be associated with the need for income resulting 
from the region's high poverty rates and the limited coverage of pension systems, especially for women (ECLAC, 2006). Taking the population over 60, "just over three out of every ten older persons are working or actively seeking work" (Huenchuan, 2009, p. 95). This increase, it is noted, is largely accounted for by women, who are more likely than those in other age groups to be in informal employment.

As regards residence characteristics, in 2005 or thereabouts an average of $62 \%$ of older people in Latin America and the Caribbean were in families containing three or even four generations, while the proportion living alone averaged no more than $9 \%$ in the region (Saad, 2005, p. 134). The figures are indicative of intergenerational arrangements involving the sharing of resources and care that can benefit both older people and other family members. If this information is combined with the data on economic and domestic activity, there seems to be a case for reviewing the estimates made for the care crisis, which factor in a rise in the demand for care from the age of 60 but do not include care provision by this population group.

Lastly, there are no precise data on older people living in institutions (residences, care homes or hospitals), but estimates suggest they are no more than $1 \%$ or $2 \%$ of those aged 60 and over (ECLAC, 2003). The quality of residential institutions for the elderly varies a great deal by cost. This is a poorly regulated and supervised sector that contains everything from profitable firms to religious or humanitarian organizations. The Pan-American Health Organization (PAHO) states that "elder abuse", which may affect older people in their own homes or in residential institutions, is a serious and growing problem in the region and that "this vulnerable group is subject to age and gender discrimination, financial exploitation, powerlessness, and physical, psychological, and social abuse" (PAHO, 2008, p. 2).

The service needs of the older population are not easy to deduce from socioeconomic or census figures and projections. This is firstly because, as has been seen, not all elderly people require care, with many older women remaining active and providing income and care to their families, and only a proportion of the elderly (albeit one that grows with age) requiring care. Secondly, it is because the services required differ greatly in nature and degree and their providers are just as various, so that they have not been precisely quantified.

All these considerations mean that comprehensive multisectoral policy approaches are required for the elderly, with legislation being supplemented by arrangements for pensions, employment, health care, housing and other services, and with the involvement of a large range of actors in the public, family and community welfare system. 
There has been some progress with incomes in the shape of the new pension reforms some countries have been implementing to make up for the pension income gaps affecting paid female workers (Uruguay) or to establish non-contributory pensions (Argentina, Barbados, Chile, Mexico and Suriname), subsidies for older adults (Colombia) or universal old-age pensions (Dignity Income in the Plurinational State of Bolivia). ${ }^{12}$ Non-contributory pensions, which mainly benefit women, and likewise the compensation or bonuses per child paid on top of pensions, represent a public acknowledgement of the contribution of unpaid domestic work to the country. Nonetheless, providing the elderly population with access to a decent income remains one of the great challenges for our countries.

Among the advances that should be noted in the area of health care is the implementation of systems of explicit universal guarantees in countries such as Brazil, Chile, Colombia, Mexico and Peru, covering treatment for some (or a number) of the diseases with the greatest incidence in the older adult population.

One of the main recommendations of international organizations is that ageing should take place at home and in an inclusive community environment. It is argued that "developing countries must avoid repeating the mistakes of some of the richer nations, which built numerous institutions for older persons. Often, community-based care can be a more effective and inclusive solution and, where there is no alternative to long-term care facilities, the process should be adapted to the local culture" (Huenchuan, 2010, p. 188). Along the same lines, the development of home-based care is recommended, with suggestions for a range of services that can be provided to people in their own homes so that they can carry on leading as active and independent a life as possible (Huenchuan and Guzmán, 2007) including, among others, volunteer services, help with housework and home nursing and medical care, in which local governments can play an important role.

The community is a good setting for the participation of older adults and for the implementation of day-to-day support services for some basic housekeeping, either in the form of voluntary services, organization of the older adults concerned or a commitment by local governments.

The role of women is crucial for the application of community and family support recommendations, and for the implementation of programmes and services. They are required not only to provide care within the home, but also to carry out mediation with services, the market or community organizations.

12 See Aguirre and Scuro (2010), Yáñez (2010) and ECLAC (2010b). 
Because incomes and public services for the elderly are inadequate, when they require permanent care the responsibility falls almost entirely on families, which often lack the physical or financial capacity to discharge it, with the result that women are overburdened. Policy seems to take little account of this. The information available provides few examples of explicit support for families and the people caring for older adults, or of measures to prevent families from becoming overburdened.

Huenchuan highlights the role of women as caregivers for the older population, but stresses the need to differentiate, for example between women who do and do not participate in the labour market. This recommendation is a reminder of the dearth of studies dealing with the diversity of family arrangements and mutual care in intergenerational households, the operation of social networks for people living alone, the dual situation of older women as providers and recipients of care, the mix of activity statuses, incomes and asset ownership, and participation in community organizations.

This section should be concluded by reaffirming the idea of a society "for all ages" upheld by Huenchuan (2010, pp. 187 and 189), who says that "the problems of older persons - and the solutions found in terms of social protection- must be set within the broader framework of the construction of a society for all [...] instead of treating action on older persons as a matter separate from the future of society as a whole".

The kind of care required, its financing and the resources to be provided for this need to be the subject of a public debate that has yet to take place.

\section{(c) The most invisible care: people with disabilities}

Progress with disabilities policy is relatively recent in the region. It is only a decade since the Inter-American Convention on the Elimination of All Forms of Discrimination Against Persons with Disabilities came into force.$^{13}$ Caring for people with disabilities is a less visible part, but perhaps the most demanding one, of the care women provide in the home. Unwelcoming environments are a further reason why people with disabilities need assistance, so that the lack of policies has the twofold effect of increasing both the dependence and marginalization of disabled people and the burden of time and work for those supporting them.

The need for care as a result of disability is increasing in the region because of several factors, most especially the demographic transition, which has increased the incidence of chronic and degenerative diseases; 13 See [online] http://www.oas.org/juridico/english/treaties/a-65.html. The Convention
was approved in 1999 and came into force in 2001. 
medical advances, which have increased survival rates in catastrophic situations; and unhealthy lifestyles, which have increased the need for health care and assistance in old age. Poverty, armed conflict and gender violence are far from negligible causes of disability. All this is compounded by a lack of policies for prevention and timely care, which would reduce the prevalence of disabilities. The lack of services is heightening social inequalities, since disabilities often require complex and costly care or rehabilitation which, when privately provided, are only available to the small portion of the population that can afford them.

PAHO (2006) estimates that about 85 million people in Latin America and the Caribbean live with some kind of disability and that just $2 \%$ of these have been able to have their needs met. It is not specified whether the figure includes temporary disabilities resulting from disease or accidents, which are included in the concept of disability in the Convention. However, analyses refer mainly to permanent disabilities, highlighting their effects on the lives of those affected in various aspects: reduced access to education and employment, inappropriate architecture and public areas, and social discrimination and marginalization, among others. Few analyses consider the effect on caregivers or the time spent on the care of temporary diseases or disabilities. ${ }^{14}$

In Argentina, for example, the first national disability survey (ENDI), for 2002-2003, found that $28 \%$ of people aged 65 and over had some type of disability, with the proportion rising to $37.8 \%$ among those over 75. In Mexico, according to the findings of the 2000 census, one in every 10 adults aged 60 and over have some physical or mental condition preventing them from carrying out their normal activities, a proportion that rises to a fifth among those aged 80 to 84 and just under a third among those aged 85 and over. In Colombia, the 2005 census showed that $10.6 \%$ of men and $10.1 \%$ of women had limitations in the 50 to 54 age group, and $38.3 \%$ of men and $37.6 \%$ of women in the 80 to 84 group.

On the basis of these indications, proposals stress that disability policies not only have to deal with medical and rehabilitation problems, but require a comprehensive approach that includes health promotion, disability prevention and functional recovery, as well as social integration and inclusion and legal, urban and institutional standards.

It is striking that many of the analyses (where they are in agreement with the comprehensive, human rights-based approach) dwell on the importance of the environment and family but ignore or barely mention the situation of the family and caregivers themselves,

14 The work women do to maintain health and care for the sick in their families is analysed in Gálvez and Matamala (2001). 
their own care requirements and the constraints on them when it comes to participation, autonomy and the deployment of capabilities, or the effect of this effort on their physical and mental health. Nor is there any special discussion of the indispensable role in linking together resources and institutions that is involved in the care of people with disabilities, necessarily involving someone else as an intermediary, without which many of the proposed measures would be ineffective. This liaison function has to be performed even in cases where families cannot afford private services or the State has no significant service provision, as the family still has to carry out shopping and chores while providing the affected person with companionship and emotional support.

Strikingly, the Inter-American Convention on the Elimination of All Forms of Discrimination Against Persons with Disabilities has nothing to say about the people providing care, or about support for the care provided by families. All its provisions are worded as though what was at issue were a bilateral relationship between the State and the person with the disability, without considering that the family is both a group affected by the disability and an agent in the rehabilitation process, with a right to care and to participation in the formulation, follow-up and evaluation of policies and programmes.

The rights of caregivers (Pautassi, 2007) have yet to be incorporated into disability policies. The example of the system set up in Spain to promote autonomy and care for dependent persons is an interesting one, both for the range of services it offers and because it provides for the possibility of financial compensation and other support (rest days, for example) for people caring for family members.

In Latin America it is possible to find some examples of caregivers being included in policies. In 2006, Chile began to develop a programme of support for home care provided to people prostrated by a severe disability or loss of autonomy, with measures that included home service provision, technical and material support and a "Caregiver's Care Plan" (Villalobos, 2006)..$^{15}$

In Colombia, meanwhile, the Faculty of Nursing of the National University of Colombia designed the "Caring for Caregivers" programme, which was tested out with 280 people in Bogotá, the intention being to "enhance the care capabilities of family caregivers looking after chronically ill people". The programme recognizes the difficulties facing caregivers and proposes measures (Barrera and others, 2010). 15 In some cases, this programme, which was implemented on a decentralized basis,
included a small stipend for the family member providing the care. 
In Ecuador, lastly (although there are other examples), it is reported that a grant equivalent to one living minimum wage has been made to about 3,000 people suffering from severe mental or physical disabilities (Government of Ecuador, 2010). The money is to be received by the family member or representative undertaking to care for the disabled person (and obliged to give up work to do so), who is also to be supplied with medicines and equipment and provided with free training in health care, hygiene, rehabilitation, nutrition and self-esteem, among other things.

What is common to these efforts is that they are small-scale, rooted in the health-care sector and intended to develop or enhance family care capabilities. In some of the Chilean trials, avoiding institutionalized treatment is an explicit aim. Accordingly, they reinforce the role of care by assigning caregivers a role ancillary to that of the institutional system. However, it is important for them to give visibility to the work of caring for people with severe disabilities and deal with some of its difficulties.

More information needs to be generated so that there can be progress on disability policies which engage with the idea of shared responsibility. There needs to be better understanding and documentation of the linkages between services and the family, bearing in mind the diversity of types and degrees of disability and the different characteristics of families, as well as the situation of people providing care and the impact of disability on the whole family group. An advance worth highlighting here is the production of time-use information and statistics (Milosavljevic and Tacla, 2007), which help to give visibility to the complex situation of home care and the cost this represents for those responsible for these tasks in terms of the time and mental and physical effort they commit to them and the loss of employment and social opportunities.

From a gender equality perspective, and as part of the effort to find more effective and sustainable interventions, it is necessary for policies to take account of the needs of families and for caregivers' rights to be made a central goal. Practically, this may involve the provision of financial compensation, health care, time off and employment and social opportunities, with consideration being given to options for reducing the burden of care work. These criteria should also be applied to State regulation and support for humanitarian institutions working with the disabled.

Paraphrasing the reference to a society for all ages, these proposals could be interpreted as reflecting the need for "a society for all abilities", requiring comprehensive, multisectoral policies that engage all levels of the State and the whole of society from a perspective of citizenship, gender equality and human rights. 


\section{Time for caring and for earning: squaring the circle}

Some decades ago now, the unequal sexual distribution of the hours devoted to the home, to work and to leisure and women's lack of time for themselves and for participation in other areas of life in society became a staple of feminist analyses, giving rise to expressions such as women's double or triple shift in paid employment, the home and the community. From these analyses there followed some original initiatives such as Italy's so-called "time law" (2000), which treats time management and use as a public policy issue. The focus on the different possible ways in which women's and men's time may be used has highlighted the interconnections and incompatibilities between social, personal, working and domestic times, and the gender subordination reflected in their distribution.

\section{(a) Reconciliation policies}

In Latin America and the Caribbean, most attention has been paid to the excessive strain placed on women's working time when they enter the labour market while retaining their domestic obligations unaltered. In fact, women were overworked before this. "A woman's work is never done," as our mothers used to say. But society has changed. As noted earlier, increasing labour market participation by women, combined with growing levels of education and civic participation, has gradually given shape to the idea that time too is a right and to demands for a redistribution of the domestic burden through service provision and the acceptance of responsibility by men and society. The arguments range from an equal right to free time and the necessity of time for civic, economic or social participation to the responsibility of all institutions for personal care and a rejection of women's exploitation in the home. Taken together, these ideas are revolutionary when set against those of earlier generations.

One way in which the issue of time use translates into policy initiatives is with policies to bring about so-called reconciliation between work and family life. These focus on the strains that arise between family and work responsibilities because of simultaneous demands on working time, and set out to relieve them in two main ways (Astelarra, 2006; ILO/ UNDP, 2009): the provision of care services for children and dependent persons, which was reviewed in the previous section, and employment measures to expand the time available to workers by means of leave and time off to care for dependent family members, a subject dealt with in this section.

Reconciliation proposals concentrate mainly on the time needed to care for dependent persons, i.e., just one aspect of reproductive work. Looking at the whole range of tasks and time devoted to reproductive 
work (a more inclusive concept than care work) gives a clearer view of the sexual distribution of labour and leisure. These are distinctions that can be important in certain contexts.

Reconciliation policies address the difficulties that arise in the domestic provision of care because of women's paid work and the strain this causes, identifying the costs for women (in terms of overwork and the loss of employment opportunities), for those requiring care and for the countries' development.

Out of this diagnosis have come proposals to reconcile working and family life, with shared social responsibility. It is as important to redistribute family care tasks between men and women as it is to strengthen the role of the State in the provision of care services and to engage the whole of society - government, businesses, male and female workers - in this task. Generating better employment opportunities for women, providing care services and promoting shared social responsibility to reconcile family and work has thus become a core policy challenge that is crucial to decent work and human development (ILO/UNDP, 2009).

With this approach, what is required from a policy standpoint is not just the development of care services but also the opportunity for people to take leave and time off in order to provide care without thereby suffering employment discrimination. This means that women and men must each take their share of leave. It should be added that ILO Convention No. 156 concerning Workers with Family Responsibilities, which has been in existence since 1981, not only incorporates agreements to prevent discrimination based on maternity but deals with the need to implement parental and/or paternity leave. Legislation on paternal leave has developed considerably in the region over recent years. According to ECLAC (2010b, p. 56), a number of Latin American and Caribbean countries have established paternity leave for birth and often for adoption too. Leave ranges from two days in Argentina and Paraguay to 14 in the Bolivarian Republic of Venezuela and 15 in Costa Rica. Between four and eight days are granted in Colombia, Peru and Puerto Rico and 10 days in Ecuador. In Chile, the mother can transfer up to a month and a half to the father under the new law on postnatal arrangements. In Uruguay, as in other countries, the length of leave differs between the private and public sectors. In the Caribbean subregion (the Bahamas, Belize, the Cayman Islands and Dominica), fathers are allowed some type of leave of differing durations. Cuba is a special case, with the law allowing fathers to share maternity leave for up to six months.

The International Labour Organization (ILO) and the United Nations Development Programme (UNDP) (2009) argue that reconciliation 
policies have had a limited impact. Although there has been some progress with paternal leave laws, as just noted, there is no evidence of any redistribution of the burden of domestic work, and nor has there been any substantial increase in public services to provide support for this. Evaluations also bring up the need to introduce incentives for men, since where they do have the right to take leave they often do not use it, either because their workplaces do not encourage it or because the fathers themselves choose not to. It is also pointed out that regulations on parental leave apply only to formal employment, seriously restricting its scope in a region with high levels of informality in labour markets. Generally speaking, reconciliation practices have centred on facilitating childcare for female workers in the formal sector, which limits their potential for the redistribution of care responsibilities.

For as long as the involvement of fathers remains limited, reconciliation policies as thus understood risk becoming a new means of perpetuating women's responsibility for care tasks. Some authors analysing the European experience note a tendency for governments to view reconciliation solely in relation to family and child welfare rather than as a means to gender equality (Stratigaki, 2004).

Nonetheless, work-family reconciliation policies have served to highlight one of the main obstacles to women's participation in labour markets, thus creating greater scope for men to take responsibility for care work and for firms to accept responsibility towards families.

Support for flexible working as a way of reconciling work and family life chimes with conservative political positions on gender, entailing a concern not only to reinforce the traditional role of mothers but also to reverse accelerating declines in birth rates, which are starting to be seen as a national problem. Flexible working squares the circle, as it means that poorer women can do relatively undemanding paid work while caring for children.

\section{(b) Measuring and valuing reproductive work}

As already noted, a broader approach to the time spent on care within the home is one that treats it as part of the work of social reproduction. Feminist theory, which was the first to highlight the tension between work in the home and paid work, stresses the relationship between productive work, which has a value in the market, and the social reproduction work done in the home, on which no monetary value is set. The latter includes not only care for dependent persons but the whole range of goods and services produced in the home, such as services provided to independent adults and the various tasks of household management and maintenance. The failure to set a monetary value on this 
work is the essence of the gender subordination of women in a number of respects: it tethers them to the domestic sphere while naturalizing their work and rendering it invisible, which helps ensure that women remain dependent upon a man and are available for domestic services. Feminist economics has had some success in incorporating unpaid domestic work into the body of economic theory by demonstrating the economic functions of such work and arguing that these are the unseen basis of the economy or, more strictly, that this is work incorporated into production that has remained concealed for the purposes of official theories. ${ }^{16}$ This line of argument reinforces the old demand for public recognition of such work and supports proposals for affording it a monetary value so that it can be incorporated into national accounts.

From the practical and political point of view, this approach goes beyond the demand for recognition of work in the home and treats this as a linchpin of the economic system.

Greater visibility for reproductive work has been made possible in the region because of the development of time-use surveys by public bodies, which is indicative of the growing - albeit still inadequateplace given to the problem in public policy. This has followed on from the recommendations on data production formulated at the fourth World Conference on Women held in Beijing (1995) and reinforced by regional agreements, particularly the Quito Consensus (2007), which called upon governments more specifically to develop instruments for the periodic measurement of unpaid work and pursue policies to value and recognize this.

A growing number of countries are generating information on unpaid work. The findings of the surveys applied in Argentina, Brazil, Chile, Colombia, Costa Rica, Cuba, Ecuador, El Salvador, Guatemala, Mexico, Nicaragua, the Plurinational State of Bolivia and Uruguay were registered in 2010 by the Gender Equality Observatory for Latin America and the Caribbean. ${ }^{17}$

Measurements are not yet carried out regularly and there is a need to improve accuracy in a number of surveys and standardize them to permit comparison between countries, a problem that has been analysed in the region in a series of international meetings on gender statistics. Some milestones in this process include the proposal by Milosavljevic and Tacla (2007) to include a time-use module in household surveys. A major part of this effort has been the proposed Classification of Timeuse Activities for Latin America and the Caribbean (CAUTAL), based on

16 ECLAC (2010b) uses Antonella Picchio's (2001) extended model of the circular flow of income, which describes the relationships between firms and households.

17 See [online] http://www.eclac.cl/oig/noticias/paginas/3/38403/TiempoTotalTrabajo.pdf. 
the recognition of "unpaid household services" as productive activities distinct from other activities termed "either productive or personal" (Gómez and Sosa, 2010).

Despite the limitations of the data, some common trends can be seen in all the countries carrying out measurements of this type: "First, total working time is greater for women than for men in all cases. Second, and also in all cases, it is women who spend the bulk of their time on unpaid work." 18

In recent years, proposals for satellite accounts covering unpaid work within the framework of the System of National Accounts have been developed on the basis of time-use surveys and international experience in valuing unpaid work in the home, a suggestion that was formulated at the fourth World Conference on Women. The satellite accounts estimate the monetary value of this work and associate it with the total value of national output. Particular progress has been made in Mexico with the measurement of time use, activity classification and satellite accounting, as a result of the joint work of the National Women's Institute (INMUJERES) and the National Institute of Statistics and Geography (INEGI). ${ }^{19}$ Initiatives along the same lines have been reported in El Salvador and Ecuador. ${ }^{20}$

Comparative measurement of women's and men's total working time (adding together paid and unpaid work) shows how unequal the distribution of total work is, how time-poor women are and how this lack of time is a manifestation of women's subjection, with unpaid work making them dependent upon those who generate income. Measurements also reveal that the extra burden of total working hours is greatest for poor women.

The limitations and challenges that should be noted with regard to time measurement are of a technical and political nature, starting with the need for regular, comparable measurements of the different activities in all the countries, a process that is now under way, combined with the incorporation of unpaid work into the national accounts, an area where progress has been more limited.

An aspect that requires greater attention is the measurement of time spent liaising between the family and other social protection actors, which is analysed in the next section.

18 ECLAC, Gender Equality Observatory for Latin America and the Caribbean, "Total paid and unpaid working time" indicator.

19 See Licea (2010) and Gómez (2008).

20 Government of Ecuador (2010). An interesting analysis of the incorporation of unpaid work in the home into the satellite accounts and its application for valuing health care can be found in Ferrán (2006). 


\section{(c) Time for liaising}

As was noted in the first part, targeted social spending policies have continued to follow maternalist models of social programmes, the cornerstone of which is the care work done by mothers in the poorest sections of society, requiring more time to be spent liaising between the family and the State. This situation is beyond the scope of reconciliation policies, centred as they are on the relationship between working and family life. However, liaison for family care purposes between the family and the State, and between the family and the market (income, consumption), requires a substantial outlay of energy on tasks such as visits to doctors, shopping, travel, registration, workshops and time spent waiting to collect subsidies.

In analysing the relationship between care and social protection, the distinction between welfare production and liaison is crucial, and this points to the importance of accurately including time spent on liaison activities in analyses of time use.

A step forward in the measurement of liaison time is the proposed Classification of Time-use Activities for Latin America and the Caribbean already mentioned, which includes a number of categories of activities that may be regarded as liaison activities, such as accompanying family members to school or health services. However, it does not include the liaison time required by social programmes such as conditional transfer programmes, which appear to be adding to women's work, as already argued.

Lamaute-Brisson takes the conceptualization of care further by arguing for the need to review the idea of a welfare triangle or diamond, since this relies on families' links with each and every one of the other agents of welfare. ${ }^{21}$

This observation underlines the need for a conceptual review of welfare, so that it is understood not as a distribution of tasks between the State, market, families and the third sector or as the sum of the contributions of each, but as the product, in a strict sense, of the linkages between them, which are operated by the person responsible for care in the household. The latter, then, must be treated not just as one actor among others, but as an actor of a different type.

Lastly, time-use measurement cannot ignore the matter of women's and men's free time, a good whose enjoyment is the expression of the freedom and autonomy enjoyed by women and men, poor and rich. The freedom to have time available to spend in ways individuals themselves

${ }^{21}$ See her article in this book. 
decide ties in directly with the idea of human development as the freedom to choose in order for the potential of individuals or groups to be fully realized (UNDP, 1995).

\section{Money for caring: conditional cash transfers}

Cash transfers to individuals are a traditional social policy tool in the region whose conception and scope have also been adjusted to reflect changes in development models.

Subsidies for care have precedents in family allowance and some types of disability support. However, the concept of a transfer to sustain or reward care is fairly recent and is associated with the gradual advance of the notion that the State bears a responsibility for personal care, as already commented upon in this text. Like other subsidies, these will be understood as a form of aid to the poorest or as a way of guaranteeing a right, depending on the social policy conceptions underlying them. Similarly, the gender assumptions incorporated into them will determine whether their effect is to reinforce the sexual distribution of labour or to even out responsibilities or whether, as is likely, there is a sometimes contradictory mix of aims and effects.

Other regions such as Europe have over two decades' experience in the provision of cash transfers "to defray the cost of care for those who cannot look after themselves" (Tobío, 2010, p. 161). These transfers are considered an enforceable right for those in need of them, as for example in the Spanish dependency system. There are numerous formulas, depending on the policy orientation of each country and including, among others, remuneration for the person providing the care or a direct cash allocation "to the people in need of care or their families, who can use it as they see fit" (Tobío, 2010, p. 159).

Different analyses have brought to light the ambivalence of measures of this type in relation to gender equality. On the one hand, they recognize care provided within the family as work and even assign it a monetary value. Furthermore, this treatment is given not only to the care of children but to that of people in different situations of dependency as well. Measures have been added over time to encourage men to take on care responsibilities. On the other hand, there has been criticism that care subsidies may perpetuate the exclusive responsibility of women and keep care work very low-paid (Otxoa, 2008), as the amounts involved are usually low. For this reason, and because disruption of working careers is entailed, they are less attractive to men. Furthermore, in some cases they seem to encourage the recruitment of other women for wages below the legal minimum, as happens with many Latin American migrants. 
It is their focus on integrating children into social protection that gives conditional cash transfer programmes their character as childcare subsidy programmes for poor families, their function being not so much to facilitate day-to-day care as to bring children into the basic network of protection provided by education and health institutions. This aspect and their targeting of the poorest are the hallmarks of conditional transfers in the region.

On the negative side, a central fact is that they all reinforce the traditional care role: not only do they finance this, but it is a contractual stipulation. Rodríguez (2011, p. 21) stresses the implications for women's time use. Drawing on evidence from the Oportunidades programme as systematized by Espinosa, she argues that women's workload increases when they become programme beneficiaries. She also points to what she calls the "inactivity trap", i.e., the fact that even when there is no condition explicitly requiring it, the demands on women's time and the obligations they accept are a constraint on their options or initiatives for participating in the labour market. If women cannot generate income on top of that from the programme, then the paradoxical outcome is that what the programme sets out to solve (lack of income) it actually promotes (women cannot generate income outside the programme) (Espinosa, 2006, p. 24).

\section{Recommendations}

In summary, the review carried out here underlines the need for social protection to be understood as the outcome of linkages between different institutions in which women have traditionally played a central role through their unpaid work, both by providing care and by acting as the liaison between households and the institutions providing protection.

Based on the observations, a series of recommendations are proposed, for analysis and social protection policies underpinned by a concept of care as a universal right and thence as a State duty and a shared responsibility for the different institutions in society:

(i) Improve information on and analyses of time and tasks relating to liaising and care in different contexts and in all the services and agencies involved with care, identifying and promoting egalitarian articulation models and assessing the linkages needed between services and families in the light of their egalitarian potential. Because of their scale, special attention should be paid to the social sectors of health care and education, whether provided by the public or private sectors or by non-profit organizations. 
(ii) Study the dual role of women as caregivers and as individuals requiring care, in different contexts, paying special attention to older women and to the youngest.

(iii) In anti-poverty policies and programmes, adopt an enhanced egalitarian gender approach that emphasizes the economic autonomy of women.

(iv) Document and analyse the different care providers and their position in welfare regimes, whether run by the State, the private sector or non-profit organizations, together with their limitations and potential vis-à-vis the egalitarian redistribution of care and the regulatory requirements and rights guarantees they need to fulfil.

(v) Incorporate into all these analyses a rights approach that includes the participation of caregivers and care recipients in the design and evaluation of policies, services and programmes.

(vi) Pursue conceptual and methodological integration of the goal of egalitarian redistribution of care in different areas of the policies and services aimed at different target groups. In particular, there is a need to move towards integrated, comprehensive dependency policies (Tobío, 2010), with the focus on new linkages between the market, the State, the community and the family that do not depend upon women.

(vii) Pursue theoretical and conceptual reflection on the care outlook and the societal transformations that can potentially turn it from a "crisis" factor into an equalizing element in social life.

(viii) In the political field, begin a public debate on how best to generate new types of linkage between the State, the market and the community centred upon an egalitarian conception of the family in societies where care is an autonomy-enhancing universal right and a priority for citizens, moving towards the formula proposed by Fraser (1996) of the "universal breadwinner" and the "universal caregiver". 


\section{Bibliography}

Aguirre, Rosario (2007), "Los cuidados familiares como problema público y objeto de políticas", Familias y políticas públicas en América Latina: una historia de desencuentros, Libros de la CEPAL, No. 96 (LC/G.2345-P), Irma Arriagada (comp.), Santiago, Chile, Economic Commission for Latin America and the Caribbean (ECLAC). United Nations publication, Sales No. S.07.II.G.97.

Aguirre, Rosario and Lucía Scuro Somma (2010), "Panorama del sistema previsional y género en Uruguay. Avances y desafíos", Mujer y Desarrollo series, No. 100 (LC/L.3190-P), Santiago, Chile, Economic Commission for Latin America and the Caribbean (ECLAC).

Anderson, Jeanine (2007), "Políticas y programas orientados a las familias en los países andinos", Familias y políticas públicas en América Latina: una historia de desencuentros, Libros de la CEPAL, No. 96 (LC/G.2345-P), Irma Arriagada (comp.), Santiago, Chile, Economic Commission for Latin America and the Caribbean (ECLAC). United Nations publication, Sales No. S.07.II.G.97.

Arriagada, Irma (coord.) (2007), "Familias y políticas públicas en América Latina: una historia de desencuentros", Libros de la CEPAL, No. 96 (LC/G.2345-P), Santiago, Chile, Economic Commission for Latin America and the Caribbean (ECLAC). United Nations publication, Sales No. S.07.II.G.97.

Astelarra, Judith (2006), "Políticas conciliatorias: conceptualización y tendencias", Cohesión social, políticas conciliatorias y presupuesto público. Una mirada desde el género, Luis Mora and María José Romero Ruiz (coords.), Mexico City, United Nations Population Fund (UNFPA)/German Agency for Technical Cooperation (GTZ).

Barrera Ortiz, Lucy and others (2010), Cuidando a los cuidadores. Familiares de personas con enfermedad crónica, Bogota, Facultad de Enfermería, Universidad Nacional de Colombia.

Barría, María Soledad (2002), "Discriminación de las mujeres en el sistema de instituciones de salud previsional, regulación y perspectiva de género en la reforma", Género y Reforma de la Salud, Cuadernillos temáticos, No. 1, Santiago, Chile, Pan American Health Organization (PAHO)/World Health Organization (WHO).

Bauman, Zygmunt (2002), En busca de la política, Mexico City, Fondo de Cultura Económica.

Durán, María Ángeles (2006), “El futuro del trabajo en Europa: el cuidado de las personas dependientes", Cohesión social, políticas conciliatorias y presupuesto público. Una mirada desde el género, Luis Mora and María José Romero Ruiz (coords.), United Nations Population Fund (UNFPA), German Agency for Technical Cooperation (GTZ).

ECLAC (Economic Commission for Latin America and the Caribbean) (2010a), Time for equality: closing gaps, opening trails (LC/G.2432(SES.33/3)), Santiago, Chile. (2010b), What kind of State? What kind of Equality? (LC/G.2450(CRM.11/13)), Santiago, Chile, June.

(2009), Social Panorama of Latin America 2009 (LC/G.2423-P), Santiago, Chile, United Nations publication, Sales No. S.09.II.G.135.

(2007), Women's contribution to equality in Latin America and the Caribbean (LC/L.2738(CRM.10/3)), Santiago, Chile. 
(2006), Facing the future of social protection: Access, financing and solidarity (LC/G.2294(SES.31/3)), Santiago, Chile.

(2003), Older Persons in. Latin America and the Caribbean: Situation and Policies. Summary (LC/L.1973), Santiago, Chile.

Ellingstaeter, Anne Lise (1999), "Dual breadwinners between state and market", Restructuring Gender Relations and Employment. The Decline of the Male Breadwinner, Rosemary Crompton (ed.), Oxford, Oxford University Press.

Esping-Andersen, Gøsta (1999), Social Foundations of Postindustrial Economies, Oxford, Oxford University Press.

Espinosa, Guadalupe (2006), “La participación de la actividad económica de las mujeres del Programa Oportunidades y su relación con la corresponsabilidad de éste y otros programas sociales", El Programa Oportunidades examinado desde el género, M. P. López and V. Salles (coords), Mexico City, United Nations Development Fund for Women (UNIFEM)/El Colegio de México.

Ferrán, Lourdes (2006), “Marco conceptual y lineamientos metodológicos de la cuenta satélite del sector hogares para medición del trabajo no remunerado en salud dentro del sistema de cuentas nacionales", paper presented at the International Workshop on Satellite Accounts: Gender and Health, Measuring Women's Unpaid Work Contribution to Health and Development, Pan American Health Organization (PAHO)/Economic Commission for Latin America and the Caribbean (ECLAC), Santiago, Chile, 5 - 6 June.

Fraser, Nancy (1996), Justice Interruptus: Critical Reflections on the "Postsocialist" Condition, Bogotá, Routledge.

Gálvez Pérez, Thelma and María Isabel Matamala Vivaldi (2001), “La economía de la salud y el género en la reforma de salud", Proyecto género, equidad y reforma de la salud. Documento, No.1, Pan American Health Organization (PAHO).

Gómez Luna, María Eugenia (2008), “Cuenta satélite de producción y consumo de los servicios no remunerados de los hogares. Propuesta metodológica", paper presented ath the IX International Meeting on Gender Statistics. 2010 Census Round, Aguascalientes, 29 September - 1 October.

Gómez Luna, María Eugenia and Viridiana Sosa Márquez (2010), “Clasificación de actividades de uso del tiempo para América Latina y el Caribe, CAUTAL. Propuesta para discusión" [online] http://www.eclac.cl/mujer/noticias/ noticias/3/40283/CAUTAL.pdf.

Government of Ecuador (2010), Informe sobre el cumplimiento del Consenso de Quito [online] http://www.eclac.org/mujer/noticias/paginas/6/38906/Ecuador.pdf.

Huenchuan, Sandra (ed.) (2010), “Ageing, Human Rights and Public Policies", Libros de la CEPAL, No. 100 (LC/G.2389-P), Santiago, Chile Economic Commission for Latin America and the Caribbean (ECLAC). United Nations publication, Sales No. E.08.II.G.94.

Huenchuan, Sandra and Luis Rodríguez-Piñero (2010), "Envejecimiento y derechos humanos: Situación y perspectivas de protección", Project Documents, No. 353 (LC/W.353), Santiago, Chile, Economic Commission for Latin America and the Caribbean (ECLAC).

Huenchuan, Sandra and José Miguel Guzmán (2007), "Políticas hacia las familias con personas mayores: el desafío del cuidado en la edad avanzada", Familias y políticas públicas en América Latina: una historia de desencuentros, Libros de la CEPAL, No. 96 (LC/G.2345-P), Irma Arriagada (comp.), Santiago, Chile, 
Economic Commission for Latin America and the Caribbean (ECLAC). United Nations publication, Sales No. S.07.II.G.97.

ILO/UNDP (International Labour Organization/United Nations Development Programme) (2009), Trabajo y familia:hacia nuevas formas de conciliación con corresponsabilidad social, Santiago, Chile.

Lamaute-Brisson, Nathalie (2011), "Redistribuir y reconocer el cuidado desde la protección social: Un marco conceptual", paper prepared for the project "Protección social e inclusión social en América Latina y el Caribe: Trabajo no remunerado y protección de las mujeres", Santiago, Chile, Economic Commission for Latin America and the Caribbean (ECLAC)/Swedish International Development Cooperation Agency (Sida).

Licea, Rosa María (2010), “Cuenta satélite de trabajo no remunerado la experiencia de México", paper presented at the VIII International Meeting on Time-Use Statistics and Public Policies, Mexico City, 30 June - 2 July.

Marco, Flavia (coord.) (2004), "Los sistemas de pensiones en América Latina: un análisis de género", Cuadernos de la CEPAL, No. 90 (LC/G.2262-P), Santiago, Chile, Economic Commission for Latin America and the Caribbean (ECLAC). United Nations publication, Sales No. S.04.II.G.129.

Martínez Franzoni, Juliana (2005), “La pieza que faltaba: uso del tiempo en los regímenes de bienestar", Nueva Sociedad, No. 199.

Martínez Franzoni, Juliana and Koen Voorend (2009), Sistemas de patriarcado y regímenes de bienestar en América Latina ¿Una cosa lleva a la otra?, Madrid, Centro de Estudios para América Latina y la Cooperación Internacional (CeALCI), Fundación Carolina.

Milosavljevic, Vivian and Odette Tacla (2007), "Incorporando un módulo de uso del tiempo a las encuestas de hogares: restricciones y potencialidades", Mujer y Desarrollo series, No. 83 (LC/L.2709-P/E), Santiago, Chile, Economic Commission for Latin America and the Caribbean (ECLAC).

Molyneux, Maxine (2006), "Mothers at the service of the new poverty agenda: Progresa/Oportunidades, Mexico's conditional transfer programme", Social Policy E Administration, vol. 40, No. 4, August.

Montaño, Sonia (2010), "El cuidado en acción", El cuidado en acción. Entre el derecho y el trabajo, S. Montaño and C. Calderón (coords.), Cuadernos de la CEPAL, No. 94 (LC/G.2454-P), Santiago, Chile, Economic Commission for Latin America and the Caribbean (ECLAC)/Spanish Agency for International Development Cooperation (AECID. United Nations publication, Sales No. S.10.II.G.35.

Montaño, Sonia and Coral Calderón (coords.) (2010), "El cuidado en acción. Entre el derecho y el trabajo", Cuadernos de la ECLAC, No. 94 (LC/G.2454-P), Santiago, Chile, Economic Commission for Latin America and the Caribbean (ECLAC)/ Spanish Agency for International Development Cooperation. United Nations publication, Sales No. S.10.II.G.35.

Otxoa, Isabel (2008), "El cuidado en la dependencia", Revista Pueblos, No. 31, March [online] http: / / www.revistapueblos.org/spip.php?article866.

PAHO (Pan-American Health Organizations) (2008), Human Rights and Health. Older Persons [online] http://social.un.org/ageing-working-group/documents/ PAHO_Human\%20Rights\%20and\%20health.pdf.

(2006), Discapacidad. Lo que todos debemos saber: 85 millones de personas con discapacidades en América Latina [online] http://new.ops.org.bo/index. php?option=com_content\&task=view \&id=684\&Itemid $=259$. 
Pautassi, Laura (2007), "El cuidado como cuestión social desde un enfoque de derechos", Mujer y Desarrollo series, No. 87 (LC/L.2800-P), Santiago, Chile, Economic Commission for Latin America and the Caribbean (ECLAC).

(2002), "Legislación previsional y equidad de género en América Latina", Mujer y Desarrollo series, No. 42 (LC/L.1803-P), Santiago, Chile, Economic Commission for Latin America and the Caribbean (ECLAC).

Pérez Orozco, Amaia (2010), Cadenas globales de cuidado. Qué derechos para un régimen de cuidados justo? , Santo Domingo, International Research and Training Institute for the Advancement of Women (INSTRAW).

Picchio, Antonella (2001), Un enfoque macroeconómico "ampliado" de las condiciones de vida, Departamento de Economía Política, Universidad de Modena.

Provoste, Patricia (2003), “Del universalismo a la focalización: El lugar del género en las políticas sociales", Femenino fin de siglo. Posmodernidad, género y cultura, Marcela Prado (ed.), Valparaíso, Comisión Interdisciplinaria de Estudios de Género, Universidad de Playa Ancha.

Provoste, Patricia and Fanny Berlagoscky (2002), "Modelo de atención y género: las condiciones socioculturales de la reforma de salud", serie Género, Equidad y Reforma de Salud, No. 4, Santiago, Chile, Pan American Health Organization (PAHO).

Rodríguez Enríquez, Corina (2011), “Programas de transferencias condicionadas de ingreso e igualdad de género ¿Por dónde anda América Latina?", Mujer y Desarrollo series, No. 109 (LC/L.3416), Santiago, Chile, Economic Commission for Latin America and the Caribbean (ECLAC).

(2005), "La economía del cuidado: un aporte conceptual para el estudio de políticas públicas", Documento de trabajo, No. 44, Buenos Aires, Interdisciplinary Centre for Public Research (CIEPP), May.

Saad, Paulo M. (2005), “Los adultos mayores en América Latina y El Caribe: Arreglos residenciales y transferencias informales", Notas de Población, No. 80 (LC/G.2276-P), Santiago, Chile, Economic Commission for Latin America and the Caribbean (ECLAC). United Nations publication, Sales No. S.05.II.G.142.

Sojo, Ana (2007), "Evolution of the link between selective anti-poverty policies and social sectors policies", CEPAL Review, No. 91 (LC/G.2333-P/E), Santiago, Chile, Economic Commission for Latin America and the Caribbean (ECLAC).

Stratigaki, Maria (2004), "The cooptation of gender concepts in EU policies: the case of reconciliation of work and family", Social Politics, vol. 11, No. 1, Oxford University Press.

Tobío, Constanza and others (2010), "El cuidado de las personas. Un reto para el siglo XXI", Colección Estudios Sociales, No. 28, Barcelona, Fundación "la Caixa".

Villalobos Courtin, Alicia (coord.) (2006), Norma de cuidados domiciliarios de personas que sufren de discapacidad severa, Santiago, Chile, Ministry of Health [online] http://www.ssmaule.cl/Pagina/articulacionRed/normaAtencionPostrado Domicilio.pdf.

Yáñez, Sonia (2010), “La dimensión de género en la reforma previsional chilena (ley $N^{\circ} 20.255$ de reforma de pensiones", Mujer y Desarrollo series, No. 101 (LC/L.3199-P), Santiago, Chile, Economic Commission for Latin America and the Caribbean (ECLAC). 


\section{Chapter III}

\section{The utilization of time-use surveys in public policy ${ }^{1}$}

Flavia Marco Navarro

Work is usually thought of as a source of income, even wealth, or at least as a way of obtaining the economic sustenance necessary to live, but there is a type of work that impoverishes the person doing it: unpaid work. As is well known, this is done predominantly by women and includes care work, parenting, housework and community or voluntary work. It meets society's care and welfare needs and makes a vital contribution that has nonetheless been denied visibility and even the status of work. While this is still largely the case in academia, official statistics and public policies, there have been substantial improvements; at the conceptual level in particular, there have been huge contributions from feminist economics and sociology, which have transcended their disciplinary boundaries and begun to penetrate into other scientific and political spheres.

There is thus a need to conjoin conceptual rigour and a methodological design that provide a more authentic picture of our social organization by recognizing situations of inequality in the composition of domestic work (ECLAC, 2004). Time-use surveys meet this challenge

This chapter is a summary of a paper by the same name published in the Women and Development series No. 119 (LC/L.3557), Santiago, Chile, Economic Commission for Latin America and the Caribbean (ECLAC), January 2013. 
by providing data that can be used to develop more efficient public policies for inequality reduction and to support their implementation. By providing information on the amount of work done, time-use surveys also furnish information that can be used to construct satellite accounts for unpaid work in general and certain aspects of it in particular, health-care work for example. They also show the relationship between employment and unpaid work, care needs and the intergenerational reproduction of the sexual division of labour, among other things.

Nineteen countries in the region have carried out time-use surveys. However, integration of their findings into public policy is incipient at best. Why? What factors would enable this integration to begin, or are already facilitating it? The purpose of this chapter is to analyse the political and institutional forces hindering or facilitating incorporation of the information provided by time-use surveys into public policy design and evaluation so that there is better linkage between the two and the potential of these surveys as a technical input for evidencebased equality strategies can be fulfilled. To this end, it will look at the cases of Costa Rica, Ecuador, Mexico and Uruguay, describing the path followed in each country by the institutions involved to implement these surveys and the process used to integrate them into public policymaking (or attempt to do so). For this purpose, a survey with open and closed questions was applied to the national statistics institutes of the four countries, national mechanisms for the advancement of women and independent experts. ${ }^{2}$ The survey was not meant to be representative but to illustrate the issues and dynamics influencing the utilization or otherwise of time-use surveys in policymaking.

\section{A. The relevance of time-use surveys for equality policies}

By the middle of the last century, women in Europe and the United States had already begun to criticize the invisibility of domestic and care work and were undertaking studies to remedy this. This research increased in scope in the 1980s, centring on the issue of reconciliation between employment and family responsibilities (Aguirre, 2005). In that same period, Latin American women were increasingly entering the labour market. ${ }^{3}$ This process varied considerably between countries,

2 The author is grateful for the valuable contributions made by these institutions and for the specialist input of Karina Batthyány, Mercedes Pedrero, Alba Pérez, Isabel Román and Soledad Salvador.

3 Female labour force participation reached a historic 38\% at the end of the 1980s and rose a further four percentage points over the 1990s (ECLAC, 2001). In 2008 the rate was 52\% in urban areas (ECLAC, 2010). 
the differences being due, among other things, to the consequences of structural adjustment programmes for household incomes and welfare. The dramatic economic situation and limited enjoyment of women's rights were compounded by the problems of coping with a job while remaining responsible for family care and housekeeping, often made harder by the withdrawal of the State from service provision in health care and education. As the years passed, feminists in the region also reacted to this situation by addressing the need to give visibility to unpaid work and, additionally, to redistribute it within the family and society.

However, the robust theoretical and conceptual output of feminist economists and sociologists specifically on the subject of unpaid work has suffered from a shortage of data needed to demonstrate and value this. Time-use surveys have filled a major gap here as a technical instrument at the service of political efforts to secure the exercise of rights. This was the view taken in the Beijing Platform for Action, which enshrined a number of commitments for progress in this area, in response to which the United Nations proposed the International Classification of Activities for Time-use Statistics (ICATUS) in 1997. As will be seen further on, an adaptation of this classification to meet the needs of Latin America and the Caribbean has been drafted and is now at the trial stage. Subsequently, in the Quito Consensus, approved by the tenth session of the Regional Conference on Women in Latin America and the Caribbean, the States undertook to develop instruments for periodic measurement of unpaid work, especially time-use surveys, incorporate their results into the System of National Accounts and design economic and social policies accordingly.

The goals of time-use surveys are to measure and give visibility to paid and unpaid work, supply inputs for valuing unpaid work and compile satellite accounts for output and consumption of unpaid household services (Gómez, 2011). The importance of time-use surveys for equality policies derives from the fact that inequalities are materialized in time use (life is time), and these inequalities give rise in turn to various other forms of injustice, since people's opportunities for participation in the workforce, politics and the community, their quality of life and even their health vary with the time available to them.

The visibility that time-use surveys can give to unpaid work is a prerequisite for its redistribution, which needs to be dealt with by different sectoral policies and comprehensive care policies. Time-use surveys also provide evidence that can serve to quantify the needs of the population, and this information can then be used to make public-sector budgeting more efficient and set baselines against which public policy efficiency can be measured. 
At the same time, time-use statistics can be employed to extend and strengthen not only economic, social and gender analysis but also the analytical capacity of the System of National Accounts itself, since the guiding criterion is the production boundary of this system and the general production boundary, including unpaid services that are produced and consumed within a household and those produced for other households (Gómez, 2011). ${ }^{4}$

\section{What time-use surveys in Latin America tell us}

In the first place, surveys reveal who is doing what in the home and for how long. However, they do not only provide information on unpaid work, but also give visibility to paid work carried out both in and outside the home, travel time and time spent on leisure and entertainment. At present, the most important objective from a gender perspective is to bring to light the distribution of unpaid work between family members. This encompasses the following types of work: (i) housework, which includes a variety of activities common to all countries (cleaning, clothes washing, ironing, cooking, shopping, administrative chores); (ii) parenting, i.e., caring for children and adolescents; (iii) caring for other family members, whether they are self-sufficient adults or the elderly or the sick; (iv) volunteering, i.e., unpaid activities for neighbourhood, religious or community organizations.

Time-use surveys in the region have yielded common findings and revealed common phenomena. ${ }^{5}$ As may be imagined, women turn out to do the great bulk of unpaid work, whatever their hours of paid employment, but time and participation rates vary with a number of factors such as age, income, education, place of residence, age of children and degree of kinship with the household head.

The women who do the most housekeeping and care work are those at the ages where they are most likely to be in paid employment, which also coincide with the prime childbearing years; wives, followed by female household heads; women with children under 6 (this is not

4 Defining the boundaries of production and work with reference to the limits of the System of National Accounts makes it possible to determine the broad analytical categories delimiting the spaces within which all the activities that people might carry out at any time of day are organized. These categories are: productive activities (divided in turn into productive activities within the System of National Accounts and productive activities outside it) and non-productive or personal activities (Gómez, 2011).

5 See Batthyány (2010), Berrocal (2010), INEGI (2010), Leiva (2010), Milosavljevic and Tacla (2007), Pérez, Vásconez and Gallardo (2008), Rodríguez (2007) and Villamizar (2011). Despite the limitations of surveys in terms of international comparability, it is possible to identify these phenomena, if not to compare their scale. 
true of men); and those living in rural areas, where the work done tends to be heavier. There is also agreement that the amount of time spent on these activities, unlike the participation rate, varies by education level: the less educated women are, the more time they spend on housekeeping and family work.

As regards the relationship between employment and unpaid work, it should be stressed that total combined working time is always greater for women and that unemployed woman spend a large portion of their time on housework, which leaves them with less time to seek paid employment.

Worryingly, time-use surveys show that the distribution of work between children and adolescents, both inside and outside the home, is perpetuating the sexual division of labour, something that is corroborated not only in the respondent's age variable but also in the children category.

As will be analysed in the next section, these findings tie in with a number of sectoral policies, despite which they have not been taken into account.

\section{Possible applications for time-use surveys in sectoral policies}

Some examples will be presented here to show the need to incorporate time-use survey data into sectoral policies. This sectoral treatment does not overlook the need to coordinate public policies between institutions and between sectors as a way of ensuring their comprehensiveness and guaranteeing the exercise of economic and social rights. Nor does it overlook the need for care policies to move from a sectoral logic towards a logic centred on the life cycles of individuals so that the different risks they face can be dealt with, with provision of care services for the youngest children and for older, sick, dependent and disabled adults based on the principles of universality and solidarity. Accordingly, the goal is for care policies to be designed and implemented on the basis of shared responsibility for families, the State and the market, combining financial transfers with high-quality social services that help both to integrate dependent groups into society and to remedy the gender injustice seen in care relationships (Aguirre, 2010).

It must be stressed at the same time that, while efforts to promote the integration of time-use surveys into public policies in the region have centred on redistribution and, above all, recognition of unpaid work, these surveys can have other applications, given that time is a resource which is affected by the characteristics of the various policies or the absence of these. 


\section{(a) In employment policies}

These policies encompass a wide range of measures and instruments in the economic, social and institutional spheres that affect the level and quality of employment. They entail wide-ranging coordination between different authorities, i.e., they are not the exclusive responsibility of labour ministries (ECLAC, 2005). Labour regulation policies, on the other hand, are those that act upon the relationship between workers and employers through provisions designed to secure rights: non-discrimination, minimum wages and social security, among others. Labour market policies, for their part, have the object of combating unemployment, mitigating its effects and supporting the population at risk of joblessness. These policies can be divided into passive ones designed to offset the loss of pay, such as subsidies, and active ones, which are meant to preserve existing jobs and support the creation of new ones, help the unemployed find work, facilitate the connection between labour supply and demand and improve the skills of the unemployed and those working in microenterprises and small businesses (Samaniego, 2002). In Latin America, labour regulation policies and active labour market policies are currently the most common (ECLAC, 2005).

There is a direct relationship between unpaid work and employment, as the time spent on the former is inversely proportional to the time available for the latter. This is why the design of labour regulation and active labour market policies ought to take the situation into account, not to promote part-time jobs for women, however, but to create linkages with other sectoral policies, encourage the redistribution of unpaid care work and promote working and organizational practices that allow time to be used differently, something that requires a rethink of the idea that time spent at work is the only occupation in the day.

Information from time-use surveys should show that unpaid working time determines whether people can or cannot participate in the labour market, what kind of positioning they can achieve there and how many hours they can devote to a paid occupation (Cassirer, 2005). Indicators developed with information from time-use surveys should give labour ministries a clear picture of the relationship between employment and unpaid labour. For this to happen, the data presented to them need to be relevant, including, for example, time spent on housekeeping and care tasks by type of employment situation (occupational group, lowproductivity sectors, branch of economic activity). Properly interpreted, these data should also reveal the relationship between informal working and childcare.

Similarly, the experience of Asian developing countries has shown that time-use surveys can capture outsourced, home-based 
and subsistence work better than traditional employment surveys (Esquivel and others, 2008). Likewise, more general time-use data need to be considered in public employment programmes, ensuring that the policies needed to accommodate women's situation do not tend to reinforce gender roles and maintain the current distribution of time use in households. Furthermore, these data should provide the State with the information it needs to encourage greater participation by men in care and parenting, for example by means of paternity leave, which is part of labour regulation policy.

Information from time-use surveys, and the household surveys they form part of, should also guide the adoption of initiatives to improve the situation of female domestic workers, as they not only reveal the scale of this type of employment but also the living conditions of these workers.

\section{(b) In social security policies}

The object of these policies is to guarantee people an adequate standard of living when certain contingencies (old age, sickness, work accidents, motherhood) make them unable to generate an income. Employment is what gives access to social security in Latin America, and disadvantages women in the labour market because the time they spend on unpaid work also undermines their social security position.

Women's unpaid work contribution to their countries' and households' economies (as revealed by time-use surveys) should provide the basis for integrating those who devote themselves exclusively to care and housework into the social security system, with a right to pensions, social health care and even insurance against accidents at work. The average economic value a housewife generates each month by her unpaid work should underpin such integration (UNESCAP, 2004). Similarly, recognition of this work should provide the basis for an equitable division of pension savings in the event of divorce or separation.

\section{(c) In poverty alleviation policies}

Analysis of the findings of time-use surveys in the context of poverty alleviation policies can provide the basis for a more thorough and multidimensional treatment of the issue by yielding insights into people's quality of life and allowing dimensions such as time poverty to be incorporated.

Freedom of time use is a dimension of well-being, but time, like money, is distributed unequally within households. Time poverty is thus a want, a deficit that affects freedom. However, a view of poverty which defines it as income or resources falling below a certain threshold 
cannot reveal how time is allocated within households, even if domestic production is needed to attain a non-poor level of consumption; thus, official standards do not properly measure household needs (Féres, 2010).

Time deprivation has adverse consequences for poverty (even if the definition is limited to income poverty), either by exacerbating it or by contributing to its reproduction. Time availability has major gender implications; it is related to vulnerability, as it determines people's ability to react to situations of risk, and it also depends on income, so that time and income are interdependent and interchangeable (Féres, 2010), which is why time is used in situations where resources of other kinds are scarce (Gammage, 2010).

Although time poverty does not necessarily coincide with other dimensions of poverty, they do tend to be found together. Time poverty is thus a fundamental and transversal dimension of development (Féres, 2010). Accordingly, the implications of time poverty for public policies are various, and combined analysis of time use, time poverty and income poverty would make it possible to evaluate the impacts of specific interventions and of macroeconomic policies, as well as being applicable to social planning generally. Adding the time dimension to the analysis opens the way for other possible interventions, in addition to the traditional package, in the area of social protection or poverty mitigation (Gammage, 2009).

Despite all this, time poverty is still not taken into account in poverty alleviation policies, notwithstanding that time-use surveys can be very helpful even for initiatives centred on income poverty. In the last two decades, the focus of income poverty alleviation policies has shifted, so that programmes with wide coverage are now applied using a variety of methods and objectives that include service provision and income transfers, sometimes made conditional on certain requirements being met. These initiatives are mainly oriented towards women, and empowerment and social recognition for women have been among their unintended effects, but often too they treat them as intermediaries between families and the State, taking the elasticity of their time for granted (Montaño, 2004).

With regard to these initiatives, it is suggested that income levels be considered in conjunction with social benefits received, such as anti-poverty vouchers, and time use, to ensure that these benefits are not reinforcing the traditional sexual division of labour and further overloading women's time. In addition, the indicators resulting from the collation of these variables can be used to evaluate anti-poverty policies 
from a perspective other than the traditional one, which addresses income poverty. For example, the time-use survey in Mexico revealed that beneficiaries of the Oportunidades programme aged between 12 and 18 spent twice as much time studying as other students of these ages who were not beneficiaries. This confirmed the effectiveness of the programme in delivering on one of its objectives. It also revealed that among poor students who were not in the Oportunidades programme, girls spent less hours studying than boys, a difference that disappeared among programme beneficiaries. Again, young and adolescents girls receiving grants from the programme were found to spend less time on housework. These indicators confirmed that another of the programme goals, the closing of gender gaps, was being met (Orozco, 2005 and 2009). It would also be helpful to carry out evaluations based on the proportion of programme beneficiaries participating in the labour market and the proportion not doing so, as some evidence suggests that certain of these programmes may be discouraging women from taking up employment (Razavi, 2005).

Similarly, it would be possible to evaluate programme costs in terms of time use (in Ecuador, for example, the 2007 time-use survey asked about time spent collecting the Human Development Bond) and check whether the fact of receiving these benefits had any impact on the distribution of housework.

\section{(d) In health-care policies}

The goal of health care must be understood as that of promoting, protecting or restoring health. Good health-care policies can hardly be achieved without knowledge of how the work of producing health is distributed (Durán, 2007). At present, families are still the intermediaries between citizens and the health-care system in much of the region, and within them it is women who deal not only with treatment and rehabilitation needs but also, and especially, with prevention. This is something that needs to be brought into the open by time-use surveys and taken into account by policymakers in this area.

A number of surveys (Mexico's, for example) make it possible to cross-reference data on people carrying out unpaid work (above a certain number of hours) and those enrolled in the health-care social security system. This indicator should be used as the basis for measures to increase coverage of "inactive" women, i.e., those who are not participating in the labour market.

Likewise, time spent caring for the sick within the family is something health-care policies need to take into account, including in future any changes observed over the years. It would be very advisable 
for time-use surveys to deal separately with care for the sick and care for those with physical or mental limitations, as was done, for example, in Ecuador's 2007 time-use survey, since while both are a form of healthcare work, they have different characteristics.

\section{(e) In education policies}

Generally speaking, the goal of education policies is to give effect to the right to a high-quality, universal education. For all that has been achieved in the region, such as the expansion of primary enrolment and the narrowing of gender gaps, there are still major challenges associated with the quality of education and differences in quality and access by income level (ECLAC, 2002). These challenges include deficiencies in initial and preschool education: coverage is minimal, being confined mainly to middle- and high-income sectors, and such access as lowincome sectors do have is often to services that are unregulated and unsupervised by the State, which gives rise to serious doubts about the quality of the care and education provided. "Equality begins in the cradle," as Michelle Bachelet, the former President of Chile, put it when she founded her Chile Crece Contigo programme to expand the provision of childcare centres. Indeed, institutionalized education at early ages is a way of making up for any lack of stimulation, education, care time and even nutrition in the home.

There is a direct relationship between education policies and women's unpaid working time, since women have to step in whenever the State or, income permitting, the market does not provide.

As regards the utilization of time-use surveys, the education ministry can be presented with data on the time use of children, for example, to evaluate the reproduction of the sexual division of labour and its repercussions for educational policy goals. There is also a need to consider the time spent on care by adults, with particular regard to the importance of ensuring that the design of education strategies does not create an excessive burden for women. Accordingly, the data presented need to be accompanied by arguments for improved quality and coverage both in institutionalized initial education (ages 0 to 4 ) and in preschool education (ages 4 to 5), and for a progressive extension of the school day.

The time-use surveys of Mexico and Uruguay ask about children's attendance at nurseries, and Mexico's also asks about social programmes for this purpose. This question provides an opportunity not only to gather data on initial education coverage but also to evaluate policy in this area. Furthermore, this variable can be cross-referenced against 
parents' employment status to evaluate the influence of institutionalized care on employment type. ${ }^{6}$

\section{B. Reconstructing history}

The time-use surveys available in the region provide important evidence of inequalities that give rise in turn to other forms of inequality (for example, the different time-use patterns of women and men have consequences for the different ways they participate in the labour market). Despite this, many of these surveys have not been used for the design of public gender equality policies. Statistics as a policy instrument should be used for more than just demonstrating the need for such policies, which is as far as things have usually gone in the region. Time-use surveys should serve as an input for defining the problem to be addressed, the goals of a public policy, the design of its strategies and specific actions, and its indicators and evaluation periods.

An attempt will now be made to describe the steps the countries considered have taken to implement time-use surveys, the institutionalization of these in national institutes of statistics, and the challenges they raise. The objective is to contextualize the factors involved in integrating time-use surveys into policy, which will be identified later. As will be seen, the method used to implement timeuse surveys and the partnerships built up in the process have a direct bearing on the type of policies subsequently influenced.

\section{The route taken: building inter-institutional partnerships}

To explore why the integration of time-use surveys into policy has been incomplete, the history of some surveys will first be reconstructed.

In Costa Rica, time-use surveys have been planned and carried out at the initiative of the Inter-institutional Technical Commission for Accounting of Women's Work, formed in 2000 under the auspices of the National Women's Institute (INAMU) with a membership comprising the Ministry of Labour and Social Security, the Institute for Social Studies on Population (IDESPO) of the National University, the Women's Studies Centre (CIEM) of the University of Costa Rica, the State Distance Learning University (UNED) and the Ministry of National Planning and

In Brazil and Uruguay, there are already studies (Aguirre, 2010) showing that women's labour market participation tends to rise when their children attend educational establishments and that this effect is greatest when the children are aged from 0 to 3 . 
Economic Policy (MIDEPLAN). ${ }^{7}$ Within this framework, the National Institute of Statistics and Censuses (INEC) was offered resources from INAMU and technical support from the other organizations on the Commission, but the 2011 national survey was ultimately carried out by IDESPO.

In the case of Ecuador, time-use surveys were originally a joint initiative of the National Women's Council (CONAMU) and the National Institute of Statistics and Censuses (INEC), with support from the United Nations Development Fund for Women (UNIFEM) - Andean Region. A commission was set up, and within that framework the project was developed, financing was sought and a number of authorities were approached and shown the potential and importance of the information, in the process of which new partnerships were forged. Subsequently, following approval of the 2008 Constitution, INEC took over the work of producing time-use statistics, which were needed to implement the new rights recognized as part of the Good Living Regime, which is incorporated into the Constitution.

In Mexico, the first time-use survey (1996) was carried out at the initiative of the newly created government mechanism to implement the Beijing Platform for Action; the second and third (2002 and 2009) were joint initiatives of the National Women's Institute (INMUJERES) and the National Institute of Statistics and Geography (INEGI). All of them were supported by UNIFEM.

In the case of Uruguay, the first time-use survey was an initiative of the Sociology Department at the Faculty of Social Sciences (FCS) of the University of the Republic. The project then became a joint initiative of the National Women's Institute (INMUJERES), the FCS and the National Institute of Statistics (INE). The 2003 survey was held in Montevideo by the FCS, while those of 2007 and 2011 were nationwide and were carried out directly by the INE with FCS support. The 2007 time-use survey was held as part of the project Women's Time Use and Unpaid Work in Brazil and Countries of the Southern Cone (2006-2007), whose representatives in the country were the INE, the FCS of the University of the Republic and INMUJERES. It was also contributed to by different national institutes of statistics, cooperation agencies and academic institutes at the meetings held as part of this project.

It can thus be appreciated that, from development to implementation, time-use surveys have generally been inter-institutional initiatives undertaken by national mechanisms for the advancement of women, national institutes of statistics, international organizations,

The Central Bank of Costa Rica was originally part of the Commission. 
academia and ministries, with the exception of the survey held in Uruguay in 2003, which was an academic initiative. With the initiative once agreed upon, the role of national mechanisms for the advancement of women has been proactive and vital: providing financing (Costa Rica) or raising it (Ecuador), developing the project (Ecuador and Mexico) or forging links with authorities to show the importance of time-use surveys and establish new alliances (Ecuador). The role of national institutes of statistics has been more varied (survey design, implementation and processing, or consulting and monitoring), but they have also been participants in the debate from the start. The surveys applied in preparation for this article likewise revealed the importance of the inter-institutional commissions in Costa Rica and Ecuador, but also some inadequacies, including the absence of key actors such as central banks.

\section{Institutionalizing time-use surveys at national institutes of statistics}

Time-use surveys should form part of national systems of statistics and be integrated into household surveys. ${ }^{8}$ This does not mean that they cannot be treated as subsystems or that any country cannot carry out an independent time-use survey if it considers this advisable. The aim should be to establish a standing household survey programme, making it possible to create databases, track issues and capture changes over time (Milosavljevic and Tacla, 2007). ${ }^{9}$ In other words, whatever formula is adopted, the goal to be pursued is the institutionalization of time-use surveys.

Institutionalization refers to the goals and activities of organizations, the rules followed, both formal (laws, regulations) and informal (ethics, trust), and the mechanisms used to implement them (Rico, 2001). Institutionalizing an issue or approach means giving continuity to its handling, including it in programme and budget planning

\footnotetext{
Although a special survey is the ideal option for attaining time-use survey goals, this is so expensive that most countries would be unable to repeat it. For reasons of political and financial viability, therefore, the most reasonable solution is to develop modules which can be attached to permanent household surveys so that they can be repeated in series (Durán, 2007). The specific time-use survey could be used to prepare the unpaid work satellite account and the module to follow up key indicators for variables usually asked about in household surveys (income, employment status).

9 Where feasible, the modules attached to household surveys could be applied every two years, with a special survey held every five or seven. The national institutes of statistics of Ecuador, Mexico and Uruguay are considering the advisability of an independent survey, both for methodological reasons and because of the opportunity this would provide to go into issues more thoroughly, expand the information on care types and recipients and obtain more detailed breakdowns of the populations studied.
} 
and coordinating it with other goals pursued by the body concerned, ensuring that the necessary institutional capabilities are in place.

The joint experience of INMUJERES and INEGI in Mexico shows that regular, systematic statistics that benefit from a programme of continuous improvement, as has largely been the case with time-use statistics, which are consolidated with every survey round, are the most useful, provide the best guarantee of quality and are the most financially viable, precisely because they are used (Eternod and Medina, 2011). Thus, this learning process has revealed factors whose virtuous interaction progressively consolidates the institutionalization of gender statistics, and time-use surveys in particular: the periodic and regular repetition of the survey, application of its findings, a guaranteed budget and continuous improvements in data quality.

Progress and learning notwithstanding, the institutionalization of time-use surveys at national institutes of statistics still presents major challenges. Implementation planning is a prerequisite if surveys are to be repeated periodically, perhaps as part of the regular household survey round, and lack of resources is a recurring obstacle. Even in countries that have a longer track record with time-use surveys, such as Mexico, "it cannot be guaranteed that they will be held if this is not resolved". ${ }^{10}$ However, the distribution of budgets, like that of time, is a question of priorities. In the case of Costa Rica, this obstacle has been overcome by means of inter-institutional agreements that have facilitated the transfer of resources between institutions; in Mexico, thanks to the negotiating work of INMUJERES and the representations made by the Equity and Gender Committee of the Chamber of Deputies to the Secretariat of Finance and Public Credit, a ring-fenced budget was made available for women and gender from 2008, making it possible to carry out the 2009 time-use survey. Nonetheless, a regular budget for time-use surveys is essential if they are to be institutionalized at national institutes of statistics.

Again, the experience of national institutes of statistics in the region shows that the production and distribution of gender statistics, and those from time-use surveys in particular, are often dependent on the role played by a particular individual (see the experiences recounted in Aguirre, 2007). The best way of facilitating the institutionalization of time-use surveys will vary from one region to another and even between countries. In the experience of South Africa, for example, the creation of a gender unit at Statistics South Africa proved a positive step (Esquivel and others, 2008), and this could be applied to cases where there are not enough staff to carry out time-use surveys, such as Costa Rica and Uruguay.

10 Response from INEGI and INMUJERES to the survey carried out for this analysis. 
To gain an idea of the information requirements of national institutes of statistics, the survey conducted for this study asked the institutes about the information requests they received in relation to time-use surveys. In the cases of Costa Rica and Ecuador, these institutions had received requests from INAMU and public universities, in the first case, and public-sector institutions and non-governmental organizations, in the second; databases and tabulations were supplied in both cases. In the other countries considered, no applications for information had been received.

When it comes to generating demand for information, the role of national mechanisms for the advancement of women is necessary but not sufficient. It is necessary for them to carry out their gender advocacy, data dissemination and oversight work, and to stimulate continuity in the production of statistics at national institutes of statistics. It is insufficient, however, because there should also be demand from other bodies, ministries for example, requiring the information for policies they are responsible for, so that both demand for and use of this information extend beyond the sectors that are already persuaded of the importance of time-use surveys, thereby also contributing to their institutionalization at national institutes of statistics.

In any event, the question arises as to whether it might be necessary to integrate a focal point with statistical qualifications into national mechanisms for the advancement of women. In Uruguay, for example, although the National Institute of Statistics carries out primary analyses, it is up to whoever requests the information to disaggregate it and draw conclusions (Calvo, 2007). In Costa Rica, too, the survey carried out for this study has revealed the need for in-house information analysis capabilities at the national mechanism for the advancement of women. This confirms the need for these mechanisms to have a statistics focal point or, failing that, for academia to be involved when national mechanisms for the advancement of women or national institutes of statistics are under-resourced.

Indeed, there are instances of universities and research centres being successfully involved to make up for a lack of installed government capacity in Costa Rica (2004 and 2011), Nicaragua (2006) and Uruguay (2003). ${ }^{11}$ However, these experiences should not obscure the goal, which is

11 In Costa Rica, IDESPO was the institution put in charge of designing, implementing and processing the time-use survey. The process was monitored and regulated in accordance with the technical specifications of INEC, which has provided support with sample definition and selection, training in economic coding and mapping. In Uruguay, the University of the Republic supplied academic experience and lessons from a similar survey held in 2003, covering Montevideo and the metropolitan area. It was also in charge of training the interviewers who collected the module information. 
for time-use surveys to form part of statistical systems. In any event, the method used to meet the requirement for installed information analysis capacity will vary from country to country; in Costa Rica and Ecuador, for example, national institutes of statistics have played an important role in preparing indicators and even, in Ecuador, as participants in inter-institutional analyses.

Lastly, it should be noted that the national institutes of statistics surveyed are extremely supportive of the goal of institutionalizing timeuse surveys and set a high value on the experience acquired, the interinstitutional work done and the new understanding of the system of household indicators that time-use surveys have provided.

Box III.1

THE INSTITUTIONALIZATION OF GENDER AND TIME-USE STATISTICS: LESSONS LEARNT IN THE PHILIPPINES

The Philippines is a good example of the challenges involved in institutionalizing gender statistics, and time-use statistics in particular. The country is notable for its good practices, both in the generation of gender indicators and in their use by some policymakers. It is a pioneer in time-use surveys, which date back to the 1990s in the country. After huge efforts, the production of gender statistics was halted owing to a lack of demand for such data. This lack of demand was attributed to inadequate comprehension of how statistics could be used for effective decision-making by policymakers, or how other actors could employ them in advocacy to influence policy. What is needed to deal with this situation, in the view of an official at the National Institute of Statistics, is capacity-building among users of statistics. However, lack of capabilities is not the only problem; lack of political will is critical as well. These two causes - lack of demand and lack of political will- seem to have been more important than the technical and methodological problems entailed in time-use research, and it is therefore essential for this research to include an education and information component.

Source: Solita Collas-Monsod, "Removing the cloak of invisibility: integrating unpaid household service in national economic accounts - the Philippines experience", Unpaid Work and the Economy: Gender, Time Use and Poverty in Developing Countries, Rania Antonopoulos and Indira Hirway (eds.), London, Palgrave Macmillan, 2010.

\section{Political and institutional factors affecting the utilization of time-use surveys in public policies}

One explicit goal of many of the time-use surveys developed in the region is to guide public policymaking, as could be appreciated at the eighth International Meeting on Time-use Statistics and Public Policy, held in $2010 .{ }^{12}$ However, this has been achieved only in certain cases.

12 Organized by the ECLAC Statistical Conference of the Americas (SCA-ECLAC), INEGI, ECLAC, UNIFEM and Mexico's INMUJERES. 
One lesson from the discussions between national mechanisms for the advancement of women at international meetings is that taking decisions on policies in the absence of statistics multiplies the potential for these policies to fail. Another is that having the information to hand is not enough: it needs to be converted into tools for public policy design, follow-up, evaluation and accountability. For this, data need to be turned into indicators, and indicators into programmes of action (Eternod and Medina, 2011).

The progress made with the application of time-use surveys in the countries considered has been substantial but incomplete. It is incomplete because in some cases surveys have been used to support proposals for policies or laws but have not yet translated into operational programmes, while in other cases a process of policymaking and learning is under way and the policies concerned have yet to be implemented. In Costa Rica, survey data were used in the formulation of the National Gender Equality and Equity Policy, in the draft bill on the unpaid work satellite account and as evidence for the proposed National Care Programme. ${ }^{13}$ In Ecuador, data were used to debate and justify some of the articles in the 2008 Constitution dealing with the economic system and the care economy, and for the policies and strategy lines of the National Plan for Good Living, the organic law dealing with public service and the organic law dealing with the economy and financial sector. The satellite account for unpaid work is currently under development, with a number of ministries of State and other organizations currently promoting this type of work (the National Secretariat for Planning and Development, the central bank, INEC, the National Assembly, the Ministry for Social Development Coordination, the Ministry for Economic Policy Coordination and the Transition Commission).

In Mexico, time-use survey data have been employed to establish the economic value of unpaid work and to construct a satellite account. In addition, according to INMUJERES and INEGI, they have been used to evaluate the Oportunidades programme, the General Law for Equality between Women and Men and the National Programme for Equality between Women and Men. They have also been used in the development of policy proposals for the labour market, reconciliation between work and family life, actions to support care, the streamlining of formalities, the effectiveness of public transport and measures to give visibility to domestic work. In Uruguay, they have been integrated into the discussion and design of the national system of care, specifically in the

13 The National Care Programme is part of the National Development Plan 2011-2014 and centres the creation of the National Network for Child Care and Development and the National Network for Elder Care. 
working group set up under the auspices of the National Social Policy Council to coordinate the design of this system with representatives from the Ministry of Public Health, the Ministry of Economic Affairs and Finance, the Ministry of Social Development and the Planning and Budget Office, with further input from the Social Security Bank, the Uruguayan Institute for Children and Adolescents, the State Health Services Administration and departmental and municipal governments (Aguirre, 2011). They have also been used to modify the National Health Fund by incorporating uninsured spouses and cohabiting partners of those covered by it.

The process followed to prepare the way for integration of timeuse surveys into public policies has differed in each case, although there are similarities. In Costa Rica, data from the time-use survey have been used in the various areas of action of INAMU to raise public awareness and strengthen the demand for more equitable services, especially as regards care. In Ecuador, when the survey was applied for the first time it was realized that there was a need to generate installed capacity in the country so that the information could be analysed and used, this actually being one of the time-use survey goals. Accordingly, workshops were held for the public sector, academia and civil society (especially women's organizations) so that they could begin to familiarize themselves with the data and the issue of unpaid work, while also relating these subjects to the development of the national system of statistics.

In Mexico, INMUJERES prepared policy proposals based on the time-use survey and presented them to the appropriate authorities, and coordinated the preparation of the satellite account with INEGI. In Uruguay, publicization of time-use survey data has been crucial to the debate on the national system of care, as discussion has turned on documents based on these data. Dissemination of data by the INE has also been extremely important, as has the participation of people such as government advisers or officials who have been working with a gender perspective and have experience with statistics. The process followed to integrate time-use surveys into public policies has thus involved deploying data in the existing debate while at the same time using them to mobilize demand.

Going by the experience of national mechanisms for the advancement of women, national institutes of statistics and independent experts from the countries dealt with in this study, it is possible to identify the factors that facilitate integration of time-use surveys into public policies or enable progress to be made in this direction. These factors will now be indicated. 


\section{(a) Indispensable partnerships and inter-institutional efforts}

One of the lessons learnt in Costa Rica has been the importance of inter-institutional processes and efforts, institutional capacitybuilding and the appropriation of data from the time-use survey by the institutions of the Inter-institutional Technical Commission for Accounting of Women's Work. In Ecuador, too, the relationship between INEC, the National Secretariat for Planning and Development, CONAMU (later the Transition Commission), the Ministry for Social Development Coordination and at one stage the Constituent Assembly all made critical contributions to the achievements described earlier.

In Mexico, 15 years of joint work by INMUJERES and INEGI have shown that to construct the statistical infrastructure necessary from a gender perspective, it is helpful for projects to be undertaken jointly by national mechanisms for the advancement of women and national institutes of statistics, supported by a broad-based medium-term statistical programme, which means deciding what surveys need to be carried out, what administrative records modified and what aspects of censuses worked on. This should ideally be done within the framework of collaboration agreements that include clear commitments, joint working programmes and resource pledges (Eternod and Medina, 2011). In Uruguay, the relationship of INMUJERES with the Social Security Bank, the Ministry of Public Health and other bodies involved in the care system has facilitated the employment of time-use survey data as an input for the debate and an underpinning for the establishment of this system. Indeed, it is possible to identify the "inter-institutional ties between the gender mechanism, INE and academia as the basis for the success of this good practice". ${ }^{14}$

\section{(b) Political will and civil society action}

In Costa Rica, government commitment and the pressure exerted by the women's movement were critical in ensuring that data from the time-use survey were employed in the National Care Programme as part of the programme for government. In Ecuador, likewise, the commitment of Constituent Assembly members with whom partnerships were forged and of high-level authorities in the executive, combined with advocacy by women's movements, was vital in bringing time-use data to bear.

In Uruguay, official time-use statistics, academic studies, action by social organizations and the political decision to review the welfare model have enabled progress to be made in incorporating the care issue

14 Reply to the survey conducted for this study by Karina Batthyány, who is a lecturer at the Faculty of Social Sciences of the University of the Republic, a researcher and an expert in the economics of care. 
into the public agenda in the last two years (Aguirre, 2010). Pressure from the Gender and Family Network has been particularly important in this.

\section{(c) The role of the legal framework}

A helpful regulatory framework enshrining the economic value of unpaid work, for example, can facilitate mobilization of the institutional initiatives necessary to conduct a time-use survey and the consequent application of the information obtained to public policy, as has happened in Ecuador. Even more general prescriptions can have a positive effect, as INMUJERES and INEGI in Mexico have pointed out in relation to the General Law for Equality between Women and Men, in compliance with which ring-fencing of the gender budget was achieved. Likewise, the INE in Uruguay has mentioned Law 18104 on Equality of Rights and Opportunities between Men and Women in the Republic as the normative framework within which the time-use survey can be continued.

However, the legal framework does not guarantee either the implementation of time-use surveys or their use for policy purposes. Yet all the countries in the region have enshrined economic and social rights in their constitutions, together with the right to equality, whose exercise by women must entail acknowledgement and redistribution of unpaid work. Time-use surveys are indispensable for the former; for the latter (the redistribution of care and housework), policy measures need to reflect reality, i.e., be based on the empirical evidence that time-use surveys provide.

\section{(d) Prompt, large-scale dissemination of data}

In all the cases considered, time-use survey findings are available on the Internet at the websites of the respective national institutes of statistics and have been published, although the scale of dissemination has varied and impacts have accordingly differed from country to country, giving rise to challenges that will be considered further on. Notwithstanding the limitations, however, the dissemination of data has facilitated the integration of time-use surveys into policy.

In Costa Rica, the importance of people having timely and easy access to databases and findings has been understood, since the time elapsing between survey implementation and the publicization of findings appears to have been a factor in the poor integration of time-use data into public policies, at least in the case of the long delay between the first time-use survey (2004) and its citing in justification of the National Care Programme (2011). In the case of Uruguay, it has already been mentioned that the dissemination of data by the INE and academia was crucial in preparing the climate for discussion of the national system of care. 
The experience of Mexico, meanwhile, reveals the importance of publicizing gender statistics to foment a culture of equality and foster a statistical culture that treats data as an expression of reality and places reliance on their usefulness (Eternod and Medina, 2011). Using information is the greatest possible stimulus to its production (Pedrero, 2005), so that if widespread and thorough use is made of the information provided by time-use surveys, this will in some degree help to ensure that they are conducted regularly. Indeed, in the survey conducted for this study, both INEGI and INMUJERES in Mexico cited the application of time-use surveys to the generation of satellite accounts for unpaid work and their employment in different branches of the federal administration, particularly the secretariats of labour and social security, health and social development, as conditions that would facilitate the periodic repetition of these surveys. Accordingly, publicization of the existence and findings of time-use surveys and their employment for policy purposes are associated with progress in institutionalizing them at national institutes of statistics, since the social expectations and demand for information generated create pressure for this.

Publicization of the findings of time-use surveys is also crucial:

(i) for civil society, as it allows of greater social oversight and advocacy by women's movements. For this it is necessary that findings be presented in a language and format that are informative even for those unversed in statistics.

(ii) for sectoral policymakers, especially ministries. Statements could be prepared for these, explaining the usefulness and implications of time-use surveys for each sectoral policy. The idea is that those responsible for making and implementing policy should be able to understand the relationship between time use and their own area of competence.

This technique has been applied successfully in Mexico as part of the joint work of INMUJERES and INEGI, with such statements being adopted as one of the ways of connecting producers and users of the most widely utilized statistics, such as those on education and health (Gómez, 2007).

These statements should contain fact files describing the indicators, as this information is usually necessary for public policy design and implementation. In Mexico, for example, the new unemployment rate has involved considerable changes, as it includes people who are available for work, i.e., intend to enter paid employment, among them women whose multiple unpaid work obligations do not leave them time to seek a job. Thus, policymakers need to know how the unemployment indicator 
is compiled and how it relates to women's and men's time use, as this helps to explain gender differences in unemployment by revealing some of the obstacles active labour market policies need to remove.

These statements and any other information supplied to the authorities responsible for formulating and implementing policy need to be relevant and persuasive and to arouse the interest of the political interlocutors involved, considering their functions and purposes. Similarly, information has to be pitched in a way that relates it to sectoral policies so that the information on domestic work can be cross-referenced against the data for each policy.

\section{(e) The construction of a technical but approachable discourse and the role of knowledge}

Publicizing time-use surveys is not enough, for this has to go along with explanations that can be understood by organizations lacking in statistical knowledge and by citizens at large. In Ecuador, lessons have been learnt about the importance of the way data are presented and the framework in which they are interpreted, since the first to question them were women's organizations that did not perceive the figures as reflecting reality. This obstacle was gradually overcome and it proved possible to get the information across to different audiences.

In all cases, time-use survey data have been employed in studies carried out at the direct initiative of academia (in Costa Rica and Uruguay) or by consultancies (for national mechanisms for the advancement of women, other government agencies or international organizations in Ecuador, Mexico and Uruguay), so that a stock of knowledge explicitly oriented towards public policymaking has been built up. The thematic emphasis varies. Thus, studies in Costa Rica have focused on the contribution of unpaid work to the welfare system; in Ecuador, they have concentrated on providing a more comprehensive approach to the economic system and the relationship between the care economy and women's unpaid work; in Mexico, the emphasis has been on methodologies for the valuation of unpaid work, poverty and care; and in Uruguay, studies have looked at the bases of social welfare, the care economy and the different needs that exist in the various types of households.

This stock of knowledge has been employed to build up a specialized discourse on unpaid work and time use, albeit to differing degrees in the countries considered, and this is facilitating efforts to incorporate the findings of time-use surveys into public policies. 


\section{Factor interaction: the politics of policymaking}

The factors identified interact in non-linear public policymaking processes, with progress and regression. According to Guzmán (2011), these processes draw together: public and private actors mobilizing resources in more or less democratic spaces and in institutional and therefore rule-bound contexts; the rules, both formal and informal, which are changeable and need to be kept operational by the actors; and frameworks of meaning, i.e., different interpretations of the problem policy is designed to address, which are continually coming into conflict.

Thus, the partnerships built up give an idea of the actors involved, of whom there are still not enough to achieve a level of application of timeuse surveys sufficient to meet the gender demands that were the original motive for the surveys. The construction of a technical discourse and its incipient incorporation into policy, along with efforts to disseminate the findings of time-use surveys, are part of the process of constructing frameworks of meaning that are shared by a range of actors but still excluded from important spheres of decision-making. New developments in the legal framework for time-use surveys and care are among the formal rules governing policy, but their vitality and impact remain weak.

Even considering that policy decisions are not taken on the spur of the moment but are part of a process, and that some progress has been made in integrating time-use surveys into policy, it is arguable that their use has yet to be institutionalized. It would seem that for the time being, except perhaps in Uruguay, the dynamics involved are still at the level of subpolitics.

Subpolitics, a concept developed by Beck (1999, cited by Guzmán, 2008), encompasses political initiatives arising outside of traditional political institutions, new political subjects and new policy content and forms of participation. Subpolitics is distinguished from politics by the way it allows agents other than the traditional ones to form part of political decision-making.

According to Guzmán and Bonan (2008), this concept can provide the basis for a more thorough analysis of the procedures and courses followed to bring problems deriving from gender inequalities on to the public agenda and into public policymaking. However, these authors also argue that the process of gender institutionalization cannot be explained by subpolitics alone; there is also a need to analyse the interaction -whether of conflict or cooperation - between subpolitics and traditional institutions. And it is precisely here that there seem to be obstacles to the integration of time-use surveys into policy. To put it another way, institutional alliances have formed with the participation of women's organizations, academia, national mechanisms for the advancement of 
women, national institutes of statistics and some ministries, but these alliances do not usually have relationships with ministries of economic affairs or finance, with central banks, or even in some cases with ministries of labour, health, education or planning beyond, at best, the presentation of proposals based on time-use survey evidence.

In the development of gender institutionalization, subpolitics needs to operate transversally in institutions and political spaces, creating sui generis political spaces in which technical and administrative logic, the logic of specialists and policymakers and the discourse of civil society all come into dialogue (Guzmán, 2011). These spaces have clearly been created in the dynamics that have given rise to the development and application of time-use surveys in public policies, but, with some exceptions, they do not seem to have penetrated into the necessary decision-making spheres.

The problem, however, is not just that some actors are absent while those present have limited decision-making power. As with the institutionalization of gender in the State, the institutionalization of timeuse survey application in policies depends not only on the commitment and political strength of the actors mobilizing new interpretations of the gender order, but also on the institutional system in which they are operating, which anticipates and orients the interpretation of reality. Consequently, it is essential that public action to transform gender relations should construct frameworks of meaning in which actors redefine the problems and their solutions (Guzmán, 2011).

\section{Challenges}

Dialogue between public policies and gender indicators is not easy. Besides the variability of interest and commitment depending on the political or social actor concerned, there is an element of unawareness of the existence and usefulness of these indicators. Then, if it is hard enough anyway for gender indicators to be taken into account in sectoral policy design, it will be harder still where time-use indicators are concerned, since policymakers are more conversant with gender indicators relating to employment, for instance, than with those relating to women's unpaid work.

The purpose of comparing the countries considered in this article was to identify similarities in the ways time-use surveys are integrated into policy and thereby glean some clues about the factors facilitating this. The hope is that this information may be useful in other cases, although this does not imply any claim of regional representativeness. 
On the basis of the information given in this article, some challenges of both a methodological and a politico-institutional nature have been identified; the latter concern the construction of new frameworks of meaning and the incorporation of actors who are important in the process of integrating time-use surveys into public policy.

\section{Methodological challenges for national institutes of statistics}

Since 2003, the Gender Affairs Division of ECLAC and the Statistical Conference of the Americas (SCA-ECLAC), with the participation of the region's governments, have been working on the methodological challenges involved in time-use surveys. ${ }^{15}$ This joint work has resulted in the preparation of the document "Directrices y referentes conceptuales para armonizar las encuestas de uso de tiempo en América Latina y el Caribe" (Gómez, 2011), which contains the Classification of Time-use Activities for Latin America and the Caribbean (CAUTAL) and is currently the subject of consultation with governments so that it can be agreed upon. The proposals indicated, now being debated by the region's governments, present some methodological challenges that ought to be addressed by national institutes of statistics, and these will now be summarized.

\section{(a) Disaggregation of activities}

The level to which activities are disaggregated has been one of the aspects most debated at specialist meetings, and what has been emphasized is the need to strike a balance, since there is the risk of unpaid work being underestimated when the list is too highly aggregated, while a very long list can also cause problems, such as long application times.

\section{(b) Training of interviewers and other staff}

Another challenge identified by the national institutes of statistics themselves in the survey conducted for this article is the training of survey interviewers so that they are able to give guidance to respondents and avoid biases in information-gathering. This is particularly important given the high percentages of illiteracy in some countries. Furthermore, in view of the complexity of field operations, it is recommended that training for both interviewers and supervisors should last at least two weeks and include a large number of practical activities so that participants are thoroughly familiarized with the survey form.

15 These are the international meetings on time-use surveys held annually since 2003, initially coordinated by UNIFEM with Mexico's INMUJERES and INEGI, and organized since 2006 within the SCA-ECLAC framework. 


\section{(c) Avoiding time leakage}

The experience and appreciation of time is a subject with strong cultural connotations, which makes it hard to capture. Furthermore, people do not usually have a clear perception of the time they spend on daily activities (Milosavljevic and Tacla, 2007), and when surveys are applied there is the drawback that they try to capture exact timings when the timings are actually only approximate (Berrocal, 2010). Bearing this in mind, questionnaire design and interviewer training are essential in helping people to remember what they have done and avoid underestimation.

\section{(d) Variables to be incorporated or standardized}

(i) Capture child work, which means not only including children in the age range of the survey but ensuring that interviewers deal properly with their direct informants, usually the parents, who tend not to declare this because children who are working are failing to attend school.

(ii) Ascertain whether older adults living in the household are self-sufficient or not. Progress is now being made with this in Costa Rica, since the 2011 survey asks about the care time spent on fully dependent elderly people, while another question asks about the care given to older adults.

(iii) Find out whether households have domestic employees. The surveys of Costa Rica, Ecuador, Mexico and Uruguay, for example, now include a question about this.

(iv) Find out about the type of school day (Milosavljevic and Tacla, 2007) and any attendance at preschool and initial education centres. This latter subject is already asked about in the surveys of Mexico and Uruguay.

(v) Include questions about people's mother tongue and selfperceived ethnic identity so that this variable is available for future analyses. ${ }^{16}$ This is already done in the surveys of Ecuador and Mexico.

\section{(e) Interview times}

Addressing complex subjects with a single questionnaire for different population groups is unquestionably a challenge in itself; it takes time to apply properly, and this may result in respondents becoming tired and uncooperative. In the case of Mexico's INEGI,

\footnotetext{
16 One constraint on household surveys is that samples may not be large enough for information on certain variables, such as ethnicity, to be disaggregated.
} 
this challenge was addressed by using a digital questionnaire with sequencing based on criteria followed by the interviewer during data collection, which facilitated interviews and reduced application times. It also proved helpful to record actual interview times, since this was the factor used to guide the supervision of fieldwork during the survey's first week, when times below the average were reported.

\section{(f) Learning from accumulated experience}

The survey carried out for this study has revealed how helpful it has been for the region's national institutes of statistics to share experiences and lessons learnt at different events, and for the time-use survey process to benefit from expert guidance. Similarly, the people consulted have recommended detailed documentation of any surveys carried out so that the experience built up can provide an input for similar operations.

\section{(g) Standardizing time-use surveys with a view to international comparability}

International comparison will only be possible when a standardized classification of activities is adopted; activities more particularly associated with a subregion or country can then be added, considering that time use is related to cultural practices and material and economic conditions (Milosavljevic and Tacla, 2007). The aim, then, is not to homogenize, or to misrepresent the cultural aspects that determine behaviour types; standardization should not entail a loss of information about the diversity of each country, but harmonization between different informationgathering instruments is desirable insofar as it makes it possible for comparisons between countries to be established (ECLAC, 2004).

The objective of the Classification of Time-use Activities for Latin America and the Caribbean (CAUTAL) is to build a consensus on a strategic instrument for the harmonization process, as it guides all stages of the work from the setting of goals and design of the informationgathering instrument to the presentation of findings. It is a classifier developed in accordance with guiding principles derived from the 2008 System of National Accounts, relating to production boundaries, and it has taken the United Nations International Classification of Activities for Time-use Statistics (ICATUS) as a benchmark. It also takes account of the latest International Labour Organization guidelines on the economically active population and the measurement of working time (Gómez, 2011).

Given its utility, it is necessary for the countries to reach a consensus on this tool as soon as possible and for consideration to be given to specific issues where harmonization needs and potential can conflict with those associated with the presentation of relevant 
information. Thus, for example, it is proposed that CAUTAL be harmonized at the two-digit level, but a three-digit category is required to reconstruct the situation of paid domestic service (Pedrero, 2011).

The challenges of standardization and international comparability also call for the creation of a basic set of indicators that can be processed from any time-use survey in the region and serve explicitly as an input for equality policies and as a yardstick for compliance with the international commitments accepted by States.

\section{Political and institutional challenges for mechanisms for the advancement of women}

\section{(a) Reaching out to uninvolved political actors}

Integrating actors such as central banks and turning them into permanent partners in intersectoral dialogue is a fundamental challenge that national mechanisms for the advancement of women need to address. Likewise, it would be good to draw in ministerial institutions other than the social cabinets of governments, including economic affairs ministries and, where they are still uninvolved, bodies that can play an important role (in the areas of employment, education, health care and social security) in the redistribution of unpaid work as well.

(b) Generating or strengthening institutional capabilities in the analysis of time-use survey information, and the need for a theoretical framework

Where this challenge is concerned, the example of Mexico shows the importance of having a protocol that enables the national mechanism for the advancement of women to analyse informationgathering instruments so that the gender perspective is incorporated into all statistical projects (Eternod and Medina, 2011). Furthermore, the availability of information analysis capabilities facilitates the making of periodic requests to national institutes of statistics for data of relevance to the programmes of national mechanisms for the advancement of women.

The challenge goes beyond this, however. The institutionalization of time-use surveys in public policies seems to require a basic theoretical framework for policy formulation and institutionalization, particularly where the economic autonomy of women is concerned. Although women's economic development and poverty alleviation (particularly through microenterprise programmes) are areas dealt with by national mechanisms for the advancement of women in the region (Fernós, 2010), economic autonomy is an area that has been addressed only recently, 
since it was not until the Mexico Consensus (2004) that public initiatives to establish or enhance this dimension of women's autonomy began to spread (ECLAC, 2011). Until 2004, furthermore, women's employment programmes were usually residual in terms of their budget and duration, and of limited impact (Rico and Marco, 2006). Priority had usually been given to issues such as gender violence, much as has happened with women's movements, which generally prioritize what happens to women's bodies. In addition, there have been major efforts in the area of women's political autonomy, especially during particular processes of change, such as constitution-drafting. This context may partly explain why it is so difficult for the findings of time-use surveys to be taken into account in public policymaking, other than their data being cited to justify the standards or objectives of equality plans.

In this situation, and with some differences between countries, time-use surveys look like isolated tools whose potential has been left untapped because they do not form part of the kind of consistent theoretical and methodological framework that would allow them to be integrated into the different areas of action of national mechanisms for the advancement of women and taken into consideration by policyimplementing bodies in the rest of the State apparatus.

(c) Disseminating time-use survey data with an easily understood interpretive framework, not just to civil society organizations but to other State bodies as well

As part of this challenge, it is essential to reach out beyond the converted, i.e., to disseminate data beyond the feminist academic community. The survey applied for this study reveals that data dissemination is inadequate in this respect. Uruguay can show good practice in this area, since the publication and dissemination of time-use surveys has even reached actors such as unions, with a major impact on public opinion. The challenge in this case is to spread the information beyond the capital.

\section{(d) Constructing a specialist discourse that permeates public policymaking}

As already indicated, the different studies undertaken in the countries on the basis of time-use surveys have gradually built up a critical mass of knowledge and constructed a specialized discourse on unpaid work and time use. The challenge, then, is for this technical - but accessible- discourse to permeate public policy and come to form part of the common stock and vocabulary of decision-makers.

This process is incipient at best. Ecuador and Uruguay deserve special mention, however: in the former, this specialist discourse 
played an important role in the drafting of the Constitution and in the formulation of the National Plan for Good Living, while in Uruguay the process now seems to be under way with the recent application of timeuse surveys and studies based on them in care policies.

\section{By way of conclusion}

Without question, time-use surveys have done a great deal to bring the issue of unpaid work, and care work in particular, onto the public agenda. Costa Rica has included care provision in its programme of government. Ecuador has made substantial legal progress in the matter of care and has begun the process of establishing a satellite account of unpaid work. Mexico, with its long tradition of producing time-use statistics, already has a satellite account, and unpaid work is taken into account when government programmes are evaluated. Uruguay has initiated an exemplary social dialogue on the design of a national system of care.

For all the progress made, the use of time statistics still seems to be at the propositional and enabling legislation stage rather than at the programmatic stage. Despite the valuable work of the institutions and actors involved in developing time-use surveys and integrating them into policy, the progress made, although substantial, has been partial, both because a learning process is being gone through and because, as already discussed, uses remain limited.

The question that arises, then, is whether the institutional alliances that have taken shape in the countries studied are up to carrying out this twofold task of first demonstrating and persuading, and then incorporating time-use surveys into particular policies. The concluding hypothesis is that they are not, at least given present dynamics. The potential of timeuse surveys for public policy is barely beginning to be explored.

For there to be progress, it is clearly necessary to mobilize resources and commitments; work out sectoral policies, but from a systemic, comprehensive perspective rather than a sectoral one, and with inter-institutional coordination; and engage with the politics of policymaking, removing institutional barriers and shaping new interpretive frameworks that enable decision-makers and social actors to challenge existing policies using the empirical evidence that time-use surveys provide. 


\section{Bibliography}

Aguirre, Rosario (2011), "Información y conocimientos para la incidencia política y la definición de la política de cuidados en Uruguay", paper presented at the International Seminar "Políticas de tiempo, el tiempo de las políticas", fortysixth meeting of the Presiding Officers of the Regional Conference on Women in Latin America and the Caribbean, Santiago, Chile, 29 - 30 November.

(2010), "Los cuidados entran en la agenda pública", Revista de Ciencias Sociales, year XXIII, No. 27, Departamento de Sociología, Universidad de la República, December.

(coord.) (2007), Encuestas de uso del tiempo y trabajo no remunerado. Reunión Técnica Subregional, Montevideo, United Nations Development Fund for Women (UNIFEM)/United Nations Development Programme (UNDP)/Universidad de la República.

(2005), “Trabajo no remunerado y uso del tiempo. Fundamentos conceptuales y avances empíricos. La encuesta de Montevideo de 2003", El tiempo, los tiempos, una vara de la desigualdad, Mujer y Desarrollo series, No. 65 (LC/L.2324-P), Santiago, Chile, Economic Commission for Latin America and the Caribbean (ECLAC). Araya, María José (2003), "Un acercamiento a las encuestas sobre uso del tiempo", Mujer y Desarrollo series, No. 50 (LC/L.2022-P/E), Santiago, Chile, Economic Commission for Latin America and the Caribbean (ECLAC).

Batthyány, Karina (2010), "El cuidado infantil en Uruguay y sus implicancias de género. Análisis a partir del uso de tiempo", Revista de Ciencias Sociales, year XXIII/ No. 27, Departamento de Sociología, Universidad de la República, December.

Beck, Ulrich (1999), La invención de lo político, Buenos Aires, Fondo de Cultura Económica.

Berrocal, Lupe (2010), “La encuesta nacional de uso de tiempo en el Perú. Avances y desafíos", paper presented at the International Meeting on Time-Use Statistics and Public Policies, Mexico City, 30 June - 2 July.

Budlender, Debbie (2008), "Time-use in South Africa", Explorations: Time Use Survey in the South, Valeria Esquivel and others, Feminist Economics, vol.14, No. 3, July.

Calvo, Carlos (2007), "La metodología de las encuestas de hogares y la incorporación de módulos", Encuestas de uso del tiempo y trabajo no remunerado. Reunión Técnica Subregional, Rosario Aguirre (coord.), Montevideo, United Nations Development Fund for Women (UNIFEM)/United Nations Development Programme (UNDP)/Universidad de la República.

Carrasco, Cristina (2005), "Tiempo de trabajo, tiempo de vida. Las desigualdades de género en el uso del tiempo", El tiempo, los tiempos, una vara de la desigualdad, Mujer y Desarrollo series, No. 65 (LC/L.2324-P), Santiago, Chile, Economic Commission for Latin America and the Caribbean (ECLAC).

Cassirer, Naomy (2005), "Policy implications of unpaid work: promoting gender equality through decent work", paper presented at the International Conference on Women's Unpaid Work Contribution to Economy: Gender, Poverty and Millennium Development Goals, United Nations Development Programme (UNDP)/Levy Economics Institute of Bard College, 1 - 3 October.

Collas-Monsod, Solita (2007), "Removing the cloak of invisibility: integrating unpaid household service in national economic accounts - the Philippines experience", Unpaid Work and the Economy: Gender, Time Use and Poverty in Developing Countries, Rania Antonopoulos and Indira Hirway (eds.), London, Palgrave Macmillan. 
CONAMU (National Women's Council of Ecuador), (2006), “Encuesta del Uso del Tiempo en Ecuador 2005", Información Estratégica series II, Quito.

Duran, María Ángeles (2007), "El desafío de una innovación necesaria: el trabajo no remunerado en las economías actuales", Encuestas de uso del tiempo y trabajo no remunerado. Reunión Técnica Subregional, Rosario Aguirre (coord.), Montevideo, United Nations Development Fund for Women (UNIFEM)/United Nations Development Programme (UNDP)/Universidad de la República.

ECLAC (Economic Commission for Latin America and the Caribbean) (2011), "El salto de la autonomía. De los márgenes al centro. Informe 2011", Project Documents, No. 436 (LC/W.436), Santiago, Chile.

(2010), What kind of State? What kind of equality? (LC/G.2450(CRM.11/13)), Santiago, Chile, June.

(2005), Social Panorama of Latin America, 2004 (LC/G.2259-P), Santiago, Chile. United Nations publication, Sales No. S.04.II.G.148.

(2004), Report on the Meeting of Experts on Time-Use Surveys (LC/L.2058), Santiago, Chile.

(2002), Globalization and Development (LC/G.2157(SES.29/3)), Santiago, Chile. (2001), Social Panorama of Latin America, 2000-2001 (LC/G.2138-P), Santiago, Chile. United Nations publication, Sales No. E.01.II.G.141.

ESCAP (Economic and Social Commission for Asia and the Pacific) (2004), From statistics to national policies on unpaid work: the Case of the Republic of Korea [online] http://www.unescap.org/stat/meet/wipuw/13.unpaid_module6_part1.pdf.

Esquivel, Valeria and others (2008), "Explorations: time use survey in the south", Feminist Economics, vol. 14, No. 3, July.

Eternod, Marcela and María Eugenia Medina (2011), “Experiencia del trabajo conjunto entre los institutos nacionales de estadística y los mecanismos para el adelanto de la mujer: el caso de México, Antigua, Guatemala", April, unpublished.

Gammage, Sarah (2010), "Encuestas de uso de tiempo y las políticas de protección social", unpublished.

(2009), Género, pobreza de tiempo y capacidades en Guatemala: un análisis multifactorial desde una perspectiva económica (LC/MEX/L955), Mexico City, ECLAC subregional headquarters in Mexico.

Gómez-Luna, María Eugenia (2010), “Directrices y referentes conceptuales para armonizar las encuestas de uso de tiempo en América Latina y el Caribe", paper presented at the International Meeting on Time-Use Statistics and Public Policies, Mexico City, 30 June - 2 july [online] http://www.eclac.cl/mujer/ noticias/noticias/3/40283/MariaGomez.pdf.

(2007), "Las estadísticas de género en el diseño y evaluación de políticas públicas", Encuestas de uso del tiempo y trabajo no remunerado. Reunión Técnica Subregional, Rosario Aguirre, (coord.), Montevideo, United Nations Development Fund for Women (UNIFEM)/ United Nations Development Programme (UNDP)/Universidad de la República.

Guzmán, Virginia (2011), "Procesos político-institucionales e igualdad de género. Chile 1980 - 2010", Ph. D. thesis, Facultad de Ciencias Políticas y Sociología, Universidad Autónoma de Barcelona, July.

Guzmán, Virginia y Claudia Bonan (2008), “La institucionalización del tema de la equidad de género y la modernización del Estado en América Latina", Aportes para el Estado y la administración gubernamental, year 14, No. 25, Buenos Aires. 
Feres, Juan Carlos (2010), “La medición de pobreza de tiempo: experiencias recientes", presentation at the eleventh session of the Regional Conference on Women in Latin America and the Caribbean, Brasilia, 14 July.

Fernós, María Dolores (2010), "National mechanism for gender equality and empowerment of women in Latin American and de Caribbean región", Mujer y Desarrollo series, No. 102 (LC/L.3203-P), Santiago, Chile, Economic Commission for Latin America and the Caribbean (ECLAC).

INEGI (National Institute of Statistics and Geography) (2010), "Encuesta Nacional de Uso de Tiempo 2009", paper presented at the International Meeting on TimeUse Statistics and Public Policies, Mexico City, 30 June - 2 July.

Leiva, Martha (2010), "Módulo de uso de tiempo EPHPM 2009 Honduras", paper presented at the International Meeting on Time-Use Statistics and Public Policies, Mexico City, 30 June- 2 July.

Milosavljevic, Vivian and Odette Tacla (2007), "Incorporando un módulo de uso de tiempo en las encuestas de hogares: restricciones y potencialidades", Mujer y Desarrollo series, No. 83 (LC/L.2709-P/E), Santiago, Chile, Economic Commission for Latin America and the Caribbean (ECLAC).

Montaño, Sonia (2004), "Experiencias valiosas que mejoran la equidad de género", Revista Gobernabilidad Democrática y Género, Santiago, Chile, Economic Commission for Latin America and the Caribbean (ECLAC), November.

Orozco, Mónica (2009), “Uso del tiempo y política social”, paper presented at the VI International Expert Meeting on Time-Use, Mexico City, National Institute on Women (INMUJERES).

(2005), "Time use: the economic contribution of Mexican women", paper presented al the International Conference on Women's Unpaid Work Contribution to Economy: Gender, Poverty and Millennium Development Goals, United Nations Development Programme (UNDP)/Levy Economics Institute of Bard College, 1 - 3 October.

Orozco, Mónica and Anitzel Merino (2011), "Pobreza de tiempo de las mujeres", paper presented at the ninth International Meeting on Public Policies, Time-Use and Care Economy: the importance of national statistics, National Institute on Women (INMUJERES), Mexico City, 29 - 30 August.

Pedrero, Mercedes (2011), "Experiencias en el uso de clasificadores de las actividades en las encuestas de uso de tiempo en la región", paper presented at the ninth International Meeting on Public Policies, Time-Use and Care Economy: the importance of national statistics, National Institute on Women (INMUJERES), Mexico City, 29 - 30 August.

(2005), “Trabajo doméstico no remunerado en México. Una estimación de su valor económico a través de la Encuesta Nacional sobre Uso del Tiempo 2002", National Institute on Women (INMUJERES) [online] http://www.inegi.org. $\mathrm{mx} /$ inegi/contenidos/espanol/eventos/vigenero/dia28/panel3_mesas_pdf/ Trabajo/Trabajo-ENUT-y-Trabajo-dom\%C3\%A9stico-no-remunerado.pdf.

Pérez, Alba, Alison Vásconez and Claudio Gallardo, (2008), El tiempo de ellas y ellos. Indicadores de la Encuesta Nacional de Uso del Tiempo-2007, Quito, National Women's Council (CONAMU)/National Institute of Statistics and Censuses (INEC). Razavi, Shahara (2005), "The relevance of women's unpaid work to social policy in developing countries", paper presented al the International Conference on Women's Unpaid Work Contribution to Economy: Gender, Poverty and Millennium Development Goals, United Nations Development Programme (UNDP)/Levy Economics Institute of Bard College, 1 - 3 October. 
Rodríguez Enríquez, Corina (2007), “La organización del cuidado de niños y niñas en Argentina y Uruguay”, Mujer y Desarrollo series, No. 90 (LC/L.2844-P), Santiago, Chile, Economic Commission for Latin America and the Caribbean (ECLAC). Rico, María Nieves (2001), “El proyecto institucionalización del enfoque de género en la CEPAL y ministerios sectoriales", Hacia la institucionalización el enfoque de género en las políticas económico-laborales en América Latina, Loreto Bravo and Nieves Rico (comps.), Seminarios y Conferencias series, No. 20 (LC/L.1667-P), Santiago, Chile, Economic Commission for Latin America and the Caribbean (ECLAC).

Rico, María Nieves and Flavia Marco (2006), “Las mujeres en el empleo sectorial en América Latina", Mujer y empleo. La reforma de la salud y la salud de la reforma, María Nieves Rico and Flavia Marco (coords.), Buenos Aires, Siglo XXI Editores. Salvador, Soledad (2011), "Hacia un sistema nacional de cuidado en el Uruguay", El desafío de un sistema nacional de cuidados para el Uruguay, María Nieves Rico (coord.), Seminarios y Conferencias series, No. 66 (LC/L.3359), Santiago, Chile, Economic Commission for Latin America and the Caribbean (ECLAC).

Samaniego, Norma (2002), "Las políticas de mercado de trabajo y su evaluación en América Latina", Macroeconomía del Desarrollo series, No. 19 (LC/L.1836-P), Santiago, Chile, Economic Commission for Latin America and the Caribbean (ECLAC).

Villamizar, María Eugenia (2011), “Uso del tiempo de mujeres y hombres en Colombia. Midiendo la inequidad", Mujer y Desarrollo series, No. 107 (LC/L.3298-P), Santiago, Chile, Economic Commission for Latin America and the Caribbean (ECLAC). 
Chapter IV

\section{Women's work: some considerations deriving from an integrated approach based on time- use surveys and employment statistics}

Corina Rodríguez Enríquez ${ }^{1}$

Women's work is an essential element in the functioning of the economic and social system. Labour market participation is the most visible dimension of women's contribution to wealth creation and to households' material living standards and economic survival. Unpaid work is the other side of the coin.

There is now a plentiful literature explaining how this dimension of women's work, although denied visibility, is essential to the functioning of the system, since it ensures that the cost of reproducing the workforce and caring for dependants (children, older adults and the sick) is low (or nil). ${ }^{2}$

The importance of women's unpaid work, both for its systemic contribution and as a determinant of persistent gender inequities in the labour market, has made it a subject of inquiry that has a particular contribution to make to the formulation of equality policies.

The author is grateful for the assistance of Florencia Chaberendian and Maggie Méndez in preparing this study.

2 See Montaño and Calderón (2010). 
In these circumstances, time-use surveys have become an essential way of producing information that can be used to ascertain, quantify and value the unpaid work people do. ${ }^{3}$ These surveys, which are increasingly common in the countries of the region, have allowed some initial assumptions to be made: (i) time use differs between men and women; (ii) women work more and for longer on housekeeping and care tasks; (iii) the time men spend on housekeeping and care does not increase when women work in the labour market; (iv) partly as a result, the intensity of time use is greatest for women who are active in the labour market (a situation usually known as women's double shift).

The information yielded by time-use surveys has also made it possible to estimate the contribution of women's unpaid work to the generation of economic value. The most widely cited figure is that for Mexico, where development of a regular time-use survey has made it possible to construct a household satellite account and arrive at an estimate for women's unpaid work, which is put at the equivalent of over $23 \%$ of GDP. ${ }^{4}$

Time-use surveys provide information about all the work people do, which means that they include work done by women in productive activities, something that is of interest when women's total time use is being investigated. This aspect of time-use surveys has been less explored, since it is believed (correctly) that labour force surveys are the right tool for measuring and characterizing this type of work.

The present chapter carefully analyses this dimension, on the premise that the characteristics of time-use surveys allow them to provide information which can supplement or call into question that yielded by labour force surveys. Accordingly, it will seek to answer these questions:

(i) What do time-use surveys reveal about women's productive work?

(ii) Do time-use surveys provide information about productive work whose characteristics mean that it is not properly captured by labour force surveys?

(iii) Likewise, what lessons do time-use surveys provide for improving the way labour force surveys capture unpaid productive work?

See Esquivel and others (2008) for a general review of time-use surveys and Milosavljevic and Tacla (2007) for a review of time-use surveys in the region.

4 The exact figure for 2009 puts this contribution at $22.6 \%$ of GDP. 
Time-use surveys also provide information about the work done by certain categories of women that labour force surveys do not adequately explore. This is particularly the case with women classified by employment statistics as inactive. The term itself is debated, of course, since women who are inactive in the labour market are assumed to be so mainly because they are very active in the home, where they are responsible for unpaid care work and housekeeping.

Accordingly, the second part of this study will also ask the question:

(iv) What do time-use surveys reveal about the work done by women classified as inactive by labour force surveys?

To take this investigation forward, the national cases of Mexico and Ecuador were explored. These are countries with a pioneering and substantial tradition in the development of time-use surveys. These countries were chosen because of this track record and also because their information-gathering strategies differ: the time-use survey in Mexico is a stand-alone survey, whereas in Ecuador it is applied as a module in the labour force survey.

The analysis is on two levels. The first is methodological, and concerns the way productive work is investigated in time-use surveys (and their similarities to and differences from labour force surveys). The second concerns quantitative information provided by time-use surveys that supplements or calls into question the findings of labour force surveys.

This is an exploratory study which does not seek to analyse information exhaustively but is meant as an initial exercise that should yield tentative answers to the questions raised and generate further questions about how an integrated analysis of the information furnished by household surveys might contribute to the characterization and understanding of women's working dynamic and the factors that condition it.

The chapter is organized into four sections. The first reviews the conceptual and methodological definitions used to explore work in time-use surveys and labour force surveys. The second analyses the contribution of women's and men's work to production activities in the System of National Accounts (SNA) insofar as this can be inferred from time-use surveys. The third presents and analyses information about the work of women treated as inactive by labour force surveys. The last section offers some conclusions. 


\section{A. The conceptual and methodological framework for collecting information on work}

The development of time-use surveys has made it possible to put in place a conceptual and methodological framework that extends the idea of productive work. As Gómez (2010, p. 9) puts it, "the proposed conceptual framework recognizes the indivisible character of work, whether paid or unpaid, i.e., total work, as a substantive category in the time-use activities of individuals and in economic, labour, social and gender analysis".

This involves extending the limits of what has traditionally been treated as productive work for the purposes of the System of National Accounts, which is used to put a value on the contribution of work to the economy. What is proposed in the context of time-use surveys is an extended conception of production encompassing both production as defined in the SNA and that carried out in the course of unpaid productive activities within households. Extending the production boundary also extends the concept of work to include that which is not recognized as such in the market but is socially useful. ${ }^{5}$

Specifically, the proposal is to consider a general production boundary that includes production within the SNA and production outside it. Thus, productive activities carried out by people at any time of day or night will be included in one of these categories, as table IV.1 shows.

To the activities included in the general production boundary are added personal activities: study and learning; social activities; attendance at cultural, entertainment and sporting events; hobbies, games and other pastimes; use of mass media; self-care.

Labour force surveys are the traditional instrument for capturing information on work carried out for production within the SNA. Timeuse surveys can be used to gather information about production work outside the SNA and personal activities. However, time-use surveys also capture information about production work that is within the SNA, as they include specific questions about paid work. This overlap between the two instruments means that they can be compared and contrasted to assess whether time-use surveys collect information on this aspect that might complete and supplement the information captured by labour force surveys.

The definition of socially useful work is itself controversial. At the extreme, any work that at least one person regards as usual might fall into this category. For the purposes of the discussion in this article, social utility is considered to be an attribute only of work that counts as productive for economic purposes. 
Table IV.1

THE GENERAL PRODUCTION BOUNDARY

\begin{tabular}{|c|c|}
\hline Production within the system of national accounts & Production outside the system of national accounts \\
\hline $\begin{array}{l}\text { - Market production } \\
\text { Goods and services }\end{array}$ & $\begin{array}{l}\text { - Unpaid services for members of the same household } \\
\text { Domestic services }\end{array}$ \\
\hline - Production for own final use & Personal care services \\
\hline $\begin{array}{l}\text { Voluntary work } \\
\text { Goods production } \\
\text { Construction } \\
\text { Owner rental services }\end{array}$ & $\begin{array}{l}\text { - Unpaid services for other households and the community } \\
\text { Services to other households } \\
\text { Services to the community } \\
\text { Unpaid volunteer services at non-profit institutions }\end{array}$ \\
\hline Paid domestic services & - Unpaid volunteer services \\
\hline $\begin{array}{l}\text { Other non-market production } \\
\text { Government services } \\
\text { Non-profit institutional services }\end{array}$ & \\
\hline
\end{tabular}

Source: M.E. Gómez Luna, "Directrices y referentes conceptuales para armonizar las encuestas sobre uso del tiempo de América Latina y el Caribe”, 2010 [online] http://www.eclac.cl/deype/noticias/noticias/2/41522/ S13_INEGI_uso_tiempo.pdf.

\section{The data collection strategy}

When time-use surveys are administered as a module within labour force surveys, questions about participation in paid work cover the same ground. Consequently, rates of participation in paid work are ascertained from the main section of labour force surveys. This is what happens in Ecuador, one of the two national cases analysed in this study.

When time-use surveys are administered separately from labour force surveys, they include specific questions about paid work, and then some differences may arise in the way data are gathered. This is the case with time-use and labour force surveys in Mexico.

There, the National Occupation and Employment Survey (ENOE) asks about activity status in the standard way for labour force surveys, i.e., with a battery of questions beginning: "Did you work for at least an hour in the past week?" If the answer is yes, respondents are considered to be employed and the questions designed to elicit a description of their occupation are put. If the answer is no, two back-up questions are asked: (1) "Did you spend at least an hour in the past week on an activity that provided you with income?" (2) "Did you spend at least an hour in the past week helping out a family member or anyone else on their land or in their business?" Positive answers to these questions also qualify respondents as employed. If the answers to both are negative, a final back-up question is asked: "Although you did not work in the past week, do you have any job or business or carry out any activity on your own account?" A negative response qualifies respondents as non-employed. If 
the answer is yes, the person may or may not be considered employed, depending on their reason for not working in the reference period.

The National Time-use Survey begins the inquiry into respondents' activity status with the question: "Did you work in the past week?" If the answer is yes, the next thing asked about is time worked, so that the remaining information is obtained in the same way as in the labour force survey. If the answer is no, the back-up questions are more elaborate than in the labour force survey, with the battery of questions including:

(1) "Did you help out any family member or anyone else on their land or in their business in the past week?"

(2) "Did you sell or make any product for sale, or carry out any building, plumbing or carpentry jobs or the like in the past week?"

(3) "Did you carry out any farming activities such as cultivating land, raising animals or the like in the past week?"

(4) "Did you provide any service for payment (cutting hair, giving lessons, washing or ironing other people's clothes) in the past week?"

If the answer to any of these questions is yes and the time declared is more than an hour a week, the person is classified as being in work. These questions are supplemented by a further one: "Were you in work in the past week but absent because of a strike, holidays, short-time working, etc.?", which is equivalent to the last back-up question in the labour force survey.

As can be seen, the time-use survey asks all respondents questions that are additional to those in the labour force survey. The labour force survey does include some of these questions but associates them with "secondary work", so that they are put to people already classified as active; in this case, the following activities are asked about: (1) selling or making products for sale (food, beauty products, clothes); (2) providing services (giving lessons, cutting hair, washing others' clothes); (3) cultivating their own land or plot and/or rearing animals; (4) helping out on a family member or other person's land or in their business.

\section{The grey area of goods production for the home}

Some of these last questions refer to production for the household itself (such as working on the respondent's own land or plot and rearing animals). This is part of what labour force surveys ask about for the "Production for own final use" component of SNA production. 
Time-use surveys obtain additional information, since they ask about goods production for household members, which is also part of this production component in the SNA. Examples of this can be found in the two national cases under review.

In the case of Mexico's time-use survey, respondents are asked whether, in the week prior to the interview, they:

1. tended or reared farmyard animals, or sowed and tended their vegetable garden or plot

2. gathered, transported or stored firewood

3. gathered fruit, mushrooms or flowers; fished or hunted

4. transported or stored water

5. produced or knitted clothing, blankets, curtains or the like.

Ecuador's time-use survey asks about production activities for self-consumption, including both primary and secondary activities. Thus, it asks respondents whether, in the last week, they:

1. tended or reared farmyard animals (hens, pigs, guinea pigs, rabbits, etc.) or took them to pasture (sheep, cows), etc.

2. collected water for their land or animals, gathered firewood, mushrooms, herbs, fruit or flowers, or spent time fishing or hunting

3. carried out any activity in their vegetable garden, plot, allotment or land such as: sowing, harvesting, weeding, preparing the land, etc.

4. made any item such as: marzipan, shell ornaments, items of ceramic or clay, rugs, lamps, curtains, figures of ivory palm, coconut palm, wood, etc.

5. prepared empanadas, preserves, sweetmeats, bread, cheese or other types of food.

These batteries of questions give a picture of the contribution of unpaid work to goods production for personal use, including that falling within the SNA production frontier, as already mentioned. Given the peculiarities of this kind of production, it can be hard to discriminate between production for own use and production for sale; while both are within the SNA production frontier, they are in different categories. 


\section{B. Women's production work in the System of National Accounts: what time-use surveys add}

The question arises as to whether the above categories represent substantial working contributions by women to SNA production, on top of the contribution in the form of paid work for the market usually identified by labour force surveys.

To attempt an answer, some specific data for Mexico, based on information yielded by the 2009 time-use survey, will be presented and analysed. ${ }^{6}$

In Mexico in 2009, 21.3\% of women and $15.6 \%$ of men stated that they did primary and secondary production work for self-consumption. Women spent an average of 11.8 hours a week on such work, accounting for $0.8 \%$ of the total weekly hours spent on all activities captured by the survey. The average for men was 8.6 hours a week, or $0.9 \%$ of total hours.

Who are the women and men who spend time on these production activities within the SNA boundary? Of the total time declared by the population as a whole to be spent on primary and secondary production activities for self-consumption, women account for $51 \%$ and men for $49 \%$.

As figure IV.1 shows, it is women in mid-life and older men who give the largest share of their time to activities of this type. Men spend more time on them than women in the younger and older age groups, which may indicate that men are most likely to carry out activities of this type before they enter the labour market and after they have retired from it.

According to the information available, the people whose unpaid work contributes most to primary and secondary production for selfconsumption within the SNA are those with the lowest level of education (see figure IV.2). Strikingly, as education levels rise, the gender gap in time spent on these activities shifts from one gender to the other: among those with up to incomplete secondary education, men contribute more time than women to these activities, while the opposite is the case among those with complete secondary education or better.

The information presented here is for category I.4., work for household self-consumption, subcategories I.4.1., primary activities, and I.4.2., non-primary activities, of the Classification of Time-use Activities for Latin America and the Caribbean (CAUTAL). 
Figure IV.1

MEXICO: SHARE OF TOTAL TIME SPENT ON PRIMARY AND SECONDARY ACTIVITIES FOR SELF-CONSUMPTION, BY AGE RANGE AND SEX, 2009

(Percentages)

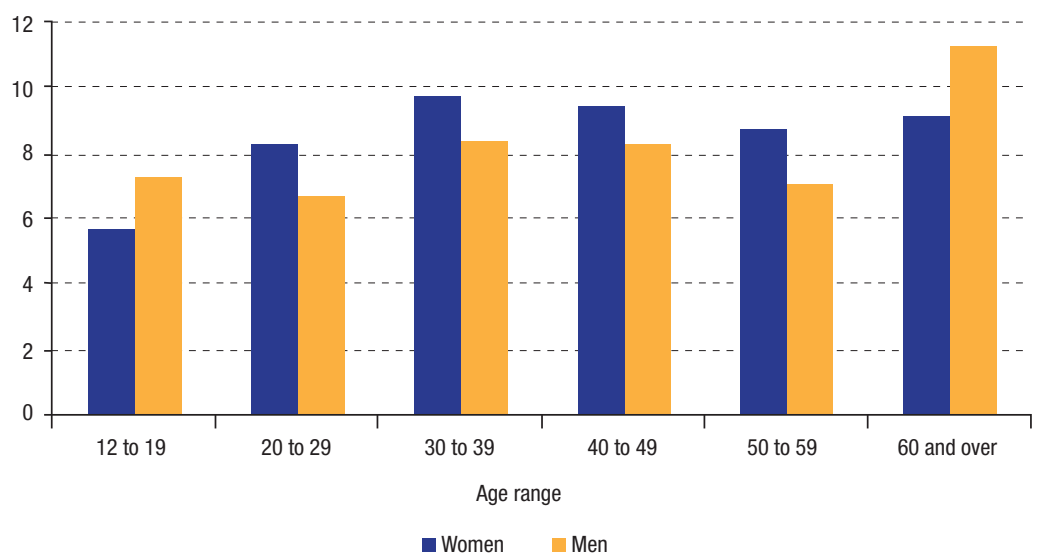

Source: Prepared by the author on the basis of data from the National Time-use Survey (ENUT), 2009.

Figure IV.2

MEXICO: SHARE OF TOTAL TIME SPENT ON PRIMARY AND SECONDARY ACTIVITIES FOR SELF-CONSUMPTION, BY EDUCATION LEVEL AND SEX, 2009 (Percentages)

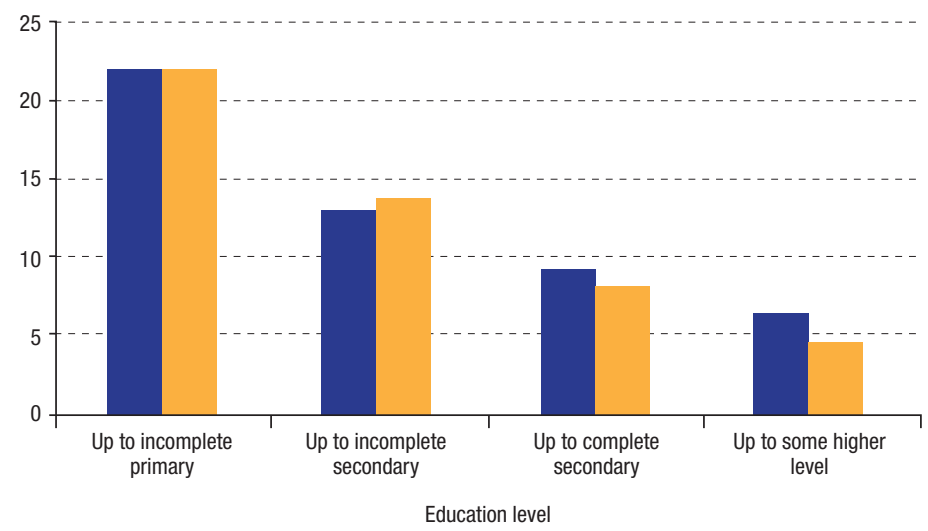

- Women Men

Source: Prepared by the author on the basis of data from the National Time-use Survey (ENUT), 2009. 
This relationship between education level and time spent on primary and secondary production activities for the household may also be influenced by activity type and household location. It is to be expected that more time would be spent on these activities in rural areas, where average education levels are lower.

Lastly, as figure IV.3 shows, it is usually the adults in households, i.e., household heads and spouses, who give most time to these tasks. Children spend less time on them, with sons giving more time than daughters.

Figure IV.3

MEXICO: SHARE OF TOTAL TIME SPENT ON PRIMARY AND SECONDARY ACTIVITIES FOR SELF-CONSUMPTION, BY KINSHIP AND SEX, 2009

(Percentages)

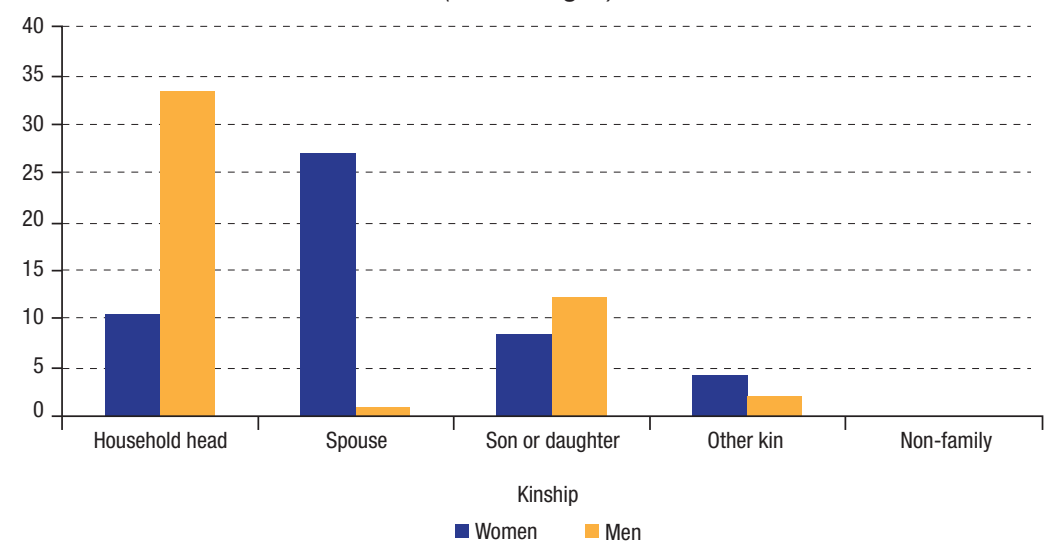

Source: Prepared by the author on the basis of data from the National Time-use Survey (ENUT), 2009.

In summary, taking the case of Mexico as an example, the proportion of people stating that they carry out unpaid primary and secondary production activities is substantial, and greater among women. If this activity (which labour force surveys pick up only partially or not at all) were taken into account in determining the economic participation rate, it might have the effect of increasing the female participation rate (if it is the case that women who spend time on these activities are not also in paid employment).

In any event, the time spent on these activities is only a small part of people's total working time. Among neither women nor men does time spent on this work amount to as much as $1 \%$ of total working time.

It is also observed that the contribution of this activity to the value of SNA production mainly comes from (i) men at non-active ages, i.e. 
older and younger men, (ii) women in mid-life and (iii) people with low levels of education.

To this contribution must clearly be added that of unpaid work falling within the general production boundary but outside the SNA. This type of work has been studied extensively in analyses of the information provided by time-use surveys on domestic and care services for members of respondents' own households, unpaid services for other households and the community, and unpaid volunteer services.

To sum up, time-use surveys serve to capture information on production within the SNA obtained from information on unpaid work done within households. This type of production, at least in the example given, does not seem to be significant in terms of the time spent on it, and thence of its economic value. But this information can undoubtedly be used to better characterize the productive work done by certain population groups: women, younger and older people, and the less educated. There is thus scope to explore ways of applying some of this research, for example by means of greater disaggregation of activities in labour force surveys, particularly when it comes to questions that ask about this kind of work. In this way, labour force surveys could make use of the experience already gained in this field of investigation with time-use surveys - one of the first gains from an integrated approach to the two instruments.

\section{What do time-use surveys reveal about the work of inactive women?}

The other aspect worth investigating in this kind of dialogue between time-use surveys and labour force surveys concerns the activities carried out by inactive women. Inactivity is a status defined by the labour force survey, covering people who do not participate in the labour market because they neither have nor are seeking a job. The point of contact lies here in the scope for using the information provided by time-use surveys to ascertain what activities inactive women engage in.

When work is looked at more globally and activities undertaken outside the market and the SNA production frontier are also considered to be productive work, the substantive contribution made to the economic and social system by women treated as inactive by labour force surveys can be appreciated.

At the same time, studying this particular population group using information from time-use surveys can provide greater clarity about the reasons for their inactivity in the labour market. 


\section{Inactivity in labour force surveys}

In labour force surveys, people are determined to be inactive by applying a battery of questions designed to establish just the opposite, i.e., that they are active, as this term is used for the purposes of employment statistics. Once people have been classified as inactive, they are not asked much more about what they do. Ultimately, the assumption is that if they are not active then they are not contributing to production.

Inactivity classifications are thus narrowly defined and themselves lack characterization: once this status has been determined, there are no further inquiries. The categories of inactive people usually established are: (i) student; (ii) housewife; (iii) retired; (iv) rentier and (v) disabled for the purposes of productive work. ${ }^{7}$

But what do inactive people, and women in particular, actually do with their time? This is the subject considered in this section, on the basis of information provided by the time-use surveys of Mexico (2009) and Ecuador (2007). In both cases, people were considered inactive when they stated that they had not carried out any activity for the market (including seeking work).

\section{Are inactive women different from active ones?}

Before observing what inactive women do with their time, it is worth ascertaining their basic sociodemographic characteristics and their profile as compared to active women. ${ }^{8}$ The two national cases analysed provide information on this point.

Reasonably enough, the age structure of active women of working age differs from that of inactive women, with a greater concentration of the youngest and oldest among the latter. This pattern is similar in both national cases, with the young somewhat more heavily represented among inactive women in Ecuador (see figure IV.4).

Women considered statistically active in the labour market are more highly educated on average than those considered inactive (see figure IV.5). This is true even of countries with different average education levels, such as those analysed. The proportion of women (both active and inactive) with secondary education or above is larger in Mexico than in Ecuador.

7 In the cases analysed, the specific questions for categorizing people as inactive are as follows. In Mexico: “Are you: (1) temporarily absent from your activity or trade? (2) a pensioner or retired person? (3) a student? (4) a full-time housekeeper? (5) prevented from working for the rest of your life by a physical or mental limitation? (6) other?" In Ecuador: "Are you (1) a rentier? (2) a pensioner or retiree? (3) a student? (4) a housewife? (5) disabled? (6) other?"

$8 \quad$ Working-age women (aged 15 to 65 ) were considered for this characterization. 
Figure IV.4

MEXICO AND ECUADOR: DISTRIBUTION OF ACTIVE AND INACTIVE WOMEN BY AGE RANGE

(Percentages)

A. Mexico, 2009

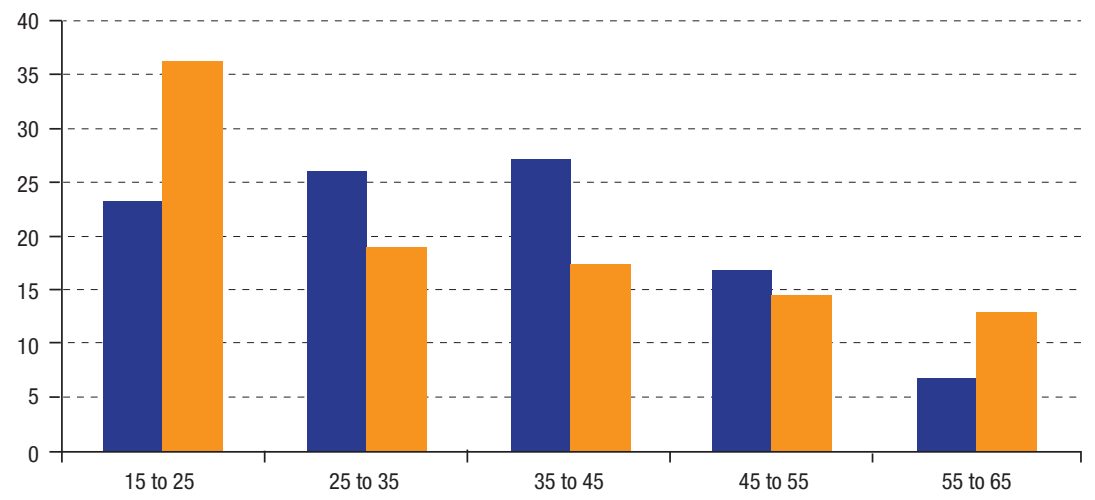

B. Ecuador, 2007

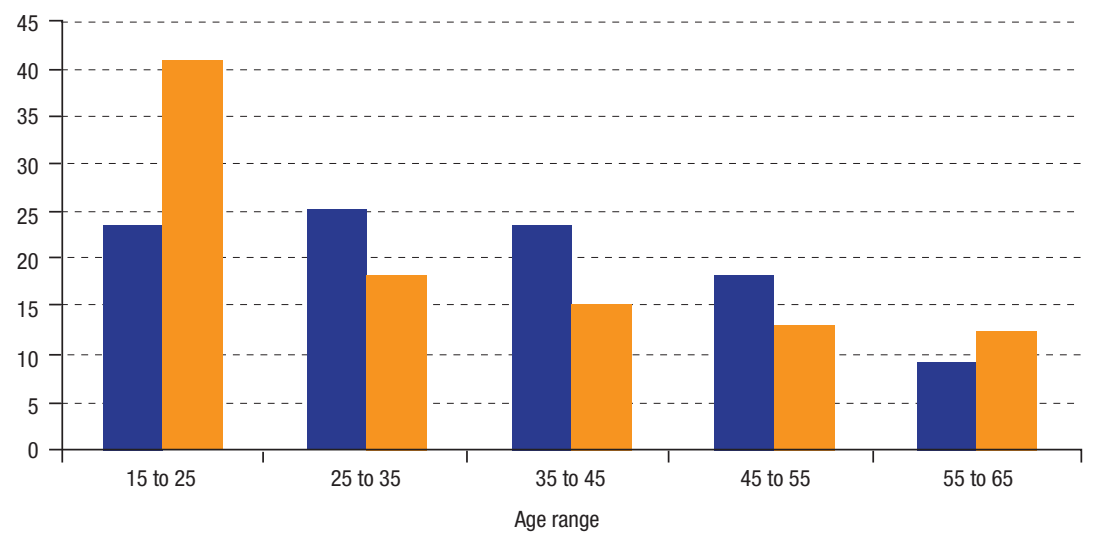

Active Inactive

Source: Prepared by the author on the basis of data from the National Time-use Survey (ENUT), 2009, and the Employment, Underemployment and Unemployment Survey (ENEMDU), 2007.

Women considered statistically active in the labour market are more highly educated on average than those considered inactive (see figure IV.5). This is true even of countries with different average education levels, such as those analysed. The proportion of women (both active and inactive) with secondary education or above is larger in Mexico than in Ecuador. 
Figure IV.5

MEXICO AND ECUADOR: DISTRIBUTION OF ACTIVE AND INACTIVE WOMEN BY EDUCATION LEVEL

(Percentages)

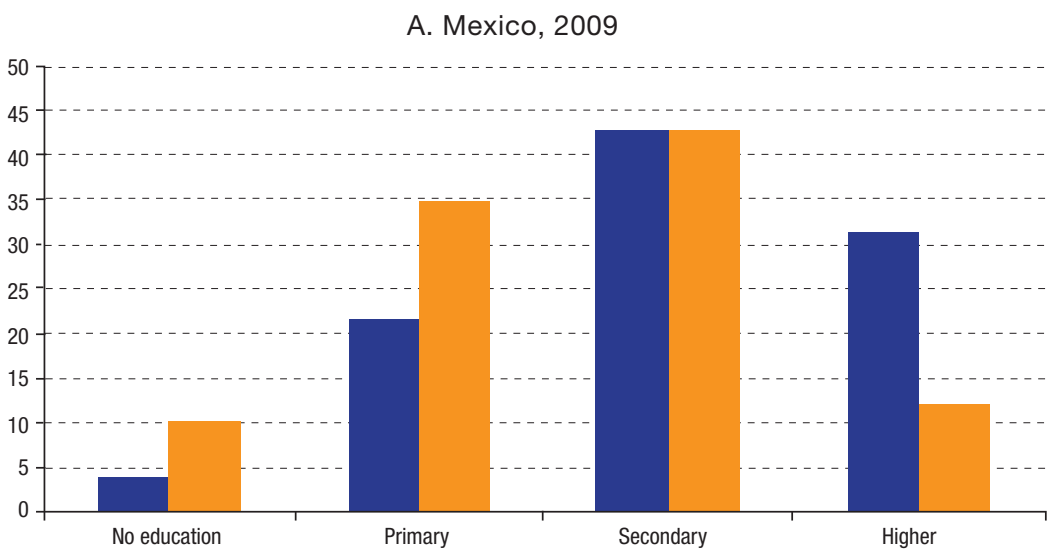

B. Ecuador, 2007

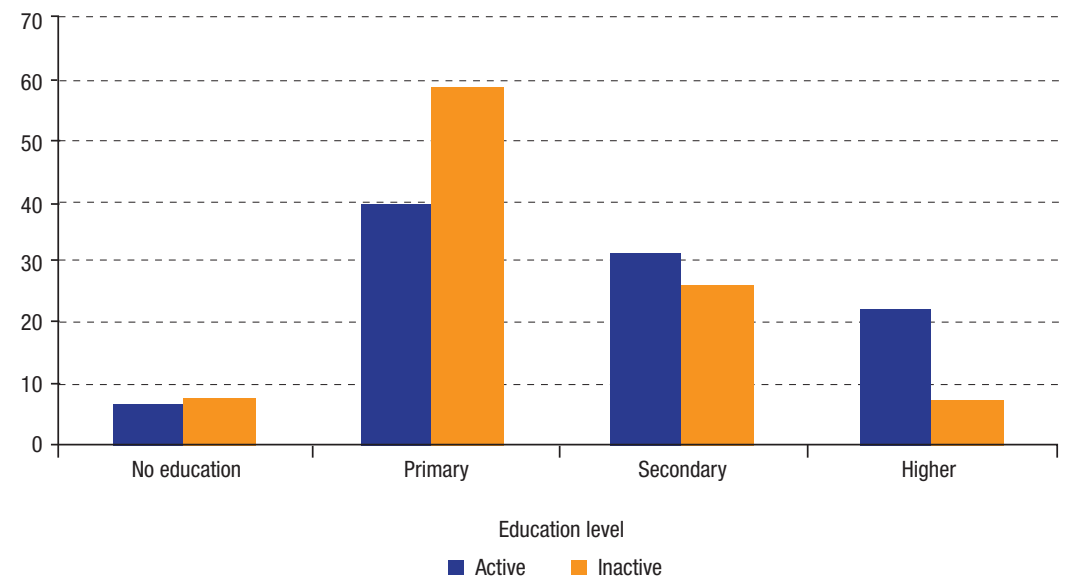

Source: Prepared by the author on the basis of data from the National Time-use Survey (ENUT), 2009, and the Employment, Underemployment and Unemployment Survey (ENEMDU), 2007.

It can also be seen that the gaps are wider at the extremes: the proportion of inactive women is substantially greater in sectors with less education (primary level), while the proportion of active women is much greater among those with higher education.

As might be expected, active women have fewer young children than inactive women, although this difference is not very marked, as figure IV.6 shows. 
Figure IV.6

MEXICO AND ECUADOR: DISTRIBUTION OF ACTIVE AND INACTIVE WOMEN BY NUMBER OF CHILDREN UNDER 12

(Percentages)

A. Mexico, 2009

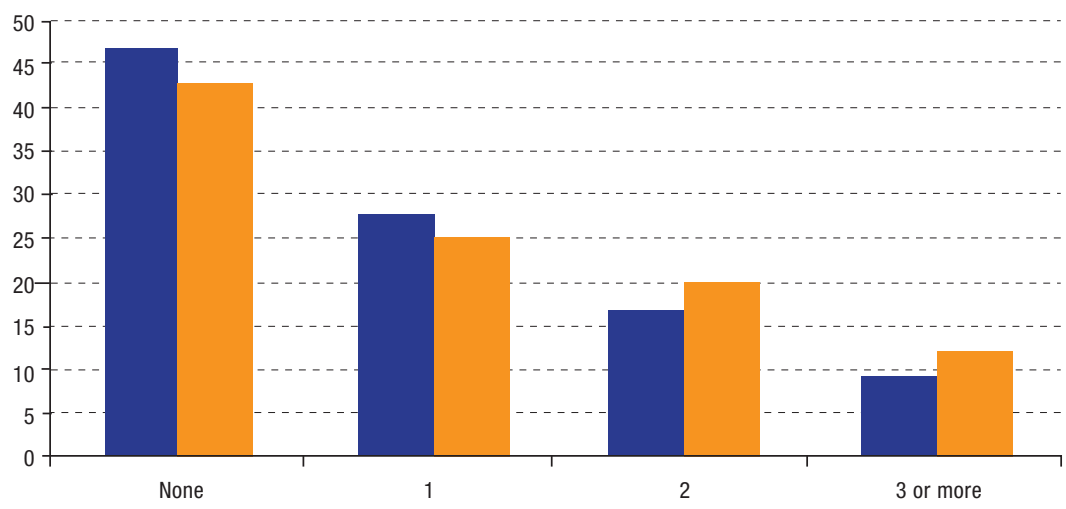

B. Ecuador, 2007

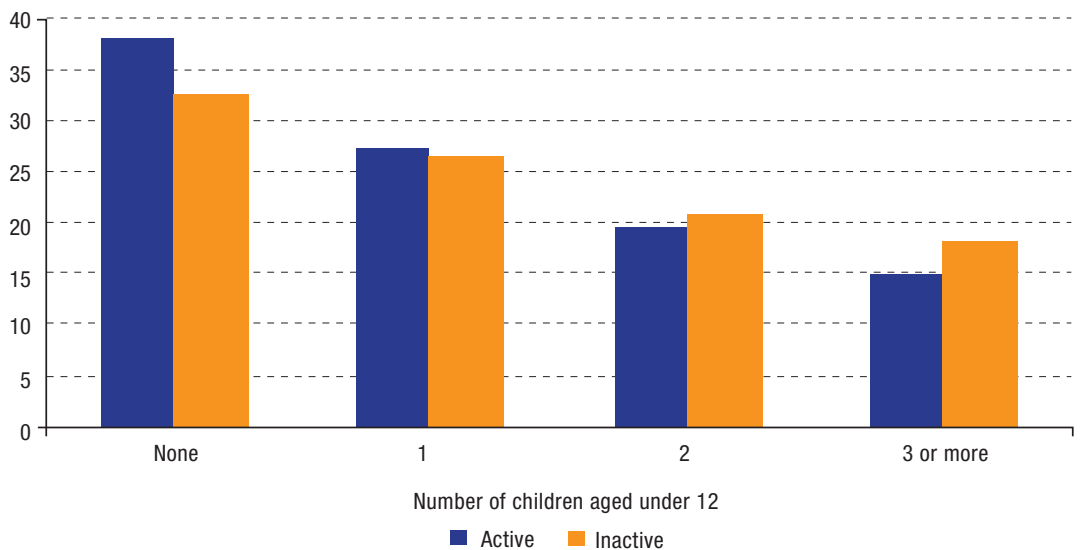

Source: Prepared by the author on the basis of data from the National Time-use Survey (ENUT), 2009, and the Employment, Underemployment and Unemployment Survey (ENEMDU), 2007.

There is a larger proportion of active women among those who do not have children under 12 and a larger proportion of inactive women among those who have three or more children of that age. The differences are more marked in Ecuador, where the average household has more young children. In this case, the gaps at the extremes (those without children under 12 and those with three or more) are wider.

In short, there are sociodemographic differences between women who participate in the labour market and those who do not, as can be 
seen in the two national cases under review. Inactive women are younger or older than active ones, have a lower level of education and have more young dependent children (although not as many more as might be expected).

What do these women do with their time, and how can it be interpreted in terms of their contribution to production? This is what will be analysed in the next section.

\section{The work of inactive women}

To analyse the work done by inactive women, it is worth examining: (i) what types of activities they say they spend time on, (ii) what proportion of their time they spend on each type of activity and (iii) whether this time distribution differs by the socioeconomic status of the households they live in.

The first point is analysed using the participation rate indicator, which is the percentage of all inactive women answering yes when asked whether they carry out a particular activity. To analyse the second point, the indicator used is the time they spend on each of the activities as a percentage of their total time. Lastly, the time spent on the different activities is correlated with sociodemographic characteristics by crossing the latter indicator with an income distribution indicator. ${ }^{9}$

As table IV.2 shows, women claim to spend time on all the major activity groups specified by the activities classifier in time-use surveys.

"Home cleaning" is the activity which the largest share of inactive women in both countries say they participate in $(50.3 \%$ in Mexico and $41.6 \%$ in Ecuador). Also substantial in both countries is participation in "food preparation and serving" (almost 34\% in Mexico and 38.5\% in Ecuador), "cleaning, care and making of clothes and footwear" (28.7\% in Mexico and almost $40 \%$ in Ecuador) and "shopping for the home and household members". In other words, the broad category of housekeeping is the one that the largest number of inactive women in those countries say they participate in. For Mexican women, "household administration" is also an important activity in terms of participation (27\%). This activity is likewise important, but less so, for Ecuadorian women ( $13 \%$ of all inactive women say they participate in it).

9 The analysis only covers working-age women (aged 15 to 65). 
Table IV.2

MEXICO AND ECUADOR: INACTIVE WOMEN'S RATE OF PARTICIPATION

IN UNPAID WORK, BY ACTIVITY TYPE

(Percentages)

Activity

Mexico Ecuador

(2009) (2007)

Work for household self-consumption (within the production boundary of the System of National Accounts)

$5.6 \quad 9.7$

Food preparation and serving

$33.7 \quad 38.5$

Home cleaning

$50.3 \quad 41.6$

Cleaning, care and making of clothes and footwear

$28.7 \quad 39.6$

Maintenance, installations and minor repairs to the home and to household items and vehicles

$3.5 \quad 10.3$

Household administration

$27.0 \quad 13.0$

Shopping for the home and household members

$15.9 \quad 18.0$

Care and support for children under 15 in the household

$13.9 \quad 22.5$

Care and support for other household members

$19.5 \quad 4.4$

Care and support for some household member with a disability

$3.6 \quad 1.5$

Unpaid activities for other households and the community and unpaid volunteer work

$5.1 \quad 2.7$

Source: Prepared by the author on the basis of data from the National Time-use Survey (ENUT), 2009, and the Employment, Underemployment and Unemployment Survey (ENEMDU), 2007.

Care of dependents is also an activity that a substantial proportion of inactive women engage in, albeit with differences between the countries, with $14 \%$ of inactive Mexican women and $22.5 \%$ of inactive Ecuadorian women being involved in caring for children under 15. This difference may be due, first, to larger family sizes in Ecuador and, second, to greater use of paid caregivers in Mexican households.

More striking, but in reverse, are the figures for participation in "care and support for other household members", which involves almost $20 \%$ of inactive Mexican women but a mere $4.4 \%$ of inactive Ecuadorian women. A relatively small proportion of inactive women in both countries care for people with some disability $(3.6 \%$ in Mexico and 1.5\% in Ecuador).

What proportion of their available time do inactive women spend on the different activities? ${ }^{10} \mathrm{~A}$ first important observation is that in both countries these women spend more than half their time on productive activities (within and outside the SNA). As figure IV.7 shows, inactive Mexican women spend almost $62 \%$ of their time from Monday to Friday on productive activities, with the share rising to $63.5 \%$ at the weekends.

10 Average hours spent on each activity as a percentage of the total each week. 
Figure IV.7

MEXICO AND ECUADOR: DISTRIBUTION OF INACTIVE WOMEN'S WORKING TIME BETWEEN ACTIVITY CATEGORIES, BY DAYS OF THE WEEK

(Percentages)

A. Mexico, 2009 - Monday to Friday

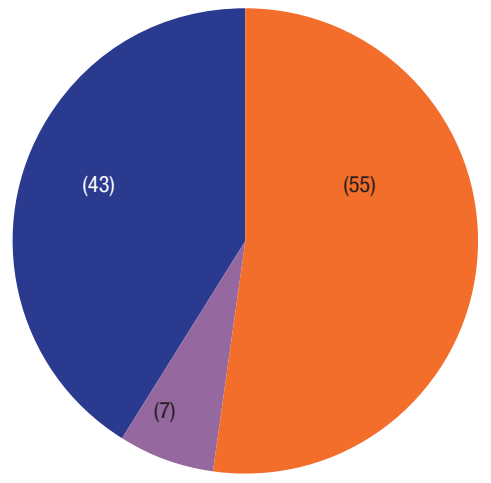

A. Ecuador, 2007 - Monday to Friday

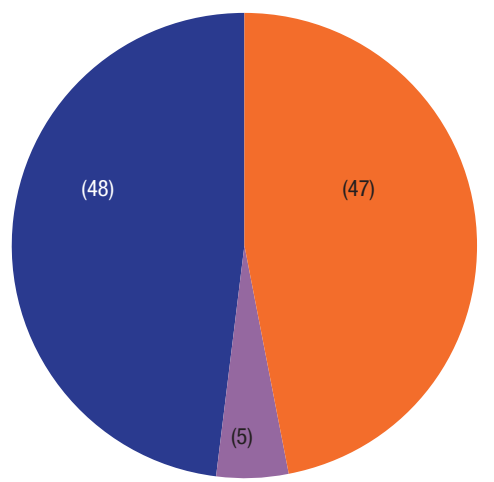

B. Mexico, 2009 - Saturday and Sunday

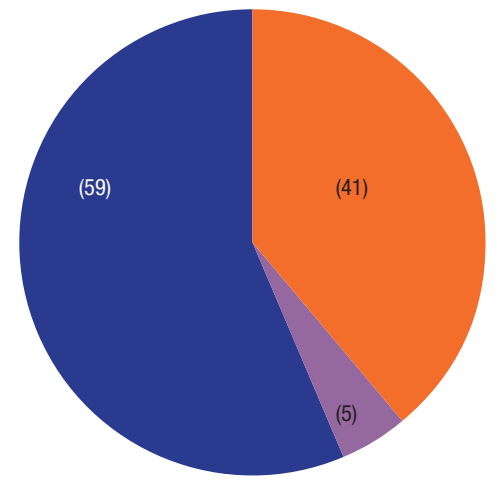

B. Ecuador, 2007 - Saturday and Sunday

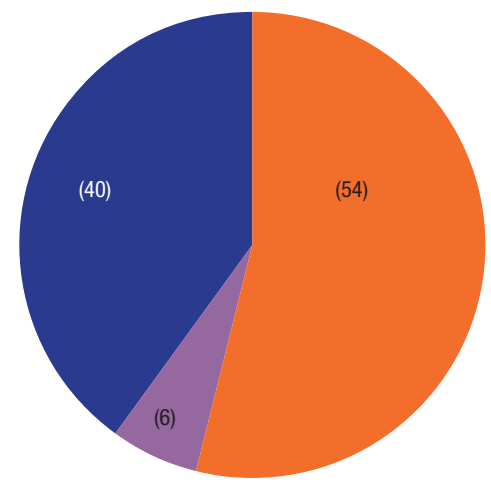

Production activities within the System of National Accounts

- Production activities outside the System of National Accounts

Personal activities

Source: Prepared by the author on the basis of data from the National Time-use Survey (ENUT), 2009, and the Employment, Underemployment and Unemployment Survey (ENEMDU), 2007.

In Ecuador, inactive women spend $52 \%$ of their time on productive activities (inside and outside the SNA) from Monday to Friday and 60\% on Saturdays and Sundays.

In both countries, inactive women spend between 5\% and $6 \%$ of their time on activities oriented towards self-consumption that are treated as productive in the SNA. 
It is important to note the increase (smaller in Mexico, more marked in Ecuador) in the time spent by inactive women on productive activities at weekends. This reveals the pressure placed upon these women by the responsibility of caring for other household members, which becomes most evident when there are children and spouses present. This takes a toll on the time these women have for themselves, and they tend to carry out their educational, socialization and self-care activities more on weekdays.

Disaggregating this information can reveal these aspects more clearly. Table IV.3 presents the proportion of women's total time spent on each group of activities, both on weekdays and at weekends.

Table IV.3

MEXICO AND ECUADOR: SHARE OF INACTIVE WOMEN'S TOTAL TIME SPENT ON DIFFERENT ACTIVITIES, BY DAYS OF THE WEEK

(Percentages)

\begin{tabular}{|c|c|c|c|c|}
\hline \multirow{2}{*}{$\begin{array}{l}\text { Share of inactive women's time spent } \\
\text { on different activities }\end{array}$} & \multicolumn{2}{|c|}{ Mexico (2009) } & \multicolumn{2}{|c|}{ Ecuador (2007) } \\
\hline & $\begin{array}{l}\text { Monday to } \\
\text { Friday }\end{array}$ & $\begin{array}{l}\text { Saturdays } \\
\text { and Sundays }\end{array}$ & $\begin{array}{l}\text { Monday to } \\
\text { Friday }\end{array}$ & $\begin{array}{l}\text { Saturdays } \\
\text { and Sundays }\end{array}$ \\
\hline $\begin{array}{l}\text { Work for household self-consumption (within the } \\
\text { production boundary of the System of National Accounts) }\end{array}$ & 6.9 & 5.0 & 5.0 & 5.8 \\
\hline Food preparation and serving & 5.8 & 5.0 & 8.7 & 9.6 \\
\hline Home cleaning & 2.2 & 2.4 & 2.0 & 2.7 \\
\hline Cleaning, care and making of clothes and footwear & 1.8 & 1.6 & 3.7 & 3.7 \\
\hline $\begin{array}{l}\text { Maintenance, installations and minor repairs to the home } \\
\text { and to household items and vehicles }\end{array}$ & 5.2 & 5.8 & 3.3 & 4.9 \\
\hline Household administration & 0.6 & 0.2 & 3.2 & 2.9 \\
\hline Shopping for the home and household members & 1.7 & 2.4 & 1.5 & 4.4 \\
\hline Care and support for children under 15 in the household & 12.1 & 12.8 & 10.5 & 10.6 \\
\hline Care and support for other household members & 7.5 & 9.6 & 4.5 & 2.7 \\
\hline $\begin{array}{l}\text { Care and support for some household member with } \\
\text { a disability }\end{array}$ & 8.9 & 9.7 & 5.9 & 7.8 \\
\hline $\begin{array}{l}\text { Unpaid activities for other households and the community } \\
\text { and unpaid volunteer work }\end{array}$ & 4.6 & 4.6 & 2.5 & 3.6 \\
\hline Study and learning & 13.2 & 2.4 & 14.6 & 3.1 \\
\hline Socializing, culture, hobbies and sport & 11.5 & 17.7 & 2.9 & 9.3 \\
\hline Personal care & 18.1 & 20.9 & 30.6 & 27.6 \\
\hline
\end{tabular}

Source: prepared by the author on the basis of data from the National Time-use Survey (ENUT), 2009, and the Employment, Underemployment and Unemployment Survey (ENEMDU), 2007.

As can be seen, of all activities deemed productive (inside and outside the SNA), it is care work that takes up the greatest amount of women's time in both countries, particularly caring for children and adolescents aged up to 15 . The time spent on this is over $10 \%$ of the total in Ecuador and 12\% in Mexico. This care time hardly varies 
between weekdays and weekends, which may indicate that the weekend availability of other household members for care activities (spouses who do not go to work on Saturdays and Sundays, for example) does not reduce the time spent by these women on this work.

Care for other household members and for people with some type of disability takes up a considerable amount of women's total time in Mexico (between 7.5\% and almost 10\%, depending on the time of the week) and somewhat less in Ecuador.

All in all, care activities account for a very large proportion of inactive women's time: ${ }^{11}$ a third in Ecuador $(29.6 \%$ from Monday to Friday and $30.7 \%$ on Saturdays and Sundays) and about 35\% in Mexico (34.3\% from Monday to Friday and $37.1 \%$ on Saturdays and Sundays).

This is considerably higher than the proportion of their time that these women spend on self-care, which in Mexico is $18 \%$ from Monday to Friday and $20.9 \%$ on Saturdays and Sundays, while in Ecuador it is 30.6\% from Monday to Friday and $27.6 \%$ on Saturdays and Sundays. ${ }^{12}$

Other activities that take up a large share of the time of women classified as inactive in the employment statistics are the group of activities necessary to maintain the home..$^{13}$ These take up about $12 \%$ of these women's total time in Mexico (11.6\% from Monday to Friday and $12.4 \%$ on Saturdays and Sundays) and rather more in Ecuador (13.7\% from Monday to Friday and $18.7 \%$ on Saturdays and Sundays).

The remainder of inactive women's time is spent on unpaid activities for other households and for the community (about 5\% of their time in Mexico and about 3\% in Ecuador). When this information is broken down, it transpires that these women spend the bulk of this time on care tasks and housekeeping in other households (which clearly represents an extension of the care and housekeeping work they do in their own homes).

Lastly, a substantial portion of their time from Monday to Friday (13.1\% in Mexico and $14.6 \%$ in Ecuador) goes on training and education.

\footnotetext{
11 The following are deemed to be care activities: food preparation and serving; care and support for children under 15 in the household; care and support for other household members; care and support for some household member with a disability.

12 Self-care activities include sleeping, eating, personal care, health care (such as attending doctor's appointments) and spiritual activities such as praying and attending religious services.

13 The following are considered to be home maintenance activities: home cleaning; cleaning, care and making of clothes and footwear; maintenance, installations and minor repairs to the home and to household items and vehicles; household administration; shopping for the home and household members.
} 
It is important to note that much of this might be due to the educational activities of women aged between 15 and 18, who are still of school age.

Socializing, culture, hobbies and sports are important for inactive women in Mexico (who spend $11.5 \%$ of their time on them during the week and over $17 \%$ on Saturdays and Sundays), but much less so for Ecuadorian women (who dedicate less than 3\% of their time to these from Monday to Friday and just under 10\% on Saturdays and Sundays).

In summary, women classified as inactive by the employment statistics are in fact highly active, participating in activities that may be considered productive on a broad view of work and production. In fact, Mexican and Ecuadorian women in this position spend about $60 \%$ of their time on productive activities (inside and outside the SNA).

The bulk of this time goes on caring for children and adolescents, but also on caring for other household members (a time commitment that increases at weekends). When the time spent on these activities is added to that spent maintaining the home (so-called housework, but also physical home maintenance and repair), the relatively small amount of women's time spent on self-care activities is explained. Indeed, if time spent asleep is subtracted from self-care time, it can be seen that the time inactive women spend on themselves is very small indeed.

The time spent on training and education in this population group is substantial, partly because the age group considered includes women who are still young enough to be in formal education. When this time is reallocated, however (at weekends), more of it goes on care activities than on specific self-care activities.

A final issue for investigation is whether there are differences in the time spent on activities of this type by women of different socioeconomic levels. This is what is analysed in the next section.

\section{The relationship between inactive women's time use and their socioeconomic position}

This analysis is carried out by observing the distribution structures of the time inactive women spend on the different activities by the socioeconomic position of their households, using the income quintile they belong to as the indicator. This exercise is carried out for Ecuador, as the information available for the country allows it.

As can be seen in table IV.4, the proportion of women deemed inactive who participate in the different activities varies by the income quintile their households belong to. A lower proportion of women from 
households in the fifth quintile participate in the different activities identified in the time-use survey, with the exception of "socializing, culture, hobbies and sport" and, with some nuances, "shopping for the home and household members".

Table IV.4

ECUADOR: INACTIVE WOMEN'S RATE OF PARTICIPATION IN DIFFERENT ACTIVITIES, BY INCOME QUINTILE, 2007

(Percentages)

\begin{tabular}{|c|c|c|c|c|c|}
\hline Activity & Quintile I & Quintile II & Quintile III & Quintile IV & Quintile V \\
\hline $\begin{array}{l}\text { Work for household self-consumption (within the } \\
\text { production boundary of the System of National Accounts) }\end{array}$ & 32.7 & 25.1 & 19.5 & 14.2 & 8.5 \\
\hline Food preparation and serving & 34.6 & 26.8 & 18.5 & 13.0 & 7.1 \\
\hline Home cleaning & 24.6 & 26.4 & 18.8 & 17.9 & 12.3 \\
\hline Cleaning, care and making of clothes and footwear & 26.3 & 24.3 & 18.6 & 17.6 & 13.2 \\
\hline $\begin{array}{l}\text { Maintenance, installations and minor repairs to the } \\
\text { home and to household items and vehicles }\end{array}$ & 18.6 & 23.7 & 21.7 & 20.7 & 15.3 \\
\hline Household administration & 24.9 & 25.9 & 20.8 & 16.7 & 11.7 \\
\hline Shopping for the home and household members & 19.5 & 24.6 & 17.1 & 24.8 & 19.0 \\
\hline Care of pets and plants & 33.6 & 27.6 & 19.7 & 13.1 & 6.0 \\
\hline $\begin{array}{l}\text { Care and support for children under } 15 \text { in the } \\
\text { household }\end{array}$ & 33.8 & 29.2 & 19.2 & 11.9 & 5.9 \\
\hline Care and support for other household members & 28.1 & 34.2 & 19.0 & 11.8 & 7.1 \\
\hline $\begin{array}{l}\text { Care and support for some household member with } \\
\text { a disability }\end{array}$ & 37.8 & 26.5 & 22.4 & 10.0 & 3.4 \\
\hline $\begin{array}{l}\text { Unpaid activities for other households and the } \\
\text { community and unpaid volunteer work }\end{array}$ & 30.2 & 25.8 & 20.0 & 14.3 & 9.8 \\
\hline Study and learning & 20.8 & 21.7 & 20.1 & 21.7 & 15.6 \\
\hline Socializing, culture, hobbies and sport & 18.6 & 21.3 & 19.3 & 21.7 & 19.1 \\
\hline
\end{tabular}

Source: Prepared by the author on the basis of data from the Employment, Underemployment and Unemployment Survey (ENEMDU), 2007.

The differences are striking, with the figures showing what is clearly a declining scale up the income quintiles from the first to the fifth in "work for household self-consumption", "food preparation and serving" and all care-related categories. Particularly evident is how much higher the proportions of women participating in these activities are in households in the first and second quintiles and how much lower in fifth quintile households. For home maintenance activities (usually considered housework), the differences are smaller but still substantial.

This information confirms the assumptions usually made about the relationship between unpaid work and women's labour force participation, and the differences associated with the economic position of the households they live in. In summary, this empirical evidence 
highlights the extent to which issues of gender and class overlap, something that has been frequently discussed in feminist literature.

Thus, the different rates of labour market participation by women at different socioeconomic levels, as recorded in the employment statistics, have their counterpart in these women's differing degrees of participation in unpaid work. Women belonging to higher-income households participate more in the labour market because they are able to delegate their role in housekeeping and care work in one way or another. Although all the women considered here are inactive, it may be inferred that women in the bottom quintiles are in this position because they have no choice, while women in the upper quintiles have more say in the matter (at least as far as their material conditions are concerned). ${ }^{14}$

In particular, the situation with specifically care-related activities is remarkable. Figure IV.8 represents some of the information contained in table IV.4, relating to the categories of activity where participation differences between quintiles are most striking.

Figure IV.8

ECUADOR: INACTIVE WOMEN'S RATES OF PARTICIPATION IN SELECTED ACTIVITIES, BY INCOME QUINTILE, 2007

(Percentages)

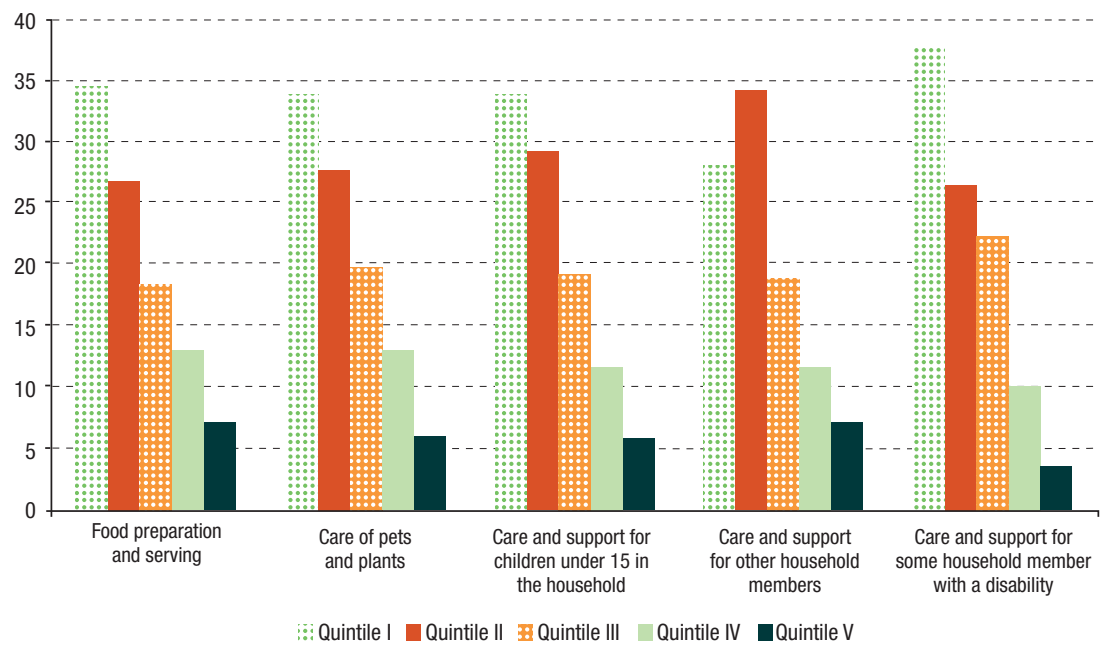

Source: Prepared by the author on the basis of data from the Employment, Underemployment and Unemployment Survey (ENEMDU), 2007.

14 There may be (and are) symbolic and cultural factors affecting women's labour force participation that weigh more heavily than strictly material factors and may likewise be assumed to operate differently depending on social class. 
What is clear in all these cases is that while participation by women from the first income quintile exceeds $25 \%$ and may even be as high as 35\%, that of women living in fifth quintile households is below $8 \%$ and in some cases, such as care for people with disabilities, below $5 \%$.

It is also striking how linear the trend is. With the exception of "care and support for other household members" (where the second quintile has a larger participation percentage than the first), percentage participation invariably declines up the quintiles. This supports the idea that women free themselves from these care activities as and when they have enough income to do so, i.e., as and when their financial position enables them to buy in care services.

As regards the time that women participating in these activities spend on each, the question arises as to whether this too differs by income quintile. This can be observed in figure IV.9 and table IV.5, which present the average time spent on each activity by women participating in them as a percentage of the total time available to them. The evidence shows that once women participate in these activities, the differences in their time commitment are not substantial.

Figure IV.9

ECUADOR: DISTRIBUTION OF INACTIVE WOMEN'S TIME USE FROM MONDAY

TO FRIDAY, BY ACTIVITY GROUP AND INCOME QUINTILE, 2007

(Percentages)

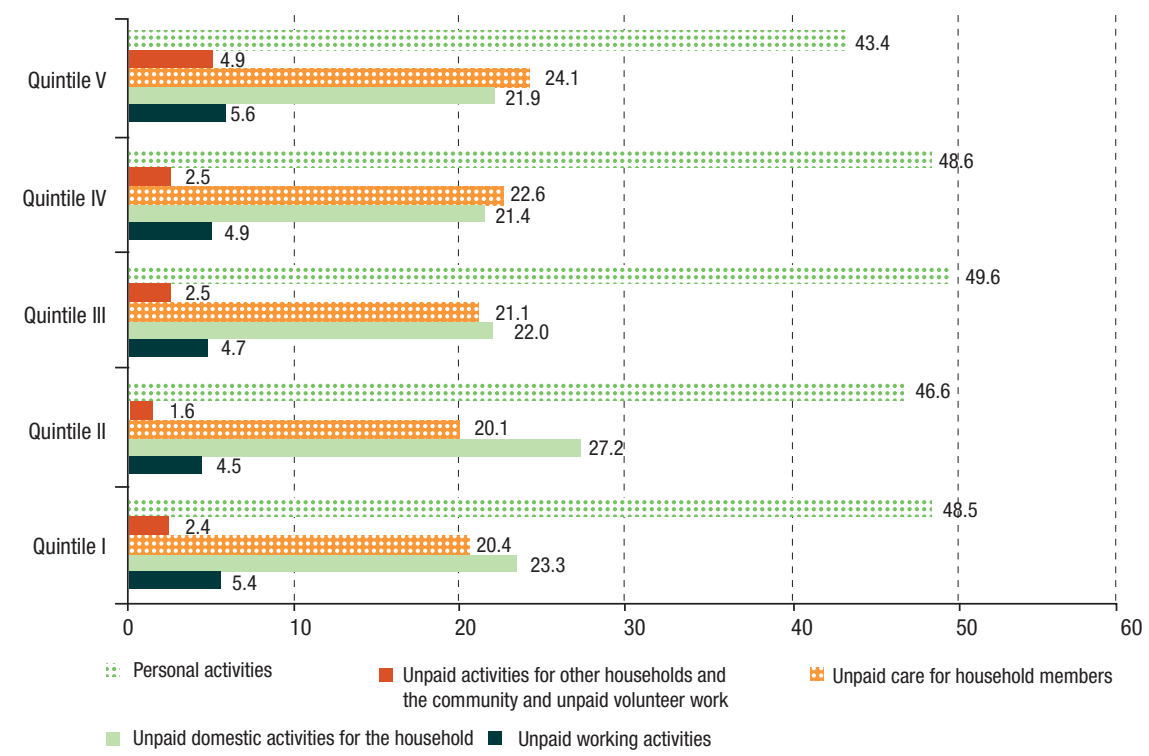

Source: Prepared by the author on the basis of data from the Employment, Underemployment and Unemployment Survey (ENEMDU), 2007. 
Table IV.5 presents a breakdown of the information by activity. It is clear, as noted earlier, that the differences by income quintile in the percentages of time spent on each of the activities are even smaller.

Table IV.5

ECUADOR: DISTRIBUTION OF INACTIVE WOMEN'S TIME USE FROM MONDAY TO FRIDAY, BY ACTIVITY AND INCOME QUINTILE, 2007

(Percentages)

\begin{tabular}{|c|c|c|c|c|c|}
\hline & Quintile I & Quintile II & Quintile III & Quintile IV & Quintile V \\
\hline $\begin{array}{l}\text { Work for household self-consumption (within the } \\
\text { production boundary of the System of National Accounts) }\end{array}$ & 5.4 & 4.5 & 4.7 & 4.9 & 5.6 \\
\hline Food preparation and serving & 8.8 & 8.5 & 9.0 & 8.3 & 8.2 \\
\hline Home cleaning & 2.0 & 2.4 & 1.7 & 2.0 & 1.5 \\
\hline Cleaning, care and making of clothes and footwear & 4.5 & 3.6 & 3.5 & 3.1 & 3.3 \\
\hline $\begin{array}{l}\text { Maintenance, installations and minor repairs to the } \\
\text { home and to household items and vehicles }\end{array}$ & 2.2 & 5.4 & 2.5 & 2.4 & 3.9 \\
\hline Household administration & 3.8 & 4.6 & 2.9 & 3.0 & 2.6 \\
\hline Shopping for the home and household members & 0.9 & 1.6 & 1.1 & 1.5 & 1.3 \\
\hline Care of pets and plants & 0.9 & 1.1 & 1.2 & 1.2 & 1.1 \\
\hline $\begin{array}{l}\text { Care and support for children under } 15 \text { in the } \\
\text { household }\end{array}$ & 10.1 & 10.1 & 11.5 & 10.5 & 10.8 \\
\hline Care and support for other household members & 4.0 & 5.1 & 3.6 & 5.1 & 4.8 \\
\hline $\begin{array}{l}\text { Care and support for some household member with } \\
\text { a disability }\end{array}$ & 6.3 & 4.9 & 6.1 & 7.0 & 8.6 \\
\hline $\begin{array}{l}\text { Unpaid activities for other households and the } \\
\text { community and unpaid volunteer work }\end{array}$ & 2.4 & 1.6 & 2.5 & 2.5 & 4.9 \\
\hline Study and learning & 13.4 & 13.8 & 15.7 & 15.5 & 14.6 \\
\hline Socializing, culture, hobbies and sport & 3.0 & 2.5 & 2.9 & 2.9 & 3.2 \\
\hline Personal care & 32.0 & 30.3 & 31.0 & 30.1 & 25.6 \\
\hline
\end{tabular}

Source: Prepared by the author on the basis of data from the Employment, Underemployment and Unemployment Survey (ENEMDU), 2007.

In summary, rates of participation in unpaid activities clearly differ depending on the income levels of the households inactive women belong to. Nonetheless, where women do participate, the structure of time use in these activities does not differ greatly, which may indicate that they are inelastic..$^{15}$

15 This issue needs to be more thoroughly explored, however, something that survey sample sizes do not always allow. 


\section{Conclusions}

The purpose of the present study was to carry out a preliminary and exploratory investigation of women's work by taking an integrated approach to labour force surveys and time-use surveys. It is important to note that the existence of two different types of surveys for capturing people's work is the consequence of a prevailing historical outlook which sets out from a restricted conception of work, limiting it to that done in the market.

The development of time-use surveys was a provocative innovation arising from a specific women's perspective and from theoretical developments in feminist thinking that criticized the partiality of the traditional outlook. What is proposed from this perspective, in effect, is a broader conception of work that extends the production considered beyond the strict definitions in the System of National Accounts in order to bring to light the value (social, but also economic) of the unpaid, unmarketed work people do inside their homes.

Considering, for example, the goods and services produced by households for their own use extends the production considered within the SNA. As was noted with regard to the national cases studied, this type of activity is inadequately explored by labour force surveys, and although it does not account for a large share of total work done, it can represent a substantial contribution by certain population groups in particular, including some groups of women.

It is to be hoped that a more thorough look at activities of this type will make it possible to capture even those dimensions whose characteristics prevent their being picked up on by labour force surveys. This would apply, particularly, to activities associated with production that is both consumed by households and supplied to the market. For example, what is the best way to deal with the work of people who look after the family vegetable garden, when the main aim is selfconsumption but a proportion of the output goes for retail sale in some community market? It can be assumed that some of the work captured by time-use surveys in this category identifies these activities. ${ }^{16}$

A comprehensive approach to work, whereby information from time-use surveys is treated as supplementing that from labour force surveys, makes it possible to incorporate any other labour endowment that produces value. Time-use surveys record the enormous commitment of time to productive activities outside the SNA that are not considered

\footnotetext{
16 It would be interesting to carry out a similar exercise with time-use surveys employing the activity diary method and ascertain whether it is possible to capture somewhat more information in this field in that way.
} 
by the usual instrument for characterizing human labour. The fact that this work is largely done by women means that it is their contribution in particular that usually remains invisible.

A special case, explored in the second part of this study, is that of women treated as inactive by labour force surveys. This categorization derives from the fact that they do not participate actively in the labour market (neither holding a job nor seeking one). The analysis carried out in this paper on the basis of information from the time-use surveys of Mexico and Ecuador proves the general assumption that this description is inappropriate.

This being so, it would be interesting to consider the possibility of using another type of description for these categories. Instead of describing women (and people generally) as economically active or inactive, it might be more accurate to describe them as active or non-active in the labour market. This would make it plain that the idea of activity is being established strictly in relation to the world of employment (or paid work). Even so, there seems to be no case for applying the term inactive or non-active to people who use their time in the way the information given here depicts.

One alternative classification option might be to distinguish between people who are active in the world of paid work (this could be abbreviated to PAE = population active in employment) and people active in the world of unpaid work or in the home $(\mathrm{PAH}=$ population active in the home). Analogously, there could be indicators of inactivity in each of these spheres. These indicators would certainly reveal a gender participation gap, but it would be the reverse of the usual one; i.e., if PAH were taken as the indicator, women would present a far higher rate than men.

The PAH could then be broken down to consider the different activities included in that category. Thus, the term PAHD could be established for participation in domestic activities (home maintenance), PAHC for participation in care activities, and so on with other new terms for categories that more accurately characterized people's lives.

For, as has been demonstrated, women who are inactive in the labour market are extremely busy with unpaid work, and it is care activities that take up the largest portion of the time available to them. This also strengthens the assumption that it is often the weight of these care responsibilities that is the main reason for non-participation in the labour market.

Thus, when an integrated view of labour force surveys and timeuse surveys is taken, it transpires that women work extremely hard and their economic contribution is very substantial. It is also true that the 
conditions under which they carry out the different types of productive work are different, starting with the basic issue of whether or not they are paid.

Women treated as inactive by employment statistics experience this type of work differently depending on their socioeconomic position. The evidence analysed shows that the lower the income quintile to which these women belong, the greater their participation in domestic production and care activities is. This strengthens existing assumptions about women's differing degrees of freedom to "choose" their own inactivity status.

In summary, this exploratory study has asserted nothing that did not already form part of the assumptions which inspired time-use surveys. What it has done is to conduct some exercises with the evidence these instruments provide, to show the limitations of labour force surveys when it comes to furnishing information about people's work. This is particularly important in the case of women, who, as has been demonstrated, make the greatest time commitment to work ignored by the employment statistics.

There is potential to explore different ways of integrating the information provided by these surveys so as to strengthen the design of regular indicators for recording people's total work, its varying composition, the different conditions under which it is done and the implications of all this for their daily lives, which can provide greater clarity on issues that are key to moving forward with effective equality policies.

\section{Bibliography}

Esquivel, V. and others (2008), "Explorations: Time-use surveys in the south", Feminist Economics, vol. 14, No. 3.

Gómez Luna, M. E. (2010), “Directrices y referentes conceptuales para armonizar las encuestas sobre uso del tiempo de América Latina y el Caribe" [online] http:/ / www.eclac.cl/deype/noticias/noticias/2/41522/S13_INEGI_uso_tiempo.pdf.

Milosavljevic, V. and O. Tacla (2007), "Incorporando un módulo de uso del tiempo a las encuestas de hogares: restricciones y potencialidades", Mujer y Desarrollo series, No. 83 (LC/L.2709-P/E), Santiago, Chile, Economic Commission for Latin America and the Caribbean (ECLAC).

Montaño, Sonia and Coral Calderón (2010), “El cuidado en acción. Entre el derecho y el trabajo", Cuadernos de la CEPAL, No 94 (LC/G.2454-P), Santiago, Chile, Economic Commission for Latin America and the Caribbean (ECLAC). 


\section{Part two}

Experience concerning the sexual division of labour and public policy 



\title{
Chapter I
}

\section{Is a new patriarchal family model taking shape in rural areas?}

\author{
Liudmila Ortega Ponce ${ }^{1}$
}

The patriarchal family model is grounded in socioeconomic and cultural constructs whereby males assume the role of head of household and breadwinner and have power and authority over the female members of the household, who occupy a subordinate position and whose primary role is the performance of domestic chores and caregiving. This model appears to be on the decline in Latin America, albeit to varying degrees in the different countries. ${ }^{2}$ Signs of this are to be found in the dramatic changes seen in the make-up of families and in other economic, demographic, social and cultural processes that have been unfolding over the past century (Rico and Maldonado, 2011; Cerrutti and Binstock, 2011; Hopenhayn, 2011). Women's increasing presence in the labour market has been highlighted as a very significant step forward. This has largely been driven by the dramatic cultural changes associated with

1 The author would like to thank Soledad Parada for her assistance in processing the data from the time-use surveys for Ecuador (2007), Guatemala (2006) and Mexico (2009).

2 The concept of a patriarchy entails complex issues relating to the development of human society that must be addressed within the framework of a variety of academic disciplines since this system permeates economic, social, political and cultural spheres of activity and has been in place throughout history. This study is not designed to delve into those issues, but it is nonetheless important to bear in mind the ramifications of this system for the organization of society in which men hold all or most of the power. 
women's desire to have an identity in their own right, autonomy and economic independence.

This article seeks to identify the paradigms of the present-day patriarchal family system in rural areas in Ecuador (2007), Guatemala (2006) and Mexico (2009) from the perspective of total workload. Total workload is understood to mean economic activities and related endeavours covered by the system of national accounts (SNA) together with those forms of work that fall outside the production boundary recognized by that system, that is, domestic chores and caregiving. ${ }^{3}$

From a relatively similar perspective, Majnoni d'Intignano (1999) put forward a stylized schema of the sexual division of labour within couples, with their historical variants, from the patriarchal model in its purest expression to the modern models in which both spouses have carved out a space in the labour market. In the model described, labour is divided, on the one hand, between the family sphere of domestic work and production for own consumption and, on the other, the sphere of market production. Women dedicate their time to domestic work, raising and educating children and caring for relatives, and this work is unpaid. By contrast, men work exclusively in the market sphere. ${ }^{4}$

In accordance with this model, this paper will look at the time-use patterns of rural women in Ecuador, Guatemala and Mexico, both at the individual level and at the level of couples composed of a male head of household and his spouse. To this end, an analysis will be conducted of the different roles taken on by women and men as producers of goods and services in the economy, broken down into production for the market, production for own use and care work.

For the purposes of the study, information was used from timeuse surveys conducted in Ecuador (2007), Guatemala (2006) and Mexico (2009). In addition, secondary sources of information, documents and studies by a wide range of authors and institutions were also consulted. ${ }^{5}$

The study first addresses the average amount of time spent on different activities ${ }^{6}$ with a view to giving an overview of the gender roles

\footnotetext{
3 Strictly speaking, the three surveys are not comparable because they do not cover the same activities for each component of total workload, as shown in table A-1 of annex I, which presents the content of the time-use variables.

4 It should be noted that Majnoni d'Intignano (1999) categorizes production for own consumption in the family sphere, whereas under the system of national accounts (SNA) it is classed as part of the set of economic activities (market and non-market).

5 Information on the methodology can be found in annex I.

6 The average amount of time spent by the population as a whole on a particular activity. This figure differs from the average amount of time dedicated by the participants in
} 
in the three countries of the study. It then examines the participation of men and women in the various labour categories and the amount of time they devote to each area classified within the SNA production boundary and those that fall outside that system, that is the division between activities in the market and the family spheres. Third, the study looks at the patterns of time use of employed women and their male peers. Lastly, the study analyses the participation of women, employed or not, in production for own consumption. This area of work has remained somewhat invisible despite contributing substantially to agricultural production and the provision of essential resources, such as water and energy, to households.

The specialization of women in care work (an activity not included within the SNA production boundary) remains the cornerstone of the sexual division of labour in rural areas. In this sense, the above-mentioned basic patriarchal model persists, but with two main variants: the traditional model with the male breadwinner and female caregiver; and a more recent variant of the male breadwinner and female producer-carer. The emergence of the second is the result of the integration of rural women into the labour market, especially wage employment, which has been on the rise in the last 15 years (Ballara and Parada, 2009; Dirven, 2011; FAO/IFAD/ILO, 2010). At the same time, women have continued to be involved in production for own use (mainly for household consumption), which is not reflected in traditional labour statistics.

\section{A. The specialization of women in unpaid work outside the production boundary}

Workloads are defined as the sum of the time devoted to economic activities that are included within the SNA production boundary and the time devoted to activities that fall outside the scope of that system, for example, the provision of unpaid services to households and the community. Household services include domestic chores and caregiving, both within the home and in other households (Gómez Luna, 2010). ${ }^{7}$

the activity, that is, the average time spent by only those who carry it out (Durán and Rogero, 2009). In this study, this is the time spent on work by the whole population aged 15 years and over.

$7 \quad$ It should be noted that the category of paid services provided to the community includes unpaid voluntary work in health care. 
Box I.1

PRODUCTION ACTIVITIES AND THE SCOPE OF THE PRODUCTION BOUNDARY OF THE SYSTEM OF NATIONAL ACCOUNTS

Included within the production boundary of the system of national accounts (SNA) are market production (agriculture, industry and services), production for own use and non-market production. Production for own use covers not only subsistence farming, but also the harvesting of uncultivated fruits or vegetables, collecting firewood and fetching water, as well as paid domestic services. The activities in this category tend to be unpaid and include the production of goods for own consumption, such as collecting firewood and fetching water, tasks which are usually carried out by women.

As to productive activities that fall outside the production boundary, the three surveys used in this study are not, strictly speaking, comparable. In Ecuador and Mexico these activities include domestic chores, caregiving, assistance to other households and activities in support of the community, while in the case of Guatemala they include only domestic chores and direct caregiving. ${ }^{a}$

Source: M.E. Gómez Luna, "Directrices y referentes conceptuales para armonizar las encuestas de uso de tiempo en América Latina y el Caribe", paper presented at the International Meeting on Time-Use Statistics and Public Policies, Mexico City, 30 June to 2 July 2010 [online] http://www.eclac.cl/mujer/noticias/noticias/3/40283/ MariaGomez.pdf; National Time-Use Survey (ENUT), Mexico, 2009, National Survey on Living Conditions (ENCOVI), Guatemala, 2006; National Survey of Employment, Unemployment and Underemployment (ENEMDU), Ecuador, 2007.

a Unfortunately, the data on the time dedicated to care and domestic chores cannot be separated for Guatemala. For more details, see annex I.

An analysis of the average amount of time spent on work (paid and unpaid $)^{8}$ shows that, in all three countries, women work longer hours than men, both in rural and urban areas.

However, in Ecuador and Mexico, the gap between women and men is wider in rural areas than in urban areas. Women in rural areas in Ecuador work an average of 11.3 hours a week more than men and the corresponding figure for Mexico is 13 additional hours. In urban areas, this difference is 8.6 hours and 11.9 hours for each country, respectively. In Guatemala, the difference between the two areas is very small: women work 1.26 hours per day more than men in rural areas and 1.24 hours per day more in urban areas (see table A-1 in annex II).

The excess burden shouldered by women is attributable to the greater amount of time they spend on domestic activities and direct care tasks than men. In rural Ecuador the differential is an extra 30 hours per week, while in Mexico it is 44 hours per week; in Guatemala, it is an extra 6 hours per day. The same pattern for these three countries can be seen in the cities, but the gaps are somewhat narrower.

8 The average time spent by the population as a whole on an specific activity is calculated by dividing the total time devoted to that activity by the total population aged 15 years and over. 
Table I.1

ECUADOR, GUATEMALA AND MEXICO: AVERAGE TIME DEVOTED TO THE PRODUCTION OF GOODS AND SERVICES WITHIN AND OUTSIDE THE PRODUCTION BOUNDARY DEFINED BY THE SYSTEM OF NATIONAL ACCOUNTS, TOTAL RURAL POPULATION AGED 15 YEARS AND OVER (Hours per week and per day)

\begin{tabular}{|c|c|c|c|c|c|c|c|c|c|}
\hline \multirow{2}{*}{$\begin{array}{l}\text { Production } \\
\text { activities }\end{array}$} & \multicolumn{3}{|c|}{$\begin{array}{c}\text { Ecuador } \\
\text { (Hours per week) }\end{array}$} & \multicolumn{3}{|c|}{$\begin{array}{l}\text { Guatemala } \\
\text { (Hours per day) }\end{array}$} & \multicolumn{3}{|c|}{$\begin{array}{c}\text { Mexico } \\
\text { (Hours per week) }\end{array}$} \\
\hline & Men & Women & $\begin{array}{l}\text { Men and } \\
\text { Women }\end{array}$ & Men & Women & $\begin{array}{l}\text { Men and } \\
\text { Women }\end{array}$ & Men & Women & $\begin{array}{l}\text { Men and } \\
\text { Women }\end{array}$ \\
\hline $\begin{array}{l}\text { Within the } \\
\text { production } \\
\text { boundary }\end{array}$ & 41.72 & 22.84 & 32.40 & 7.23 & 2.44 & 4.66 & 45.17 & 13.72 & 28.87 \\
\hline $\begin{array}{l}\text { Outside the } \\
\text { production } \\
\text { boundary }\end{array}$ & 9.99 & 40.17 & 24.89 & 0.65 & 6.70 & 3.90 & 15.73 & 60.21 & 38.78 \\
\hline Total & 51.72 & 63.01 & 57.29 & 7.88 & 9.14 & 8.56 & 60.90 & 73.92 & 67.65 \\
\hline
\end{tabular}

Source: National Time-Use Survey (ENUT), Mexico, 2009, National Survey on Living Conditions (ENCOVI), Guatemala, 2006; National Survey of Employment, Unemployment and Underemployment (ENEMDU), Ecuador, 2007.

In fact, the differences in the average times spent on activities within and outside the production boundary by men and women indicate that unpaid work outside the production boundary is the almost exclusive domain of women, while men are primarily responsible for paid work within the production boundary.

In Ecuador and Mexico, rural women spend nearly $80 \%$ of their time on unpaid work that falls outside the production boundary; in Guatemala they spend over $90 \%$ of their time on such tasks. Meanwhile, men in Ecuador, Mexico and Guatemala spend 65.2\%, 71.9\% and 75.4\%, respectively, of their time on paid work.

A closer look at women's and men's share in and contribution to each component of unpaid work outside the production boundary reveals a clear dividing line between services provided to other households and services provided to the community.

In the first case, as shown in figure I.4, women's contribution exceeds that of men for both household chores and direct care provision. In Ecuador, the differential is over 60 percentage points for each of these activities; while in Mexico, it is 71.4 percentage points for household chores and 47 percentage points for caregiving. 
Figure I.1

ECUADOR: SHARES OF MEN AND WOMEN IN THE TOTAL TIME DEVOTED TO PRODUCTION ACTIVITIES WITHIN AND OUTSIDE THE PRODUCTION BOUNDARY DEFINED BY THE SYSTEM OF NATIONAL ACCOUNTS, BY AREA OF RESIDENCE, POPULATION AGED 15 YEARS AND OVER

(Percentages)

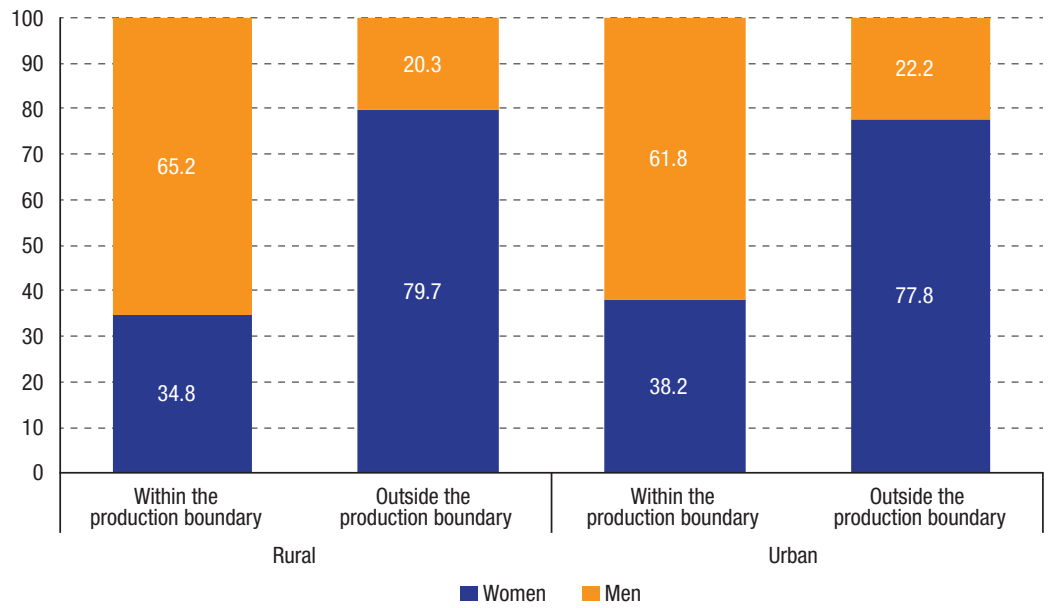

Source: National Survey of Employment, Unemployment and Underemployment (ENEMDU), Ecuador, 2007.

Figure I.2

GUATEMALA: SHARES OF MEN AND WOMEN IN THE TOTAL TIME DEVOTED TO PRODUCTION ACTIVITIES WITHIN AND OUTSIDE THE PRODUCTION BOUNDARY DEFINED BY THE SYSTEM OF NATIONAL ACCOUNTS, BY AREA OF RESIDENCE, POPULATION AGED 15 YEARS AND OVER (Percentages)

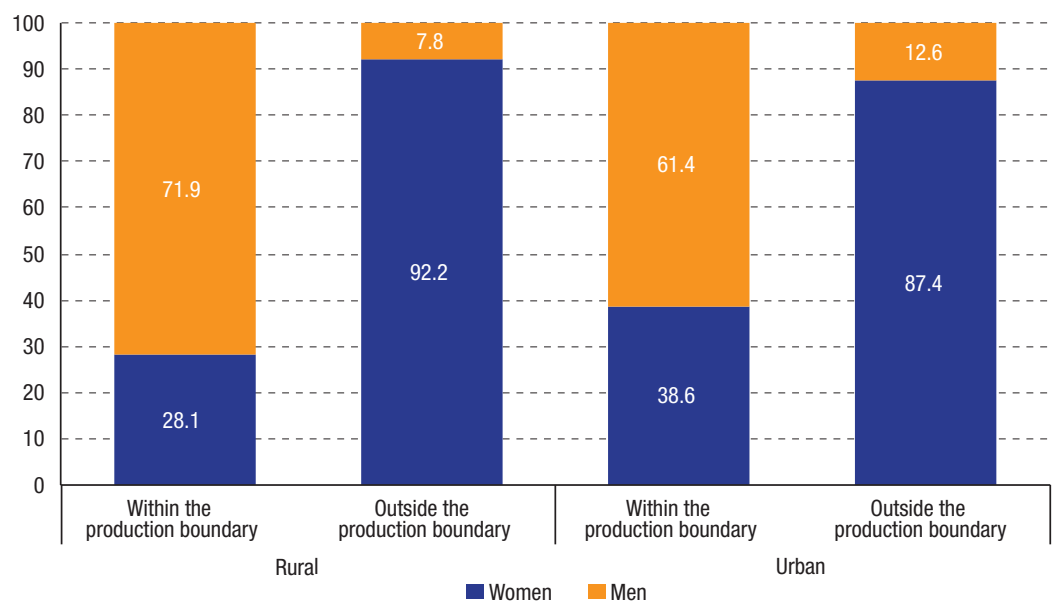

Source: National Survey on Living Conditions (ENCOVI), Guatemala, 2006. 
Figure I.3

MEXICO: SHARES OF MEN AND WOMEN IN THE TOTAL TIME DEVOTED TO PRODUCTION ACTIVITIES WITHIN AND OUTSIDE THE PRODUCTION BOUNDARY DEFINED BY THE SYSTEM OF NATIONAL ACCOUNTS, BY AREA OF RESIDENCE, POPULATION AGED 15 YEARS AND OVER

(Percentages)

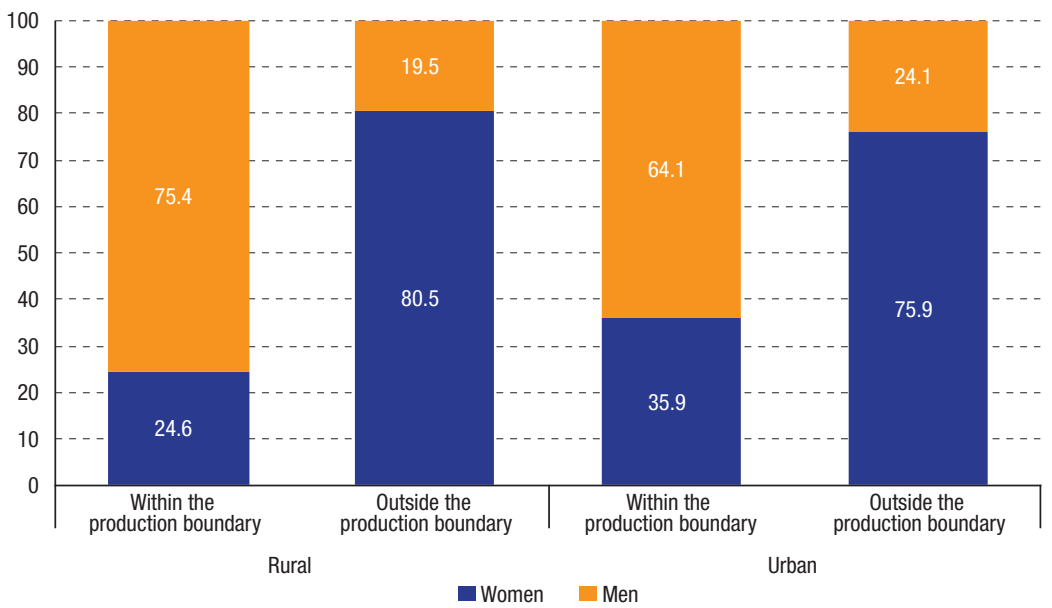

Source: National Time-Use Survey (ENUT), Mexico, 2009.

Figure I.4

ECUADOR AND MEXICO: SHARES OF MEN AND WOMEN IN THE TOTAL TIME SPENT ON PRODUCTION ACTIVITIES THAT FALL OUTSIDE THE PRODUCTION BOUNDARY OF THE SYSTEM OF NATIONAL ACCOUNTS BY TYPE OF ACTIVITY, RURAL POPULATION AGED 15 YEARS AND OVER (Percentages)

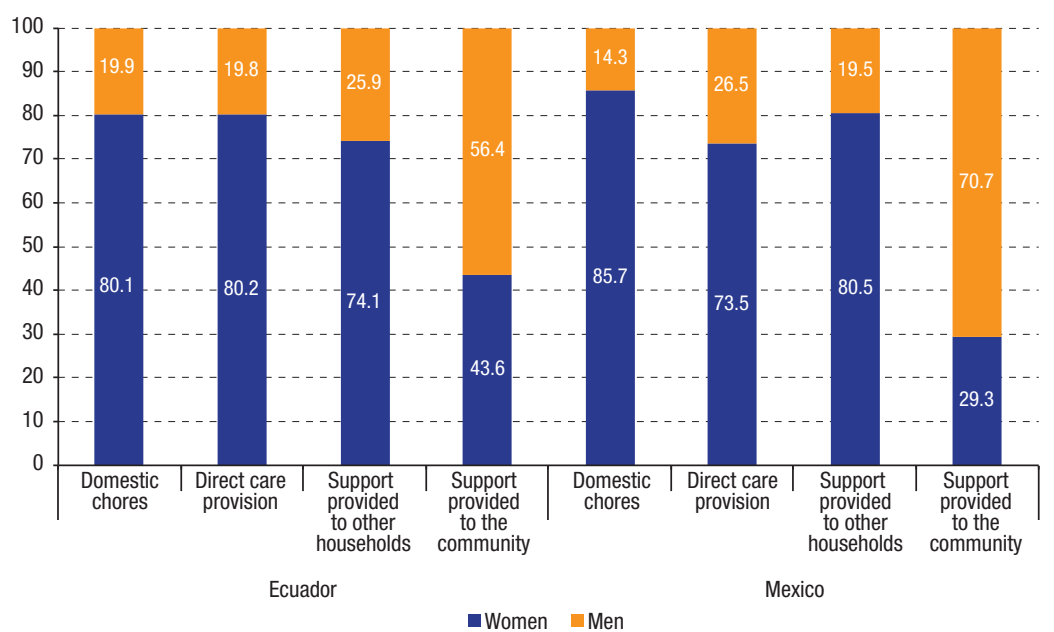

Source: National Time-Use Survey (ENUT), Mexico, 2009, National Survey of Employment, Unemployment and Underemployment (ENEMDU), Ecuador, 2007. 
In the second case, the situation is reversed: in Mexico men devote three times as much time to unpaid services to the community as women. In Ecuador the situation is more balanced, but men's contribution is still greater. That is possibly because men have more time available for such tasks (especially taking account of the total time that women spend on the combination of paid and unpaid work). This reveals another potential gap in the development opportunities available to men and women since participation in community activities requires a certain social and political engagement in the broadest sense.

By contrast, even in the case of activities outside their own homes, women tend to remain in the private sphere of the extended family and neighbourhood, contributing a very high proportion of the support provided to other households (74.1\% in Mexico and 80.5\% in Ecuador), especially in relation to housework, care and other unpaid tasks. ${ }^{9}$

In sum, in terms of the average amount of time spent, the sexual division of labour as per the patriarchal model in its purest expression remains a reality and is even more marked in rural areas than in the urban world. Nevertheless, the role of rural women in economic activity merits investigation. While their share in the time devoted to SNAproduction activities is smaller than that of men, it is interesting to note that it is also smaller than that of urban women. In Guatemala and Mexico, the difference is over 10 percentage points in favour of urban women, and in Ecuador it is over 3 percentage points.

\section{B. Women and economic activity: between the market and the family sphere}

Even though rural women devote less time to economic activities categorized within the SNA production boundary than men, their level of participation is remarkable considering the purely patriarchal marketeconomy-based model described by Majnoni d'Intignano (1999).

An initial look at the time spent on the first two components of economic activity defined within the SNA production boundary reveals that rural women contribute less time to market production than men (see figures I.1, I.2 and I.3). In Ecuador, Guatemala and Mexico, women account for $34.8 \%, 28.1 \%$ and $24.6 \%$, respectively, of total time spent on this component.

In the case of Mexico, unpaid services to other households comprise domestic chores and care provision without remuneration. In Ecuador, reference is made only to "assistance to other households". 
This is attributable to the fact that women's participation rate in economic activity is quite low and that employed women spend less time on average on market-production activities than employed men.

According to the activities declared by respondents in time-use surveys, the participation rates of rural women within the production boundary continue to be lower than those of men. In Ecuador, Guatemala and Mexico, $80.9 \%, 64.1 \%$ and $62.9 \%$, respectively, of women aged 15 years and over engage in production for the market or for own use, compared with $91.6 \%, 84.3 \%$ and $88.0 \%$ of men from the same countries (see tables A-2 and A-3 in annex II).

Regarding the time spent on these activities, in Ecuador, for example, employed women work 35.5 hours per week on market production compared with 43.6 hours for employed men. Gaps between men and women vary by country and may have to do with the labourmarket dynamics and farming practices in each country (see tables A-4, A-5 and A-6 in annex II).

On the other hand, rural women account for a larger proportion of the total time spent on production for own use than men in the three countries. In Guatemala, in particular, they contribute $60.2 \%$ of the time spent on these activities, while in Ecuador and Mexico, the contributions of men and women are a little more balanced.

The proportion of women involved in production for own use is far greater than the proportion of men, which helps to offset the fact that the average number of hours that women devote to this form of production is slightly lower than that observed among men.

According to traditional statistics on economic participation and employment, the time women spend on paid work is associated with the recent integration of rural women into the labour market, which has been on the rise in the past 15 years (Ballara and Parada, 2009). Thus, the estimated $44 \%$ surge in labour-force participation among rural women (ECLAC/FAO/ILO, 2010) largely explains the increase in the rural economically active population in this period.

This increase can be attributed to various processes - the application of neoliberal economic policies and failure to implement State policies on agriculture and rural development- over the last two decades that affected the economic environment in which agricultural and rural activities are carried out, thus influencing the employment structure for men and women and the population's socioeconomic conditions (Deere, 2005; ECLAC/FAO/ILO, 2010; Lastarria-Cornhiel, 2008; Chiappe, 2005). 
Figure 1.5

ECUADOR, GUATEMALA AND MEXICO: SHARES OF MEN AND WOMEN IN THE TOTAL TIME SPENT ON MARKET PRODUCTION AND PRODUCTION FOR OWN USE, RURAL POPULATION AGED 15 YEARS AND OVER

(Percentages)

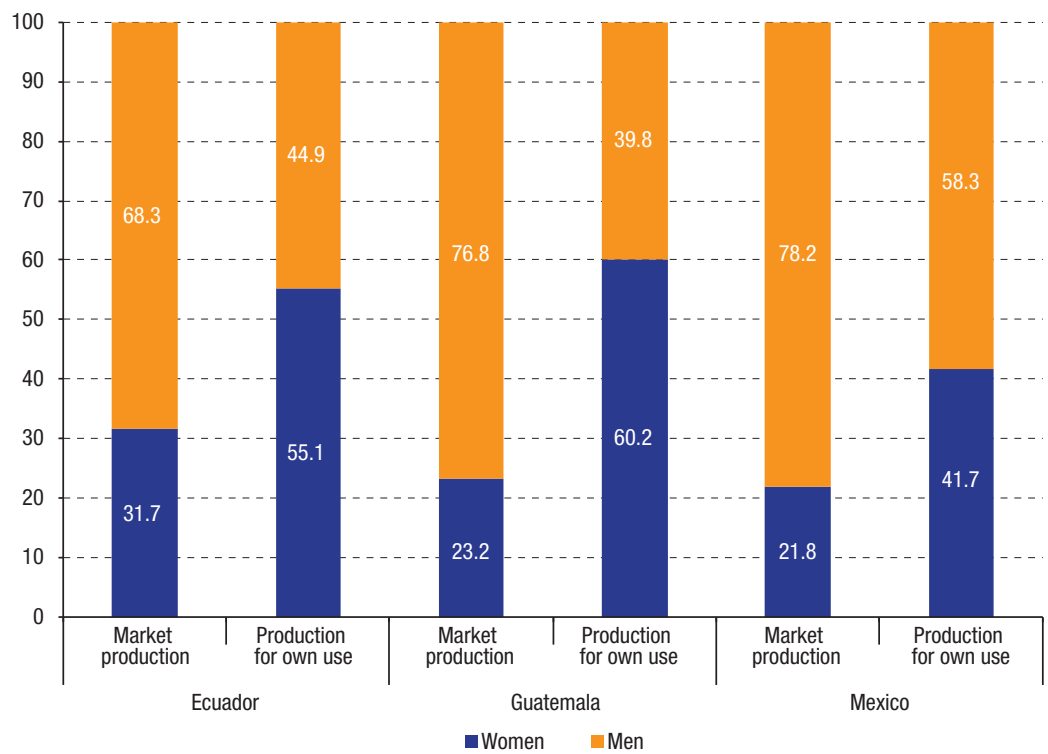

Source: National Time-Use Survey (ENUT), Mexico, 2009, National Survey on Living Conditions (ENCOVI), Guatemala, 2006; National Survey of Employment, Unemployment and Underemployment (ENEMDU), Ecuador, 2007.

Families involved in small-scale agriculture have seen their living conditions deteriorate, forcing them to employ a variety of coping strategies, such as the integration of rural women into paid employment, the diversification of rural agricultural employment through the development to a greater or lesser extent of export crops and agribusiness, the diversification of production activities towards non-agricultural rural employment for both men and women and the emigration of both men and women from rural areas, ${ }^{10}$ which has been reflected in the increase in the number of female heads of household and women breadwinners (Bentancor and Modrego, 2011).

10 In Ecuador and Guatemala — countries with high migration rates - more men than women in the 20-24 age group migrate (Ballara and Parada, 2009). 


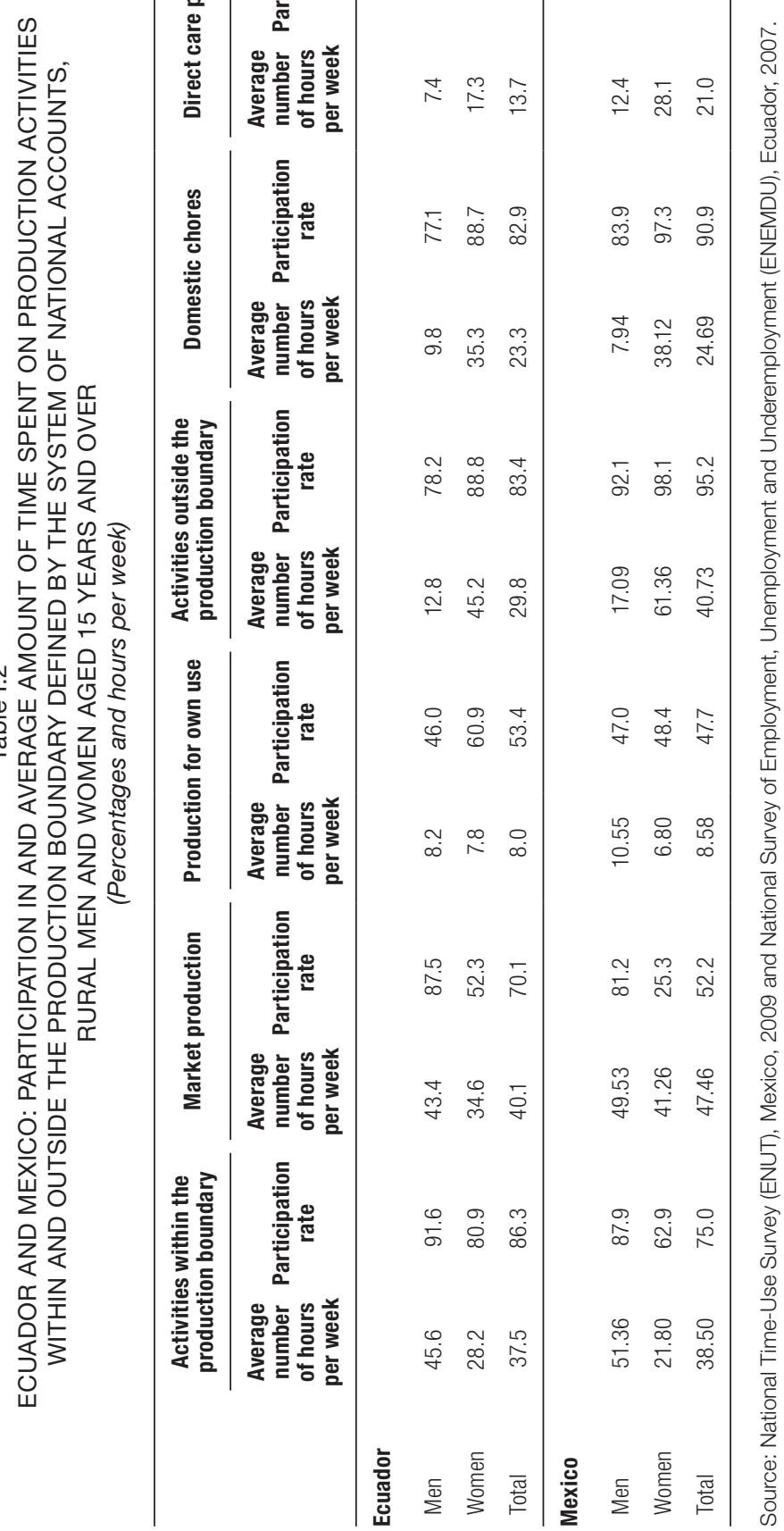


Table I.3

GUATEMALA: PARTICIPATION IN AND AVERAGE AMOUNT OF TIME SPENT

ON PRODUCTION ACTIVITIES WITHIN AND OUTSIDE THE PRODUCTION BOUNDARY DEFINED BY THE SYSTEM OF NATIONAL ACCOUNTS, RURAL MEN AND WOMEN AGED 15 YEARS AND OVER

(Percentages and hours per day)

\begin{tabular}{|c|c|c|c|c|c|c|c|c|}
\hline & \multicolumn{2}{|c|}{$\begin{array}{l}\text { Activities within the } \\
\text { production boundary }\end{array}$} & \multicolumn{2}{|c|}{ Market production } & \multicolumn{2}{|c|}{$\begin{array}{l}\text { Production for } \\
\text { own use }\end{array}$} & \multicolumn{2}{|c|}{$\begin{array}{l}\text { Activities outside the } \\
\text { production boundary }\end{array}$} \\
\hline & $\begin{array}{l}\text { Average } \\
\text { number } \\
\text { of hours } \\
\text { per day }\end{array}$ & $\begin{array}{l}\text { Participation } \\
\text { rate }\end{array}$ & $\begin{array}{l}\text { Average } \\
\text { number } \\
\text { of hours } \\
\text { per day }\end{array}$ & $\begin{array}{l}\text { Participation } \\
\text { rate }\end{array}$ & $\begin{array}{l}\text { Average } \\
\text { number } \\
\text { of hours } \\
\text { per day }\end{array}$ & $\begin{array}{l}\text { Participation } \\
\text { rate }\end{array}$ & $\begin{array}{l}\text { Average } \\
\text { number } \\
\text { of hours } \\
\text { per day }\end{array}$ & $\begin{array}{l}\text { Participation } \\
\text { rate }\end{array}$ \\
\hline Men & 8.62 & 83.8 & 8.72 & 76.8 & 1.70 & 31.1 & 2.24 & 29.2 \\
\hline Women & 3.81 & 64.0 & 6.40 & 27.3 & 1.45 & 47.6 & 7.14 & 93.8 \\
\hline Total & 6.36 & 73.2 & 8.04 & 50.2 & 1.54 & 40.0 & 6.10 & 63.9 \\
\hline
\end{tabular}

Source: National Survey on Living Conditions (ENCOVI), Guatemala, 2006.

In 12 countries (including the three of interest in this study) women's participation in rural employment climbed by $15.6 \%$ between 2000 and 2008, thus outpacing the increase in men's participation, which rose by $5.7 \%$. Households comprising a couple ${ }^{11}$ composed of a male head of household and a spouse have therefore seen a shift in their distribution according to the employment status of the two partners. In addition to households with a male breadwinner and a female caregiver, in all three countries there are now households where the head of household and the spouse are employed (see table A-7 in annex II). Ecuador is, in some respects, the most advanced country in this regard: in $48.6 \%$ of households comprising a couple, both partners have jobs, a rate that exceeds even that of traditional couples where the spouse does not work. By contrast, traditional households predominate in Mexico (68.7\%) and to a lesser extent in Guatemala (52.3\%). Boosting the proportion of households with two breadwinners in these two countries may have been made more difficult by the lack of employment opportunities, as evidenced by the higher percentage of couples in Guatemala and Mexico in which neither partner is employed ( $21.8 \%$ and $11.3 \%$, respectively) ${ }^{12}$

Women's increased overall labour force participation can be attributed largely to a sharp rise in women's involvement in rural nonagricultural employment $(29.0 \%)$, which contrasts with a much lower increase in agricultural employment (2.3\% between 2000 and 2008) (Dirven, 2011). In Ecuador, Guatemala and Mexico, approximately 30\%,

Only households in which both members of the couple were present were included.

12 These figures may be attributable to the particular season in which the surveys were conducted. 
$70 \%$ and $75 \%$, respectively, of rural women are employed in rural nonagricultural activities (Ballara and Parada, 2009).13 Nevertheless, this employment can represent a last resort and involve precarious, informal and temporary jobs (ECLAC/FAO/ILO, 2010; ECLAC, 2003), as seen, for example, in Guatemala where women working on an own-account basis in rural non-agricultural employment work in small-scale commerce, domestic service and craftwork.

In short, the process of reconfiguring the agricultural sector and diversifying towards the non-agricultural sector has had a different impact on the employment structure in each of the countries in this study. In Ecuador and Guatemala, more than half (66\% and 56\%, respectively) of rural workers are employed in agriculture, with a high proportion of those being own-account workers on small-scale family farms (ECLAC/ FAO/IICA, 2010) and unpaid workers. According to the time-use surveys analysed for this study, unpaid workers represent almost $20 \%$ of the employed labour force, and $34.7 \%$ and $29.8 \%$, respectively, of employed women in Ecuador and Guatemala (see tables I.4, I.5 and I.6).

By contrast, only about a third of rural workers are employed in agriculture in Mexico, where non-farm wage employment assumes a greater role, accounting for $43.6 \%$ of the employed population, according to the same source. This is likely a consequence of the protracted series of crises in the small- and medium-scale farm sector triggered by steep reductions in financing and in agricultural credit (ECLAC, 2007). Another factor is that many small-scale producers do not have land: in 2002 , only $49 \%$ of rural households owned either private plots or had a share of communally owned land. As a result, the members of over $50 \%$ of all households have no option but to work as wage earners in the agricultural sector or in a non-agricultural activity, either near their homes or elsewhere (Dirven, 2011). In short, wage earners account for the largest proportion of male and female rural workers $(62.4 \%$ and $57.8 \%$, respectively), followed by own-account workers ( $28.2 \%$ and $31.5 \%$, respectively), according to the National Time-Use Survey of 2009.14

The diversification of income sources has resulted in the creation of non-agricultural households or mixed households (that combine agricultural and non-agricultural income), in addition to households that depend on non-labour income, especially public transfers or remittances.

13 In Ecuador, closer links between rural and urban sectors have been forming since the 1990s; industries and agribusinesses have been set up in rural areas and large numbers of rural workers have moved to the cities to work in factories, in the construction industry and in the services sector. These activities generate the largest share of permanent jobs for rural wage earners (Martínez, 1991 and 2000).

14 It is worth noting that unpaid workers represent only $8 \%$ of the employed rural population according to the National Time-Use Survey 2009. 
According to the surveys analysed for the purposes of this study, $36 \%$ of the rural population in Ecuador lives in diversified households and 19.4\% lives in non-agricultural households. In Guatemala, non-agricultural households account for one third of the rural population and mixed households represent $23.8 \%$ (see table A-8 in annex II).

\section{Working rural women: combining economic activities and care responsibilities}

In this context, what does the average working day or week for employed women and men look like? To shed light on how employed men and women spend their time, an analysis is conducted of their participation in and the time they devote to the various components of total workload (paid and unpaid) and the different activities they carry out in relation to each component, according to the worker's occupational category and household type.

The following analysis is based on the data contained in tables I.4, I.5 and I.6 which present the employed population's participation in and average time spent, first, on market production and production for own use and, second, on unpaid work that falls outside the production boundary. However, it is not possible to calculate total work time using these averages because the participation rates differ according to the type of work.

The majority, indeed, almost all employed women (88.8\%, 92.4\% and $99 \%$ in Ecuador, Guatemala and Mexico, respectively) carry out work that can be categorized within the SNA production boundary and work outside that boundary.

If direct care provision and domestic chores are considered separately, which is possible only for Ecuador and Mexico, the participation profiles of employed women vary by country. In Ecuador, almost 9 out of every 10 employed women devote time to domestic chores, while a little less than half spend time providing direct care. In Mexico, the difference between the participation rates for these two activities is much smaller: $98.2 \%$ and $80.2 \%$, respectively (see tables A-4, A-5 and A-6 in annex II). ${ }^{15}$

15 More research is needed into measuring employed women's involvement in the provision of care, compared with that of women who are classed as economically inactive. In general terms, in order to provide direct care services, an individual must have the ability to care for another person (which depends on factors such as the carer's good health), both dependent and independent persons must be present in the household, the carer must have the time and space required to fulfil the care responsibilities (in addition to completing other domestic chores) or share them with other women in the household. In Ecuador, for example, daughters contribute $13 \%$ of the total time spent on household chores. 
出

$\stackrel{\text { 峞 }}{\gtrless}$

还品

은 닝

号品品

○出出

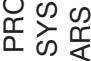

닌

$\vdash \vdash$

岗它

क岀す

山之承

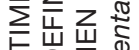

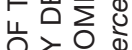

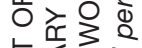

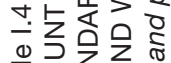

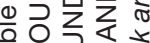

匹

山己

不

일옹

인무

之웜

Z뻐

经这

О

它以

은

밍

这是

ن்

这票

仓઼

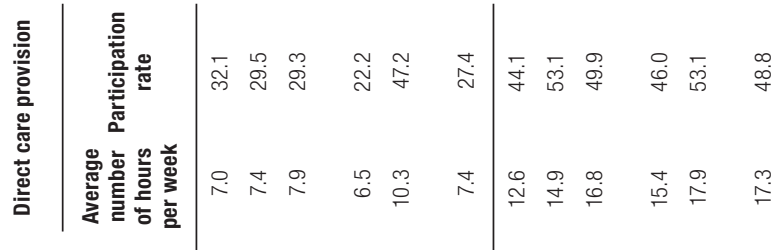

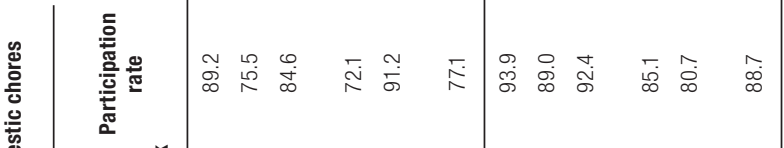

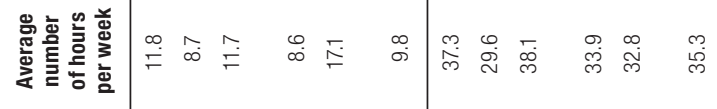

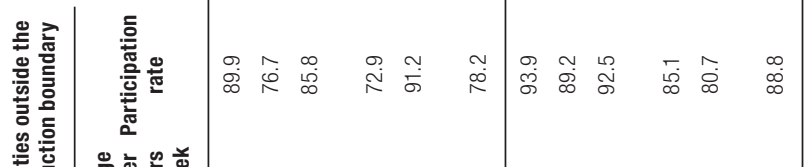

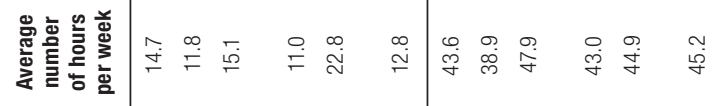

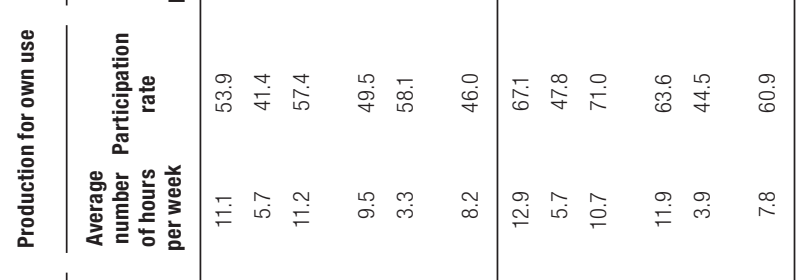

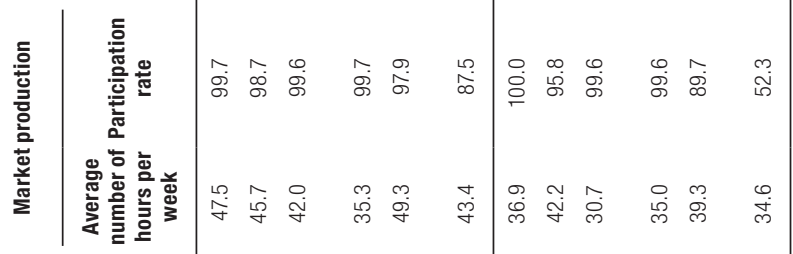

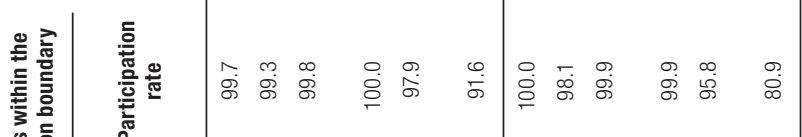

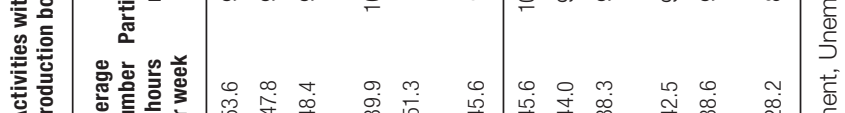




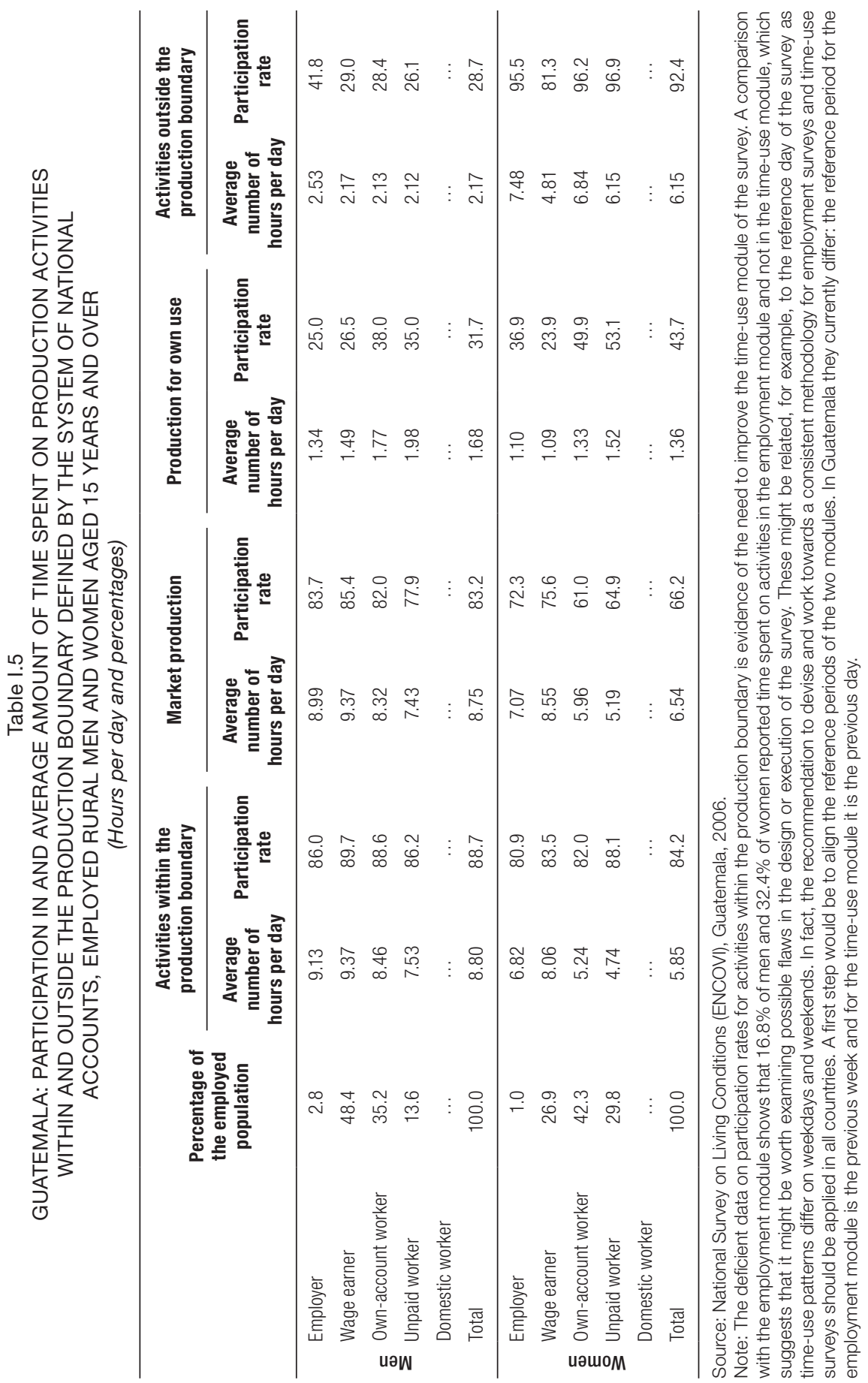




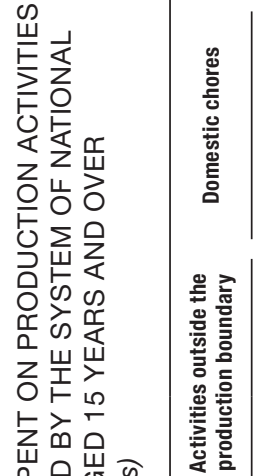

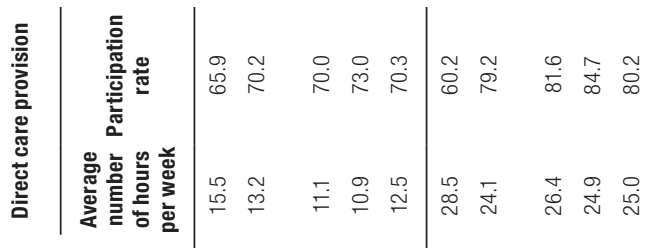
ஸ岂皆

山 $\frac{Z}{4}$

$\sum$ 岀崩过

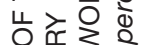

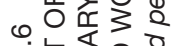

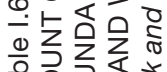

응ำ

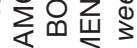

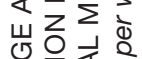

난

岃고옳

《ㅇํำ

은

这安

z폰

乙山

을

芯吉

응ํㅇ

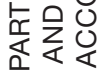

它

\begin{tabular}{|c|c|c|c|c|}
\hline 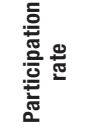 & 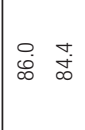 & $\begin{array}{lll}\infty & 0 & 0 \\
\infty & 0 & \stackrel{\infty}{0} \\
\infty & \infty & \infty\end{array}$ & ○ें & 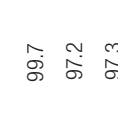 \\
\hline 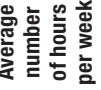 & 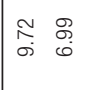 & 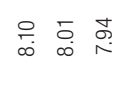 & 을 尽 & 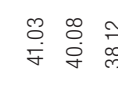 \\
\hline
\end{tabular}

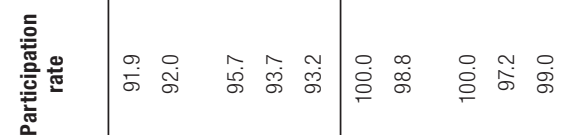

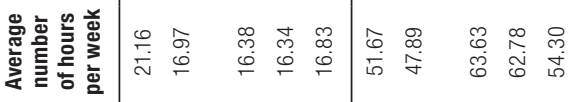

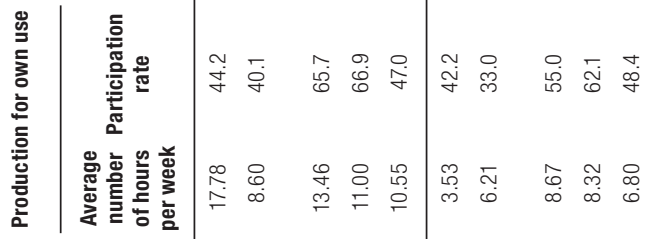

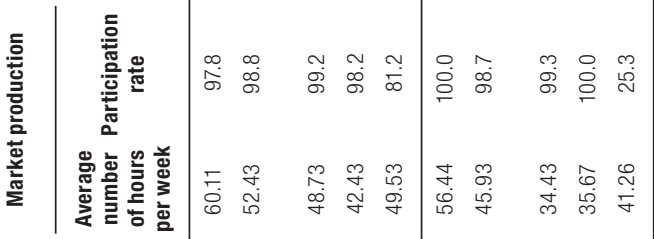

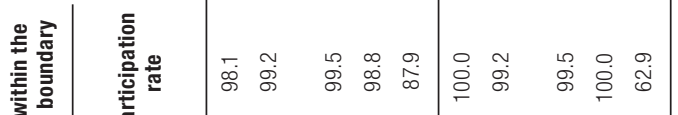

ஜे

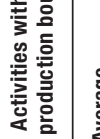

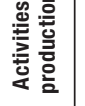

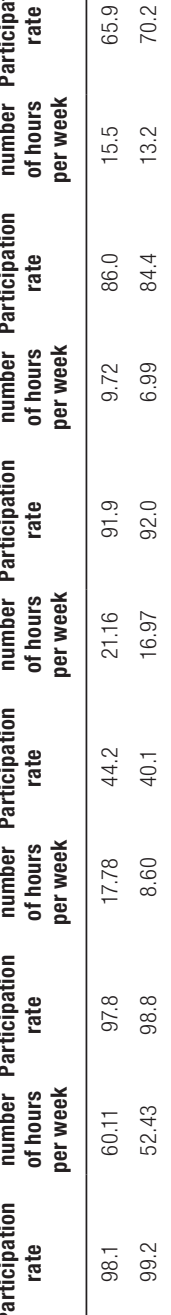

0
$\frac{0}{x}$
2
2

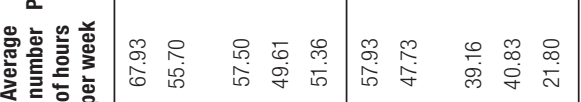

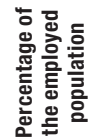

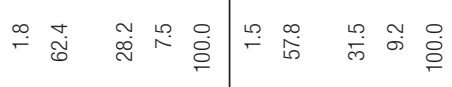

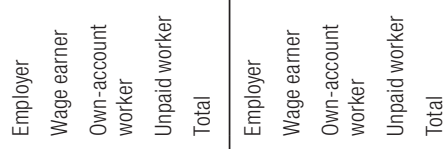

แəพ 
Beyond these considerations, it is worth highlighting that in Ecuador and Mexico, the participation rates of employed men in household chores are quite high (over 70\%), even though employed men devote much fewer hours to these tasks than employed women: 25.5 hours and 25.8 hours per week, respectively.

In Ecuador only $28.8 \%$ of employed men participate in direct care provision, devoting an average of 7.5 hours per week, while employed women who provide care spend double that amount of time on the same activity. The case of Mexico is striking as $70.3 \%$ of employed men spend on average 12.5 hours on direct care (against 25 hours for $80.2 \%$ of employed women).

In sum, though their level of involvement varies by country, men are not totally absent when it comes to care work (direct care provision and household chores), even in traditional couples with a male breadwinner and female caregiver (see table I.7) ${ }^{16}$ However, the figures confirm the specialization of women in these tasks. It can, in fact, be concluded that, on the whole, employed women combine economic activities (as defined by the SNA) with unpaid care work..$^{17}$

This translates into dual-provider households, where the head and spouse have different workloads (see table I.7). In Guatemala, where employed male heads of household have little involvement in total care work (30.7\%), most employed female spouses combine paid employment and care work, without the assistance of any institutional mechanisms to help reconcile the two.

Thus, in addition to spending 5.3 hours on activities that fall within the SNA production boundary, employed women in Guatemala spend 7 hours a day on unpaid care work. In Ecuador and Mexico, although the participation rates for employed men in total care work are very high (over $80 \%$ ), their contribution in terms of the average number of hours per week is very small compared with the time dedicated by their employed spouses to these tasks: employed female spouses in Ecuador spend about 50 hours per week on care work and their Mexican counterparts spend about 70 hours per week, meanwhile, employed male heads of household from these countries devote 14.6 hours and 21 hours, respectively.

At the level of individuals, the aggregation methods for the two types of work differ according to occupational category, especially when

16 The tasks carried out by men should be identified in order to shed more light on the functions assigned to each gender in care work.

17 Furthermore, the average amount of time women spend on direct care work is very high. For example, employed women in rural Mexico devote a total of 54.30 hours per week to care activities. This average would be higher if the minority of employed women who do not carry out these tasks were excluded. 


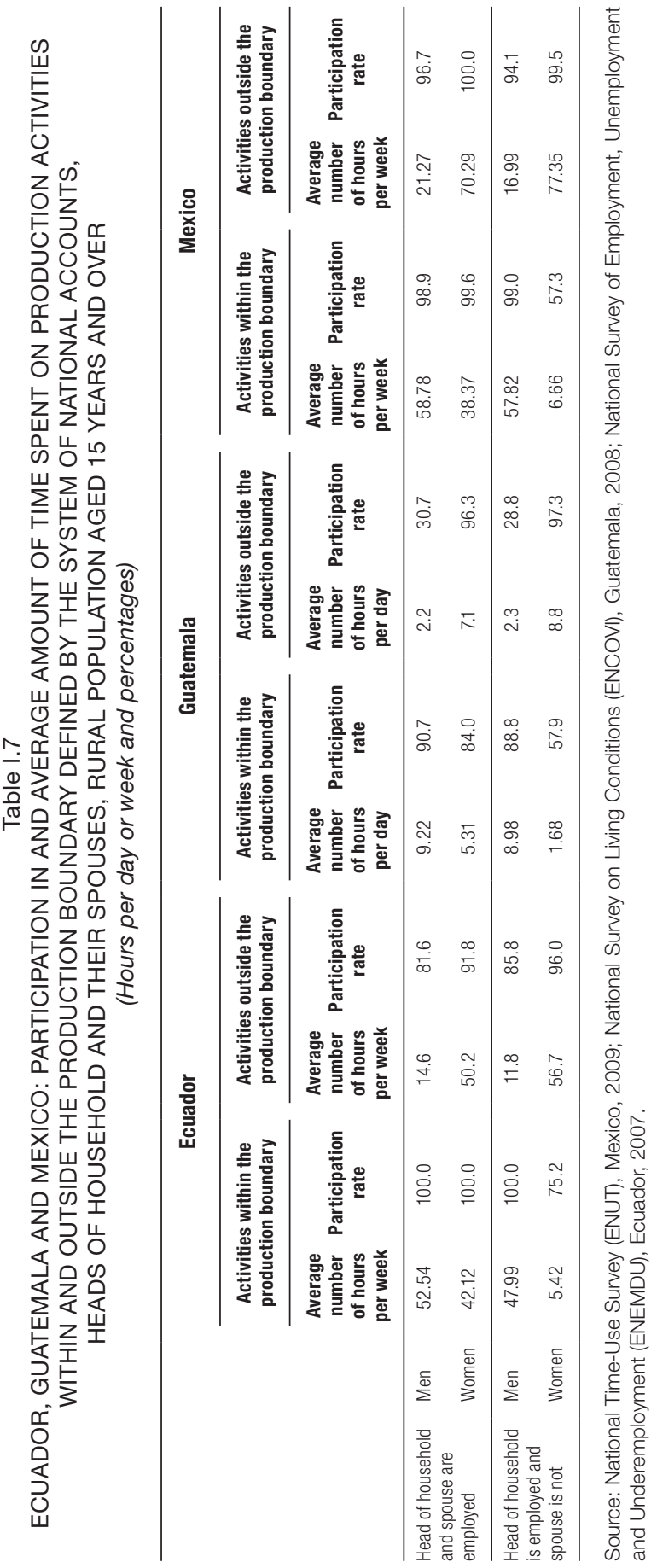


comparing female wage earners, own-account workers and unpaid workers. The participation rates of these three categories of workers in non-SNA production activities (also referred to as total care work), though not identical, are similar; however, employed women tend to devote more time to economic activity and less time to care than own-account workers and unpaid workers in the three countries. For example, $92.5 \%$ of female own-account workers in Ecuador dedicate 47.9 hours per week to overall care work against $89.2 \%$ of female wage earners who devote an average of 38.9 hours. In the case of Mexican women, $100 \%$ of own-account workers devote 63.6 hours per week, while $98.8 \%$ of wage earners spend 47.9 hours per week on care activities, that is, 15 hours less.

It is important to highlight the case of unpaid workers with respect to the other two occupational categories mentioned above. They make up $34.7 \%$ of rural employed women in Ecuador and $29.8 \%$ in Guatemala. The participation rates for these workers in the two major types of work are high and, in the case of Ecuador, they devote similar amounts of time to economic activity to those in the categories that earn an income. This points to the extreme exploitation of these rural women, who may not be aware of it because of their tendency to consider their participation in and contribution to production as complementing and supporting the work of the family. This inequity compounds the inequity of their care burden. Unpaid female family workers spend more hours on care and work outside the SNA production boundary than female wage earners in both Ecuador and Mexico (the participation rates for these two groups are comparable).

Undeniably, there has been a reconfiguration of the patriarchal model in its purest form as women have entered the commercial sphere (according to official statistics) and to some extent men have taken on caregiving tasks (though the specific tasks have yet to be identified). The magnitude of these changes varies depending on the country. Though certain limitations preclude a rigorous comparison between these countries, it could be argued that Ecuador has made the most progress, while Guatemala is lagging behind, as shown by the low participation of men in care work; the marked predominance of traditional couples in Mexico indicates that there is still a long road ahead, with a female labour participation rate of under $50 \%$.

These changes have not eradicated women's specialization, as a historical construct, in care work. Beyond the variations seen in the different occupational categories, the distribution of time devoted to unpaid care work is not related directly to the time that men and women spend on paid work (activities within the SNA production boundary) - the same situation is also observed in urban areas and is common to other countries and societies (Batthyány, 2011; Aguirre, 2005; Ironmonger, 1996). 
Another key area is the variations in patterns of aggregation for employed women, in terms of market production, production for own use and care work. Future research should investigate the position of unpaid female workers in couples and compare their time-use patterns with those of female spouses who are wage earners or own-account workers. The next step in characterizing the sexual division of labour from the perspective of total workload is to analyse the roles of women in production for own use.

Box 1.2

TIME USE OF RURAL INDIGENOUS WOMEN

The indigenous population accounts for $14.4 \%$ of the total population in Ecuador, $50.9 \%$ in Guatemala and $18.9 \%$ in Mexico. Indigenous women's participation in market production is 28.4 percentage points and 5.3 percentage points higher than it is for non-indigenous women in Ecuador and Guatemala, respectively. However, in Mexico, the participation of nonindigenous women is 4.1 percentage points higher than it is for indigenous women. In Ecuador, indigenous women devote more time (3.1 hours) to such work than non-indigenous women, while in Guatemala and Mexico nonindigenous women devote 1.0 hours and 6.5 hours more, respectively, than indigenous women.

The participation rates for rural indigenous women in market-production activities are 13.8 percentage points lower than those for men in Ecuador, 48.8 percentage points lower in Guatemala and 61.9 percentage points lower in Mexico. Their contribution in terms of the amount of time spent is also much smaller.

The situation is the reverse in the case of production for own consumption. Indigenous women's participation rate in this area of production is $63 \%$ in Ecuador, $50.1 \%$ in Guatemala and $70.8 \%$ in Mexico, which is higher than it is for men by 15 percentage points, 18.1 percentage points and 2.1 percentage points in the same countries. The situation is more balanced in Mexico, where the gap in participation is narrower and the average time that men devote to production for own-consumption is only three hours more. In Ecuador and Guatemala, the contribution is similar for men and women. In Ecuador, men devote 12.0 hours per week to this form of production, while women dedicate 12.4 hours per week. In Guatemala, men devote 1.7 hours per day and women 1.6 hours.

In the area of care work (household chores and direct caregiving), indigenous women's participation rates in Ecuador and Mexico are 10 percentage points and 6 percentage points higher than those of men, respectively. These figures pale in comparison to the indicators for Guatemala, however, where the gap is 60 percentage points. In Ecuador and Mexico, indigenous women devote nearly three and five times as many hours as men to household chores. The same situation is reflected in the figures for the amount of time devoted to such work by non-indigenous men and women (with a ratio of 3.7 in Ecuador and 4.7 in Mexico).

Source: National Time-Use Survey (ENUT), Mexico, 2009, National Survey on Living Conditions (ENCOVI), Guatemala, 2006; National Survey of Employment, Unemployment and Underemployment (ENEMDU), Ecuador, 2007. 


\section{Women in production for own use: between tradition and invisibility}

The percentages of employed women engaged in production for own use, which includes production for household consumption, fetching water and collecting firewood, vary by country: $61.8 \%$ of employed women in rural areas of Ecuador are engaged in this form of production, $43.7 \%$ in Guatemala and $42.7 \%$ in Mexico (against $47.8 \%, 31.7 \%$ and $49.4 \%$ of employed men from the same countries, respectively). The average amount of time spent on these tasks is also significant (see tables A-4, A-5 and A-6 in annex II).

It is important to emphasize that the participation rates of rural women in this area of production surpass their participation rates in market production. That is to say that, in addition to employed women, women who are categorized as economically inactive or unemployed are also involved in production for own use. Furthermore, the participation rate among inactive or unemployed women in production for own use is higher than that for men in the same situation in the three countries (see tables A-4, A-5 and A- 6 of annex II).

This is evidence that production for own use is an important area to study with respect to gender roles in relation to labour and the economic value of time spent on such activities.

In rural areas production for own use is key to the survival of households. In this regard, women contribute not only by providing food and other goods for household well-being, but also by securing the inputs required for agriculture in the absence of financial resources (Campillo, 1994).

Surveys conducted in 18 countries in Latin America have shown that rural women's workload includes not only small-scale cultivating, for example growing vegetables in the garden, but also tending to large livestock (pasturage and feeding) and to the family plot, which have traditionally been regarded as men's work (Kleyson and Campillo, 1996; Campillo, 1994). The surveys also revealed the degree of flexibility in the assignment of tasks, with women taking on agricultural tasks that were traditionally performed by men when the male members of the household begin to work as wage earners and households become part of the market economy.

With regard to the above, the highest participation rates in production for own consumption among employed women in the three countries are seen among unpaid workers and own-account workers, not wage earners. This link with smallholder agriculture is even more 
obvious when analysing time use by type of household (according to the sources of labour and non-labour income). In Ecuador and Guatemala, the participation rates of women (and also of men) in production for own use are higher in agricultural households, followed by diversified or mixed households, then non-agricultural households (see tables A-8, A-9 and A-10 in annex II).

Concerning the time spent on production for own use, in Guatemala, men spend a little longer than women on these activities in all of the different categories of household (agricultural, non-agricultural and mixed). In Ecuador, a similar situation is seen, with the exception that women in non-agricultural households spend an hour longer than men on these activities.

This raises some questions regarding the measurement of the female (and male) labour participation rate according to international standards established by the International Labour Organization (ILO). The conceptual framework on which that measurement is based is the System of National Accounts. The economically active population includes those who participate (or wish to participate) in economic activity, which includes market production and also production for own use.

The exploratory comparison below compares the data for Mexico on employment status as derived from traditional questions from employment surveys ${ }^{18}$ and from the questions on work time from timeuse surveys. Strictly speaking, this is not a true comparison as the same figure shows two different indicators: the traditional labour participation rate and what is referred to as the broader participation rate which incorporates economically inactive and unemployed persons who are involved in production for own use. ${ }^{19}$

Although gaps are observed between these two indicators for both men and women, the gap is much greater for rural women, drawing attention to the invisibility of the work they carry out. There is a difference of approximately 35 percentage points between the highest labour participation rate observed in the group aged 30-39 years according to the traditional method of measurement and the broader participation rate calculated on the basis of the National Time-Use Survey (see figure I.6). Moreover, for women the gap widens substantially for older age groups, while the distance between the two lines remains

18 In Guatemala and Ecuador, the time-use modules were aligned with the modules on activity and employment status. In the case of Mexico, questions about activity and employment status of the National Time-Use Survey (ENUT) 2009 were based on Mexican employment surveys.

19 This leads to a larger employed population consisting of a greater proportion of unpaid workers, predominantly unpaid female workers. 
almost parallel for men in all age groups. This suggests that when rural women cease to participate in recognized economic activity, they remain as active as men in the sphere of production within the production boundary, as shown by the shape of the activity curve by age.

Figure I.6

MEXICO: LABOUR PARTICIPATION RATE ACCORDING TO THE FRAMEWORK OF THE INTERNATIONAL LABOUR ORGANIZATION (ILO) AND THE SYSTEM OF NATIONAL ACCOUNTS (SNA) AND BROADER LABOUR PARTICIPATION RATE BASED ON TIME USE BY SEX AND AGE GROUP, RURAL POPULATION AGED 15 YEARS AND OVER

(Percentages)

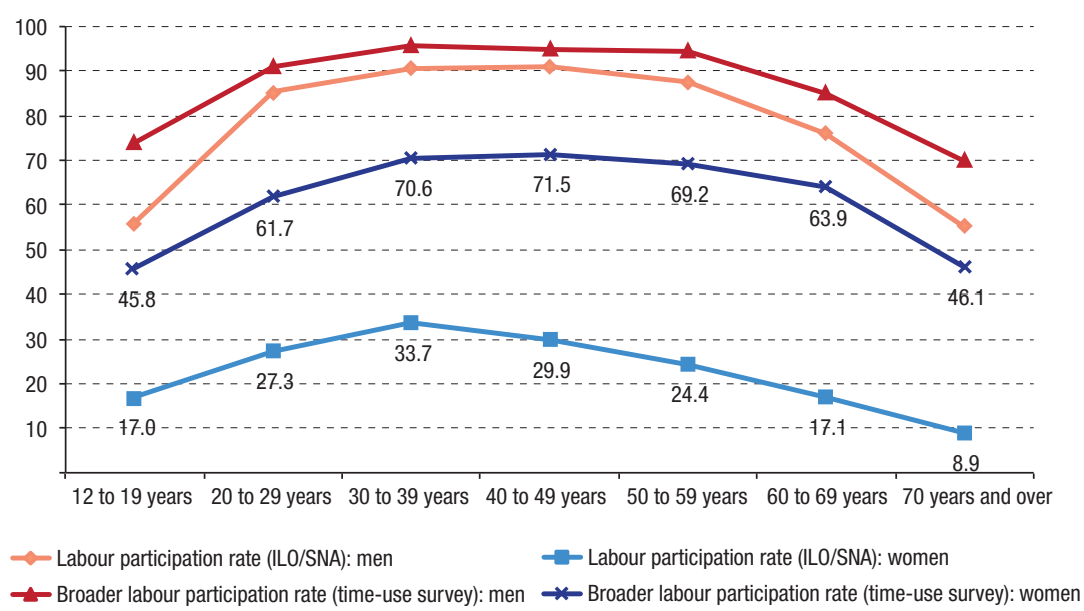

Source: National Time-Use Survey (ENUT), Mexico, 2009.

This is in line with earlier research using time-use surveys which had detected that in the second half of the 1990s the number of women participating in agricultural economies was between two and five times the number cited according to official statistics for Central America, and that in the agricultural sector in the Andean region, the work of some 5 million women was invisible (Kleyson and Campillo, 1996; Campillo, 1994)..$^{20}$

20 These findings were obtained in a project executed by the Inter-American Institute for Cooperation in Agriculture (IICA) and the Inter-American Development Bank (IDB) in the mid-1990s in which 2000 rural women (food producers) in 18 countries in Latin America were interviewed individually, and a large number of collective interviews were conducted on agricultural sites. The project applied various methodologies with a view to remedying the invisibility detected in relation to women's work, for example: checking the secondary activity performed by women classified as inactive and adding the women who reported performing productive work in agriculture to the list of active women; assuming that at least one adult woman works on every smallholding and thus ensuring that the number of women was equivalent to the number of small production 
There are still gaps in the data collected on the different types of labour that women carry out in the commercial and non-commercial farming sectors owing, for example, to gender bias in the selection of survey respondents, women's own perceptions of their work and the failure to account for multitasking.

Another influential factor may be the existence of patriarchal attitudes that cause institutions or their staff to equate the economic support of households with the resources provided exclusively by men, in part because the male traditionally handles contacts with the outside world. Consequently, unless the survey design provides specifically for responses from women, the information gathered about the work that they do may be incomplete.

In fact, when the main respondent is a woman who is responsible for running a farm household, the results indicate that women are involved in every stage of the production cycle: preparing the land, planting, managing and tending the crops, fertilization, harvesting, post-harvest tasks (transport, storage, drying, packing), fruit-picking, egg collection, milking, on-farm food processing and marketing. ${ }^{21}$ In addition to all this, there are the tasks involved in raising livestock (pasturage, feeding), tending garden crops and craftwork..$^{22}$

Another reason why some of the activities performed by women may not be recorded is that, within this shared spatial and temporal context of productive activities that fall inside and outside of the SNA production boundary, they and their families may not consider some of the activities that they carry out to be work. ${ }^{23}$

In addition, they may underestimate the amount of time that they devote to non-agricultural activities that they perform at the same time as other tasks. Or it may also be the case that many tasks remain invisible because they are not performed during the particular season when the surveys are conducted. For example, it has been found that between the

units; applying the average rates of economic participation obtained in surveys conducted by the project to the working-age population engaged in agriculture and retabulating the results of the special modules previously used in household surveys (Kleyson and Campillo, 1996).

21 Most of the farms in the 18 Latin American countries where the interviews were conducted were semi-commercial enterprises.

22 Studies conducted in the 1990s showed that the average workday for women in the Andean region and Central America was long (between 14 hours and 19 hours). Half of that time was spent on caregiving, while the other half was spent on farmwork, incuding 4.5 hours working the family plot, 2 hours tending to livestock and approximately 1.5 hours on tending the garden and making items to sell. As noted earlier, these women tended to carry out two or more tasks at the same time (Kleyson and Campillo, 1996).

23 In Central America, $70 \%$ of the women surveyed in the IICA/IDB project were performing farmwork, but only $30 \%$ of them described themselves as producers (Campillo, 1994). 
time that crops are planted and the time that they are harvested, women spend most of their time tending livestock (both large and small animals) and milking because during that period less fieldwork is required, although they continue to perform that type of work as well.

But the above is not enough to explain the gap between traditional participation rates and the broader participation rates calculated on the basis of the time-use survey conducted in 2009. It is worth noting, as described in the summary of the survey methodology (INEGI, 2009), that the respondent for the section of the questionnaire on labour participation had to belong to a specified age group and provide information on their employment status and also on their time use in the subsequent section. In other words, women were direct respondents.

With regard to the formulation of the questions, in an attempt to include those who reported not having worked during the past week, the question on labour participation followed the ILO/SNA model and incorporated agricultural work (cultivating crops, raising animals, etc.) without explicitly specifying whether the production was for the market. The gap between the observed participation rates might be explained then by the omission under this question of water and firewood collection, tasks often considered purely domestic but which were defined as goods-producing activities in SNA 1993 because of their importance in developing countries.

To some degree, the fact that gathering firewood and fetching water are not included in the question on labour participation is understandable since the subsequent questions on the characteristics of employment are difficult to apply to these activities. Nevertheless, these activities can and should be evaluated, in accordance with the SNA. In addition, they take up time that could be spent on paid work.

By contrast, certain production activities for own use that are not included in the ILO/SNA-based question are explicitly mentioned in the question on the time devoted to this type of work; these include the preparation of food or agro-food products, ${ }^{24}$ the collection of wild fruits and the manufacture or weaving of clothing, tablecloths or curtains.

Establishing how much influence these two hypotheses have on the difference between the rates would require a thorough investigation of the data that goes beyond the scope of our study, but is nevertheless highly recommended.

24 The National Survey of Employment, Unemployment and Underemployment (ENEMDU) (2007) in Ecuador included the production of empanadas, for example. 
It is important to highlight the progress made in filling in the gaps in the records on how much time women producers devote to work in all of the aspects of the agricultural cycle in which they participate. However, a more thorough investigation is required because it is not yet clear whether women's market production and participation in small-scale agriculture are well recorded. Two factors play a role in this. First, women divide their time seamlessly between the family plot, the vegetable garden and the home. Second, for small-scale farmers the line between agricultural production for own consumption and that for sale is blurred. ${ }^{25}$

As time-use surveys are improved in terms of data collection on production for households' own use, one challenge is to gather more information on the participation of women and the time they spend on market production in the family setting. To this end, harmonizing employment surveys with time-use surveys would be a constructive step that would enhance both.

With these improvements women's contribution to the national economy could be assessed more accurately. To date, assessments of the socioeconomic impact of disasters have given an indication of the significant magnitude of rural women's contribution to the economy as agents of production. For example, the value of the poultry being raised by women on their household plots in Tabasco, Mexico, to sell as Christmas approached, which were then lost in a flood, was estimated at 4.5 million pesos, which was equivalent to $13 \%$ of the value of that state's total poultry output at the time that the disaster hit. In Guatemala, the indigenous weavings (for which there is a great demand in tourism markets) and raw materials destroyed by Hurricane Stan in 2005 were valued at 43 million quetzales (ECLAC, 2005 and 2007).

Improving and harmonizing time-use surveys and employment surveys would not only give credit where credit is due, it would also provide a more accurate picture of the region's economies, which could then serve as a foundation for updating public policy and obtaining better returns on investments in agriculture and associated activities. Bringing to light the contribution of rural women to countries' economies could also serve as a valuable means of empowering women.

25 Generally speaking, small-scale producers do not distinguish between production for consumption and that intended for sale, and their profit margins can be difficult to identify. It is therefore important to support NGOs offering training in business management to small production units so that they can maintain adequate records and make cost estimates, including the value of the work of family members. 


\section{E. Conclusion}

In sum, the economic and social foundation of the patriarchal model in rural areas has undergone significant changes, leading to processes that have tended to reduce women's economic dependence on male providers. However, gender inequality in the area of unpaid work persists, as confirmed by the disparities between employed men and women - to the disadvantage of women - in their participation in and time contribution to care work. Then there is the invisibility of the economic contribution of rural women in the area of market production, pointing to the influential cultural attitudes and ideological positions inherent to the system.

The changes that have taken place are resulting in households where both spouses are employed, especially in Ecuador. Wage employment in agricultural and non-agricultural activities, whether in relation to agribusiness or commerce, has offered one way of breaking with the traditional patriarchal model. Despite the difficulties that women in this category of employment currently face owing to a lack of care services, infrastructure and other basic services, it has given them the opportunity to earn their own tangible income, take an active role in society and become aware of their rights as workers, including the principle of freedom of association and the right to organize. In this regard, the situation of women employed in floriculture in Ecuador is worthy of particular note (Newman, 2002; Salazar Salinas, 2009). ${ }^{26}$ It is interesting to note, moreover, that female wage earners devote more time to their economic activities and less time to care than self-employed female workers and unpaid female workers in the three countries.

While certain non-agricultural activities that have led to increased wage employment, including among rural women, family farming continues to be a very important activity in all three countries. Women play a crucial production role in this family farming, notwithstanding the shortcomings of public policy in this area in recent decades, the deterioration in production conditions for small agricultural enterprises and declining living conditions for the families that run small-scale farms.

The case of unpaid female workers merits closer scrutiny: these women spend a similar amount of time engaged in economic activities and unpaid work as people who are paid for their labour, but they

26 These changes, which are strongly influenced by countries' cultural, legal and ideological characteristics, can be fast or slow, but the transition that women are making towards being recognized (both by others and by themselves) as economic and social agents is a significant step forward, as shown in a study on wage earners employed in floriculture in Ecuador (Newman, 2002). 
lack economic autonomy and independence, which sets the stage for disregard and mistreatment. Appropriate legislation and practical measures are needed to assert these women's right to a wage and to the corresponding social benefits.

A core policy package is therefore needed to provide support for agricultural and non-agricultural production. In all three countries, but particularly in Ecuador, family farms (especially those run by women) need support in the form of financing, technical advisory services, training and producer associations so that they can become links in existing agribusiness and commercial chains.

It is also necessary to strengthen the new processes that are gaining ground in the countries of Latin America as closer links are forged between rural areas and more economically buoyant urban areas. These links are paving the way for employment opportunities in more productive, higher-paying jobs. Low education levels are a barrier to obtaining such jobs in non-agricultural sectors as they call for specialist knowledge that rural women do not possess. In all three countries included in this study, but especially in Guatemala, only a very small percentage of women have completed secondary school or a technical course of instruction (13 years or more of schooling), ${ }^{27}$ which tends to be a requirement for the more productive and higher-paying jobs that are created when a certain combination of factors and conditions are present. ${ }^{28}$

This situation is linked not only to negative social indicators in terms of education, but also to the quality and amount of time available to the current and future generations of rural women. More specifically, the question arises as to whether the majority of these women have the time to study or obtain the training that they would need to take advantage of these higher-skilled job opportunities. If they did, it would

27 In 2006, less than $1 \%$ of economically active rural women in Guatemala had completed 13 years or more of schooling (ECLAC, 2010). The percentages were higher in Ecuador (6.3\% in 2009) and Mexico (8.2\% in 2008), but were still low.

28 According to a series of studies focusing on rural non-farm employment, a number of factors have to be in place in order for this type of employment (which may be either own-account or wage employment) to be more productive and pay better than jobs in the farm sector or in the types of rural non-farm jobs that can be described as representing a last resort. Those factors include economic buoyancy in the region concerned owing to the presence of "growth drivers" (tourism, industry, agribusiness, services, etc.), urban-rural connectivity (infrastructure) and a sufficiently educated and informed workforce (Reardon and Berdegué, 2004; ECLAC, 2003; Dirven, 2011; Bentancor and Modrego, 2011). 
benefit both society and the economy as a whole, since this type of transition has been shown to be a decisive factor in the reduction of rural poverty. ${ }^{29}$

In order for women, including indigenous women, to avail themselves of their inalienable right to make better use of their time to enhance their stock of human capital, a new approach needs to be taken to the design of public policies to promote investments that will speed up the pace of technological and social progress in rural areas with a view to boosting women's productivity both in relation to their economic activities and unpaid care work. ${ }^{30}$ Furthermore, it is hoped that these investments will lead to the creation of suitable institutional networks for the delivery of services to children and older adults so that women can have the time to attend educational venues or training courses provided by public or private agencies or NGOs, and thus have the time to generate their own income and to devote to their own well-being. ${ }^{31}$

Although the above-mentioned measures are certainly called for, gender inequality must be addressed by establishing new cultural constructs and crafting a more advanced legal structure that will break down the stereotypes that have led to the undervaluation of women's rights and their contributions to their households, the economy and society. Providing support to both sexes will enable them to share the time devoted to paid and unpaid work more equally.

29 Between 1990 and 2005, the labour-force participation rate for women in rural areas jumped by $70 \%$ in Chile, $129 \%$ in Ecuador and 103\% in Mexico. In these same countries, poverty and extreme poverty levels in rural areas fell by more than twice as much as they did in Latin America as a whole (ECLAC/FAO/ILO, 2010).

30 It is important to remember that fetching water is a time-consuming chore for many women. Building infrastructure or finding suitable means of supplying rural households with water would lighten these women's workload and save them time. The lack of running water in the home makes it necessary for women to spend more time performing production activities for own consumption and acts as a constraint on their participation in market production and the average time they can devote to such activities.

31 These training providers should also be backstopped by public institutions. 


\section{Bibliography}

Aguirre, Rosario (2005), “Trabajo no remunerado y uso del tiempo. Fundamentos conceptuales y avances empíricos. La encuesta Montevideo 2003", El tiempo, los tiempos, una vara de desigualdad, Mujer y Desarrollo series, No. 65 (LC/L.2324-P), Santiago, Chile, Economic Commission for Latin America and the Caribbean (ECLAC), July. United Nations publication, Sales No. S.05.II.G.71.

Ballara, Marcela and Soledad Parada (2009), El empleo de las mujeres rurales. Lo que dicen las cifras, Santiago, Chile, Economic Commission for Latin America and the Caribbean (ECLAC)/Food and Agriculture Organization of the United Nations (FAO).

Batthyány, Karina (2011), "Autonomía de las mujeres y división sexual del trabajo", Las familias latinoamericanas interrogadas. Hacia la articulación del diagnóstico, la legislación y las politicas, Seminarios y Conferencias series, No. 61 (LC/L.3296-P), Santiago, Chile, Economic Commission for Latin America and the Caribbean (ECLAC).

Bentancor, Andrea and Félix Modrego (2011), "Estrategias de sustento de los hogares rurales y su evolución. Análisis de cuatro países latinoamericanos", Documento de Trabajo, No. 5, Santiago, Chile, "Conocimiento y Cambio en Pobreza Rural y Desarrollo" project, Latin American Center for Rural Development (RIMISP).

Campillo, Fabiola (1994), Productoras de alimentos: politicas agrícolas frente a las mujeres productoras de alimentos en América Latina y el Caribe, San José, Inter-American Institute for Cooperation on Agriculture (IICA)/Inter-American Development Bank (BID).

Cerrutti, Marcela and Georgina Binstock (2011), "Cambios en las familias latinoamericanas y demandas para la acción pública", Las familias latinoamericanas interrogadas. Hacia la articulación del diagnóstico, la legislación y las políticas, Seminarios y Conferencias series, No. 61 (LC/L.3296-P), Santiago, Chile, Economic Commission for Latin America and the Caribbean (ECLAC).

Chiappe, Marta B. (2005), La situación de las mujeres rurales en la agricultura familiar de cinco países de América Latina, Montevideo, Latin American Association of Development Organizations (ALOP), May.

Deere, Carmen (2005), The Feminization of Agriculture? Economic Restructuring in Rural Latin America, United Nations Research Institute for Social Development (UNRISD).

Dirven, Martine (2011), “El empleo rural no agrícola y la disminución de la pobreza rural. ¿Qué sabemos en América Latina en 2010?”, Documento de trabajo, No. 2, Santiago, Chile, Latin American Center for Rural Development (RIMISP).

Durán Heras, María Ángeles and Jesus Rogero García (2009), "La investigación sobre el uso del tiempo", Cuadernos metodológicos, No. 44, Madrid, Centro de Investigaciones Sociológicas (CIS).

ECLAC (Economic Commission for Latin America and the Caribbean) (2010), Social Panorama of Latin America, 2010 (LC/G.2481-P), Santiago, Chile. United Nations publication, Sales No. E.11.II.G.6.

(2007), México: Notas sobre el financiamiento rural y la política crediticia agropecuaria (LC/MEX/L.825), Mexico City, ECLAC subregional headquarters in Mexico. (2005), Efectos en Guatemala de las lluvias torrenciales y la tormenta tropical Stan, (LC/MEX/R.895), Mexico City, ECLAC subregional headquarters in Mexico. 
(2003), Empleo e ingreso en las actividades rurales no agropecuarias de Centroamérica y México (LC/MEX/L.577), Mexico City, ECLAC subregional headquarters in Mexico.

ECLAC/FAO/IICA (Economic Commission for Latin America and the Caribbean/ Food and Agriculture Organization of the United Nations/Inter-American Institute for Cooperation on Agriculture) (2010), The Outlook for Agriculture and Rural Development in the Americas: A perspective on Latin America and the Caribbean, Santiago, Chile.

ECLAC/FAO/ILO (Economic Commission for Latin America and the Caribbean/ Food and Agriculture Organization of the United Nations/International Labour Organization) (2010), Politicas de mercado de trabajo y pobreza rural en América Latina, Santiago, Chile, FAO Regional Office for Latin America and the Caribbean.

FAO/IFAD/ILO (Food and Agriculture Organization of the United Nations/ International Fund for Agricultural Development/International Labour Organization) (2010), Gender Dimensions of Agricultural and Rural Employment: Differentiated Pathways out of Poverty, Rome.

Gómez Luna, M.E. (2010), “Directrices y referentes conceptuales para armonizar las encuestas de uso de tiempo en América Latina y el Caribe", paper presented at the International Meeting on Time-Use Statistics and Public Policies, Mexico City, 30 June - 2 july [online] http://www.eclac.cl/mujer/noticias / noticias/3/40283/MariaGomez.pdf.

Hopenhayn, Martín (2011), "Igualdad y derechos: una mirada a las familias", Las familias latinoamericanas interrogadas. Hacia la articulación del diagnóstico, la legislación y las políticas, Seminarios y Conferencias series, No. 61 (LC/L.3296-P), Santiago, Chile, Economic Commission for Latin America and the Caribbean (ECLAC).

INEGI (National Institute of Statistics and Geography) (2009), "Encuesta Nacional sobre el Uso del Tiempo. ENUT 2009. Síntesis metodológica" [online] http:/ / www.inegi.org.mx/est/contenidos/espanol/metodologias/encuestas/ hogares/sm_ENUT2009.pdf.

Ironmonger, Duncan (1996), “Counting outputs, capital inputs and caring labor: estimating gross household product", Feminist Economics, vol. 2, No. 3, Melbourne.

Kleyson, Brenda (1996), Productoras agropecuarias en América del Sur, San José, InterAmerican Institute for Cooperation on Agriculture (IICA)/Inter-American Development Bank (BID).

Kleyson, Brenda and Fabiola Campillo (1996 ), Productoras de alimentos en 18 países de América Latina y el Caribe: sintesis hemisférica, San José, Inter-American Institute for Cooperation on Agriculture (IICA)/Inter-American Development Bank (BID).

Lastarria-Cornhiel, Susana (2008), Feminización de la agricultura en América Latina y África, Tendencias y fuerzas impulsoras, Santiago, Chile, Latin American Center for Rural Development (RIMISP).

Majnoni d'Intignano, Beatrice (1999), Égalité entre femmes et hommes: aspects économiques, Paris, Conseil d'Analyse Économique.

Martínez, Luciano (2000), "La especificidad del empleo rural", Antología de estudios rurales, Quito, Latin American Faculty of Social Sciences (FLACSO)/ International Legume Database and Information Service (ILDIS). 
(1991), Dinámica de los campesinos artesanos en la Sierra Central del Ecuador, Quito, Latin American Faculty of Social Sciences (FLACSO).

Milosavljevic Vivian and Odette Tacla (2008), “Las encuestas del uso del tiempo: su diseño y aplicación", La economía invisible y las desigualdades de género. La importancia de medir y valorar el trabajo no remunerado, Washington, D.C., Washington, D.C., Economic Commission for Latin America and the Caribbean (ECLAC)/ Higher Council for Scientific Research (CSIC)/ Pan American Health Organization (PAHO).

Newman, Constance (2002), "Gender, time use, and change: the impact of the cut flower industry in Ecuador", World Bank Economic Review, vol. 16, No. 3.

Reardon, Thomas, Julio Berdegué and Germán Escobar (2004), “Empleo e ingresos rurales no agrícolas en América Latina: síntesis de implicaciones de políticas", Seminarios y Conferencias series, No. 35 (LC/L.2069-P), Santiago, Chile, Economic Commission for Latin America and the Caribbean (ECLAC).

Rico, María Nieves and Carlos Maldonado Valera (2011), “QQué muestra la evolución de los hogares sobre la evolución de las familias en América Latina?", Las familias latinoamericanas interrogadas. Hacia la articulación del diagnóstico, la legislación y las políticas, Seminarios y Conferencias series, No. 61 (LC/L.3296-P), Santiago, Chile, Economic Commission for Latin America and the Caribbean (ECLAC).

Salazar Salinas, M.G. (2009), Una visión empresarial de la responsabilidad social en la Floricultura, parroquia Ayora, Cayambé, Ecuador, Quito, Latin American Faculty of Social Sciences (FLACSO). 


\section{Annexes}

\section{Annex I}

\section{Methodological notes}

\section{(a) Information sources}

The study used time-use surveys conducted in Ecuador, Guatemala and Mexico.

The databases on Ecuador and Guatemala were prepared by the Statistics and Economic Projections Division of ECLAC, which was also responsible for assessing the consistency of information and generating a new set of variables with a view to comparing the data with that pertaining to other Latin American countries. The database on Mexico was obtained directly from the National Institute of Statistics and Geography (INEGI) of Mexico (www.inegi.org.mx).

Ecuador: National Survey of Employment, Unemployment and Underemployment (ENEMDU), 2007.

A substantial amount of information on households was gathered in the time-use module of this survey on employment, unemployment and underemployment in urban and rural areas conducted nationwide in December 2007 by the National Statistics and Census Institute (INEC).

Sample size: Households: 18,933

Population: 76,922

Expanded sample: Households: 3,405,347

Population: 1,3682,302

Guatemala: National Survey on Living Conditions (ENCOVI), 2006.

Questions on time use were contained in one of the modules of the National Survey on Living Conditions (ENCOVI) conducted nationwide between March and September 2006 by the National Institute of Statistics (INE).

Sample size: $\quad$ Households: 13,686

Population: 68,739

Expanded sample: Households: 2,653,000

Population: $12,987,829$ 
Mexico: National Time-Use Survey (ENUT), 2009.

This specific and independent survey was executed nationwide by the National Institute of Statistics and Geography (INEGI) from October to November 2009.

Sample size: $\quad$ Households: 16,925

Expanded sample: Households: 28,669,293

Population: 107,837,971

\section{(b) Data processing}

The variables used were those included in the modules on time use and employment, as well as other classificatory variables contained in the household surveys, and the time-use survey in the case of Mexico.

The variables referring to time-use activities were categorized using the two-digit and one-digit codes of the Classification of TimeUse Activities for Latin America and the Caribbean (CAUTAL) presented in Gómez Luna (2010). The CAUTAL definitions are consistent with the architecture of the System of National Accounts (SNA).

The time-use variables used are presented in table A.1.

Other variables were defined in order to classify households according to the source of their income. Four household types were identified, namely:

Agricultural households: $100 \%$ of income is from agriculture.

Non-agricultural households: $100 \%$ of income is from activities unrelated to agriculture.

Households dependent on non-labour income: 100\% of income is from transfers.

Diversified or mixed households: those that do not fit into any of the above categories and whose income comes from a combination of agricultural and non-agricultural sources and/or transfers (from the State or family remittances). 


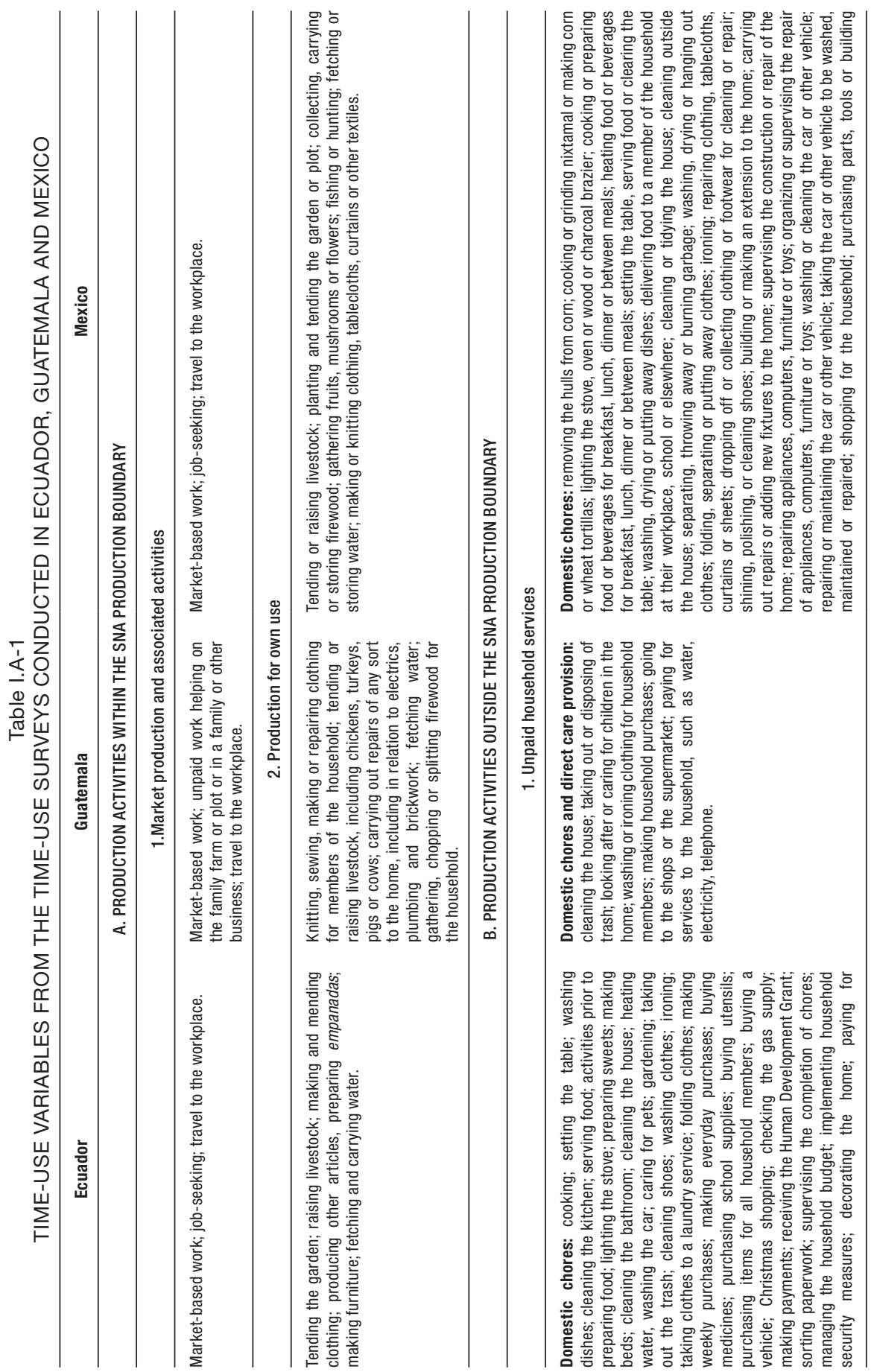




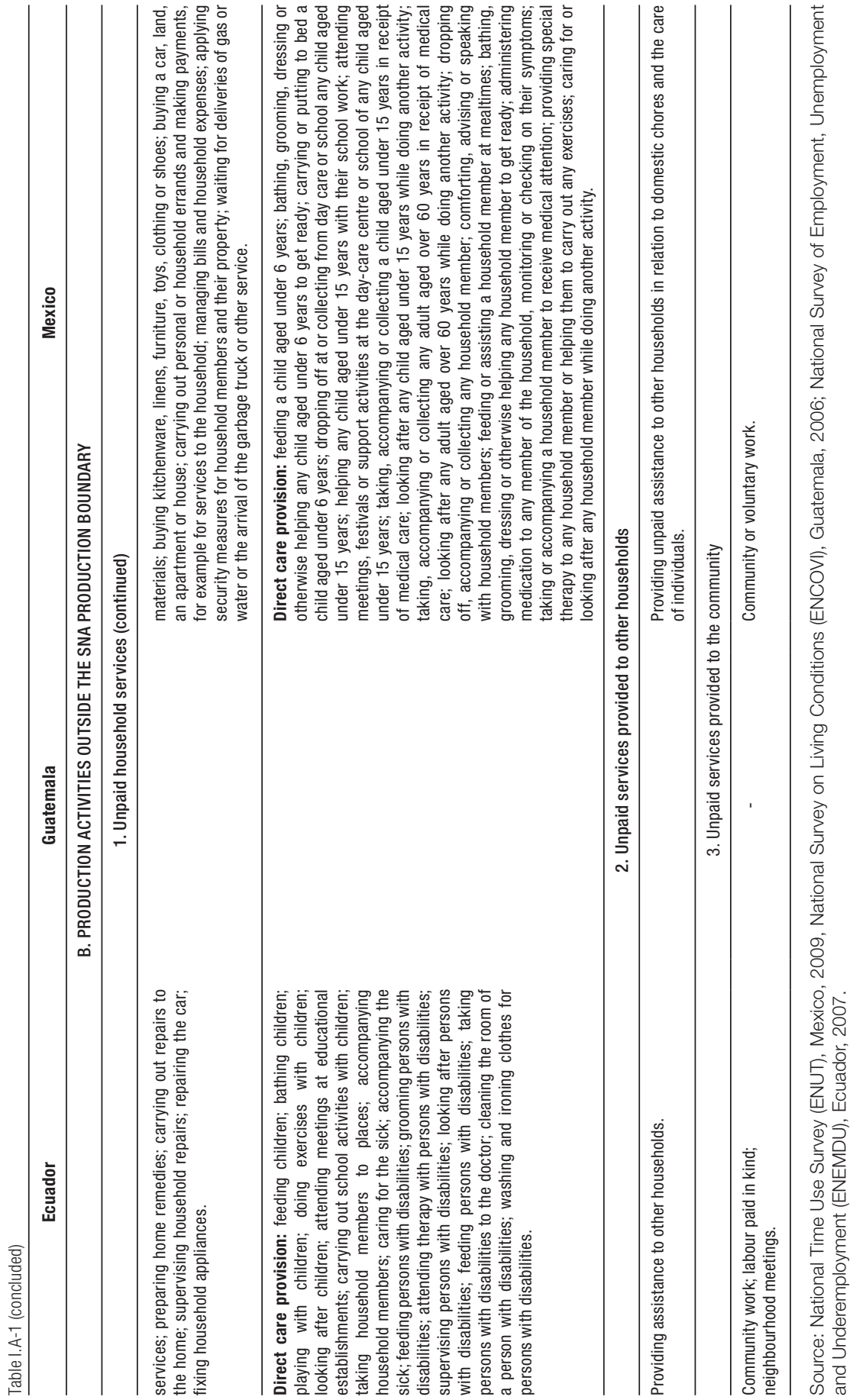




\section{Annex II}

\section{Tables}

Table II.A-1

ECUADOR, GUATEMALA AND MEXICO: AVERAGE TIME SPENT BY THE TOTAL URBAN POPULATION AGED 15 YEARS AND OVER ON THE PRODUCTION OF GOODS AND SERVICES WITHIN AND OUTSIDE THE PRODUCTION BOUNDARY DEFINED BY THE SYSTEM OF NATIONAL ACCOUNTS (Hours per week or per day)

\begin{tabular}{|c|c|c|c|c|c|c|c|c|c|}
\hline & \multicolumn{3}{|c|}{$\begin{array}{c}\text { Ecuador } \\
\text { (Hours per week) }\end{array}$} & \multicolumn{3}{|c|}{$\begin{array}{l}\text { Guatemala } \\
\text { (Hours per day) }\end{array}$} & \multicolumn{3}{|c|}{$\begin{array}{c}\text { Mexico } \\
\text { (Hours per week) }\end{array}$} \\
\hline & Men & Women & $\begin{array}{l}\text { Men and } \\
\text { Women }\end{array}$ & Men & Women & $\begin{array}{l}\text { Men and } \\
\text { Women }\end{array}$ & Men & Women & $\begin{array}{l}\text { Men and } \\
\text { Women }\end{array}$ \\
\hline $\begin{array}{l}\text { Activities } \\
\text { within the } \\
\text { production } \\
\text { boundary }\end{array}$ & 39.97 & 22.75 & 31.00 & 6.81 & 3.55 & 5.03 & 41.54 & 20.71 & 30.53 \\
\hline $\begin{array}{l}\text { Non-SNA } \\
\text { production }\end{array}$ & 11.60 & 37.43 & 25.05 & 0.95 & 5.45 & 3.41 & 18.12 & 50.88 & 35.44 \\
\hline Total & 51.57 & 60.18 & 56.05 & 7.76 & 9.00 & 8.44 & 59.66 & 71.59 & 65.97 \\
\hline
\end{tabular}

Source: National Time-Use Survey (ENUT), Mexico, 2009; National Survey on Living Conditions (ENCOVI), Guatemala, 2006; National Survey of Employment, Unemployment and Underemployment (ENEMDU), Ecuador, 2007.

Table II.A-2

ECUADOR AND GUATEMALA: LABOUR PARTICIPATION RATE FOR ECONOMIC ACTIVITY WITHIN THE PRODUCTION BOUNDARY DEFINED BY THE SYSTEM OF NATIONAL ACCOUNTS BASED ON TIME USE BY SEX AND AGE, TOTAL RURAL POPULATION AGED 15 YEARS AND OVER (Percentages)

\begin{tabular}{lccccccc}
\hline & \multicolumn{3}{c}{ Ecuador } & & \multicolumn{3}{c}{ Guatemala } \\
\cline { 2 - 3 } \cline { 7 - 8 } & Men & Women & Total & & Men & Women & Total \\
\hline 15 to 19 years & 76.3 & 63.0 & 70.1 & & 76.7 & 56.5 & 66.1 \\
20 to 29 years & 95.0 & 81.6 & 88.4 & & 87.3 & 63.0 & 73.4 \\
30 to 39 years & 98.0 & 88.1 & 93.0 & & 89.1 & 69.9 & 78.5 \\
40 to 49 years & 98.5 & 90.9 & 94.7 & & 87.5 & 71.8 & 79.3 \\
50 to 59 years & 97.6 & 88.1 & 92.8 & & 87.5 & 68.7 & 77.5 \\
60 to 69 years & 94.4 & 84.0 & 89.3 & & 85.5 & 66.1 & 75.8 \\
70 years and over & 76.9 & 63.3 & 70.3 & & 71.0 & 44.5 & 58.8 \\
Total & 91.6 & 80.9 & 86.3 & & 84.3 & 64.1 & 73.4 \\
\hline
\end{tabular}

Source: National Survey on Living Conditions (ENCOVI), Guatemala, 2006; National Survey of Employment, Unemployment and Underemployment (ENEMDU), Ecuador, 2007. 
Table II.A-3

MEXICO: LABOUR PARTICIPATION RATE FOR ECONOMIC ACTIVITY WITHIN THE PRODUCTION BOUNDARY DEFINED BY THE SYSTEM OF NATIONAL ACCOUNTS BASED ON TIME USE BY SEX AND AGE, TOTAL RURAL POPULATION AGED 15 YEARS AND OVER (Percentages)

\begin{tabular}{lccc}
\hline & Men & Women & Total \\
\hline 15 to 19 years & 73.7 & 45.8 & 60.2 \\
20 to 29 years & 91.1 & 61.7 & 75.0 \\
30 to 39 years & 95.7 & 70.6 & 82.1 \\
40 to 49 years & 94.9 & 71.5 & 82.7 \\
50 to 59 years & 94.2 & 69.2 & 81.5 \\
60 to 69 years & 85.0 & 63.9 & 74.6 \\
70 years and over & 69.8 & 46.1 & 58.9 \\
Total & 88.0 & 62.9 & 75.0 \\
\hline
\end{tabular}

Source: National Time-Use Survey (ENUT), Mexico, 2009. 


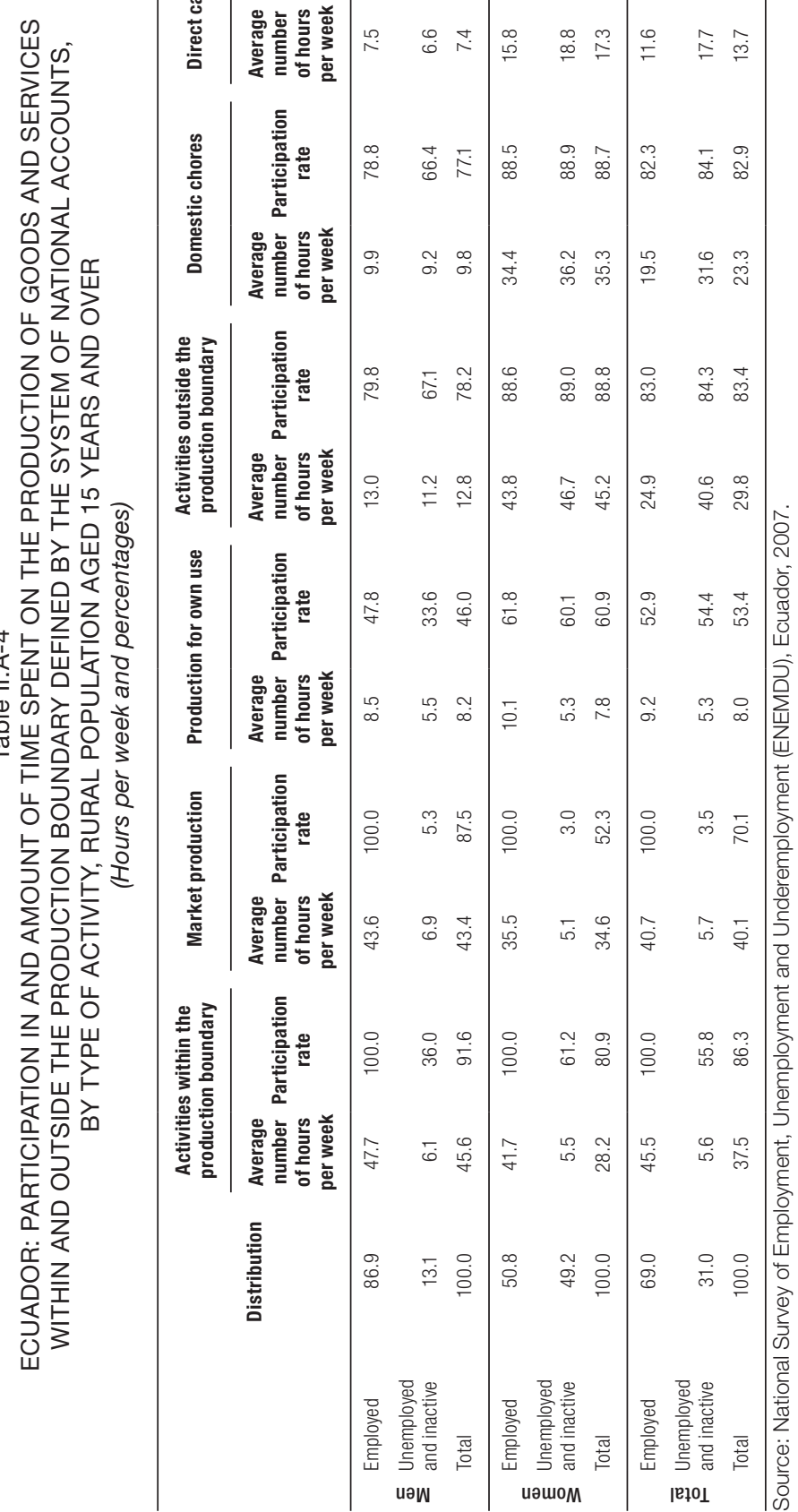




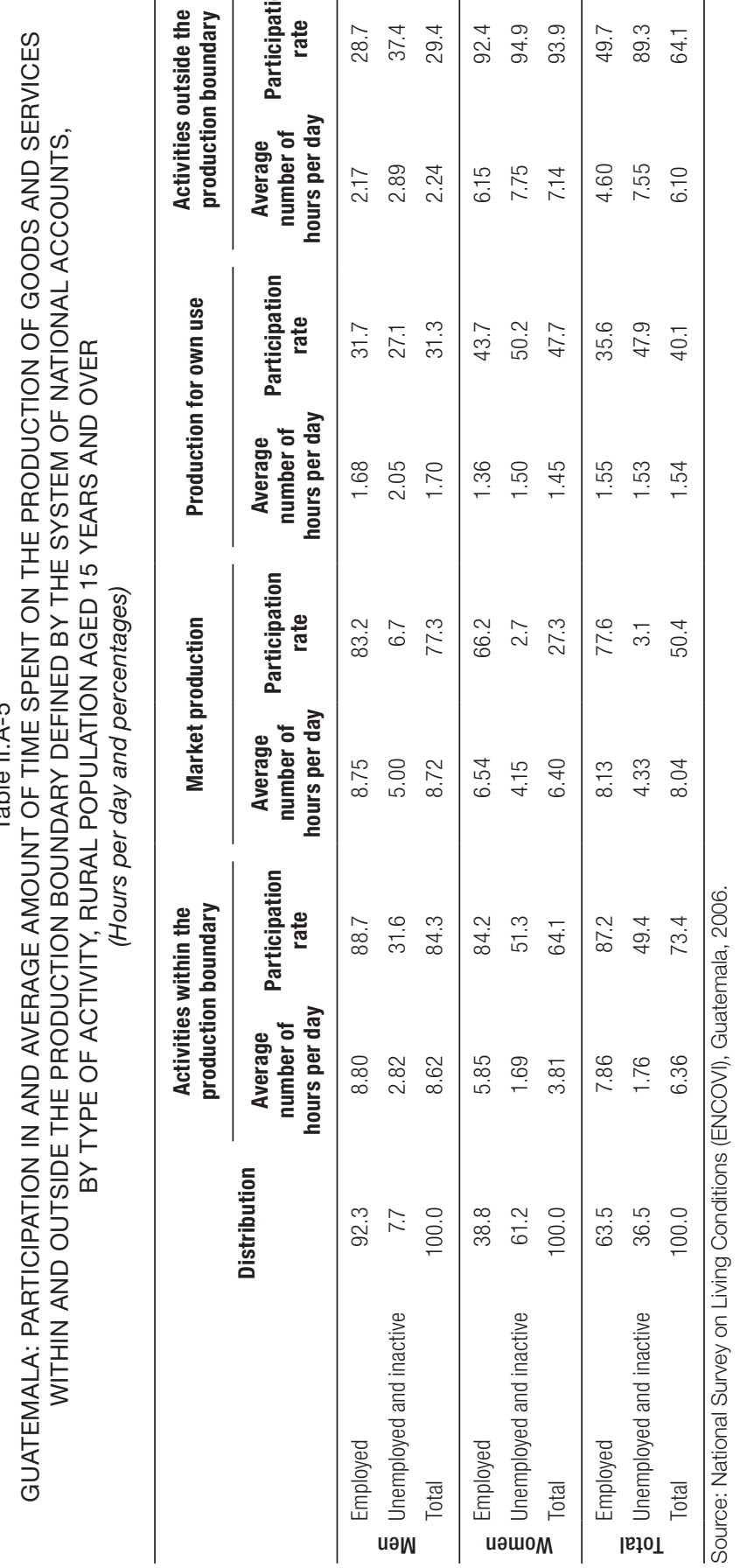




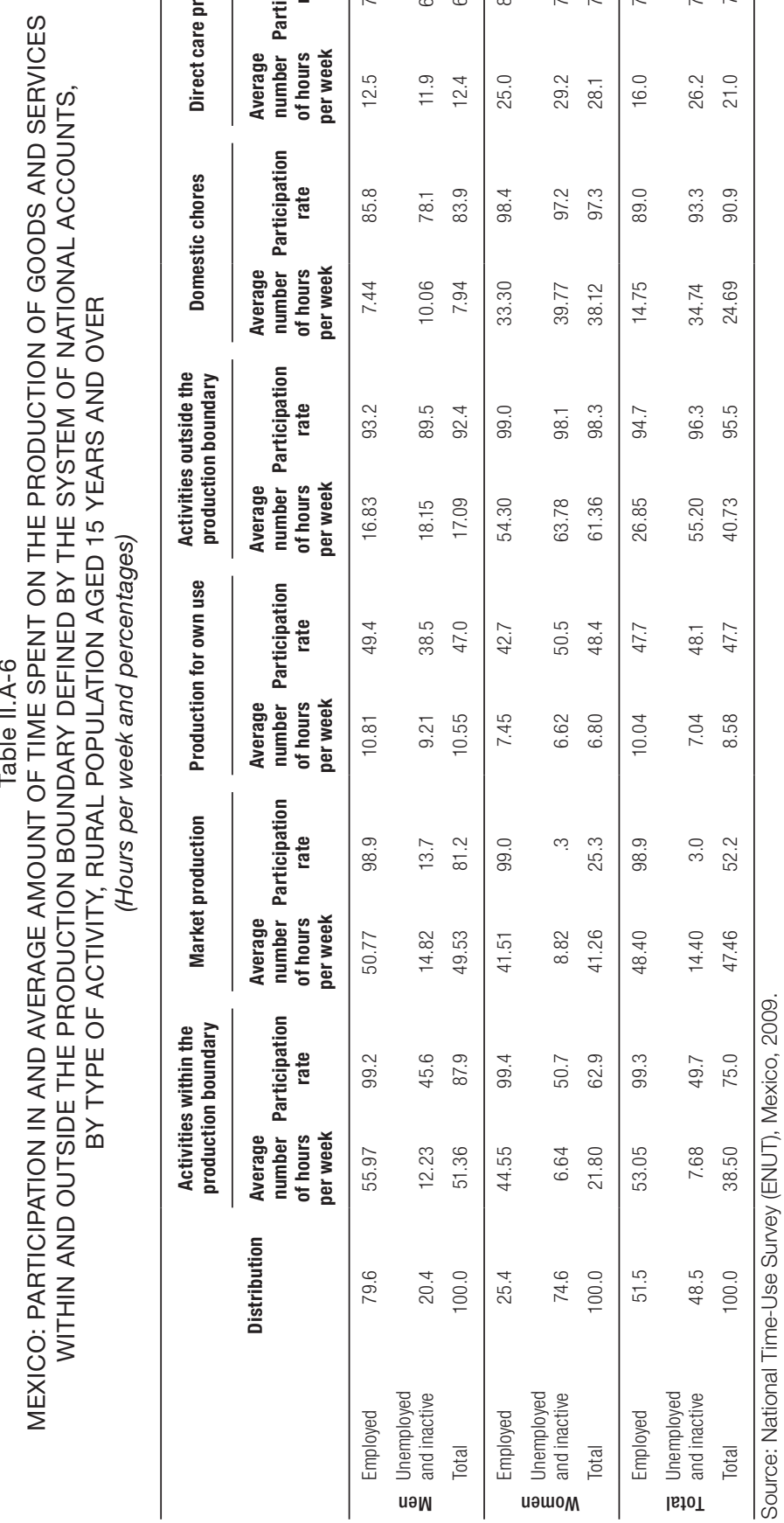


Table II.A-7

ECUADOR, GUATEMALA AND MEXICO: DISTRIBUTION OF RURAL HOUSEHOLDS

COMPRISING A HEAD OF HOUSEHOLD AND SPOUSE BY THE COUPLE'S

EMPLOYMENT STATUS

(Percentages)

\begin{tabular}{lccc}
\hline & Ecuador & Guatemala & Mexico \\
\hline Neither is employed & 4.4 & 21.8 & 11.3 \\
Head of household and spouse are employed & 48.6 & 25.3 & 18.0 \\
Head of household is employed and spouse is not & 45.6 & 52.3 & 68.7 \\
Head of household is unemployed and spouse is employed & 1.4 & 0.6 & 1.9 \\
Total & 100.0 & 100.0 & 100.0 \\
\hline
\end{tabular}

Source: National Time-Use Survey (ENUT), Mexico, 2009; National Survey on Living Conditions (ENCOVI), Guatemala, 2006; National Survey of Employment, Unemployment and Underemployment (ENEMDU), Ecuador, 2007.

Table II.A-8

ECUADOR AND GUATEMALA: DISTRIBUTION OF RURAL HOUSEHOLDS

BY SOURCE OF INCOME

(Percentages)

\begin{tabular}{lclr}
\hline & Ecuador & Guatemala \\
\hline Agricultural households & 37.7 & Agricultural households & 39.4 \\
Non-agricultural households & 19.4 & Non-agricultural households & 33 \\
Households dependent on non-labour income & 6.9 & Households dependent on non-labour income & 3.9 \\
Mixed households & 36.0 & Mixed households & 23.8 \\
Total & 100 & Total & 100 \\
\hline
\end{tabular}

Source: National Survey on Living Conditions (ENCOVI), Guatemala, 2006; National Survey of Employment, Unemployment and Underemployment (ENEMDU), Ecuador, 2007. 


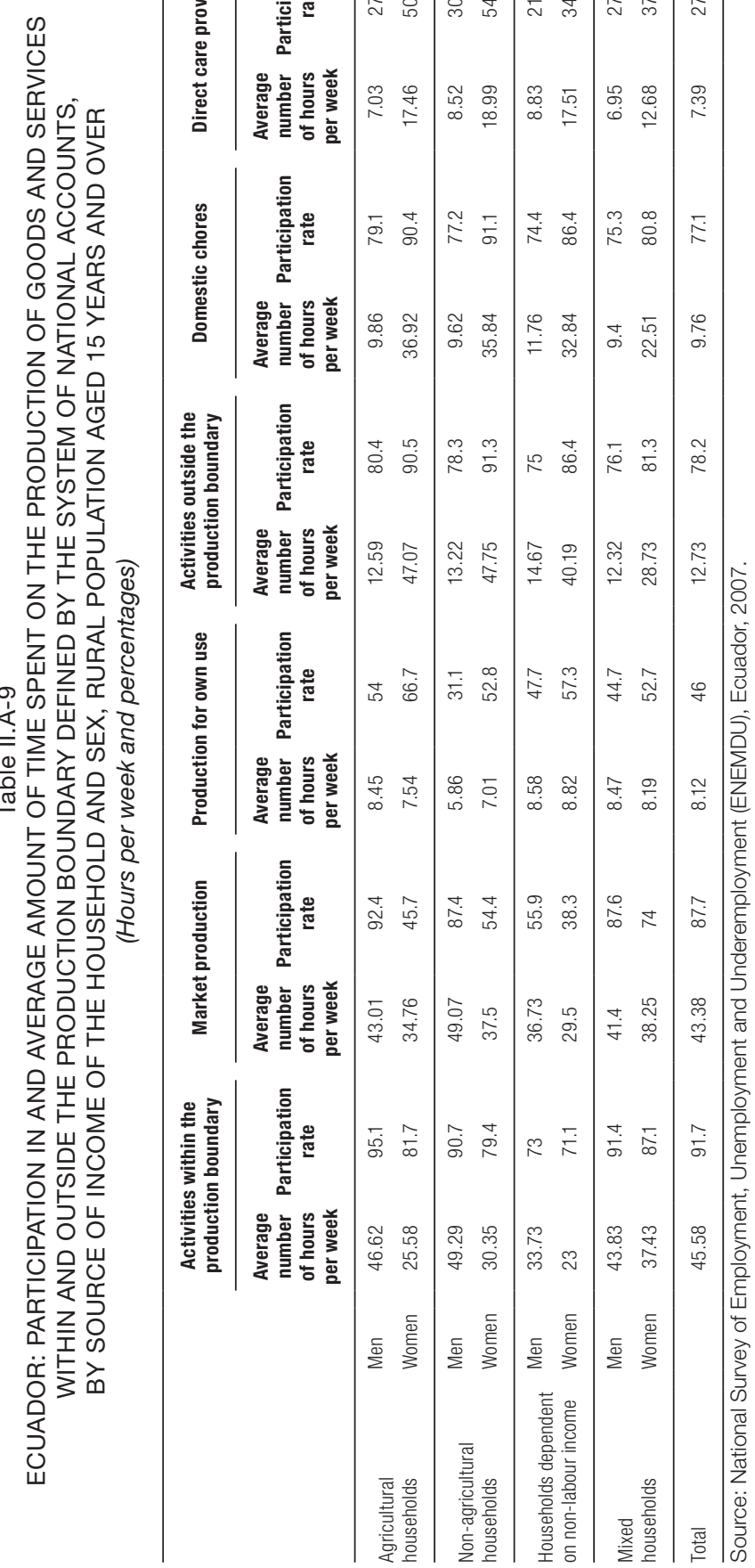




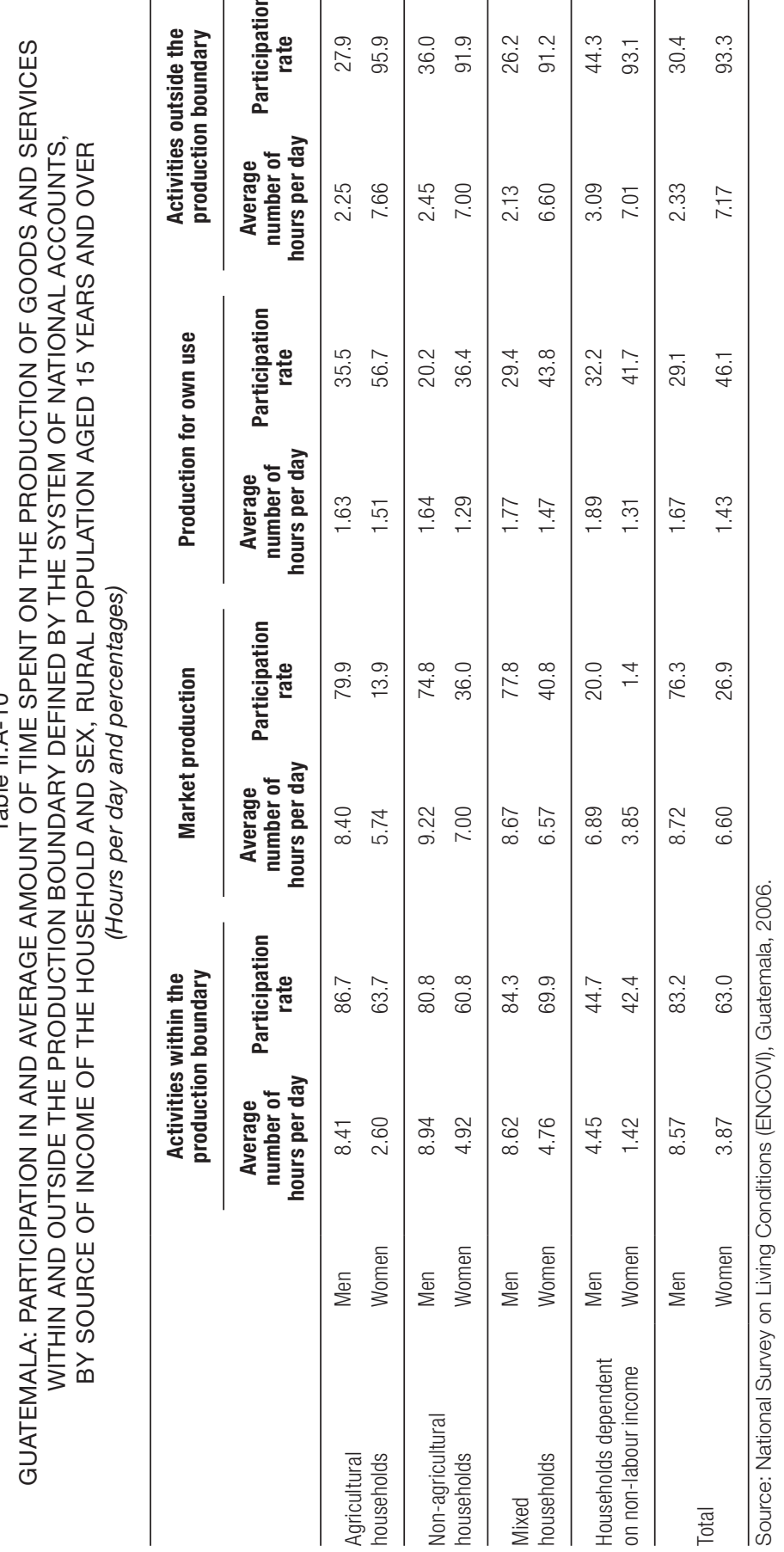




\section{Annex III}

\section{Measurement of labour participation and time devoted to production for own use}

Figure III.A-1

QUESTION ON LABOUR PARTICIPATION AND TIME DEVOTED TO PRODUCTION FOR OWN USE IN THE NATIONAL TIME-USE SURVEY OF MEXICO, 2009

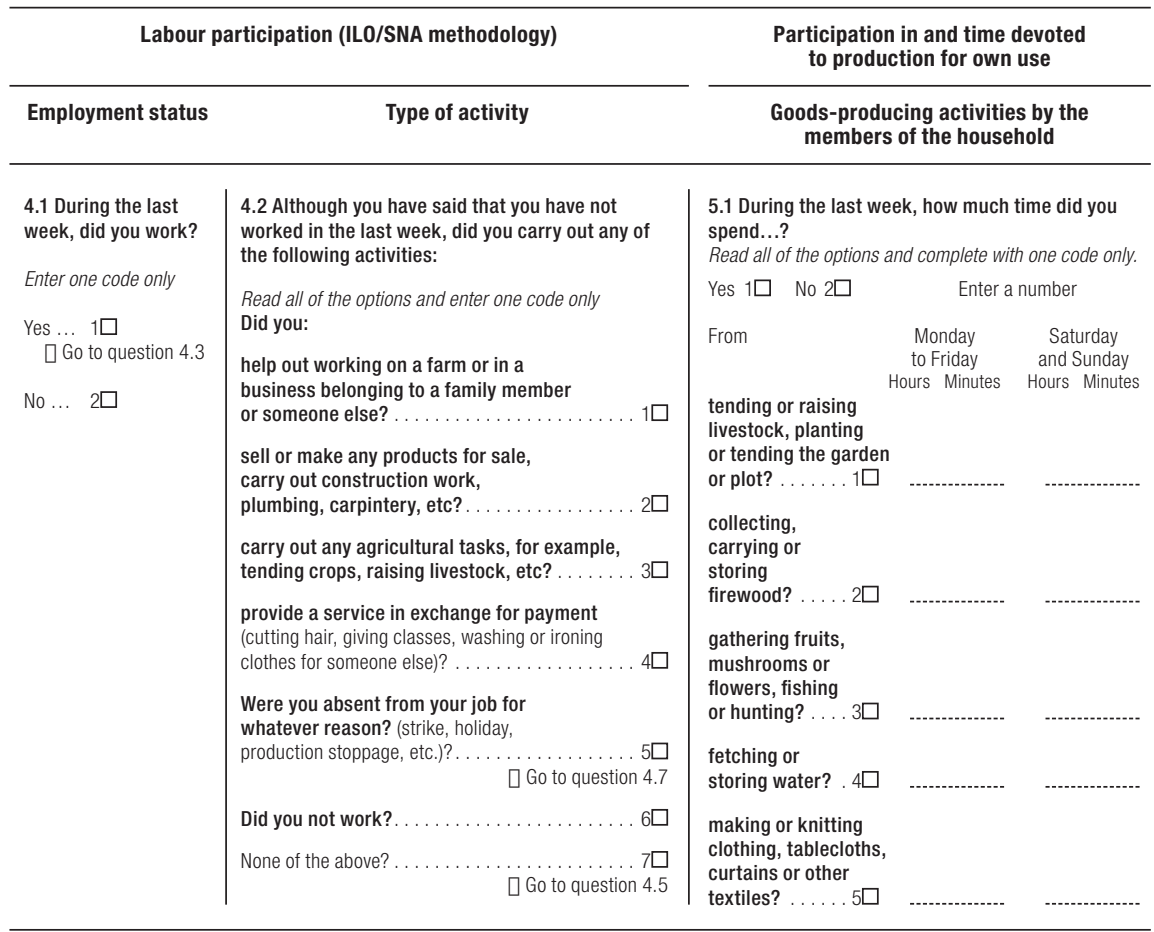

Source: National Time-Use Survey (ENUT), Mexico, 2009 [online] http://www.inegi.org.mx/sistemas/ microdatos2/Microdatos_archivos/enut/2009/doc/cuest_enut2009.pdf (ECLAC translation). 
Chapter II

\title{
Models of the intrahousehold division of total labour: Ecuador and Mexico
}

\author{
Soledad Salvador \\ (with the collaboration of Estefanía Galván)
}

The aim of this report is to provide a more in-depth study into the distribution of total labour (paid and unpaid) among the members of different types of household and analyse the determining factors. A distinction is made between two-parent, lone-parent and extended households, because work is organized according to different rationales within them, based on the sexual and inter-generational division of labour. The cases of Ecuador and Mexico are studied on the basis of time-use, employment and income surveys in both countries.

\section{A. Theoretical framework for the analysis}

The sexual division of labour (the unequal distribution of paid and unpaid work among men and women) is the basis for a society's gender inequalities. The fact that women are concentrated in the reproductive sphere places them in a subordinate position when it comes to negotiating the distribution of power and resources in society. This is because reproductive work carried out within households tends to be 
unpaid, a daily requirement and is taken for granted (it is thought that someone will limitlessly take responsibility for carrying it out). ${ }^{1}$

\section{Sexual division of labour and social organization of care}

One immediate consequence of the sexual division of labour is women's disadvantaged position in the labour market. Despite having increased their labour participation, they still work fewer paid hours, have higher unemployment rates, more job insecurity and experience occupational segregation and labour discrimination that results in a lower income. ${ }^{2}$ Beyond the progress made, women's political and industry participation remains limited. ${ }^{3}$

Esping-Andersen (2009), in the recent publication The Incomplete Revolution. Adapting to Women's New Roles, suggests that women's roles have undergone an incomplete revolution because the changes have been more focused on economic matters than on family life, and that the revolution has been highly stratified (which leads to greater social inequality). Esquivel (2011) finds that, in Latin America, income inequality is a central aspect of economic functioning, as gender inequalities for unpaid work are superimposed on (and mutually reinforced by) inequality in labour income.

However, it is not only how paid and unpaid work is distributed in the home that is important, but also the extent to which the State, market and community provide services and benefits to help reduce the burden of care in the household (as part of what is termed the social organization of care). There are institutional factors that shape this distribution, such as legislation on paid working hours, regulations on work leave and conditional income transfer policies. ${ }^{4}$

Elson (2002) states that ignoring this work in formulating policies and policy models presupposes that women have a limitless capacity for carrying it out. In other words, if the income and resources required to produce and maintain human resources become scarce, women are expected to have the time and capacity needed to compensate for such problems.

2 For an analysis of these repercussions in various countries, see Antonopoulos (2008).

3 There are studies about other countries, such as that by Álvarez and Miles (no date) on Spain, which describes the adverse effects of the unequal distribution of paid and unpaid work on the subjective well-being of women. The analysis focuses on couples in which both individuals have paid work, and analyses their subjective well-being by asking them about their level of life satisfaction.

4 For an empirical analysis of the various interactions between the sexual division of labour and the provision of services and benefits by the State, market and community (particularly in terms of child care in several Latin America countries), see Montaño and Calderón (2010). For a theoretical analysis on possible links between the sexual division of labour and various types of policy (social, macroeconomic and labour), see Rodríguez and Esquivel (2011). 
As posited by Picchio (1999), it should be borne in mind that unpaid work in the family sphere is the heart of the social reproduction process that is ultimately responsible for harmonizing other forms of work and/ or absorbing any deficiencies. Rather than just distributing this work among various institutions (State, market, family and community) and between sexes, we must also ensure that work carried out in the household and family sphere is not distorted by prevailing logic in the labour market and the supply of services and benefits that seek to contribute to this work. This refers to the ideal worker model, which is increasingly associated with the person with no family responsibility who can be freely available to work longer or inflexible hours, and who is offered working hours that do not include overtime (or travel time) or do not cover the needs of the person requiring care (for instance, transport to the place of service delivery). At the same time, health services are increasingly seeking to transfer some care tasks to families, as part of strategies developed to improve efficiency in the sector.

\section{Time-allocation models}

Analysing the distribution of time for paid and unpaid work in households tends to involve looking at factors that explain the distribution. Several theoretical approaches have been developed for this purpose. One of the pioneering approaches from an economic perspective was introduced by Gary Becker (1965), who used neoclassical assumptions to suggest that the distribution of domestic, care and market work fits in with the theory of comparative advantages. This means that household members specialize in tasks in which they are the most productive, as an efficiency criterion prevails. Women therefore carry out domestic and care work (unpaid work) and men carry out market work (paid work). Many criticisms have been levelled at this approach, including the one that it ignores the dynamics of conflicts of interest, bargaining and power relations within households (Gardiner, 1997).

Alternative approaches include bargaining models, and particularly Amartya Sen's proposed "cooperative conflicts". In cooperative conflict models, the organization of labour and resources within families are thought to be the result of bargaining among members, and particularly between individuals in a couple. These models assume that the fact that household members are dependent on each other for the production and distribution of (commercial and non-commercial) goods and services makes it in their interest to cooperate, although this does not eliminate conflict in the distribution of tasks and resources. Sen (1985, cited in Gardiner, 1997) suggests that members of a couple have an interest in cooperating to raise their standard of living above that which they would 
have achieved without the other person. The conflict of interests arises in terms of how to distribute the rewards of this cooperation and how to allocate paid and unpaid work. The conflict is resolved to the advantage of the individual with the greater economic 'fall-back'. This fall-back depends on individual capacity, income, wealth, retirement rights and access to State support or other family members. It is generally considered that the position of men and women in paid work outside the domestic unit is what defines their bargaining power within the unit and the distribution of economic resources among members. Folbre and Hartmann (1988, cited in Gardiner, 1997) suggest that this motivates women to increase their participation in the labour market. In a model developed by Ott (1992, cited in Gardiner, 1997), women's bargaining power is thought to increase in line with their level of education and independent income, while this bargaining power is thought to decrease in proportion with the husband's income and if there are children in the household. ${ }^{5}$

Lastly, there are other views, such as "assortative mating", whereby people with similar preferences in terms of dedication to paid or unpaid work tend to come together. In this case, the dedication of both partners is similar, unlike the approaches described above. Deding and Lausten (2006) state that, despite being based on different arguments, the comparative advantages approach (Becker) and the bargaining models lead to similar predictions in terms of distribution of paid and unpaid work in couples. In both cases, each partner in the couple allocates more time to one type of work and less to the other. Under the "assortative mating" approach, both partners will allocate similar amounts of time to both types of work.

Lastly, it is worth mentioning approaches based on "doing gender", which consider that the day-to-day lives of couples reproduce and support the cultural rules of gender division of labour in the household. Gender becomes the main identity that cancels out other mechanisms of labour allocation. As a result, women carry out the largest proportion of work in the household, while men carry out the bulk of paid work.

Various empirical studies (Esquivel, 2009; Deding and Lausten, 2006) affirm that there is no single model operating here, but that there may be a combination of models. For instance, Esquivel (2009) concludes that economic incentives and "doing gender" are relevant to explain behaviour in Buenos Aires households. The findings of Deding and Lausten (2006) demonstrate that the "assortative mating" theory and "doing gender" can be observed in Danish couples.

\footnotetext{
5 Agarwal (1997) carries out a more detailed analysis of possible determining factors of bargaining power, and critiques the conclusions of these models.
} 


\section{B. Background}

There are two clear trends in Latin America in terms of time spent by men and women on paid and unpaid work (Montaño, 2010):

(i) In all countries, for which data were available, total time spent working (paid and unpaid) is greater for women.

(ii) In all cases, women spend a larger proportion of their time on unpaid work.

Espejo, Filgueira and Rico (2010) analysed changes in unpaid working hours over a lifetime by sex and household income quintile in five countries (including Ecuador and Mexico). They found that women's burden of unpaid work and the intensity of variations were very different depending on the stage of the life cycle and level of household income (although this was not the case among men).

Such evidence has also been found in northern countries (in Europe and North America). According to Orloff (2002), there are country variations in terms of the quality of work carried out by women, and how paid and unpaid work are combined, but the basic pattern remains the same: men "specialize" in paid work and do little around the house, while women bear most of the burden of unpaid work (increasingly in combination with employment).

\section{Ecuador}

Information on Ecuador shows that being a woman, in a rural area, with low levels of education and from an indigenous background combine to produce the worst conditions for being overworked. Ethnicity appears to be the variable most strongly associated with discrimination, as indigenous men work substantially more hours per week on average than Afro-descendents or Mestizos (Pérez, Vásconez and Gallardo, 2008).

Living as a couple does not alleviate the work overload, but rather increases it and accentuates social role allocation. Depending on the type of task, men and women participate differently in domestic activities: food preparation and caring for children and the disabled is mainly carried out by women, whereas men spend more time on, inter alia, repairing and maintaining housing or services. The difference in the average number of hours men and women spend on paid work is smaller than the difference in the average time spent on unpaid work (an average of 8 hours difference for paid work and 23 hours difference for unpaid work) (Pérez, Vásconez and Gallardo, 2008). 
Armas, Contreras and Vásconez (2009) suggest a probable positive correlation between poverty and domestic workload, stating that the greater workload for the poorest women and families could be attributable to several reasons, including: greater number of children, lack of support from services and infrastructure, and fewer opportunities to earn their own income. The authors found that having children under the age of 5 almost doubles women's workloads, although this does not impact men. As the number of children under the age of 5 increases, men spend more time carrying out paid work, whereas women change in the opposite direction (towards more unpaid work). This means that, when a larger family results in the need for a higher income, the impact is absorbed by the unpaid care economy rather than the market economy (because of the structure of the labour market).

\section{Mexico}

A study of the 2009 National Time-Use Survey by the Federal Government and the National Institute of Women (INMUJERES) shows that women spend $47.7 \%$ of their time on domestic work and care work. For men, on the other hand, most of their weekly time is taken up by working in the labour market. Among the indigenous and rural population, the gender gaps are wider, as men spend more time on paid work and women spend longer on unpaid work. As in Ecuador, the overall work burden is greater for indigenous men and women. Taking the employed population alone, total time indicators increase and gender gaps are doubled (and tripled) among the indigenous population.

Non-attendance at school among young people and adolescents is related to their greater participation in domestic work and care work (especially among women).

\section{Descriptive analysis}

The statistical information used to analyse the case of Ecuador is the National Employment, Unemployment and Underemployment Survey (ENEMDU) from December 2007, which included the 2007 National Time-Use Survey. For Mexico, the 2009 National Time-Use Survey was used. The categories used, which are from the classification of time-use activities for Latin America and the Caribbean (CAUTAL), are paid work, unpaid work and personal activities. Unpaid work was disaggregated into three one-digit categories: "unpaid domestic activities for one's own household", "unpaid care for household members" and "unpaid activities for other households, the community and unpaid voluntary work". 
Throughout the analysis, it should be borne in mind that Mexico (unlike Ecuador) records all activities carried out simultaneously, which probably increases the number of hours of unpaid work. Ecuador only records indirect care related to childcare. The survey asks whether the person was looking after a child from the household while carrying out another task. Mexico identifies all activities carried out and then asks which were carried out simultaneously. ${ }^{6}$

In Mexico and Ecuador, men and women spend a similar amount of time on personal activities, and this does not depend on whether they are employed or not. The most significant differences between the sexes were in the time spent on paid work: in Ecuador, men spend almost twice as long as women; while in Mexico time spent by men is easily double that spent by women. In terms of time spent on unpaid work, women spend three times as long in both countries. In the unpaid work category, the largest difference lies in unpaid domestic activities (see table II.1).

Among employed people, women clearly have a double working day, with a similar amount of time spent on both types of work (paid and unpaid), while men spend three times more time on paid than unpaid work.

Lastly, it is interesting to note that employed people who increase the time spent on paid work do not see a significant reduction in unpaid work, but in the time spent on personal activities.

In households including couples, the sexual division of labour is accentuated where there are children. Men carry out more paid work and women carry out more unpaid work when there are children, whereas the time spent by women on paid work and men on unpaid work does not change.

The hours of paid work carried out by female heads of loneparent households are higher than those carried out by female heads or spouses in two-parent households, but they still spend a considerable amount of time on unpaid work (similar to the hours they spend in the labour market). Male heads of lone-parent households work fewer hours of paid work compared with male heads or partners in two-parent households, and they spend longer on unpaid work (although this is still significantly less than the time spent by women). ${ }^{7}$

The most commonly featured simultaneous activities in the 2009 survey were: (a) media use with: personal activities, with housework, with food preparation/clothing and shoe care and with studying or paid work; (b) food preparation with laundry and clothing and shoe care, or housework; and (c) housework with laundry, and clothing and shoe care.

7 In Ecuador and Mexico, 82\% and 88\% (respectively) of lone-parent households are headed by women. 
Table II.1

ECUADOR AND MEXICO: AVERAGE TIME SPENT BY THOSE AGED OVER 12 ON PAID WORK, UNPAID WORK AND PERSONAL ACTIVITIES, BY SEX ${ }^{a}$ (Hours per week)

\begin{tabular}{|c|c|c|c|c|c|c|}
\hline \multirow{2}{*}{$\begin{array}{l}\text { Category of activities } \\
\text { under CAUTAL }{ }^{\mathrm{b}}\end{array}$} & \multicolumn{3}{|c|}{ Overall average } & \multicolumn{3}{|c|}{ Employed } \\
\hline & M & w & $\begin{array}{l}\text { Difference } \\
\text { (W-M) }\end{array}$ & M & W & $\begin{array}{l}\text { Difference } \\
\text { (W-M) }\end{array}$ \\
\hline \multicolumn{7}{|l|}{ Ecuador } \\
\hline A. Paid work activities & 36.6 & 19.2 & -17.4 & 48.7 & 40.8 & -7.9 \\
\hline B. Unpaid work activities & 13.1 & 40.4 & 27.3 & 13.8 & 39.9 & 26.1 \\
\hline $\begin{array}{l}\text { Unpaid domestic activities for one's own } \\
\text { household }\end{array}$ & 10.3 & 32.9 & 22.6 & 10.8 & 33.4 & 22.6 \\
\hline Unpaid care for household members & 2.4 & 8.7 & 6.3 & 2.6 & 8.2 & 5.6 \\
\hline $\begin{array}{l}\text { Unpaid activities for other households, the } \\
\text { community and unpaid voluntary work }\end{array}$ & 0.4 & 0.5 & 0.1 & 0.5 & 0.6 & 0.1 \\
\hline C. Personal activities & 93.8 & 93.9 & 0.1 & 90.6 & 89.0 & -1.6 \\
\hline \multicolumn{7}{|l|}{ Mexico } \\
\hline A. Paid work activities & 37.8 & 16.4 & -21.4 & 54.6 & 45.6 & -9.0 \\
\hline B. Unpaid work activities & 17.8 & 53.3 & 35.5 & 18.2 & 49.5 & 31.3 \\
\hline $\begin{array}{l}\text { Unpaid domestic activities for one's own } \\
\text { household }\end{array}$ & 7.4 & 29.8 & 22.4 & 7.1 & 27.3 & 20.2 \\
\hline Unpaid care for household members & 9.9 & 22.2 & 12.3 & 10.7 & 21.3 & 10.6 \\
\hline $\begin{array}{l}\text { Unpaid activities for other households, the } \\
\text { community and unpaid voluntary work }\end{array}$ & 0.5 & 1.2 & 0.7 & 0.4 & 0.9 & 0.5 \\
\hline C. Personal activities & 95.3 & 94.7 & -0.6 & 86.1 & 85.3 & -0.8 \\
\hline
\end{tabular}

Source: Author's own data, based on microdata from the National Institute of Statistics and Geography (INEGI)/ National Institute for Women (INMUJERES), 2009 National Time-Use Survey (all for Mexico); and the National Institute for Statistics and Censuses (INEC)/National Council for Women (CONAMU), and 2007 National TimeUse Survey (for Ecuador).

a $\mathrm{M}$ : men; W: women.

b CAUTAL: Classification of time-use activities for Latin America and the Caribbean.

As for the time that the sons and daughters of two-parent and lone-parent households spend on both types of work, there is an intergenerational transmission of gender roles as (employed or otherwise) males spend much less time on unpaid work than the females. When they are employed, the time spent by men on paid work is higher —and this is more significant in the case of Ecuador (see table II.2).

In extended households, gender roles are replicated among other household members as women (employed or otherwise) spend significantly more hours on unpaid work than men (see table II.3). Given that these households tend to belong to lower income groups, more time is spent on unpaid work by daughters and female heads or partners in childless homes. The increased unpaid work of daughters in two-parent and lone-parent households goes hand in hand with a reduction in the time spent on such work by female heads or partners. This may also be 
partly because any young children are born to the daughters, rather than to the female heads or partners.

Table II.2

ECUADOR AND MEXICO: AVERAGE TIME SPENT BY THOSE AGED OVER 12

ON PAID AND UNPAID WORK IN NUCLEAR HOUSEHOLDS, BY TYPE OF HOUSEHOLD, RELATIONSHIP AND EMPLOYMENT STATUS, BY SEX ${ }^{a}$

(Hours per week)

\begin{tabular}{|c|c|c|c|c|c|c|c|c|}
\hline \multirow{3}{*}{ Type of nuclear household } & \multicolumn{4}{|c|}{ Heads or partners } & \multicolumn{4}{|c|}{ Sons or daughters } \\
\hline & \multicolumn{2}{|c|}{ Employed } & \multicolumn{2}{|c|}{ Not employed } & \multicolumn{2}{|c|}{ Employed } & \multicolumn{2}{|c|}{ Not employed } \\
\hline & M & W & $\mathbf{M}$ & W & $\mathbf{M}$ & w & M & w \\
\hline
\end{tabular}

Ecuador

Couples with no children

A. Paid work activities

B. Unpaid work activities

Two-parent households
A. Paid work activities
B. Unpaid work activities

Lone-parent households
A. Paid work activities
B. Unpaid work activities

$\begin{array}{rrrr}48.7 & 43.0 & 2.0 & 1.6 \\ 14.1 & 33.1 & 15.4 & 40.2\end{array}$

$\begin{array}{llll}50.9 & 41.7 & 5.7 & 1.0\end{array}$

$\begin{array}{llll}41.4 & 34.0 & 0.9 & 0.5\end{array}$

$\begin{array}{llll}14.0 & 47.2 & 19.4 & 64.7\end{array}$

$5.7 \quad 22.5$

$8.5 \quad 16.6$

$\begin{array}{llllllll}49.1 & 44.0 & 3.6 & 1.7 & 46.3 & 42.5 & 1.0 & 1.1\end{array}$

$\begin{array}{llllllll}25.4 & 42.2 & 21.7 & 47.4 & 11.0 & 20.6 & 11.0 & 20.7\end{array}$

\section{Mexico $^{\mathrm{c}}$}

\section{Couples with no children}

\section{A. Paid work activities \\ B. Unpaid work activities}

Two-parent households
A. Paid work activities
B. Unpaid work activities

Lone-parent households
A. Paid work activities
B. Unpaid work activities

$\begin{array}{rrrr}54.0 & 45.5 & 6.6 & 0.9 \\ 15.8 & 36.5 & 19.8 & 46.5\end{array}$

$\begin{array}{rrrrrrrr}57.8 & 43.5 & 9.9 & 1.2 & 48.4 & 46.0 & 2.3 & 0.7 \\ 21.4 & 67.2 & 28.5 & 81.7 & 11.3 & 21.4 & 11.8 & 21.4\end{array}$

$\begin{array}{llllllll}51.8 & 48.6 & 6.5 & 2.8 & 51.1 & 49.9 & 2.4 & 1.3\end{array}$

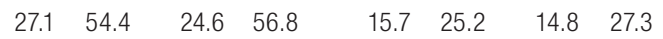

Source: Author's own data, based on microdata from the National Institute of Statistics and Geography (INEGI)/ National Institute for Women (INMUJERES), 2009 National Time-Use Survey (all for Mexico); and the National Institute for Statistics and Censuses (INEC)/National Council for Women (CONAMU), and 2007 National TimeUse Survey (for Ecuador).

a $\mathrm{M}$ : men; W: women.

b In Ecuador, $98 \%$ of households with couples have a male head of household and a female partner; $82 \%$ of lone-parent households are headed by a woman.

c In Mexico, $96 \%$ of households with couples have a male head of household and a female partner; $88 \%$ of lone-parent households are headed by a woman. 
Table II.3

ECUADOR AND MEXICO: AVERAGE TIME SPENT BY THOSE AGED OVER 12

ON PAID AND UNPAID WORK IN EXTENDED HOUSEHOLDS, BY TYPE OF HOUSEHOLD, RELATIONSHIP AND EMPLOYMENT STATUS, BY SEX ${ }^{a}$

(Hours per week)

\begin{tabular}{|c|c|c|c|c|c|c|c|c|c|c|c|}
\hline \multirow{3}{*}{ Type of extended family } & \multicolumn{4}{|c|}{ Heads or partners } & \multicolumn{4}{|c|}{ Sons or daughters } & \multicolumn{3}{|c|}{ Others } \\
\hline & \multicolumn{2}{|c|}{ Employed } & \multicolumn{2}{|c|}{$\begin{array}{c}\text { Not } \\
\text { employed }\end{array}$} & \multicolumn{2}{|c|}{ Employed } & \multicolumn{2}{|c|}{$\begin{array}{c}\text { Not } \\
\text { employed }\end{array}$} & Employed & \multicolumn{2}{|c|}{$\begin{array}{c}\text { Not } \\
\text { employed }\end{array}$} \\
\hline & $\mathbf{M}$ & w & $\mathbf{M}$ & w & $\mathbf{M}$ & W & M & w & W & M & w \\
\hline
\end{tabular}

Ecuador $^{b}$

Couples with no children

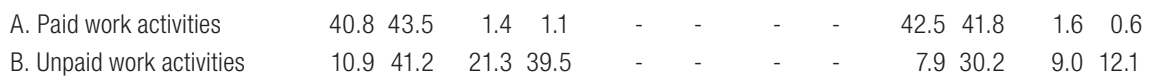

Two-parent households
A. Paid work activities

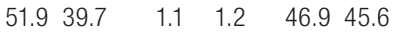
$2.0 \quad 1.0$
50.143 .0
$\begin{array}{ll}0.7 & 0.7\end{array}$
B. Unpaid work activities
$\begin{array}{llll}13.1 & 45.8 & 16.1 & 58.8\end{array}$
9.327 .3
9.230 .8
8.327 .7
$\begin{array}{lll}8.0 & 30.7\end{array}$

Lone-parent households

\begin{tabular}{|c|c|c|c|c|c|c|}
\hline A. Paid work activities & 47.842 .5 & 1.3 & 47.845 .1 & 1.4 & 48.540 .3 & 0.7 \\
\hline B. Unpaid work activities & 18.040 .4 & 15.742 .6 & 12.432 .7 & 10.043 .3 & 9.827 .6 & 10.135 .5 \\
\hline
\end{tabular}

Mexico $^{\circ}$

Couples with no children

\begin{tabular}{|c|c|c|c|c|c|c|c|c|}
\hline A. Paid work activities & 54.548 .1 & 1.2 & - & - & - & - & 51.846 .9 & $\begin{array}{ll}1.5 & 0.4\end{array}$ \\
\hline B. Unpaid work activities & 16.150 .2 & 18.460 .3 & - & - & - & - & 11.229 .1 & 10.133 .2 \\
\hline \multicolumn{9}{|l|}{ Two-parent households } \\
\hline Paid work activities & 57.146 .1 & 9.3 & 52.1 & 46.6 & 4.6 & 1.2 & 54.848 .5 & 3.1 \\
\hline Unpaid work activities & 19.260 .7 & 17.871 .8 & 15.4 & 43.5 & 13.5 & 46.3 & 147 & 14.1 \\
\hline
\end{tabular}

Lone-parent households

$\begin{array}{lrrrrrrrrrrrr}\text { A. Paid work activities } & 53.3 & 47.7 & 5.3 & 1.6 & 55.9 & 50.7 & 4.2 & 1.3 & 54.8 & 48.2 & 2.9 & 0.9 \\ \text { B. Unpaid work activities } & 17.4 & 53.8 & 15.1 & 52.1 & 16.9 & 44.4 & 16.3 & 55.5 & 16.7 & 44.6 & 16.4 & 47.6\end{array}$

Source: Author's own data, based on microdata from the National Institute of Statistics and Geography (INEGI)/ National Institute for Women (INMUJERES), 2009 National Time-Use Survey (all for Mexico); and the National Institute for Statistics and Censuses (INEC)/National Council for Women (CONAMU), and 2007 National TimeUse Survey (for Ecuador).

a M: men; W: women.

b In Ecuador, 8\% of extended lone-parent households are headed by a woman.

c In Mexico, $96 \%$ of households with couples have a male head of household and a female partner; $88 \%$ of lone-parent households are headed by a woman.

The age of the youngest child clearly affects the time needed for caregiving and domestic chores (see table II.4). Men and women, regardless of whether they are employed or not, carry out more hours of unpaid work in the household when there are children aged 0 to 5 (although the difference is significantly larger among women). Similarly, 
men spend more time on paid work when the children are young, while women spend more time on paid work when the children are older (over 14).

Table II.4

ECUADOR AND MEXICO: AVERAGE TIME SPENT BY PEOPLE AGED OVER 12 ON PAID AND UNPAID WORK ACCORDING TO AGE OF YOUNGEST CHILD, BY SEX (Hours per week)

\begin{tabular}{|c|c|c|c|c|c|c|c|c|}
\hline \multirow{3}{*}{ Households by age of youngest child } & \multicolumn{4}{|c|}{ Ecuador } & \multicolumn{4}{|c|}{ Mexico } \\
\hline & \multicolumn{2}{|c|}{ Employed } & \multicolumn{2}{|c|}{$\begin{array}{c}\text { Not } \\
\text { employed }\end{array}$} & \multicolumn{2}{|c|}{ Employed } & \multicolumn{2}{|c|}{$\begin{array}{c}\text { Not } \\
\text { employed }\end{array}$} \\
\hline & M & W & M & w & M & W & M & w \\
\hline \multicolumn{9}{|l|}{ Households with youngest child aged 0 to 5} \\
\hline A. Paid work activities & 51.5 & 41.6 & 2.1 & 0.9 & 57.2 & 44.0 & 6.5 & 1.0 \\
\hline B. Unpaid work activities & 16.6 & 52.5 & 12.8 & 61.8 & 27.2 & 82.1 & 26.7 & 87.9 \\
\hline \multicolumn{9}{|c|}{ Households with youngest child aged 6 to 13} \\
\hline A. Paid work activities & 49.6 & 40.0 & 1.1 & 0.8 & 55.5 & 44.8 & 3.6 & 1.2 \\
\hline B. Unpaid work activities & 11.4 & 37.9 & 9.2 & 37.2 & 17.6 & 54.7 & 13.3 & 47.5 \\
\hline \multicolumn{9}{|c|}{ Households with youngest child aged 14 to 17} \\
\hline A. Paid work activities & 44.4 & 42.5 & 1.0 & 0.7 & 53.6 & 46.3 & 4.4 & 1.2 \\
\hline B. Unpaid work activities & 8.8 & 33.4 & 9.1 & 28.1 & 12.9 & 38.9 & 12.6 & 39.3 \\
\hline \multicolumn{9}{|c|}{ Households with youngest child aged 18 plus } \\
\hline A. Paid work activities & 47.6 & 42.9 & 1.9 & 1.3 & 54.3 & 48.6 & 4.8 & 1.2 \\
\hline B. Unpaid work activities & 10.2 & 31.5 & 11.4 & 40.1 & 14.9 & 38.1 & 16.4 & 48.5 \\
\hline
\end{tabular}

Source: Author's own data, based on microdata from the National Institute of Statistics and Geography (INEGI)/ National Institute for Women (INMUJERES), 2009 National Time-Use Survey (all for Mexico); and the National Institute for Statistics and Censuses (INEC)/National Council for Women (CONAMU), and 2007 National TimeUse Survey (for Ecuador).

a $\mathrm{M}$ : men; W: women.

\section{Typology of two-parent households (with and without children) according to the sexual division of labour within the couple}

What follows is a proposed classification of two-parent nuclear households (with or without children) that identifies the distribution of paid and unpaid work between the partners in a couple. The classification extends the one proposed by Aguirre (2009), which was an adaptation of others (including Martínez, 2008).

The first two types of family are those in which the distribution of paid and unpaid work follows the traditional pattern. This means that the man basically dedicates himself to paid work and the woman to unpaid work. Where both are unemployed or inactive (second type 
of family), the woman remains responsible for, and carries out the bulk of, the care work. The parameter used to identify the distribution of unpaid work between the sexes measures the ratio of work carried out by women against that carried out by men. The values 0.5 and 1.5 are used to define whether the distribution is traditional (ratio of more than 1.5), equal (between 0.5 and 1.5) or inverted (below 0.5).

The third type, which is the modified traditional family, is made up of a man working for the market as the main breadwinner, and the women working in the market part time (less than 30 hours per week) and spending a high proportion of time on unpaid work.

Another type of family is one in which the time spent on paid work is more evenly spread, while maintaining traditional role distribution at home. This is the dual-income family in the traditional template. This is the second largest type of family after the traditional family, for which national policies are designed.

The fifth and sixth types of family are egalitarian, in the sense that paid and unpaid work are evenly distributed therein, with the categories corresponding to employed people (full or part time) and unemployed or inactive people, respectively. The next two types are those that differ from traditional patterns, either because the woman carries out more paid work than the man (type 7) or because the man carries out more unpaid work than the woman (type 8). The final type of family is where paid work is distributed according to traditional patterns, while the distribution of unpaid work is equal.

In Mexico, the first type of family is significantly more common (representing almost half of two-parent families), followed by the double-income family with a traditional template (see table II.6). The third main type of family is where both partners are not working or inactive with a traditional distribution of unpaid work. In Ecuador, the main two types of family are the same as in Mexico, but the doubleincome family with traditional template represents a higher proportion of the total, and the modified traditional family is in third place (see table II.5). In both countries, the main types of family are clearly concentrated around a traditional format for the distribution of unpaid work. This confirms the hypothesis of the incomplete revolution put forward by Esping-Andersen, as the most significant changes may be under way in the distribution of paid work, while the distribution of unpaid work remains unchanged. 
Table II.5

ECUADOR: TYPOLOGY OF TWO-PARENT FAMILIES BY TIME SPENT ON PAID WORK (PW) AND UNPAID WORK (UW) BY HEADS OF HOUSEHOLD AND PARTNERS ${ }^{a}$

(Percentages and hours per week)

\begin{tabular}{|c|c|c|c|c|c|c|}
\hline \multirow{2}{*}{ Types of family } & \multirow{2}{*}{ Percentage } & \multicolumn{2}{|c|}{ UW } & \multirow{2}{*}{$\mathrm{W} / \mathrm{M}$} & \multicolumn{2}{|c|}{ Total work } \\
\hline & & w & M & & W & M \\
\hline 1. Traditional family (woman unemployed or inactive $e^{b}$ ) & 39.6 & 61.8 & 10.2 & 6.1 & 62.2 & 61.5 \\
\hline 2. Unemployed/inactive family with traditional UW distribution & 4.1 & 41.9 & 7.9 & 5.3 & 42.4 & 8.6 \\
\hline 3. Modified traditional family & 10.7 & 57.5 & 10.2 & 5.6 & 75.3 & 64.1 \\
\hline 4. Dual-income family with traditional template & 28.4 & 47.7 & 10.7 & 4.5 & 94.0 & 63.8 \\
\hline 5. Egalitarian family with part-time or full-time $\mathrm{PW}^{\mathrm{c}}$ & 5.5 & 37.9 & 34.5 & 1.1 & 86.3 & 87.2 \\
\hline 6. Egalitarian unemployed/inactive family & 1.0 & 37.3 & 36.9 & 1.0 & 37.5 & 37.7 \\
\hline 7. Family with inverted PW roles & 3.6 & 41.8 & 15.6 & 2.7 & 86.9 & 28.3 \\
\hline 8. Family with inverted traditional roles in UW & 4.3 & 3.8 & 31.6 & 0.1 & 32.5 & 72.4 \\
\hline 9. Traditional family in terms of PW and egalitarian in UW & 2.9 & 46.3 & 42.7 & 1.1 & 51.4 & 88.4 \\
\hline Total & 100.0 & 51.3 & 13.9 & 3.7 & 72.2 & 61.5 \\
\hline
\end{tabular}

Source: Author's own data, based on the National Institute for Statistics and Censuses (INEC)/National Council for Women (CONAMU), and 2007 National Time-Use Survey.

a $\mathrm{M}$ : men; W: women.

b $95 \%$ of these women are inactive.

c $93.5 \%$ of couples work full time.

Table II.6

MEXICO: TYPOLOGY OF TWO-PARENT FAMILIES BY TIME SPENT ON PAID WORK (PW) AND UNPAID WORK (UW) BY HEADS OF HOUSEHOLD AND PARTNERS ${ }^{a}$

(Percentages and hours per week)

\begin{tabular}{|c|c|c|c|c|c|c|}
\hline \multirow{2}{*}{ Types of family } & \multirow{2}{*}{ Percentage } & \multicolumn{2}{|c|}{ UW } & \multirow{2}{*}{ W/M } & \multicolumn{2}{|c|}{ Total work } \\
\hline & & W & M & & W & $\mathbf{M}$ \\
\hline 1. Traditional family (woman unemployed or inactive ${ }^{b}$ ) & 47.4 & 82.0 & 15.6 & 5.3 & 82.9 & 73.2 \\
\hline 2. Unemployed/inactive family with traditional UW distribution & 10.2 & 64.9 & 15.0 & 4.3 & 65.9 & 25.3 \\
\hline 3. Modified traditional family & 6.0 & 79.7 & 17.2 & 4.6 & 99.8 & 77.3 \\
\hline 4. Dual-income family with traditional template & 16.0 & 61.9 & 16.5 & 3.7 & 112.1 & 75.4 \\
\hline 5. Egalitarian family with part-time or full-time $\mathrm{PW}^{\mathrm{c}}$ & 4.0 & 55.8 & 51.4 & 1.1 & 108.1 & 108.5 \\
\hline 6. Egalitarian unemployed/inactive family & 2.1 & 55.7 & 53.5 & 1.0 & 57.7 & 63.1 \\
\hline 7. Family with inverted PW roles & 4.7 & 58.0 & 26.4 & 2.2 & 102.5 & 39.8 \\
\hline 8. Family with inverted traditional roles in UW & 3.7 & 9.0 & 60.7 & 0.1 & 23.9 & 104.3 \\
\hline 9. Traditional family in terms of PW and egalitarian in UW & 3.9 & 61.0 & 57.4 & 1.1 & 64.6 & 109.9 \\
\hline Total & 100.0 & 70.4 & 21.6 & 3.3 & 85.9 & 70.1 \\
\hline
\end{tabular}

Source: Author's own data, based on the National Institute of Statistics and Geography (INEGI)/National Institute for Women (INMUJERES), 2009 National Time-Use Survey.

a $\mathrm{M}$ : men; W: women.

b $99 \%$ of these women are inactive.

c $95.4 \%$ of couples work full time.

This pattern can be observed in most countries, even in the developed world. Lewis (2001) suggests that, beyond the erosion of the male provider model, there has not been a change towards the dual- 
career or universal provider model (as described by Fraser (1997)), but rather in most western countries, women's low wages mean that the change has been towards a one-and-a-half provider model (types 3 and 4) more than an egalitarian dual-provider or dual-career model (type 5).

\section{Typology of lone-parent households}

The typology for lone-parent households identifies the working hours of the female head of household and the age of the youngest child, as this largely determines the unpaid workload in the household. The time spent by various household members (head and children) is then calculated.

Interestingly, Ecuador has many female heads of household who work full time in the labour market, unlike in Mexico where a large proportion of female heads of household are inactive.

In Mexico and Ecuador alike, female heads of household and their daughters spend longer working in the household when there are small children. In Ecuador, the time that sons spend on unpaid work does not change, whereas in Mexico sons behave similarly to women (when there are small children) - although the time they spend is significantly lower.

Table II.7

ECUADOR: TIME SPENT ON UNPAID WORK (UW) BY FEMALE HEADS AND

CHILDREN IN LONE-PARENT HOUSEHOLDS, BY EMPLOYMENT STATUS OF WOMAN AND AGE OF YOUNGEST CHILD

(Percentages and hours per week)

\begin{tabular}{lrrrr}
\hline $\begin{array}{l}\text { Employment status of the head of household } \\
\text { and age of the youngest child }\end{array}$ & Percentage & UW of head & UW of son & UW of daughter \\
\hline $\begin{array}{l}\text { Youngest child aged } 0 \text { to } 5 \\
\text { Female head unemployed or inactive }\end{array}$ & 3.5 & 65.0 & 12.6 & 37.2 \\
$\quad$ Female head in part-time work & 3.7 & 65.1 & 7.6 & 21.3 \\
$\quad$ Female head in full-time work & 9.7 & 58.2 & 11.8 & 24.5 \\
Youngest child aged 6 to 13 & & & & \\
$\quad$ Female head unemployed or inactive & 5.1 & 51.4 & 9.7 & 21.3 \\
Female head in part-time work & 8.1 & 52.9 & 7.4 & 18.5 \\
Female head in full-time work & 18.3 & 47.4 & 10.0 & 19.7 \\
Youngest child aged 14 plus & & & & \\
$\quad$ Female head unemployed or inactive & 19.5 & 43.6 & 9.6 & 22.7 \\
$\quad$ Female head in part-time work & 7.8 & 47.3 & 7.8 & 20.4 \\
Female head in full-time work & 24.3 & 41.4 & 9.6 & 18.7 \\
\hline
\end{tabular}

Source: Author's own data, based on microdata from the National Institute for Statistics and Censuses (INEC)/ National Council for Women (CONAMU), and 2007 National Time-Use Survey. 
Table II. 8

MEXICO: TIME SPENT ON UNPAID WORK (UW) BY FEMALE HEADS AND CHILDREN IN LONE-PARENT HOUSEHOLDS, BY EMPLOYMENT STATUS OF WOMAN AND AGE OF YOUNGEST CHILD

(Percentages and hours per week)

\begin{tabular}{lcccc}
\hline $\begin{array}{l}\text { Employment status of the head of household } \\
\text { and age of the youngest child }\end{array}$ & Percentage & UW of head & UW of son & UW of daughter \\
\hline $\begin{array}{l}\text { Youngest child aged } 0 \text { to } 5 \\
\quad\end{array}$ & 7.0 & 99.0 & 19.7 & 36.6 \\
$\quad$ Female head unemployed or inactive & 1.5 & 85.9 & 12.2 & 28.7 \\
$\quad$ Female head in part-time work & 7.7 & 83.7 & 24.6 & 33.7 \\
$\quad$ Female head in full-time work & & & & \\
Youngest child aged 6 to 13 & 9.1 & 75.0 & 13.7 & 26.4 \\
$\quad$ Female head unemployed or inactive & 4.7 & 73.5 & 10.5 & 25.0 \\
$\quad$ Female head in part-time work & 16.2 & 59.5 & 14.6 & 25.9 \\
$\quad$ Female head in full-time work & & & & \\
Youngest child aged 14 plus & 29.8 & 45.7 & 15.7 & 27.5 \\
$\quad$ Female head unemployed or inactive & 4.9 & 50.4 & 12.5 & 25.9 \\
$\quad$ Female head in part-time work & 19.0 & 44.6 & 13.3 & 25.7 \\
\hline Female head in full-time work &
\end{tabular}

Source: Author's own data, based on microdata from the National Institute of Statistics and Geography (INEGI)/ National Institute for Women (INMUJERES), 2009 National Time-Use Survey.

In summary, the type of household, presence and age of children, level of education, labour market participation (or lack thereof) and household income level are all relevant variables in identifying the paid and unpaid workload of men and women. The next stage of the analysis will attempt to identify determining factors in the distribution of paid and unpaid work in two-parent families (with or without children) and the main characteristics for determining the time that men and women (heads or partners) spend on unpaid work in one-parent and extended households.

\section{Bargaining models in two-parent households (with and without children)}

This stage of the analysis aims to use econometric tools to identify the relative effect of a series of previously analysed variables on the time spent on unpaid work by each partner in two-parent households. According to bargaining models, this may depend on the economic incentives derived from relative and absolute levels of employment income (one's own and the partner's), as well as on other restrictions such as the time spent by each household member and the couple on 
paid work, employed or unemployed status, level of schooling and the presence of children in the household. These models only apply to nuclear households that include couples.

The Tobit method is used to estimate these models because the dependent variable (hours of unpaid work) is bounded at zero (in other words, there are no negative values) and there are many zeros (violating the assumption of normally distributed residuals, which is the prerequisite for applying Ordinary Least Squares).

The dependent variable in all the models is the time spent on unpaid work by women or men (male/female heads of household or partners), while the time spent on unpaid work by the partner is considered to be the independent variable. This follows Deding and Lausten (2006), who suggest that an individual's paid work, the partner's paid work and the partner's unpaid work are the main independent variables that explain an individual's own unpaid work.

Four specifications to the model were considered, following Esquivel (2009). ${ }^{8}$ Two were used to detect the relevance of absolute resources (one person's wages and the partner's wages) in determining the time spent on unpaid work of each partner. Monthly income and hourly income were taken into account. Hours spent on paid work (by the individual and the partner), employment situation, age of the individual and children and educational level of the individual and the partner were controlled for.

The other two modelizations considered relative resources (proportion of monthly and hourly wages in the total wages of the individual and the partner), as well as the square of the proportion. The square of the income proportion seeks to identify nonlinearity in the ratio between time spent on unpaid work and proportion of income. Total family income is also included as a control variable to test whether the nonlinear relation between household work and wages (captured by the squared term) is related to household income. ${ }^{9}$

\footnotetext{
8 The database used by Esquivel (2009) has no information on the time spent on unpaid work by partners (as the questions only cover the time spent by one individual).

9 Gupta (2006, cited in Esquivel, 2009) criticizes the use of relative proportion of wages to test the "relative resources" hypothesis because of the finding that couples' wages increase with the relative income of the woman but then decrease, which implies that women whose income represents the highest proportion of household income belong to the poorest households (namely those in which the partner is unemployed or outside the workforce). If this were the case, it is unclear whether it is their high proportion of family income or low absolute family income that explains their higher domestic workload.
} 
The subsample used includes heterosexual couples in nuclear households, with or without children. In Ecuador, the database only included heterosexual couples, while in Mexico there was a $1.6 \%$ of homosexual couples not included in the analysis.

To avoid confusing factors relating to decisions between wages, paid work hours and domestic work, all cases in which one partner in the couple was retired or a pensioner were left out of the analysis in this section.

\section{Summary of results from Ecuador and Mexico}

(i) A partner's unpaid work is always significant for men and women (heads or partners), even if the impact is limited.

(ii) In terms of income levels, monthly income (the individual's and the partner's) is not a significant factor in determining time spent on unpaid work by each head or partner. The only significant factor (in a negative direction) is hourly wages for women in Ecuador.

(iii) The proportion represented by wages (monthly or hourly) in the total labour income of the entire couple is more relevant for women. When that proportion increases, the time women spend on unpaid work decreases. This ratio has been observed for various levels of household income.

(iv) The hours of paid work carried out by male or female heads and partners are also significant, as this makes a large contribution to reducing the time they spend on unpaid work. In this case, the impact is greater among men.

(v) In both countries, the time women spend on unpaid work increases in proportion with the time that their partners spend on paid work. It is only in Ecuador that this ratio also applies to men.

(vi) Another highly relevant variable in determining the unpaid workload of both partners is the number of small children, with the effect always being greater for women.

(vii) The level of tertiary education is significant in determining the time spent by men on unpaid work (in a positive direction) in both countries, while the level of women is only significant (in a negative direction) in Ecuador. This means that men with a higher level of education carry out more unpaid work, while this is reversed (in Ecuador) for women. 


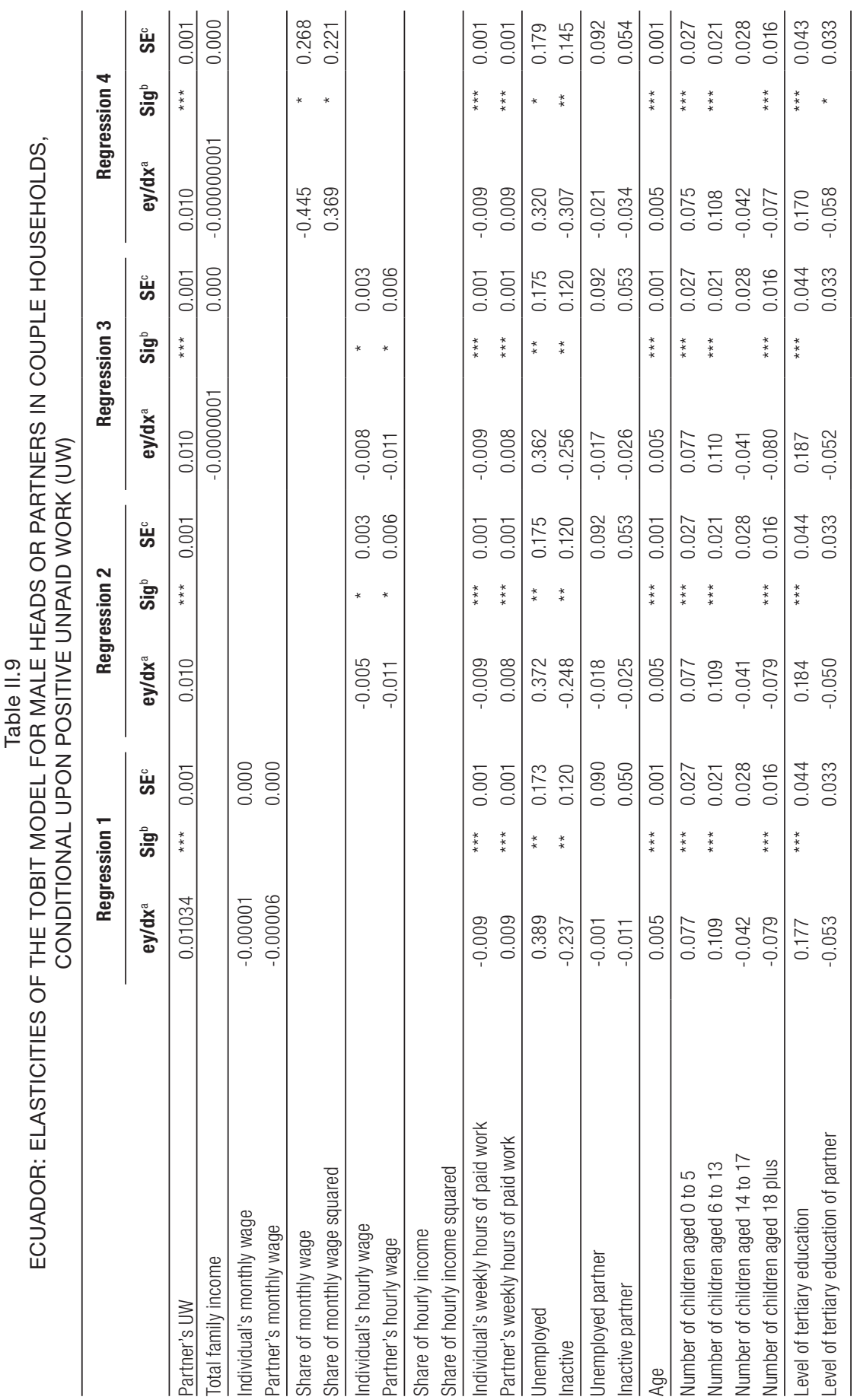




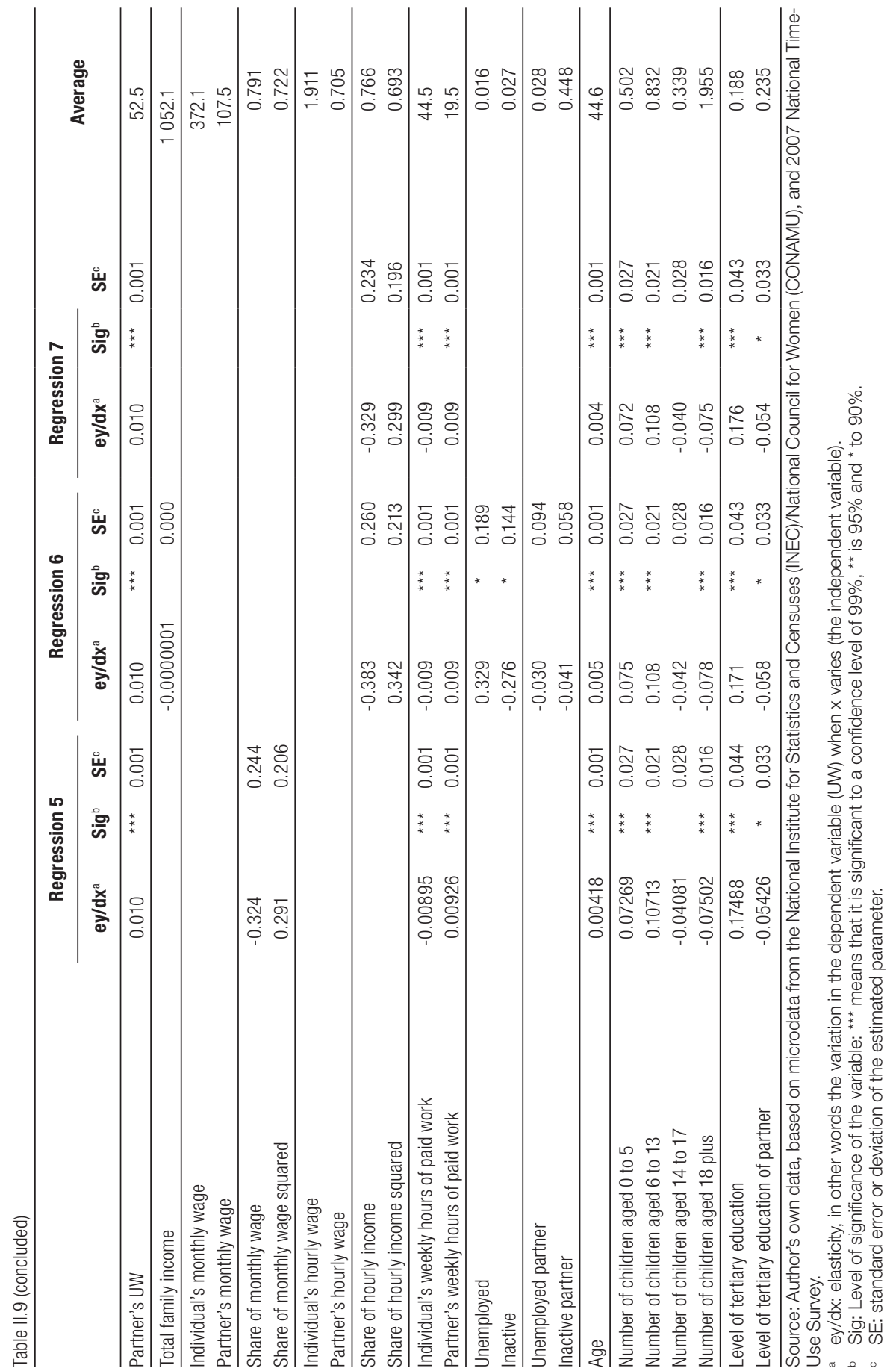




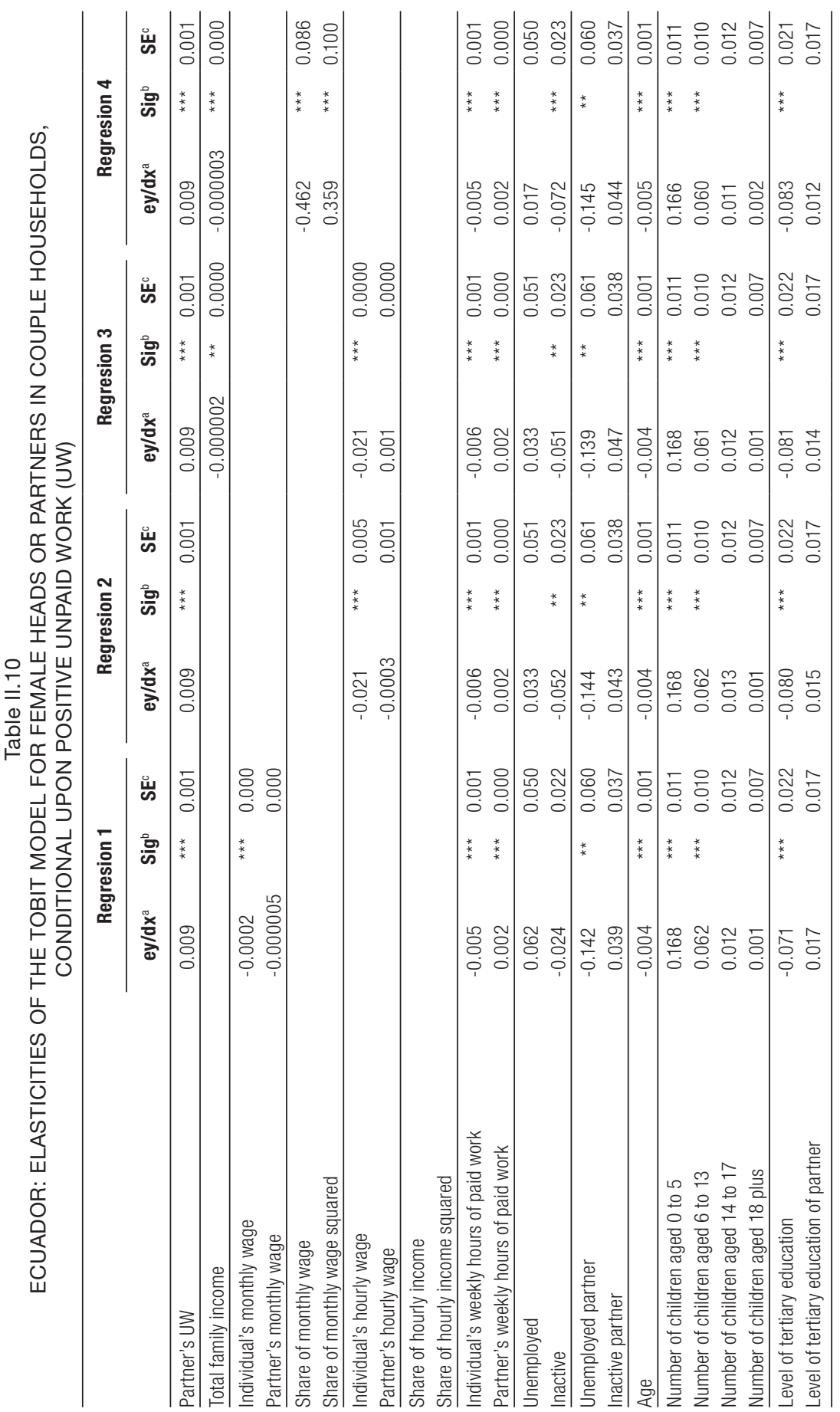




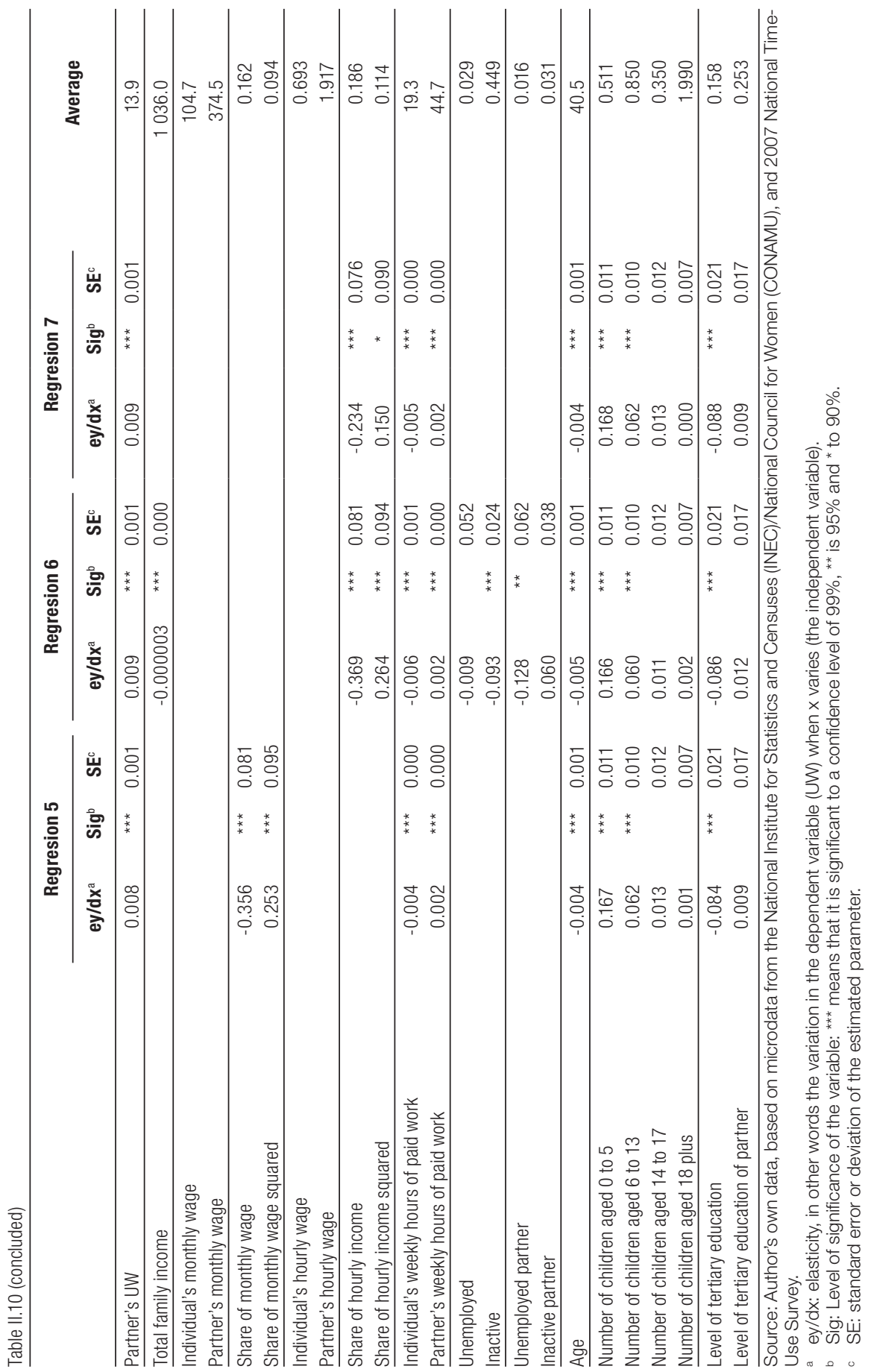




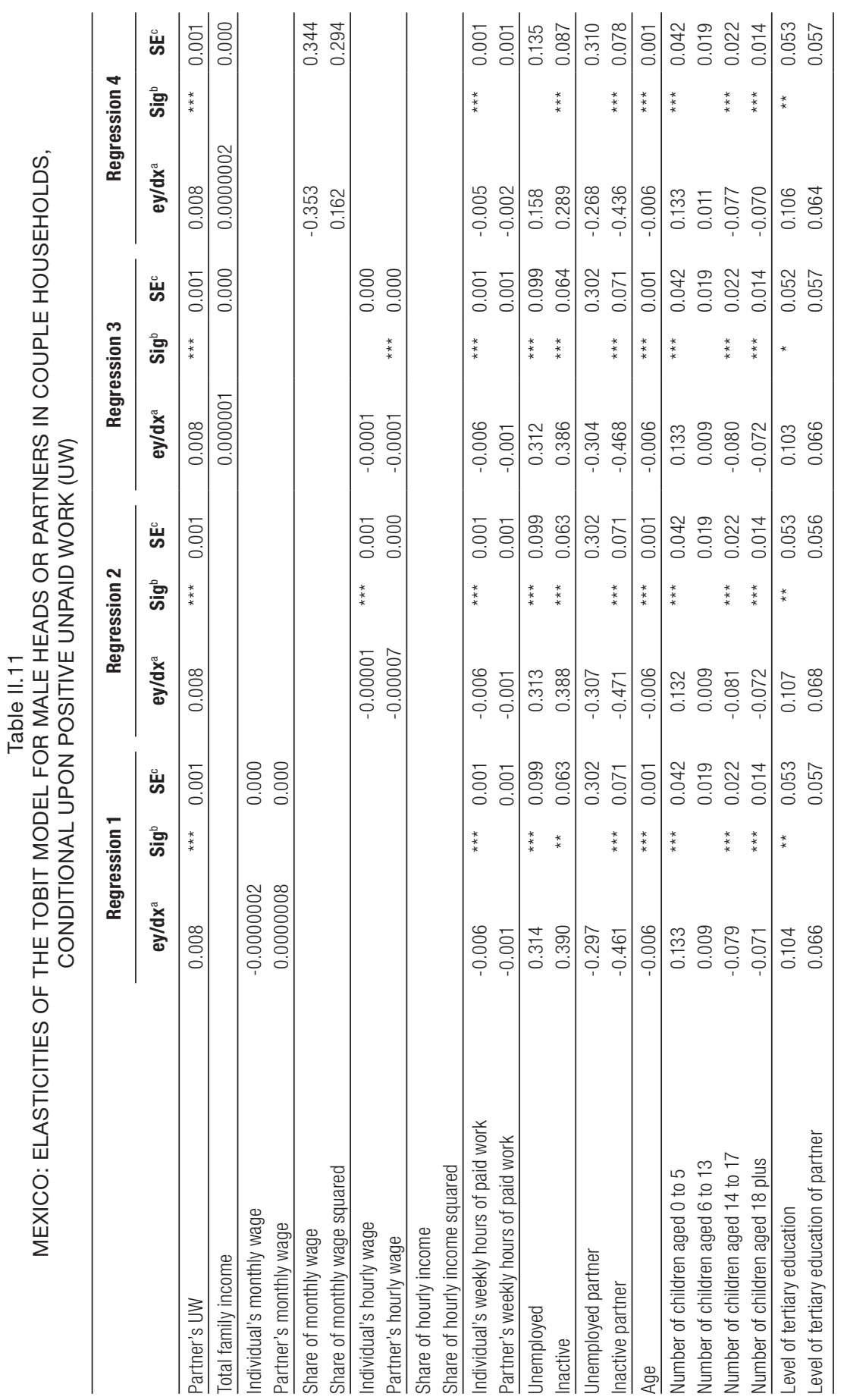




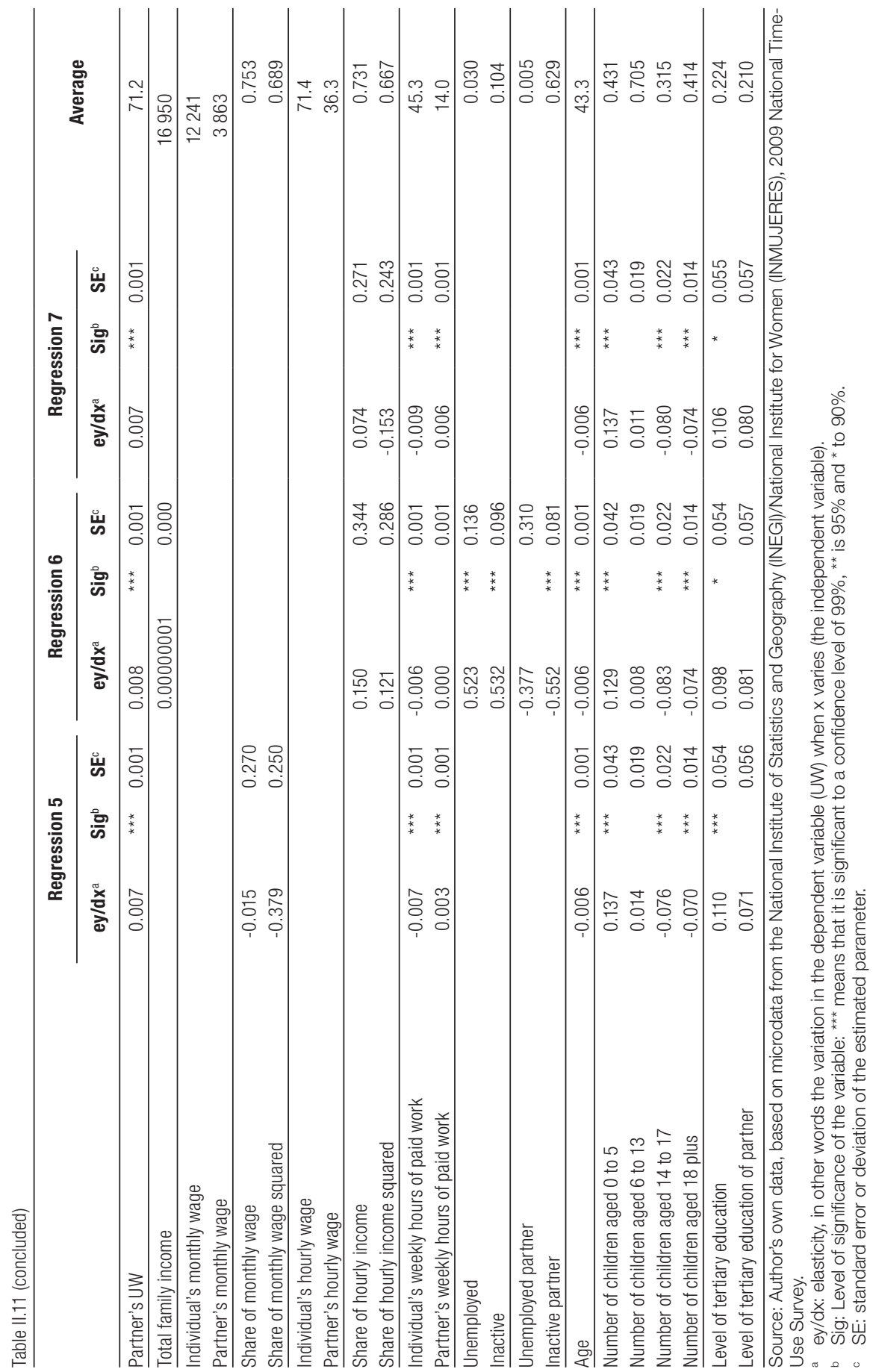




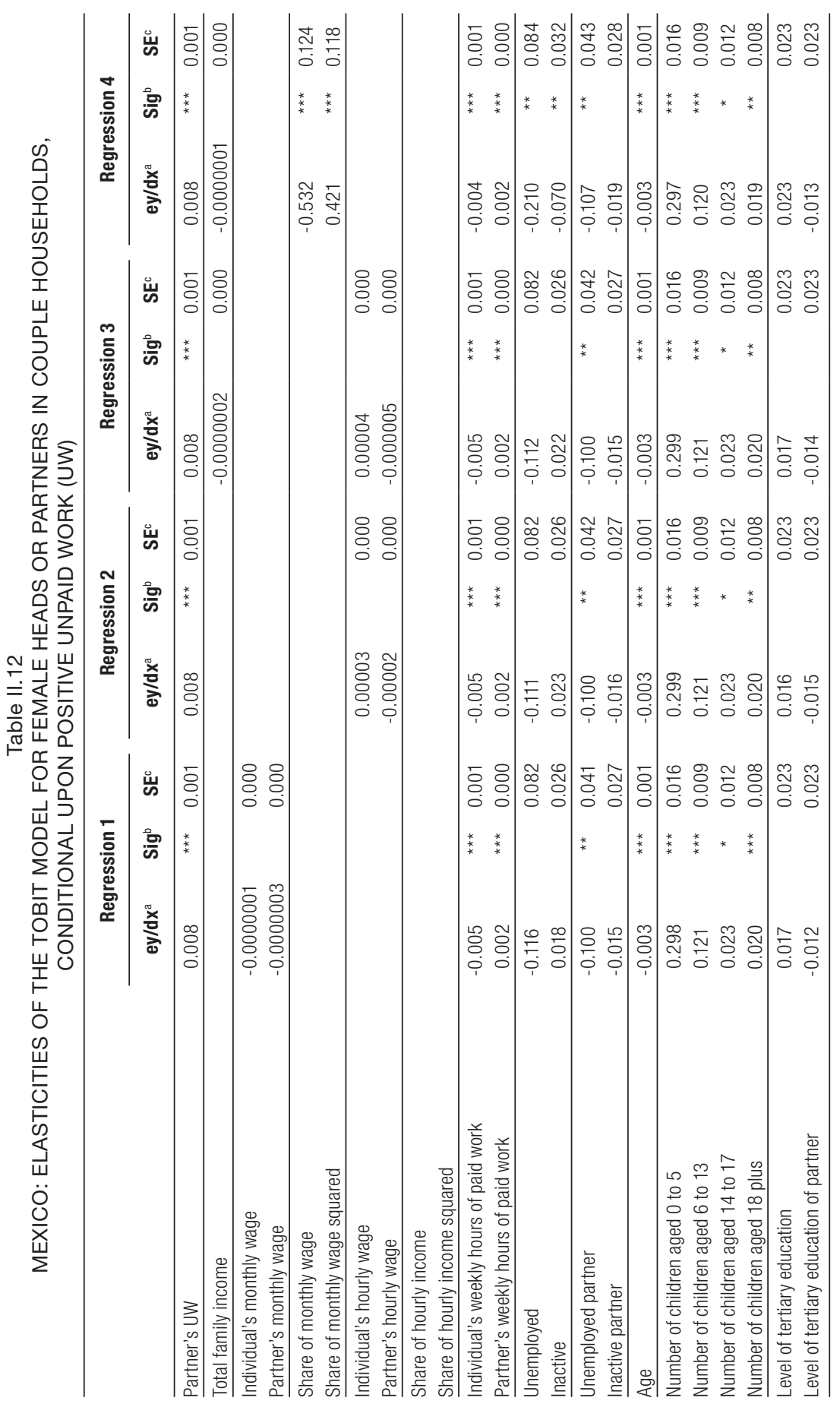




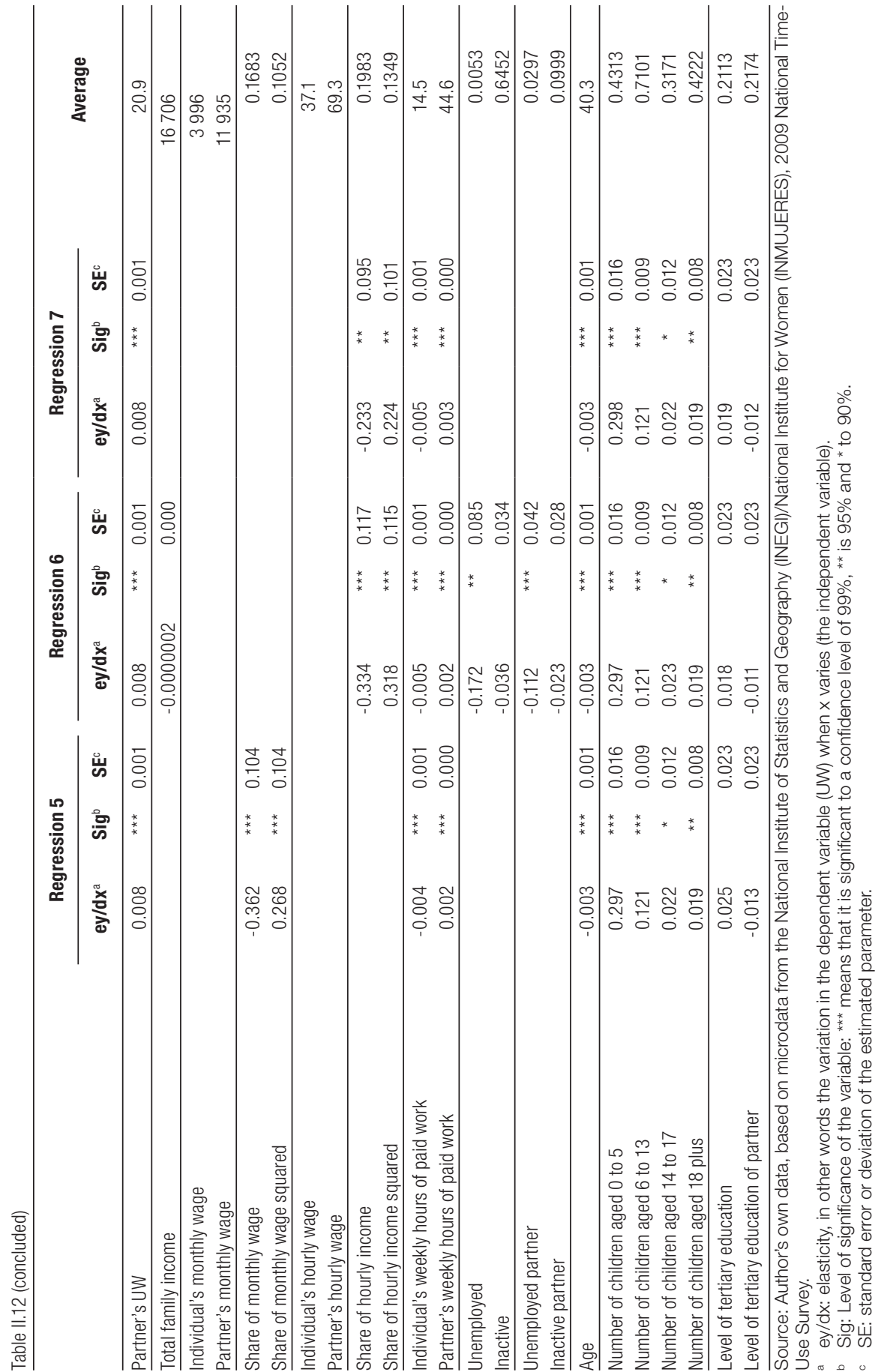




\section{E. Determining factors of unpaid work in lone-parent and extended households}

The aim of analysing the determining factors of unpaid work in loneparent and extended households is to identify the most relevant features that explain the volume of work carried out in these households. For loneparent households, the possible participation of children is considered, while in extended households (lone-parent and two-parent), the work contributed by other household members is also considered.

For one-parent households, only those headed by women are considered, as they make up a very high proportion of this category ( $82 \%$ in Ecuador and 88\% in Mexico). Explanatory variables included unpaid work by sons and daughters and other household members in extended families, employment status, level of education, age, age squared (a proxy for experience) and the age of children.

Generally speaking, across all types of household, the work contributed by other household members (children or others) was not significant enough to explain the unpaid workload of female heads or partners. When the variable is statistically significant, the volume of impact is very small (less than $1 \%$ ).

The most relevant variables for determining the unpaid work of heads and partners in lone-parent and extended households are: employment status and the presence of young children. The reduction of unpaid work among the employed is larger for men. The increase in unpaid work when heads of either gender and partners have small children is greater among women than men. Level of education is only significant for heads of either gender and partners in two-parent extended households, with a positive sign for both sexes in Mexico and a negative sign for women in Ecuador. 
Table II.13

ECUADOR AND MEXICO: DETERMINING FACTORS OF UNPAID WORK (UW) OF FEMALE HEADS OF LONE-PARENT HOUSEHOLDS

\begin{tabular}{|c|c|c|c|c|c|c|}
\hline \multirow{2}{*}{ Variables } & \multicolumn{3}{|c|}{ Ecuador } & \multicolumn{3}{|c|}{ Mexico } \\
\hline & $e y / d x^{a}$ & $\mathrm{Sig}^{\mathrm{b}}$ & $\mathbf{S E}^{\mathrm{c}}$ & $e y / d x^{a}$ & $\mathrm{Sig}^{\mathrm{b}}$ & $\mathbf{S E}^{\mathrm{c}}$ \\
\hline UW by son & 0.0054 & $* \star *$ & 0.0016 & 0.0018 & & 0.0013 \\
\hline UW by daughter & 0.0027 & $* *$ & 0.0012 & 0.0013 & & 0.0009 \\
\hline Employed & -0.2308 & $* \star *$ & 0.0522 & -0.2208 & *** & 0.0440 \\
\hline Secondary education & -0.0180 & & 0.0395 & 0.0614 & & 0.0515 \\
\hline Tertiary education & -0.0282 & & 0.0254 & -0.0100 & & 0.0199 \\
\hline Age & 0.0145 & * & 0.0088 & 0.0137 & * & 0.0079 \\
\hline Age squared & -0.0002 & $* *$ & 0.0001 & -0.0002 & $* * *$ & 0.0001 \\
\hline Children aged 0 to 5 & 0.3248 & $* \star *$ & 0.0509 & 0.5037 & *** & 0.0561 \\
\hline Children aged 6 to 13 & 0.0904 & 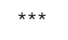 & 0.0214 & 0.2240 & 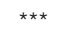 & 0.0422 \\
\hline Children aged 14 to 17 & -0.0837 & $\star \star *$ & 0.0315 & 0.0502 & & 0.0597 \\
\hline
\end{tabular}

Source: Author's own data, based on microdata from the National Institute of Statistics and Geography (INEGI)/ National Institute for Women (INMUJERES), 2009 National Time-Use Survey (all for Mexico); and the National Institute for Statistics and Censuses (INEC)/National Council for Women (CONAMU), and 2007 National TimeUse Survey (for Ecuador).

a ey/dx: elasticity, in other words the variation in the dependent variable (UW) when $\mathrm{x}$ varies (the independent variable).

b Sig: Level of significance of the variable: ${ }^{\star \star \star}$ means that it is significant to a confidence level of $99 \%$, ${ }^{* \star}$ is $95 \%$ and * to $90 \%$.

c SE: standard error or deviation of the estimated parameter.

Table II.14

ECUADOR AND MEXICO: DETERMINING FACTORS OF UNPAID WORK (UW) OF FEMALE HEADS OF EXTENDED LONE-PARENT HOUSEHOLDS

\begin{tabular}{|c|c|c|c|c|c|c|}
\hline \multirow{2}{*}{ Variables } & \multicolumn{3}{|c|}{ Ecuador } & \multicolumn{3}{|c|}{ Mexico } \\
\hline & $e y / d x^{a}$ & $\mathbf{S i g}^{\mathrm{b}}$ & $\mathbf{S E}^{\mathrm{c}}$ & $e y / d x^{a}$ & $\mathrm{Sig}^{\mathrm{b}}$ & $\mathbf{S E}^{\mathrm{c}}$ \\
\hline UW of others & 0.0005 & & 0.0010 & -0.0003 & & 0.0005 \\
\hline UW by son & 0.0051 & $\star \star \star *$ & 0.0013 & 0.0048 & *** & 0.0017 \\
\hline UW by daughter & 0.0017 & & 0.0011 & 0.0022 & *** & 0.0005 \\
\hline Employed & -0.1477 & $\star \star$ & 0.0612 & -0.2186 & 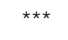 & 0.0605 \\
\hline Secondary education & 0.0095 & & 0.0574 & -0.0116 & & 0.0745 \\
\hline Tertiary education & -0.0354 & & 0.0276 & -0.0217 & & 0.0262 \\
\hline Age & 0.0500 & 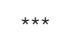 & 0.0106 & 0.0070 & & 0.0128 \\
\hline Age squared & -0.0005 & $* * *$ & 0.0001 & -0.0002 & * & 0.0001 \\
\hline Children aged 0 to 5 & 0.2327 & $\star *$ & 0.0915 & 0.2314 & ** & 0.1176 \\
\hline Children aged 6 to 13 & 0.0766 & * & 0.0438 & 0.1116 & * & 0.0609 \\
\hline Children aged 14 to 17 & -0.0748 & & 0.0515 & -0.1090 & * & 0.0628 \\
\hline
\end{tabular}

Source: Author's own data, based on microdata from the National Institute of Statistics and Geography (INEGI)/ National Institute for Women (INMUJERES), 2009 National Time-Use Survey (all for Mexico); and the National Institute for Statistics and Censuses (INEC)/National Council for Women (CONAMU), and 2007 National TimeUse Survey (for Ecuador).

a ey/dx: elasticity, in other words the variation in the dependent variable (UW) when $\mathrm{x}$ varies (the independent variable).

b Sig: Level of significance of the variable: ${ }^{\star \star \star}$ means that it is significant to a confidence level of $99 \%$, ${ }^{\star \star}$ is $95 \%$ and ${ }^{*}$ to $90 \%$.

c SE: standard error or deviation of the estimated parameter. 
Table II.15

ECUADOR AND MEXICO: DETERMINING FACTORS OF UNPAID WORK (UW) OF FEMALE HEADS OF EXTENDED TWO-PARENT HOUSEHOLDS

\begin{tabular}{|c|c|c|c|c|c|c|}
\hline \multirow[t]{2}{*}{ Variables } & \multicolumn{3}{|c|}{ Ecuador } & \multicolumn{3}{|c|}{ Mexico } \\
\hline & $e y / d x^{a}$ & $\mathbf{S i g}^{\mathrm{b}}$ & $\mathbf{S E}^{\mathrm{c}}$ & $e y / d x^{a}$ & Sig $^{\mathrm{b}}$ & $\mathbf{S E}^{\mathrm{c}}$ \\
\hline UW of others & -0.000003 & & 0.0005 & -0.0005 & & 0.0004 \\
\hline UW by son & 0.0047 & $* \star \star$ & 0.0010 & 0.0021 & $* *$ & 0.0010 \\
\hline UW by daughter & 0.0025 & $* \star *$ & 0.0006 & 0.0012 & $* \star \star$ & 0.0003 \\
\hline Employed & -0.2033 & $* * \star$ & 0.0240 & -0.2816 & $* * *$ & 0.0332 \\
\hline Secondary education & -0.0023 & & 0.0277 & 0.0660 & & 0.0428 \\
\hline Tertiary education & -0.0712 & $\star \star \star *$ & 0.0111 & 0.0314 & $\star \star *$ & 0.0157 \\
\hline Age & 0.0113 & $\star *$ & 0.0053 & -0.0037 & & 0.0088 \\
\hline Age squared & -0.0002 & $* * *$ & 0.0001 & -0.0001 & & 0.0001 \\
\hline Children aged 0 to 5 & 0.1606 & $* * \star$ & 0.0274 & 0.2422 & $* \star \star$ & 0.0455 \\
\hline Children aged 6 to 13 & 0.0158 & & 0.0149 & 0.0985 & $* * *$ & 0.0281 \\
\hline Children aged 14 to 17 & -0.0275 & & 0.0236 & -0.0937 & $* * *$ & 0.0256 \\
\hline
\end{tabular}

Source: Author's own data, based on microdata from the National Institute of Statistics and Geography (INEGI)/ National Institute for Women (INMUJERES), 2009 National Time-Use Survey (all for Mexico); and the National Institute for Statistics and Censuses (INEC)/National Council for Women (CONAMU), and 2007 National TimeUse Survey (for Ecuador).

a ey/dx: elasticity, in other words the variation in the dependent variable (UW) when $x$ varies (the independent variable).

b Sig: Level of significance of the variable: ${ }^{\star \star *}$ means that it is significant to a confidence level of $99 \%$, ${ }^{* *}$ is $95 \%$ and * to $90 \%$.

c SE: standard error or deviation of the estimated parameter.

Table II.16

ECUADOR AND MEXICO: DETERMINING FACTORS OF UNPAID WORK (UW) OF MALE HEADS OF EXTENDED TWO-PARENT HOUSEHOLDS

\begin{tabular}{|c|c|c|c|c|c|c|}
\hline \multirow{2}{*}{ Variables } & \multicolumn{3}{|c|}{ Ecuador } & \multicolumn{3}{|c|}{ Mexico } \\
\hline & $e y / d x^{a}$ & $\mathbf{S i g}^{\mathrm{b}}$ & $\mathbf{S E}^{\mathrm{c}}$ & $e y / d x^{a}$ & $\mathrm{Sig}^{\mathrm{b}}$ & $\mathbf{S E}^{\mathrm{c}}$ \\
\hline UW of others & 0.0010 & & 0.0009 & 0.0010 & & 0.0006 \\
\hline UW by son & 0.0169 & 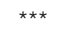 & 0.0029 & 0.0036 & $\star \star *$ & 0.0017 \\
\hline UW by daughter & 0.0036 & $* * *$ & 0.0012 & 0.0004 & & 0.0005 \\
\hline Employed & -0.3632 & *** & 0.1225 & -0.1744 & ** & 0.0695 \\
\hline Secondary education & -0.0405 & & 0.0551 & 0.0407 & & 0.0634 \\
\hline Tertiary education & -0.0333 & & 0.0233 & 0.0739 & ** & 0.0293 \\
\hline Age & -0.0129 & & 0.0109 & -0.0082 & & 0.0143 \\
\hline Age squared & 0.0001 & & 0.0001 & 0.0000 & & 0.0001 \\
\hline Children aged 0 to 5 & 0.1521 & 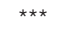 & 0.0497 & 0.3387 & $\star \star \star \star ~$ & 0.0756 \\
\hline Children aged 6 to 13 & -0.0151 & & 0.0295 & 0.0519 & & 0.0432 \\
\hline Children aged 14 to 17 & 0.0344 & & 0.0461 & -0.0949 & * & 0.0533 \\
\hline
\end{tabular}

Source: Author's own data, based on microdata from the National Institute of Statistics and Geography (INEGI)/ National Institute for Women (INMUJERES), 2009 National Time-Use Survey (all for Mexico); and the National Institute for Statistics and Censuses (INEC)/National Council for Women (CONAMU), and 2007 National TimeUse Survey (for Ecuador).

a ey/dx: elasticity, in other words the variation in the dependent variable (UW) when $\mathrm{x}$ varies (the independent variable).

b Sig: Level of significance of the variable: ${ }^{\star \star \star}$ means that it is significant to a confidence level of $99 \%$, ${ }^{\star \star}$ is $95 \%$ and * to $90 \%$.

c SE: standard error or deviation of the estimated parameter. 


\section{F. Conclusions and recommendations}

Available evidence shows that the largest overall workload is carried out by women (and even more so by employed women). Women's time is more affected by unpaid work, whereas this is not the case for men. Within unpaid work, domestic chores represent the largest workload and the most unequal distribution among the sexes.

Information on Ecuador and Mexico shows that the indigenous population, living in rural areas in households with young children, have the heaviest unpaid work burden (and the most striking gender differences).

These and other characteristics are identified in this report, including the fact that having young children means that women carry out more unpaid work, while men also carry out more paid work. Also, women's paid work increases in line with the age of children (as they have less unpaid work to do). In addition, fewer than $50 \%$ of households in the countries analysed correspond to the two-parent household with a traditional role distribution among men and women (and this is the type targeted by most social policies implemented in our countries). In any event, there is a transformation under way in the distribution of household roles towards a sharing of paid work among the sexes, but without yet sharing unpaid work (tendency towards the dual-career model with traditional distribution of unpaid work roles). In both countries, unpaid work was distributed evenly in just $9 \%$ of households, while the unpaid work roles were inverted in another $4 \%$ of households (with male heads of household or partners spending at least $50 \%$ more of their time on unpaid work than their partners).

The typology of lone-parent households demonstrates that sons and daughters follow the same division of labour as between heads and partners of two-parent households, with daughters following the same pattern as female heads: greater time spent on unpaid work when there are small children in the household. These results seem to suggest a tendency for people to reproduce the gender model of their parents.

The bargaining models indicate, as shown in previous research, that economic incentives are combined with "doing gender". In twoparent households, it is easier for women to negotiate or allow themselves less participation in unpaid work when their economic contribution has a greater impact on household income. However, the presence of young children or the time spent by women and their partners on paid work do significantly impact this bargaining, because the time spent on unpaid work differs by sex. For men, this is affected by their working hours and the number of children. For women, in addition to those two factors, 
the working hours of the partner are also relevant. Gender differences are accentuated as individual paid working hours have more effect on men's unpaid work hours, while the number of small children has more impact on women's unpaid work hours. Similar patterns are observed for lone-parent and extended families, as the most relevant variables for determining unpaid workload are employment status (which affects men more) and the number of small children (which impacts more on women).

This shows that policies should aim to develop childcare services for young children and standardize working hours, with a particular focus on mainly male sectors (such as transport) that involve long working hours. Such policies would form part of what should be a care system. In the Quito Consensus adopted in August 2007 at the ECLAC Regional Conference on Women in Latin America and the Caribbean, the region's countries already committed to implementing actions that redistribute unpaid work between the sexes and among institutions (the State, market and family).

It is vital to bear in mind that the State's role as care service provider determines the care burden delegated to families, the voluntary sector and the market — as well as the possibility of giving and receiving quality care. As women have provided such care in an unpaid way, they have borne the cost of providing care services or benefits, and this produces economic, social and political inequalities. The system should therefore be defined with due consideration for whoever is bearing the costs of the lack of care services or benefits.

\section{Bibliography}

Agarwal, Bina (1997), "Bargaining and gender relations: within and beyond the household", Feminist Economics, vol. 3, N 1.

Aguirre, Rosario (2009) "Uso del tiempo y desigualdades de género en el trabajo no remunerado", Las bases invisibles del bienestar social, Rosario Aguirre (ed.), Montevideo, National Institute of Statistics (INE).

Álvarez, Begoña and Miles, Daniel (no date) “Women's subjective well-being and housework allocation", Universidad de Vigo [online] https: / / editorialexpress. com/cgi-bin/conference/download.cgi?db_name=IAFFE2009\&paper_id=106.

Antonopoulos, Rania (2008), "The unpaid care work-paid work connection", Working Paper, $N^{\circ}$ 541, The Levy Economics Institute, July.

Armas, Amparo, Contreras, Jackeline and Vásconez, Alison (2009), La economía del cuidado, el trabajo no remunerado y remunerado en Ecuador, Quito, the National Council for Women (CONAMU)/National Institute for Statistics and Censuses (INEC)/Spanish Agency for International Development Cooperation (AECID)/ United Nations Development Fund for Women (UNIFEM).

Becker, Gary S. (1965), "A theory of the allocation of time", The Economic Journal, vol. $75, \mathrm{~N}^{\mathrm{o}} 299$. 
Deding, Mette and Lausten, Mette (2006) "Choosing between his time and her time? Paid and unpaid work of Danish couples", International Journal of Time Use Research, vol. 3, No 1.

Elson, Diane (2002), Macroeconomics and Macroeconomic Policy from a Gender Perspective, University of Essex.

Espejo, Andrés, Filgueira, Fernando and Rico, Nieves (2010), "Familias latinoamericanas: organización del trabajo no remunerando y de cuidado", Documentos de Proyectos, No 354 (LC/W.354), Santiago, Chile, Economic Commission for Latin America and the Caribbean (ECLAC).

Esping-Andersen, Gøsta (2009), The Incomplete Revolution. Adapting to Women's New Roles. Cambridge, Polity Press.

Esquivel, Valeria (2011), “La economía del cuidado en América Latina: poniendo a los cuidados en el centro de la agenda", Atando cabos; deshaciendo nudos, San Salvador, Área de Práctica de Género, United Nations Development Programme (UNDP).

(2009), "Time use in the City of Buenos Aires. Measuring, analyzing and valuing unpaid care work", Thesis for PhD in Economics, Institute for the Study of the Americas(ISA), School of Advanced Study, University of London.

Fraser, Nancy (1997), Iustitia interrupta, reflexiones críticas desde la condición postsocialista, Bogotá, Siglo del Hombre Editores, Universidad de los Andes.

Gardiner, Jean (1997), Gender, Care and Economics, London, Macmillan.

Federal Government of Mexico/INMUJERES (National Institute of Women) (2009), "Las desigualdades de género vistas a través del estudio del uso del tiempo. Resultados de la Encuesta Nacional sobre Uso del Tiempo 2009" [online] http:/ / cedoc.inmujeres.gob.mx/documentos_download/101184.pdf.

Lewis, Jane (2001), "The decline of the male breadwinner model: the implications for work and care", Social Politics, vol. 8, No 2 .

Martínez Franzoni, J. (2008), Domesticar la incertidumbre en América Latina: Mercado laboral, política social y familia, San José, Editorial Universidad de Costa Rica.

Montaño, Sonia (2010), "El cuidado en acción", El cuidado en acción. Entre el derecho y el trabajo, S. Montaño and C. Calderón (coords.), Cuadernos de la CEPAL, N 94 (LC/G.2454-P), Santiago, Chile, Economic Commission for Latin America and the Caribbean (CEPAL)/Spanish Agency for International Development Cooperation (AECID)/United Nations Development Fund for Women(UNIFEM). United Nations publication, Sales No: S.10.II.G.35.

Montaño, Sonia and Calderón, Coral (coords.) (2010), “El cuidado en acción. Entre el derecho y el trabajo", Cuadernos de la CEPAL, Nº 94 (LC/G.2454-P), Santiago, Chile, Economic Commission for Latin America and the Caribbean (CEPAL)/ Spanish Agency for International Development Cooperation (AECID)/United Nations Development Fund for Women(UNIFEM). United Nations publication, Sales No.: S.10.II.G.35.

Orloff, Ann Shola (2002), “Women's employment and welfare regimes: globalization, export-orientation and social policy in Europe and North America", Social Policy and Development Programme, Document, N ${ }^{\circ} 12$ (PP-SPD-12), Geneva, United Nations Research Institute for Social Development (UNRISD).

Pérez, Alba, Vásconez, Alison and Gallardo, Claudio (2008), El tiempo de ellas y ellos. Indicadores de la Encuesta Nacional de Uso del Tiempo 2007, Quito, the National Council for Women (CONAMU)/National Institute for Statistics and Censuses (INEC). 
Picchio, A. (1999), "Visibilidad analítica y política del trabajo de reproducción social", Mujeres y economía, C. Carrasco (ed.), Barcelona, Icaria-Antrazyt.

Rodríguez Enríquez, Corina (2005), “Economía del cuidado y política económica: una aproximación a sus interrelaciones", document presented at the 38th meeting of the Presiding Officers of the ECLAC Regional Conference on Women in Latin America and the Caribbean, Mar del Plata (Argentina) [online] http:/ / www.eclac.org/mujer/reuniones/mesa38/C_Rodriguez.pdf. 


\section{Chapter III \\ Social protection and unpaid work: redistribution of caregiving tasks and responsibilities, a case study of Costa Rica ${ }^{1}$}

Pablo Sauma

A rigid sexual division of labour is one of the continuing barriers on the path to gender equality. This rigidity is especially significant in terms of the responsibility assigned to women for caregiving in the home, which limits gender equality in paid work and other public spheres. The main challenge to breaking down this barrier is to redistribute total work, both paid and unpaid, with the latter consisting mainly of care provided in the home. It is therefore recommended to increase not only the role of the State, market and society, but also men's participation in dependent care tasks, as prerequisites for achieving a society where men and women are both breadwinners and caregivers (ECLAC, 2010).

More specifically, the Division for Gender Affairs of the Economic Commission for Latin America and the Caribbean (ECLAC) believes that care should be considered as a field of social protection. It states that the care issue must be resolved by means of the institutional equation formed by the State, businesses, families and the third sector. It also argues that the path towards equality between men and women entails:

This chapter is a summary of a paper on the same subject, published in the Mujer $y$ Desarrollo series, No. 116 (LC/L.3519), Santiago, Chile, Economic Commission for Latin America and the Caribbean (ECLAC), September 2012. 
(i) changing the time use of women and men and (ii) de-segmenting the employment system. This requires promoting a coordinated set of care policies ranging from social protection (to at least release women's time), to employment policies (to increase women's labour force participation and reverse the mechanisms that produce or reproduce discrimination against women in employment systems) and development policies (which determine job levels and quality, as well as the types of production chain), including the territorial dimension of development.

The aim of this case study of Costa Rica, which was conducted simultaneously with that of Ecuador, is to answer the question: Which social protection policies are required to achieve the objective of redistributing and recognizing unpaid care work between men and women in the region?

\section{A. Sociodemographic scenario and demographic estimates of care needs}

Costa Rica is a country in the advanced stage of a demographic transition process that began in the mid-twentieth century with the baby boom and is expected to end in around 2060.

This process, triggered by an improvement in people's living standards, especially in such areas as health and education, has led to a significant increase in life expectancy at birth, coupled with sharply reduced fertility and birth rates. Comparing current estimates with those of 1950, life expectancy has increased by around 23 years for women and 20 years for men (INEC/CCP, 2008). The drop in the total fertility rate has been huge: from around 7 children per woman in 1961 to 1.96 children per woman in 2007.

As a result of these changes -especially the reduction in the fertility rate- Costa Rica's population will grow slowly in the coming years, from 4.6 million in 2010 to 5.3 million in 2025 and 6.1 million in 2050. Nevertheless, there will continue to be significant changes in the population by age group, as the number of older adults in Costa Rica (aged 65 years and over), which had already increased from just over 200,000 in 2000 to around 300,000 in 2010, is estimated to double by 2025 and double again by 2050 .

In terms of the number of people, after Costa Rica has attained an optimal level of childcare, future demand will level off, whereas demand for care services and solutions for older adults will continue to grow. While it might be said that the short-term priority should be placed on childcare, addressing the care of older adults at a later date, this does 
not mean that the required investment for the care of this segment of the population can be postponed; investment should begin now, as this population group is growing all the time. In conjunction with investment, programmes should be scaled up to train and specialize human resources in the care of older people, and new programmes implemented to prepare for and raise awareness of old age, in the latter case bearing in mind that cultural change tends to take many years.

\section{Analysis from the perspective of households}

The increase in Costa Rica's older adult population is reflected in the composition of households. The household surveys of 1990, 2000 and 2009 show that the percentage of households with people in this age group is increasing gradually and that there are now older adults in one in five Costa Rican households. There has also been a rise in the number of households with two or more older adults among its members, totaling $5.7 \%$ of all Costa Rican households in 2009.

What is most striking, though, is the large and sustained increase in the percentage of households comprising only older adults, which rose from $3.4 \%$ of all Costa Rican households in 1990 to $6 \%$ in 2009. Such households also represent a high proportion of all households with at least one member in that age group, which in 2009 was almost one in three (29.9\%).

In contrast, the percentage of households with members aged 0 to 6 years fell significantly as a percentage of all Costa Rican households, from nearly half of households in 1990 (47.5\%) to just over one in four in 2009. Despite this decline, and consistent with population projections, the number of households with members aged 0 to 6 years increased in absolute terms between 1990 and 2000 (from approximately 300,000 to 360,000), but levelled off between 2000 and 2009 and is unlikely to change much in the future.

The percentage of households where older adults live with children aged 0 to 6 years has also decreased, counting for barely $1.9 \%$ of all households in 2009. Clearly, then, the issues of childcare and care of older adults are of concern for different households, as few households care for both age groups.

\section{Demographic projections of care needs}

In line with the trend already observed, the number of households with older adults is expected to continue to grow slowly but surely. According to a conservative estimate, assuming that the percentage of 
the older adult population cared for in nursing homes continues grow at the same rate as in the past 10 years, by 2025 there will be one older adult in one in four Costa Rican households $(25 \%)$ and more than one older adult in $7 \%$ of households, while just over $10 \%$ of all Costa Rican households will comprise only older adults (that is to say, around $45 \%$ of all households with older adults among their members) (Sauma, 2011). As a result of the above factors, households with members aged 0 to 6 years will continue to shrink as a percentage of all households, although their number is expected to remain stable.

Thus, the future outlook for Costa Rica is not only for an increase -in both absolute and proportional terms - in the number of households with older adults, but also for a rise in the number of households comprising only older adults and a reduction in the number of potential caregivers in households where older adults live with people of other ages. In homes with children aged 0 to 6 years, the ability of household members to participate in the labour market is constrained.

\section{An approximation of levels of dependency among older adults}

An important aspect of care of older adults is their level of dependency, which determines the type and complexity of services to be offered. Costa Rica's Social Protection Board (JPS) defines as dependent a person who requires ongoing support from others and who has severe functional and mental health problems, adding that older persons may be described as dependent when they have lost their functional independence and need help from others to function in their daily lives (JPS, 2010).

Dependency includes physical, social and mental aspects. It is usual to define different levels of dependency, ranging from low to high, and determining them tends to be highly complex, requiring a series of specific assessments of each individual by specialists. Knowledge of the different dependency profiles according to complexity is key to proper planning of services in the network of care. For example, it is necessary to ascertain the number of cases where older adults require the direct and constant accompaniment of either a person or care institution.

For the purposes of this chapter, it was deemed desirable to examine dependency profiles, based specifically on the activities of daily living, that is to say, the actions carried out by individuals to meet their basic and self-care needs, such as eating, dressing, moving around, bathing or using the toilet (CONAPAM, 2010). 
Estimates were based on the database from the first round of a project to study longevity and healthy ageing, entitled "Proyecto Costa Rica: Estudio de Longevidad y Envejecimiento Saludable (CRELES)" (Rosero-Bixby, Fernández and Dow, 2005). ${ }^{2}$ In this case, the level of dependency is determined on the basis of the difficulty experienced by adults in performing activities of daily living, considering both basic functions (specifically getting in and out of bed, bathing, walking, using the toilet and eating) and instrumental functions (shopping, taking medication, cooking and managing money).

Table III.1 shows that, while nearly 7 out of 10 older adults (living in individual households) have no difficulty in performing activities of daily living, 3 out of 10 experience difficulties with at least one activity. ${ }^{3}$

A total of $13.8 \%$ of people aged 65 years and over living in individual households experience difficulty in performing one or two activities of daily living, which can be termed a low level of dependency; $8.1 \%$ have difficulty in performing three or four such activities, meaning they have a medium level of dependency; and $8.3 \%$ have difficulty in performing five or more activities, signifying a high level of dependency.

An important factor is that levels of dependency increase with age. According to the same survey (see table III.1), the average age of people experiencing no difficulty in performing the relevant activities of daily living is 72 years, whereas the average age of people with the greatest dependency is 82 years. An estimated 67,000 older adults in Costa Rica were aged 80 years or over in 2010, a figure set to rise to 122,000 in 2025 and 400,000 in 2050 (INEC/CCP, 2008).

2 The overall objective of the study is to determine the extent and quality of life of Costa Rica's older adults, and causal factors thereof. As part of the investigation, a representative sample of Costa Rica's population aged 60 years and over living in individual households was interviewed. The information provided in this chapter corresponds to the first round of the survey, conducted in 2005, excluding people aged between 60 and 64 years.

3 The 2008 study by the Central American Population Centre/National Council for Older Persons (CCP/CONAPAM) used the same database to analyse dependency. The study considered separately functional mobility (climbing stairs, walking, pushing objects, raising the arms), basic functionality (getting in and out of bed, bathing, walking across the room, using the toilet, eating) and instrumental functionality (shopping, taking medication, cooking, managing money). Even though the study did not analyse the three dimensions together, when functional mobility activities are considered jointly with basic functional activities the result is a much higher prevalence of dependency than that estimated in the current study $(64.3 \%$ experiencing difficulty in performing at least one functional mobility activity or basic functional activity). The difference is that, unlike in the $2008 \mathrm{CCP} / \mathrm{CONAPAM}$ study, the current estimate considers only basic and instrumental functionality but not functional mobility. The current estimate is more in line with customary international estimates, using the Katz Index of Independence in Activities of Daily Living, which measures mobility in terms of moving in and out of bed. 
Table III.1

COSTA RICA: PREVALENCE OF DEPENDENCY IN THE POPULATION AGED 65 YEARS AND OVER LIVING IN INDIVIDUAL HOUSEHOLDS, ESTIMATED ON THE BASIS OF THEIR DIFFICULTY IN PERFORMING ACTIVITIES OF DAILY LIVING, 2005 (Percentages)

\begin{tabular}{lcc}
\hline Difficulty in performing activities of daily living (ADL) & Percentage & Average age $^{a}$ \\
\hline Entire population group & 100.0 & 74 \\
No difficulty in performing ADL & 69.9 & 72 \\
Difficulty in performing one or two ADL & 13.8 & 76 \\
Difficulty in performing three or four ADL & 8.1 & 79 \\
Difficulty in performing five or more ADL & 8.3 & 82 \\
\hline Source: Prepared by the author on the basis of data from the Central American Population Centre (CCP)/ \\
Instituto de Investigaciones en Salud (INISA)/Universidad de Costa Rica, "Proyecto Costa Rica: Estudio de \\
Longevidad y Envejecimiento Saludable (CRELES)", first round, 2005. \\
a This refers specifically to difficulties with: walking (crossing from one side of a room to the other); bathing \\
(including getting in and out of the bath); eating (including cutting up food and filling a glass); getting in and \\
out of bed; using the toilet (including sitting down and getting up from the toilet); preparing a hot meal; \\
managing one's own money; shopping (for groceries or clothing, for example); and taking medication.
\end{tabular}

While a more detailed dependency analysis should also include the prevalence of certain diseases requiring higher levels of care for sufferers, such as arthritis or Alzheimer's disease, which, together, constitute the requirements to be met by the care system, the current approximation reveals that a large percentage of older adults in Costa Rica need an extensive time commitment from their caregivers. Given that the current estimate considers only older adults living in individual households, the great majority of whom are cared for by their (mainly female) relatives, it is imperative to move towards a model that redistributes caregiving tasks and responsibilities.

\section{B. Care provision to children and dependent older people}

\section{Arrangements in the domestic sphere}

Costa Rica has been conducting nationwide household surveys since 1976. The 2004 survey included a time-use module that makes it possible to identify differences in men and women's work, as well as to deepen understanding of dependent care within the home. ${ }^{4}$ The figures

4 Between 1987 and 2009, the instrument used was the multi-purpose household survey (EHPM), for which the field work is carried out in July each year (this year, between 5 July and 4 August) and is nationwide. The module was applied to the entire sample of 13,399 homes, and the reference population was people aged 12 years and over living in these homes. The information was obtained by direct interview, endeavouring 
presented here have been processed by the author from the information in the survey database. ${ }^{5}$

Social time-use analysis refers to the way in which society as a whole (in this case, the entire population aged 12 years and over) divides its time between the various activities considered. This is done by calculating a (daily) average of the entire population, irrespective of whether everyone performs a particular activity. Table III.2 shows social time use, differentiating women's time use from that of men.

As seen in the table, the daily average social time that women spend working (in the broadest sense) compared with the daily average time they spend on non-work activities does not differ from that of men: women spend 7 hours 27 minutes working and 16 hours 33 minutes on non-work activities, whereas men spend 7 hours 26 minutes working and 16 hours 34 minutes on non-work activities. However, there is a drastic difference in the composition of the social time spent working because, while women spend 5 hours 28 minutes on unpaid work and 1 hour 59 minutes on paid work, the reverse is true for men, who spend 1 hour 37 minutes on unpaid work and 5 hours 49 minutes on paid work.

A breakdown of unpaid work into domestic and non-domestic work reveals virtually no difference in the average social time spent by women and men on non-domestic work (11 minutes and 13 minutes, respectively), which is low in relative terms. Unpaid work by women therefore consists almost exclusively of domestic work and, within this category, in descending order of importance: typical household chores (washing, ironing, cooking and cleaning); direct care of dependents; and other household activities.

Whereas $84.3 \%$ of women aged 12 years and over did unpaid work, only $50.5 \%$ of men in the same age group did (see table III.2). In contrast, $59.4 \%$ of men aged 12 years and over did paid work, compared with only $24 \%$ of women in the same age group.

always to interview the direct informant, although in cases where this was not possible, the information was obtained from indirect informants. In interviews held between Tuesdays and Saturdays, interviewees were asked about the activities carried out over the previous 24 hours, and in interviews held on a Monday, interviewees were asked about the activities carried out the previous Saturday and Sunday, meaning that the information covered 48 hours. A comprehensive and detailed explanation of the module methodology can be found in a document by Costa Rica's inter-agency technical committee on accounting for women's work (Comisión Técnica Interinstitucional de Contabilización del Trabajo Femenino, 2006).

5 The more general results differ very slightly (by a few minutes) from the estimates published by Costa Rica's inter-agency technical committee on accounting for women's work (Comisión Técnica Interinstitucional de Contabilización del Trabajo Femenino, 2008), owing to differences in methods of adjustment for unreported information. 
Table III.2

COSTA RICA: DAILY AVERAGE SOCIAL TIME, PARTICIPATION RATES AND DAILY

AVERAGE EFFECTIVE TIME SPENT ON ACTIVITIES AMONG THE POPULATION

AGED 12 YEARS AND OVER, BY SEX, 2004

(Hours/minutes and percentages)

\begin{tabular}{|c|c|c|c|c|c|c|}
\hline \multirow[t]{2}{*}{ Type of activity } & \multicolumn{2}{|c|}{$\begin{array}{c}\text { Daily average social } \\
\text { time }^{\mathrm{a}}\end{array}$} & \multicolumn{2}{|c|}{ Participation rate $^{b}$} & \multicolumn{2}{|c|}{$\begin{array}{l}\text { Daily average } \\
\text { effective time }\end{array}$} \\
\hline & Women & Men & Women & Men & Women & Men \\
\hline Total & 24 hours & 24 hours & & & & \\
\hline WORK & $\begin{array}{r}7 \text { hours } \\
27 \text { minutes }\end{array}$ & $\begin{array}{r}7 \text { hours } \\
26 \text { minutes }\end{array}$ & & & & \\
\hline Unpaid work & $\begin{array}{r}5 \text { hours } \\
28 \text { minutes }\end{array}$ & $\begin{array}{r}1 \text { hour } \\
37 \text { minutes }\end{array}$ & 84.3 & 50.5 & $\begin{array}{r}6 \text { hours } \\
8 \text { minutes }\end{array}$ & $\begin{array}{r}2 \text { hours } \\
58 \text { minutes }\end{array}$ \\
\hline Unpaid domestic work & $\begin{array}{r}5 \text { hours } \\
17 \text { minutes }\end{array}$ & $\begin{array}{r}1 \text { hour } \\
24 \text { minutes }\end{array}$ & 83.9 & 47.1 & $\begin{array}{r}5 \text { hours } \\
58 \text { minutes }\end{array}$ & $\begin{array}{r}2 \text { hours } \\
45 \text { minutes }\end{array}$ \\
\hline $\begin{array}{l}\text { Washing, ironing, cooking, } \\
\text { cleaning }\end{array}$ & $\begin{array}{r}3 \text { hours } \\
31 \text { minutes }\end{array}$ & 24 minutes & 77.4 & 21.8 & $\begin{array}{r}4 \text { hours } \\
17 \text { minutes }\end{array}$ & $\begin{array}{r}1 \text { hour } \\
44 \text { minutes }\end{array}$ \\
\hline $\begin{array}{l}\text { Care of children, the sick, older } \\
\text { persons }\end{array}$ & $\begin{array}{r}1 \text { hour } \\
9 \text { minutes }\end{array}$ & 19 minutes & 32.3 & 12.2 & $\begin{array}{r}3 \text { hours } \\
22 \text { minutes }\end{array}$ & $\begin{array}{r}2 \text { hours } \\
27 \text { minutes }\end{array}$ \\
\hline Other activities ${ }^{d}$ & 38 minutes & 40 minutes & 82.7 & 38.5 & $\begin{array}{r}5 \text { hours } \\
46 \text { minutes }\end{array}$ & $\begin{array}{r}2 \text { hours } \\
27 \text { minutes }\end{array}$ \\
\hline Unpaid non-domestic work & 11 minutes & 13 minutes & 9.6 & 9.2 & $\begin{array}{r}1 \text { hour } \\
44 \text { minutes }\end{array}$ & $\begin{array}{r}2 \text { hours } \\
14 \text { minutes }\end{array}$ \\
\hline Activities for the home ${ }^{e}$ & 5 minutes & 8 minutes & 6.8 & 6.9 & $\begin{array}{r}1 \text { hour } \\
16 \text { minutes }\end{array}$ & $\begin{array}{r}1 \text { hour } \\
52 \text { minutes }\end{array}$ \\
\hline $\begin{array}{l}\text { Activities for the community, } \\
\text { voluntary work }\end{array}$ & 5 minutes & 5 minutes & 3.1 & 2.5 & $\begin{array}{r}2 \text { hours } \\
36 \text { minutes }\end{array}$ & 3 hours \\
\hline Paid work & $\begin{array}{r}1 \text { hour } \\
59 \text { minutes }\end{array}$ & $\begin{array}{r}5 \text { hours } \\
49 \text { minutes }\end{array}$ & 24.0 & 59.4 & $\begin{array}{r}7 \text { hours } \\
50 \text { minutes }\end{array}$ & $\begin{array}{r}9 \text { hours } \\
6 \text { minutes }\end{array}$ \\
\hline OTHER ACTIVITIES & $\begin{array}{r}16 \text { hours } \\
33 \text { minutes }\end{array}$ & $\begin{array}{r}16 \text { hours } \\
34 \text { minutes }\end{array}$ & & & & \\
\hline Training activities & 40 minutes & 38 minutes & 13.5 & 11.7 & $\begin{array}{r}4 \text { hours } \\
41 \text { minutes }\end{array}$ & $\begin{array}{r}5 \text { hours } \\
1 \text { minute }\end{array}$ \\
\hline Leisure activities $^{\dagger}$ & $\begin{array}{r}4 \text { hours } \\
53 \text { minutes }\end{array}$ & $\begin{array}{r}5 \text { hours } \\
18 \text { minutes }\end{array}$ & 89.7 & 88.1 & $\begin{array}{r}5 \text { hours } \\
9 \text { minutes }\end{array}$ & $\begin{array}{r}5 \text { hours } \\
36 \text { minutes }\end{array}$ \\
\hline Personal needs and care ${ }^{g}$ & $\begin{array}{l}10 \text { hours } \\
59 \text { minutes }\end{array}$ & $\begin{array}{r}10 \text { hours } \\
38 \text { minutes }\end{array}$ & 100.0 & 100.0 & $\begin{array}{r}10 \text { hours } \\
59 \text { minutes }\end{array}$ & $\begin{array}{r}10 \text { hours } \\
38 \text { minutes }\end{array}$ \\
\hline
\end{tabular}

Source: Prepared by the author on the basis of data from the National Statistics and Census Institute (INEC), multi-purpose household survey "Encuesta de Hogares de Propósitos Múltiples (EHPM), Módulo de uso del tiempo 2004".

a Average social time is calculated by dividing the total time spent on a particular activity by the total population aged 12 years and over. It is expressed in hours and minutes.

b The participation rate is calculated by dividing the total number of people aged 12 years and over who spent time on a particular activity by the total population aged 12 years and over. It is expressed as a percentage.

c Average effective time is calculated by dividing the total time spent on a particular activity by the total population aged 12 years and over who spent time on that activity. It is expressed in hours and minutes.

d Includes shopping for and putting away household items, paying bills or carrying out banking transactions (including travel time), gardening, caring for plants and pets, mending appliances, carrying out house repairs, washing, cleaning or maintaining the family car or other transport vehicle, or taking it to the repair or specialist workshop.

e Includes collecting water or firewood, caring for chickens, milking, growing crops, fishing, making sour cream, cheese or other products, in all cases solely for home consumption.

f Includes religious activities, physical exercise, playing, walking, reading, watching television, listening to the radio, going to parties, dancing, going to the cinema, meeting friends, chatting, talking on the telephone, craftwork and other recreational activities.

g Includes rest (sleeping and napping) and personal care activities, such as eating, bathing and dressing. 
In the specific case of dependent care (unpaid), 32.3\% of women (nearly 1 in 3 ) participated, compared with only $12.2 \%$ of men (a little over 1 in 10).

An analysis of the effective time that people spend on the different types of activity as a daily average shows that women who perform unpaid work spend 6 hours 8 minutes on this activity, whereas men spend 2 hours 58 minutes (see table III.2). Women who perform paid work spend 7 hours 50 minutes on this activity, while men spend 9 hours 6 minutes.

With regard to dependent care, women who participate $32.3 \%$ of all women) spend an average effective time of 3 hours 22 minutes a day on this activity, whereas men providing dependent care $(12.2 \%$ of all men) spend 2 hours 27 minutes.

Before making a more in-depth analysis of the time people spend on caring for dependents, it is useful to analyse the work performed by men and women from two important angles: age group and income level. As figure III.1 shows, the effective time women spend on unpaid work increases sharply in the 12-17 year age group and 25-34 year age group, after which it stabilizes until the 55-64 year age group and decreases in the 65 year-plus age group.

The time women spend on paid work also increases with age in the younger age groups but, from the 35-44 age group onwards, it diminishes gradually but steadily. The heavier domestic workload of women aged 35 to 64 years should be recognized as an obstacle to their greater participation in paid work. Also, while estimates relate to women's participation in the paid labour market at the time of the survey, limiting the scope for a longitudinal analysis, they reflect, to some extent, a generational change in that, as time goes by, the labour force participation of younger women gradually increases.

The effective time men spend on paid work increases sharply until the 25-34 age group, after which it stabilizes until the 45-54 age group and then begins to decrease. The effective time men spend on unpaid work increases in line with age, but only very gradually. In the latter case, while acknowledging the limitations of point estimates to approximate a longitudinal analysis, the survey data appear to show no evidence of a generational change, which would produce a reverse of the current situation (that is to say, younger men would spend more time on unpaid work); instead the data appear to indicate that the change in men's time is part of the life cycle. 
Figure III.1

COSTA RICA: DAILY AVERAGE EFFECTIVE TIME SPENT ON PAID

AND UNPAID WORK, BY SEX AND AGE GROUP, 2004

(Minutes)

\section{A. Women}

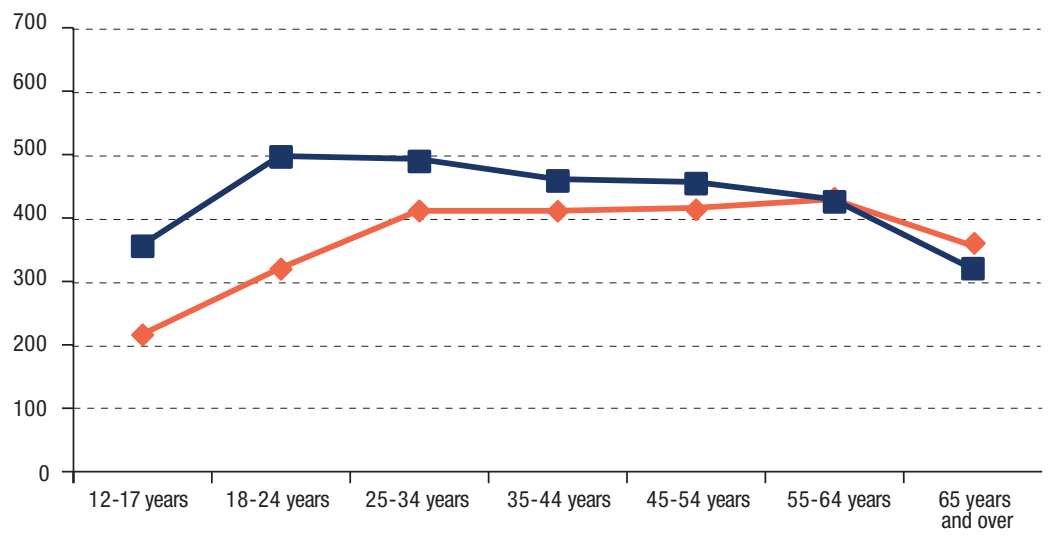

B. Men

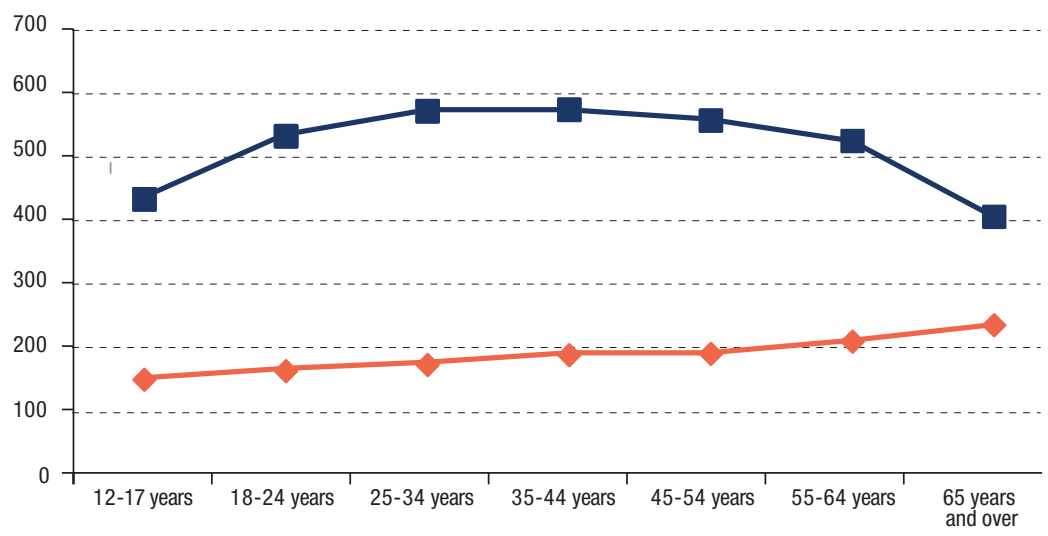

Age group

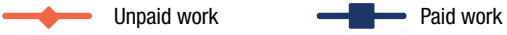

Source: Prepared by the author on the basis of data from the National Statistics and Census Institute (INEC), multi-purpose household survey "Encuesta de Hogares de Propósitos Múltiples (EHPM), Módulo de uso del tiempo 2004". 
Figure III.2 shows the effective time spent by women and men on paid and unpaid work by income level, in this case, by deciles of households ranked by per capita income. ${ }^{6}$ The result in the case of women is very clear: as income levels rise (relatively wealthier households), the effective time women spend on paid work increases and the time they spend on unpaid work decreases. This behaviour should not be analysed unidirectionally because there is, in fact, a combination of causes and consequences. Women's paid work increases the level of household income, which enables some households to hire domestic help. However, in many relatively poorer households, engaging in paid work results in longer working hours for women, who are obliged to perform unpaid work in addition to paid work. From the perspective of care, consideration needs to be given to the fact that the poorest households (by per capita income) not only bear a heavier demographic burden in terms of children, adolescents and older adults, they are also unable to delegate tasks to hired personnel, compounded by more limited access to or availability of the goods and services that would reduce the time they spend on household chores.

In the case of men, the effective time spent on paid work increases gradually in line with rising income levels until the eighth decile, after which it levels off (see figure III.2). The time men spend on unpaid work does not change significantly, that is to say it is not affected by income level.

As table III.2 shows, according to the 2004 time-use module the female population aged 12 years and over spends a daily average social time of 1 hour 9 minutes on caring for dependents (children, older adults, sick people), whereas the male population spends only 19 minutes. As stated earlier, the participation rates in dependent care are $32.3 \%$ of women and $12.2 \%$ of men, with those caring for dependents spending a daily average effective time of 3 hours 22 minutes for women and 2 hours 27 minutes for men. Below is a more in-depth analysis of those providing dependent care and the characteristics of their households.

The time-use module asked people how much time they spent exclusively on caring for and attending to sick people, children or others requiring their attention, apart from cooking, washing and ironing time. No distinction was made for the time spent on each type of dependent (older people, children, sick persons or those with disabilities), or for whether the people to whom they provided services belonged to the same household. Moreover, as the household survey does not enquire about care recipients' disease or disability, the only variable available for analysis is their age.

6 Households in the top two deciles correspond to poor households, where poverty lines are used. 
Figure III.2

COSTA RICA: DAILY AVERAGE EFFECTIVE TIME SPENT ON PAID AND UNPAID WORK, BY SEX AND PER CAPITA HOUSEHOLD INCOME DECILE, 2004a (Minutes)

A. Women

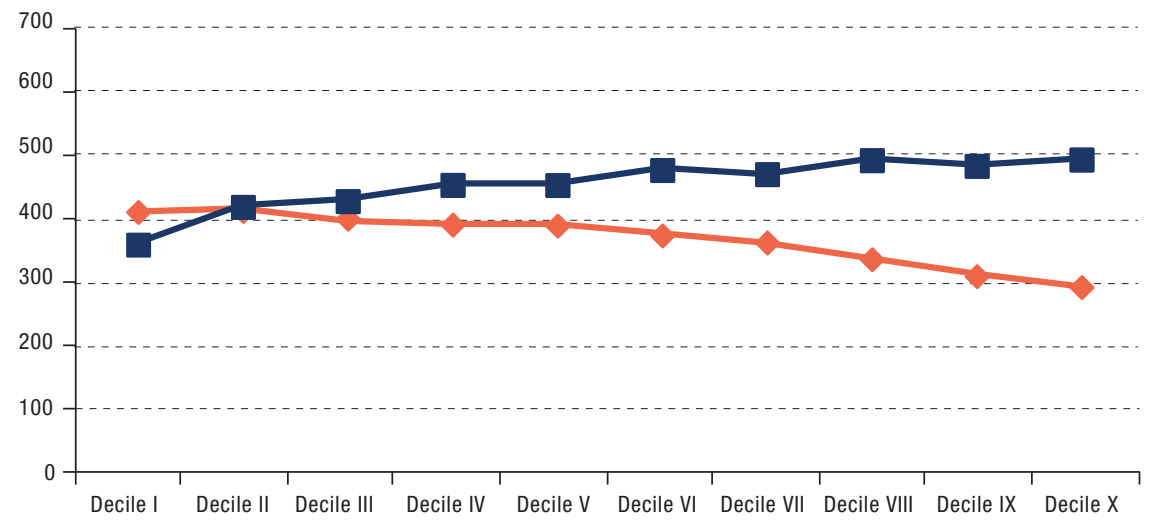

B. Men

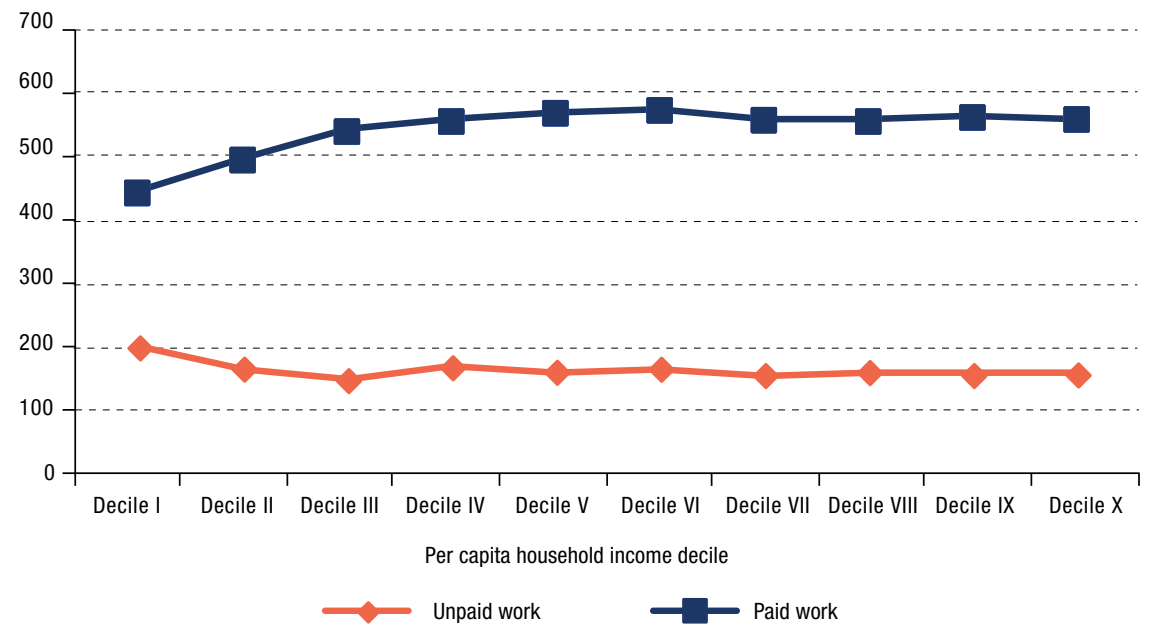

Source: Prepared by the author on the basis of data from the National Statistics and Census Institute (INEC), multi-purpose household survey "Encuesta de Hogares de Propósitos Múltiples (EHPM), Módulo de uso del tiempo 2004".

a Includes only people aged 12 years and over from households with known income.

The households with members who spent time on the direct care of dependents were divided into four categories: (i) households where there are older adults (aged 65 years and over) but no children aged 12 years or under; (ii) households where there are children aged 12 years 
or under but no older adults; (iii) households where there are older adults and children aged 12 years or under; and (iv) households where there are neither older adults nor children aged 12 years or under, but are presumed to have a dependent household member (adolescent, older person under the age of 65 years requiring care, sick person or person with a disability), or to provide care services to family or non-family members not living in the home.

Of all those who provided care to dependents, $73.5 \%$ were women, a percentage that varies little according to the four household categories, and which reaches a maximum of $79 \%$ in the case of households with both older adults and children aged 12 years or under. Strikingly, an analysis of the distribution of women caregivers by type of household reveals that $76.6 \%$ belong to households where there are only children aged 12 years or under. The same is true of men, with $77.2 \%$ belonging to households where there are only children aged 12 years or under.

As regards caregivers' kinship with the male head of household, $42.1 \%$ of household members performing direct care tasks are the head's wife or female partner. If these women carers are added to the $11.5 \%$ women carers who are heads of household and the $14.6 \%$ who are daughters, together they account for $68.2 \%$ of all household members performing care tasks, that is to say, almost 7 out of 10 (see table III.3). Male heads of household account for $18.8 \%$ of caregiving household members, which is also a high figure.

Table III.3

COSTA RICA: DISTRIBUTION OF HOUSEHOLD MEMBERS PERFORMING DIRECT CARE TASKS, BY SEX AND KINSHIP WITH THE MALE OR FEMALE HEAD OF HOUSEHOLD, 2004 ${ }^{a}$

(Percentages)

\begin{tabular}{lcc}
\hline Kinship with the male or female head of household & Women & Men \\
\hline Male or female head of household & 11.5 & 18.8 \\
Husband or wife, male or female partner & 42.1 & 0.7 \\
Son or daughter & 14.6 & 5.2 \\
Son-in-law or daughter-in-law & 1.1 & 0.6 \\
Grandson or granddaughter & 0.6 & 0.3 \\
Father, mother, father-in-law or mother- in-law & 1.0 & 0.1 \\
Other & 2.6 & 0.8 \\
Subtotal & 73.5 & 26.5 \\
\hline
\end{tabular}

Source: Prepared by the author on the basis of data from the National Statistics and Census Institute (INEC), multi-purpose household survey "Encuesta de Hogares de Propósitos Múltiples (EHPM), Módulo de uso del tiempo 2004".

a The sum of the percentages by sex and kinship with the male or female head of household totals $100 \%$ of male and female caregivers. 
Box III.1

PROFILE OF MALE CAREGIVERS

Men make up $26.5 \%$ of all caregivers (more than one in four) and spend an average effective time of 2 hours 27 minutes per day on direct care.

Just over half of all male caregivers (55.4\%) are aged between 25 and 44 years. The effective time men in the different age groups spend on direct care tasks tends to be similar, although the youngest men (aged 12 to 17 years) spend the least time and the oldest men (aged 65 years and over) spend the most time. The youngest men come from large households, which largely explains their caregiving activity. The oldest men belong to households with fewer members.

A total of $71.1 \%$ of all male caregivers are heads of household and this proportion is higher among older age groups. A total of $79.4 \%$ of all male caregivers are employed, a percentage that rises in line with age, before peaking and then decreasing among older age groups.

Lastly, $71.7 \%$ of male caregivers have not completed secondary education, although this percentage decreases in the 25-54 age group, where almost one in three male caregivers have completed secondary education or higher.

Source: Prepared by the author on the basis of data from the National Statistics and Census Institute (INEC), multi-purpose household survey "Encuesta de Hogares de Propósitos Múltiples (EHPM), Módulo de uso del tiempo 2004".

\section{Provision of formal direct care services by third parties}

In Costa Rica, primary education coverage is $100 \%$ and virtually all children aged 7 to 12 years attend school. The present analysis therefore focuses on childcare services for preschool children under the age of 6 years and 3 months, which are very limited as discussed below. The analysis begins with care services for preschool children and follows with those for older adults.

\section{(a) Children under the age of 6 years and 3 months}

CostaRica's publiceducation system provides twolevels of preschool childcare services: the "transition" level, which caters to children over the age of 6 years and 3 months, and "interactive II" level, which caters to children aged between 5 years and 3 months and 6 years and 3 months. Coverage at the transition level is high, with a net enrolment ratio of $93.7 \%$ in 2009 (MEP, 2009). At transition level, 88.3\% of total enrolment is in State schools and the remaining $11.7 \%$ in private schools. This is not the case with interactive II level, where the same source quoted a net enrolment ratio of only $55.8 \%$ in 2009 . At interactive II level, $83.8 \%$ of total enrolment is in State schools and $16.2 \%$ in private schools. ${ }^{7}$

7 The coverage of interactive II level is lower because, in recent years, the Ministry of Public Education (MEP) has prioritized the goal of $100 \%$ childcare coverage at the transition level. 
Two important aspects of current care services need to be analysed. One is the care schedule. Care services are provided according to two main schedules: an extended schedule lasting 10 hours or more and a part-time schedule typically lasting between four and seven hours. If childcare is to cease to constrain the effective labour force participation of women and men, care services should be provided throughout the time people are at work (that is to say, an ordinary eight-hour working day), plus travel time.

The second aspect warranting analysis is the classification of care services according to institutional sector, taking into consideration care provision and financing. Costa Rica's childcare services can be divided into three groups: (i) services provided by public institutions with public funding (irrespective of whether there is a payment by families); (ii) services provided by private entities with private funding; and (iii) services provided by private entities with public funding (irrespective of whether there is a payment by families). For the purposes of this study, the first group is referred to as public care services, the second group as private care services and the third group as public/ private care services. ${ }^{8}$

(i) Public services. There are two main types: care services open to the public (irrespective of household poverty requirements and other factors) and the childcare centres of public institutions catering exclusively or mainly to the children of their employees (closed services).

(ii) Private services. There are two types: purely commercial care services provided by private companies that produce and sell services to third parties, and care services provided to specific groups by private organizations, using their own funding.

(iii) Public/private services. In Costa Rica there is a public/ private programme of community day-care centres (hogares comunitarios), which are privately run but funded by the Joint Institute for Social Aid (IMAS). The programme was launched in 1991 with the aim of promoting the creation of microbusinesses specializing in childcare run by mothers (madres comunitarias) who provide day care to a small number of children in their own homes, enabling low-income people to join the labour market. 


\section{(b) Older adults (aged 65 years and over) ${ }^{9}$}

There are three main forms of care for older adults: nursing homes, homes for the elderly and day-care centres. Nursing homes are facilities where older adults live permanently and which, in addition to lodging, provide comprehensive services, including: medical, paramedical and nursing services; physical and occupational therapy; welfare services; balanced meals; mental stimulation; recreational, occupational and cultural activities; spiritual support and laundry facilities. Such care facilities are also expected to have trained permanent staff, suitable ancillary equipment and an appropriately distributed physical plant adapted to the needs of older adults.

Homes for the elderly are a variant of nursing homes, which emerged in response to the housing problems of those without family resources. Homes for the elderly provide older adults with protection and cater to their needs. Homes for the elderly are open and those living in them are free to receive visitors and go out into the community. There are two types: group and individual homes for the elderly: A group home for the elderly is a dwelling housing a small group of less than 20 people, which provides basic services, including: meals; laundry facilities; recreational, occupational, cultural and physical activities; mental stimulation; social contact and resocialization. An individual home for the elderly is a dwelling where a functionally autonomous older adult lives independently.

Day-care centres cater to older adults according to a variety of daytime schedules, and provide meals, recreational therapy and other basic services. Such care facilities are also expected to have trained permanent staff, suitable ancillary equipment and an appropriately distributed physical plant adapted to the needs of older adults. Day-care centres are a complement to family life and foster a close relationship between older adults, their families and the community.

There is a fourth form of care for older adults that has been little used to date but is part of the strategy for expanding the National Care Network for older adults, which is a priority for Costa Rica's current administration. It is home care, which the National Council for Older Persons (CONAPAM) defines as care and assistance provided to older adults in their usual place of residence in performing any activities required by their level of dependency (CONAPAM, 2010). These include assisting older adults with daily bathing, preparing and serving meals, cleaning the house, medical care (including accompanying them to

9 The information in this section was drawn from Sauma (2011). 
doctors' appointments), use of public transport, shopping or making payments, for example. The time and type of assistance will therefore depend on the needs identified for each person.

There are no public services (provided and funded by the public sector) in the area of care for older adults, which is dominated by public/ private services and a few private services. Public/private services are provided by non-profit organizations (legally constituted as associations or foundations) that receive public funding, topped up by contributions from beneficiaries according to their ability to pay. Private services are provided and sold by private (for-profit) companies.

CONAPAM was established by Comprehensive Law 7935 of 1999 on Older Persons and is the lead agency in matters of ageing and old age. The responsibilities assigned by law to CONAPAM include some relating directly to care services for older adults, such as participating in accreditation processes within its scope of competence and encouraging the granting of accreditation or recommending the withdrawal of the respective accreditation and keeping updated records of individuals and legal entities accredited by the Ministry of Health to provide services to older adults.

The Ministry of Health is responsible for the accreditation of facilities providing care services to the older adult population, in accordance with the guidelines in the general regulations for issuing Ministry of Health operating licences (Executive Decree 34728$\mathrm{S}$ of 2008). ${ }^{10}$ The aim of this accreditation is to assure users that such facilities meet the minimum structural indicators of continuous quality improvement to provide the services that they explicitly claim to offer, with an acceptable risk to users.

In Costa Rica in mid-2010 there were a total of 71 nursing homes (including 13 homes for the elderly) and 49 day-care centres, run by 113 non-profit organizations. They catered for a total of 4,324 older adults (2,051 men and 2,273 women): 2,774 in day-care centres (1,522 men and 1,252 women) and 1,550 in nursing homes (529 men and 1,021 women).

The coverage of publicly funded care services is low: in 2010 no more than $2 \%$ of the older adult population was catered for by Costa Rica's three main publicly funded forms of care (nursing homes, homes for the elderly and day-care centres). Public spending on such programmes is also low and, in 2009, it amounted to just $0.06 \%$ of Costa Rica's gross domestic product (GDP).

10 The regulations state that, for health-care and related facilities, the operating licence is equivalent to a certificate of approval. 
In addition there are 14 private, for-profit, facilities, chiefly nursing homes, located in high-income residential areas. While no information is available on the population they serve, they tend to be small facilities (usually caring for fewer than 25 people), whose data is not expected to modify the previous figures substantially.

The specific goal of the network proposed in the current national development plan -Plan Nacional de Desarrollo 2011-2014 (MIDEPLAN, 2010) - is to increase the coverage of publicly funded forms of care by 2,500 people between 2011 and 2014 .

\section{The care space: an unbalanced institutional equation}

Care services are provided by households, the State, businesses and the third sector, acting in an interrelated manner. In chapter 1 of this book, Lamaute-Brisson states that these care institutions form a relational area involving four types of relationship: relationships of allocating caregiving tasks and responsibilities to individuals; care relationships between people in need of care and caregivers; labour relations between caregivers and their institutions; and inter-institutional relationships between stakeholders. In its analysis of the care space, this chapter therefore explores the main potential roles and relationships within and across care institutions.

As this chapter will show, the institutional equation is rather unbalanced: the bulk of care services are provided in the domestic sphere, chiefly within but also between households, placing a far greater burden on women; some services are provided and funded by the State; and, lastly, a handful of services are funded by businesses and the third sector.

\section{Households}

As a whole, households are both providers and receivers of care services. The same situation is reproduced within households themselves, where some members provide care services while others receive them.

A high percentage of households have among their members children aged 0 to 6 years and older adults. The proportion is even higher if children aged 7 to 12 years are included. While the household survey fails to capture information on the population that is dependent for reasons of disability or illness, figures available on the presence of children and older adults provide evidence of a very large potential population requiring care services. 
It is important to note that this analysis does not consider people living permanently in nursing homes, hospitals or other care facilities as forming part of a household. However, the number involved is very small (1,550 older adults in 2009, representing around $0.5 \%$ of people in that age group). Irrespective of whether such services are inadequate for those requiring them on account of their level of dependency, Costa Rica's model of care for the older adult population focuses on ensuring that, as far as possible, older adults remain within their own family and community, and actively participate in any decisions directly affecting their welfare (article 16 of the Comprehensive Law on Older Persons).

According to the information provided by the time-use module in the 2004 household survey, 57.8\% of households with children aged 12 years or under or older adults have members who perform direct care tasks. A further $15 \%$ of households with no children or older adults have members who perform direct care tasks, which, as mentioned earlier, presumably indicates that they are households with a dependent member (adolescent, older person under the age of 65 years requiring care, sick person or person with a disability), or else households where a member provides care to a family (or non-family) member not living in the same household.

The 2004 time-use module confirms that three situations exist in households:

(i) The prevailing division of labour means that the burden of direct care falls chiefly on women: $32.3 \%$ of women and $12.2 \%$ of men participate in direct care of the population aged 12 years and over, with the daily average effective time spent on direct care totalling 3 hours 22 minutes for women and 2 hours 27 minutes for men. The burden of support tasks also falls mainly on women.

(ii) The different generations care for one another: mothers and fathers care for their children, as well as their own fathers and mothers; grandmothers and grandfathers care for their grandchildren; and, in some cases, grandchildren care for their grandmothers and grandfathers.

(iii) People also care for those in their own generation: although the 2004 time-use module did not identify care receivers in the home, available data supports the conclusion that within households there are children and adolescents caring for children, older adults caring for other older adults, and other forms of intragenerational caregiving. 
(iv) However, as just over half of caregivers (53.3\%) are aged between 25 and 44 years and $80.5 \%$ are aged between 18 and 54 years, care is predominantly intergenerational.

In this overall context, two situations should be kept in mind: (i) not all the time spent by household members on caregiving is for members of their own household; and (ii) not all the care received by household members is provided by members of their own household.

In the first case, members of a household may provide unpaid care services to people who are not household members. The ties between them are diverse: they may be family members (mostly grandchildren, but also other dependent relatives) or non-family members (such as older adults or children in the community).

In the second case, apart from care provided by household members, dependents may receive care services in their own home from domestic service workers and external carers. In the specific case of older adults, the aforementioned CRELES survey on longevity and healthy ageing by the Central American Population Centre/National Council for Older Persons (CCP/CONAPAM) found that the primary caregiver for 1 in 10 older adults is a female domestic service worker and, for a further 1 in 10, it is another non-family member (2008, p. 93).

Household members may also receive paid or free care services outside the home, in such facilities as nurseries or day-care centres for older adults.

As the coverage of formal care services (so described because they are provided by public institutions, businesses and legally constituted, properly regulated organizations) tends to be low, it is necessary to acknowledge the existence of a broad set of what can be described as informal arrangements enabling households to meet their care needs alongside formal care services. Informal services are provided mainly by individuals, in either the care receiver's or caregiver's home, and are unregulated. While there are no figures on the scale of informal care services, apart from the presumed contribution of domestic service, it is likely to be very large. Household survey questionnaires should therefore be improved - especially in modules focusing on care- in order to investigate (both formal and informal) care services fully.

\section{State}

The State is directly responsible for regulating care services, providing some and funding others, as analysed below. 
(i) Regulation. Responsibility for regulating childcare lies with the Ministry of Public Education (MEP) and the Comprehensive Childcare Board (CAI), while that for regulating the care of older adults lies with the Ministry of Health (accreditation of care facilities) and CONAPAM.

(ii) Service provision. The Government provides direct care services in only one case, via the programme of Education and Nutrition Centres and Comprehensive Childcare Centres (CEN-CINAI) run by the Ministry of Health's Directorate-General for Child Nutrition and Development (DGNDI). However, the Government is currently promoting increased care services as part of the National Care Network for children and older adults, with the aim not only of expanding services in the CEN-CINAI programme, but also increasing the participation of new stakeholders, especially municipalities in the public sphere.

(iii) Funding. The CEN-CINAI programme is financed by the national budget, in addition to $2.62 \%$ of the Fund for Social Development and Family Allowances (FODESAF). ${ }^{11}$ Associations and foundations providing care services to older adults are funded from three sources: national lottery receipts distributed by JPS; FODESAF funding; and receipts from the tax on liquor, beer and cigarettes, the latter two channelled through CONAPAM. According to estimates (Sauma, 2011), in 2009 a total of 10,086,500,000 Costa Rican colones were transferred to nursing homes and day-care centres, representing $0.06 \%$ of Costa Rica's GDP. Three quarters of this sum $(75.6 \%)$ was transferred by JPS and the remaining $24.4 \%$, by CONAPAM. According to the same author, public funds cover only two thirds of the total cost of the services provided by these organizations, obliging them to turn to other funding sources. In addition, some public stakeholders contribute indirectly, such as the Costa Rican Social Security Fund (CCSS) in the area of health and pensions, and support is provided in a number of areas by public institutions in the national education system (including MEP and State universities) and the National Institute of Women (INAMU), to name but a few.

11 This percentage is stipulated by Law 8783 reforming the law on social development and family allowances. 


\section{Businesses}

Traditionally the business sector's involvement has been confined to the sale of services by firms purely for profit (such as nurseries, schools and nursing homes). As mentioned earlier, there are no records on the number of childcare facilities operating in Costa Rica, or on the population they serve or their care schedules, for instance. In the case of care services for older adults, there is a register of facilities accredited by the Ministry of Health, but no further information (such as the population served) is available.

Sauma (2009) identified only one case of services provided to specific groups by private organizations using their own funding: the 'Centro Infantil Renzo Zingone' workplace nursery in the Zeta Industrial Park (free zone), which receives a small State contribution. The International Labour Organization (ILO, 2010a) also identified the workplace nursery of the El Angel company, providing one worker and a space allocated to caring for children while their parents are working. In any case, the business sector has very little involvement in this area.

\section{Third sector}

In the third sector, several key stakeholders are involved in the care of children and older adults, either in support of care providers or as care providers themselves.

First and foremost, a large number of non-profit associations and foundations are involved in providing care services to the older adult population (nursing homes, day-care centres and, increasingly, home care). According to CONAPAM records, in mid-2010 there were 113 organizations running 71 nursing homes and 49 day-care centres in Costa Rica, as stated earlier. Sauma (2011) reported that most of these organizations had been established out of a vested interest by an individual or group of people with community or religious ties, to address the problems of the older adult population. They are financed by public funds (transfers from the public sector) and private funds, the latter from direct payments by beneficiaries (according to their ability to pay), as well as donations and other sources.

Second, in the specific case of the CEN-CINAI programme, since 2005 it has been compulsory for each care facility to have a legally constituted "Specific Development Association Pro CEN-CINAI and Community Welfare", made up of members of the community, which manages State funding for the purchase of perishable goods, promotes community fund-raising to cover operating expenses and improve the 
centre, and assists in the selection of programme beneficiaries. Up to now, the associations have comprised mainly women, but this is expected to change in the near future following the enactment of Law 8901 of 2010 on the minimum percentage of women to be included on the boards of associations, unions and solidarity associations, which states that such boards must ensure the equal representation of both sexes. ${ }^{12}$

Two additional stakeholders have been involved in the provision of childcare services: unions and solidarity associations. However, the results have not been entirely satisfactory, mainly owing to the high costs of providing services, which forced one trade union childcare centre to close down ${ }^{13}$ and a solidarity association to open its childcare services to the general public. ${ }^{14}$

\section{By way of conclusion}

An analysis of the care space from an institutional perspective reveals that Costa Rica does not have a real system of care for children and older adults, understood as a system with universal coverage for those who need it, in which all the institutions involved play a relevant and properly coordinated role that is balanced in terms of the distribution of caregiving tasks and responsibilities (which includes their distribution within each sphere, especially the domestic sphere).

\section{Relationships between the care space and the employment system}

\section{Paid employment}

In Costa Rica, there has been a significant increase in women's participation in the paid labour market in the past two decades. This has been reflected in a gradual rise in the net participation rate (of women aged 15 years and over) from $32.9 \%$ in 1990 to $43.5 \%$ in 2010, in contrast to

12 Solidarity associations are groups of employees from the same company who manage a portion of their members' unemployment funds and enjoy the support of the company's owners.

13 The solidarity nursery, Guardería Solidaridad, run by the Confederation of the Costa Rican Workers Movement (CMTC) from 2002 to 2005.

14 The Generación Norte Preescolar preschool established by the Solidarity Association of Employees of the Nation and Related Subsidiaries (ASENACSA). The school is open to the general public but children of association members are granted a discount on their tuition fees, representing the portion contributed jointly by the other members to cover the costs of running the school. 
the male participation rate, which has shown a slight downward trend. In 1990, women accounted for $29 \%$ of the labour force, rising to $34 \%$ in 2000 and $38 \%$ in 2010.

Women's open unemployment rates are higher than men's. On average over the aforementioned period, the female unemployment rate outstripped that of men by 3.1 percentage points, with annual differences of between 2.1 percentage points and 4.6 percentage points. The gap was generally wider between 2005 and 2010 (covering a period of greater economic expansion (2005-2007), followed by the economic crisis (2009) and slow recovery (2010)) than between 2000 and 2004.

Women clearly predominate in industries related to direct care and indirect support care, specifically in education, health and social services, community and personal services, and domestic service. These are areas where women have job opportunities in part because they can transfer into employment the caregiving skills they have acquired at home.

On average, women devote less time to paid work than men in all occupational groups, although the widest gaps in terms of hours occur in craft production, construction, mechanics, graphic arts and skilled manufacturing, followed by skilled jobs in agriculture, livestock and fisheries, unskilled jobs, and jobs in local sales and direct services to people. A total of $51.5 \%$ of employed women work in unskilled jobs or local sales and direct services to people. Furthermore, $67.7 \%$ of women in unskilled jobs and $64.8 \%$ of women in sales and direct services to people work in the informal non-agricultural sector.

The 2010 national household survey (ENAHO) revealed a highly significant result: taking all employed workers together, there is no difference in the average hourly earnings of men and women. However, within occupational groups the situation differs, with women earning more than men in two groups and vice versa in the remaining groups.

The occupations where women's average hourly earnings exceed those of men are managerial jobs in the civil service and private enterprise (where women earn $7.1 \%$ more) and unskilled jobs (where women earn $17.5 \%$ more). While their higher earnings in unskilled jobs is, to some extent, the result of including the non-cash compensation received by female domestic service workers as part of labour income, it does not fully explain the difference.

The occupational categories where women's average hourly earnings are the furthest below those of men are local sales and direct services to people (where women earn 20.6\% less), intermediate-level technical and professional jobs ( $20 \%$ less) and installation and operation of facilities and machinery ( $18 \%$ less). 
There is one occupational group where both men and women's hourly earnings are far in excess of those in the other occupational groups where women's participation is concentrated. They are, in descending order: managerial jobs in the civil service and private enterprise; professional, scientific and intellectual jobs; and intermediatelevel technical and professional jobs.

Another important aspect that should be included in this analysis is production chains, that is to say, linkages between the care space and the rest of the economy. However, it is beyond the scope of this study because Costa Rica does not perform surveys of care facilities (the most appropriate type of survey for this purpose).

By way of conclusion, a high percentage of women work in paid jobs in the commercial and industrial sectors, as well as in direct caregiving and indirect support care (specifically in the areas of education, health and social services, community and personal services, and domestic service), with the proportion of women employed in the latter areas outstripping that of men. These are areas where women have job opportunities in part because they can transfer into employment the caregiving skills they have acquired at home. While a fair number of women work in managerial and professional jobs, as well as in the civil service, just over half work in unskilled jobs or in sales and direct services to people. Furthermore, women's reduced time availability to work in paid employment drives them into the informal sector and lower-paid jobs.

\section{Linkages between households and the employment system}

Of all those in paid employment, $70.5 \%$ of women but only $26.2 \%$ of men also perform direct caregiving and support tasks. The gap is huge and underscores the unequal burden of care faced by women, even when they engage in paid employment.

Table III.4 shows the daily average effective time that women and men in paid work spend on direct care tasks for children, older adults or sick people, as well as support tasks (washing, ironing, cooking and cleaning).

Each day women in paid work spend an average of 40 minutes more than men on all activities, including paid work and direct caregiving and support tasks. Men and women differ in terms of the time they spend on paid work and the unpaid activities considered, with women spending 71 minutes less than men on paid work and 111 minutes more on other activities. 
Table III.4

COSTA RICA: DAILY AVERAGE EFFECTIVE TIME SPENT ON CAREGIVING AND SUPPORT TASKS AND ON PAID WORK BY EMPLOYED PEOPLE AGED 12 YEARS AND OVER, BY SEX, 2004

(Minutes and percentages)

\begin{tabular}{|c|c|c|c|c|}
\hline \multirow[t]{2}{*}{ Type of activity } & \multicolumn{2}{|c|}{$\begin{array}{c}\text { Time } \\
\text { (minutes per day) }\end{array}$} & \multicolumn{2}{|c|}{$\begin{array}{l}\text { Time spent } \\
\text { (percentages) }\end{array}$} \\
\hline & Women & Men & Women & Men \\
\hline Total & 632 & 592 & 100.0 & 100.0 \\
\hline Paid work & 490 & 561 & 100.0 & 100.0 \\
\hline Direct care and unpaid support tasks & 142 & 31 & 70.5 & 26.2 \\
\hline Time spent only on direct care & 11 & 13 & 7.0 & 10.5 \\
\hline Time spent only on support tasks & 69 & 11 & 44.0 & 12.5 \\
\hline Time spent on direct care and unpaid support tasks simultaneously & 62 & 7 & 19.5 & 3.2 \\
\hline
\end{tabular}

Source: Prepared by the author on the basis of data from the National Statistics and Census Institute (INEC), multi-purpose household survey "Encuesta de Hogares de Propósitos Múltiples (EHPM), Módulo de uso del tiempo 2004".

Table III.4 also confirms that women in paid employment spend little time solely on direct care and that support tasks and tasks performed in conjunction with direct care place the greatest burden on women.

Table III.5 shows the average time spent by employed women on paid work and on direct caregiving and support tasks by type of dependent living at home. It reveals that the employed women spending the most time on direct caregiving and support tasks are those from households with children aged 0 to 12 years (192 minutes), followed by those from households with children aged 0 to 6 years (166 minutes) and those with children aged 0 to 12 years and older adults (163 minutes). Next in terms of time spent on direct caregiving and support tasks come women from households only with children aged 7 to 12 years (150 minutes) and, to a lesser degree, women from households only with older adults and from those with no children or older adults. In the latter case, the time spent by women on direct care tasks would indicate the presence in the home of people with disabilities who are not captured in the survey or that care is provided to members living outside the home, that is to say, functionally independent older adults.

As expected, in homes with children aged 0 to 6 years and 0 to 12 years, the time spent on direct caregiving and support tasks simultaneously is much higher than in other cases.

There is an inverse correlation between time spent on paid work and time spent on direct caregiving and support tasks, albeit with exceptions, as evidenced in the case of women living in households with children aged 
0 to 6 years who spend not only the second longest time on caregiving activities but also the longest time on paid work. As a result, these women are the ones who spend the most total time on both activities. This makes it extremely important to ascertain the level of formal and informal direct care support available to such households in general, and to the women concerned, in particular. Unfortunately, as mentioned earlier, the survey employed in this study fails to capture this information.

Table III.5

COSTA RICA: DAILY AVERAGE EFFECTIVE TIME SPENT ON CAREGIVING AND SUPPORT TASKS AND ON PAID WORK BY EMPLOYED WOMEN AGED 12 YEARS AND OVER, BY TYPE OF DEPENDENT AT HOME, 2004 (Minutes)

\begin{tabular}{|c|c|c|c|c|c|c|}
\hline \multirow[b]{2}{*}{ Type of dependent at home } & \multirow[b]{2}{*}{ Total } & \multicolumn{4}{|c|}{ Direct caregiving and unpaid support tasks } & \multirow[b]{2}{*}{ Paid work } \\
\hline & & Total & $\begin{array}{l}\text { Time spent } \\
\text { only on } \\
\text { direct } \\
\text { caregiving }\end{array}$ & $\begin{array}{l}\text { Time spent } \\
\text { only on } \\
\text { support } \\
\text { tasks }\end{array}$ & $\begin{array}{l}\text { Time spent on } \\
\text { direct caregiving } \\
\text { and unpaid } \\
\text { support tasks } \\
\text { simultaneously }\end{array}$ & \\
\hline Total & 632 & 142 & 11 & 69 & 62 & 490 \\
\hline $\begin{array}{l}\text { No older adults or children aged } \\
0 \text { to } 12 \text { years }\end{array}$ & 611 & 111 & 3 & 91 & 17 & 500 \\
\hline Only older adults & 593 & 116 & 10 & 69 & 37 & 477 \\
\hline Only children aged 0 to 6 years & 669 & 166 & 25 & 29 & 112 & 503 \\
\hline Only children aged 7 to 12 years & 629 & 150 & 8 & 88 & 55 & 479 \\
\hline Only children aged 0 to 12 years & 662 & 192 & 16 & 46 & 130 & 469 \\
\hline $\begin{array}{l}\text { Older adults and children aged } \\
0 \text { to } 12 \text { years }\end{array}$ & 657 & 163 & 21 & 43 & 99 & 494 \\
\hline
\end{tabular}

Source: Prepared by the author on the basis of data from the National Statistics and Census Institute (INEC), multi-purpose household survey "Encuesta de Hogares de Propósitos Múltiples (EHPM), Módulo de uso del tiempo 2004".

With regard to women's labour force participation according to the type of work they do (paid work only or paid work in addition to direct caregiving and support tasks), the percentage of self-employed women is significantly higher (double) in the case of women who perform both direct caregiving and support tasks, compared with women who do only paid work. The latter are more likely to be private-sector employees.

Broadly speaking, women who perform paid work and live in households with dependents (children aged 0 to 12 years and older adults) spend more time on direct caregiving and support tasks and less time on paid work than women living in households with no dependents (see table III.5). As table III.4 and table III.5 show, even in the latter case, the time employed women spend on support tasks (111 minutes) exceeds the time spent by employed men (31 minutes). 
While the household survey employed in this study fails to capture information on the use of formal care services (in specialist facilities) or informal care services provided by family or non-family members, in order to quantify their impact, it is safe to assume heavy use of such services. The situation of women in the paid labour market needs to be improved because care responsibilities affect their chances of joining it. This calls for policies of employment and productive development for women to be developed alongside care policies.

\section{E. Public policy for the redistribution of caregiving tasks and responsibilities}

In Costa Rica, the bulk of care services are provided in the domestic sphere, chiefly within but also between households, placing a far greater burden on women. The State plays a secondary role by regulating the services of third parties, as well as funding some programmes and providing a handful of services directly. Businesses and the third sector have even less involvement.

In addition to their limited coverage, publicly funded care services have a selection bias towards the population living in poverty, which limits the access of the population which, while not poor, experiences problems with care.

The conclusion, as stated earlier, is that Costa Rica does not have a real system of care for children and older adults, understood as a system with universal coverage for those who need it, in which all the institutions involved play a relevant and properly coordinated role that is balanced in terms of the distribution of caregiving tasks and responsibilities (which includes their distribution within each sphere, especially the domestic sphere).

In households, the unequal distribution of the burden of direct caregiving and support tasks between men and women not only increases women's working hours, it also affects the way in which women participate in the paid labour market and their economic independence. Action to strengthen the dependent-care system and equalize the distribution of the care burden within households would release time for women to increase their labour force participation and gain more economic independence. However, more free time is not enough in itself: progress is also needed in developing and implementing employment and productive development policies for women. 


\section{Care as part of the social protection system}

Below is an analysis of care policies implemented in Costa Rica as part of the National Policy for Gender Equality and Equity (PIEG) and the enhanced National Care Network, including specific recommendations to boost their impact and help them to become an integral part of the social protection system.

\section{(a) National Policy for Gender Equality and Equity (PIEG)}

A PIEG priority objective, set in 2007, is to ensure that, by 2017, every woman requiring childcare services to enable her to engage in paid work has at least one quality public, private or public/private care option, as a concrete step towards social responsibility in care and recognition of the value of domestic work (INAMU, 2007, p. 62).

To achieve this objective, PIEG plans not only to expand the care infrastructure but also to implement actions to promote cultural change towards shared responsibility for care between men and women, as well as shared social responsibility by the different stakeholders. According to INAMU, positioning care as a social issue calls for progress to be made not only with new services but also with cultural change, and care must evolve from being a purely women's issue to an issue affecting both men and women, and from a private family matter to a public concern of the State and business community (INAMU, 2007, p. 35).

\section{(b) National Care Network}

This programme originated from an expansion of existing services but promotes the implementation of new services and forms of care. With regard to childcare, the programme aims specifically to expand the provision of care to the poor population aged 0 to 6 years through the CEN-CINAI programme (on a part-time and full-time basis respectively) and to increase the involvement of municipalities and other stakeholders in the provision of such services, as well as in defining and delivering new services (such as Childcare and Development Centres (CECUDI) run by municipalities and private entities). As regards the care of older adults, the programme proposes to expand home care as well as care in nursing homes and day-care centres.

The target set for the National Care Network in the National Development Plan (MIDEPLAN, 2010) is to serve an additional 15,000 children and 2,500 older adults between 2011 and 2014.

However, several important issues must be taken into account if significant progress is to be achieved in developing and consolidating the network. Each of these issues is described below. 
(i) Estimating the real need for care services and current arrangements

While the coverage of care services provided by third parties is low, the true requirements for care services for children under the age of 7 years and for older adults are in fact unknown. Although the 2011 population census will provide valuable information on the characteristics of Costa Rica's population, further efforts will be needed to ascertain care requirements. In the case of children, the household survey should include a specific module, first, to ascertain families' current arrangements to meet their care needs and, second, to make an approximation of the scale of demand for third-party care services and their main characteristics (such as a longer care schedule or location). For example, mothers in an INAMU focus group stated that a set of conditions would need to be met for them to delegate care outside the family, including trained staff, appropriate infrastructure and proximity to the workplace (INAMU, 2007, p. 35).

\section{(ii) Advancing towards universal services}

The main characteristic of the services underpinning the National Care Network, for both children and older adults, is that they target the population living in poverty. While in most cases this is laid down in legislation allocating funding to programmes, there must be a move towards a more universal model, where the main requirement for access to services is not household poverty, but the need for services. A system should also be introduced to allow beneficiaries' families to make direct (out-of-pocket) payments based on their ability to pay.

In the case of older adults, it is paramount to consider their level of dependency because in many cases they and their families have incomes that are far above the poverty line but are still insufficient to enable them to afford the kind of care required by a highly dependent person, meaning that they need public-sector support. The recommendation in this case is to define clear rules for access and direct payment of publicly funded care services, in line with older adults' income and level of dependency.

(iii) Defining requirements and goals by 2025 and further specifying the model of care and its financing

In view of the need for universal services, the information on current care requirements in the 2011 population census must be integrated with information captured by household surveys or specific modules within them, in order to estimate requirements and define care goals until at least 2025 .

In conjunction, more progress is needed in defining Costa Rica's model of care, considering new forms of care and programmes and estimating its implementation cost and form of financing. 
The implementation cost and form of financing the model of care are highly relevant. As it is costly to provide children and older adults with decent quality of care, substantial financial resources must be assigned to it, with clearly identified funding sources. Naturally, the amount of resources will depend on the care goals set, but must be assumed to be high.

With regard to funding sources, in the future Costa Rica should discuss whether State funding of the model of care should continue to be welfare-based or whether it should instead be incorporated into the social security system (as in Japan and Germany for older adults, and Mexico for children). ${ }^{15}$

\section{(iv) Proper management of the network}

The National Development Plan 2011-2014 (MIDEPLAN, 2010) assigns responsibility for the National Care Network to IMAS, in conjunction with the National Child Welfare Agency (PANI) and the Ministry of Health's Directorate of Education and Nutrition Centres and Comprehensive Childcare Centres (CEN-CINAI) for children, and CONAPAM for older adults. Regardless of the physical location, a highlevel technical team should be appointed to lead, plan and implement the inter-agency coordination required by the network.

Apart from planning, including estimating the cost of expanding and funding the network and human resource requirements (discussed below), this technical team should also undertake tasks relating to information system development, continuous monitoring and evaluation, and an ongoing cost estimation of the different forms of care, considering complexity profiles where necessary.

In addition to its permanent staff, the network should therefore also rely on an interdisciplinary support team of health professionals, engineers, architects, lawyers, social workers and other technicians and professionals to support decision-making, protocol development, legal reforms and to help address any other tasks or challenges that may arise.

\footnotetext{
15 The Mexican Social Security Institute (IMSS) includes nurseries in social security coverage, in order to cover the risk of any female worker, widower, male divorcee or other person with legal custody being unable to care for their infant children during the working day. This insurance is funded from a 1\% premium on the base salary, to be covered in full by the employer regardless of whether the employer has workers benefiting from the service. Its limitation is that it covers only the population covered by social security. Germany in 1994 and Japan in 1997 approved the establishment of dependent insurance as a new branch of social security. Later, further countries including Austria and Luxembourg, moved in the same direction. Each of these countries has established rules on employee and employer contributions (see Jaccoud, 2010 for more details).
} 
(v) Accreditation of care facilities

As mentioned earlier, responsibility for regulating facilities lies with MEP and CAI for childcare and the Ministry of Health (accreditation of care facilities) and CONAPAM for the care of older adults.

While, in general, compliance with a number of minimum requirements is already required, there needs to be a move towards a system of accreditation that periodically assesses the extent to which service quality exceeds the minimum standards set. The accreditation system should include both public and private facilities.

(vi) Caregiver training and accreditation of prior learning

Where childcare services are not provided by preschool teachers, or where care for older adults is not provided by professionals, caregivers should be given further training and the skills of those who have worked in care for many years without proper training should be accredited.

This is particularly important given the current shortage of such training in Costa Rica's educational institutions, which can only be compounded by the current and future demand arising from the network expansion.

\section{(c) Expansion of public interactive level II}

As mentioned earlier, public interactive level II serves children aged between 5 years and 3 months and 6 years and 3 months. In 2009 the net enrolment ratio for this segment was $55.8 \%$ (MEP, 2009), including enrolment in State schools (83.8\%) and private schools (16.2\%). One of Costa Rica's specific targets as part of the Millennium Development Goals is to achieve $72.3 \%$ coverage at public interactive level II by 2015 (MIDEPLAN, 2010). While care at this educational level is part-time, from the standpoint of this study it is important to expand coverage to $100 \%$. This means that MEP should plan to include the necessary actions to achieve $100 \%$ coverage within a reasonable time frame.

\section{Policies of employment and productive development for women}

The redistribution of care tasks in the home and consolidation of care as part of the social protection system would release women's time to increase their labour force participation. However, as participation alone is not enough to ensure greater equality between men and women, two additional types of policy should be implemented: employment policies that promote women's employment and reverse the mechanisms producing or reproducing discrimination against women in employment 
systems; and productive development policies that improve the level and quality of jobs (especially those of women), including production chains.

There is a wide range of policy options for fostering women's employment and productive development but this study focuses on two: PIEG actions, which are already being implemented; and the window of opportunity for women's employment and productive development offered by the expansion of care services for children and older adults.

Before detailing these options, the following two important aspects must be taken into account when analysing and formulating policies and actions for women's employment and productive development.

First, many of the women whose time would be released by redistributing the care burden and who may be interested in participating in the labour market are aged between 25 and 54 years and have low levels of education. Of the women listed as inactive in the 2010 household survey, the main activity of $64.9 \%$ of those in the $15-24$ age group was study and, for $31.7 \%$, housework. However, the situation changes significantly among older women: more than $85 \%$ in the $25-54$ age group list housework as their main activity; in the 55-64 age group, $24.5 \%$ are retired and $63.9 \%$ are engaged in housework. In addition, $58 \%$ of inactive women in the 25-54 age group have primary education or less. So, while labour force participation appears to pose no problem for younger and relatively more educated women, the opposite is true for older, less educated women. To avoid informal employment becoming the main option for such women, activities such as training, labour inspection and support for small and medium enterprises will need to be strengthened.

The second aspect is highly positive from the standpoint of this analysis. While men's net labour force participation rate has remained stable in recent years and even shows a slight downward trend, the female participation rate has increased. Based on employment figures by sex and GDP growth rates between 2000 and 2010, together with population projections for the period 2011 to 2025, it is estimated that an average annual GDP growth rate of $4 \%$ (slightly less than the average observed in the above-mentioned years) would require $2.5 \%$ annual growth in the number of people employed. If the current male labour force participation rate continues unchanged, this would lead to growing demand for female employment, meaning that the net female participation rate would need to increase by $4 \%$ between 2010 and 2015, another 7\% between 2015 and 2020 and a further 9\% between 2020 and 2025. Although this approximation could be affected by many variables, it suggests that increasing women's employment is key to Costa Rica's economic growth. 


\section{(a) National Policy for Gender Equality and Equity (PIEG)}

A PIEG priority objective, set in 2007 , is to ensure quality paid work and income generation for women, and for Costa Rica to have abolished by 2017 the main causes of income inequality between women and men -female unemployment and under-employment- as part of a general improvement in Costa Rica's employment system (INAMU, 2007, p. 63).

To achieve this objective, PIEG proposes to promote quality employment for women by: enhancing social security coverage and improving women's employability; changing legislation to remove discrimination; increasing labour protection and training; and creating new sources of employment for women, especially in the most disadvantaged areas (INAMU, 2007, pp. 64-65).

Two observations emerge from a review of the PIEG action plan on paid employment and income generation, which should both be taken into account when updating the plan. First, there is clearly no explicit linkage between the proposed actions, and the plan sets no priorities. It is recommended to adjust the plan to address these points. Second, there is an imbalance between the number of actions aimed at promoting quality female employment and the number aimed at creating new sources of employment for women, which is a particularly important goal from the standpoint of this analysis. In addition, two of the proposed actions relate more to matching labour supply with labour demand than to creating jobs for women. It is therefore recommended to strengthen job-creation measures, including those relating to the provision of paid care services.

An assessment of progress in implementing the action plan up to 2010 (INAMU, 2011) revealed that results had been unsatisfactory and even acknowledged that the objective of creating paid work and generating income was one of the two where there had been the least progress (INAMU, 2011, p. 4).

\section{(b) Expansion of care services: a window of opportunity for women's employment and productive development}

In addition to releasing time for women, the expansion of care services represents a window of opportunity for women's employment and productive development, in terms of job levels and quality and the development of production chains.

On the one hand, the expanded care services will increase the number of women recruited to cover the new services, and on the other, new forms of care by organized women's groups should also be promoted to boost women's job creation. This would entail women establishing 
cooperatives or public limited companies and concluding agreements with municipalities or competent institutions in the case of the National Care Network, for the care of both children and older adults.

Expanded care provision and the resulting job creation create backward and forward economic linkages. The new jobs raise household incomes, in turn increasing the consumption of goods and services produced by other care facilities. These facilities then need to hire more male and female employees, which boosts demand for care services.

The above-mentioned factors make it particularly important to train the women who will participate in the paid provision of care services. This entails defining and expanding training provision, which could form part of the women's vocational training programme at Costa Rica's national vocational training institute (INA), as proposed in the PIEG action plan.

One innovative childcare strategy might be to establish a programme to encourage the private provision of care services for children from poor and vulnerable households, by paying a government grant as a means of ensuring that services are available to all those who need them.

The programme should meet the following requirements:

(i) care must be provided in facilities that meet certain minimum pre-established standards;

(ii) the care provider must have legal status (such as a private company, cooperative, worker-owned public limited company, association or foundation);

(iii) non-professional staff in charge should have minimum certified training and must at least have direct advisory support from a professional;

(iv) facilities must be accredited and regulated by MEP or CAI, as appropriate.

To provide care services, the formation of women's groups as cooperatives or worker-owned public limited companies should be promoted and prioritized in addition to private companies.

As infrastructure costs represent a costly investment for service providers willing to participate in the programme, a grant should be established to compensate, over a period of time, care facilities that build special infrastructure. There are also a number of options for municipalities, private companies and other organizations to supply the infrastructure, so the grant would only be for operating the services. 
The public institution(s) responsible for the programme would be the same as for the National Care Network. The success of any such initiative depends on an ongoing process of accreditation to ensure that beneficiary children are receiving the promised quality of care.

To conclude, while the expansion of care services is expected to provide excellent opportunities, they might not be enough in themselves to create all the quality jobs required by women who are already in the labour force but are unemployed or in low-quality jobs, or by women that wish to work and whose time will gradually be released as the care network is consolidated. To increase the impact of expanded services, it is also important to support production growth by means of direct linkages with caregiving.

\section{Bibliography}

CCP/CONAPAM (Central American Population Centre/National Council for Older Persons) (2008), Primer informe del estado de situación de la persona adulta mayor en Costa Rica, San José, Universidad de Costa Rica.

Comisión Técnica Interinstitucional de Contabilización del Trabajo Femenino (2008), " $i 2+2=6$ ? El trabajo que hacen mujeres y hombres en Costa Rica no se cuenta igual. Principales resultados del módulo de uso del tiempo 2004", Estudios Especiales series, No. 3, San José, National Statistics and Census Institute (INEC).

(2006), "Sistematización de los aspectos teóricos y metodológicos utilizados en el diseño y aplicación del módulo de uso del tiempo en Costa Rica", Colección Metodologías, No. 15, San José, National Institute of Women (INAMU), July.

CONAPAM (National Council for Older Persons) (2010), Red de atención progresiva para el cuido integral de las personas adultas mayores en Costa Rica, San José.

ECLAC (Economic Commission for Latin America and the Caribbean) (2010), What kind of State? What kind of equality? (LC/2450(CRM.11/13)), Santiago, Chile.

Gindling, T.H. and Juan Diego Trejos (2002), "Cambios en la desigualdad del ingreso laboral en Costa Rica 1976-1999: medidas y causas", Revista Ciencias Económicas, vol. 23, No. 1-2, San José, Faculty of Economic Sciences, Universidad de Costa Rica.

ILO (International Labour Organization) (2010a), Trabajo decente y corresponsabilidad social en el cuido: Retos en el camino hacia la igualdad, San José, ILO Country Office for Central America, Haiti, Panama and Dominican Republic. (2010b), Labour Overview, 2010. Latin America and the Caribbean, Lima, ILO Regional Office for Latin America and the Caribbean.

INAMU (National Institute of Women) (2011), Informe de balance de cumplimiento del plan de acción 2008-2010 de la Política Nacional para la Igualdad y Equidad de Género (PIEG), San José.

(2008), Plan de Acción 2008-2012: Política Nacional para la Igualdad y Equidad de Género, San José. (2007), Politica Nacional para la Igualdad y Equidad de Género (PIEG), San José. 
INEC/CCP (National Statistics and Census Institute/Central American Population Centre) (2008), Estimaciones y proyecciones de población por sexo y edad (cifras actualizadas), 1950-2050, San José, Universidad de Costa Rica (UCR).

Jaccoud, Luciana (2010), “Envejecimiento, dependencia y oferta de servicios asistenciales: un nuevo desafío para los sistemas de protección social", Envejecimiento en América Latina: sistema de pensiones y protección integral, Antonio Prado and Ana Sojo (eds.), Libros de la CEPAL, No. 110 (LC/G.2475-P), Santiago, Chile, Economic Commission for Latin America and the Caribbean (ECLAC). United Nations publication, Sales No. S.10.II.G.71.

JPS (Social Protection Board) (2010), “Diagnóstico de necesidades de las poblaciones en estado de pobreza o vulnerabilidad", La Gaceta, No. 83, San José, 30 April.

Lamaute-Brisson, Nathalie (2011), "Redistribuir y reconocer el cuidado desde la protección social: Un marco conceptual", paper prepared for the "Protección social e inclusión social en América Latina y el Caribe: Trabajo no remunerado y protección de las mujeres" project, Santiago, Chile, Economic Commission for Latin America and the Caribbean (ECLAC)/Swedish International Development Cooperation Agency (ASDI).

MEP (Ministry of Public Education) (2009), Expansión del sistema educativo costarricense 2009, San José, Department of Statistical Analysis.

MIDEPLAN (Ministry of National Planning and Economic Policy) (2010), Plan Nacional de Desarrollo 2011-2014 "María Teresa Obregón Zamora", San José.

Rosero-Bixby, Luis, Xinia Fernández and William H. Dow (2005), "Proyecto Costa Rica: Estudio de Longevidad y Envejecimiento Saludable (CRELES)", San José, Central American Population Centre (CCP)/Instituto de Investigaciones en Salud (INISA)/Universidad de Costa Rica.

Sauma, Pablo (2012), "Protección social y trabajo no remunerado: Redistribución de las responsabilidades y tareas del cuidado. Estudio de caso Costa Rica", Mujer y Desarrollo series, No. 116 (LC/L.3519), Santiago, Chile, Economic Commission for Latin America and the Caribbean (ECLAC).

(2011), "Elementos para la consolidación de la Red nacional de cuido de las personas adultas mayores en Costa Rica", Seminarios y Conferencias series, No. 63 (LC/G.2450/Rev.1), Santiago, Chile, Economic Commission for Latin America and the Caribbean (ECLAC).

(2009), "Propuestas de promoción de aumento de infraestructura de cuido de niños y niñas con la participación de sectores alternativos", Informe de consultoría, San José, National Institute of Women (INAMU)/United Nations Population Fund (UNFPA). 

Chapter IV

\section{Social protection and unpaid work: redistribution of caregiving tasks and responsibilities, a case study of Ecuador ${ }^{1}$}

Alison Vásconez Rodríguez

Recent shifts in the emphasis of Ecuador's welfare system have refocussed attention on the State's role as provider and regulator of basic social services, the recognition of work as a key factor in welfare and growth, and the need to gear social and economic policies towards reducing inequality. At the same time, recent global crisis events have shown not only that economic systems are too weak to ensure sustainable employment and development but also that families use a wide variety of strategies to survive crises and actually shore up these systems. Many of their survival strategies have involved domestic and care work, which has also stepped in to cover social services in the absence of the State. Historically women have been in charge of covering these services, mostly at the expense of their own opportunities and well-being, with adverse consequences for the economy and society's welfare.

In these times of economic, political and policy change, consideration should therefore be given to a comprehensive re-gearing of

This chapter is a summary of a paper on the same subject, published in the Mujer $y$ Desarrollo series, No. 116 (LC/L.3519), Santiago, Chile, Economic Commission for Latin America and the Caribbean (ECLAC), September 2012. 
welfare systems with equity, recognition and recompense, to guarantee people's right to care in sustaining life, under the shared responsibility of the State, families and the market.

\section{A. Macrodata on productive and reproductive work in Ecuador}

Ecuador has one of the lowest inactivity rates in Latin America. In line with regional trends, it has been declining over the past two decades: in 1990, a total of $30 \%$ of the working-age population declared they were inactive while, in 2009, this had fallen to $22 \%$. Moreover, growth in women's labour force participation has reduced the proportion of people devoted exclusively to unpaid domestic work (housework). Among the working-age population outside the labour market, almost all those dedicated exclusively to unpaid care work in the home are women. In 1990, a total of 35\% of the workingage population was dedicated exclusively to such work. This percentage has decreased more than the actual inactive category, especially since the second half of 2005, falling to $28 \%$ in 2009. It is less common for men to withdraw from or fail to enter the labour market, although the number does increase slightly during periods of economic recession (in Ecuador this has happened twice in the past 20 years: in 1999 and 2009).

It is noteworthy that women's increasing labour force participation has consisted mainly of various forms of part-time work, with the result that the average working time women spend on household tasks per week may not have shrunk, bearing in mind that $95 \%$ of the female population aged 15 years and over perform such tasks, and that $85 \%$ spend more than 20 hours per week on them, whereas $80 \%$ of men devote fewer than 8 hours per week on household tasks. This would indicate that the distribution of domestic work has remained the same despite women's changing work patterns. According to the 2007 national timeuse survey, Ecuadorian society as a whole spends more time on domestic work than on work in the labour market.

The number of hours spent on work in the labour market has remained stable and shows cyclical behaviour, where a larger increase occurs when output growth is higher, as illustrated by data available since 2003 on unpaid care work in the home. ${ }^{2}$ Meanwhile, the time

Since 2003, employment surveys conducted as part of the household survey system have included a set of questions on time spent on unpaid care work in the home. These questions are asked of people over the age of 10 years, and the same set of questions is asked every year to make the data comparable. Although the questions are quite general and allow little subdivision, they are useful in gauging general trends. This means that 
women spent on domestic work grew, except in 2009, when the recession in the wake of the global financial crisis caused the female labour supply to increase (see table IV.1). Another point of note is that between 2003 and 2005 the time spent on care work in the home decreased in the case of both women and men. This occurred during a period of mounting hours of work spent in the labour market, in a context of significant economic growth, suggesting that some households used paid care services, seemingly confirmed by the fact that time spent in paid employment remained high while care time also rose, albeit at a lower rate than in 2003.

Figure IV.1

ECUADOR: TIME SPENT PER WEEK ON WORK IN THE LABOUR MARKET AND ON CARE WORK, BY SEX, 2003-2009

(Hours per week)

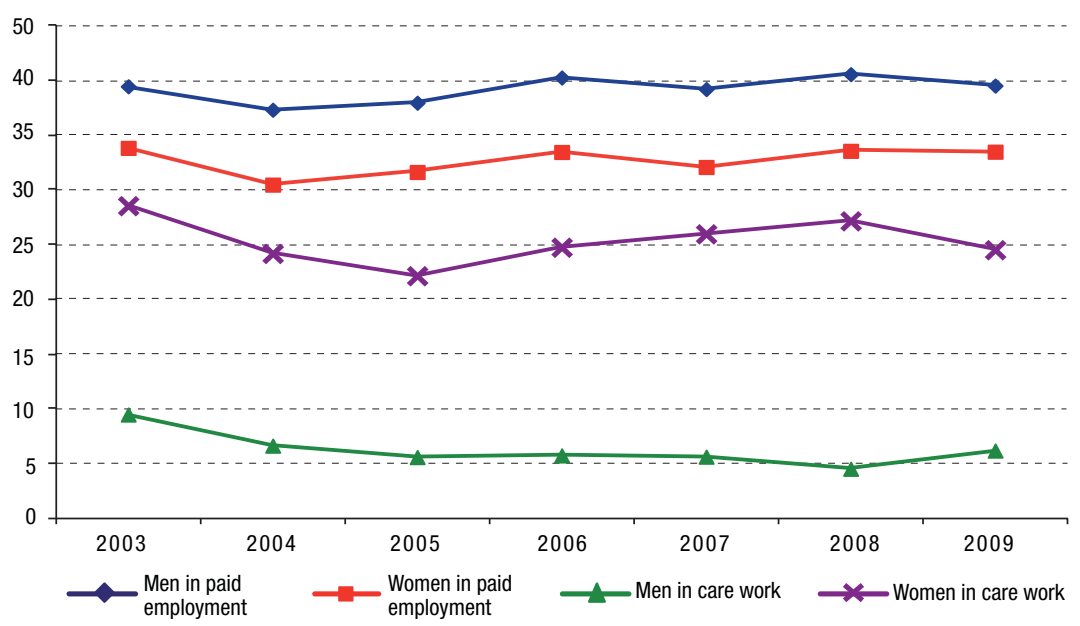

Source: Prepared by the author on the basis of National Statistics and Census Institute (INEC), national survey of urban employment, unemployment and under-employment "Encuesta Nacional de Empleo, Desempleo y Subempleo Urbano" (ENEMDU), 2003-2009.

the specific results of the employment surveys (average hours) cannot be compared with those of the 2007 national time-use survey, which is detailed and aimed specifically at analysing the different domestic and care activities. 


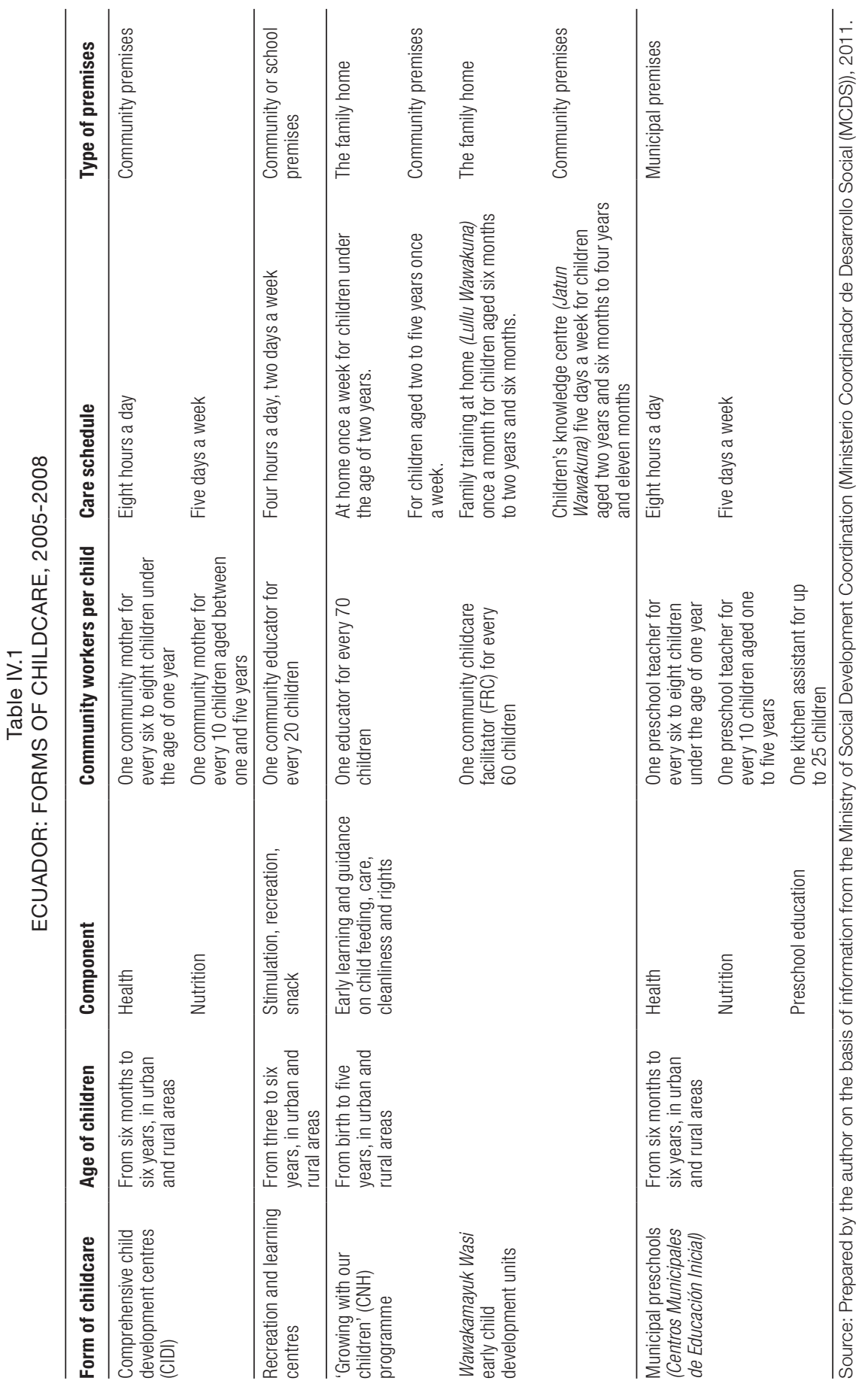




\section{B. Sociodemographic context and demographic estimates of care needs}

\section{Demographic trends}

Ecuador is a country in demographic transition, with a projected average population growth rate of 1.3\% per year between 2000 and 2015 . At present, $51 \%$ of its 15.5 million inhabitants are women. As a result of steadily rising urbanization, $65 \%$ of the population was urban in 2010 and this proportion is set to grow still further, at least for the next 15 years.

With regard to Ecuador's age structure, over the past 20 years the population under the age of 15 years has decreased (ageing at the bottom of the pyramid). Young adolescents (the 15-29 age group) account for $27.7 \%$ of the total population and their number doubled in absolute terms between 1975 and 2005. The share of the 30-60 age group also increased, while that of the over-65 age group doubled over the same period. As a result, there has been a steady decline in demographic dependence, which is expected to usher in the so-called "demographic dividend".

According to official projections of Ecuador's population, in 2025 the share of infants up to the age of 20 years will remain the same, with people under the age of 15 making up $18 \%$ of the total population and those over the age of 65 making up 13\% (doubling their current share). Demographic dependence will keep dwindling until the five-year period 2015-2020, when the demographic dividend will emerge. Demographic dependency ratios will start to rise again in 2020. This makes it crucial to grasp this five-year window of opportunity offered by the demographic dividend by using education and job-creation policies to offset future dependency. Nevertheless, the need for care is greatest among people under the age of 15 years and over the age of 65 .

The trend in Ecuador's fertility rate is downward, albeit with differing patterns. During the 1970s, fertility declined mainly among women in the 25 to 29 age group, probably as a result of their mass entry into the labour market.

\section{Structure of Ecuadorian households and projected demand for care}

All this has brought about a number of changes in Ecuador's households, including a reduction from five to four people per household between 1990 and 2009. The country has also seen a growing trend 
towards single-parent households, rising from $21 \%$ of all households in 1990 to $31 \%$ in 2008 , with around $70 \%$ of these households headed by women. A more recent trend is the increase in single-person households, doubling between 1990 and 2009 to around 8\% of all households. While the proportion of female-headed households living in poverty has declined over the past 10 years, there are still more male heads of household in the highest income quintiles in urban areas and more women heads of household in the lowest income quintiles in rural areas. Women heads of household also tend to have less education, higher unemployment and big wage lags.

There is a downward trend in the number of households with children under the age of five years, while the number of households without minor children is increasing. In 1990, almost 50\% of Ecuadorian households contained children under the age of five years, whereas by 2009 this had dropped to $30 \%$.

However, the most rapid changes in family structure have occurred in the higher-income sectors and in urban areas. The majority of households with small children continue to be concentrated in the poorest quintiles: $54 \%$ of households with more than three children under the age of five are in the poorest income quintile and around $80 \%$ of the poorest households have children under the age of 15 years ( $30 \%$ of which have more than three children). In contrast, only $16 \%$ of Ecuadorian households have members over the age of 65 years and they are distributed fairly evenly across the different socio-economic groups, with the poorest households having only a slightly larger share.

Half of Ecuadorian households are nuclear and are distributed more or less evenly across the different social classes. The majority of extended households with a family nucleus are in the lowest-income strata, while the majority of single-person households and extended households with non-relatives are in the highest-income strata. In line with regional trends, the number of single-parent households has increased as a proportion of all households and the majority are headed by women, as already mentioned.

Thus, demand for care in Ecuador is still greatest among children under the age of five and those of school age, who are present in almost half of Ecuadorian households but predominate in the poorest sectors. This has a direct impact on the number of hours women in the lowest social strata devote to work and to caregiving.

According to Durán (2006), the population requiring care consists primarily of children, older adults, sick or disabled people and those working long hours in paid employment. Using the qualitative 
methodology, weightings are assigned according to the age structure of the population, defined on the basis of demographic dependence. ${ }^{3}$ As the 18-64 year group is assumed to require less care than the other population groups, it is assigned a value equal to one unit (that is to say, it takes one unit of care to meet its needs). ${ }^{4}$ Based on this unit, the groups are given a coefficient of care needs in accordance with the different stages of life (age ranges).

Taking into account Ecuador's process of demographic transition, as well as migration and the entry of women into labour market, the scale of care is defined between one and five. ${ }^{5}$ The scales change between periods according to the projected values of the population structure. ${ }^{6}$

These scales are used to calculate the care time required. One unit of care (the basic care needed to sustain a person) is considered to equal two hours per day and is used to calculate the care needs of other groups. According to the first estimate, for 2010, care needs total 21 billion hours, equivalent to around 7 million full-time jobs, which slightly exceeds Ecuador's current economically active population.

As the coverage of care services is quite low (according to data from official surveys), if the estimated needs using this scale are correct, it would point to unmet demand, which needs to be determined more accurately. In around 2025, the relative size of the over-65 population will increase, especially the 65-74 age group, and the youngest population will shrink. According to this scale, if the ratio between coverage and needs stays the same, care needs will increase by $15 \%$ between now and 2025. In an extreme scenario where there are no State services, assuming that all those in non-dependent age groups devote all their time to care, this would require a weekly commitment of around 42 hours from the entire 18-64 age group.

This methodology is based on the Oxford scale used to estimate the monetary needs of households, which assigns unit values to adult earners and lower values to other adults and minors.

4 The scale may or may not have decimal values. In the case of Ecuador, it was decided to develop a scale with integers between one and five.

5 This section is based on a paper by Vásconez and Pérez (2008) entitled "La demanda actual de cuidados en América Latina: el caso de Ecuador" presented at the international course "Redistribución del tiempo, un indicador de igualdad", organized by the Economic Commission for Latin America and the Caribbean (ECLAC) in June 2008.

6 As these weightings are not a statistical exercise but a qualitative scale, the categories are discrete. This procedure is based on a methodology developed by María Ángeles Durán to estimate demand for care in Spain. For a description of the Madrid scale, see Durán (1999 and 2000). 
Figure IV.2

ECUADOR: AGE STRUCTURE OF DEMAND FOR CARE (QUALITATIVE SCALE), 2009 AND 2025

(Percentages)

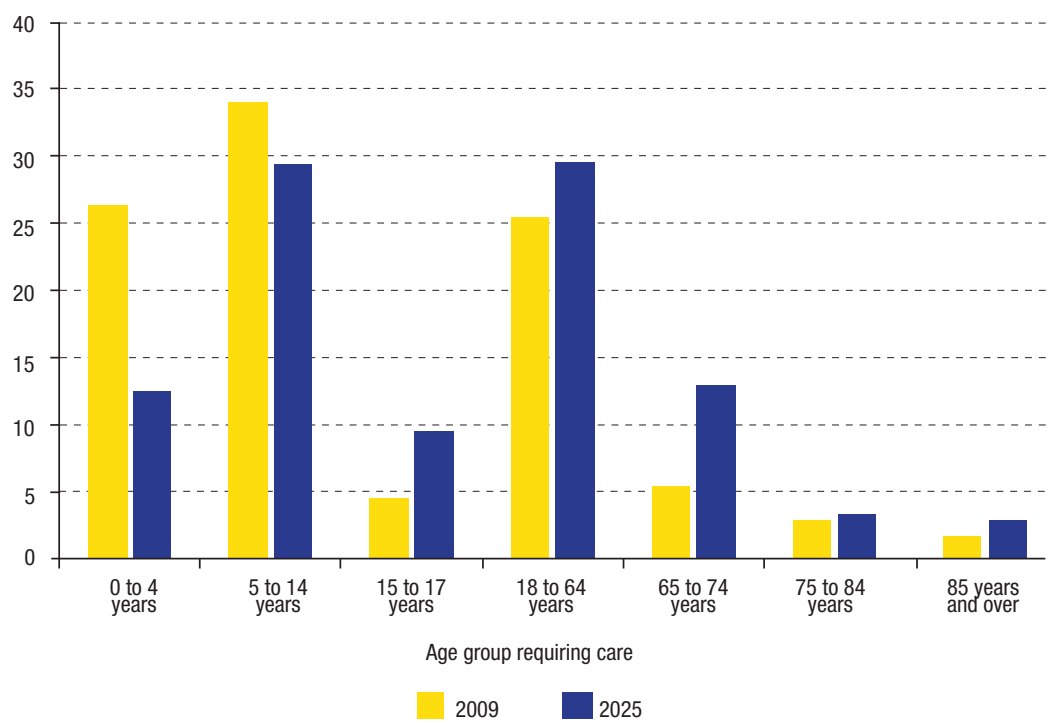

Source: Prepared by the author on the basis of a paper by A. Vásconez and A. Pérez entitled "La demanda actual de cuidados en América Latina: el caso de Ecuador", presented at the international course "Redistribución del tiempo, un indicator de igualdad", Santiago, Chile, Economic Commission for Latin America and the Caribbean (ECLAC), June 2008.

\section{Care of children and dependent older adults}

\section{Childcare}

At present, most care is provided by State institutions. Private institutions have very low coverage and generally cater to the more affluent population sectors. From the 1990s, a range of programmes began to be offered in Ecuador, targeting the low-income population to varying degrees. They include childcare programmes, funded primarily by multilateral banks. The public sector supplies $76.5 \%$ of childcare services. Apart from fee-charging entities, private care providers include the Church and foundations, although the percentage is small.

Child development funds ran until 2006 to finance childcare projects by means of social tendering to non-governmental organizations and grass-roots communities, using a system similar to outsourcing, that is to say, State-funded subcontracting. This process also accredited implementing organizations, which were controlled by the State. 
Table IV.1 shows the forms of care in operation until 2008, revealing widely varying strategies of care, schedules and components.

These programmes hired mainly mothers in the capacity of child-minders (madres cuidadoras, translated literally as "mother childminders"), which reproduced both culturally and materially the sexual division of labour and devaluation of women's work: the community input allowing nurseries and childcare centres to operate takes the form of women caring for children. While the entire community benefits from the service, "community mothers" (madres comunitarias, MRC) are paid (an allowance) less than the market value of their work. The rationale behind such social programmes is complex because they link the existence of these services to the lower value placed on care work. As it is a rationale applied only to services for people in the lowest economic strata (those in the middle and upper social strata rarely use such services), it reproduces a rationale of "poor services for the poor". So far there has been no study of how much the State saves with this form of care based on undervaluing the work of mother childminders, and neither has the State attempted to move towards different forms of care.

Nor has the design of these programmes managed to integrate a vision that combines the welfare and development of the under-fives with social organization around paid work and the public care services needed to reconcile work and family life. Women use a variety of strategies to resolve the mismatch between their working hours and the public care services available, mainly under-employment and informal employment to increase their flexibility to combine productive and reproductive work.

In terms of coverage, national statistics do not allow for a detailed analysis of all care users, except children under the age of five years and, to some extent, school-age children served by education or school feeding programmes. ${ }^{7}$ According to the living conditions survey (ECV) for 2006, it is mainly mothers who care for children under the age of five ( $70 \%$ of primary carers). Little of the responsibility for care of the under-fives is shared with other household members and fathers' have surprisingly little involvement: less than family members aged 10 years and over. In rural areas, even more mothers care for the under-fives $(85 \%$ of primary carers).

Two main data sources have been used for this section: (i) the 2006 living conditions survey $(\mathrm{ECV})$ for data on who takes care of children under the age of five years and health issues, as it is the only household survey that includes this data; and (ii) the 2010 national survey of urban employment, unemployment and under-employment (ENEMDU) for data on childcare and education coverage. 
A new institutional framework is now being proposed based on the new constitutional context where the State is resuming direct involvement in the provision of care services. Under this new framework, a centralized institution for child and family development was established under the Ministry of Economic and Social Inclusion (MIES) to bring together the above-mentioned programmes, phasing out the social tendering process while maintaining the same forms of care (now staffed by people recruited directly by MIES). Further linkages with child-feeding, housing, health, integrated rural development and education programmes are also being proposed. These linkages are intended to operate in decentralized regions and subregions defined by MIES.

Projects for the comprehensive development of children under the age of five years have been conducted through the National Child and Family Institute (INNFA), as well as through MIES, over the past three years (2008-2010). Child development is believed to result from an interaction between three human dimensions: biological, psychological and social. There are two main forms of care provision: children's centres for good living (CIBV) and the 'Growing with our children' (CNH) programme. Their general components are day care, health, nutrition, education, recreation and family education. The CIBV form of care caters primarily to children aged 3 months to 59 months whose parents work outside the home, have no adult to take care of them or have one who is unable to protect them adequately. Children attend daily permanent centres run by permanent staff, in a warm, safe environment to ensure comprehensive child development. The service operates with CIBV coordinators and outreach workers for care and for nutrition.

The 'Growing with our children' programme caters to children aged 0 to 59 months who can stay at home because there is an adult able to provide proper day care. The people responsible for home-based childcare receive training in comprehensive child development matters through home visits and attendance of group activities. The programme provides individual home care for children aged 0 to 23 months and group care for children aged 24 to 59 months in community premises. The service is run by an outreach worker for comprehensive child development.

While it is still too early to judge the outcomes of this new institutional framework, assessments of child development and nutrition programmes have been positive in terms of nutrition indicators (Muñoz, 2009). Further studies focusing on child development and its determinants conclude that services should target children under the age of five years and that care provided by the family is essential. For this reason, children have been monitored for several years, evaluating 
their development in accordance with a set of variables, including the care they receive from their families (Shaady, 2010). Once again, this throws into question the idea of making families responsible for care.

\section{Care of older adults}

Care centres for older adults are administered directly by MIES on an hourly basis, in geriatric centres. According to the 2001 census, there are more than 800,000 older adults in Ecuador. Schkolnik (2007) points out that this is the age group for which care is the least adequate and is relatively "invisible". Although Ecuador's Law on the Rights of Older Adults promotes a culture of protecting older adults and promotes measures such as lower tariffs for public and private services and special places for the care of older adults, social security and health care coverage for this group are still very limited, as are programmes for older adults, many of which have inherited a charity and welfare vision with no move towards a vision of rights and universality.

Care-related public services for this population group are provided through an MIES grant to geriatric centres, most of which are run by private organizations or foundations on a residential, dayor semi-residential care basis and cater to over 7,000 people. Other MIES services for older adults include handling legal or health cases, supporting organizations and issuing statutory administrative approvals to operate. ${ }^{8}$ Older adults in the poorest population quintiles are entitled to the human development grant (BDH), which covers around $30 \%$ of Ecuador's total older adult population.

Moreover, many older adults of both sexes care for other household members, particularly in households with migrant mothers. According to the 2007 time-use survey, women over the age of 65 years spend between an average of three to four hours a day on care and unpaid domestic work, which is roughly $50 \%$ of the time devoted by women of childbearing age. Given the incidence of disease and disability in this age group, clearly many are not receiving the care they need. For instance, $20 \%$ of older adults receive no form of care at all and, of these, 135,000 (14\%) are over the age of 75 years and living alone. At the same time, $70 \%$ of the older adult population performs caregiving tasks, according to data from the 2010 survey on health, welfare and ageing

Processing social hardship cases for older adults; technical and legal advice on comprehensive geriatric care; information on the specific rights of older adults; legal advocacy; operating licences for geriatric centres; advice on setting up older adult care centres; (approval of) social projects for older adults; providing training to organizations for older adults and older adult care centres; and contractually agreed financial grants to organizations for older adults. See [online] www.mies.gov.ec. 
(SABE), conducted by MIES. ${ }^{9}$ While many older adults use the public health service for hospitalization or secondary care, they use private services for outpatient health care, meaning that their out-of-pocket health spending amounts to more than $60 \%$ of their budget. Moreover, the incidence of chronic disease in women is almost double that of men, making them a highly vulnerable population.

According to the 2010 national survey of urban employment, unemployment and under-employment (ENEMDU), around $60 \%$ of all those over the age of 65 years are inactive and 30\% are under-employed. Overall, only $23 \%$ of inactive older adults and $11 \%$ of under-employed older adults are covered by general social insurance. Women are even more unprotected. Of all women over the age of 65 years, $75 \%$ are registered as inactive (compared with $44 \%$ of men) and only $3 \%$ work full time (compared with $15 \%$ of men). However, in the first case, twice as many men as women are covered by general social insurance, owing to their record of contributions and the current social security model based on a male breadwinner (who pays social security contributions and is assumed to provide his family with income). According to the 2010 ENEMDU survey, older women have no coverage under Ecuador's Universal Health Insurance Programme (PRO-AUS).

Geriatric care is provided by social organizations that run Centres for the Comprehensive Care of Older Adults in the form of day-, residential or home care, and it is planned to expand services through private co-financing schemes. However, public care coverage for older adults is limited. According to the SABE survey, most outpatient health care is provided by private institutions and only half of older adults have access to public health services covering hospital stays and tests. Moreover, the incidence of disease is much higher in older women than in older men, and it is women who are the least protected by health insurance systems. A large proportion of older adults is abandoned (around $7 \%$ ) or lives alone. However, more than half of men and over $70 \%$ of women provide care to other family members. This lends even greater support to the need for State care services and free and universal health protection for older adults.

\section{Education and health}

Ecuador has made significant progress with school enrolment. According to the 2010 ENEMDU survey, 97.3\% of school-age children in urban areas and $95.4 \%$ of those in rural areas are enrolled in the 9 This survey covered a total of 5,235 people over the age of 65 years in 15 of Ecuador's
21 provinces. 
education system. While grade repetition and non-enrolment rates are not high, the 2007 time-use survey shows that girls not enrolled in the education system shoulder a heavier burden of domestic work (see figure IV.3).

Figure IV.3

ECUADOR: TIME SPENT ON DOMESTIC WORK AND WORK IN THE LABOUR MARKET BY PEOPLE UNDER THE AGE OF 15 YEARS, BY ENROLMENT

IN THE EDUCATION SYSTEM, 2007

(Hours per week)

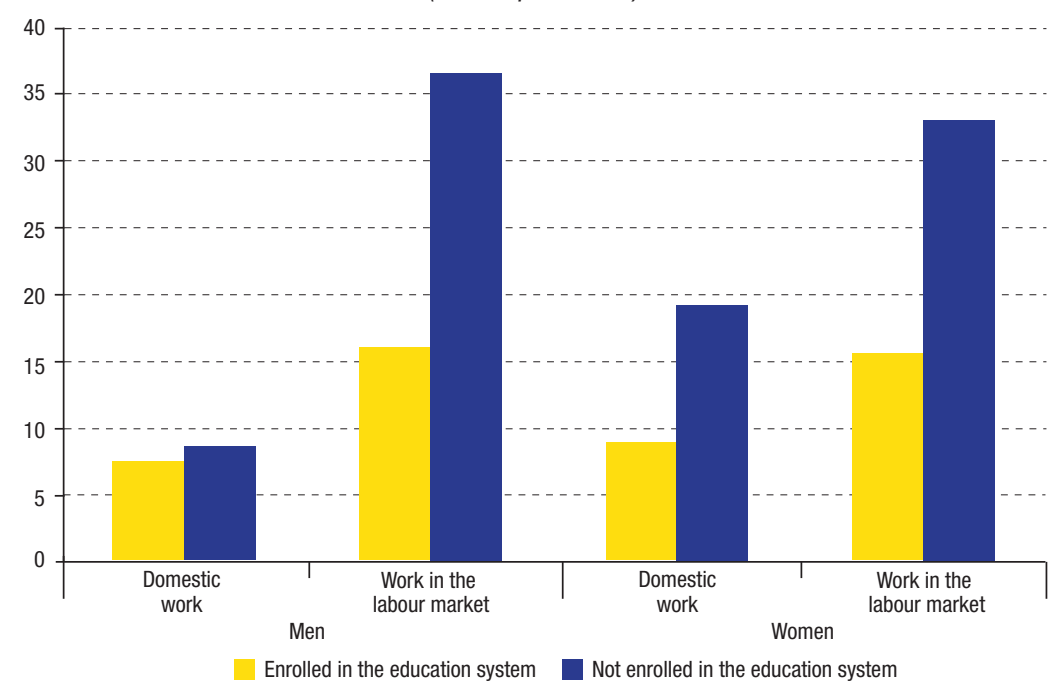

Source: Prepared by the author on the basis of National Statistics and Census Institute (INEC), national timeuse survey "Encuesta Nacional de Uso del Tiempo", 2007.

While the gap between men and women in terms of time spent on domestic work is wider than for work in the labour market, while the difference in the amount of time spent on domestic work between people attending school and those who do not is also wider among women.

Education provision in rural areas is almost entirely public, while in urban areas it is mostly public, although many children are in private education. Private schools offer a growing range of extracurricular activities, which potentially releases time for home-based women caregivers. In contrast, central government schools provide very few extracurricular services, although in the past five years such provision has increased in municipal schools (run by some local governments, especially in the larger cities). 
School feeding programmes set up to improve the nutrition of children from poor households mean that access to education may also boost the supply of food available. School feeding programmes serve mainly rural areas, where they cover $54.7 \%$ of households, whereas in urban areas they cover approximately $20 \%$ of households. A point of note is that school feeding programmes rely heavily on women for unpaid or poorly paid food preparation work. These school feeding programmes are now being restructured in order to ensure a more consistent policy line and a more appropriate system of impact assessments. The reason is twofold: not only has there been insufficient growth in coverage up to now but, most importantly, nutrition and school enrolment outcomes have been insignificant except among the captive population, which has been receiving government food supplements for several years.

As regards health services, according to the 2006 living conditions survey the majority of the population does not visit the doctor when they are ill, meaning that health care is an added household duty. Moreover, one third of the population fails to use health services because they cannot afford them. Health services are provided by both the State and the private sector. Five years ago, a universal health policy was developed and tabled, providing everyone with access to any available service, whether public or private (in the latter case subsidized by the State). This has not yet come to fruition. Moreover, the bill promoting social security coverage for people performing care work (discussed below) includes health as a priority component, especially for women over the age of 65 .

With respect to paid domestic work, the 2010 ENEMDU survey shows that the poorest households have no access to it and only $10 \%$ of households in the second and third quintiles have access, compared with $25 \%$ of the wealthiest households.

\section{Arrangements in the domestic sphere}

Ecuadorian women have an average total workload of 69 hours a week, compared with 52 hours for men. Women aged 25 to 30 years spend the most time on domestic work and unpaid care work (increasing their total workload at the expense of work in the labour market). In contrast, the time men spend does not vary greatly according age.

In Ecuador, the total time spent on paid and unpaid work averages 50 hours a week. As much of the population spends time on both paid and unpaid work, the average effective time is only slighter higher than this figure: 56 hours per week. While the participation rate in domestic work is also high, women spend virtually triple the time spent by men (see table IV.2). 
Table IV.2

ECUADOR: AGGREGATE INDICATORS OF WEEKLY WORKLOAD, 2007

(Hours/minutes and percentages)

\begin{tabular}{|c|c|c|c|}
\hline & $\begin{array}{c}\text { Weekly average social } \\
\text { time }^{\mathrm{a}} \\
\text { (Hours/minutes) }^{\text {tours }}\end{array}$ & $\begin{array}{c}\text { Weekly average } \\
\text { effective time } \\
\text { (Hours/minutes) }^{\mathrm{b}}\end{array}$ & $\begin{array}{c}\text { Participation } \\
\text { rate }^{\mathrm{c}} \\
\text { (Percentage) }\end{array}$ \\
\hline \multicolumn{4}{|c|}{ Total work } \\
\hline Men & 47 hours 10.6 minutes & 50 hours 51.7 minutes & 93 \\
\hline Women & 54 hours 19.9 minutes & 60 hours 51.6 minutes & 97 \\
\hline Total & 50 hours 47.2 minutes & 56 hours 26.6 minutes & 95 \\
\hline \multicolumn{4}{|c|}{ Domestic and care work } \\
\hline Men & 12 hours 24.3 minutes & 13 hours 22.4 minutes & 93 \\
\hline Women & 33 hours 0.5 minutes & 41 hours 56.2 minutes & 97 \\
\hline Total & 22 hours 48.1 minutes & 23 hours 59.6 minutes & 95 \\
\hline
\end{tabular}

Source: Prepared by the author on the basis of National Statistics and Census Institute (INEC), national timeuse survey "Encuesta Nacional de Uso del Tiempo", 2007.

a Average social time is calculated by dividing the total time spent on a particular activity by the total population. It is expressed in hours and minutes.

b Average effective time is calculated by dividing the total time spent on a particular activity by the total population who spent time on that activity. It is expressed in hours and minutes.

c The participation rate is calculated by dividing the total number of people who spent time on a particular activity by the total population. It is expressed in percentages.

A total of $83 \%$ of caregivers (those spending the longest time on unpaid care work in the home) are women aged 15 to 45 years, with a predominance of women over the age of 25 (slightly above the average marriage age) - primarily wives $(60 \%)$ and daughters (20\%) - according to their kinship with the head of household. Marriage increases substantially women's likelihood of providing care and the intensity of such care, although civil unions are common too. In addition, there is a clear relationship between poverty and intensity of care. Households suffering poverty and job insecurity have more caregiving members (see table IV.3).

Table IV.3

ECUADOR: PROFILE OF WOMEN CAREGIVERS, 2007

(Percentages)

\begin{tabular}{llc}
\hline Status & Characteristics & Percentage \\
\hline & Married & 46.3 \\
& Separated & 6.1 \\
\multirow{3}{*}{ Marital status } & Divorced & 2.0 \\
& Widowed & 3.0 \\
& Cohabiting & 24.4 \\
& Single & 18.2 \\
\hline
\end{tabular}


Table IV.3 (concluded)

\begin{tabular}{llc}
\hline Status & Characteristics & Percentage \\
\hline \multirow{3}{*}{ Age } & 65 years and over & 3.1 \\
& 46 to 64 years & 13.5 \\
& 26 to 45 years & 59.4 \\
& 15 to 25 years & 24.0 \\
\hline \multirow{4}{*}{ Income decile } & Decile I & 29.7 \\
(decile I = the poorest) & Decile II & 10.3 \\
& Decile III & 10.9 \\
& Decile IV & 8.2 \\
& Decile V & 8.1 \\
& Decile VI & 6.4 \\
& Decile VII & 7.0 \\
& Decile VIII & 6.3 \\
& Decile IX & 7.9 \\
& Decile X & 5.2 \\
\hline \multirow{3}{*}{ Employment status } & Employed in the formal sector & 12.3 \\
& Under-employed & 16.2 \\
& Employed in the informal sector & 18.6 \\
& Unemployed & 6.6 \\
& Inactive & 46.2
\end{tabular}

Source: Prepared by the author on the basis of National Statistics and Census Institute (INEC), national timeuse survey "Encuesta Nacional de Uso del Tiempo", 2007.

According to the 2007 time-use survey, the most time-consuming activity for women in Ecuador - as in most Latin American countries where such measurements have been conducted - is providing food. This may stem from a number of factors: preparing and serving food have traditionally been central to family cohesion, a token of a woman's affection for her immediate family (sons, daughters and husband) and extended family (grandchildren and other relatives) and a way to socialize, celebrate, reward and show appreciation. Even though more and more families are away from home at meal times, family meals are still extremely important and most food is freshly prepared (see table IV.4).

Measuring time spent also enables a comparison to be made, in macro terms, between the relative contribution of paid work included in national accounts and of domestic and care work. For instance, if the total time spent on unpaid food-related tasks in the home is added to paid working time in agriculture, catering services and the food industry, foodrelated tasks in the home are found to account for more than half the total. If unpaid childcare time is added to paid working time in the education and childcare sector, unpaid childcare time accounts for $70 \%$ of the total. This means that $70 \%$ of the total work devoted by Ecuadorian society to children's care and education is unpaid care work (see figure IV.4). 
Table IV.4

ECUADOR: DISTRIBUTION OF THE TIME SPENT BY WOMEN IN URBAN AND RURAL AREAS ON UNPAID DOMESTIC AND CARE WORK, BY ACTIVITY, 2007

(Percentages)

\begin{tabular}{lcccccc}
\hline & \multicolumn{2}{c}{ Urban areas } & & \multicolumn{2}{c}{ Rural areas } \\
\cline { 2 - 3 } \cline { 5 - 6 } & $\begin{array}{c}\text { Percentage } \\
\text { of total work } \\
\text { time }\end{array}$ & $\begin{array}{c}\text { Percentage of } \\
\text { domestic and } \\
\text { care-work time }\end{array}$ & & $\begin{array}{c}\text { Percentage } \\
\text { of total work } \\
\text { time }\end{array}$ & $\begin{array}{c}\text { Percentage of } \\
\text { domestic and } \\
\text { care-work time }\end{array}$ \\
\hline Food & 14.4 & 31 & & 18.3 & 33 \\
Clothing & 11.6 & 25 & & 10.7 & 19 \\
Childcare & 13.6 & 30 & & 16.2 & 30 \\
Care of sick and disabled people & 1.0 & 2 & & 1.3 & 2 \\
Subsistence production & 0.9 & 2 & & 5.6 & 10 \\
Management & 4.4 & 10 & & 2.7 & 5 \\
Total & 45.8 & & & 54.8 &
\end{tabular}

Source: Prepared by the author on the basis of National Statistics and Census Institute (INEC), national timeuse survey "Encuesta Nacional de Uso del Tiempo", 2007.

Figure IV.4

ECUADOR: AVERAGE TIME SPENT PER WEEK ON DOMESTIC SUPPORT WORK AND UNPAID CARE WORK, BY AREA AND ETHNIC SELF-IDENTIFICATION, BY SEX, 2007ª (Hours)

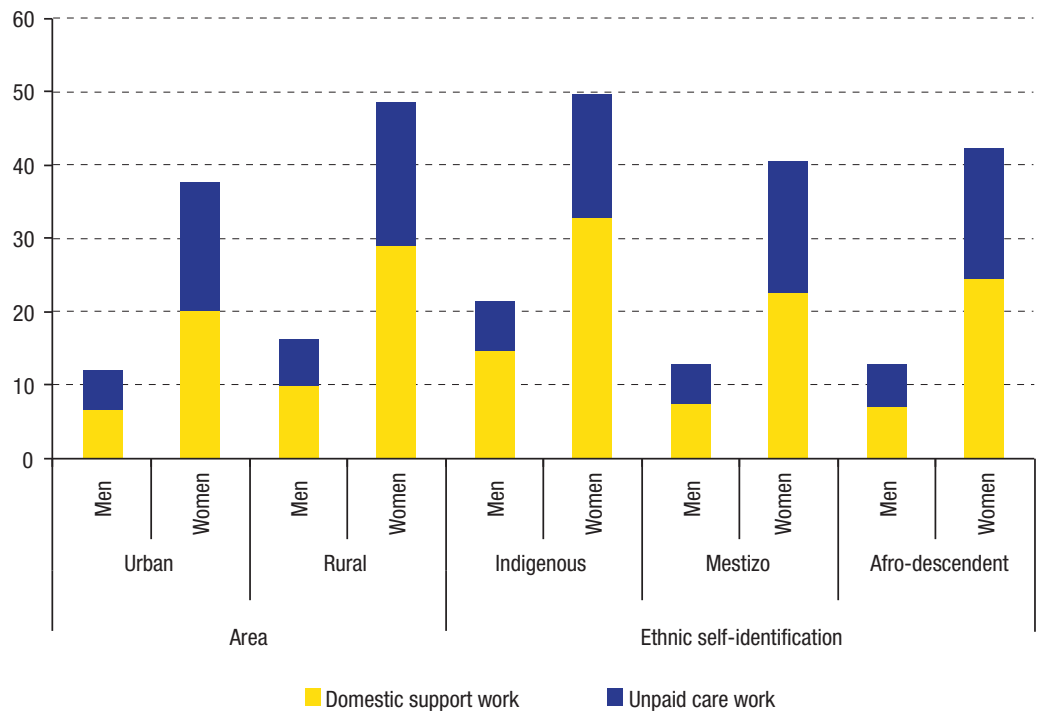

Source: Prepared by the author on the basis of National Statistics and Census Institute (INEC), national timeuse survey "Encuesta Nacional de Uso del Tiempo", 2007.

a Domestic support work includes work in domestic services, management and administration. 
Moreover, the burden of direct caregiving (to children and sick or disabled people) and domestic support work (work in domestic services, management and administration) is heavier in rural areas and for indigenous women. Rural women spend an average 48 hours per week on domestic and care work combined, while indigenous women spend an average 49 hours per week.

The obvious inequity in the workload at the macro level is compounded by further inequities. The burden of sustaining families does not fall uniformly on the entire population. The correlation between poverty and burden of domestic work is evident from the disparities between average hours worked in the labour market and on unpaid caregiving by men and women in the different income quintiles. There is a clear inverse relationship between unpaid domestic work and income levels (measured by per capita income quintile) and hence job opportunities, especially for women (see figure IV.5).

Figure IV.5

ECUADOR: AVERAGE TIME PER WEEK SPENT ON DOMESTIC SUPPORT WORK AND UNPAID CARE WORK, BY INCOME QUINTILE, BY SEX, 2007ª (Hours)

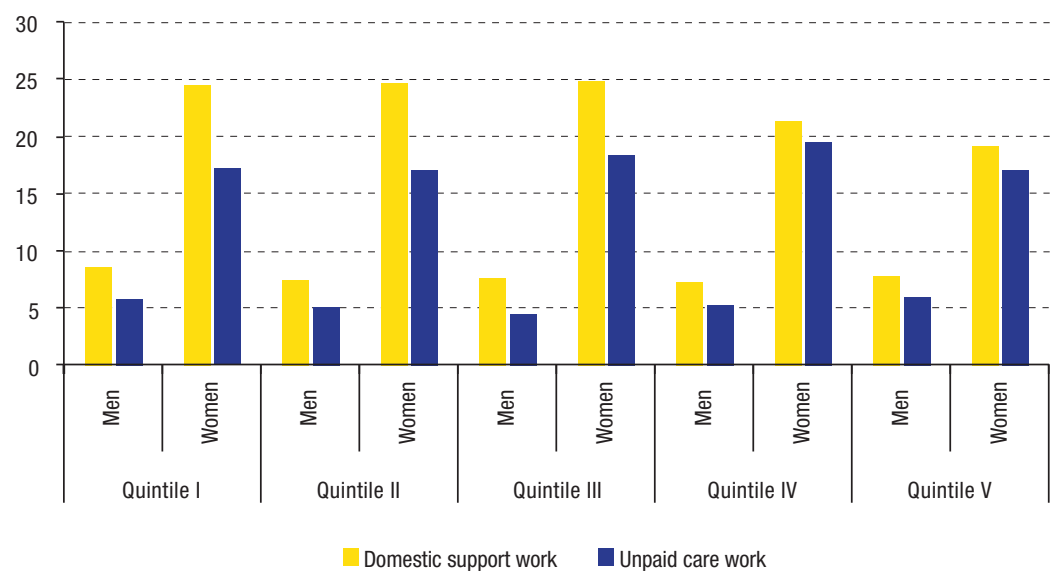

Source: Prepared by the author on the basis of National Statistics and Census Institute (INEC), national timeuse survey "Encuesta Nacional de Uso del Tiempo", 2007.

a Domestic support work includes work in domestic services, management and administration.

Based on figure IV.5, possible reasons for the heavier burden of domestic work shouldered by women and the poorest families may be presumed to include: a larger number of children; lack of support services and infrastructure; and fewer opportunities to earn their own income. It also shows that domestic support work decreases in the 
lowest income quintiles, whereas direct caregiving increases (albeit not in equal proportion) until the fourth quintile and decreases only in the top income quintile. One reason might be that wealthier families receive support in other areas of domestic work, freeing their time for childcare.

Moreover, direct caregiving accounts for $16 \%$ of women's total available time (excluding rest and self-care time) - even more in urban areas- compared with $6 \%$ of men's time. Support tasks require the greatest commitment, accounting for between $33 \%$ and $44 \%$ of women's weekly time, with the heaviest burden in rural areas.

\section{E. Institutional equation in the care space: justice mechanisms and principles}

Two primary and two secondary institutional stakeholders can be identified based on the above analysis. The two primary stakeholders - the State and households - share care roles to a varying degree. The State plays the central role of regulating all services, except paid domestic work, and has developed policies on education, health, nutrition and child development. While the State has specifically regulated education and health service organization, content and protocols, it has failed to regulate the quality of either public or private service providers, despite this being one of the State's functions. Education and health are both mainly State-funded but families have financed part of the health care and education provided by some institutions, including for medicines, educational materials and teacher recruitment.

Nevertheless, private health and education services also play a key role (except in preventive health care) and their coverage is increasing. These services are expensive, especially health care, although some institutions offer rebates or discounts for low-income clients, without this being part of State policy. As most older adults use private health centres for outpatient care and medical consultations, this can be a large budget item for them (SABE, 2010).

In the area of child development, the State has regulated the basic principles of service and forms of care, which have been extremely diverse. While child development is State-funded, service provision has been shared between State-run and outsourced centres. Social tendering was used for outsourced centres until 2008 and, since then, communities or civil society groups have been called upon to run services directly, after receiving training. The same has happened with care centres for older adults, which have continued to be State-run but hire temporary contract workers and private catering services. 
Both secondary institutional stakeholders - businesses and the third sector- have played a fairly marginal role in the provision of care for children and older adults. However, the operating rationale of these services cannot be ascertained in detail because they are not regulated by the State authority. Even though childcare services must be registered with the National Child and Family Institute, their operation is decentralized and is not controlled.

Despite the fact that companies with more than 50 employees are legally obliged to provide childcare services, this is not complied with and coverage is extremely low; neither is State control effective in such cases. While businesses comply with paid maternity leave entitlement (especially in medium and large enterprises), paternity leave is still not fully developed and there are no official data to verify compliance. The following diagram depicts the institutional equation in Ecuador's care space.

Ecuador's care space fails to cover some of the dimensions required for fulfilling women's labour and welfare rights. There is no universal system of care to recognize and value care work and reward it fairly. Not only does sexual division of labour in the home impact on the entry of women into the labour market, the principles underlying a discriminatory gender system also impact on the labour market. As the employment system is based on a male breadwinner deemed to devote all his time to work in the labour market, caregiving is considered not as a workforce investment or part of the value-added of work but as a cost assigned to female workers, further limiting their access to quality jobs.

This suggests that in care policy, as in employment and production, the gender system is still at work in interaction with the economic system. Women's participation is volatile and countercyclical. The education and service system has barely changed. Although the institutional matrix should adopt a rights-based approach and recognize everyone's work, it has not been possible to mainstream this into State institutions and private enterprise. Social protection policies not only continue to use the time and work of women to channel benefits and perform the unpaid work that the State should rightfully do, in addition this occurs in activities and branches considered by society as "female".

Care services continue to be structured according to the concept of the traditional family and formal work as employees; they do not allow women to participate fully in the labour market, or in education, culture or other aspects of welfare. Care services do not improve women's employability but instead use their cheap labour for extra support. 
Moreover, despite the recent constitutional and legal changes that have taken place in Ecuador, marginalization and exploitation persist in the absence of a strong and efficient system of labour inspection and rights enforcement. Even though more and more women (and men) are self-employed and starting ventures, they do so under informal and unskilled arrangements; the business and personal services sector is the biggest employer of this type of labour, which in the case of women relates to caregiving.

\section{Diagram IV.1}

ECUADOR: INSTITUTIONAL EQUATION IN THE CARE SPACE

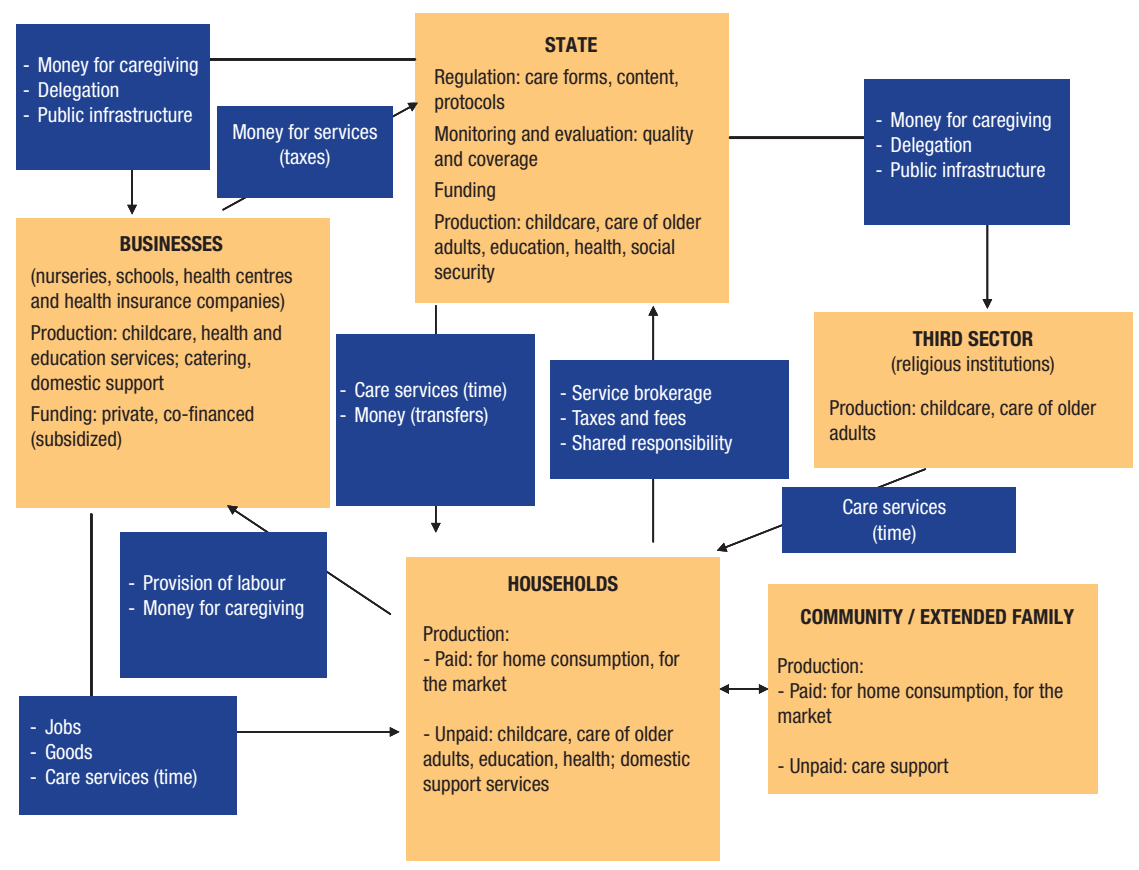

Source: Author.

The workload and other factors described above have engendered inequality not only in terms of time and resources but also between men and women's work, between rich and poor women and between the money and care economies. Redistribution is required on all three fronts. 


\section{F. Relationships between care work and the employment system}

\section{Paid care services}

In care or care-related sectors (personal services, health, education and training), the vast majority of workers are employed in either the public sector (predominantly in health and education) or the private sector (in childcare and education). This is confirmed by the fact that more than $65 \%$ of men working in these sectors are in education and health; in the case of women, $60 \%$ work in education and domestic service. Most men working in services are professionals or technicians. In the case of women, many are unskilled workers, so it may be assumed that, even though they are employed by the Government or private sector the work they do is not high value-added, nor is their potential pay.

Overall, around $23 \%$ of the working economically active population is employed in services relating to care and domestic work. Food-related tasks account for the largest share of paid care, with this sector employing $7 \%$ of the economically active population.

\section{Domestic service employment}

Five per cent of Ecuador's working population is in domestic service and $95 \%$ are women. In 1988, the female economically active population working in domestic service accounted for $14 \%$. Twenty years later, this share was $11 \%$. Paid domestic work is classed as unskilled, even though levels of education among domestic service workers are much the same as the national average, except the proportion with higher education (see figure IV.6). This would indicate that domestic service workers are not, on average, less qualified than the rest of the working population but that their tasks are considered to be of low grade and quality, signalling a gender bias that is manifested in wage differentials, as discussed below.

According to the 2010 ENEMDU survey, 12.3\% of female domestic workers are affiliated to the State social insurance, $10 \%$ to the general insurance and $2 \%$ to the rural population insurance. A higher percentage is insured than in the self-employed and unpaid family workers' groups.

Women domestic staff work a six-day week, totalling an average of 42 working hours. Ten per cent of female domestic workers live in the homes of the families for which they work during the business week, at the very least, and leave at weekends, meaning that on weekdays they are required to work at any time of the day or night. 
Figure IV.6

ECUADOR: DISTRIBUTION OF THE WORKING POPULATION IN DOMESTIC SERVICE AND THE TOTAL WORKING POPULATION, BY LEVEL OF EDUCATION, 2010

(Percentages of the employed economically active population)

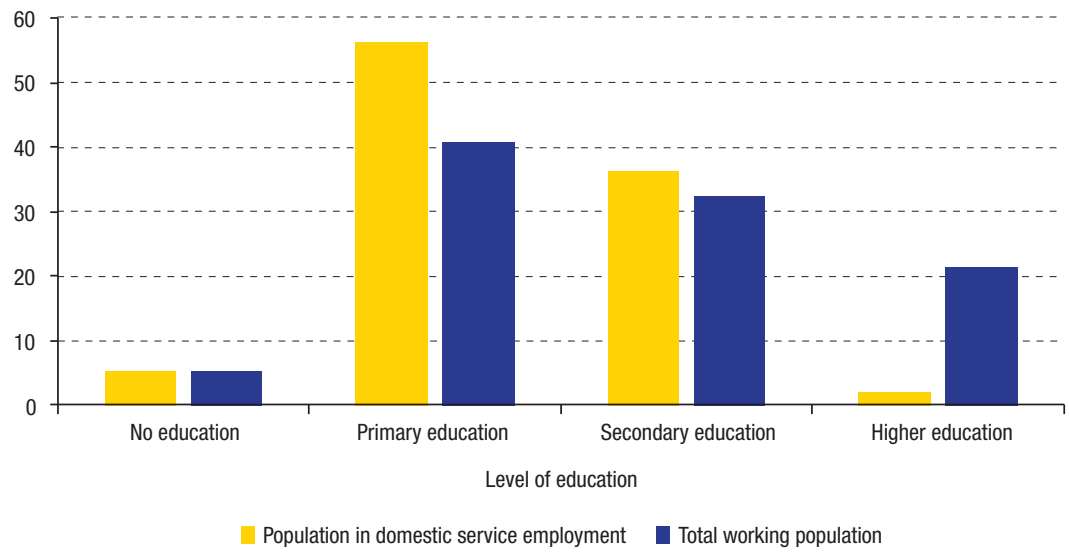

Source: Prepared by the author on the basis of National Statistics and Census Institute (INEC), national survey of urban employment, unemployment and under-employment "Encuesta Nacional de Empleo, Desempleo y Subempleo Urbano" (ENEMDU), 2010.

Moreover, an average 55\% of female paid domestic staff work for less than the statutory minimum wage, compared with $70 \%$ of all women. As the market is a generic institution, the operations performed in it reflect this structure. The average labour income of a female domestic worker in 2009 barely exceeded the income of unpaid workers (who receive in-kind payments or other non-wage earnings) and was $10 \%$ lower than the statutory minimum wage for domestic work. This labour income is equivalent to: $71 \%$ of the average hourly labour income of all those working for pay; $18 \%$ of the income of people in the employer category; $67 \%$ of the income of self-employed workers; and $72 \%$ of the income of other unskilled workers.

Turnover among domestic service workers is high. They tend to work an average of six to eight months before resigning (Vásconez, 2005). Although $30 \%$ of female domestic workers in Ecuador's urban centres are internal migrants (domestic service is the occupational category with the highest proportion of migrants), the number of those from the same or other urban centres is growing. Men tend to contact potential employers directly when seeking a domestic service job, while women tend to do so through friends or family. Ecuador has no mass jobvacancy information systems; even though there are agencies dedicated specifically to recruiting female domestic workers, most do not use them to find work. 
In 2010, a new regulation on domestic work was enacted to raise the statutory minimum wage for domestic work to the general statutory minimum wage, as well as to introduce statutory entitlements, such as annual leave. Also, a recent public consultation resulted in a decision to punish with imprisonment any employers failing to affiliate their employees to the social security system. Coupled with an appropriate labour inspection and monitoring system, this should do much to improve the conditions of domestic service employment. However, the affordability of this more expensive service for low-income households will need to be assessed.

\section{Characteristics of the population participating in the labour market: labour market segmentation}

Changes in the labour market in recent decades, global systemic crises - one of which is ongoing - and processes of demographic change in the status of women and gender relations are symptomatic of a number of major trends in Latin America generally and Ecuador in particular. They include: changes in family structures and hence in demand for care; changes in women's employment status stemming from shrinking formal job-creation capacity in the public and private sectors; intensification of work in the labour market, as a result of the increase in the number of hours per week spent by the general population on paid work (and hence in women's total workload); and changes in the ways household responsibilities are discharged, by such means as commodifying care services, transferring responsibilities to other household members, or globalizing care.

Women's labour force participation in Ecuador has therefore been growing steadily for the past 25 years, speeding up in the late 1980s and 1990s. While the number of women job seekers also increased during crisis periods, in most cases it was to work in the informal sector. However, as women remained in the labour market following the economic recovery, this informal employment situation has also persisted. The gap in women's labour force participation tended to narrow in the early 2000s and widen slightly thereafter, which may be a result of the crisis. Although there is no data on such a long time series, between 2000 and 2005 the labour force participation of rural women rose from $47 \%$ to $50 \%$, after which it began to decrease slightly, mirroring the trend in urban areas. The biggest drop in participation occurred among the population aged 12 to 17 years, of both sexes and in both urban and rural areas. There is also a high turnover rate among women working for the labour market. While the rationale of labour force participation is fairly similar for men and women, that is to say, their labour supply increases and 
decreases at similar times, women's labour force participation is much more volatile, unstable and sensitive to business cycles, with a higher probability of withdrawal from the labour force.

The educational profiles of the economically active population are similar for women and men. While the profiles for the two sexes are much the same at intermediate levels (those with primary and secondary education), there are more women than men with no education and with higher education. Even though the educational coverage of men and women is similar and, in fact, more women than men are enrolled in higher education, $70 \%$ of those with higher education are situated in the top two income quintiles and predominantly in urban areas; that is to say, for poor rural women, higher education is a structural factor limiting their job and income prospects, which serves to compound other gender and social class barriers.

The unemployed, both men and women, are well qualified: $30 \%$ have higher education and 33\%, secondary education. This suggests that unemployment stems from oligopsony in the labour market and the need to keep down labour costs, as well as to the low priority accorded to labour force skills by businesses whose competitiveness rationale is based on cost rather than productivity.

Under-employment is the most striking feature of women employed in large or medium enterprises or microbusinesses. Only 15\% of women are under-employed because they work fewer hours than desired; the remainder earn less than the legal minimum wage or work more than the statutory maximum hours, or a combination of the two. There is also high male under-employment. Moreover, around 100,000 women and 60,000 men do not actively seek work but are willing to work (hidden unemployment). If people who are inactive for reasons of time or coercion are included, the potential labour supply not used by the labour market totals $23 \%$, and $70 \%$ of this percentage are women. The problem of under-employment is more acute in rural areas, where $72 \%$ of men and $82 \%$ of women are under-employed, compared with $44 \%$ of men and $54 \%$ of women in urban areas. In contrast, unemployment is more of a problem in urban areas.

Women are at a disadvantage throughout their working lives, even during what are considered the most productive periods. When people are younger, men work more, but younger men and women are both in the invisible under-employment category and twice as many women as men are unemployed. As they grow older, men reach their peak level of suitable employment, mainly in the $30-39$ age range (around $70 \%$ of the economically active population), whereas women's suitable employment peaks at $49 \%$ in the over- 40 age group, where labour force participation begins to decline. 
The employed female population is concentrated mainly in the informal sector, defined as small business activities, usually with no taxpayer's identification number (RUC) or accounting records according to the National Statistics and Census Institute (INEC). Men are employed chiefly in the so-called modern (formal) sector.

The sector generating the largest urban female employment is trade. The agricultural sector employs $32 \%$ of men and $22 \%$ of working women (the vast majority of whom live in rural areas). It is the sector where workers' levels of education are the lowest, especially women's: $67 \%$ of female farm workers have primary education and $19 \%$ have no education at all. Moreover, a large proportion of women with higher education work in the modern sector, although this does not guarantee pay commensurate with their qualifications. Those with higher education are more likely to work as professionals in financial services and higher education, which do not generate a large number of jobs.

Most women living in urban areas are private-sector employees or self-employed workers, while in rural areas most tend to be selfemployed workers or unpaid family workers. The latter occupational category has been growing, especially since the mid-1990s. The majority of men work as private employees or day-labourers, although many are also self-employed. There is a worryingly high incidence of unpaid work among women: only in this and the domestic service categories do women form the majority.

Most people with higher education work as private employees ( $46 \%$ of men and $48 \%$ of women). Many of those with higher education work in the civil service, a sector that has been employing increasing numbers of female professionals over the past three years.

Most of the employed female population is in the "unskilled" group, which is considered low-productivity work. There is also a high percentage of women (compared with men) in scientific and professional jobs, unlike five years ago. This difference is even more marked among those with higher education.

According to employment survey categories, most workers have a temporary, casual or seasonal contract, but there are also many with a permanent or stable contract. Nearly half of women have fairly stable employment. However, women continue to earn less than men: the gap is around $10 \%$ in civil service appointments (usually management positions) and $12 \%$ for permanent contracts.

However, stable employment is no guarantee of compliance with other labour rights. Health insurance and pension coverage is 30\% in urban areas and $19 \%$ in rural areas. 
Neither the so-called formal sector (where $43 \%$ of men and $39 \%$ of women work) nor full-employment jobs (full-time work at or above the minimum wage) comply with health and pension coverage: $50 \%$ of formal-sector workers are uninsured and, in the full-employment category, around $61 \%$ of men and $53 \%$ of women are uninsured. Among the inactive population, $15 \%$ of men and $8 \%$ of women have social security coverage, which probably means retirement benefit.

A final point is that, even though the wage gap between men and women has narrowed over time, it is still around $25 \%$ for workers who have completed secondary education. The gender wage gap is wider in the so-called informal sector and wider still among self-employed workers, although it is also sizeable in manufacturing and in the (femalepredominated) service sector.

\section{Relationship between work in the labour market and care work in the home}

Under-employed women perform the largest amount of unpaid domestic work, given the nature of under-employment (added to the fact that, in many cases, unpaid domestic work is performed in the homes or communities where families live). Women informal workers and domestic workers also bear a very heavy burden of unpaid domestic and care work. This would point to a relationship between occupations less valued by the market, or employment vulnerability, and low value accorded by households or stronger gender stereotypes.

Even though care time limits the number of hours spent on work for the labour market, a minimum of care needs to be provided and it is women who take responsibility for it, whether or not they work in the labour market. Although there is clearly an objective time constraint, it is impossible to determine the precise trade-off between the two types of work, undoubtedly because basic care work is performed at the expense of rest time.

A total of $61 \%$ of women working less than 25 hours per week in the labour market spend more than 40 hours per week on domestic work. However, there are no major differences in the burden of domestic work among women in other forms of employment: between $30 \%$ and $40 \%$ of women working full time (or even longer) also spend more than 40 hours a week on care work in the home. Thirty per cent of women working more than 46 hours a week spend more than 40 hours on domestic work (see table IV.5). 
Table IV.5

ECUADOR: WOMEN AND MEN'S BURDEN OF UNPAID DOMESTIC WORK, BY HOURS OF WORK IN THE LABOUR MARKET, 2007

(Percentages)

\begin{tabular}{|c|c|c|c|c|c|c|}
\hline \multirow{3}{*}{ Unpaid domestic work } & \multicolumn{6}{|c|}{ Work in the labour market } \\
\hline & \multicolumn{2}{|c|}{$\begin{array}{l}\text { Percentage working } \\
\text { less than } 25 \text { hours }\end{array}$} & \multicolumn{2}{|c|}{$\begin{array}{l}\text { Percentage working } \\
26 \text { to } 45 \text { hours }\end{array}$} & \multicolumn{2}{|c|}{$\begin{array}{l}\text { Percentage working } \\
\text { more than } 46 \text { hours }\end{array}$} \\
\hline & Women & Men & Women & Men & Women & Men \\
\hline No unpaid domestic work & 1.3 & 7.3 & 1.7 & 6.1 & 2.5 & 7.5 \\
\hline Under 10 hours per week & 6.7 & 52.0 & 11.8 & 49.7 & 17.0 & 53.6 \\
\hline Between 10 and 20 hours per week & 7.5 & 18.5 & 14.1 & 22.5 & 18.3 & 21.2 \\
\hline Between 20 and 40 hours per week & 23.5 & 14.4 & 33.1 & 15.0 & 32.6 & 12.7 \\
\hline More than 40 hours per week & 61.1 & 7.7 & 39.3 & 6.8 & 29.5 & 4.9 \\
\hline
\end{tabular}

Source: Prepared by the author on the basis of National Statistics and Census Institute (INEC), national timeuse survey "Encuesta Nacional de Uso del Tiempo", 2007.

\section{Identifying gaps in the current system of care}

The care system is severely constrained by two fundamental weaknesses: (i) it is not a system structured around a central core of care targeted at those most in need of it; and (ii) it is not organized to provide support to caregivers. Not only are the structure and approach of social security and care services still geared towards a family with a main breadwinner and a housewife whose chief responsibility is care, State care services also rely on women's time for support. While most recent proposals for institutional change (detailed below) entail increased coverage and better pay for care services, the fact that they have not yet been implemented means that they cannot be evaluated.

Although demand for care continues to be met by households, in many cases it diminishes the quality of life of women, most of whom are already working in the labour market, with minimum involvement of men in care work. Table IV.6 describes the main limitations and shortcomings in Ecuador's care provision. 
Table IV.6

ECUADOR: MAIN SHORTCOMINGS IN THE CARE SYSTEM

\begin{tabular}{|c|c|c|}
\hline Sector/policy & Effectiveness & Equity \\
\hline Social protection & $\begin{array}{l}\text { - Insufficient local services } \\
\text { - Unawareness of the needs of older adults } \\
\text { providing informal care } \\
\text { - Low care coverage for people with } \\
\text { disabilities } \\
\text { - Low care coverage for older adults, } \\
\text { especially women } \\
\text { - Lack of State regulation and control of } \\
\text { - } \text { service quality } \\
\text { - Lack of programme linkages and unequal } \\
\text { - Limited coverage of feeding programmes }\end{array}$ & $\begin{array}{l}\text { - Unequal burden of domestic work } \\
\text { associated with poverty and employment } \\
\text { vulnerability } \\
\text { - Unequal access to care services, more } \\
\text { limited for poor households } \\
\text { - Insufficient access to social protection } \\
\text { for older adults in rural coastal and } \\
\text { highland areas }\end{array}$ \\
\hline $\begin{array}{l}\text { Employment } \\
\text { and work in the } \\
\text { labour market }\end{array}$ & $\begin{array}{l}\text { - Non-compliance with paternity leave } \\
\text { entitlement } \\
\text { - Low coverage of workplace childcare } \\
\text { services } \\
\text { - Social security coverage low and linked with } \\
\text { formal work as employees } \\
\text { - Low pay and skills of home-care service } \\
\text { providers } \\
\text { - Opening hours insufficient and not } \\
\text { organized around the needs of working } \\
\text { parents }\end{array}$ & $\begin{array}{l}\text { - Unemployment and under-employment } \\
\text { linked with a heavier workload and lower } \\
\text { social protection }\end{array}$ \\
\hline $\begin{array}{l}\text { Organization of } \\
\text { care systems }\end{array}$ & $\begin{array}{l}\text { - Low coverage of care and domestic services } \\
\text { - Current organization fails to integrate care } \\
\text { services into a system } \\
\text { - Care responsibilities constrain the access of } \\
\text { the inactive female population to paid work, } \\
\text { generating a high opportunity cost }\end{array}$ & $\begin{array}{l}\text { - Concepts of care system and care economy } \\
\text { missing from social policy agendas } \\
\text { - Social security and protection focus and } \\
\text { programme implementation assume gender } \\
\text { roles and use women's time } \\
\text { - Lack of a system of care for the life cycle } \\
\text { and family }\end{array}$ \\
\hline
\end{tabular}

Source: Author.

\section{G. Scenario for a public policy nexus to redistribute caregiving tasks and responsibilities}

\section{Ecuador's legal framework for maternity protection and for supporting workers with family responsibilities}

Ecuador's fundamental laws on labour and social security have been designed around a family model comprising a male breadwinner working in the labour market to earn the family's income and a wife responsible for household duties. This is how the wage came to be conceptualized as including the family among its beneficiaries (family wage concept), as were social security benefits, many of which are linked 
with work as employees. Recent legislation has amended some of these concepts, beginning with the different conceptions of work, labour rights, wages and social security defined by the new Constitution of the Republic of Ecuador, passed in September 2008. Progress has also been made in setting standards to eliminate precarious forms of employment and institute maternity and paternity benefits.

\section{(a) New Constitution of the Republic of Ecuador}

Ecuador's new Constitution defines a framework of opportunities for realizing women's rights and gender equity. Its overall approach is based on a different conception of the economy, production and labour. In the case of the economy, the Constitution speaks of a social, solidarity-based economic system that places equity and distributive justice at its core and recognizes basic inequalities (including those of gender). Although it recognizes reproductive work in the home as part of production, it fails to define these concepts. The Constitution not only recognizes that domestic work is productive and reproduces the workforce, it also establishes a link between domestic work and the economy as a whole.

The Constitution maps out a number of waypoints in the labour sphere (articles 325, 326, 329, 331, 332 and 333). It recognizes the right to work in all its forms, including subsistence and care work, which it explicitly considers as productive work. It also asserts that the State guarantees women equal access to employment, training, job promotion and career advancement, as well as to self-employment (just like the rest of the population). The Constitution also states that the necessary steps will be taken to abolish inequalities, prohibit and penalize any form of direct or indirect discrimination, harassment or violence against women at work. It also recognizes women's right to equal pay, in accordance with the principle of equal pay for work of equal value. Although work incentives depend upon developing this point, it has not been discussed within the legislative framework.

Another important aspect of the Constitution is that it guarantees respect for workers' reproductive rights, including: the elimination of occupational hazards affecting reproductive health; access to employment and job stability without restriction on grounds of pregnancy or number of children; maternity and nursing rights; and entitlement to paternity leave. It also prohibits the dismissal of women workers on grounds of pregnancy or maternity, or any sort of discrimination related to reproductive roles.

In parallel with recognizing unpaid subsistence and care work in the home as productive work, the Constitution requires the State to: 
promote conditions of employment in keeping with care needs; provide appropriate services, infrastructure and opening hours; and promote responsibility-sharing and reciprocity between men and women in domestic work and family obligations. A basic premise for this is social security coverage for all those performing unpaid work in households. However, the legislative debate on this issue is complex, as the source of the extra funding required is unclear, although it should come mainly from existing social security funds, a matter for which it will be difficult to secure employers' agreement. A large portion of the funding will also come from tax revenue, although much of the social security institution's resources already come from State subsidies.

In addition, article 69 of the Constitution recognizes the obligation of both father and mother to provide care, parenting, education, food, comprehensive development and protection of the rights of their children, especially when parents are separated. It also mentions parents' shared responsibility for the care of their family.

Despite all these provisions in its Constitution, Ecuador has still not ratified Convention 156 of the International Labour Organization (ILO) on workers with family responsibilities. Nor has it ratified ILO Convention 183 on maternity protection, although national legislation already includes this requirement.

With regard to public sector employment, a clear concern is the absence of a redefinition of public service care in the new Constitution's reforms to ensure a more interventionist and proactive State, even though many of the supplementary definitions of work and care, as well as the policy proposed in Ecuador's national plan for good living (PNBV), refer to public care support.

While the policy appears neutral, that is not the case because it fails to take into account differences - not only in access, opportunities and availability of such factors as time but also in access to decisionmaking and positions of responsibility (such as managerial posts) arising from the naturalization of women's primary role as homemakers and secondary workers performing undervalued tasks. In the absence of a gender perspective, gaps widen owing to basic inequalities stemming from this naturalization of care. It is important, therefore, for the new State model (containing elements of equity, regulation and stronger State presence in planning, services and rights enforcement) to consider how to construct a new model of public administration for structural change and which elements this model should contain in terms of employment and working conditions. While the Constitution promotes a strong and proactive interventionist State, it fails to include among the State's functions care infrastructure maintenance and provision. 
Reconciling work and care responsibilities also calls for the creation of equal job opportunities for men and women and breaking down the barriers to women's entry into and continuance in the labour market under decent conditions. In the labour market itself, it also means gradually overcoming gender stereotypes and valuing work without bias. The debate on the value of work is therefore central to wage-setting and resetting as general labour market policy, especially in sectors where activities are typically performed by women.

Ensuring that reforms are introduced and pay equity policies enforced is vital to the welfare of Ecuador's people and economy. According to a 2005 study by the Integrated System of Social Indicators of Ecuador (SIISE) in connection with meeting the Millennium Development Goals, Ecuador could increase its chances of reducing poverty by $40 \%$ by boosting women's labour force participation (narrowing the opportunity gap) (León, 2005). Women forego (opportunity cost) the equivalent of $30 \%$ of Ecuador's gross domestic product by not participating in the labour market in order to fulfil household duties (Vásconez, 2008). At the macro level, reconciling work and care responsibilities would therefore have a huge impact on people and their welfare.

Thus the (State or other) funding required to pay for care services should come from a general redistribution of public resources (from the State budget) and private resources (from employers). Institutional and economic reforms are vital to ensuring responsibility-sharing and hence the reconciliation of work and care responsibilities.

\section{(b) Background and recent changes in the legal framework}

The Constitution declares the State's intent to enhance its response to future care demand to some degree. However, to realize this intent, demand needs to be quantified and pinpointed across every line of government intervention. Recognition of domestic work as productive and maternity and paternity leave entitlement call for a set of measures to achieve universality, which should include informal and self-employed workers. Legislation on social security for unpaid work also needs to be extended as part of general social security reform. Some of these aspects are now being developed and are described below.

\section{(c) Maternity, paternity and other family-related issues}

Ecuador's Labour Code provides specific rules for maternity protection. Article 154 prohibits the termination of an employment relationship on the grounds of pregnancy. Any employer who terminates the relationship unilaterally must compensate the woman with the equivalent of one year's pay, in addition to any statutory benefits to which she is entitled (SIUDEL, 2008). In addition, no employer is allowed 
to terminate the employment contract of a woman who remains absent from work for up to one year as a result of a disease medically certified to have been caused by pregnancy or childbirth and rendering her unfit to work.

Article 152 of the Labour Code states that women are entitled to maternity leave in the period 2 weeks before and 10 weeks after delivery; the entire 12-week period during which women should not work may be taken after delivery. Furthermore, article 27 of the General Regulations for Subsidies states that a maternity allowance shall be paid for 12 weeks ( 2 weeks before and 10 weeks after delivery), $75 \%$ of which is to be covered by the woman's social security contributions and the remainder by the employer. Article 155 of the Labour Code stipulates that, in businesses or workplaces without a nursery, mothers should work only a six-hour day for a period of nine months after delivery. Indeed, workplace nurseries are mandatory for business units with 50 or more workers, posing a constraint on small businesses and economic units, which employ more than $60 \%$ of the economically active population.

Two recent changes in the law by the Legislative Committee of the Constituent Assembly are worthy of mention. The first is a constitutional mandate to abolish precarious forms of employment, including outsourcing and labour market intermediation, and to regulate part-time work by giving part-time workers the same benefits as the rest of the labour force working full time. However, this mandate does not extend to self-employed workers.

The second important legal change introduces paternity leave. To enforce this measure, the Labour Code and Civil Service and Administrative Careers Act were amended to apply to both the public and private sectors. The regulations state that male workers are entitled to 10 days' paid leave as from their child's birth. This shall be extended by a further five days in the case of multiple births or caesarean delivery, or by eight days if the child is born premature or with a disability or degenerative disease. The regulations also state that, if the mother dies in childbirth or while on maternity leave, the father is entitled to a total of 25 days' paid leave. The same leave period is granted to male workers whose children are hospitalized or have a degenerative disease. Although this reform was approved unanimously, there is disagreement over the source of funding for paternal leave, with the legislature arguing that it should be provided mainly by the employer.

\section{(d) Social security and general realization of rights}

A number of bills for social security reforms have been introduced into the National Assembly. One of the proposed reforms is to grant 
social security to those performing unpaid work in the home and for self-consumption. As mentioned earlier, the most important debate centres on financing and coverage. A measure like this will be extremely important, especially in terms of providing health and security services to women, in particular the poorest and those under working age. However, discussion is needed on the likelihood of this measure emphasizing women's role as full-time carers. This makes it important to establish it as a complement to far-reaching reforms aimed at creating decent work and realizing labour rights, as well as promoting well-paid domestic work, or the use of subsidies for State care services.

The latest report on monitoring compliance with the agreements of the National Women's Council (CONAMU, 2008) expresses a general concern about wage gaps between men and women, arguing that the State should take steps to ensure equal pay and benefits in both the public and private spheres, as well as to guarantee equal pay for work of equal value. The report states that women had complained to labour inspectors and to police stations for women and families of having been dismissed on grounds of pregnancy, maternity leave or marital status. The women complained that, upon learning that their female workers were pregnant, employers would fire them on any pretext, or subject them to work endangering their pregnancy. According to the compliance-monitoring report, women had also complained of being replaced by other workers during their period of breast-feeding leave. This calls for reinforcement of the laws penalizing rights infringements, setting up expedited complaints mechanisms and strengthening inspection systems.

\section{Gender perspective in Ecuador's social policy matrix}

Prior to the 1980s, during what could be described as a statist stage, social policy in Latin America in general and Ecuador in particular focused on women as beneficiaries of social assistance, dependent and represented by their husband (or father). It was this that determined the gender-based allocation of resources within households, given that position is determined not only by a person's real contribution but also by perceptions of that contribution. Women have been disadvantaged because society values monetary contributions to the household more highly than the unpaid contribution of domestic work, which is reflected in the distribution and control of resources and welfare between women and other household members. Social security and employment protection schemes structured around people's employment status heighten women's dependence and cover women outside the labour force only if they are wives or daughters. This valuation is transmitted to the market and even to social services. 
Starting in the mid-1980s, a changing welfare system was accompanied by a shrinking family wage, with limited stable jobs and the entry into the labour market of a less skilled labour force more liable to slip back into unemployment. The increasing participation of women in the labour force also changed their position as economic actors and their dependence. However, women's role as primary caregivers has not changed, nor has the popular consciousness or market signals, relegating women to a secondary role as earners, with women finding it hard to enter the labour force but exiting from it easily and their labour perceived as more costly than men's owing to their caregiving tasks. All this is reflected in women's lower relative pay for equal skills and work.

As a result, care provision ${ }^{10}$ in Ecuador has undergone periods of socialization and commodification. Socialization refers to the transition of services from the market to the State, which was particularly marked in the late 1980s and has tended to return in recent years. Commodification refers to the production of well-being (of care, in this instance) by the market, as a result of a deliberate policy of withdrawal of public social services in a context where the economy is viewed as the cornerstone of public policy, in the interests of efficiency and fiscal austerity.

As a result of these two processes, in a situation where the State fails to provide services and families may have no access to private services either, the production of well-being overburdens families and, when this happens, tasks are relegated to women.

\section{(a) Social protection and economic inclusion}

In the area of social protection, a social policy focused on targeting has led to conditional cash transfer policies targeted predominantly at poor women being implemented throughout the region, particularly in Ecuador since the late 1990s. Women are targeted mainly because of two factors: (i) a trend towards the feminization of poverty; and (ii) a belief that women are able to channel State benefits to family welfare more effectively. In other words, there is an assumption that it is more efficient to target the poorest, while relying on women's supposed selflessness and generosity and using their time and roles to ensure family access to services. Despite weak conditionality because Ecuador performs no universal, systematic checks of compliance, one of the most important indirect results of cash transfers has been to increase school enrolment in families in the poorest quintiles of the population, suggesting that women, as the direct recipients of cash transfers, are channelling income into education as a priority.

10 For the purposes of this analysis, the social organization of care includes health services, education, social protection, food and nutrition, and the care of children, people with disabilities and older adults. 
Over and above the efficiency and equity constraints already identified in care systems, clearly the overall thrust of the social protection system's targeted policies and interventions continues to make women responsible for care, even where this is provided through the State. Cash transfer programmes are based on the State sharing responsibility with the family (mothers), while the opening hours of childcare services prevent mothers from engaging in paid work. What is more, childcare services employ women with low wages and poor training. Social protection focuses more on "inclusion" than on advancement or empowerment, and there is a danger that focusing benefits too much on cash transfers (credit, access to cheap food, and housing and other allowances) could lead to dependency or a poverty trap.

Even though the policy focus has shifted in line with constitutional changes, in a social policy aimed at fighting poverty and inequality, the most "vulnerable" population, represented by human development grant beneficiaries (poor women, people with disabilities and older adults), continues to be regarded as the most important policy target. This leads to policies to complement social protection actions by including new benefits tied to the grant, such as credit, housing and food price subsidies. However, the design of the current grant is unlike that of previous administrations in that it also links productive elements, through public procurement and government contract manufacturing to create jobs and horizontal and vertical economic chains. These initiatives are part of a policy of economic inclusion, which aims to boost solidaritybased popular economy ventures, one priority of which is to promote the economic participation of women entrepreneurs and women-led economic organizations.

Economic inclusion focuses on revamping the relationship between economic and social policy by linking a package of social benefits to the productive potential of individuals and communities. Moreover, it highlights different forms of economic organization that coexist with and fuel the "formal" economy, as well as endeavouring to revalue work, especially domestic work, which is an entirely novel approach. In this respect, economic inclusion does not adopt a welfare approach (although it strengthens the vision of a State that regulates and provides public services) but instead emphasizes the potential and capacities of grassroots and small-scale social economy systems as alternatives to capitalism. However, the financial and legal arrangements for these activities are still in the early stages and no ex ante evaluations are available, nor is there any official information on the micro-level development of initiatives benefitting women. 


\section{(b) Job creation policy}

As regards economic and production policy for job creation, little progress has been made in government agendas in terms of employability and productivity. The coverage of training and technical and university education has remained the same, although progress has been made in the initial evaluation and accreditation of universities and higher education institutions. However, education and labour policy alike have failed to address one of the most important problems of all: the transition from secondary, technical or higher education to work and gender barriers to women professionals entering positions of leadership and responsibility. No information is available on the difficulties faced by young men and women in securing jobs, although there is evidence that unemployment among people in the 18-24 age group is double that of the general population and twice as many women are unemployed as men. While it is not their most fertile age, women in the 18-24 age group are already starting to marry or form civil unions and have children, coupled with the fact that their burden of domestic work is triple that of younger women (which does not happen with men, as discussed earlier). There needs to be a more in-depth analysis of the relationship between higher education and the first job, on the one hand, and the domestic and care work burden, on the other. Programmes for matching job supply with demand (whose coverage is rather low, according to information from the system for democratic governance (SIGOB) in 2010), do not consider strategies for reconciling work and family responsibilities to include the restructuring of working hours, lifelong learning, or the organization of work as a continuum between production and reproduction. Job-matching programmes are still geared to the needs of employers and, in the case of seasonal or temporary employment, to the needs of production and the economy.

Even though programmes and interventions to assist microenterprises and businesses in the social and solidarity economy include strong female participation and specific support for women's groups and women-led associations, they maintain two fundamental biases: first, the supply of funding and initiatives is geared towards "typically female" activities, such as cooking, sewing, beauty care and childcare; second, they fail to take into account the fact that these new productive and organizational responsibilities may place a strain on domestic and care work, as the benefits package does not include additional care services, except in the case of associations formed to provide community care services. What is more, such initiatives are still at an early stage and a future evaluation should be made of their gender impacts, handling of labour rights and sustainability. 


\section{H. Public policy nexus}

The chief constraints on women's welfare from the standpoint of their working, family and productive lives continue to stem from a gender system based on the sexual division of labour, which not only transfers gender roles into the labour market and social protection but also creates segmentation, discrimination and severe inequities in terms of time, labour and access to resources for women compared with men and for the care economy compared with the rest of the economy. As mentioned earlier, the presence of small children, lack of responsibility-sharing in household tasks and unavailability of childcare services are coupled with poverty, poor access to suitable infrastructure and home appliances and equipment, insecure working conditions and low wages. Moreover, families with the worst employment problems (under-employment and informal jobs) also tend to have a heavier burden of domestic work, as do families and individuals that are highly dependent economically. A thorough analysis is needed of home-based work for the labour market because, while it gives women some facilities to cope with the burden of domestic work, in many cases it reduces control over their own time as there are no clear boundaries between the two spheres of life.

This makes it necessary to consider complex policies that go beyond the sphere of work and social protection. Based on the concept of poverty as a deprivation of the resources needed to meet needs (including time), a policy to ensure employment protection and social security in a flexible environment is not enough when the set of deprivations includes: uncertainty about the period of work and time management, expected and agreed pay and the possibility of becoming unemployed (with no unemployment insurance); or, in the case of a widespread crisis, the fear that the State will be unable to provide basic living standards, forcing reliance on unpaid domestic work.

This does not mean appealing to an outdated welfare system that failed to contribute effectively to men and women's well-being in the past. A fresh look at State institutions as rights-enforcers need not entail a heavy or inefficient apparatus that is far from equitable. Any alternative policy should support the consolidation of working arrangements that are flexible but organized on the basis of citizenship and rights, with a sizeable component of participation, recognizing different forms of work and contributing capital and assets for the development of each form. A more integrated policy should incorporate the entire working population and, in the specific case of women, bear in mind the interaction between work for the labour market and domestic work. An integrated policy should also be underpinned by an acknowledgement that the economy is an interaction between the micro level (individuals and households), 
meso level (institutions) and macro level, as well as between the different economic actors, including men and women. It should also recognize that the economy is a system that should aim to secure people's wellbeing, in market and non-market, tangible and intangible spaces. This means that it must be multisectoral in design to address all the various areas: macroeconomic, labour/productive and social protection/care.

\section{Macroeconomic and funding policy}

From the macroeconomic perspective, any policy seeking to end the gender system's structural inequalities in terms of care and work should aim for an overall redistribution of resources to the care economy.

A basic strategy is to highlight and quantify the care economy's contribution, both to analyse the functioning of the economy more holistically and to move towards restructuring macroeconomic aggregates and redefining economic goals, including integrated definitions of production, work, prices and wages. Any restructuring of the models used to explain the operation of markets and model policy impacts should include broader indicators of welfare and more complex explanations of the labour market (especially labour supply). In line with modelling, more light may be shed on the functioning of economies in recession if care inflows and the role of care in the economy are seen as economic adjustment mechanisms. This recommendation follows from research and knowledge on this functioning using non-traditional methodologies and indicators, including those related to the time dimension as part of value creation and transmission. In Ecuador there is already an initiative for developing household satellite accounts based on the 2007 time-use survey.

A further element of macro policy is funding the care infrastructure as a priority for a basic fiscal agreement. Current and future financing requirements for care need to be properly quantified as part of the reform of the solidarity-based social security system. In addition, care-related sectors should set care coverage goals as a performance indicator of general and sectoral fiscal policy when drawing up the national budget. This also includes local budgets.

At the moment it is difficult to ascertain how much public expenditure is earmarked for care, except in terms of staff salaries. Any redistribution policy would necessarily entail changing spending priorities and tax policies. Ecuador's current tax burden is quite low compared with other countries in the region and the rest of the world and a fairly small proportion of the population declare their taxes because, as already mentioned, most are outside the formal tax system. An effort 
is needed to restructure the tax system and incorporate economic units and self-employed and informal workers, to ensure a more progressive system of taxing revenue and income in the future. However, this should form part of a comprehensive tax reform to make current tax-system progressivity more efficient, as well as to broaden the tax base and set up mechanisms to control tax evasion.

On the expenditure side, macrofiscal and sector performance goals need to be better regulated and a spending package earmarked from domestic resources needs to be defined, which should include care. The challenge is to promote a fiscal covenant that prioritizes care systems, so that this becomes a permanent fiscal priority. A further source of funding is the social security system, which currently invests heavily in other sectors (including energy, oil and public infrastructure). At present social security funds are deposited in a new institution acting as lender of first resort - Bank of the Ecuadorian Social Security Institute (BIESS) which has sizeable capital and brokers a large amount of funds from members. In addition, some family allowances, such as maternity and paternity leave, are already being funded from members' contributions. Under a universal insurance scheme, one option is to extend insurance coverage to the care of children and older adults. Another option is to fund services using a common fund (that is, through taxes).

\section{Employment policy}

The main aim of labour and employment policy is to ensure that responsibility for caregiving is shared with employers and among the various forms of work, as well as to strengthen the guarantees relating to family responsibility. The cornerstone of this policy is therefore the social reorganization of work to take into account work for the labour market and care work.

The reorganization of work calls for a profound transformation, which could include: changing working hours to make them flexible for both men and women; reorganizing leave arrangements; defining periods of care at certain stages of the family life cycle; strengthening workplace nurseries; employer support to meet family protection, health and safety needs; designing and establishing compulsory social security as a universal right; and incorporating the concept of quality time for workers to enhance their productivity. Such long-term changes call for a thorough dialogue and the conclusion of basic social agreements involving all key stakeholders: employers, employees, self-employed workers and the State. The micro- and macroeconomic importance of social support for care and the resulting gains in efficiency, productivity 
and equity need to be ascertained and disseminated. Public and private institutions and households have yet to internalize these concepts or their implications.

At the same time it is necessary to strengthen mechanisms for worker monitoring and enforcement of: the right to maternity and paternity leave; non-discrimination against women of childbearing age and pregnant women; and gender non-discrimination in general. Workers' organizations were severely weakened in the 1980s and 1990s and have still not recovered, especially as a large proportion of workers are no longer employees. Workers in small businesses and economic units, self-employed workers and domestic workers need to be better organized to facilitate discussion of the most appropriate ways of ensuring the universal right to care. Discussions of social security reforms are currently under way, centred on financing, particularly for health, as opposed to the option of strengthening health provision as a universal right without linking it to the social security system. The definition of at least emergency basic healthcare coverage for older adults and people with no record of contributions living in poor households needs to be promoted. Also, Ecuador should take the immediate step of signing ILO Convention 156 on workers with family responsibilities.

Discussions should also focus on wage-setting, in the framework of both the care system and general wage regulation. The principles of non-discrimination, equal pay and non-exploitation call not only for changes in labour demand and the abolition of unequal pay for equal work, but also for a reassessment of wages, which are set on the basis of criteria with a possible gender bias. The resumption of wage bargaining based on unbiased criteria and with greater participation of women (including self-employed and domestic service workers) is key to achieving fair pay; progress in this respect could help to break down other barriers to women earning an adequate income and participating in the labour force. Part of this discussion involves setting fair wages for care-related work, including education, health, domestic service employment and childcare. An immediate step would be to grant the minimum wage and full statutory benefits to women working for public care services as mother child-minders.

\section{Social protection and care policies}

In the area of social protection there needs to be a move towards the establishment of a decentralized system of universal care by: first, quantifying and evaluating current provision in detail, especially private care; second, setting care standards, quality and costs, human resources 
and infrastructure; and lastly finding the best service providers, including private providers funded or co-funded by the State wherever possible.

To achieve a decentralized system of care it is essential to create geographically based protection and care pathways that also include local users of care services. This service infrastructure could be organized to tie in with MIES district-based services, which are also linked with participation and monitoring spaces (human rights councils). This is useful for pinpointing demand, available supply, subsidies and the necessary funding. ${ }^{11}$ However, as these district structures are still being set up, a suggested transitional measure is to improve and expand the current infrastructure of childcare services, providing childcare at times to suit families' needs and in accessible locations. In remote or dispersed rural communities, well-paid childcare services could be delivered in communities themselves by care providers who have been given suitable education and training.

Going a little beyond the proposal of ILO and other organizations for establishing and covering a minimum social protection threshold (or "floor"), this floor could usefully contain a basic package of care, as the first milestone on the path to expanding it into a universal system of care. The advantage is that this floor would not be left uncovered and is a necessary, socially agreed-upon starting point. This "care basket" could even be part of the basic needs basket used to measure price and wage levels, just like the poverty line. Some countries in the region have already begun to develop expanded measures of poverty and well-being that include time and care. ${ }^{12}$

These and other changes require employers, workers and the State to engage in a process of dialogue and social agreement regarding employment in formal, non-formal, associative and solidarity-based enterprises. Support for self-employed workers should come from solidarity-based social security, albeit with a voluntary contribution, as well as from the care infrastructure.

The approach of conditional cash transfer programmes also needs to be reformulated urgently. The first option is to gradually decouple conditionality, measuring the impact of alternative policies and variables on enrolment and health care, including: grants; subsidies to educational units; and the expansion of education infrastructure and services close to homes.

11 The Ministry of Economic and Social Inclusion (MIES) is currently conducting a nationwide census of supply and demand for social protection services, which may be very useful for this type of initiative. The proposal for district-based services is under discussion.

12 For example, Argentina did so as part of a project on expanded indicators of economic well-being conducted in 2010 by the Levy Economics Institute of Bard College and the United Nations Development Programme (UNDP). 
The second option, which does not preclude the first, is to initiate a process of family exit from this protection system, also decoupling entitlement to other human development grant benefits, such as credit, housing or food. Decoupling is important, first and foremost, because credit and productive financing should not be restricted to poor people; instead it should be a benefit to ensure the economic and productive inclusion of women who have had no chance to earn an income. Second, decoupling is important because if other benefits, such as credit, continue to be poverty-linked, there will be no incentive to exit from poverty, owing to the high opportunity cost this would entail, which could create a poverty trap. Exit or decoupling should be encouraged by providing access to funding and productive assets, which would increase people's ability to sustain themselves without reliance on cash transfers. ${ }^{13}$

This is a slow process that requires intensive intervention to create jobs and expand care services and educational, local production and other opportunities. ${ }^{14}$ It calls for mechanisms to: support initiatives with local potential, which should be studied in more depth; strengthen public procurement systems; and encourage private procurement of products from small associative business ventures receiving support as part of the human development grant decoupling process. This also entails strengthening mass training programmes, as well as local financing instruments and mechanisms. An interesting option might be to form interregional trade chains and create products with a "social label" for foreign markets, which is already being studied in connection with policies for the solidarity economy.

The third option is to extend cash transfers, free of other benefits, to the entire population, as part of a universal basic income scheme. ${ }^{15}$ This proposal has already been analysed by feminist economists (Benería and Floro, 2006) who believe that some of its benefits would be to help to: decouple non-contributory social protection from the gender system; redress the problem of women's unequal balance of power in the family arising from their lack of monetary contribution; and encourage women to seek more "decent" work with better prospects. The debate on the basic

13 The current proposal for decoupling the cash transfer goes along these lines. However, the proposed scheme would allow families who rise above the poverty line established by the national social register of individual families potentially eligible for State programmes to keep the other benefits they already receive but the State would aid and support them to access broader employment and credit programmes. However, this strategy, which could be classed one of economic empowerment, is not yet clear.

14 Although there is currently a proposal along these lines, its impact on families and other factors have not been measured.

15 This would entail increasing the basic income to above the current amount of the human development grant, causing financing problems that tend to be the main impediment to any universal scheme. 
income has been ongoing in Europe and some Latin American countries for several years. The main bone of contention is whether to introduce a universal scheme when persistent problems of inequality in countries of the region are deemed to require priority to be given to the poorest or lowest-paid sectors of the population, including unpaid women caregivers. Yet the basic income is not intended to serve as payment for work but rather to guarantee a minimum transfer to all citizens of a country. ${ }^{16}$

\section{Production and productivity policies}

In Ecuador, the starting point for production and productivity policies would need to be fairly basic; it would be a question not just of mainstreaming the care and gender equity perspective but also of developing production-oriented policies and programmes. Current care provision fails to generate production linkages because of its limited scope, low job creation and poor standard of training and professionalization. Even though the wage of domestic workers has been raised to the statutory minimum wage, domestic service work remains undervalued by society. Care services could establish linkages with the education and training system by incorporating technical training courses for care and household service professionals (they already exist for health and cooking professionals); they could also create jobs by building new infrastructure for education, community health and the care of children and older adults. Tourism programmes for older adults could also be developed as part of their socialization and protection process. The tourism industry (community-based, eco- or traditional tourism) could form part of this initiative, potentially achieving wide coverage of the older adult population by subsidizing poor people through differential pricing and encouraging older adults to travel to other countries in the region.

In addition, there should be increased public procurement from private providers of catering, cleaning, childcare (such as childminders' organizations), specialist health care, tailoring and catering services organized as associations, communities, businesses and small local economic units. While women's organizations could provide such services, men would also need to be involved in delivering them. This would require education and training provision by public and private institutions open to gender equity-based participation. In addition, some sort of government incentive could be used to encourage the private sector to use such service providers.

16 See the wide-ranging discussion on the universal ("citizen's") basic income by a number of authors from Argentina's Interdisciplinary Centre for the Study of Public Policy (CIEPP). 
However, efforts to create jobs and opportunities for women will need to go beyond care services and small business ventures, which historically have been limited. Stronger labour reforms will be required to ensure non-discrimination in entry, pay and career advancement for all women wishing to enter the labour market, together with enforcement and monitoring mechanisms, as mentioned earlier. Technical education for women at secondary and post-secondary level should be strengthened and encouraged by thoroughly overhauling the education system to mainstream the gender perspective. In the case of universities, remedial education incentives should be introduced for degrees where there is a gender bias against either women or men. A job and career evaluation system to remove such a bias could be made a key part of this process. Moreover, continuing training is needed for people who have been out of work for a long time (or who have worked for only a short time after their studies), in order to narrow knowledge gaps and limit such barriers to entry. This remedial training should provide the core skills and knowledge required for the market and production.

On the production side, training and economic inclusion processes are needed to promote the removal of gender bias and prioritize innovation and the entry of women into non-traditional, high-technology, high-productivity industries, through vocational training, enhanced technical education at upper secondary and higher education levels and greater availability of student grants for scientific and vocational degrees in high demand. A reform of the baccalaureate is under study, which must be linked with the recent legal changes in higher education. Such a reform is vital to increase equity in upper secondary education.

Over and above the Constitution, the main prerequisite for eliminating gender bias in the labour market is reconsideration and social recognition of the value of care work and shared social responsibility for caregiving. An overall redistribution of work and time between men and women and between the money and care economies should serve as the basis for creating productive opportunities for women. 


\section{Bibliography}

Benería, Lourdes and María Floro (2006), “Informalización del mercado laboral, género y protección social: reflexiones a partir de un estudio en hogares pobres urbanos en Bolivia y Ecuador", La persistencia de la desigualdad. Género, trabajo y pobreza en América Latina, G. Herrera (ed.), Serie Foro, Quito, Latin American School of Social Sciences (FLACSO).

CONAMU (National Women's Council) (2008), Constitución de la República del Ecuador. Derechos de las mujeres, Quito.

Durán, María Ángeles (2006), "El futuro del trabajo en Europa: el cuidado de las personas dependientes", Cohesión social, politicas conciliatorias y presupuesto público. Una mirada desde el género, Luis Mora and María José Romero Ruiz (eds.), United Nations Population Fund (UNFPA), German Agency for Technical Cooperation (GTZ).

(2000), "Si Aristóteles levantara la cabeza", Colección Feminismos, Madrid, Cátedra.

(ed.) (1999), The Future of Work in Europe, Brussels, Directorate-General for Employment, Social Affairs and Equal Opportunities, European Commission.

INEC (National Statistics and Census Institute) (2010), Encuesta sobre Salud, Bienestar y Envejecimiento (SABE), Quito.

León, Mauricio (2005), "Simulaciones para reducción de pobreza en Ecuador, metodología y resultados", Ecuador: hacia el cumplimiento de los ODM, Objetivo 1, documento interno, Quito, Secretaría Técnica del Frente Social.

Muñoz, Fabián (2009), "Evaluación del estado nutricional de los niños y niñas en los centros infantiles del INFA", Quito, Programa Aliméntate Ecuador.

Schkolnik, Susana (2007), Protección social de la tercera edad en Ecuador, Quito, Economic Commission for Latin America and the Caribbean (ECLAC)/ Ministerio de Coordinación de Desarrollo Social/Ministerio de Bienestar Social.

Shaady, Norberto (2010), "Early childhood development in Latin America and the Caribbean: access, outcomes, and longitudinal evidence from Ecuador", Quito, Ministerio Coordinador de Desarrollo Social/Inter-American Development Bank (IDB).

SIUDEL (Sistema de Información de Derecho Laboral) (2008), [online] http: / wwww. ceime.net/siudel/index.php.

Vásconez, Alison (2008), "Valoración del trabajo doméstico no remunerado en Ecuador: una aproximación inicial", Working document, Quito, National Women's Council (CONAMU).

Vásconez, Alison and Alba Pérez (2008), "La demanda actual de cuidados en América Latina: el caso de Ecuador", paper presented at the International Course "Redistribución del tiempo, un indicador de igualdad", Santiago, Chile, Economic Commission for Latin America and the Caribbean (ECLAC), June. 


\title{
Chapter V
}

\section{Home care and the recovery of subjectivity: the case of Mexico ${ }^{1}$}

Atenea Flores-Castillo

\begin{abstract}
Care - as a social phenomenon - must be observed from the perspective of various disciplines, since the sexual division of labour cannot be explained solely on the basis of economic or sociological theory. The interlinkings of politics, culture, economics and society are especially important in making a diagnosis and considering public policy responses.
\end{abstract}

(Montaño and Calderón, 2010)

Most research on how population ageing affects labour needs and availability in the care sector, and on the implications for the independence and autonomy of women (as unpaid or poorly paid labour), has been conducted from the viewpoints of demography and economics. But human complexity being as it is, the research should also extend to other disciplines that can take affective and emotional aspects into account. Thus, the recommendation that care services be provided

This chapter is a summary, with some alterations and amplifications, of the work "Cuidado y subjetividad: Una mirada a la atención domiciliaria [online] http://www. cepal.org/publicaciones/xml/3/46313/2012-15_S112MD_Cuidado_y_subjetividad._ Una_mirada_a_la_atencion_domiciliaria.pdf. 
in a way that is functional for the development of the economic system - and which, as a consequence, affords priority to those who engage or will engage in economic reproduction- must be complemented by an integrated approach that considers the recipients of care, regardless of the place they occupy in the economic system, their age or any other individual characteristic. That is, as well as looking at what is happening in society and in the family, research must explore what happens to the individuals receiving and giving care.

This research study looks at what happens to older persons, those with disabilities or the terminally ill, and to their caregivers, during processes of illness and care, considering in particular the loss of subjectivity (that is, the loss of their capacity as subjects) and its recovery through home care. First, we consider the status of population ageing in Latin America and the Caribbean and its impacts in terms of rising physical and mental disability. Then we look at lessons learned from the home care for the vulnerable population programme in Mexico City. The third section examines care from the perspective of philosophy and psychoanalysis, focusing on caregivers and receivers. The idea is to propose the elements of a theoretical platform for dovetailing these disciplines with economics, and for analysing the phenomena that caregivers and receivers can experience, since they have emotional impacts that should be addressed. The final section presents the conclusions.

\section{A. Population ageing and disability in Latin America and the Caribbean}

Several European and a few Latin American countries are already experiencing population ageing. The developing countries in general will experience it in the medium term. In Latin America and the Caribbean, older persons will double as a percentage of the total population between 2010 and 2050: from 10\% today to an estimated 21.7\% (ECLAC/CELADE, 2009).

Population ageing has occurred in three ways: first, the population aged 60 and over has increased relative to the total population; second, the older age group has aged, i.e. the elderly population (aged 75 and over) has increased within the group aged 60 and over; and, third, old age has become feminized, in other words, the proportion of women has increased in both groups. Population ageing is explained both by falling birth rates (the number of live births per thousand inhabitants) and falling fertility rates (the number of births with respect to the female population of child-bearing age), and by declining mortality rates associated with two types of factors: 
(i) Women's higher life expectancy at birth, which has been expressed in the feminization of old age, as a result not only of biological factors, but also of behavioural ones, since women seek preventive medical care more often than men, and

(ii) A shift in the types of sickness and death, known as the epidemiological transition. This is associated, in particular, with a fall in child mortality as infectious childhood diseases are better controlled and a relative increase in deaths from chronic and degenerative illnesses.

These phenomena lead to an increase in the number of persons with disabilities, not only those who are ageing, but also those who are caring for them, since people in general live longer and experience a higher incidence of chronic and degenerative illnesses. This pushes up demand for health care in general, and for long-term and palliative care, in particular, whether hospital- or home-based.

According to estimates in the World Health Survey cited in the World Report on Disability (see table V.1), disability prevalence at a threshold score of 50 (those experiencing very significant difficulties in their everyday lives) in the population overall is $1.0 \%$ for men in high-income countries and $1.7 \%$ for men in low-income countries, rising to $1.8 \%$ and $3.3 \%$ for women in those countries, respectively, and rising again to $4.4 \%$ and $9.1 \%$ for persons aged 60 and over in the respective groups of countries (the information is not disaggregated by sex for this age range). This report also draws attention to differences with respect to The Global Burden of Disease, 2004 (see table V.2), which gives substantially higher figures (WHO, 2011).

Table V.1

DISABILITY PREVALENCE AT A THRESHOLD SCORE OF 50 (THOSE EXPERIENCING VERY SIGNIFICANT DIFFICULTIES IN THEIR EVERYDAY LIVES) IN 59 COUNTRIES

(Percentages)

\begin{tabular}{lcc}
\hline & High-income countries $^{\mathbf{a}}$ & Low-income countries $^{\mathbf{b}}$ \\
\hline Men & 1.0 & 1.7 \\
Women & 1.8 & 3.3 \\
Population aged 60 and over & 4.4 & 9.1 \\
Total & 2.0 & 2.3 \\
\hline
\end{tabular}

Source: World Health Organization (WHO) and World Bank, World Health Survey, 2011, p. 28.

a Countries with per capita GDP of over US\$ 3,255 at 2004 prices.

b Countries with per capita GDP of under US\$ 3,255 at 2004 prices . 
Table V.2

ESTIMATED PREVALENCE OF SEVERE DISABILITY

(Percentages)

\begin{tabular}{lccc}
\hline Severe disability & World & High-income countriesa & Americas \\
\hline Men aged 60 and over & 9.8 & 7.9 & 9.2 \\
Women aged 60 and over & 10.5 & 9.0 & 9.2 \\
All ages & 2.9 & 3.2 & 2.6 \\
\hline
\end{tabular}

Source: World Health Organization (WHO), The Global Burden of Disease: 2004 update, 2008 [online] http:// www.who.int/healthinfo/global_burden_disease/GBD_report_2004update_full.pdf.

a Countries with per capita GDP of over US\$10,066 at 2004 prices.

The differences between the information provided by these two sources may be attributed in part to their radically different definitions of "high-income countries": countries with a per capita GDP of over US\$ 3,255 at 2004 prices for the World Health Survey, but of over US\$10,066 at 2004 prices for The Global Burden of Disease.

As for the main causes of disability, the World Health Organization (WHO) estimated that in 2004 neuropsychiatric disorders caused 30\% of years lived with disability (YLDs) among those aged over 15 years. The burden of these disorders is similar for women and men, but the prevalence of depression is over $50 \%$ higher among women than men (see table V.3).

Table V.3

MAIN CAUSES OF YEARS LIVED WITH DISABILITY (YLD) BY SEX, 2004 (Percentages)

\begin{tabular}{|c|c|c|c|}
\hline \multicolumn{2}{|l|}{ MEN } & \multicolumn{2}{|l|}{ WOMEN } \\
\hline Cause & $\begin{array}{l}\text { Percentage of } \\
\text { total YLDs }\end{array}$ & Cause & $\begin{array}{l}\text { Percentage of } \\
\text { total YLDs }\end{array}$ \\
\hline Depressive disorders & 8.3 & Depressive disorder & 13.4 \\
\hline Alcohol use disorders & 6.8 & Refractive errors a & 4.6 \\
\hline Hearing loss & 4.8 & Hearing loss & 4.3 \\
\hline Refractive errors ${ }^{a}$ & 4.7 & Cataracts & 3.2 \\
\hline Schizophrenia & 2.8 & Osteoarthritis & 3.1 \\
\hline Cataracts & 2.7 & Schizophrenia & 2.6 \\
\hline Bipolar disorder & 2.5 & Anaemia & 2.4 \\
\hline Chronic obstructive pulmonary disease & 2.4 & Bipolar disorder & 2.3 \\
\hline Asthma & 2.2 & Birth disorder & 2.3 \\
\hline Falls & 2.2 & Alzheimer's and other dementias & 1.9 \\
\hline
\end{tabular}

Source: World Health Organization (WHO), The Global Burden of Disease: 2004 update, 2008 [online] http:// www.who.int/healthinfo/global_burden_disease/GBD_report_2004update_full.pdf, p. 37.

a Difficulty of the eye in focusing light, which reduces visual acuity. 
With regard to disability-adjusted life years (DALYs) -years of potential healthy life lost owing to premature death, poor health or disability-depression causes $4.3 \%$ of the total and is the third leading cause worldwide, surpassed only by acute respiratory infections and acute diarrhoeal disease. However, in middle-income and upper-middleincome countries, depression is the leading cause, representing $5.1 \%$ and $8.2 \%$ of the total, respectively. This proportion holds steady in projections to 2030, when it is estimated that depression will be the main cause of DALYs worldwide.

Moreover, according to $\mathrm{WHO}$, one in four people experience a mental disorder at some time in their lives. Depression - a potentially fatal disease and therefore requiring early diagnosis - is among the more frequent. Its worst-case outcome is suicide (WHO states that 850,000 depression-related suicides are committed each year). The average age for depression ranges from 25 to 30 and, as noted earlier, it is more frequent among women than men.

Although no consensus exists about the situation with older persons, certain studies suggest that depression is twice as prevalent in this age group as in the general population. In Chile, a national study on dependence among older persons found that $18 \%$ of this population group suffers from depression, the third most frequent condition among chronic illnesses, after arterial hypertension and type II diabetes. Percentages for men and women are not reported, but are stated to be higher among women.

Disability as a result of neuropsychiatric disorders -and depression in particular- is a public health problem whose impact in terms of reducing well-being and productivity justifies its consideration in public policies.

Both the health sector and the social sector have provided care for these population segments. Mexico and Costa Rica, for example, have run medical schemes, while Argentina and Chile have opted for social programmes. In both types, it has been found necessary to include psychological care, especially for those who perform care work. The following section describes the experience with the Home Care for the Vulnerable Population Programme in Mexico City. A hallmark of this programme was that it was created from the outset to provide psychological care for the vulnerable and for their primary caregivers (family members or neighbours) and professionals. 


\section{B. Psychological care in the home care for the vulnerable population programme in Mexico City}

The Home Care for the Vulnerable Population Programme (PADPV) in Mexico City was launched in March 2008 to provide continuity for the home medical visits for older persons scheme implemented by Mexico City's public health services in 2005. This programme found that $13 \%$ of the older population was unable to travel to health centres and therefore needed home-based care (Secretariat of Health of the Federal District, 2008). The PADPV scheme was innovative in that it included, from the outset, psychological care both for the vulnerable and for their caregivers. This section offers a summary of the programme's main features and the lessons learned from providing psychological care in one health district in 2008.

Home care programmes were first implemented in Europe and have been found to be effective in reducing costs in comparison with hospital-based services. Such schemes have also been implemented in Latin America and the Caribbean, among other regions, as both social and medical programmes. The social programmes are staffed by nonprofessionals who receive special training, as in Argentina and Brazil. The medical programmes are staffed by health professionals, as in Costa Rica and Mexico. Chile does not have a government programme as such, but the National Service for Older Adults funds a social scheme run by the Movement for the Emancipation of Chilean Women (MEMCH), a non-governmental organization which provides home care for around 800 older persons per month.

Care, then, is being provided in varying proportions by four agents: the State, the market, non-governmental organizations and families, more specifically, usually, women. As well as the economic repercussions and the implications in terms of caregivers' independence and autonomy, there are psychological effects. Although an awareness is beginning to emerge that caregivers are the least cared for, few studies look at the process they experience, although undoubtedly psychological care is now being viewed as something that both unpaid and professional caregivers need.

Programmes like those in Argentina and Mexico testify to governments' concern with tackling the psychological aspect of paid and unpaid caregiving. Argentina began to implement a national programme for home-based caregivers in 1996, which provided training for caregivers in two stages: the first provided training for caregivers and the second developed the actual care work. No provision was made at either stage for psychological advisers. But a psychological component 
had to be included (in 2007 for the first stage and in 2008 for the second) owing to the constant demands from caregivers. They repeatedly expressed in different ways the need for some training in psychology to care for both patients and their families, and also to help caregivers themselves deal with the consequences of their care work (Arias, 2009). Mexico City's home care for the vulnerable population programme (PADPV) made provision from the outset for a psychologist to support patients and their primary caregivers, ${ }^{2}$ as well as the members of home care teams (Secretariat of Health of the Federal District, 2008, p. 35).

\section{Characteristics of the home care for the vulnerable population programme in Mexico City}

The programme targets the vulnerable population, defined as individuals or groups of individuals who have a limited ability to perform basic physical, mental, social and occupational activities as a result of somatic, psychological or social impairments, as well as their primary caregivers, regardless of whether they are family members or not (Secretariat of Health of the Federal District, 2008). The general objective of the programme is to provide preventive medical care in the home of the vulnerable individual or individuals. It has two specific objectives: (i) to build a home care system of comprehensive services for the uninsured population, in order to guarantee universal coverage in the Federal District and address processes of sickness and health in terms of promotion, prevention, risk elimination and damage repair, at the levels of the individual, the family and the community, and (ii) to contribute to the full development of the capacities and potential of the population identified as vulnerable and ensure that this population receives decent treatment and access to free, comprehensive and timely health services.

The scheme aims to provide comprehensive, quality, free preventive medical care for people who do not have social security coverage in other institutions. ${ }^{3}$ The care is provided by multidisciplinary

2 In general the term "primary caregiver" is used to refer to family members, neighbours or friends who perform this role; "professionals" refers to those who are paid and have professional qualifications to provide care, and "formal caregivers" refers to those who receive payment for providing care although they do not have professional qualifications. In this work, "primary caregivers" refers to family members, neighbours or friends, and "secondary caregivers" to formal or professional caregivers.

3 In Mexico health services are provided by public (government) and private institutions. Among the public services are those which cater to civil servants (Social Service Institute for State Workers - ISSSTE) and workers in the army, the navy and Petróleos Mexicanos (PEMEX). Among the private services is the Mexican Social Security Institute (IMSS), which caters to workers in private enterprise (formal employment). Finally, the 
teams comprising a doctor, a nurse, a social worker and a psychologist. The purpose of the scheme is to achieve universal coverage in the Federal District of Mexico City; reduce hospital stays (thereby reducing costs for both hospitals and families); give patients and their families more autonomy in order to contribute to the full development of their capacities and potential; and provide medicines and materials for dressings and for clinical and laboratory tests. Patients over 70 with some type of disability are eligible for care whether or not they are registered with a social security institution (Flores-Castillo, 2010).

In 2008 the programme had 70 physicians, 20 nurses, 6 social workers and 3 psychologists. 22,820 home visits were conducted, of which care was provided in 18,800 (in approximately $10 \%$ of cases care could not be delivered for a variety of reasons: among others, the patient was not there, no caregiver was present, or the address registered did not exist). Of that total, 15,972 cases consisted of care for persons aged over $60,10,692$ for persons with disabilities and 773 for terminal patients (Secretariat of Health of the Federal District, undated). Notably, the scheme was awarded the federal government's national innovation and quality prize in 2008.

\section{Home-based psychological care in one Mexico City health district}

The Miguel Hidalgo health district in Mexico City covers a geographical area similar to a municipality. In 2005 it had a population of 353,534 , of whom $53.8 \%$ were women. Around $6 \%$ of the women, and $4 \%$ of the men, were aged 70 or over. In 2008 the programme had five doctors, one nurse and a psychologist to cover the five health centres in the Miguel Hidalgo district, so nursing staff from other centres were needed to make up the teams and offer the home care service, since the PADPV rules required at least two staff to be present whenever care was provided.

Under the definitions of the PADPV programme, psychological care has four objectives: to afford importance to the emotional, social and spiritual needs of patients and their families; to promote acceptance of the illness and the constant changes it involves; to provide skills to help the target individuals deal better with these conditions; and to provide emotional support during illness and at the time of death. The role of the psychologist is to help patients and their families to face the disease and

Secretariat of Health offers services to workers in the informal sector at low cost, or even free of cost, as in the case of the programme examined here. In addition, each Mexican state has its own health systems. 
the interpersonal and social problems it may cause, provide support for disability and emotional assistance during illness, and support families as the patient nears the end of life. The psychologist provides emotional and educational support, individually or collectively, including to the home care team. Finally, it is also part of the psychologist's responsibility to coordinate the psycho-emotional support needed by patients and caregivers, and by home care staff (doctors and nurses), and to provide doctors and nurses with the tools necessary to deliver quality care (Secretariat of Health of the Federal District, 2008). In short, under the programme the psychologist is responsible for providing psychological care to patients and their primary caregivers (family members or neighbours) and secondary caregivers (formal or professional), as well as for training professional caregivers to deliver quality treatment.

\section{(a) Method}

In 2008, 398 psychological consultations were given to 87 patients. ${ }^{4}$ The target population was determined by the criteria established in the programme, and the decision on whether to include an individual in the programme was taken by the doctor on the basis of these criteria. Then the decision on whether psychological support was required for a particular patient and her or her caregivers was taken, also by the doctor, who would request a psychological evaluation.

The psychological evaluation began with one or more psychological interviews and, if considered relevant, the diagnostic tools of integrated geriatric assessment. Mental function was assessed first using the Folstein mini mental state exam, which is used to diagnose cognitive decline and screen for dementia. Where the Folstein test yielded scores below the Health Secretariat's threshold of 24, the Informant Questionnaire on Cognitive Decline in the Elderly (IQCODE) was used to establish the caregiver's assessment of the patient over time (comparing 10 years ago with the present time). Then a differential diagnosis for depression was conducted using an abbreviated five-response version of the Yesavage geriatric depression scale. If this was positive, the 15-response version was used, as well as the diagnostic criteria of the Classification of Mental and Behavioural Disorders developed by WHO, and those of the Diagnostic and Statistical Manual of Mental Disorders (DSM IV) of the American Psychiatric Association.

Lastly, the Zarit interview was used to measure caregiver burden as part of the caregiver assessment.

The information - which is held in each patient's clinical files- was obtained from interviews, clinical histories of mental health and instruments for determining mental state. 


\section{(b) Findings on the sociodemographic and epidemiological profile of the population treated}

The high percentage of women $(76 \%)$ and of individuals with a physical dysfunction was the most distinctive characteristic of the population targeted by the programme (see box V.1).

With regard to mental functionality, the mini mental state exam found that $62 \%$ showed cognitive decline and $16 \%$ did not. The test was not considered necessary for the other $22 \%$. Following the differential diagnosis, mental conditions were found to be distributed as follows: in $15 \%$ of cases no pathology was observed, $37 \%$ showed cognitive decline, $14 \%$ depression, $10 \%$ grief, $8 \%$ dementia and $16 \%$ other conditions. ${ }^{5}$ In terms of distribution by sex, women accounted for $78 \%$ of cases of cognitive decline, $83 \%$ of depression, $56 \%$ of grief and $71 \%$ of dementia. A heavy gender bias was observed in mental conditions, suggesting that treatment should incorporate a gender perspective.

Box V.1

SOCIODEMOGRAPHIC PROFILE AND PHYSICAL DYSFUNCTIONALITY

It is important to note that $76 \%$ of the patients treated in 2008 under the home care for the vulnerable population programme (PADPV) in Mexico City were women. There may be several reasons for this: the gender composition of the population aged over 70 (in the Federal District the nationwide trend is sharpened, with $61 \%$ women and $39 \%$ men); the percentage of consultations given in 2008 by the home care teams in Miguel Hidalgo health district $(63.17 \%)$; the fact that women tend to seek medical care more often than men and, finally, the higher prevalence among women of the main mental disorders found: cognitive decline, depression, grief and dementias (notably, the patients treated included caregivers incorporated into the programme ${ }^{\mathrm{a}}$ ).

The average age of men treated under PADPV in 2008 was 67.5 years, eight years younger than the average for women treated, and five years younger than life expectancy at birth which, according to the National Institute of Statistics and Geography (INEGI), was 77.5 years for women and 72.7 years for men that year (i.e. a difference of five years in favour of women). The eight year gap may be explained by the presence of several men with disabilities who were much younger (around 45), as a result of the higher risk of cardiovascular disease and the higher accident rate among men compared with women of the same age.

With regard to the different vulnerable groups, 53\% were persons with disabilities, $30 \%$ had chronic degenerative diseases, $7 \%$ were terminally ill patients and the remaining $10 \%$ were not in any of these categories.

(continued)

\footnotetext{
5 Schizophrenia, mental retardation, adjustment disorder (caregiver burnout syndrome),
} anxiety disorder, conversion disorder and differential diagnosis. 
Box V.1 (concluded)

With respect to physical functionality, under the scale of basic daily life activities it was found that $30 \%$ of patients showed severe dysfunction, and $26 \%$ moderate dysfunction; $28 \%$ were functional and $16 \%$ were not candidates for assessment under this scale. According to the Lawton Instrumental Activities of Daily Living Scale (IADL), 47\% were found to have severe instrumental dysfunction, $22 \%$ moderate instrumental dysfunction, and $7 \%$ slight instrumental dysfunction. Eight per cent were functional and the remaining $16 \%$ were not assessed on this scale.

The proportion of patients with a disability $-53 \%$ - shows, in the first place, that home care was in fact being provided to one of the vulnerable groups for which it was intended. The disabilities were distributed as follows: $2 \%$ corresponded to a hearing disability, $22 \%$ to a mental disability, $63 \%$ a motor disability and $13 \%$ a visual disability.

The work with terminal patients showed that most older persons wished to die in their own homes. The main concerns expressed were: Am I going to die? How? Will it hurt? Why am I in such pain? These sorts of questions showed how vulnerable and defenceless these people felt, and underscored the need for someone to explain what was happening to them. This function was partly covered by the doctor, but needed to be complemented by the psychologist for the emotional aspect.

Of the caregivers, $93 \%$ were women and $40 \%$ were later enrolled in the PADPV scheme for some kind of medical condition. Their average age was 64 , with a standard deviation of 20 , which reflects the small size of the sample and the extreme ages of some of the caregivers.

Source: Prepared by the author.

a After the work was carried out in 2008 , some of the caregivers were incorporated as patients and separate figures are not available for each group.

\section{(c) Lessons learned}

This section reflects briefly on findings with respect to patients, their caregivers, the relationship between them, the role of the psychologist and the conceptualization of care for these groups.

\section{(i) The patients}

Most of the treatments were multimodal in nature. In all cases consultations with patients or caregivers touched upon continuity of treatment, and particular treatment was given depending on the needs of each patient: (i) In cases of cognitive decline, treatment for patients and caregivers was psycho-educational, as well as play therapy with some patients; (ii) In cases of depression and dementia, doctors prescribed pharmacological treatment and psycho-educational treatment was given as well, in the first case to patients and their family members and/or caregivers, and in the second to caregivers only; and (iii) Lastly, patients going through grieving processes as a result of recent diagnosis of 
terminal illnesses received grief support (aiming to listen to their needs and convey them to family members, and help them to prepare for death) and in containing or intervening in the event of family crisis.

In several cases, patients experienced a sensation of abandonment or mistreatment, and in others they reported feeling unlike themselves: "I don't feel like me, I feel like someone else". It was also observed that men often denied their feelings.

\section{(ii) The caregivers}

The work with the caregivers consisted of support and encouragement of self-care. Caregivers were found to be highly vulnerable. Mostly women, caregivers are the least cared for; they perform work which is physically and emotionally demanding, and this accounts for the fact that the main pathologies identified in this group were what are known as adjustment disorders (burnout) and grief.

Male caregivers generally maintained an emotional distance from events around them and express their pain through impatience or denial: one family member stated, "I don't know what [my grandmother] is waiting for to die.... Don't do anything else to her. Leave her be. Let her die now".

It may be said in general that there was little opportunity for caregivers, whether women or men, to express their pain and feel that what was happening to them was important. They were invited to leave the house at least once a week (since many of them cared for their dependants seven days a week) and resources and strategies for dealing with their situation were considered. One of the steps taken was to invite them to attend a course for caregivers, which included a session with information on caregiver grief and burnout, and another course in which they could voice what they felt as caregivers and realize that feelings of anger, depression or exhaustion were shared by others in the same situation.

\section{(iii) The patient-caregiver relationship}

Sometimes a patient's illness can act as a pretext for airing old conflicts between siblings. This manifested in different perceptions of the disease and disagreement over what sort of care was needed. Little was said about the feelings generated by the illness, such as anger, guilt and the omnipotence arising from a sacrificial attitude, often on the part of a female caregiver. For some caregivers, the patient's illness was an opportunity to play a leading role, to feel useful and indispensable, but this later led to burnout. Such caregivers took ownership of the situation, reproaching other family members for not helping more, and then became martyrs, which gave them a control over the family. Any attempt 
by another family member to help was met by an ambiguous response: first they would accept the help but would then reject it saying; "No one but me can look after for him/her properly".

A struggle was also observed between the caregiver and the care recipient. The caregiver sometimes did not wish to continue, but did so for a variety of reasons, despite possibly receiving mistreatment.

\section{(iv) The role of the psychologist}

The main lesson drawn from this experience with respect to the role of the psychologist is that it is essential to listen to and support both patients and caregivers and not be judgmental, all of which is easier said than done.

With respect to judging, it quickly becomes clear that when a patient is being mistreated, there is a story behind the situation and listening and working with the caregivers to change the treatment is more effective than asking them to care for the patient better or even threatening them with prosecution. This achieves nothing but a closed door the next time the home care teams calls.

Listening and supporting are also necessary in order to bring about a process of subjectification, that is, to help the patient find him or herself again, identify his or her wishes and take the decisions necessary to realize them, if that is possible. This helps towards acceptance of the disability or the proximity of death, which in turn eases despair and, possibly, permits moments of acceptance. Listening encourages caregivers to allow themselves to process what is happening to them. Opportunities are sought for both patients and caregivers to recognize the losses they are experiencing and to externalize the feelings that are paralysing them. Recognizing those opportunities allows them to act and decide what they want to do about the situation instead of hiding from the pain.

The psychological work thus has to do with getting the patient and the caregiver to verbalize so that each can self-subjectify: the patient, among other things, in order to be able to make decisions; and the caregiver, to avoid burnout. This is how they can learn to deal with impotence and recognize the impossibility of returning the other to health.

The psychologists - although this applies to the other members of the team, as well- must receive training in various areas, to avoid coming across as "the ones who know about loss and death". Such an attitude can lead them to give advice more akin to a method of hiding the anxiety generated by constant proximity to loss, in general, and to death, in particular, when what patients and their families need is someone to 
support them in the process. Training is needed in two directions: one, for giving care to others (on listening, age-related mental disorders, sleep disorders, processing grief and depression, and crisis intervention, among others) and the other, for self-care on the job to avert professional burnout.

\section{(v) Conceptualizing care}

The type of care examined in this work is different from the care given to children and healthy adults. It is the care of another person who is experiencing loss (of roles, functions, health or life), which brings with it suffering, grief, depression and burnout (for both the recipient and the giver of care).

Because it consists of transactions between people, care involves power relations, with all that implies. It is a process originating in concern for the other, leading to the activity of caring for that person. But this process also requires concern for oneself and, above all, concern for oneself as a caregiver. That is, it means passing from worry, which gives torment with no way out, to an occupation which, in the case of persons with disabilities or severe illnesses, can at least give shape to thoughts and feelings through verbalization, words and the expression of wishes.

The persistence and irreducible nature of pain have made the concept of care a question to which human beings seek an answer. The following section proposes a theoretical framework for rationalizing inclusion of the psychological dimension in home care and in the care economy.

\section{Dimensions of care}

As a topic of reflection, care has been present in Western culture since at least the fifth century B.C. Plato discussed care in Apology (in which Socrates is condemned to death for his care of Athenian society) and in other dialogues. In Greco-Roman antiquity, care (epimeleia heautou for the Greeks and cura sui for the Romans) referred, first, to "concern" for oneself, and this is reflected in the Latin cogitatus, the past participle of cogitare, formed by co, fully, and agitare, to be agitated, concern oneself, occupy oneself mentally, consider. Second, it referred to the activity of "occupying oneself with oneself", particularly with the soul. In the Romance languages, therefore, the word for care is etymologically related to thinking, caring, care and curing. "Care" in English comes, with very similar meanings, from the Proto-Germanic karo, wail, lament, through the Old English caru or cearu, meaning sorrow, anxiety, grief, burdens of mind, or serious mental attention.

This sense of concern and occupation with the soul later came to include practices related to caring for the body (first one's own, 
then that of others), and from there to responsibility for the other, be it the responsibility of the doctor, the psychologist, the psychiatrist or psychoanalyst, or indeed a religious minister (such as a priest, pastor or rabbi). Thus the term "care" in the modern sense refers to occupying oneself with the well-being of someone (or something).

\section{Care from a psychoanalytical and philosophical perspective}

The human individual cannot be understood without the concept of care. Precisely because of our care needs, we must create an artificial environment - culture - to survive. This is why we say that the individual is not natural, but cultural. We live in society to prevail, first, over the forces of exterior nature and, second, over the forces of interior nature: "Human civilization [...] presents, as we know, two aspects to the observer. It includes on the one hand all the knowledge and capacity that men have acquired in order to control the forces of nature and extract its wealth for the satisfaction of human needs, and, on the other hand, all the regulations necessary in order to adjust the relations of men to one another ..." (Freud, 1927, p. 6). From this arises morality, which implies following rules and observing customs. Human beings need rules to control their impulses and govern their relations with others, and these rules give rise to laws. Care, from the perspective of psychoanalysis, serves a purpose of defence against internal and external threats, forging social bonds for facing these threats.

Heidegger sought a basis in myth and symbol to demonstrate the importance of care. He chose the fable of Cura, attributed to Hyginus, a first century B.C. Romano-Hispanic writer. The fable shows that man ("homo", from humus, earth) has his origins in care and is devoted to care from birth to death. Thus care is not contingent and dispensable, but necessary:

The following self-interpretation of "being-in-the-world" as "Cura" is laid down in an old fable:

"In crossing a river, Cura gathered clay and, engrossed in thought, began to mould it. When she was thinking about what she had already made, Jupiter arrived. Cura asked him to grant it spiritus, 'breath' or 'spirit'. He granted her request readily, but when she also asked to give her creation her own name, he forbade this, insisting that it had to carry his name. While the two were arguing, Earth (Tellus) arose and wanted it to have her name because she had made her body available for it. The judgement was finally rendered by Saturn. He determined that since the spiritus was granted by Jupiter, he should have it in death; Tellus, or Earth, would receive the body she had given; because Cura, or Care, had been the creator, she would keep her creation as 
long as it lived. To resolve the debate, homo, "human being," would be the name, because it was made from humus, earth."

This testimony [...] becomes especially significant not only in that Care is here seen as that to which human 'being-in-the-world' belongs 'as long as it lives' [...]: This entity has the 'origin' of its being in Care" (Heidegger, 1927).

Thus, care is constructed around the concept of helplessness, of vulnerability, which, from the beginning, suggests an experience of total powerlessness associated with the prematurity of birth. This vulnerability requires the presence of someone to provide care, be it in infancy, adulthood or old age. Care then becomes a responsibility for others: doctors take care of physical health and priests or ministers of spiritual health or salvation, with the associated social implications. Since the individual ceases to take care of him or herself and lets others provide care, care is then what forms the social bond.

The common notion of care is, then, one of an action that comes from outside and, ideally, is curative, palliative, liberating. It is an action carried out by an "other" in whom knowledge is deposited, be it in a domain physical (the body), mental (emotions or feelings and cognition) or spiritual (the soul). The recipient of care - whether provided by a physician, a psychologist or a minister of the faith- is expected to be passive: to let him or herself be cared for, to follow the prescriptions of those who know. It is forgotten that care, both in the sense of concern (solicitude or thought that concerns) and in the sense of taking care of someone's well-being, requires an active stance on the part of the care recipient. Insofar as care recipients take charge of themselves, concern themselves with their own needs, and occupy themselves with their own well-being, they can make the transition from dependence to autonomy. Care is, then, an activity for dealing with the internal and external forces of nature: care is taken to survive and given so that the other may survive, to keep oneself and others active, to have quality of life and death, to enjoy and to share, to avoid one's own solitude and that of others; to contain pain; to be with the other, to have a place and for the other to have one, in short, to make social bonds.

The groups whose care is studied here have in common the fact that they are going through major losses: of roles (in the case of retirement), of functions (in the case of some diseases or the loss of a limb), of health (in the case of serious illnesses) or life (in the case of the terminally ill). Since all losses generate grief (from the Latin gravare, to cause grief or pain) or mourning (from the Proto-Germanic murnan, to remember sorrowfully, through the Old English murnan, to mourn, long after), the caregivers for these people, as well as carrying out care work 
per se (and often continuing as well with regular work in and outside the home), are in contact with individuals who are going through a grieving process as a result of their loss. That is to say, this is an emotionally more demanding type of care than care for children and healthy adults. Children and the healthy have a promising future, whereas the future for these other groups is uncertain and emotionally upsetting for both the givers and the receivers of care. The following section examines the main characteristics of grief, to understand why caregivers in this particular area are more emotionally burdened and at risk of mental disorder.

\section{Care from the perspective of the recipient}

Of all possible losses, loss of life is the most tragic. Perhaps this is why the literature specializing in grief has focused mainly on the experiences of those left behind when a loved one dies. However, both the Classification of Mental and Behavioural Disorders of WHO and the Diagnostic and Statistical Manual of Mental Disorders (DSM IV) of the American Psychiatric Association afford it a minor place: the first mentions but does not describe, and the second devotes less than half a page to it, and notes that a "normal" grieving process should last around two months.

Freud defines mourning as a reaction to the loss of a loved one, or of any substituted abstraction such as one's homeland, freedom, or an ideal (Freud, 1915). This loss may be through death or for a different reason: "The object has not perhaps actually died, but has been lost as an object of love (e.g. in the case of a betrothed girl who has been jilted)." ${ }^{\prime \prime}$ Mourning has several characteristics: while it lasts, interest in the outside world, capacity to love and productivity all decline. This is a normal reaction: "although mourning involves grave departures from the normal attitude to life, it never occurs to us to regard it as a pathological condition and to refer it to medical treatment. We rely on its being overcome after a certain lapse of time, and we look upon any interference with it as useless or even harmful" (Freud, 1915). To recover the capacities thus affected, the grieving person must perform mourning work, which consists of withdrawing all attachments to the loved person, that is, recognizing at a mental level that the person is no longer there, and directing one's energy towards other activities and other

Here by "object" we understand a person. The reason for using this term has to do with Freud's theory of drives, which underlay his entire work, but is beyond the scope of this research. Further details may be consulted in Freud's 1915 paper Triebe und Triebschicksale (literally, "Drives and their destinies"). 
people, which is achieved by expressing what one is feeling, verbalizing, talking about it. ${ }^{7}$

When this work is postponed for too long, then the individual falls into a state of pathological grief which, if prolonged, can give rise to melancholia, a sort of acute depression in which the sufferer cannot regain a sense of meaning in life and is liable to commit suicide. In a state of melancholia, the subject identifies him or herself with the lost object and all the anger felt against the object for abandoning the subject is turned against him or herself. This is why it is so important to support grieving, because it can lead to depression and thence to suicide. Grief work is, then, the attempt to register the loss to make it accepted, and at the same time give the lost object a place in another dimension, so that the subject lets go of the lost object, releases it and can continue with his or her own life.

Since the grieving processes arising from the terminal stage of illness have been found to be similar to other types of losses, there follows a description of the grief process which is unleashed when someone receives a diagnosis of this sort.

In 1969 Doctor Elisabeth Kübler-Ross, a psychiatrist, published her first book based on her work with terminally ill patients. Her model, which consisted of five stages (denial, anger, bargaining, depression, acceptance), has become a classic in the literature on work with terminal patients (Kübler-Ross, 1969), and has also been extended to apply to other types of losses. Her ideas have been used over and again, to a greater or lesser extent, by those working with grief. There follows a description of the stages of grief she proposed, introducing some other ideas arising from the experience of fieldwork in home-based psychological care for older persons, the disabled or the terminally ill in 2008, 2009 and the first half of 2010.

The first stage of grief is denial and isolation, manifested in the patient's reaction to the news of a major loss, such as the loss of health from a terminal disease. A typical expression is: "No, this can't be true, it can't be happening to me". Freud called this a turning away from reality, whose function is to keep something away from the self. This is why people who have received the news of a terminal illness are often seen to constantly change doctor (thinking that the previous ones have misdiagnosed) or to try all types of alternative medicine. In the view of Kübler-Ross, the caregiver could not help the care recipient unless he or

Recognition at the cognitive level is not an issue in most deaths, because we have seen the body of the person who died and attended a burial or cremation. By contrast, pathological grieving is more likely in cases where no body is found. 
she had worked through the idea of their own death and examined their own reactions to being with this type of patient.

When denial can no longer be sustained, it is replaced by feelings of anger, rage, envy and resentment, especially towards the health team and family members, making it hard for the caregivers to provide support at this stage. The task of the caregiver at this point is to allow the grieving person to express the anger (and possibly encourage them to do so) and avoid engaging with the aggression received. The psychological preparation of the caregivers is important, because they need to know that they are likely to receive anger or demands which are not really directed at them, and they must therefore avoid taking this sort of aggression personally; the caregiver is merely a pretext for the grieving person to express him or herself and the question that therefore needs to be asked is where all the anger is coming from. Usually, a grieving person who is listened to will calm down. This is achieved not by stopping the despair with comments that could create false expectations, but by allowing the person to verbalize the despair, to give it shape by expressing it. The idea of the intervention is to generate a space in which the care recipient can "get it all out" and thus avoid acting out what is felt. For this, the caregiver has to be receptive, respectful and non-defensive, and must listen and to accept irrational anger. When the grief is for the loss of a loved one, the anger helps the mourning work to progress, because that force, that destructive energy, is what cuts the affective bonds with the deceased. Like in the case of loss of health, the anger is irrational and reflects an emotional rather than a cognitive break. The loss of the other is first painful, but underneath there is anger (Why did s/he leave me?) which is blocked by sadness or guilt, hence the importance of expressing it. So caregiving means coexisting with grief and that is why grief must be worked through, because of the risk mentioned earlier that the person will destroy themselves by turning the anger at the lost person against themselves.

In the bargaining stage, the person who has suffered a loss - of health (as with the terminal stages of a disease) or a limb (from amputation) - attempts to make a deal with a higher being to postpone the inevitable. In the first case, the person may be unsatisfied with life and wants more time to deal with unfinished business. In both cases, promises are made to a higher being in exchange for being allowed to live longer to be there for a particular event, or to keep the endangered limb. From the psychological point of view, these promises appear to be associated, on the one hand, with omnipotence (since the petitioner supposes that the other has the power to prolong life) and, on the other, with a sensation of failure, of not having done what had to be 
accomplished during life. The patient promises and promises himself to keep the bargain in exchange for a little more time.

In the depression stage, the patient begins to acknowledge the significance of failing health (or other loss) and the proximity of death, the financial burden of treatment and unemployment. These are moments of preparation for the final separation, in which there is often irrational guilt or shame. At this point, words of encouragement have no meaning and can even trigger anger. Here, again, caregivers need to know: listening is even more important at this time. The care recipient must be allowed to express what the loss means, in order to arrive at acceptance. This is a necessary depression: it has to happen to allow the individual to feel better, to be able to accept subjection to the finite and the impossibility of double meaning: that of being eternal and that of satisfying the demands of the other. It is a process similar to what Freud calls melancholia: profoundly painful dejection, cessation of interest in the outside world, and a lowering of self-regard as a result of unconscious processes that ultimately lead the subject to seek selfpunishment (Freud, 1915).

Acceptance, not to be confused with happiness, gives moments when it seems that the grief has gone, that the struggle is over and that what lies ahead is "the final rest before the long journey" (Kübler-Ross, 1969). At this stage the family needs more support, although the grieving person's greatest need is to live to the end with dignity. Acceptance is not always possible. It is achieved partially insofar as the grieving person has previously been allowed to express his or her anger, fears and hopes to a willing listener.

It is a common occurrence, in the course of the illness, for the individual to become viewed - by him or herself and the caregiversas a suffering body, in a sort of de-subjectification, that is, a loss of subjectivity, of the condition of being a subject understood as a person with capacities and the right to make decisions. Expressions like the "one with AIDS", "the one that's dying", "the diabetic", and suchlike place the focus on the disease and the individual disappears behind it. Godyer's account is illustrative:

"I had never been so conscious of people's bodies as when I began working in nursing homes. Patients, especially those with dementias like Alzheimer's Disease, were often handled without any awareness or consideration of their 'selfness', handled as if they were only bodies and nothing else [...] Many became limp, [...] refusing to move themselves or help in any way even if they could.. Refusing also to speak, these patients began to seem like heavy lumps of flesh, nothing else - all body ... (Fine, 2005, p. 251). 
It is interesting to observe how this process develops to the point where it becomes a challenge to revert the loss of subjectivity. As will be seen later, subjectivity loss affects primary and secondary caregivers, as well. Home care helps to facilitate the recovery, as far as possible, of subjectivity lost through fear, anxiety and pain in patients and caregivers, because it enables verbalization, the expression of the discourse built by individuals in these population groups to explain what is happening to them. The grieving process as experienced by caregivers is discussed in the following section.

\section{Care from the perspective of the caregiver}

Family members (and even professionals) who perform care work also go through the grief process described in the previous section (denial, anger, bargaining, depression and acceptance), because they are suffering, with varying degrees of proximity, the loss of that person. They are resignifying their own grief, as well as doing what has to be done to care for the person and, often, continuing to carry out domestic tasks and work outside the home.

So, to support the patient in any significant way requires working with the caregivers too, since they are obliged to make major adjustments in their lives and can feel alone and resentful, not only towards other family members who do not help out, but also towards the patient for being terminally ill or for having a disability.

The relationship between the caregiver and the care receiver is, then, more complex than might be thought. Caregiving, like any transaction between individuals, is permeated with conflict, because the effects of caregiving on the giver translate, among other things, into loss of available time for employment or leisure, which impacts on the relationship between the giver and the receiver of care. The literature on this subject constantly mentions characteristics related to subjective and psychological (emotional) dimensions. It talks of gratification and the satisfaction of carrying out a job, and social recognition and gratitude, of de-subjectification, of the burden of care, of stress and of burnout, anger and guilt, of exhaustion, depression, anxiety, solitude and resentment, among others.

The following paragraphs review some of the emotional states which can arise from the proposed definition of care as something that makes a social bond, which means that it involves power relations between acknowledgement of the person providing care and the person receiving it. The caregiver wants to be acknowledged, both by the person he or she is caring for and by peers (other family members, for example). The first type 
of acknowledgement is usually given, but caregivers can find themselves feeling unsatisfied because this recognition comes from someone who is not their "equal", an ill patient. This can unleash resentment against the patient and, possibly, mistreatment by the caregiver, who sees the patient as preventing him or her from engaging in other sorts of activities. The picture of care and the actors involved shows that mistreatment can come from either side: hate and rage on the part of caregivers on the one hand, and satisfaction on the part of the care recipient at having a hold over the caregiver, on the other. The roles of subject and object thus alternate between the giver and the receiver of care.

The caregiver may also develop resentment towards other family members who do not give sufficient support. But the care recipient also wants recognition, and in general has it from the caregiver, which can on occasion even prevent improvement. Stories abound of people who fail to get better because they fear losing attention or that their caregiver would lose his or her raison d'être. Thus, the other's need embodies the risk of losing oneself in him or her. The problem is that this results in wretchedness from the frustration of de-subjectification, of no longer being oneself. This can be seen in people who have been caregivers for long periods, because they feel that no one cares about them and all that matters to everyone else is the person they are looking after. At times they may feel rebellious and wish to get rid of the other, to have the patient gone, dead, so that they can be free of the anxiety, mental pain and overwork, but then this gives way to feelings of guilt.

In secondary caregivers, guilt may arise from not going to the home or from not wanting to. In primary caregivers, especially family members, hostile feelings about the situation or about the person being cared for turn into guilt, which may take the form of self-reproach and obsessive ideas, and the sensation of being tied to the care recipient, or being a victim of circumstance. This makes them into slaves, bound to stoically provide care and bear what "fate" has given them, feeling that they are giving up their lives for someone else.

When the caregiver experiences the act of caregiving as a sacrifice, a double debt is generated: first, the debt owed by the care recipient and, second, that owed by others who should be providing care and are not doing so. This is important in understanding that unpaid caregivers may expect some kind of payment or, at least, recognition. Otherwise, an unpayable debt builds up which may be expressed as resentment towards peers, usually family members who do not help out, and towards the care recipient, and thus the conflict is fuelled. Sometimes a relationship of subjugation can develop, insofar as caregivers may believe themselves irreplaceable, that the care recipient cannot live 
without them. But the truth may be the reverse: the caregiver's identity as an individual has fused with his or her identity as a caregiver, so that without the caregiving there is a feeling of nothingness. This is known as de-subjectification, and is a similar process to that experienced by those receiving care. So, here, too, there is a loss of subjectivity, of the caregiver's identity as a subject.

A slave-master dialectic thus arises, from which there is no way out as long as the differentiation between care recipient and caregiver remains. The caregiver remains trapped in this subject-object relationship and can end up hating the person he or she looks after. Care, then, involves a substantial element of dominance, from which it is impossible to break free unless caregivers acquire an awareness and another space in which to exercise their independence and autonomy. The caregiver, feeling at centre stage, exerts control over the others (the non-caregivers) and over the care recipient.

Caregiving can become a defence against ill wishes, losses, or the world. It can become a means of isolation, of avoiding being with the other (either with the care recipient or with other family members and acquaintances), but it can also be a way of giving life meaning. Some caregivers find an identity in care work. That is why former caregivers, finding themselves freed from that work, often soon find a way to continue to provide care and thus fill the gap. In clinical practice it is common to hear that caregivers feel and think that their work gives them worth only when they are engaged in caregiving, that they "are" only through that activity. This is another manifestation of the desubjectification that takes place in the caregiving process.

Caregivers can also come to imagine that they share the pain of the care recipient, that only they understand, that only they know how to care for them properly and do things the right way. This is yet another means of self-victimization, because it increases the solitude and represents an attempt to appropriate the other (not only the care recipient, but also the family) and create a situation of indebtedness. Care providers can establish symbiotic relationships and avoid being separated from the person they care for, so that ultimately it is the care recipient who governs the life of the caregiver. Caregivers who enter this dynamic are inclined to forget that it was, consciously or otherwise, their own decision (because they did not want or could not find a way to say no). They remind themselves constantly that they have to keep doing it because no one else can do it as well as they do, and this places them in an all-powerful situation and affords secret satisfaction.

The satisfaction most commonly reported comes from the social recognition of the help provided to others. Among the factors 
undermining that is stress, however. Neri notes that the experience of being responsible for elderly people is overwhelming: "Tired, depressed, anxious, lonely and feeling trapped in a role and in tasks that compete with what he or she used to be free to do, yet the caregiver must provide help for the activities of daily life, help the elderly person with cognitive tasks involving memory, orientation and attention, deal with crises like falls, provide emotional support, take the elderly person to health services, interact with professionals and... deal with family conflicts" $^{\prime \prime}$ (Neri, 2010). Caregivers can even experience professional exhaustion, or burnout, which is defined as a set of physical, emotional and/or mental symptoms caused by continuous work with people who have psychological, social or physical problems. Burnout has been studied in different populations for more than 40 years, but it has yet to be recognized in the Diagnostic and Statistical Manual of Mental Disorders (DSM IV) of the American Psychiatric Association. The WHO Classification of Mental and Behavioural Disorders includes it under "Problems related to life-management difficulty" (Z73.0), but does not describe it.

Another disorder frequently found in the population studied is depression. As noted earlier, depression is more common in women than in men and its prevalence is twice as high in older persons. Unlike the situation with younger adults, in whom depression manifests mainly on an emotional plane, depression in the elderly takes the form of cognitive alterations or somatic symptoms such as loss of interest in normal activities, fatigue, sleep disorders, cognitive and memory problems, thoughts of death and despair. Depressive symptoms are also more prevalent among those who have chronic illnesses or have suffered major losses, the socially and economically vulnerable, those lacking social support, women and those with functional disabilities and health problems perceived to be stressful (Neri, 2010, p. 307).

Caregiving in these groups brings with it a heavy emotional burden. The basic processes involved range from satisfaction to obligation, passing through resentment and unwillingness to continue providing care, and leading to a loss of subjectivity. These processes are not the outcome exclusively of loss; rather, the loss triggers the emergence, within the care relationship, of a series of latent conflicts which may have been brewing all life long but had gone unnoticed before. Hence, caregivers must have a space in which they can say everything they need to. Just as with patients, this space can be provided by home care, especially if the teams have a psychologist. This can help these groups to work through their losses of functions, roles, health and

$8 \quad$ Free translation from the original. 
life as something inevitable, or to assimilate them as situations which bring together sufferers, caregivers (primary and secondary) and the community, supporting those who deal with them. The following section briefly examines caregiving from the point of view of the care economy.

\section{Caregiving from the economic perspective}

The care economy has been associated with the provision of goods, services, time and monetary transfers by three agents - the State, the private sector and the family - to resolve the care needs the workforce must meet in order to develop and sustain itself (ECLAC, 2010). Accordingly, it looks at the provision of services, whether paid (health, education, maintenance of the home and kindergartens) or unpaid (domestic work).

Theoretical analyses of care from the economic point of view date back to the 1970s (Esquivel, 2011). Domestic work was first analysed as a requirement for capitalism to function, i.e. for the production and reproduction of the labour force. Later, the category of unpaid work, then care for spouses and children, began to be treated as a labour factor in the economic system. Underlying this definition is a productivist bias, because the care work it includes is that directed towards members of society who are or will be economically productive.

More recently, a number of authors have proposed more inclusive definitions. Caregiving is also said to be for the development and maintenance of the social fabric (Salvador, 2007), for people (Rodríguez, 2005) or for human beings (Lamaute-Brisson, 2011), which provides a basis on which to include non-participants in economic reproduction among the recipients of care. Nancy Folbre, a United States feminist economist, notes: "Parents aren't simply raising adorable kids. They are also producing little units of human capital units that are likely to grow up [and] get jobs"... (Folbre, 2011, pp. 324-325). But, Folbre goes on to argue, the "human capital" metaphor has its limits and the development of human capacities should be approached as an end in itself. Spending on dependants should be viewed as a form of commitment rather than an investment.

This represents the shift from "enabling the population to join the paid labour market or to become self-employed workers and regulating the labour force for economic activity" (ECLAC, 2010) -i.e. from the care of homo economicus ${ }^{9}$ - to the care of all individuals, including

Homo economicus is man who maximizes his benefits. The 2002 Nobel Prize for economics was awarded to Kahneman for demonstrating that the economic man does not exist, that man does not maximize his benefit function but is altruistic. 
those who were once productive (such as retirees) and those who never were, because they were outside the formal economic circuit (such as informal employees, homemakers, the underemployed and persons with disabilities or serious illnesses). Care is thus viewed as a right which may be demanded from two positions: to provide care and to be cared for (Pautassi, 2008).

The foregoing definitions coincide with that proposed by Fisher and Tronto - who construe care as "a species of activity that includes everything we do to maintain, perpetuate and repair our 'world' so that we can live in it as well as possible" (Fisher and Tronto, 1990) - insofar as they are more inclusive than definitions that emphasize activities performed to reproduce the labour force. Tronto, a political scientist, insists upon the need to shift away from this productivist bias and place care at the very centre of human life to deal with the physical, emotional and relational needs of human beings in response to the global care crisis. At the same time, she proposes defining an "anti-paradigm", placing one's own and other people's well-being at the heart of human existence (Tronto, 2009). This proposal explicitly combines two elements: first, care of one's own well-being and, second, placing self-care before care of others (without neglecting, in either case, the emotional dimension and relational aspects). This proposal coincides with the conceptualization of care given above, based on such disciplines as psychoanalysis and philosophy.

The disciplines discussed in this work (psychoanalysis, philosophy, economics and political science) concur in viewing care as essential for life and as a builder of social bonds, meaning that it encompasses more than "productive" populations. In addition, three of them proclaim the importance of putting self-care first and care for others after.

\section{Conclusions}

Population ageing is being accompanied by the "ageing of ageing", the feminization of old age and the epidemiological translation, generating an increase in disability, both physical and neuropsychiatric. Accordingly, care needs, which are met mainly by women, are increasing too. In 2004 neuropsychiatric disorders accounted for 30\% of years lived with disability (YLDs) and depression was the most common such disorder in middle- and high-income countries. By 2030, depression is expected to be the main cause of YLDs worldwide, making it a public health matter which is, moreover, more common among women than among men and twice as prevalent in older persons and the chronically ill than among the general population. 
In response to ageing and disability, the governments of the region have begun to implement social and medical home care programmes which have helped to reduce costs (for the public sector and families alike) and have had an impact on the well-being of their beneficiaries. The involvement of psychologists in these schemes testifies to governments' interest in tackling a hitherto little considered area of health. Mexico City's Secretariat of Health created the home care for the vulnerable population programme for older persons, those with disabilities and the terminally ill. From the outset, the programme included psychological care for the target population, as well as for primary caregivers and home care teams. Consistently with the findings of other studies in Latin America and the Caribbean, a gender bias was found in the main disorders (both in cognitive decline and in depression and dementias, which were more frequent among women) and that the great majority of caregivers were women. It was also observed that the nature of caregiving in these groups is different from the care of children and healthy adults. It is the care of people who are experiencing major loss (of roles, functions, health or life), which makes it an emotionally more demanding type of care. Primary and secondary caregivers therefore need training in psychology-related areas to be able to deal with the demands they face.

The concept of care was examined briefly from the perspectives of psychoanalysis and philosophy, and from the points of view of the givers and receivers of care. Finally, the proposals made from the perspective of the care economy were mentioned. It was shown that care exists to deal with the internal and external forces of nature and therefore accompanies human beings from birth until death. It is, then, an activity that forms social bonds and is therefore riven with conflicts. These conflicts are worse when the care relationship involves recipients of the sort considered here since, as noted earlier, they are going through losses that generate processes of grieving and desubjectification. Some of the emotional states experienced by caregivers are also discussed. These include gratification, satisfaction, recognition and social acknowledgement, as well as exhaustion, a feeling of being overwhelmed, anxiety, resentment and guilt. These testify to the desubjectification which caregivers risk, and which can be expressed as burnout or depression.

A productivist bias was found to exist in the way caregiving is construed. This needs to change to encompass not only those who are or will be productive, but all members of society, including the groups studied here. This requires State policies. Including the psychological dimension in home care for all groups experiencing loss, and for their 
caregivers, can help to tackle the well-being (and probably economic) costs of these emotional processes.

Home-based psychological care enables care recipients and their caregivers to recover the subjectivity they have lost as a result of illness and caregiving. It enables them to recover, in other words, their capacity as decision-making subjects. This sort of care thus represents an opportunity to deal with mounting needs by training certain groups to provide care in the home, and thus alleviate families of sole responsibility. It presents the possibility of a care economy involving new actors and new relations between them, developing a second level of caregiving that has a place for self-care education, caregiver training and psychological treatment for those involved and thus forming teams of "caregivers' caregivers". As well as reducing the economic costs for the public sector and for families, this affords dignity to old age, disability and illness, which will, in turn, generate well-being and social cohesion.

Achieving this will take new schools and new curricula in technical and university studies for nursing, medicine, psychology and social work, among others. Curricula should include such subjects as psychogerontology, medico-legal support and palliative care. This will open up a new market segment which could have multiplier effects on the economy. Further research is needed to provide statistical information and new knowledge on care needs and to analyse viable sources of financing.

\section{Bibliography}

Arias, Claudia (2009), "Los cuidados domiciliarios en situaciones de pobreza y dependencia en la vejez: la experiencia argentina", Envejecimiento y sistemas de cuidados ¿Oportunidad o crisis?, Project Document, No. 263 (LC/W.263), Santiago, Chile, Economic Commission for Latin America and the Caribbean (ECLAC).

ECLAC (Economic Commission for Latin America and the Caribbean) (2010), What kind of State? What kind of equality? Summary (LC/G.2451(CRM.11/4)), Santiago, Chile.

ECLAC/CELADE (Economic Commission for Latin America and the Caribbean/ Latin American and Caribbean Demographic Centre -Population Division of ECLAC) (2009), "Estimaciones y proyecciones de las poblaciones de América Latina y el Caribe" [online database] http:/ / www.cepal.org/celade/ proyecciones/basedatos_BD.htm [date of reference: 8 August 2011].

Esquivel, Valeria (2011), "La economía del cuidado: un recorrido conceptual", Aportes al debate del desarrollo en América Latina: una perspectiva feminista, Buenos Aires, Red de Género y Comercio-América Latina.

Fine, Michael D. (2005), "Indiviadualization, risk and the body: Sociology and care" [online] http://triarahmawati.blog.fisip.uns.ac.id/files/2011/12/junitsosio1.pdf. 
Fisher, Berenice and Joan C. Tronto (1990), "Toward a feminist theory of caring", Circles of Care: Work and Identity in Women's Lives, Albany, State University of New York Press.

Flores-Castillo, Atenea (2010), “Implicaciones del acompañamiento tanatológico a personas en etapa terminal”, Mexico City, Instituto Mexicano de Tanatología.

Folbre, Nancy (2011), "Reflections. Nancy Folbre interviewed by Shahra Razavi", Development and Change, vol. 42, No. 1.

Freud, Sigmund (1927), “El porvenir de una ilusión”, Obras completas, volumen XXI, Buenos Aires, Amorrortu Editores.

(1915), “Duelo y melancolía”, Obras completas, volumen XIV, Buenos Aires, Amorrortu Editores.

Heidegger, Martin (1927), Being and Time, John Wiley \& Sons, 1967.

Kübler-Ross, Elisabeth (1969), On Death and Dying, New York, Macmillan.

Lamaute-Brisson, Nathalie (2011), "Redistribuir el cuidado para un nexo de políticas públicas. Un marco conceptual", forthcoming.

Montaño, Sonia and Coral Calderón (coords.) (2010), "El cuidado en acción: entre el derecho y el trabajo", Cuadernos de la CEPAL, No. 94 (LC/G.2454-P), Santiago, Chile, Economic Commission for Latin America and the Caribbean (ECLAC). United Nations publication, Sales No. S.10.II.G.35.

Neri, Anita Liberalesso (2010), “Desafios ao bem-estar físico e psicológico enfrentados por idosos cuidadores no contexto da família: dados do FIBRA Campinas", Cuidados de longa duração para a população idosa: um novo risco social a ser assumido?, Rio de Janeiro, Institute of Applied Economic Research (IPEA).

Pautassi, Laura (2008), "Nuevos desafíos para el abordaje del cuidado desde el enfoque de derechos", Futuro de las familias y desafío para las políticas (LC/L.2888-P/E), Santiago, Chile, Economic Commission for Latin America and the Caribbean (ECLAC). United Nations publication, Sales No. S.08.II.G.25.

Rodríguez Enríquez, Corina (2005), “Economía del cuidado y política económica: una aproximación a sus interrelaciones", documento presentado en la $38^{\circ}$ reunión de la Mesa Directiva de la Conferencia Regional sobre la Mujer de América Latina y el Caribe, Mar del Plata (Argentina) [online] http:/ / www. eclac.org/mujer/reuniones/mesa38/C_Rodriguez.pdf.

Salvador, Soledad (2007), Comercio, género y equidad en América Latina: Generando conocimiento para la acción política. Estudio comparativo de la "economía del cuidado" en Argentina, Brasil, Chile, Colombia, México y Uruguay, Red Internacional de Género y Comercio Capítulo Latinoamericano, October.

Secretariat of Health of the Federal District (2008), "Programa de Atención Domiciliaria para Población Vulnerable", Mexico City, Servicios de Salud Pública del Distrito Federal (SSPDF).

(n/d), "Premio Nacional a la Innovación en Calidad en Salud. Eje de vínculo: Alternativas a la hospitalización: modelo en atención primaria no quirúrgico. Programa de atención domiciliaria para población vulnerable".

Tronto, Joan (2009), "The political and social economy of care", paper presented at the Conference on Political and Social Economy of Care, United Nations Research Institute for Social Development (UNRISD), 6 March.

WHO (World Health Organization) (2011), “World Report on Disability 2011” [online] http: / / whqlibdoc.who.int/publications / 2011/9789240685215_eng.pdf [date of reference: 17 August 2011]. 
(2008), "The Global Burden of Disease: 2004 update" [online] http:/ / www. who.int/healthinfo/global_burden_disease/GBD_report_2004update_full.pdf [date of reference: 2 September 2011].

(1992), The ICD-10 Classification of Mental and Behavioural Disorders. Clinical Descriptions and diagnostic guidelines [online] http:/ /www.who.int/ classifications/icd/en/bluebook.pdf. 


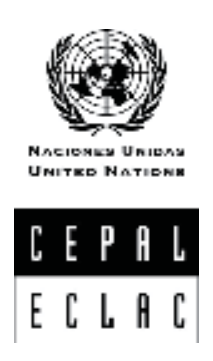

\section{Publicaciones de la CEPAL ECLAC publications}

Comisión Económica para América Latina y el Caribe Economic Commission for Latin America and the Caribbean Casilla 179-D, Santiago de Chile.

Véalas en: www.cepal.org/publicaciones Publications may be accessed at: www.eclac.org

Contacto / Contact: publications@cepal.org

\section{Revista CEPAL / CEPAL Review}

La Revista se inició en 1976 como parte del Programa de Publicaciones de la Comisión Económica para América Latina y el Caribe, con el propósito de contribuir al examen de los problemas del desarrollo socioeconómico de la región. Las opiniones expresadas en los artículos firmados, incluidas las colaboraciones de los funcionarios de la Secretaría, son las de los autores y, por lo tanto, no reflejan necesariamente los puntos de vista de la Organización.

La Revista CEPAL se publica en español e inglés tres veces por año.

CEPAL Review first appeared in 1976 as part of the Publications Programme of the Economic Commission for Latin America and the Caribbean, its aim being to make a contribution to the study of the economic and social development problems of the region. The views expressed in signed articles, including those by Secretariat staff members, are those of the authors and therefore do not necessarily reflect the point of view of the Organization.

CEPAL Review is published in Spanish and English versions three times a year.

\section{Informes periódicos institucionales I Annual reports}

\section{Todos disponibles para años anteriores I Issues for previous years also available}

- Balance Actualizado de América Latina y el Caribe 2012 - abril de 2013, 24 p.

- Updated Economic Overview of Latin America and the Caribbean 2012 - April 2012, 24 p.

- Balance Preliminar de las Economías de América Latina y el Caribe 2012, 84 p. Preliminary Overview of the Economies of Latin America and the Caribbean 2012, $82 \mathrm{p}$.

- Estudio Económico de América Latina y el Caribe 2012, 162 p. 
Economic Survey of Latin America and the Caribbean 2012, $154 \mathrm{p}$.

- Panorama de la Inserción Internacional de América Latina y el Caribe 2011-2012, 126 p.

Latin America and the Caribbean in the World Economy 2011-2012, 116 p.

- Panorama Social de América Latina, 2012, 252 p. Social Panorama of Latin America, 2012, 238 p.

- La Inversión Extranjera Directa en América Latina y el Caribe 2011, Documento informativo, $152 \mathrm{p}$.

Foreign Direct Investment in Latin America and the Caribbean 2011, Briefing paper, $142 \mathrm{p}$.

- Anuario Estadístico de América Latina y el Caribe 2012 / Statistical Yearbook for Latin America and the Caribbean 2012, $224 \mathrm{p}$.

\section{Libros de la CEPAL}

118 Sistemas de innovación en Centroamérica. Fortalecimiento a través de la integración regional, Ramón Padilla Pérez (ed.), 2013, 222 p.

117 Envejecimiento, solidaridad y protección social en América Latina y el Caribe. La hora de avanzar hacia la igualdad, Sandra Huenchuan, 2013. 190 p.

117 Ageing, solidarity and social protection in Latin America and the Caribbean Time for progress towards equality, Sandra Huenchuan, 2013, 176 p.

116 Los fundamentos de la planificación del desarrollo en América Latina y el Caribe. Textos seleccionados del ILPES (1962-1972), Ricardo Martner y Jorge Máttar (comps.), 2012, 196 p.

115 The changing nature of Asian-Latin American economic relations, German King, José Carlos Mattos, Nanno Mulder and Osvaldo Rosales (eds.), 2012, 196 p.

114 China y América Latina y el Caribe. Hacia una relación económica y comercial estratégica, Osvaldo Rosales y Mikio Kuwayama, 2012, 258 p.

114 China and Latin America and the Caribbean Building a strategic economic and trade relationship, Osvaldo Rosales y Mikio Kuwayama, 2012, 244 p.

113 Competitividad, sostenibilidad e inclusión social en la agricultura: Nuevas direcciones en el diseño de políticas en América Latina

y el Caribe, Octavio Sotomayor, Adrián Rodríguez y Mônica Rodrigues, 2012, 352 p.

112 El desarrollo inclusivo en América Latina y el Caribe. Ensayos sobre políticas de convergencia productiva para la igualdad, Ricardo Infante (ed.), 2011, 384 p.

111 Protección social inclusiva en América Latina. Una mirada integral, un enfoque de derechos, Simone Cecchini y Rodrigo Martínez, 2011, 284 p.

110 Envejecimiento en América Latina. Sistema de pensiones y protección social integral, Antonio Prado y Ana Sojo (eds.), 2010, 304 p.

109 Modeling Public Policies in Latin America and the Caribbean, Carlos de Miguel, José Durán Lima, Paolo Giordiano, Julio Guzmán, Andrés Schuschny and Masazaku Watanuki (eds.), 2011, $322 \mathrm{p}$.

108 Alianzas público-privadas. Para una nueva visión estratégica del desarrollo, Robert Devlin y Graciela Moguillansky, 2010, 196 p.

107 Políticas de apoyo a las pymes en América Latina. Entre avances innovadores y desafíos institucionales, Carlos Ferraro y Giovanni Stumpo, 2010, 392 p.

106 Temas controversiales en negociaciones comerciales Norte-Sur, Osvaldo Rosales V. y Sebastián Sáez C. (comps.), 2011, 322 p. 


\section{Copublicaciones recientes I Recent co-publications}

Decentralization and reform in Latin America. Improving Intergovernmental Relations, Giorgio Brosio and Juan Pablo Jiménez (eds.), ECLAC / Edward Elgar Publishing, United Kingdom, 2012.

Sentido de pertenencia en sociedades fragmentadas. América Latina desde una perspectiva global, Martín Hopenhayn y Ana Sojo (comps.), C PAL Siglo Veintiuno, Argentina, 2011.

Las clases medias en América Latina. Retrospectiva y nuevas tendencias, Rolando Franco, Martín Hopenhayn y Arturo León (eds.), C PAL Siglo I, Mé ico, 2010.

Innovation and Economic Development. The Impact of Information and Communication Technologies in Latin America, Mario Cimoli, André Hofman and Nanno Mulder, ECLAC / Edward Elgar Publishing, United Kingdom, 2010.

Las clases medias en América Latina. Retrospectiva y nuevas tendencias, Rolando Franco, Martín Hopenhayn y Arturo León (eds.), C PAL Siglo Veintiuno, Mé ico, 2010.

Sesenta años de la CEPAL. Textos seleccionados del decenio 1998-2008, Ricardo ielschowsky (comp.), C PAL Siglo Veintiuno, Argentina, 2010.

El nuevo escenario laboral latinoamericano. Regulación, protección y políticas activas en los mercados de trabajo, J rgen eller (ed.), C PAL Siglo Veintiuno, Argentina, 2010.

Internacionalización y expansión de las empresas eléctricas españolas en América Latina, Patricio Rozas albontín, C PAL Lom, Chile, 2009.

\section{Coediciones recientes / Recent co-editions}

Juventud y bono demográfico en Iberoamérica, Paulo Saad, im Miller, Ciro Martínez y Mauricio Holz, C PAL OIJ FPA, Chile, 2012.

Perspectivas económicas de América Latina 2013. Políticas de Pymes para el Cambio Estructural, OCD C PAL, Chile, 2012.

Latin American Economic Outlook 2013. SME Policies For Structural Change, OECD / ECLAC, Chile, 2012.

Perspectivas de la agricultura y del desarrollo rural en las Américas: una mirada hacia América Latina y el Caribe 2013, C PAL FAO IICA, Chile, Octubre, 2012.

Reforma fiscal en América Latina. ¿Qué fiscalidad para qué desarrollo?, Alicia árcena y arcís Serra (editores), C PAL S GI CIDO, Chile, 2012.

La sostenibilidad del desarrollo a 20 años de la Cumbre para la Tierra. Avances, brechas y lineamientos estratégicos para América Latina y el Caribe, C PAL aciones nidas, 2012.

Sustainable development 20 years on from the Earth Summit. Progress, gaps and strategic guidelines for Latin America and the Caribbean, ECLAC I United Nations, 2012.

Perspectivas económicas de América Latina 2012.Transformación del Estado para el desarrollo,

C PAL OCD , 2011.

Latin America Outlook 2012. Transforming the State for Development, ECLAC/OECD, 2011.

Perspectives économiques de l'Amérique latine 2012. Transformation de l'État et Développement, CEPALC I OCDE, 2012.

Breeding Latin American Tigers. Operational principles for rehabilitating industrial policies,

Robert Devlin and Graciela Moguillansky, ECLAC / World Bank, 2011.

Espacios iberoamericanos: Hacia una nueva arquitectura del Estado para el desarrollo,

C PAL S GI , 2011.

Espaços ibero-americanos: A uma nova arquitetura do Estado para o desenvolvimento. CEPAL I SEGIB, 2011. 


\section{Cuadernos de la CEPAL}

100 Construyendo autonomía. Compromiso e indicadores de género, Karina atthyáni Dighiero, 2012, $338 \mathrm{p}$.

99 Si no se cuenta, no cuenta, Diane Alméras y Coral Calderón Maga a (coordinadoras), 2012, $394 \mathrm{p}$.

98 Macroeconomic cooperation for uncertain times: The REDIMA experience, Rodrigo Cárcamo-Díaz, 2012,164 p.

97 El financiamiento de la infraestructura: Propuestas para el desarrollo sostenible de una política sectorial, Patricio Rozas albontín, José Luis onifaz y Gustavo Guerra García, 2012, 414 p.

96 Una mirada a la crisis desde los márgenes, Sonia Monta o (coordinadora), 2011, 102 p.

95 Programas de transferencias condicionadas. Balance de la experiencia reciente en América Latina y el Caribe, Simone Cecchini y Aldo Madariaga, 2011, 226 p.

95 Conditional cash transfer programmes. The recent experience in Latin America and the Caribbean, Simone Cecchini and Aldo Madariaga, 2011, 220 p.

94 El cuidado en acción. Entre el derecho y el trabajo, Sonia Monta o Virreira y Coral Calderón Maga a (coords.), 2010, $236 \mathrm{p}$.

93 Privilegiadas y discriminadas. Las trabajadoras del sector financiero, Flavia Marco avarro y María ieves Rico lbá ez (eds.), 2009, 300 p.

\section{Cuadernos estadísticos de la CEPAL}

40 América Latina y el Caribe: Índices de precios al consumidor. Serie enero de 1995 a junio de 2012. Solo disponible en CD, 2012.

39 América Latina y el Caribe: indicadores macroeconómicos del turismo. Solo disponible en CD, 2010.

38 Indicadores ambientales de América Latina y el Caribe, 2009. Solo disponible en CD, 2010.

37 América Latina y el Caribe: Series históricas de estadísticas económicas 1950-2008. Solo disponible en CD, 2009.

\section{Observatorio demográfico / Demographic Observatory}

dición biling e (espa ol e inglés) ue proporciona información estadística actualizada, referente a estimaciones y proyecciones de población de los países de América Latina y el Caribe. Incluye también indicadores demográficos de interés, tales como tasas de natalidad, mortalidad, esperanza de vida al nacer, distribución de la población, etc.

Desde 2013 el Observatorio aparece una vez al a 0.

Bilingual publication (Spanish and English) proving up-to-date estimates and projections of the populations of the Latin American and Caribbean countries. Also includes various demographic indicators of interest such as fertility and mortality rates, life expectancy, measures of population distribution, etc.

Since 2013, the Observatory appears once a year. 


\section{Notas de población}

Revista especializada ue publica artículos e informes acerca de las investigaciones más recientes sobre la dinámica demográfica en la región, en espa ol, con res menes en espa ol e inglés. ambién incluye información sobre actividades científicas y profesionales en el campo de población.

La revista se publica desde 1973 y aparece dos veces al a 0 , en junio y diciembre.

Specialized journal which publishes articles and reports on recent studies of demographic dynamics in the region, in Spanish with abstracts in Spanish and English. Also includes information on scientific and professional activities in the field of population.

Published since 1973, the journal appears twice a year in June and December.

\section{Series de la CEPAL}

Comercio Internacional Desarrollo Productivo Desarrollo Territorial Estudios Estadísticos y Prospectivos Estudios y Perspectivas ( ogotá, rasilia, uenos Aires, Mé ico, Montevideo)

Studies and Perspectives ( he Caribbean, ashington) Financiamiento del Desarrollo Gestión Pública Informes y Estudios Especiales Macroeconomía del Desarrollo Manuales Medio Ambiente y Desarrollo Asuntos de Género (ex Mujer y Desarrollo) Población y Desarrollo Políticas Fiscales Políticas Sociales Recursos Naturales e Infraestructura Reformas Económicas Seminarios y Conferencias.

Véase el listado completo en www.cepal.org publicaciones

A complete listing is available at www.eclac.org publications 
Las publicaciones de las Naciones Unidas y de la Comisión Económica para América Latina y el Caribe (CEPAL) se pueden adquirir a través de:

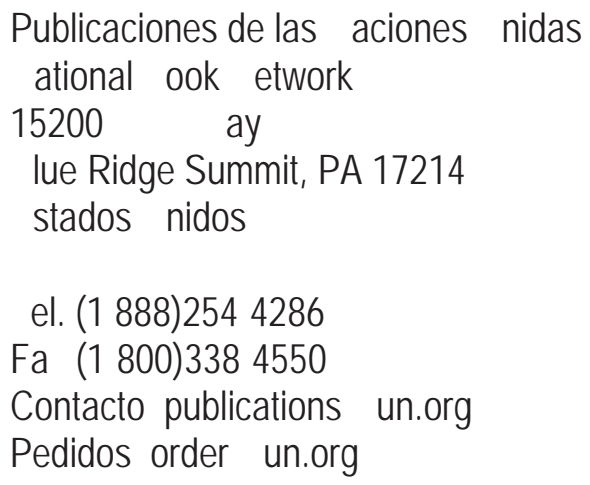

Publications of the United Nations and the Economic Commission for Latin America and the Caribbean (ECLAC) can be ordered through:

\author{
nited ations Publications \\ ational ook etwork \\ 15200 ay \\ lue Ridge Summit, PA 17214 \\ USA \\ Tel. (1 888)254-4286 \\ Fax (1-800)338-4550 \\ Contact:publications@un.org \\ Orders order un.org
}




\section{REDISTRIBUTING CARE}

\section{THE POLICY CHALLENGE}

This publication offers a representative sample of the thinking developed over recent years in relation to time use, time-use measurement and related policies in Latin America. The issue of care and its importance and meaning have become part of the gender agenda in the region, especially since the tenth session of the Region Conference on Women in Latin America and the Caribbean, held in Quito in 2007.

Care is a multidisciplinary concept in which the sexual division of labour is understood as part of an exclusionary development model, in which the provision of services (for free, by women) is in crisis. As the subject of study and public policy, care is undergoing a transition from association with subjectivity and affection towards full recognition as a right and, therefore, as a global public good. The studies set forth in this book show how very different phenomena, such as demographic changes, changes in epidemiological profiles, women's education and entry into the paid labour market, and State responses are intertwined in the new understanding of care.

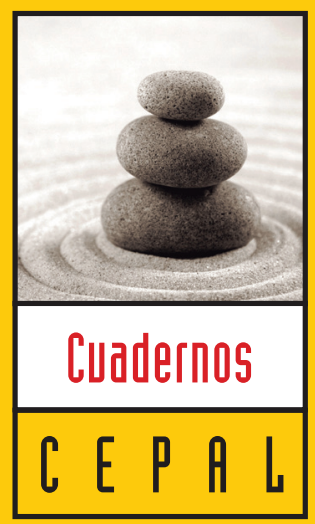

ECONOMIC COMMISSION FOR LATIN AMERICA AND THE CARIBBEAN (ECLAC)

COMISIÓN ECONÓMICA PARA AMÉRICA LATINA Y EL CARIBE (CEPAL)

www.eclac.org

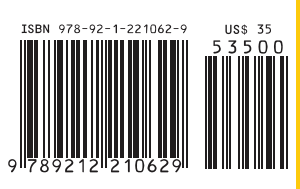

First edition

Printed at United Nations • Santiago, Chile • E.13.II.G.9 - September 2013

ISSN 0252-2195 • ISBN 978-92-I-221062-9 • E-ISBN 978-92-I-0560I7-7 • 2012-997

Copyright (C) United Nations 2013 